Claus Dierksmeier

Qualitative Freedom -

Autonomy in

Cosmopolitan

Responsibility

Translated by

Richard Fincham 
Qualitative Freedom - Autonomy in Cosmopolitan Responsibility 
Claus Dierksmeier

Qualitative Freedom -

Autonomy in Cosmopolitan Responsibility

望 Springer 


\author{
Claus Dierksmeier \\ Institute of Political Science \\ University of Tübingen \\ Tübingen, Baden-Württemberg, Germany
}

\author{
Translated by Richard Fincham \\ American University in Cairo \\ New Cairo, Egypt
}

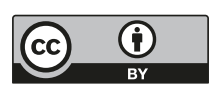

Published in German by Published by Transcript Qualitative Freiheit - Selbstbestimmung in weltbürgerlicher Verantwortung, 2016.
ISBN 978-3-030-04722-1
ISBN 978-3-030-04723-8 (eBook)
https://doi.org/10.1007/978-3-030-04723-8

Library of Congress Control Number: 2018964905

(C) The Editor(s) (if applicable) and The Author(s) 2019. This book is an open access publication.

Open Access This book is licensed under the terms of the Creative Commons Attribution 4.0 International License (http://creativecommons.org/licenses/by/4.0/), which permits use, sharing, adaptation, distribution and reproduction in any medium or format, as long as you give appropriate credit to the original author(s) and the source, provide a link to the Creative Commons licence and indicate if changes were made.

The images or other third party material in this book are included in the book's Creative Commons licence, unless indicated otherwise in a credit line to the material. If material is not included in the book's Creative Commons licence and your intended use is not permitted by statutory regulation or exceeds the permitted use, you will need to obtain permission directly from the copyright holder.

The use of general descriptive names, registered names, trademarks, service marks, etc. in this publication does not imply, even in the absence of a specific statement, that such names are exempt from the relevant protective laws and regulations and therefore free for general use.

The publisher, the authors, and the editors are safe to assume that the advice and information in this book are believed to be true and accurate at the date of publication. Neither the publisher nor the authors or the editors give a warranty, express or implied, with respect to the material contained herein or for any errors or omissions that may have been made. The publisher remains neutral with regard to jurisdictional claims in published maps and institutional affiliations.

This Springer imprint is published by the registered company Springer Nature Switzerland AG The registered company address is: Gewerbestrasse 11, 6330 Cham, Switzerland 


\section{Note on Translation}

I am very pleased to have had the opportunity to translate Professor Claus Dierksmeier's monograph, Qualitative Freiheit: Selbstbestimmung in weltbürgerlicher Verantwortung (Bielefeld: transcript Verlag, 2016) from the original German into American English. The tremendous breadth and depth of this work nonetheless presented some unusual challenges for the translator, both because of the manner in which, for large parts of it, the author connects a quite technical discussion of the intricacies of late-eighteenth and early-nineteenth century German philosophy with a more contemporary discourse on globalization ethics and also because of its interdisciplinary nature - the discussion seamlessly gliding back and forth between topics within metaphysics, ethics, political theory, and economics. In translating such a work, it soon became apparent that it was neither possible nor desirable to employ the kind of consistency in the translation of technical terms that one might expect from, say, the translation of a treatise by a long-since-departed eighteenth-century philosopher or an academic journal article by a contemporary economist. These challenges have, however, been circumvented by the fact that our author took a very active role in the translation process. The initial drafts of this translation were thoroughly reviewed and amended by Professor Dierksmeier, while that subsequent iteration was further reviewed and amended by the translator. Professor Dierksmeier's (American) wife, Laura, also thoroughly reviewed the manuscript, so as to convert some of the native inflections of the (English) translator into terms and expressions more familiar to an American readership. The final version of this translation thus emerged as the result of a "dialectical process" and is one in which all involved are now confident that all technical terminology, either for which there is no direct natural - English equivalent or which could - potentially - prove ambiguous (hence admitting of mistranslation), has upon each specific occasion of its use and in accordance with its particular context been translated with the best possible Englishlanguage term to convey the author's meaning and intension.

In translating the discussions of the work of Immanuel Kant and Johann Gottlieb Fichte constituting the first quarter of this study, I was fortunate enough to have at my disposal for consultation authoritative translations of the works of all of these authors. The publication in the same year as the German-language version of this 
monograph of the Lectures and Drafts on Political Philosophy volume within The Cambridge Edition of the Works of Immanuel Kant series meant that it was possible for all quotations from Kant to follow these highly regarded Cambridge Edition translations. These editions translate Kant with a rigorous terminological consistency and an emphasis on literalness. As previously discussed, I do not consider these to be desirable virtues in translating Professor Dierksmeier himself when he is speaking in his own voice. But since these editions both aim to recreate - as far as is possible - for the English-language reader the experience of reading Kant in the original and are now employed within the vast majority of English-language Kant scholarship, I decided to ensure that all of the quotations from Kant conform with those in the Cambridge Edition translations. The English translations of Fichte's works have (so far) not enjoyed the same uniform format, and a good many of his works (especially those composed after 1800) have yet to be translated into English. Nonetheless - in the vast majority of cases - where good-quality recent translations already exist, those translations have similarly been employed here. Mostly, that has meant quoting from Fichte, Foundations of Natural Right (Cambridge, Cambridge University Press, 2000) - but Fichte: Early Philosophical Writings (Ithaca, Cornell University Press, 1993) and J. G. Fichte and the Atheism Dispute (1798-1800) (Routledge, 2010) have also been quoted from where appropriate.

In spite of the guidance that the aforementioned works could provide, however, probably the greatest challenge facing this translation was the translation of the German Recht, the multifarious compound nouns including this term, and the adjectives derived from it, such as, e.g., rechtlich and rechtmäßig. Whereas "ein Recht auf" and the plural "Rechte" quite evidently correspond to the English "a right to" and "rights," respectively, there is no English term that naturally and unambiguously corresponds to "das Recht" in quite the same way. One possibility would of course be to translate "das Recht" as "law," just as the term Naturrecht would seem most obviously translated as "natural law" and the adjective widerrechtlich most adequately translated as "unlawful." Nonetheless, translators of the eighteenth- and nineteenth-century German philosophy almost invariably reject this solution, fearing its capacity to obscure the conceptual connection between "das Recht" and "die Rechte," as well as due to concern about the ambiguous instances of the term Recht (where it is not clear whether the former or the latter sense is intended) within the writings of their long-since-departed authors. Accordingly, a consensus seems to have arisen among such translators that "das Recht" is most adequately translated simply as "right." And indeed, this is the approach taken within the Cambridge Edition translations of Kant's Rechtslehre, the translations of Fichte's Grundlage des Naturrechts and Hegel's Grundlinien der Philosophie des Rechts (as is of course apparent from their respective titles, Foundations of Natural Right and Elements of the Philosophy of Right), and the translation of K. C. F. Krause's Das Urbild der Menschheit - which remains to this day the only one of Krause's works to have ever been published in English translation. The price that is paid for consistency and lack of ambiguity, however, is that this solution can, at times, lead to phrases and expressions which sound unduly abstract and unnatural in English (and, indeed, this is something that readers may possibly perceive as they read through some of the 
quotations from Kant and Fichte within this volume). Whereas this may well be a price worth paying when translating long-departed authors who we are hardly able to ask about the precise meaning of any potentially ambiguous expression they employ, it soon became clear that using the same approach to translating those passages in which Professor Dierksmeier speaks within his own voice to show what Kant and Fichte are able to offer contemporary discussions within political theory and economics would produce an English-language discourse sounding intolerably artificial and unnatural. This problem was, however, fortunately obviated by the fact that Professor Dierksmeier is very much still alive and, as such, he could decide for himself about the most appropriate translation of these terms within the specific contexts in which they are employed. A pragmatic approach has thus been adopted here, with the result that although "das Recht" and "rechtlich" are translated as "right" and "rightful" within discussions of their use within eighteenth-century philosophical texts, when the discussion turns to contemporary sociopolitical and economic questions, the terms are - where appropriate - more often than not translated as "law" and "lawful" or "legal," respectively. Hopefully this pragmatic approach has resulted in a text that will prove accessible to both historians of philosophy and those more interested in contemporary sociopolitical questions.

Another potential problem facing this translation concerned the most adequate translation of the terms Verstand, verständig, and Verständigkeit on the one hand and the terms Vernunft, vernünftig, and Vernünftigkeit on the other. The former terms are typically used to describe the kind of thinking employed within mathematics, whereas the latter terms are typically used to describe the kind of thinking we employ when addressing moral questions - as well as the problems of metaphysics. This becomes an ossified technical distinction within the works of Kant as well as his late-eighteenth- and nineteenth-century philosophical successors. As Englishlanguage scholars of these figures will be well aware, however, it has long since been established by almost unanimous consensus that, when translating Kant or Hegel, for example, these terms are best captured by the distinction between understanding and reason. Hence such scholars would no doubt expect to find "Verstand" translated as "understanding," "verständig" as "understandable," "vernünftig" as "rational," and "Vernünftigkeit" as "rationality." Once eighteenth- and nineteenthcentury philosophy enters into a serious discourse with twentieth-century political theory and economics, however, the aforementioned orthodoxy can no longer be maintained. The problem emerges insofar as more recent rational choice theorists, utility theorists, or game theorists - or anyone who reduces the human being to the homo economicus model - precisely use the adjective "rational" to describe selfinterested utility-maximizing behavior which conforms to, and can be predicted in terms of, mathematical algorithms. Within a discourse upon such theories, verständig thus becomes synonymous with the German adjective "rational" and is thus, obviously, best translated as "rational," and "Verständigkeit" thus becomes synonymous with "Rationalität" and is thus best translated as "rationality." Within this study, therefore, the vitally important distinction between Verstand and Vernunft had to be expressed within terms perhaps contrary to the expectations of Englishlanguage scholars of German philosophy in order to prevent that important 
distinction from being lost. Accordingly, within this translation, one frequently finds "Verstand" translated as "ratio," "verständig" as "rational," and "Verständigkeit" as "rationality." Meanwhile, "Vernunft" is still - as everyone would expect - translated as "reason," but "vernünftig" is translated as "reasonable" and "Vernünftigkeit" as "reasonableness." Exceptions to this rule occur only within the discussions of specific passages from Kant and Fichte within the first sections of the text; otherwise it is applied throughout the whole of the book. Again, I hope that these decisions have resulted in a text that will be accessible and understandable by all of the various audiences for which it is intended and directed.

Finally, I would like to thank Hans Földeak and the late Christina Stockinger for assisting me with some of the initial drafts of this translation. I would also like to thank the American University in Cairo for providing me with faculty support grants enabling me to spend two summers in Tübingen to work on this translation.

Cairo Egypt

Richard Fincham in Summer 2018 


\section{Contents}

1 Introduction ...................................................................................

1.1 Why Think About Freedom?..........................................................

1.1.1 Freedom and Globality........................................................... 4

1.1.2 Freedom and Everyday Life.................................................. 10

1.1.3 Freedom and Academic Philosophy ……………………........ 14

1.2 Why Not Negative Versus Positive Freedom? ……………………..... 17

1.2.1 The History of the Distinction................................................. 18

1.2.2 Current Use of the Concept of Freedom ................................ 24

1.2.3 Some Outstanding Developments ......................................... 29

1.3 How Should We Talk About Freedom? ................................................ 33

1.3.1 Metaphysical Theories of Freedom........................................ 34

1.3.2 Quantitative Theories of Freedom........................................... 37

1.3.3 Qualitative Theories of Freedom............................................ 40

2 Metaphysics of Freedom....................................................................... 45

2.1 Reflexive Freedom (Immanuel Kant)............................................... 47

2.1.1 How Much Metaphysics Does Freedom Require?................. 47

2.1.2 Outer Freedom: The Good and the Law............................... 55

2.1.3 Social Rights?................................................................. 60

2.1.4 Societal Self-Regulation...................................................... 65

2.2 Directive Freedom (Johann Gottlieb Fichte)...................................... 72

2.2.1 Epistemology and Metaphysics of Law ………………….... 75

2.2.2 Social Philosophy ................................................................ 88

2.2.3 Economic Philosophy.......................................................... 92

2.2.4 Socialism Versus Social-Democracy ....................................... 99

2.3 Participative Freedom (Karl Christian Friedrich Krause) .................. 103

2.3.1 Reception, Context, and Method........................................... 106

2.3.2 The Freedom of Nature and of Humanity ............................. 112

2.3.3 Private and Public Interest................................................... 126

2.3.4 Procedural Policy in Global Responsibility …………........... 138

2.4 Results and Implications ............................................................. 153 


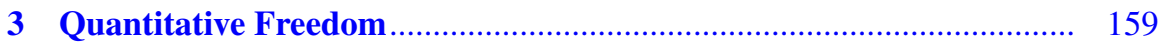

3.1 Liberal Allocation (Friedrich August von Hayek) ............................ 166

3.1.1 Genesis of the Neo-Liberal Concept of Freedom .................. 167

3.1.2 Validity of the Neo-Liberal Concept of Freedom .................. 170

3.1.3 Legal and Political Philosophy.............................................. 174

3.1.4 Economic and Social Philosophy ....................................... 178

3.2 Liberal Distribution (John Rawls) ..................................................... 185

3.2.1 Approach and Method......................................................... 186

3.2.2 Transcendental or Transactional Freedom?............................ 191

3.2.3 Relativist Versus Dogmatic Liberalism ................................. 197

3.2.4 Whose Freedom?............................................................ 206

3.3 Results and Implications ............................................................. 213

4 Qualitative Freedom ………........................................................... 223

4.1 Fair Freedom (John Kenneth Galbraith) ………………................ 226

4.1.1 Democratized Economics...................................................... 227

4.1.2 Democratic Economy......................................................... 230

4.1.3 Critique of Neoclassical Economics .................................... 233

4.1.4 Critique of Neoliberal Economic Policy .............................. 240

4.2 Responsible Freedom (Amartya Sen) …………………………...... 245

4.2.1 Critique of the Neoclassical Paradigm .................................. 247

4.2.2 Critique of Reductionist Concepts of Freedom..................... 256

4.2.3 Freedom Through "Capabilities" .......................................... 261

4.2.4 Cosmopolitan Freedom ....................................................... 267

4.3 Results and Implications ............................................................... 272

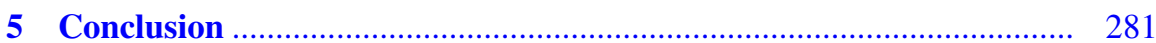

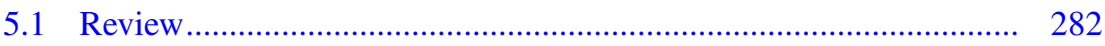

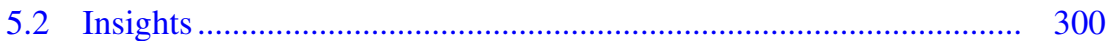

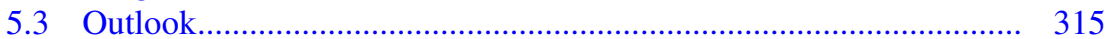

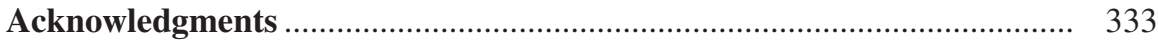

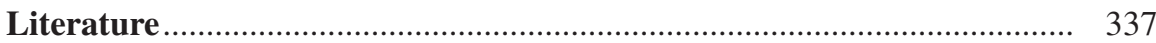




\section{Chapter 1 \\ Introduction}

Freedom is indivisible, and when one man is enslaved, all are not free.

John F. Kennedy

A genuine liberal will emphasize as crucial the complete correlation between the means used and the consequences that follow.

John Dewey

\subsection{Why Think About Freedom?}

Freedom is a fascinating idea. It empowers and encourages all human beings towards a dignified life. More and more individuals and institutions appeal to the idea of freedom in order to overturn repressive life-circumstances. No one needs to explain the value of freedom to the oppressed. Wherever freedom is absent in practice, it is seldom lacking a cherished place in theory. The institutionalized consciousness of freedom, political liberalism, often grows in synch with the obstacles facing freedom.

But to identify and combat the lack of freedom is easier than shaping liberties already won. Wherever the harsh, black shadow of oppression is swept aside, the bright white light of freedom is refracted within the prism of the most multifarious ideas of liberty. The black and white of freedom fighters becomes replaced by the more nuanced ideological tinges of open societies. Within their colorful array of social and political blueprints, there resides both opportunities and dangers for liberalism. For within open societies, the once unquestioning urge for freedom now inexorably gives rise to the urgent question: Which freedom and whose freedom is to be upheld when the freedoms of some collide with the freedoms of others?

Freedom is constantly called upon to strengthen or to weaken certain conventions, to commend or to condemn individual, corporate, and collective practices, and to legitimize as well as to criticize political systems. Defenders just as much as detractors of the status quo alike, by invoking the selfsame ideal, are bringing to 
light tensions within the idea of freedom. Does the freedom of the environmental campaigner have priority over economic freedom or vice versa? Does that of the champion of direct democracy have priority over that of the friends of parliamentary representation? Should religious liberty have priority over the freedoms of nonbelievers? Ought we to prioritize the freedom of those living today over that of coming generations? How are we to deal with the ecological damage and social side effects that unfettered economic freedom produces? How is economic freedom related to political freedom? Do they require and strengthen one another, or does the one in fact undermine the other? Might there be an excess of certain freedoms?

These questions stimulate vital deliberations: Do we adequately grasp the idea of freedom as such when equating it with a decrease of limitations and an increase in options? Or does freedom have immanent boundaries? Must even rules of fairness and commands of responsibility be considered as a diminution of freedom? Or do they rather articulate a desire for a freedom in and for sustainable ways of living? Are voluntarily chosen commitments negations or manifestations of freedom?

In short, as soon as freedom no longer fights with constraint and compulsion, liberalism begins to struggle with itself. Having eaten from the tree of knowledge and having learned the bitter lesson that the freedom of a few can ruin the presuppositions for the freedom of others - of everyone - liberal thinking lost its innocence. In its lack of social, moral, and ecological reflection today's liberalism is confronted by its own original sin and deplores the loss of its former paradise of moral clarity. The haste with which many liberals these days reach for moral fig leaves bespeaks their embarrassed state of original ethical nakedness. From now on, it seems, the friends of freedom must make their home in a world endangered by freedom itself. Henceforth liberalism must live by the sweat of its brow and earn its bread through a reform of its own idea and ideal of freedom. The present work endeavors to contribute to this reform.

Reading this volume will be easier if one is from the outset clear about where this intellectual journey is going. For this reason, I would like, right at the beginning, to confess that this book is intended for various target-groups and therefore argues at different levels. The aims and tone of the presentation change precisely for this reason. First, I wish to give a new direction to the academic discourse concerning the philosophy of freedom. The main part of this book, up until and including Chap. 4 , is dedicated to this purpose. Second, I wish to provide momentum to a morally, socially, and ecologically sustainable liberalism, which is the focus of the last chapter of the book. Both aspects, however, are essentially connected. The applied part requires academic foundations for its legitimacy and, conversely, the theory requires practical application in order to establish its relevance.

Yet those people who are theoretically dedicated to the idea of freedom are not always the same as those who practically care about the vicissitudes of liberalism. As a consequence, I have attempted to compose this study in such a way that it does not require everyone to work with academic meticulousness. All of the theoretical chapters therefore end with a section emphasizing their respective "results and implications." Readers primarily interested in the practical consequences of my investigation will, by consulting these sections, be well prepared for their ultimate presentation in Chap. 5. 
The academic aim of the book is easily enough stated, but not so quickly cashed out. First of all I wish to clarify the idea of freedom conceptually by readjusting the common distinction between negative and positive freedom into the dialectical conceptual dichotomy of quantitative and qualitative freedom (as is detailed in Sect. 1.2). I describe this dichotomy as dialectical since a closer consideration of both categories shows that, first, earlier theories of freedom are able to be conclusively traced back to those two categorical determinations whereby, second, a hierarchical ordering and prioritizing of quantitative and qualitative aspects arise so that, third, it becomes clear how the one uniform idea of freedom can be legitimately differentiated - from place to place as well as from one time to another - within different ways of living freely.

The perspective of quantity and quality chosen here is not entirely new. ${ }^{1}$ Mainly we find the quantitative preoccupation championed in theories of "negativelyliberal," libertarian or neo-liberal origin. ${ }^{2}$ Conversely, the conception of qualitative freedom has some similarities with the concept of "positive freedom" (about which there is more in Sect. 1.2.3), although it is to be clearly distinguished from it as a result of its important procedural dimension. Qualitative freedom does not wish to stipulate ex cathedra which freedoms should apply to certain people and certain groups, but rather authorizes those respectively affected to come to an agreement themselves about that stipulation - in forms which could be justified in the name and interest of the freedom of all mankind. This aspect - the irreversible globality of the idea of freedom - is something which I shall expound on presently (in Sect. 1.1.1).

\footnotetext{
${ }^{1}$ Karl Mannheim (1893-1947), Erich Fromm (1890-1980), and Theodor Adorno (1903-1969) talk of qualitative aspects of freedom, but not in a technical sense. In these thinkers, the concept of 'qualitative freedom' surfaces only occasionally but is not systematically worked out. Certainly, even as early as 1979, Charles Taylor introduced "qualitative discriminations" within the philosophy of freedom, but he did not extend these ideas into a self-contained theory, see Charles Taylor, "What's Wrong with Negative Liberty?" in Alan Ryan \& Isaiah Berlin, The Idea of Freedom: Essays in Honour of Isaiah Berlin (Oxford \& New York: Oxford University Press, 1979), 177193. It should also be noted that, unlike what might be supposed by judging the book by its cover, Matthew Kramer in no way arrives at a theory of qualitative freedom, but rather attempts to trace back all qualitative dimensions of the idea of freedom to quantitative aspects ("the perimeter of a person's latitude," "the extent," "the numerical expressions," etc.) and then trace these back to a theory of negative freedom ("the sheer physical proportions") (Matthew H. Kramer, The Quality of Freedom [New York: Oxford University Press, 2003], 7-11). Yet in theoretical philosophy (looking for an alternative to debates about determinism versus indeterminism) the concept of qualitative freedom has already been tried out in Thomas Buchheim, Unser Verlangen nach Freiheit kein Traum sondern Drama mit Zukunft (Hamburg: Meiner, 2006). In regard to the practical philosophy in the foreground of this investigation and in systematic opposition to conceptions of quantitative freedom, the conception of qualitative freedom has up to now, as far as I am aware, not yet been worked out. I myself have, however, already sketched my own position in some essays, above all in: Claus Dierksmeier, "Qualitative oder quantitative Freiheit," Rechtsphilosophische Hefte 12 (2007), 107-119; as well as in Claus Dierksmeier, "Welche Freiheit?", Liberal, Vierteljeahreshefte für Politik und Kultur 4 (2010), 9-13; and in Claus Dierksmeier and Michael Pirson, "The Modern Corporation and the Idea of Freedom," Philosophy in Management, 9:3, 2010, 5-25.

${ }^{2}$ For a definition and critique of "negative freedom" see Sect. 1.2. For the use of "neoliberal" see note 119.
} 
The sociological, economic, and political aims of this study are connected in their intention of realigning liberalism: from a theory often only insufficiently reflecting upon its moral, social, and ecological responsibility to a conception which makes the idea of freedom's immanent cosmopolitan obligation the center of its argumentative elaboration. I discuss this motivation in more detail in the following two sections of this chapter.

\subsubsection{Freedom and Globality}

Our little blue planet is home to all humankind - and is also increasingly perceived as such. Yesterday's surroundings (Umwelt) are increasingly turning into today's lifeworlds (Mitwelt), which noticeably impacts upon all local activities. Our actions here and now influence the living conditions of distant peoples and future generations. In addition to tribal leaders and local communities, regional subcultures and nation states, communes and clans, sheikdoms and states, fanatics and fundamentalists, ever more novel actors appear upon the world stage: Colossi of business and luminaries of science, media and militia, donors and sponsors, refuges and rockstars, hackers and whistleblowers, social networks as well as civil society movements all enter in the action and flux of the world. No longer restricted to the local level, the strands of activity so initiated mesh into a fabric ever more difficult to penetrate. The mutable stasis of formerly stable powers yields increasingly to the immutable dynamics of fluctuating forces. Thus the global exchange of commodities, information and people changes the face of the earth with breath-taking speed.

Humanity communicates, travels, and trades more freely today than ever before. One has ever easier access to news, commodities, and contacts. Global information, encounters, and incitements, which, still in the late nineteenth century, were the prerogative of a few learned travelers like Alexander von Humboldt, are now a matter of course to a constantly increasing number of world citizens. Speeded up by exponentially increasing exchange of information, innovative conventions rapidly take root. In the blink of an eye, lifestyles and idols from the most obscure corners of the planet or internet populate our global consciousness. The broadening of the views and insights as well as the increasing exchange of world-views (Weltbilder) and self-images (Selbstbilder) have encouraged and empowered many to liberate themselves from obsolete ways of life, to try other paths, and to begin something new: both within their communities and also by turning their backs upon them. - It is evident that this enhances the freedom of many, although, obviously, not all people.

This gain in options has a price. That the new communication media levels physical distances is one person's blessing and another's curse: Little remains private, practically nothing is local anymore; and where the citizens of this world are not controlling their information, their informational self-determination becomes a con- 
stantly endangered good. Likewise, economic freedom in a global economy, unrestrained by global governance contains enormous opportunities, but also serious risks: If left unprotected against the ice-cold wind of global profit seeking, many biological systems vanish, customs disappear, political orders fall, and languages die out.

Although there has always existed a cross-cultural exchange of commodities and information, our age differs dramatically from previous epochs. We live in a world no longer only of globalization, but rather of globality. In a world that in many respects is already cosmopolitan, since we increasingly devise private activities, local business dealings, and national politics with reference to their worldwide reception. Like it or loathe it, our interests are bound up with the interests of other persons and states. The domestic affairs of distant countries have long since developed into matters of national security. And the crises of the global commons (the over-fishing of the seas, the warming of the climate, the consumption of fossil fuels, etc.) are transforming yesterday's national foreign policy into today's global domestic politics (Weltinnenpolitik). ${ }^{3}$ History has made us all cosmopolitans.

Whether by means of global epidemics or as a result of the epilepsies of the world market - we cannot but acknowledge that our actions produce remote effects as unforeseeable as they are unintended. Although single processes of globalization can still be slowed, stopped, and even reversed, this does not hold for the general trend. The breadth and depth globalization has already assumed compels us already to think in terms of the category of globality: A calculation on the planetary scale, the assessment of a long chain of consequences, an anticipation of world-wide developments. Therefore, whether we slow or stop any future impetus towards globalization, the fundamental change of paradigm remains: away from locally bounded economic and political bookkeeping and towards the perspective of globality.

Wherever the later significance of our activities surpasses our earlier intentions, we must face the following: Whatever we now bequeath the planet might be fully deciphered only in the future, but the responsibility for our message to coming generations already rests with us presently. This situation - the globality and intertemporality of the consequences of our actions - changes radically how freedom is experienced, perceived, and conceived. The extension of its responsibility towards the planetary as well as the future dimension forces itself upon the contemporary consciousness as an imperative of sustainability. Since freedom has an effect beyond the culturally familiar boundaries of space and time, it also must itself be evaluated beyond them. Whoever acts globally must act with cosmopolitan responsibility.

\footnotetext{
${ }^{3}$ See Peter Dudy, Menschenrechte zwischen Universalität und Partikularität: Eine Interdisziplinäre Studie zur Idee der Weltinnenpolitik (Münster: Lit, 2002); Scott Jasper, ed., Securing Freedom in the Global Commons (Stanford, Califoria, 2010); and Kirstin-Maike Müller, Konzepte einer Weltinnenpolitik (Hamburg: Institut für Friedensforschung und Sicherheitspolitik an der Universität Hamburg, 1999).
} 
Global crises and problems force humanity to search for common solutions. The implementation of these solutions, however, often demands global institutions, and those institutions usually only work efficiently when founded upon common values. Yet, the more the current search for global moral criteria increases, the more suspicion many sense in regard to the values so summoned. Some shun every universalism and fear it might produce a global world order with uniform procedures crushing all cherished diversity. For reasons of cultural sensibility and moral empathy, should we not rather prefer the regional over the universal imperative? Should we not therefore support a cultural relativism of values and norms?

Certainly, an enforced world-monoculture that with uniform procedures did violence to all diversity is undesirable. In the age of globality, however, a relativistic stance, according to which each and everyone sees only their own norms as valid, is just as inappropriate. Wherever human beings interact, there is the threat of conflicts which require arbitration. Only at the utmost risk to our surroundings (Umwelt) and lifeworld (Mitwelt) can we live out our freedom without coordination. Only at the cost of the deepest mistrust on all sides can freedom dismiss all bounds and refuse every universal stricture. Where everyone is at once party and judge there is a threat of eternal strife. Each increase in the possibility of conflict enhances the yearning for the reality of arbitration.

In lockstep with the effects of private as well as collective politico-economic activity, the law must thus gradually develop beyond the bounds of national legal systems. And since every judiciary requires a legislative body and this, in turn, requires an executive, economic globalization creates the demand for a politically lawful globalization. ${ }^{4}$ Yet, at the same time, laws and courts on their own cannot put things right. As the sword of the law often proves too short and at other times too coarse a weapon, juridical coercion (Zwang) must be supported by moral impulse (Drang). Actions reflect attitudes - and thus up to now no legal-system has survived, which was not also morally legitimated, complemented, and differentiated. Law and morals, although distinct, can only be successful when they are working together.

We thus have to consider what mediates between the particular and the universal, between families and state, between morality and law. The intermediary level of civil-society must be investigated in its own moral forms, differing from context to context. Whether freedom be granted in societies, organized in companies, channeled by networks, charged within movements, whether it manifests itself in trends, rites, or customs, in each such case and scenario, it comes with a certain, specific responsibility: an ethical dimension, which while closely corresponding with morality and right, does not culminate within them. Only when this intermediary level of ethicality (Sittlichkeit) is likewise included, can fair and sustainable structures for mankind's economic networking and political striving be established (aufzubauen) and - catering differently to different contexts and cultures - extended (auszubauen).

\footnotetext{
${ }^{4}$ See Joseph E. Stiglitz, Making Globalization Work (New York: W. W. Norton \& Co., 2006).
} 
Freedom must be balanced and differentiated by responsibility in three differing ways: On the micro-level of individual morality, on the meso-level of social conventions and norms, as well as on the macro-level of general law. All three levels those of the individual, those of the associations, as well as those of governments - point towards the cosmopolitan framework they operate in. What affects all must also be effected by and in the interests of all. More than ever before, our thinking today therefore requires a moral compass for cosmopolitan questions, which adjusts and aligns morality, ethicality (Sittlichkeit), and law, notwithstanding their necessary functional differences. Our joint world requires a unifying ethos (Ethos).

While it was hitherto the hallmark of moral idealists to call for a use of freedom according to universalizable maxims, as if we were accountable to "the entire world," now even self-declared realists recognize as the bellwether of the present that our enlightened self-interest increasingly overlaps with the precepts of moral cosmopolitanism. In amazement, the hardcore empiricist notices how an idealistic ethic (Ethik) proves itself to be a realistic methodology. In politics and economics, as well as in ecology and culture, it turns out time and time again that freedom endures only when used with cosmopolitan responsibility. Ethics features increasingly as a strategy of sustainability.

Then again, one person's god is another person's idol; truth over here equals heresy over there. The more intense the cultural exchange and the pace of social change become, the more sharply we confront the problem that regional customs, religious traditions, and the conventions of the past no longer enjoy ubiquitous and unquestioned authority. Every thrust of globalization narrows the scope of traditional ethics. And, with every increase in plurality, our life suffers the loss of long familiar bonds. To prevent the growing difference of individual norms resulting in an increasing indifference to all values, we urgently need to determine to which ethical standards we are to hold fast to in the future.

Universalist philosophers have forever attempted to outline precisely such goals and principles with authority for all of humankind. However, these attempts often suffered from two problems; from principle objections against their theoretical validity and from pragmatic doubts about their practical efficacy. On principle it was asked: Why, actually, should rules drawn up within one place or time also be valid in another? Pragmatically it was objected: How could values neatly drafted on the drawing board of pure thinking at all be adequate to the multi-colored fabric of our multi-faceted life?

Whoever wants to respond to the fact of our global existence and with a worldwide ethical pact must answer both objections. Can we find principles with the power to resolve - not only familiar - but also completely unprecedented problems? In order to motivate, as well as to legitimate global action we require an ethic that unlocks the past for the present, instead of one which, in its glance towards yesteryear, obstructs the path towards the future. At the same time, the factual divergence of norms found upon this planet is neither to be crushed nor concealed. We thus 
require an ethic in harmony with the different cultures and traditions of this world. The era of unilateral nationalism is over in politics just as much as in moral philosophy. The world needs universalism and difference; that is the cosmopolitan mandate, to which current theories in globalization ethics have to correspond. ${ }^{5}$

This book argues that, in this age of late modernity, such an ethic is best sought in the results of a qualitatively oriented idea of freedom. That may seem surprising: For does not every human being have a different view of freedom? Is not freedom therefore an idea that divides rather than unites? Is there really (only) one idea of freedom, which could be just as global and as differentiated as the very problems it aims to solve? Moreover we should consider: Why make freedom so central? Why burden the (too narrow?) shoulders of liberalism with the extensive topic of globalization? Do not Western attitudes thus become the measure of all things, with political predilections influencing our choice of principle, and occidental values from the outset suppressing the polyphony of the cosmopolitan symphony? I do not think so.

Within the ranks of all values proclaimed around the globe, freedom deserves a special place. Certainly, there are cultures which, according to their explicit selfunderstanding, are not based upon the idea of freedom. Yet everyone implicitly claims freedom qua self-determination, even and especially when the liberty to lead one's life as one sees fit is denied. Even individuals and groups ascribing to completely illiberal modes of life place importance upon doing so autonomously. Any commitment to values, not least fanatical ones, becomes absurd when enforced. De facto therefore even fundamentalists lay claim to freedom: as and for selfdetermination. Consequently, they have no convincing reason to deny others theoretically the very same autonomy they themselves make use of practically. Since this individual freedom cannot be consistently denied, it must consequently be granted to others: All the liberal thinkers reconstructed within this book agree about that. For to recognize what one claims for oneself, and to approve what there is no good reason to militate against, is but the very nature of reason. In this indirectly self-justifying structure, the idea of freedom is unique, and thus recommends itself for the clarification of cross-cultural moral questions of value.

While the idea of freedom is invoked worldwide, people understand it extremely differently from one place to the next. No universal form seems to correspond to its global employment. Not everyone understands the same thing by freedom - quite the contrary. The genesis and validity of the idea of freedom appear severed; in places where freedom reigns in the kingdom of ideas, it does not necessarily manifest itself also in practice. Due to this variety of the understanding of freedom (both proclaimed and lived) and in the face of rising challenges and controversies produced by globalization, it is high time for a reassessment of the idea of freedom.

\footnotetext{
${ }^{5}$ See Anthony Appiah Kwame, Cosmopolitanism: Ethics in a World of Strangers (London: Penguin, 2007); Claus Dierksmeier, Humanistic Ethics in the Age of Globality (Basingstoke: Palgrave Macmillan, 2011).
} 
Not incidentally, the discourse about the essence and value of freedom takes place globally. ${ }^{6}$ Some propagate an "Eastern" understanding of freedom (inner, spiritual freedom from dependencies and material desires) against a flatly hedonistic "Western" liberalism. ${ }^{7}$ Others locate the decisive rupture among conceptions of freedom, not so much between East and West, but rather between a conservative Northern and a progressive Southern ideal of freedom. ${ }^{8}$ For example, within writings dealing with the philosophy of liberation, it is common to contrast the emancipatory ideas of freedom of the Global South against the North's conceptions of freedom, which are often perceived as conservative. ${ }^{9}$ Does one therefore have to think about the planet as divided into different hemispheres of freedom, with the Northwest in the role of the insensitive egoist? Hardly. The struggle for the idea of freedom is not only a fight between states and regions, but also one well within those cultural spheres. ${ }^{10}$

Even within the northwestern zone, stylized by such geographical schemes as the universal malefactor, one nevertheless finds extreme differences of opinion concerning how freedom is actually constituted. Angloamerican bestselling authors like Jeremy Rifkin and George Lakoff are good examples. Rifkin describes and supports, for instance, a tension between European (i.e. attractive and sustainable) and American (i.e. unattractive and ruthless) views about freedom. ${ }^{11}$ The emphatic dis-

\footnotetext{
${ }^{6}$ For details see Rolf Steltemeier, Liberalismus: Ideengeschichtliches Erbe und politische Realität einer Denkrichtung (Baden-Baden, 2015).
}

${ }^{7}$ See Joseph Mitsuo Kitagawa, Spiritual Liberation and Human Freedom in Contemporary Asia (New York: Peter Lang, 1990).

${ }^{8}$ See José Luis Rebellato, La Encrucijada De La Ětica: Neolibaralismo, Conflicto Norte-Sur, Liberación (Montevideo: Multiversidad Franciscana de América Latina: Nordan Comunidad, 1995).

${ }^{9}$ See the contributions in Mabel Moraña, Enrique D. Dussel \& Carlos A. Jáuregui, eds., Coloniality at Large: Latin America and the Postcolonial Debate (Durham: Duke University Press, 2008) as well as in Carlos A. Jáuregui \& Mabel Moraña, Colonialidad Y Critica En América Latina: Bases Para Un Debate (Puebla, Mexico: Universidad de las Américas Puebla, 2007); Kamilamba Kande Mutsaku, Desarrollo y Liberación: Utopias Posibles Para Africa y América (México, D.F. Tec de Monterrey, Campus Estado de México: Porrúa, 2003) and Robert Taylor, ed., The Idea of Freedom in Asia and Africa (Stanford: Stanford University Press, 2002).

${ }^{10}$ See Oded Balaban and Anan Erev, The Bounds of Freedom: About the Eastern and Western Approaches to Freedom (New York: P. Lang, 1995).

${ }^{11}$ Within this discourse there is a rather schematic attitude that "Americans hold a negative definition of what it means to be free and, thus, secure. For us, freedom has long been with autonomy. If one is autonomous, he or she is not dependent on others or vulnerable to circumstances outside of his or her control. To be autonomous, one needs to be propertied. The more wealth one amasses, the more independent one is in the world. One is free by becoming self-reliant and an island unto oneself. With wealth comes exclusivity, and with exclusivity comes security. [...] For Europeans, freedom is not found in autonomy but in embeddedness. To be free is to have access to a myriad of interdependent relationships with others. The more communities one has access to, the more options and choices one has for living a full and meaningful life. With relationships comes inclusivity, and with inclusivity comes security" (J. Rifkin, The European Dream: How Europe's Vision of the Future is Quietly Eclipsing the American Dream [New York: Polity, 2004], 13). See also: Mark Leohard, Why Europe Will Run the 21 st Century (London \& New York: Fourth Estate, 2005). 
tinction between a rather compassionately-relational theory of freedom and a harshly-absolute one is, however, also found within the USA itself. Lakoff, for example, derives precisely this distinction from a conflict between the ideals of freedom of the Democrats and Republicans. ${ }^{12}$

Such schemata are extremely limited in terms of their cognitive value; they fail to do justice to the phenomena in question by disguising overly the internal diversity of opinions within the described camps. It would, however, also be mistaken to believe that one gets closer to the truth by further differentiating through ever subtler subdivisions, for example, by distinguishing within the USA between the Republicanism of the coastal states and that of the inland states, and then again by differentiating between the urban, suburban, and provincial strata of the population, or by distinguishing along the lines of religious communities, ${ }^{13}$ or breaking things down historically (along, e.g. the conflict lines of the American civil war). ${ }^{14}$ This all seems as pointless as it is laborious.

Supporters of different concepts of freedom exist in every culture, after all. ${ }^{15}$ There is no region upon the earth so homogenous that each and all of its proponents of liberal view-points would neatly agree upon one single conception of freedom. ${ }^{16}$ So, the fact that, in spite of their obvious unsuitableness, attempts at geographical clustering continue to put in an appearance, indicates, above all, an unsatisfied need for orientation in matters concerning freedom. Just as horoscopes react - though miserably ineptly - to a genuine striving for meaning within the human heart, those cultural-morphological derivations correspond to a similar type of need for clarity about the idea of freedom. My work aims to respond to this very yearning for order and orientation.

\subsubsection{Freedom and Everyday Life}

Our everyday life is shot through with the implications of our ideas about freedom. The prevalent conceptions of freedom diverge not only theoretically, but also lead to tangible practical differences. Intellectual indifference concerning questions of freedom thus translates, willingly or unwillingly, into an affirmation of predominant types of freedom. Whoever remains undecided still decides - namely for the

\footnotetext{
${ }^{12}$ See George Lakoff, Whose Freedom? The Battle over America's Most Important Idea (New York: Farrar, Straus and Giroux, 2006).

${ }^{13}$ See John G. Sperling \& Suzanne Helburn, The Great Divide: Retro Vs. Metro America (Sausalito: PoliPoint Press, 2004).

${ }^{14}$ See Eric Foner, ed., Voices of Freedom: A Documentary History (New York: W. W. Norton \& Co., 2011).

${ }^{15}$ See Svetlana Boym, Another Freedom: The Alternative History of an Idea (Chicago: University of Chicago Press, 2010).

${ }^{16}$ See Amartya Sen, Identity and Violence: The Illusion of Destiny (New York: W. W. Norton \& Co., 2006).
} 
established set of freedoms. Whoever withdraws from the discussion about freedom through poses of neutrality in no way displays impartial equanimity, but rather takes a partisan stand for the status quo. Abstention supports the currently dominant ideas of freedom, and is just as worthy of criticism or in need of justification as the standpoints that it strengthens.

If, for example, some (politicians, for instance) reduce freedom to but a choice amongst given parties or others (economists, say) to merely a choice between extant options of consumption, liberal philosophy must come to the fore. It has to question the structures which admit precisely these and no other possibilities. Why reduce freedom to the very options granted by market and power? Why relate freedom only to choices within the system, and not also to the choice of the system itself? Why, moreover, limit freedom only to acts of choice and not also think about creating new options and changing others so as to create novel opportunities?

Which notions of freedom are we employing here respectively? Does, for instance, economic freedom at times constrain the freedom to enjoy unpolluted nature, the freedom for cultural self-creation, and non-conformist personal development? And where then are our priorities? Which freedom and whose freedom should have precedence? A simple declaration of loyalty to the abstract idea of freedom does clearly not suffice but must translate into serious efforts at its conceptual concretization. That is to say, the discourse concerning freedom has much more than merely an academic significance and hence cannot be confined to the ivory tower of academic debates. In the realm of freedom, the battle of ideas interconnects with the war between systems; and the critique of power showcases the power of critique.

The battle over freedom illustrates that and how ideas can change the world. Hardly ever is the practical effect of philosophy so evident as in the patent distinctions within the organization of culture, politics, and business, which start from diverging conceptions of freedom (like, for example, in North and South America) or which are championed by different liberal parties such as, for example, by the liberally conservative VVD and the progressively liberal D66 in Holland. ${ }^{17}$ Thinking about our personal and political liberties cannot, therefore, be left only to professional thinkers. It is the calling of any and all citizens. The philosophical profession can enrich, stimulate, and broaden these reflections, however it cannot replace the civic discourse.

That is why in what follows I do not simply put forward a ready-made conception of philosophical liberalism. Rather I develop my position step by step by means of the reconstruction of important theories of freedom, first, through the approaches of Kant, Fichte, and Krause, as variations of liberalism in the eighteenth and nineteenth centuries, and then through the theories of Rawls and Hayek as well as Galbraith and Sen as representatives of the debates about freedom in the twentieth century and the present. As a result, readers are not simply spoon-fed the conception (of quantitative and qualitative freedom) introduced in this book. It rather gradually

\footnotetext{
${ }^{17}$ See Rudy Andeweg and Gale Irwin, Politics and Governance in the Netherlands (London \& New York, 2009).
} 
emerges in front of their eyes as the result of following in the footsteps of some of the most important modern philosophies of freedom.

I am of the opinion that the idea of qualitative freedom here presented articulates well the contemporary consciousness of the problems of citizens with liberal leanings. For some liberals these days feel more at home in the conservative camp because they prefer freedom to be expressed in terms of responsibility rather than license. Other friends of freedom move to the left because they recognize that freedom needs preconditions that the market is often unable to provide. Others question political liberalism for ecological reasons because it seems to ride roughshod over nature's needs. Thus, the cause of freedom is more and more surrendered to those who aspire to a freedom, not moving towards, but rather moving away from responsibility and ethical commitment. Political liberalism is thus threatened with moral hypothermia. Whoever fights for freedom just for his own interests or for the sake of material goods (namely financial goods) surely betrays the liberal flag as soon as these interests are able to be more adequately materialized elsewhere. Such friends, however, hurt liberalism more than any foes.

Critical voices from inside our open societies and extreme voices from outside both claim that without rigorous normative goals the acid bath of capitalist culture will disintegrate the liberal ideal into a multitude of hedonistic idols: Freedom would thus evaporate into the liberty to consume. ${ }^{18}$ Why however - those who do not consider themselves as belonging to the liberal camp will ask - should traditional values and morals be sacrificed in the name of such an idol at all? Why, for example, be unfaithful to God in order to serve Mammon? Why cut solidarity in order to make space for selfishness? Why push back decent and just modes of life for a vision of freedom orientated at a ruthless maximization of profits or a voracious hunt for amusements? ${ }^{19}$ Why speak only of business freedom and not also of freedom from business? ${ }^{20}$ Why equate liberalism with capitalism? ${ }^{21}$

Why is there this tendency towards a moral depletion of liberalism? What drives the flight from values and the peculiarly materialist economic narrowness in liberal thinking? It seems to me that in the course of the last 250 years many of the liberal avant-garde have taken a disastrously wrong path. Their theories have distanced and alienated themselves from foundations which - if only they had been consistently spelled out - could have connected liberal philosophy with those very dimensions of ecological, social, and cultural sensibility and sustainability for the lack of which liberalism stands now everywhere accused. ${ }^{22}$

\footnotetext{
${ }^{18}$ See Zygmunt Bauman, Freedom (Milton Keynes: Open University Press, 1988), 92-97.

${ }^{19}$ See Crawford Brough Macpherson, Democratic Theory: Essays in Retrieval (Oxford: Clarendon Press, 1973), 91.

${ }^{20}$ See Lisa Maria Herzog, Freiheit gehört nicht nur den Reichen: Plädoyer für einen Zeitgemässen Liberalismus (München, 2014).

${ }^{21}$ See Karl Hermann Flach, Noch eine Chance für die Liberalen; oder, die Zukunft der Freiheit: Eine Streitschrift (Frankfurt am Main: S. Fischer), 17.

${ }^{22}$ See Pankaj Mishra, From the Ruins of Empire the Revolt against the West and the Remaking of Asia (London: Allen Lane, 2012).
} 
That is to say, something rings true in these criticisms of liberal thought. Yet I am no pessimist. Up until now every crisis of liberalism has proven to be a chance for the revitalization of the idea of freedom. ${ }^{23}$ Self-complacency, much rather than criticism, is a threat to liberalism. Where liberalism does not confront the critical demands of the present, the cozy milieu of liberal parties becomes suffocated by the uncanny fug of partisan liberals. In narcissistically embracing itself, liberalism condemns itself to autoerotic infertility and thus eventually to extinction. Fecundity, on the other hand, results from interaction with one's other. Only they who seek out the other will find themselves. Only they who feel at home with alterity can house themselves. This is especially true of the intellectual eros of freedom. The idea of freedom must hence be more interested in its challengers than its sycophants.

The task, pursued throughout the whole of this book, of working towards a theory of freedom doing justice to the globality and interculturality of our lives, results from these theoretical and practical aims. In a world in which the course of events rips apart once obligatory rules, the eternal and intercultural principles of philosophers prove especially apt for establishing new reference points. ${ }^{24}$ From time immemorial, philosophy has made a noble virtue out of the necessity of thinking unaided by unquestioned certainties and unquestionable authorities. ${ }^{25}$ Where the implicit validity of morals and traditions cannot (any longer) be counted upon, the capacity to explicitly trace and competently criticize the presuppositions of legitimacy already inherent within social speech and action pays off. Thus does practice require philosophy.

Of course, theories alone cannot repair the world; but insofar as they show us new possibilities, they do herald the way to alternative realities. ${ }^{26}$ In view of the pressing global problems and the shockingly uninspired way in which the political world responds to them, the intellectual renewal of the idea of freedom and the search for a viable liberalism do indeed not seem to be idle undertakings. The very globality that challenges our contemporary notions of freedom thereby also provides us with a touchstone. At all times, human freedom has been conceptualized according to a framework which gave it meaning ( Sinn), i.e. both significance and direction. Today this is especially necessary again. As, however, the ethical guidelines of orientation

\footnotetext{
${ }^{23}$ See Friedrich Naumann, Gegenwart und Zukunft des Liberalismus: Mit einer Federzeichnung nach einem Porträt Friedr. Naumanns von Schneider-Franken (München: Buchhandlung Nationalverein, 1911).

${ }^{24}$ See Henry S. Richardson \& Paul Weithman, ed., Development and Main Outlines in Rawl's Theory of Justice (New York: Garland, 1999) and Henry S. Richardson \& Paul Weithman, ed., The Two Principles and their Justification (New York: Garland, 1999).

${ }^{25}$ See Michel Foucault, Von der Freundschaft als Lebensweise: Michel Foucault im Gespräch (Berlin: Merve, 1984).

${ }^{26}$ As Martha Nussbaum says, "theories are only one influence on people's lives, but they are one influence (Martha Craven Nussbaum, Frontiers of Justice: Disability, Nationality, Species Membership [Cambridge MA: Harvard University Press, 2006], 223). She also tells us that "the answers to large philosophical questions have practical significance. They shape our sense of what is possible" (ibid. 415).
} 
of culture and religion are often formed and conditioned by the contexts to which they owe their generation, in our globalized world, merely local and regional standards will not suffice, and the question about unconditional, context-independent guidelines can no longer be postponed. Freedom must be related to values that can exert a unifying force over all borders and across every plurality. The idea of freedom thus leads to the project of a global ethos.

\subsubsection{Freedom and Academic Philosophy}

In the historical hit parade of philosophy, the idea of freedom is a golden oldie; and - especially because of the turbulent history of the previous century - in the past decades, debates concerning political and economic freedoms have been very animated. In most countries, analytic philosophy dominated the academic scene, and this holds true up to now in the Anglo-American world. In light of that it may well seem surprising that this investigation begins with a chapter about the metaphysics of freedom. Many analytic philosophers, after all, are hugely skeptical about metaphysics. And since some of them are downright hostile to it, and denigrate in particular the theories of German Idealism, which we will be dealing with extensively later on, as "philosophically defunct", ${ }^{27}$ our point of departure is in need of a brief defense.

At the beginning of the twentieth century, analytic philosophy was shaped by positivist thinkers, then, towards the middle of that century, by linguistically oriented schools, and finally, at the end of the century, by naturalist schools. Its most outstanding champions accordingly attempted to reduce time-honored philosophical problems and questions (such as, for example, about the essence of freedom) first to logical problems, then to linguistic problems and finally to problems of natural science..$^{28}$

Popular within all analytic camps is the assumption that scientifically serious philosophizing only truly began with Gottlob Frege (1848-1925), so that the work of previous thinkers can at best be considered a quarry for contemporary intellectual constructions. Now, this opinion must of course not necessarily be uncritically accepted (angenommen), it certainly should be apprehended (ernst genommen) since it still continues to shape the attitude of many professional philosophers who are wont to banish all metaphysical systems of thought to the mythical infancy of actual philosophy (characterized by formal logic and the analysis of language). Exalted metaphysical reasoning must - in their eyes - be cut back to the boundaries of sober understanding. Scientific philosophizing has to either maintain itself only

\footnotetext{
${ }^{27}$ Brian Leiter, The Future for Philosophy (Oxford: Oxford University Press, 2004), 23.

${ }^{28}$ See Christopher Gefwert, Wittgenstein on Thought, Language and Philosophy: From Theory to Therapy (Aldershot: Ashgate, 2000) and James F. Peterman, Philosophy as Therapy: A Interpretation and Defence of Wittgenstein's Later Philosophical Project (Albany: SUNY Press, 1992).
} 
within the ambit of the empirically observable and logically compelling ${ }^{29}$ or at least obediently subordinate itself to the predominate use of language and ideas. ${ }^{30}$ These demands have their downsides however.

These postulates have much more serious implications for the critique of society than their modest and scientifically sober sound lets on. Whoever produces political ideas like that of freedom only from measurable facts or the common use of language slows down their social dynamic of development. Why? Because theories solely orientated at the given empirical or linguistic inventory shift the critique of what is given, i.e. at the status quo, into the private sphere. Only a philosophy committed to a normative tension of its concepts in respect to reality can center on the objective truth of critique. ${ }^{31}$ Positivism however - in its epistemological as well as its linguistic variant - knows only of subjective opinions. These either prevail in society and/or in the use of language, or they do not. Until they do, though, they are, positivistically speaking, virtually unreal and therefore as irrelevant as a strictly private language. Consequently a philosophical critique of ideas and society would be assigned roughly the same status as personal complaints about the weather. That theoretical exile of critique to the private sphere also promotes its banishment from public practices insofar as it incapacitates academic scholarship to promote counterfactual ideals. Defused theories cannot lead to social explosions. Philosophy thus degenerates into affording anodyne indulgences to the established order. ${ }^{32}$

The permanently resonant assumption of, for example, the champions of the Vienna Circle, that philosophical controversy concerning ideas and principles is ultimately avoidable and could be therapized away by more exact terminological distinctions has in the meantime had its day. ${ }^{33}$ Today, even in the Anglo-American

\footnotetext{
${ }^{29}$ See Otto Neurath \& Rainer Hegselmann, Wissenschaftliche Weltauffassung, Sozialismus und Logischer Empiricismus (Frankfurt am Main: Suhrkamp, 1979), Moritz Schlick, Allgemeine Erkenntnislehre (Berlin: Springer, 1918).

${ }^{30}$ Representative of that is: Ludwig Wittgenstein, Philosophical Investigations (Oxford: Blackwell, 1953).

${ }^{31}$ See Martha Craven Nussbaum, "Human Functioning and Social Justice in Defense of Aristotelian Essentialism," Political Theory 20:2 (1992), 202-246.

${ }^{32}$ Herbert Marcuse's critique put forward at the beginning of the 1960s, which states that linguistic philosophising too easily gives up its counterfactual potency is, mutatis mutandis, still valid. See Chapter 6 in Herbert Marcuse, Der Eindimensionale Mensch: Studien zur Ideologie der Fortgeschrittenen Industriegesellschaft (Neuwied \& Berlin: Luchterhand, 1967).

${ }^{33}$ Ludwig Wittgenstein decisively contributed to this change of attitude (and thus to the fading of positivism even in analytic philosophy). Earlier on within his program of a logical purification formulated in his Tractatus he certainly made a sustained contribution to logical positivism (see Ludwig Wittgenstein \& Bertrand Russell, Tractatus Logico-Philosophicus [London: Kegan Paul, 1922]). He later deviated from this program, however, because he could only explain the logical inconsistency of language through the philosophical analysis of everyday language, including the evaluations and intuitions it comprises (see Ludwig Wittgenstein, Philosophical Investigations [Oxford: Blackwell, 1953]). For a detailed discussion see Wolfgang Kienzler, Wittgensteins Wende zu seiner Spätphilosophie 1930-1932: Eine historische und systematische Darstellung [Frankfurt am Main: Suhrkamp, 1997]). The fundamental assumption of Wittgenstein's earlier philosophy that "the correct method of philosophy [...] actually [would be] this: To say nothing other than what is able to be said, i.e. propositions of natural science" (TLP 6.53), eventually changed. The
} 
world where analytic approaches have dominated the academic scene up to now, it is no longer believed that the "future for philosophy" lies in purely conceptual endeavors. ${ }^{34}$ - Ever fewer adhere to the view that the conflict about the idea of freedom could simply be resolved by linguistic distinctions. ${ }^{35}$ Although the philosophical investigation of language is still regarded as a very important means of philosophical cognition, it is no longer seen as the end of philosophical work. In its place, richer arguments have again moved into the center of philosophical thinking. ${ }^{36}$ An anthology about the philosophy of freedom designed for the AngloAmerican market thus bluntly declares, for example, that:

\begin{abstract}
Thirty to forty years ago, some philosophers believed that the controversies between negative-liberty theorists and positive-liberty theorists could be cleared up through a search for linguistic errors. Very few contemporary philosophers believe as much. Neither side in the negative/positive controversies is guilty of linguistic impropriety [...]. Virtually everybody now recognizes that the relevant considerations for one's choice between negativeliberty doctrines and positive-liberty doctrines are moral and political values and theoretical-explanatory values (such as clarity, precision, and parsimony).$^{37}$
\end{abstract}

This new spirit helps to bridge the gap, which for a long time had been said to be irreconcilable, between analytic and other traditions of philosophy. The decline of the analytic school's claim to be its sole representative opens up space within academic philosophy for other methods, like the dialectical, hermeneutical, phenomenological, and deconstructive thinking defended in the approaches of Continental European, Latin-American, Asian, or African philosophy. In these traditions, there always predominated the procedure, now also acclaimed among analytic philosophers, of making the method fit the facts and not vice versa. ${ }^{38}$ Never before were the chances of a methodological "crossover" in the discipline therefore so favorable.

resultant position is that the deeper problems of our lives are neither condemned to silence (TLP 6.52-57), nor said to begin only when and where all questions concerning the philosophy of language are already answered, but rather must be grasped as the inevitable product of everyday language when we win the "struggle against the bewitchment of our understanding by language's ways" (PU 109). This occurs as soon as we grasp how our language speaks for itself as a form of living (see PU 120-126). The philosophy of language in the spirit of the late Wittgenstein is therefore less the project of rejecting metaphysical questions as meaningless, but more the attempt to understand - through the probing exploration of meaningful speech - how the urgent problems of life arise as a result of the 'inexpressible' within language. Hence the late Wittgenstein too recognizes that the ultimate questions of metaphysics cannot be avoided - which is not to say that they can necessarily be answered. For more details see Friedrich Glauner, Sprache und Weltbezug: Adorno, Heidegger, Wittgenstein (Freiburg: Alber, 309).

${ }^{34}$ See Leiter, The Future for Philosophy.

${ }^{35}$ See J. Norman, "Taking "Free Action" Too Seriously," Ethics 101:3 (1991), 505-520.

${ }^{36}$ See Judith N. Shklar and Bernard Yack, eds., Liberalism without Illusions: Essays on Liberal Theory and the Political Vision of Judith Shklar (Chicago: University of Chicago Press, 1996).

${ }^{37}$ See Ian Carter, Matthew Kramer \& Hillel Steiner, Freedom: A Philosophical Anthology (Malden: Blackwell, 2007).

${ }^{38}$ See Bruce Wilshire, Fashionable Nihilism: A Critique of Analytic Philosophy (Albany: SUNY Press, 2002). 
Presently philosophers of all schools actively occupy themselves with mutual cooperation, in the common service of the joint cause. ${ }^{39}$

The theory of freedom profits from this situation. As a result of the methodological relaxation in the philosophical discourse, it is finally possible to also let go of petrified positions. There are numerous unjustified prejudices to be eliminated, such as that the idea of "positive freedom" is primarily championed by continental philosophers, while concepts of "negative freedom" are instead at home within the analytic camp (see Sect. 1.2); or that normative conceptions of freedom are typically harbored by the political left, while descriptive conceptions are said to tend to the political right - and more of this ilk.

My suggested application of the concepts of quantitative and qualitative freedom hopes to make the debate more flexible again, and proposes two revisions:

First, the debate about freedom should be clarified. Many of the usual labels negative versus positive freedom, formal versus material freedom, procedural versus substantial freedom, idealistic versus materialistic conceptions of freedom, libertarian versus communitarian freedom, etc. - do less justice to the issue at hand then the more precise and appropriate disjunction between the quantity and quality of freedom. I hope to show that this very differentiation has implicitly been in play in the background of many theories of freedom, and that a lot is achieved by explicitly bringing it to the foreground. Communicating in accurately defined concepts can assist us in verifying whether we also think in clear categories.

Second, one has to shift from thinking of the predicates of freedom in terms of binary oppositions towards conceptualizing them dialectically (see Sect. 1.3.3). Instead of using attributes which strive in completely opposed directions and reciprocally cancel out their logical powers, more appropriate labels should be found for the idea of freedom, which are able to relate to one another productively and thus augment their respective forces. By means of the labels of quantitative and qualitative freedom, still unencumbered by political connotations, I hope that a more integrative idea of freedom can be achieved than before, namely a conception which can constructively resolve the tensions between freedom and responsibility as well as freedom and sustainability.

\subsection{Why Not Negative Versus Positive Freedom?}

In some writings on political and economic theory, in much popular philosophy, and in almost all party-political writings, the language of negative and positive freedom is still very much in use. ${ }^{40}$ It characterizes concepts of freedom according to whether

\footnotetext{
${ }^{39}$ See the interesting studies which Jack Reynolds has assembled about the current rapprochement between analytic and continental philosophy in Jack Reynolds, ed., Postanalytic and Metacontinental: Crossing Philosophical Divides (London: Continuum, 2010).

${ }^{40}$ See for example: Detmar Doerring, Traktat Über Freiheit (München: Olzog, 2009) and Wolfgang Kersting, Verteidigung des Liberalismus (Hamburg: Murmann, 2009).
} 
they merely define themselves negatively - via the absence of coercion - or whether they also say something positively about freedom, with respect to its preconditions and aims. This kind of terminology has long since fallen out of favor within academic philosophy - and for good reason (for more about this, see Sect. 1.2.3). Yet it was only very recently that the corresponding insights also appeared within more popular publications. ${ }^{41}$ Before we proceed to elaborate the alternative favored here, i.e. the distinction between quantitative and qualitative freedom, we must hence briefly explain - first historically, then systematically - why we bypass the traditional distinction of negative versus positive freedom.

\subsubsection{The History of the Distinction}

A reference to their genealogy can illustrate how the concepts of negative and positive freedom in no way achieve what they intend. Isaiah Berlin (1909-1997) is often cited as the spiritual father of this distinction. ${ }^{42}$ But he merely popularized expressions he had found in the British Idealists, Thomas Hill Green (1836-1882) and Francis Herbert Bradley (1846-1924). They, in turn, were influenced by the work of Georg Wilhelm Friedrich Hegel (1770-1831), who had developed the distinction between (a) negative and formal freedom and (b) concrete and substantial freedom, in his engagement with the philosophy of Johann Gottlieb Fichte (1762-1814). So, this deceptively simple distinction carries a lot of historical baggage, and it may be surmised that precisely this excessive burden unduly hinders and trammels our thinking about freedom.

What was taking place when these concepts were first introduced? Hegel accused Fichte's conception of human existence of possessing too little regard for the objective conditions of life and a too great regard to the purely 'subjective spirit.' $\mathrm{He}$ charged Fichte with establishing the essence of humanity ("I") through the exclusion of all contexts (which Fichte summarized coldly as "not-I"). But, according to Hegel, whoever seeks freedom principally in the negation of the world and environment it shares, transforms freedom itself into a "fury of destruction." In its lack of positive commitments, negative freedom ends up merely centered on itself; theoretically this leads to formalistic emptiness and practically towards absurd ways of living - to a "fanaticism of destruction" of traditional orders. ${ }^{43}$ In what follows we

\footnotetext{
${ }^{41}$ For example, Udo di Fabio correctly stresses that the distinction between "negative" and "positive" does not achieve "the analytic level which is today both possible and necessary" (Udo di Fabio, Die Kultur der Freiheit (München: Beck, 2005), 81.

${ }^{42}$ As well as the classic "Two Concepts of Liberty" see especially "From Hope and Fear Set Free" and "Political Ideas in the 20th Century" in Isaiah Berlin, Henry Hardy and Ian Harris, Liberty: Incorporating Four Essays on Liberty (Oxford: Oxford University Press, 2002).

${ }^{43}$ Georg Wilhelm Friedrich Hegel, Hegels Werke in 20 Bänden [Hereafter TWA] (Frankfurt and Main: Suhrkamp, 1969), 7, 50. Translated in Hegel's Philosophy of Right (London, Oxford \& New York, 1967), 22.
} 
will examine whether this criticism is warranted, especially in regard to Fichte's social philosophy (see Sect. 2.2.1) as well as in regard to the concept of freedom in general (see Chap. 3).

Later on, there arose a similar discussion in England, which was of formative importance for the current understanding of the concept of negative and positive freedom as well as stylistically instructive for current vulgar liberalism. There and then, the distinction became loaded with political significance. Under the leadership of Jeremy Bentham (1748-1832), James Mill (1773-1836) and David Ricardo (1772-1823), English social philosophy had granted priority to the concept of utility before the principle of freedom. The British utilitarians assigned freedom a functional value, as opposed to an absolute one. They appreciated the license it granted to individuals to act in the manner that proves most utilitarian. Utility equals that which brings pleasure and avoids pain. Therefore, instead of reasoning about the proper quality of freedom, the utilitarians aimed at quantifying utility in the correct way. Utility had a materialistic odor and as such seemed more measurable than freedom or liberty which were suspected of undue idealistic tendencies. ${ }^{44}$ Liberalism smelled of vague philosophy, utilitarianism tasted of rigorous science.

The utilitarian surveying of freedom occurred as follows: Since total license would lead to chaos and thus to collective loss of benefits, a view toward aggregate social utility provides the best gauge for maximizing the average amount of individual options. Herein the legislative apparatus proves helpful, which summarily coordinates the separate interests of people and prioritizes preferences according to the majority principle. There were of course concerns that a tyranny of the lowest common denominator could arise and prove hostile to freedom. Yet, without much further ado, James Mill, the father of John Stuart Mill and a founding father of British utilitarianism, eliminated such concerns by means of a rhetorical device: "The community cannot have an interest opposite to its interest. To affirm this would be a contradiction in terms. The community within itself, and with respect to itself, can have no sinister interest." 45 A newfangled version of the old wisdom: Blessed is he who believes.

Herbert Spencer (1820-1908) already saw that this did not bode well for freedom. Hence he aimed to balance the principles of utility and liberty through the formation of a "liberal utilitarianism." ${ }^{46}$ In the evaluation of liberties, direct considerations of utility are to be pushed back in favor of the indirect pursuit of utility within liberal forms of living. Spencer assumed that the common good is best

\footnotetext{
${ }^{44}$ In this work, following the prevailing use of the English language, both concepts are treated as synonyms; it is for this reason also useful to refer to a study pars pro toto which pursues their etymological and political differences: David Hackett Fischer, Liberty and Freedom (OUP USA, 2004).

${ }^{45}$ James Mill, "Government" in Edwin A. Burtt, The English Philosophers: From Bacon to Mill (New York: The Modern Library, 1939), 861.

${ }^{46}$ See D. Weinstein, Equal Freedom and Utility: Herbert Spencer's Liberal Utilitarianism (Cambridge: Cambridge University Press, 1998).
} 
enlarged when the individuals who contribute to society are given ample space to unfold their talents and pursue their interests. Utility and freedom could be reconciled, if only the high utility of freedom - e.g. for the development of productive innovations - were adequately recognized, and for this reason personal liberties would be protected by law. ${ }^{47}$ As before, utility thus remains the ultimate criterion from which freedom is assessed and estimated, ${ }^{48}$ although the legislator is no longer supposed to pursue benefits to society directly, but rather indirectly, with the help of liberal procedures.

A similar attempt to reconcile liberality and utility was undertaken by John Stuart Mill (1806-1873). ${ }^{49}$ In his Principles of Political Economics he too interconnects liberty and utility. However, after first assessing the value of actions in their utility, and then in their contribution to human happiness, he appears ultimately undecided about what really comprises the latter. Mill's concept of happiness includes demands for human rights, calls for women's rights, and concerns about cultivated civility ${ }^{50}$ to such an extent as to discourage certain countervailing ideas of happiness: The coarser and more chauvinistic the people, the less their utility calculi find appreciation and consideration within Mill's work. For John Stuart Mill could certainly not agree with Bentham's proposition that, in respect to the promotion of happiness, the children's game "pushpin" is just as good as "poetry," ${ }^{1}$ and he instead declared that "it is better to be a human being dissatisfied than a pig satisfied; better to be Socrates dissatisfied than a fool satisfied. And if the fool, or the pig, are of a different opinion, it is because they only know their own side of the question. The other party to the comparison knows both sides." ${ }^{52}$ - A quite important insight in respect of the tendency of some modern economists to equate freedom simply with the fulfilment of preferences.

After having reduced all ethical criteria to but one (utility), John Stuart Mill diligently attempted to rescue the principles of freedom and justice from his own radicalism - i.e. from their utilitarian challenge. Thus, however, the question emerges,

\footnotetext{
${ }^{47}$ This position receives renewed support within the work of current utilitarians: mutatis mutandis in the differentiation between utility as decision-making criteria and decision-making procedure, see for example: James Griffin, "The Distinction between Criterion and Decision Procedure: A Reply to Madison Powers," Utilitas 6:2 (1994), 177-82.

${ }^{48}$ See David Lyons, "Utility and Rights"in J, Roland Pennock \& John W. Chapman, Ethics, Economics and the Law (New York: New York University Press, 1982).

${ }^{49}$ See the following: Alan Ryan, The Philosophy of John Stuart Mill (Basingstoke: Macmillan, 1987); John Charvet, A Critique of Freedom and Equality (Cambridge: Cambridge University Press, 1981), 95; and John Gray, "Mill's and Other Liberalisms," Critical Review 2:2-3 (1988), $12-35$.

${ }^{50}$ See Nussbaum, Frontiers of Justice, 346.

51 "Prejudice apart, the game of push-pin is of equal value with the arts and sciences of music and poetry." Jeremy Bentham, The Rationale of Reward (London: R. Heward, 1830).

${ }^{52}$ John Stuart Mill, Utilitarianism (Longman, 1864). See also: Dissertations and Discussions: Political, Philosophical and Historical: Reprinted Chiefly from the Edinburgh and Westminster Reviews (London: J. W. Parker, 1856), 389.
} 
which ultimately has priority in cases of conflict, the primary value (utility) or the secondary values (liberty, justice) $?^{93}$ At this point, a reversal of the direction of argument, entailing a radical self-justification of freedom, seems to be in the air, however it is not seized upon. At long last, the utility citizens gain from legal security constitutes the sole reason for all normative obligations, including those required in the name of protecting liberty. Mill's defense of freedom thus remains orientated extrinsically around the inefficiency of excessive or contingent restrictions of liberties, or, conversely, around the utility of their moderate and lawful provision. While the intrinsic value of freedom certainly shines through several passages of his work, Mill does not hold on to it. In short, Mill's accomplishment is to foreshadow a path for freedom as a self-justifying principle, but his failure lies in not having walked down that alley. ${ }^{54}$

At any rate, this was how Thomas Hill Green (1836-1882) saw it. He thought the utilitarian founding of freedom allowed the promotion of a freedom "that can be enjoyed by one man or a set of men at the cost of freedom to others." ${ }^{55}$ In contrast, Green declared that freedom is legitimized as well as limited by the autonomy it facilitates. With the concept of "positive freedom" Green attempted then to give expression to the social-democratic notion that everyone has the right to conditions that make his or her freedom realizable. However, not only this notion. ${ }^{56}-$ For Green, the concept of "positive freedom" had an internal as well as an external aspect. Green also adopted the following formula: "We do not mean merely freedom to do as we like irrespective of what it is that we like. [...] When we speak of freedom as something to be highly priced, we mean a positive power or capacity of doing or enjoying something worth doing or enjoying." ${ }^{57}$

The success of this formula proved fatal. The great popularity of this moralphilosophical dimension of Green's theory with the protagonists of speculative idealism belatedly appearing in England made the concept of "positive freedom" a welcome target for their opponents. They simply assumed that whoever differentiates between a good and a bad use of freedom also separates a true and a false self within a human being, and demands that the true and higher self subjugate the lower and the false self - if necessary with the help of collectives. ${ }^{58}$

\footnotetext{
${ }^{53}$ See Chin Liew Ten, ed., Mill's On Liberty: A Critical Guide (Cambridge: Cambridge University Press, 2008). See also the discussion with Peter Ulrich, Dorothea Bauer and Michael S. Assländer, eds., John Stuart Mill: Der Vergessene Politische Ökonom und Philosoph (Bern: Haupt, 2006).

${ }^{54} \mathrm{John}$ Rawls rates the beginnings of Mill's project more highly in John Rawls and Barbara Herman, Lectures of the History of Moral Philosophy (Cambridge: Cambridge University Press, 2000), 343, 366.

${ }^{55}$ Thomas Hill Green and Richard Lewis Nettleship, Works of Thomas Hill Green (London \& New York: Longmans, Green \& Co., 1889) III, 370.

${ }^{56}$ Avital Simhony, "On Forcing Individuals to be Free: T. H. Green's Liberal Theory of Positive Freedom," Political Studies, 39:1 (1993), 303-320.

${ }^{57}$ T. H. Green, ibid.

${ }^{58}$ This suspicion persisted until the 1960s, such as within the works of Isaiah Berlin. See Melvin Richter, The Politics of Conscience: T. H. Green and His Age (Cambridge: Harvard University Press, 1964), 202.
} 
Such metaphysics quickly leads to totalitarianism. One only needs to also declare that the law is only obligated to protect 'true' freedom and not 'false' liberties. Then already one can ascribe to that state the care for the virtuous life of its citizens, even through compulsory measures. So it may seem that this theory legitimates the abolition of actual liberties in the name of ethical freedom. The bourgeois liberties (Abwehrfreiheiten) thus run the risk of being drowned in the holy waters of morality. Although this interpretation was a crude, even ludicrous caricature of most of the British Idealists, it did not arise without reason. Fichte's legal and economic philosophy, for example, follows this pattern at times (see Sect. 2.2.3); and Stalinists as well as Nazis knew cleverly to use similar arguments in order to disguise their totalitarian objectives as expressions of such allegedly "higher freedom."59

Ludwig von Mises (1881-1973), Friedrich August von Hayek (1889-1992), and Isaiah Berlin (1909-1997), who all found asylum within England and the USA in the 1930s, had had to watch from up close how in Germany and Russia the liberal heritage of the nineteenth century was thus redefined for the justification of illiberal collectivisms. No wonder they wanted to help to bring renewed prestige to the bourgeois liberties, which, though guaranteed in the Anglo-American sphere, had meanwhile been discredited elsewhere as inimical to solidarity. Green's concept of "positive freedom" fell victim to their concern. Without further ado, they declared it a gateway to that totalitarianism they had recently escaped only by a hair's breadth and barricaded themselves behind the walls and ramparts of "negative freedom."

Mises and Hayek above all rejected Green's social-democratic orientation and defended the astonishing opinion that even the smallest step beyond the sphere of negative freedom would bring society irrevocably in the direction of compulsory socialism; a view to which, incidentally, Friedrich August von Hayek quite clearly did not hold when working out his social philosophy (see Sect. 3.1.4). Isaiah Berlin attacked from a different angle. While he expressly sympathized with Green's social concerns (more about this later), he took issue with his metaphysics. He deemed Green's concept of "positive freedom" to be based upon a "metaphysical doctrine of the two selves"; and Berlin feared that a dualistic fallacy allegedly contained therein, when politically applied, would leave the door wide open to illiberalism. ${ }^{60}$

Both interpretations, however, the socialistic as well as the metaphysical, do not do justice to T. H. Green. ${ }^{61}$ Green had by no means adhered to a metaphysical conception of a divided self, but was rather expressly opposed to conceptions that proceed.

\footnotetext{
${ }^{59}$ For more information about this see Stalin's response to a statement of the British Foreign Minister in which he complained about the lack of freedom in Russia, which appeared in Pravda in 1951: http://www.revolutionarydemocracy.org/rdv9n2/stalin.htm. See also Hans Freyer, Revolution von Rechts (Jena: E. Diedrichs, 1931).

${ }^{60}$ For more information about this and the following, see Avital Simhony, "Beyond Negative and Positive Freedom: T. H. Green's View of Freedom," Political Theory 21:1 (1993), 28-54.

${ }^{61}$ Maria Dimova-Cookson, "A New Scheme of Positive and Negative Freedom: Reconstructing T. H. Green on Freedom," Political Theory 31:4 (2003), 508-32.
} 
as if there were really two characters in a man, empirical and intelligible, one determined by motives in which there is no freedom, the other determined by reason only in a way which excludes determination by motive and is free. In truth there is only one character. ${ }^{62}$

Due to certain predispositions and experiences, every character is differently formed and develops independent ideas of the good - in the plural. ${ }^{63}$ Every single human being follows a "varied nature of his view of the good" ${ }^{64}$; society as a whole must therefore allow that the good be pursued "in many different forms." 65 Therefore, it is not for the state to define how personal characters should be constituted and which ideas of the good they ought to aspire to. Rather Green understands "freedom in the positive sense" explicitly as "liberation of the powers of all men equally for contributions to the common good." ${ }^{66}$ In personally assuming that burden (Bürde) of assuming responsibility on one's own terms consists the dignity (Würde) of freedom. The state cannot and must not interfere here. "All that one man can do to make another better is to remove obstacles and supply conditions favorable to the formation of good character." 67

Whereas it is incumbent on the individuals freely to contribute to the common good, to society corresponds the obligation of making all individuals capable to take on this task. Consequently, the state should guarantee the material, health and pedagogical conditions required for reasonable autonomy. ${ }^{68}$ In this vein Green declares "the ideal of true freedom is the maximum power for all members of human society to make the most of themselves"; an expression which strongly reminds us today of Amartya Sen's concept of capabilities (see Sect. 4.2.2) ${ }^{69}$ Positive freedom is thus afterwards employed by Green to denote capacitation for reasonable self-determination. ${ }^{70}$

The "reciprocal claim of all upon all"71 to assist with the acquisition of these very capabilities is, however, says Green to be qualified recursively, i.e. so that this demand can be maintained "without detraction from the opportunities of others" and thus not at all by means of totalitarian methods. ${ }^{72}$ The state may remove indi-

\footnotetext{
${ }^{62}$ T. H. Green, "Lectures on the Philosophy of Kant" in Works of T. H. Green, II, 93.

${ }^{63}$ See Thomas Hill Green \& A. C. Bradley, Prolegomena to Ethics (Oxford: Clarendon Press, 1899), 136.

${ }^{64}$ Ibid., 308.

${ }^{65}$ Ibid., 283.

${ }^{66}$ Thomas Hill Green \& Richard Lewis Nettleship, Works of Thomas Hill Green, III, 372.

${ }^{67}$ Thomas Hill Green \& A. C. Bradley, Prolegomena to Ethics, 308.

${ }^{68}$ See Thomas Hill Green, Lectures of the Principles of Political Obligation (Longmans, Green \& Co., 1941), 209.

${ }^{69}$ This is why, for example, Amartya Sen also refers very affirmatively to Green's concept of "positive freedom" (decidedly in contrast to Berlin's interpretation of Green), see Sen, RF 586f. There is more about this is Chapter 2.3.1. note 151 as well as in Chapter 4.2.2.

${ }^{70}$ Green \& Nettleship, Works of Thomas Hill Green, III, 372.

${ }^{71}$ Green, Prolegomena to Ethics, 285.

${ }^{72}$ See ibid., 354.
} 
vidual hindrances with the "realization of the capacity for beneficial exercise of rights" only insofar as it can do so "without defeating its own object by vitiating the spontaneous character of that capacity." 73 That is, the idea of freedom provides not only the foundations (Grund) but also the limits (Grenze) of social policy. Freedom is the measure of solidarity, not vice versa. Positive freedom (at least Green's version of it) is therefore far better than its reputation; and it is quite obviously not opposed to the fundamental rights defended by concepts of negative freedom. ${ }^{74}$ The legitimate concerns of theories of positive freedom need to be preserved within the conception of freedom elaborated here.

\subsubsection{Current Use of the Concept of Freedom}

The schism between negative and positive freedom is unsatisfactory not only historically, but also systematically. The term negative freedom rather poorly describes the actual concerns of its supporters. They actually always want to protect something positive, namely, certain personal liberties. ${ }^{75}$ Let us zoom in on that more closely: The standard definition of freedom as "absence of physically coercive interference or invasion of an individual's person and property"76 may be taken as typical of supporters of theories of negative freedom; and certainly it is representative of the positions of libertarians. ${ }^{77}$ This immediately shows that the element of negation emerges only secondarily, namely, against attacks upon a primarily posited - and thus previously to be positively defined - sphere of freedom. Whoever refuses to allow every substantial characterization of freedom to enter through the front door, must nevertheless allow it in by the back door. Whoever says "you are 'free' when you can constrain other people from constraining you"78 quite unconsciously defines negative freedom in terms of a positive good to be protected. ${ }^{79}$

This thought, suggested already by Hegel (§§ 5, 17 Elements of the Philosophy of Right), was vividly illustrated by Francis Herbert Bradley (1846-1924):

\footnotetext{
${ }^{73}$ Green, Lectures of the Principles of Political Obligation, 210.

${ }^{74}$ See John Christman, "Liberalism and Individual Positive Freedom," Ethics 101:2 (1991), 343-59.

75 "The very idea of "negative liberty" [...] is an incoherent idea; all liberties are positive, meaning liberties to do or to be something; and all require the inhibition of interference by others" (Martha Craven Nussbaum, Creating Capabilities: The Human Development Approach [Cambridge, MA: Harvard University Press], 65).

${ }^{76}$ Murray Newton Rothbard, The Ethics of Liberty (Atlantic Highlands: Humanities Press, 1982), 215.

${ }^{77}$ See Johan \& Paul Hospers, Libertarianism: A Political Philosophy for Tomorrow (Los Angeles: Nash, 1971) and Jan Narveson, The Libertarian Idea (Philadelphia: Temple University Press, 1988).

${ }^{78}$ Bruno Leoni, Freedom and the Law (Princeton: Van Nostrand, 1961), 56.

${ }^{79}$ See Friedrich A. von Hayek, The Constitution of Liberty (Chicago: Regnery, 1972).
} 
[...] we all want freedom. Well then, what is freedom? 'It means not being made to do or be anything. "Free" means "free from".' And are we to be quite free? 'Yes, if freedom is good, we can not have too much of it.' Then, if 'free' = 'free from', to be quite free is to be free from everything - free from other men, free from law, from morality, from thought, from sense, from - Is there anything we are not to be free from? To be free from everything is to be - nothing. Only nothing is quite free, and freedom is abstract nothingness. If in death we cease to be anything, then there first we are free, because there first we are - not.

Every one sees this is not the freedom we want. "Free" is "free from", but then $I$ am to be free. It is absurd to think that I am to be free from myself. I am to be free to exist and to assert myself.' Well and good; but this is not what we began with. Freedom now means the self-assertion which is nothing but self-assertion. It is not merely negative - it is also positive, and negative only so far as, and because, it is positive.

[...] Reflection shows us that what we call freedom is both positive and negative. There are then two questions - What am I to be free to assert? What am I to be free from? ${ }^{80}$

Bradley thus shows, on one hand, that negative freedom, in order not to be without content, must, first, affirmatively relate to something, e.g. to the modern individual bent upon self-determination. ${ }^{81}$ Second, it follows that negative and positive freedom are but two aspects of one and the same thing, namely a freedom determining itself by an inclusion and exclusion of its contents, a thought which at the time was also formulated by Bernard Bosanquet (1848-1923) and became generally very popular within British Idealism. ${ }^{82}$

Negative freedom depends upon positive freedom, not only linguistically (sprachlich), but also objectively (sachlich); its internal focus rests in many ways upon external presuppositions. For the mere formation of an individual's life plan, for instance, which can occur under the protection of negative freedom, certain characteristic preconditions are required (consistent and stable decision-making, discipline in the implementation, etc.). ${ }^{83}$ Its existence is partially dependent upon certain "positive" liberties (for instance, access to education and training). In the broader sense it also implies that one has at one's disposal further fundamental goods (food, health care, etc.); and it is only positive freedom - according to the familiar terminology - that grants everyone reliable access to these preconditions. $^{84}$

Furthermore, freedom must be able to relate to and reify itself within objects. ${ }^{85}$ In order to (negatively) protect it within these concrete relations, certain institutions

\footnotetext{
${ }^{80}$ Francis Herbert Bradley, Ethical Studies (Oxford: Clarendon Press, 1927), 56f.

${ }^{81}$ See Guido De Ruggiero, The History of European Liberalism (Boston: Beacon Press, 1959), 352 .

82 "The higher sense of liberty, like the lower, involves freedom from some things as well as freedom to others" (Bernard Bosanquet, The Philosophical Theory of the State [Macmillan: London, 1899], 127). Bosanquet suggests that negative freedom emancipates us only from being enslaved by others, whereas positive freedom emancipates us from being enslaved by ourselves.

${ }^{83}$ See Joseph Raz, The Morality of Freedom (Oxford: Clarendon, 1986), 408.

${ }^{84}$ See Stanley Isaac Benn, A Theory of Freedom (Cambridge: Cambridge University Press, 1998), 181 and Raz, Morality, 407.

${ }^{85}$ See Philippe van Parijs, Real Freedom for All: What (If Anything) Can Justify Capitalism? (Oxford: Clarendon Press, 1995), 22.
} 
must (positively) be created. For instance, the protection of private property rests on the presupposition that things can be legally appropriated (in and through certain forms, such as by a law like the 'ius primae occupationis') so as to make lawful ownership possible. But these legally protected rights can mostly only be legitimated and enforced if those disadvantaged by them also profit by the selfsame rules. Here, too, positive freedom (e.g. in form of the compensatory acts of distributive justice) is prior to negative freedom (e.g. in the protection of property in forms of transactional justice). ${ }^{86}$ Thus we can say: Without positive freedom there is no justice; without justice there is no functioning society; without society there is no protection of individual's self-determination; thus without positive freedom there is no negative freedom. ${ }^{87}$

Many contemporary philosophers of freedom are consequently no longer asking whether to add elements of positive freedom to theories of negative freedom, but only which? Many follow Gerald MacCallum, who reinvented the wheel first designed by Hegel and the British Idealists. He declared - now however from a foundation of conceptual analysis instead of a metaphysical one - that freedom never exists abstractly, but is always only socially mediated and constructed. In MacCallum's understanding, freedom is “always (freedom) of something (an agent or agents, from something, to (do, not do, become or not become) something, it is a triadic relation." 88 One should therefore situate (socio-democratic) demands for the societal preconditions of personal autonomy within the principle of freedom instead of (like Isaiah Berlin) locating it outside of it. ${ }^{89}$ For MacCallum, the key question is hence not whether a certain hindrance to freedom would be caused by human action. "The only question is whether the difficulties can be removed by human arrangements." 90

The upshot is obviously not appreciated within libertarian circles - albeit for ideological rather than logical reasons. Yet, even libertarians have typically nothing against positive freedom, as long as it is understood strictly morally. The positive concretization of our freedom, by, for instance, moral commitments and virtues, does meet with their explicit consent. What they would like to avoid is merely social compulsion and governmental coercion. On this point, therefore, libertarians and friends of positive theories of freedom could actually amicably agree. An accord of harmonious consonance typically drowned out, though, by the many other dissonances between them.

\footnotetext{
${ }^{86}$ See Gerald Allan Cohen, Self-Ownership, Freedom and Equality (Cambridge: Cambridge University Press, 1995).

${ }^{87}$ See Onora O'Neill, “Autonomy, Coherence, and Independence" in David Milligan and William Watts Miller, Liberalism, Citizenship, and Autonomy (Aldershot: Avebury, 1992), 212-221.

${ }^{88}$ Gerald C. MacCallum, "Negative and Positive Freedom," The Philosophical Review 76:3 (1967), 314.

${ }^{89}$ See ibid.

${ }^{90}$ Ibid., $325 f$.
} 
Theories of positive freedom surpass the conceptual sphere of negative freedom in so many ways, in fact, that their central concern remains unclear to many libertarians (and also to some liberals). Doctrines of positive freedom usually offer several of the following supplements to negative freedom: (1) the will's commitment to rationality; (2) the will's focus on moral laws and ethical values; (3) the collective orientation towards cultural and historical contexts; (4) the establishment of participatory republican models of government; (5) the granting of certain pedagogical, cultural presuppositions of autonomous decision-making; as well as (6) the economic presuppositions of private autonomy. Whoever rejects some of these aspects does not have to refuse them all; conversely, whoever stands for some of these dimensions does not need to fight for them all. ${ }^{11}$ And that prevents a uniform stance. While the supporters of negative freedom mostly march separately but strike together, proponents of positive freedom fail to form a coherent front. Their camp is united only in being disunited. They struggle amongst themselves just as fiercely as they fight supporters of theories of negative freedom. More poignantly formulated: The concept of negative freedom is clear but sterile; the idea of positive freedom is fertile but unclear.

This is borne out especially by the works of Isaiah Berlin. After he had unwillingly become a neoliberal figurehead through his critique of Green's positive freedom, he ostentatiously espoused social-democratic preferences; and thus he ended up being chastised both by the camp of positive freedom and by that of negative freedom: from the first, because of his original (supposedly libertarian) positions, and from the second, for his subsequent (supposedly not at all libertarian) postures. ${ }^{92}$ His oscillation between politically incompatible poles on the basis of ambiguous conceptual-theoretical commitments serves as a lesson in the misguided polarization between negative and positive freedom and therefore deserves particular attention here.

Widely noted was Berlin's rejection of any such conception of positive freedom that would authorize a paternalistic state, in the name of ethical freedom, to carrying out all kinds of interventions into individual life plans. Yet while he centered this discussion on the opposition of negative and positive freedom, the case was not as clear-cut as Berlin pretended. One can neither subsume his political views (such as his harsh critique of laisser-faire politics and the social evils they cause) conclusively under the concept of negative freedom, nor can all plausible alternatives to such a view simply be lumped under the label of positive freedom.

Berlin reduced the concept of positive freedom to but the single one interpretation, which he rejected, of a doctrinal exegesis on the part of the state of what is to be understood by freedom. With that, however, he disguises that it would be as completely conceivable to support a concept of freedom, which is by no means

\footnotetext{
${ }^{91}$ See Christman, "Liberalism and Individual Positive Freedom."

${ }^{92}$ Along with the classic "Two Concepts of Liberty" see also "From Hope and Fear" and "Political Ideas in the 20th Century" in Isaiah Berlin, Henry Hardy and Ian Harris, Liberty: Four Essays.
} 
reduced to the aspects of negation, but incorporates positive aspects in a liberal way, based on the citizens' negotiating for and with one another about how they wish to use their shared lifeworld for the benefit of the freedom of all. With Berlin's conceptual means, this alternative model cannot be clearly differentiated from a morally paternalistic government (Tugendstaat). One cannot avoid the impression that Berlin even pays homage to the model of a "night-watchman state" (Nachtwächterstaat), although - ironically quite against his intentions - he decidedly rejected such a minimal state and rather favored a socially dynamic model of politics. Berlin regretted this impression and the libertarian appropriation of his thinking it invited, and attacked both in later years fiercely. ${ }^{93}$ In the following passage he retrospectively clarifies his position:

It is doubtless well to remember that belief in negative freedom is compatible with and (so far as ideas influence conduct) has played its part in, generating great and lasting social evils. [...] Advocacy of non-interference (like 'social' Darwinism) was, of course, used to support politically and socially destructive policies which armed the strong, the brutal, and the unscrupulous against the humane and the weak, the able and ruthless against the less gifted and the less fortunate. [...] The bloodstained story of economic individualism and unrestrained capitalist competition does not, I should have thought, today need stressing. Nevertheless, in view of the astonishing opinions which some of my critics have imputed to me, I should, perhaps have been wise to underline certain parts of my argument. I should have made even clearer that the evils of unrestricted laissez-faire, and of the social and legal systems that permitted and encouraged it, led to brutal violations of negative liberty - of basic human rights [...]. And I should perhaps have stressed (save that I thought this too obvious to need saying) the failure of such systems to provide the minimum conditions in which alone any degree of significant negative liberty can be exercised by individuals or groups, and without which it is of little or no value to those who may theoretically possess it. For what are rights without the power to implement them? I had supposed that enough had been said by almost every serious modern writer concerned with this subject about the fate of personal liberty during the reign of unfettered economic individualism $-[\ldots]$. All this is notoriously true. Legal libertarians are compatible with the extremes of exploitation, brutality, and injustice. The case for intervention, by the state or other effective agencies, to secure conditions of both positive, and at least a minimum degree of negative, liberty for individuals, is overwhelmingly strong. ${ }^{94}$

Unsurprisingly this slap in the face produced a libertarian furor, especially since in this context Berlin also explicitly lends support to positive freedom in the sense of political autonomy:

Positive liberty, conceived as the answer to the question, 'By whom am I to be governed?', is a valid universal goal. I do not know why I should have been held to doubt this, or, for that matter, the further proposition, that democratic self-government is a fundamental

\footnotetext{
${ }^{93}$ This corrigendum produced bitter accusations from libertarians. Murray Rothbard especially criticized Berlin for his "assaults on laissez-faire" and let himself become carried away in the amusing accusation that, "Berlin goes on to attack such pure and consistent laissez-faire libertarians as Cobden and Spencer on behalf of such confused and inconsistent classical liberals as Mill and de Tocqueville" (Rothbard, The Ethics of Liberty, 216).

${ }^{94}$ This and the following quotes are taken from Berlin, Hardy and Harris, Liberty: Four Essays, xliv-xlivii.
} 
human need, something valuable in itself, whether or not it clashes with the claims of negative liberty or of any other goal.

Against the background of these self-explanations, or rather, self-relativizations, one must reflect on whether there continues to be any merit to the distinction between negative and positive freedom. It actually seems more to hinder than to help the notions it is supposed to express. In my view, talk of negative versus positive freedom suggests a fundamental distinction where there is none, i.e. where in truth contingent differences are at stake like modes of realization (voluntariness versus enforceability) or fields of application (internal determination of the will versus its external exercise). Thus, the focus upon positive versus negative aspects in the debate about freedom obscures our view of the actually relevant categorical differences. These, however, can rather be found in the interplay between a quantitative and qualitative orientation of freedom; an orientation that can be expressed both in negative and positive forms by rights concerning the defense of existing freedoms as well as counterfactual entitlements (Abwehrrechte wie durch Anspruchsrechte).

\subsubsection{Some Outstanding Developments}

Academic philosophy has distanced itself from the negative-positive schema for quite some time now, characterizing it as a false disjunction and attempting to transform the awkward duality by trinomial models, enriched by e.g. a republican, ${ }^{95}$ a solidaristic $^{96}$ or a psychological $l^{97}$ freedom ${ }^{98}$; and some of the authors discussed in subsequent chapters also take this path. In my opinion the works of Amartya Sen are the most convincing attempts in this direction, as they distinguish between a substantive freedom and a procedural freedom, i.e. between communitarian and libertarian moments within the idea of freedom, in a persuasive attempt to synthesize them (see here Sect. 4.2.2).

Nonetheless, instead of repairing old machinery with new spare parts, I am suggesting replacing it with something new. What has already been said concerning theories typically at home in the camp of negative or positive freedom is also true of these trinomial concepts. They can be far less confusingly reconstructed by means of arguments that predominantly locate the significance of freedom either in its quantitative or its qualitative dimension. For their concern is typically a question either of the number or the respective nature of options. The above mentioned third

\footnotetext{
${ }^{95}$ See Quentin Skinner, Liberty before Liberalism (Cambridge: Cambridge University Press, 1998). ${ }^{96}$ See Parijs, Real Freedom for All, 28.

${ }^{97}$ See Christian Bay, The Structure of Freedom (Stanford: Stanford University Press, 1970), 58.

${ }^{98}$ See Carter, Kramer \& Steiner, Freedom; see also Virginia Hodgkinson, and Michael Foley, eds., The Civil Society Reader (Lebanon: Tufts University Press, 2009). In the German discourse this third aspect is mostly claimed to be "social freedom." See Axel Honneth, Das Recht der Freiheit Grundriß einer demokratischen Sittlichkeit (Frankfurt am Main, 2011).
} 
aspects and perspectives can, in most cases, be integrated into one or the other perspective. Further, quantity and quality are sharp categories, not arbitrarily chosen labels. One may therefore expect that they, unlike other attributes, can also be brought into a clearly cognizable dialectical order so that their relationship turns out to be both more differentiated and less arbitrary than with the conventional dual or tripartite schemata.

From the outset we should note that the attributes of negative and quantitative, on the one hand, and positive and qualitative, on the other, do not fully correspond with one another. Especially in the sphere of positive freedom, the theory of qualitative freedom introduces an important differentiation. It differentiates between conceptions that analyze the structurally-abstract conception of qualitative freedom and others trying to establish its concretely-material design. This distinction is best expressed terminologically as one between the (structural) idea and the (particular) concepts of qualitative freedom, i.e. between a uniform guiding vision of freedom and its various forms of implementation. We will work out this distinction in more detail with the help of the philosophy of Kant (see Sect. 2.1.4) and Krause (see Sect. 2.3.4). It will serve us throughout the entire book as a compass.

The incapacity of numerous other theories of freedom to distinguish clearly between the level of the idea and that of the concept appears to me to be a fundamental problem within the current debate. It results in an inability to differentiate the postulate that one should at all be debating the quality of freedom from a plea for a certain form of qualitative freedom, which is partly to blame for the fear that various liberals and almost all libertarians have for any step beyond the narrow confines of negative freedom. Since a clear-cut distinction between the philosophical idea of freedom and its political application has hitherto been lacking, the defense of the substantive nature of freedom in general was time and again falsely identified with the championing of certain (e.g. social-liberal) positions in particular.

Libertarians, for instance, like to accuse the supporters of positive freedom of a "confusion" between freedom and its accompanying values. Bruno Leoni (19131967), for example, attributes a "semantic confusion" to all who infer possible limits for negative freedom from seeing the earth as the common property of mankind, i.e. all who believe that one owes more to the freedom of others than merely abstaining from infringing on it. ${ }^{99}$ Friedrich August von Hayek seconded this accusation with the claim that all thinkers who wish to enrich freedom through social justice fall victim to another "confusion" between freedom, on the one hand, and other desirable things like welfare, wealth, or a socially active government, on the other. ${ }^{100}$ Murray Rothbard (1926-1995) criticizes Isaiah Berlin for how his (revised) theory falls foul of the severe "confusion" that leads to the view that the community might owe substantial opportunities to the individual. ${ }^{101}$ Confused philosophers all

\footnotetext{
${ }^{99}$ See Leoni, Freedom and the Law, $54 \mathrm{f}$.

${ }^{100}$ See Friedrich A. von Hayek, The Constitution of Liberty (Chicago: University of Chicago Press, 1960), $16 \mathrm{ff}$.

${ }^{101}$ See Rothbard, The Ethics of Liberty, 216.
} 
around; it only remains to ask: on which side of the controversy? For obviously what is at stake here is not a question of a Babylonian confusion of language, but rather a conflict of values underlying the differing usage of language. ${ }^{102}$ In the background of the diverging ways of speaking there are substantial questions like "which freedom" and "whose freedom"?

Abraham Lincoln already went straight to the heart of the matter a good 100 years before the debate about Berlin's essay:

We all declare for liberty; but in using the same word we do not all mean the same thing. With some the word liberty may mean for each man to do as he pleases with himself, and the product of his labor; while with others the same word may mean for some men to do as they please with other men, and the product of other men's labor. Here are two, not only different, but incompatible things, called by the same name - liberty. And it follows that each of the things is, by the respective parties, called by two different and incompatible names - liberty and tyranny.

The shepherd drives the wolf from the sheep's throat, for which the sheep thanks the shepherd as a liberator, while the wolf denounces him for the same act as the destroyer of liberty, [...]. Plainly the sheep and the wolf are not agreed upon a definition of the word liberty; and precisely the same difference prevails today among us human creatures. ${ }^{103}$

Whether one now reads this speech in its own historical context of the American civil war and the emancipation of slaves or with regard to current debates in globalization ethics about the economic enslavement of impoverished strata of populations, one thing remains the same: Supporters of positive freedom will constantly insist, along with Lincoln, that the question concerning the concept of freedom should not simply be decided by the "wolf's dictionary" (ibid). The idea of freedom is therefore not contingently, but rather necessarily, controversial; normative aspects are included within its determination, not by mistake, but due to the need for value judgments. ${ }^{104}$

Precisely because the concept of freedom most appropriate for the here and now is constantly being fought over, the structural idea of freedom has to be outlined in such a way that it can integrate such differences, e.g. by rendering its ultimate concretion, not through academic definitions, but through political procedures. Theories of positive freedom often lack, however, this dimension of procedural freedom, which is indispensable to all liberal practices, tending to concretize the idea of freedom ex cathedra. For this reason too there is no going back to the negative-positive dualism.

Once, however, one frees oneself from this staid manner of speaking, one will discover that the negative-positive distinction is much like a badly adjusted pair of glasses. As soon as one takes them off, optical illusions disappear. And there are many of them: Some authors loudly declare that they follow a purely negative concept of freedom and thereby starkly misrepresent their own theory (as, for example,

\footnotetext{
${ }^{102}$ See Kramer, The Quality of Freedom, vii.

${ }^{103}$ Abraham Lincoln, The Collected Works of Abraham Lincoln (New Brunswick: Rutgers University Press, 1953) vol. 7.

${ }^{104}$ See Christine Swanton, Freedom: A Coherence Theory (Indianapolis: Hackett, 1992), 1-10.
} 
Hayek, see Sect. 3.2). Others are charged to hold certain views that their concept of positive freedom does not at all contain (as demonstrated by the unjustified criticism of Green), or find their theories employed in a way which they themselves reject (like Isaiah Berlin). These and other obscurities in the depiction of freedom are due to the poor focus of the negative-positive lens.

Philosophy, insofar as it wants to promote consistent action through consequent thinking and coherent speaking, may not idly pass by the possibility of unravelling tangled debates. Conceptual distinctions are the more efficacious and useful the more fundamental and truer to the phenomena they are. The categories of quantity and quality thus recommend themselves. They immediately signal their elementary meaning and at the same time they allow recourse to a broad methodological arsenal from the natural sciences (for the modelling of quantitative relations) as well as on the part of the humanities (as custodians of qualitative points of view). While - formulating archetypically and with some exaggeration - the former delimit their object of investigation through selective definitions according to criteria that are as objective and value-free as possible, the latter attempt to break down the phenomena studied by them through recourse to subjective experience and ideals. ${ }^{105}$

These methodological alliances and emphases in turn clarify the debate. It is by no means accidental that authors who follow the methodological ideal of natural science, above all neo-classically ${ }^{106}$ orientated economists, mostly attempt the extrinsic quantitative modelling of spheres of freedom (e.g. through game theory and rational choice theories ${ }^{107}$ ), while, conversely, authors in the humanities attempt to procure the idea of freedom with primarily qualitative methods. Both approaches bring different treasures to the surface. The question concerning which method should enjoy priority and how both ought to relate to one another must be decided

\footnotetext{
${ }^{105}$ Of course the comparison formulated here only provides a very crude orientation. The actual situation is in no way as polarized into opposed cognitive paths as was at one time claimed (as by Charles Percy Snow in Two Cultures [London, 1959]). Yet even with a differentiated view (as, for example, with Stefan Hornbostel, "Schism oder Diversifikation: Das Verhältnis von Natur-, Sozialund Geisteswissenschaften" in M. Dreyer, U. Schmidt \& K. Dicke, eds., Geistes- und Sozialwissenschaften an der Universität von Morgen [Wiesbaden: Springer Fachmedien, 99-123]) the distinction remains between causally-explicating and contextually-reasoning methods (established by Dilthey and Gadamer) characteristic of the relationship between natural sciences and the humanities - and thus it also retains relevance for the mental and physical characteristics of freedom, which are difficult to understand without some kind of phenomenological assistance. Concerning this see also: Buchheim, Unser Verlangen nach Freiheit kein Traum, sondern Drama mit Zukunft.

${ }^{106}$ Traditionally, we understand by neoclassical economic-theory the type produced by and after Alfred Marshall (1842-1924). The concept neoclassical - brought into circulation by Thorstein Veblen - refers to a fusing of the system of "classical" economics (Smith, Ricardo, etc.) with the subsequent works of Austrian marginalism (Menger et al.). For more about this concept see Jurg Niehans, A History of Economic Theory: Classical Contributions, 1720-1980 (Baltimore \& London: Johns Hopkins University Press, 1990), 159ff.

${ }^{107}$ For further information about the role of game theory in the philosophy of freedom see Sect. 3.2.4 on Hayek; for further information about the function of rational choice theories see Sect. 4.2.1 on Sen.
} 
by the phenomenon in question. In the course of our argumentation we have to grasp which categories capture most precisely the essence and reality of freedom and determine the methodological question accordingly.

\subsection{How Should We Talk About Freedom?}

Freedom is a necessarily contested idea. ${ }^{108}$ Hence we cannot simply pick up some definition of freedom and run with it towards issues of practical application. Rather one has first to clarify the effect of different concepts of freedom upon everyday life - morally, socially, politically, legally, and economically. One can do this in many different ways. I consider it most meaningful to follow the historical development of the idea of freedom within previous centuries. The heated philosophical debates about the problems with freedom of the recent past clarify the very problem of freedom itself, namely, that the idea of freedom behaves like a lens and a prism at one and the same time. Depending on how one thinks about freedom, one either perceives different parts of the world (when freedom functions like a lens) or one sees the very same aspects in different colors (when freedom functions like a prism). Therefore, it is hardly surprising that intellectuals confronting freedom's role in society passionately talk at cross-purposes.

This linguistic confusion is in no way accidental. It rests on a disagreement about the mental frames and categories by which freedom is best grasped. Without tackling this conceptual ambiguity, we can hardly hope for linguistic clarity. Therefore, I aim first to sketch the complex contours of the issue in order then to take in hand gradually the categorical construction of the idea of freedom. Upon a conceptual canvas unfurled in front of the reader I hope to make visible layer after layer of those meanings that shape and color our current understanding of freedom. That is why I proceed in a historical-systematic fashion, transforming the selected theories of the philosophy of freedom into a dialectical trajectory culminating in the present. Thereby a continuous thread of questions raised by Kant and his successors connects up until their recent answers by contemporary philosophers. With every historical step our train of thought is systematically enriched in order to culminate finally with present questions and problems - for instance within the framework of capability theory.

${ }^{108}$ See B. Gallie, "Essentially Contested Concepts," Proceedings of the Aristotelian Society 56 (1995), 167-198. 


\subsubsection{Metaphysical Theories of Freedom}

In the first part of this book a great deal of space is devoted to the philosophy of Immanuel Kant (1724-1804) and his successors in order to consider their central idea that freedom is not negated but rather manifested by reasonable boundaries. That epochal insight was first formulated within the sphere of metaphysical systems. These metaphysics favored the formation and influenced the formulation of conceptions oriented at the critique of freedom by reason. Before one can set about morally interpreting or utilizing these conceptions of freedom in moral, political, legal, and economic philosophy, it is necessary to understand their innermost foundations.

But prior to that reconstruction of the metaphysical theories of freedom discussed here, I wish to say a few words in defense of this approach. In the meantime an ever growing number of analytically-schooled philosophers (like, e.g., Charles Taylor, Bert Dreyfus, Hans Sluga, Alva Noë, Sean Kelly, Mark Wrathall, Hans-John Glock and Gary Gutting, to name but a few) are certainly increasingly making use of texts from the speculative tradition and consider them to be instructive. Their influence, however, is hardly enough to enable us to proclaim cheerfully the hope that the gap between the two camps - previously declared to be forever insurmountable - is already bridged. Nor suffices the fact that in the camp of continental philosophy most have learnt to express themselves with analytic jargon and impressively dress up their texts with an Anglo-American apparatus of footnotes. No, whoever wishes to tempt colleagues from the analytic bank into an intellectual current unfamiliar to them first must show what is to be found on the river's other bank.

Yet far from imposing an onerous burden, the resulting pressure to present explicitly the relevance of speculative thought rather proves to be a blessing in disguise for philosophy. The analytic sandblast has the power to bring forth the true reliefs of metaphysical arguments, which otherwise would remain hidden under veneers of language and the superficial incrustations of a hagiographic and historicist patina. Philosophy benefits from having to explain nowadays why it, at times, opts for theorizing in opposition to apparent experience and the everyday use of language. ${ }^{109}$ To its challenge, metaphysics owes a welcome concentration on the essential.

In this vein, followers of metaphysical understandings of philosophy point out, for example, the indispensability of understanding philosophical trains of thought within their historical and systematic constellations: Whenever the contextual anchoring of certain ideas impacts their content, also thinkers who simply aim at breaking out intellectual building-blocks are well-advised to scan cautiously the foundations of the objects they excavate. ${ }^{110}$ Hence analytic philosophers proceeding

\footnotetext{
${ }^{109}$ See Josef Piper, Verteidigungsrede für die Philosophie (München, 1966).

${ }^{110}$ See Dieter Henrich, Konstellationen: Probleme und Debatten am Ursprung der Idealistischen Philosphie (1789-1795) (Stuttgart: Klett-Cotta, 1991).
} 
with historical attentiveness (today no longer a species on the side-lines), too, demand a minimum of constellation-research as well as philological expertise. ${ }^{111}$

Nevertheless, philosophers still differ about the more comprehensive question whether metaphysical foundations are not only hermeneutically relevant, but might also be substantially decisive in order to judge the correctness of certain philosophical positions. Here lies the actual point at issue; and since in what follows we give so much attention to the reconstruction of the idea of freedom during the history of German Idealism from Immanuel Kant (1724-1804) to Karl Christian Friedrich Krause (1781-1831) we do suppose that metaphysical thinking still has its legitimate place within today's philosophy. Yet such a claim can hardly be abstractly and universally proven, as if one could preliminarily clarify the function of metaphysics and then move on to more profane philosophical dealings. Instead metaphysical theory - just like any other theory - underlies the criteria of sound scholarliness, for example, the requirements of argumentative stringency and parsimony as well as textual plausibility and intellectual fecundity. ${ }^{112}$ Whoever in the battle of competing doctrines can produce consistent theories of roughly equal explanatory potential with fewer presuppositions will - as long as powerful paradigms do not stand in the way $^{113}$ - win the day. The meaning and pertinence of metaphysical thinking is consequently best evaluated through concrete examples.

The claim that a certain theorem cannot be detached from its metaphysical context without losing content must be examined on a case by case basis; not only when this is put forward on the part of analytic philosophers as a knock-down argument, ${ }^{114}$ but also when continental philosophers bear that claim as a magical shield, in order to defend themselves against the formal challenges of propositional logic. In both cases the potential of the employed foundations decides whether the respective metaphysical groundwork strengthens or weakens the ideas in question. Of course, not all metaphysical foundations ultimately impact the factual level of practical philosophy. Their reconstruction is thus not always required. Some metaphysicians formulated ideas within their systems, which, outside of them, can just as easily convince.

But that is not true throughout. Whether for instance the function of freedom lies either in attributing value to an otherwise worthless world (as is claimed by epistemological libertarianism ${ }^{115}$ ) or in perceiving and realizing values inherent in the

\footnotetext{
${ }^{111}$ See Don Garret, "Philosophy and History in the History of Modern Philosophy," in Leiter, ed., The Future for Philosophy (Oxford \& New York, 2004). 58.

${ }^{112}$ See Carter, Kramer \& Steiner, Freedom, 5.

${ }^{113}$ See Thomas S. Kuhn, The Structure of Scientific Revolutions (Chicago: University of Chicago Press, 1962).

${ }^{114}$ See Hans Reichenbach \& Maria Reichenbach, Der Aufstieg der Wissenschaftlicheen Philosophie (Berlin-Grünewald: Herbig), 13, 82ff.

${ }^{115}$ Epistemic, voluntative, and political libertarianism are not necessarily identical. The first denies that intrinsic values can reside within the world and can be derived from it (libertarian theory of knowledge). The second holds natural determinism and free will to be incompatible (incompatibalism) and gives freedom precedence (libertarian theory of the will). Political libertarianism concentrates on the practically external freedom of human beings (libertarian theory of action) and would
} 
world, this question is no idle speculation: The answer profoundly influences our everyday practice. In the first case, for example, there are no fundamental problems with an extensive exploitation of nature; in the second case the inherent value of nature places principled boundaries upon our use of the environment. The metaphysical foundations of the arguments dealt with here thus do evidently have huge practical significance.

Sometimes - e.g. with models which teleologically appropriate the historical present on behalf of a speculatively prescribed future (one thinks, for example, of the communist paradise promised by historical-dialectical materialism) - it appears unproblematic to dispose of the supporting metaphysical structures unceremoniously. Now and then, on the other hand, the appeal to the counterfactual critical potential of morally-metaphysical ideas may deserve a more measured approach. Is there, for example, within the power of our freedom to critically question and normatively surpass all extant options, a phenomenon which by and for itself requires metaphysical expression? ${ }^{116}$ Can freedom perhaps be adequately expressed only by an idea that necessarily points beyond any one of its implementations? ${ }^{117}$ These questions cannot yet be decided, but it can be said that the justification of metaphysical theories of freedom has to take place on a case by case basis - in constant critical adjustment with our intuition. The contribution of metaphysics to clarifying the idea of freedom has to be evaluated according to its theoretical power and practical fecundity and not from anti- or pro-metaphysical predisposition. The analytic flail can thus help to separate the metaphysical wheat from the speculative chaff.

Conversely, some sensitivity to metaphysical thinking can be of use within analytic approaches. For speculative convictions have imperceptibly found their way into the attempts even of those thinkers whose proud claim it was to philosophize completely free of metaphysics (as, e.g. Rawls, see Sect. 3.2.2). Often, certain fundamental assumptions concerning the conditions of our everyday life, as well as the scientifically correct way of exploring them, enter into the structure of their theories of politics and economics. Those ontological and epistemological assumptions, however, which are not infrequently introduced ad hoc or simply presupposed, can often be only supported by arguments of a metaphysical nature. ${ }^{118}$

\footnotetext{
like to see these limited as little as possible, as, for instance, is the case in R. Malcom Murray \& Jan Narveson, eds., Liberty, Games and Contracts: Jan Narveson and the Defence of Libertarianism (Aldershot: Ashgate, 2007).

${ }^{116}$ See David Christopher Schindler, The Perfection of Freedom: Schiller, Schelling and Hegel between the Ancients and the Moderns (Eugene, Oregon: Cascade Books, 2012).

${ }^{117}$ See Herbert Marcuse, Reason and Revolution: Hegel and the Rise of Social Theory (London: Oxford University Press, 1941).

${ }^{118}$ John Gray, for instance, judges that "some useful variant of the idea of a real or rational will may survive the demise of the rationalist metaphysics [...] in which it has traditionally been embedded." For some kind of "norm of human nature" is required by philosophical liberalism in order not to remain within empty abstractions. This "dependency of views of freedom on conceptions of man" is said to be honestly acknowledged by analytic philosophers (John Gray, Liberalism: Essays in Political Philosophy (London \& New York: Routledge, 1989), 59f.).
} 
Nevertheless, while metaphysicians find themselves in a reflexive relationship to their own explicitly speculative axioms and mostly self-critically justify them, this is not always true of theories of analytic provenance. These are often shaken at their foundations by the discovery of implicit metaphysical structures, especially insofar as the latter explicitly derive their claim to validity from their alleged distance to metaphysics. The analytic philosopher's complaint about metaphysics then proves to be a boomerang that hits home with all the more force. Whereas a short and direct path often leads from the metaphysics of freedom to a theory of freedom critically conscious of its own premises, many analytical-empirical theories reach that very destination by means of re-routing. For the former, the royal road of argumentative reconstruction stands open, for the latter only the winding paths of deconstruction. An insight succinctly formulated already by Francis Herbert Bradley who remarked that, "so long as you refuse to read metaphysics, so long will metaphysical abstractions prey upon you." 119 Nolens volens, the analytical understanding is thus brought back to metaphysical reason.

\subsubsection{Quantitative Theories of Freedom}

While up until the middle of the nineteenth century Continental European philosophy anchored the idea of freedom metaphysically, the Anglo-American world has since the late eighteenth century turned towards empirically orientated ideas of freedom. Their aim was to adhere to what could be grasped through the senses alone and, as it were, to capture freedom physically. Not without reason. The long, bitter, religiously motivated, or at least theologically legitimated, civil wars had exhausted many. Everyone wanted to bring to an end that Christians were, in the name of their metaphysical convictions, injuring one another in life and limb. Many thinkers thus wanted to bring about clarity and precision concerning who could place limits upon whom, how, and for what reason. Thomas Hobbes (1588-1679) already explained freedom thoroughly in physicalist terms: "By LIBERTY, is understood, according to the proper signification of the word, the absence of external impediments." ${ }^{20}$ Water, Hobbes explained, "kept in by banks, or vessels" is not (any longer) free; water, which follows its own current, on the other hand, (still) is. Freedom is accounted for, therefore, not with a view to its content and inner direction, but is purely defined externally, via negationis, through the absence of corporeal coercion and physical influence:

LIBERTY, or FREEDOM, signifieth (properly) the absence of opposition; (by opposition, I mean external impediments of motion;) and may be applied no less to irrational, and inanimate creatures, than to rational. For whatsoever is so tied, or environed, as it cannot move, but within a certain space, which space is determined by the opposition of some external body, we say it hath not liberty to go further. And so of all living creatures, whilst they are imprisoned, or restrained, with walls, or chains. ${ }^{121}$

\footnotetext{
${ }^{119}$ F. H. Bradley, Ethical Studies (London: Henry S. King \& Co., 1876), 56.

${ }^{120}$ Thomas Hobbes, Leviathan (Oxford, 1996), Chapter XIV.

${ }^{121}$ Ibid., Chapter XXI.
} 
The inverse conclusion also follows. A man suffering mania or experiencing a drug-induced high, as long as he remains physically undisturbed, would have to be regarded as free. This interpretation is explicitly affirmed by Hobbes. He expressly does not want liberty to be understood as freedom of the mind (e.g. emancipation from such addiction), but rather as physical freedom - freedom to move. He therefore repeatedly defines "liberty in the proper sense" as "corporal liberty; that is to say, freedom from chains, and prison." The physical possibilities of citizens "to choose their own abode, their own diet, their own trade of life" constitutes, in his eyes, the kernel of freedom. Accordingly, society's laws are felt to be "artificial chains" ${ }^{122}$; freedom can only exist beyond the latter in a sphere that is not (yet) ruled by law. The less one is restricted by such limits the freer one is. Thus understood, freedom means freedom from all limitations; it defines itself negatively by their absence. The fewer boundaries, the more freedom; the more freedom, the better; the result is a quantitative understanding of freedom.

The second part of the book investigates Rawls and Hayek, two representative supporters of quantitatively directed theories, which describe freedom in relation to its outer circumference and the number of enclosed options. Our explicit demand for freedom is thereby reinterpreted as the implicit wish to maximize the number of our choices. One thus wants to avoid recourse to the inwardness of freedom and sticks to the secure channel of mathematization in order to bring the ship of freedom safely into the harbor of the rule of law. Why risk engagement with subjective abysses and metaphysical maelstroms? Why abandon oneself to the winds of a speculative spirit and the constantly shifting currents of qualitative intuitions?

The characteristic model of this positivism of freedom (famous within the Chicago School of Economics and infamous outside of it) was provided by Jeremy Bentham (1748-1832): "You and your neighbor, suppose, are at variance: he has bound you hand and foot, or has fastened you to a tree: in this case you are certainly not at liberty as against him: on the contrary he has deprived you of your liberty." 123 This form of arbitrary violence, according to Bentham, on average profits the criminal less than it costs the victim. That is why the legislator should interfere as a neutral trustee for the quantitative liberty of all. His regulatory power "cuts off on the one side or the other the portion of the subject's liberty," in order to maximize society's aggregate amount of liberties.

Liberty then is of two or even more sorts, according to the number of quarters from whence coercion, which it is the absence of, may come: liberty as against the law, and liberty as against those ... wrongdoers. In the same proportion and the same cause by which the one is increased, the other is diminished.

Both options - to act according to the law or against it - are not subjected to any substantial examination. One simply has to balance, at which intersection of both curves, the individuals come away, on average, with the most freedom. According

\footnotetext{
${ }^{122}$ Ibid., Chapter XXI, 6.

${ }^{123}$ Jeremy Bentham, Of Laws in General, Herbert Lionel Adolphus Hart, ed. (London: Athlone Press, 1970), 253f.
} 
to the maximizing-orientated logic of quantity certain boundaries are to be placed upon individual freedom. The argument follows the geometrical schema of countless bodies in bounded space: If each one moves simply as it pleases that will unavoidably lead to unpleasant collisions. One therefore must set rules of coordination reinforced by coercion that (by here and there curtailing a little the individuals' sphere of freedom) enlarge the total amount of compossible liberties (and thus, ultimately, everybody's sphere of freedom).

For this insight, no moral reason is required, a calculating rationale suffices. ${ }^{124}$ The necessary system of regulation is hence presented as a legal structure detached from the - qualitative - debate about the good life. Everyone could accept its strictures (as has been said, again and again, from Thomas Hobbes to John Rawls) regardless of their ultimate moral or religious orientation, only because of a clever - quantitative calculation of one's own advantage, i.e. his or her private sphere of options. ${ }^{125}$ The liberal constitutional state can thus be justified, or so it seems, with minimal presuppositions, as a mere means of maximizing individual options. This independence from normative guidelines recommends the quantitative conception of freedom, it is said, for cultural export and the legal governance of a continually globalizing world. ${ }^{126}$

All is not well, however. The model forces into the private sector each aspect that does not rhyme and chime with the logic of a quantitative growth in the individual's range of options. Often the concrete contexts of everyday freedom are depreciated. The environment, society, and posterity (Umwelt, Mitwelt und Nachwelt) play only a marginal role in theories of quantitative freedom. Respect for others who are socially, economically, or medically weak, or legally underprivileged, or politically discriminated against, or regard for non-autonomous nature appears strikingly insincere in quantitatively orientated liberalisms. And that has systematic reasons.

The theory of quantitative freedom is orientated around the model of a rational exchange. When, however, one has reached the point where the respect for the other is conceptualized as a negation (qua limitation) of one's own interests, one will grant this only insofar as one receives something similar in return. The conception of law within quantitative liberalism functions according to hypothetical, not categorical justifications; it motivates conditionally, not unconditionally. This holds true for positive and negative duties alike. One supports others when and only insofar as they can be obliged to give support of an equal quantitative value; otherwise one might withhold cooperation. Where no symmetrical exchange takes place, strictly speaking a reason for entering into society remains absent. How could one be obligated either to refrain from hurting or towards helping others, if as a rational utility-maximizer one gains nothing for oneself? We illustrate the problems that beset such approaches to constructing a robust philosophy of freedom by means of the work of Hayek (Sect.

\footnotetext{
${ }^{124}$ See Joel Feinberg, Freedom and Fulfilment: Philosophical Essays (Princeton: Princeton University Press, 1992).

${ }^{125}$ See Mark E. Button, Contract, Culture and Citizenship: Transformative Liberalism from Hobbes to Rawls (Pennsylvania State University Press, 2008).

${ }^{126}$ See Milton Friedman \& Rose D. Friedman, Free to Choose: A Personal Statement (New York: Harcourt Brace Jovanovich, 1980); Michael Novak, "Economics as Humanism," First Things: A Monthly Journal of Religion and Public Life 18:2 (1997).
} 
3.1) and Rawls (Sect. 3.2). For these problems invariably drive liberal thinking towards qualitative determinations of thought.

\subsubsection{Qualitative Theories of Freedom}

It is evident to everybody that a small amount of good choices is preferable to a large amount of unpleasant options. Let us imagine - following an example from the Nobel-prize winner Amartya Sen - two worlds, which in respect of the options for freedom present within them are numerically identical. The one contains the unattractive freedom to contract smallpox, while the other, as a result of political intervention and the subsequent eradication of the pathogen, enables the freedom of living without fear of that disease. ${ }^{127}$ Viewed quantitatively, i.e. with regard only to the amount of available options, both worlds are comparable. Qualitatively there is of course a stark difference: But this shows up solely in concepts of freedom orientated around human weal and woe. Sheer quantity can hence hardly be the ultimate core of freedom. In the face of such a comparison, our reasoning by no means calculates, but judges; it does not measure, it evaluates.

The idea of qualitative freedom represents the corresponding attempt to differentiate meaningful from meaningless freedom. The question "Which freedom?" should predominate over the question "How much freedom?" The basic idea is: Only after we know about the goodness and quality of a certain option can we judge how much of this freedom we should grant to others and ourselves. ${ }^{128}$ Thereby a theory of qualitative freedom does not exclude the category of quantity, but rather includes it: while taking pre-eminence, it in no way intends to replace it. From a qualitative viewpoint, it is neither inevitably true to say "the more, the better", nor, conversely, "less is more". Rather our assessment will always proceed by saying "it depends": upon which freedom or whose freedom is claimed, and in which context.

Heteronomy can destroy freedom, but can self-imposed boundaries? For example, a promise that one friend gives to the other could be conceptualized - quantitatively - as a drastic reduction of the number of possible future behaviors to but one single one option: a disadvantage in need to be weighed up against the advantages offered by that friendship. Or - qualitatively - one can recognize in that promise a realization instead of a reduction of one's own freedom. The individual can be proud of keeping his word to his friend. Loyalty need not be bought by utility, it can also express an attitude the promising party has to his friend and to the world at large. Similarly, one can conceive that autonomously provided limitations do not negate our freedom but rather manifest it - in favor of, for instance, our social, natural, and cultural environment. ${ }^{129}$ For often what matters to us is less the maximization of

\footnotetext{
${ }^{127}$ See Amartya Sen, RF 602.

${ }^{128}$ See Gerald Dworkin, The Theory and Practice of Autonomy (Cambridge: Cambridge University Press, 1988), 14.

${ }^{129}$ See Philip Pettit, A Theory of Freedom: From the Psychology to the Politics of Agency (Oxford: Oxford University Press, 2001).
} 
abstract options, and rather their concrete optimization, i.e. of the enabling and enhancement of particularly prized freedoms. ${ }^{130}$

The following chapters will show in detail that this idea of qualitative freedom has precursors and paragons in continental philosophy. Yet, the idea of a qualitative discussion of freedom also found and finds well-known supporters among AngloAmerican thinkers. John Locke, for instance, already qualitatively distinguished liberty from license according to whether or not a certain option could co-exist with reasonable laws. According to Locke, a human being in the so-called 'state of nature' has neither the freedom "to destroy himself" nor the freedom "to harm another in his life, health, liberty, or possessions." ${ }^{131}$ Natural freedom aims at an appropriate, and not adverse, realization of human nature. Locke certainly shares Hobbes' demand for extending individual freedom as far as possible, but does not go as far as regarding every governmental norm as a negation of liberty. It is more the case that he sees, in accordance with the natural law tradition of Stoicism, medieval philosophy, and late scholasticism, that some normative functions of the state are able to augment the freedom of the individual:

\begin{abstract}
For Law, in its true Notion, is not so much the limitation as the direction of a free and intelligent agent to his proper interest, and prescribes no farther than is for the general good of those under that law: could they be happier without it, the Law, as an useless thing, would of itself vanish; and that ill deserves the Name of Confinement which hedges us in only from Bogs and Precipices. So that, however it may be mistaken, the end of Law is not to abolish or restrain, but to preserve and enlarge Freedom: for in all the states of created beings capable of laws, where there is no law, there is no Freedom: for Liberty is to be free from restraint and violence from others; which cannot be, where there is no law: But Freedom is not, as we are told, A Liberty for every man to do what he lists: (for who could be free, when every other Man's Humour might domineer over him?) But a Liberty to dispose, and order as he lists, his person, actions, possessions, and his whole property, within the Allowance of those Laws under which he is, and therein not to be subject to the arbitrary Will of another, but freely follow his own. ${ }^{132}$
\end{abstract}

By replacing the laws of the strong with the strength of laws, not freedom is reduced but its suppression. For Locke, therefore, freedom is not freedom from the state, but rather freedom via the state. While in Hobbes' quantitative manner of thinking reasonable laws signify a loss of individual freedom, Locke understands them as beneficial to liberty. By stressing the reasonableness of governmental regulations, Locke puts a stop to all approaches which understand freedom as nothing more than the unobstructed realization of given preferences.

To replace this qualitative restriction with a quantitative procedure, that is, simply counting out and granting equal validity to all preferences, leads not to especially liberal, but rather to especially absurd conditions. Crazy, cruel, or inhumane preferences are not the same as average, everyday preferences. ${ }^{133}$ Some options have less to do with

\footnotetext{
${ }^{130}$ See Jon Elster, Ulysses and the Sirens: Studies in Rationality and Irrationality (Cambridge: Cambridge University Press, 1979).

${ }^{131}$ John Locke, "The Second Treatise of Government," in Peter Laslett, ed., Two Treatises of Government (Cambridge, 1960).

${ }^{132}$ Ibid., $305 \mathrm{f}$.

${ }^{133}$ See Gray, Liberalisms: Essays in Political Philosophy, 59.
} 
autonomy than others. For example, the freedom of religious self-expression, on the one hand, and the freedom to purchase groceries at any hour, on the other, are significantly dissimilar and should be treated differently by the state. Do we not therefore require a theory of freedom which can capture and evaluate such qualitative divergences?

But which determination could we give to the idea of freedom so that meaningful limitations are facilitated, but foreign, arbitrary, and illiberal curtailments are prevented? In the quantitative logic, boundaries for individual freedom that serve to protect the freedom of all express unloved, albeit necessary, limitations on freedom, i.e. they are seen as a primary disadvantage to freedom, which only secondarily can be offset against the advantage of increased security or utility. From the qualitative point of view, they appear differently: as affirmative acts of an all-round realization of freedom. External limits and immanent boundaries are not alike. Metaphorically speaking: A wall constrains the freedom of movement in a different way than one's own skin. One may eventually win freedom by tearing down a wall, but one will hardly win it by tearing up one's own skin.

When the idea of qualitative freedom demands basic defensive rights (Abwehrrechte) (like freedom of expression, freedom of religion, freedom of movement) against infringements upon these by third parties or the state, this occurs quite differently than in theories of quantitative freedom. Unlike the latter, the qualitative consideration does not resort to hypothetical calculations whereby if the granting of those rights appears generally useful then it is rational to impose corresponding restrictions. Instead the logic of qualitative freedom categorically takes up the issue: Because securing these protective rights makes it possible for citizens to undertake the independent qualifications of their personal freedoms - within certain boundaries - they therefore are unconditionally called upon to grant each other these selfsame kinds of freedoms. The conditioned validity - depending on proofs of reciprocal utility - of the quantitatively liberal derivation of protecting freedoms from undue regulations is therefore surpassed by an unconditional logic in the qualitatively liberal approach.

The idea of qualitative freedom therefore also extends to asymmetrical relationships. We owe the establishment and granting of their rights to freedom also to people from whom we receive nothing in return. Be they distantly living human beings or members of future generations, or be they severely handicapped or senile persons. Every single human being's claim to freedom depends - qualitatively observed - not on his or her equivalent contribution or utility, but rather is recognized in and for itself: as the fundamental right of every person, as the universal human right. In this regard, Martha Nussbaum and Amartya Sen continually pose the question concerning which capabilities human beings require in order to first and foremost transform abstract rights into concrete opportunities, or in what way the use of certain freedoms on our part obligates us to enable our fellow man to seize such freedoms. ${ }^{134}$

\footnotetext{
${ }^{134}$ See Benedetta Giovanola, "Re-Thinking the Anthropological and Ethical Foundation of Economics and Business: Human Richness and Capabilities Enhancement," Journal of Business Ethics 88:3, 421-444; Domènec Melé, "Editorial Introduction: Towards a More Humanistic Management," ibid. 413-416.
} 
At the same time, the idea of qualitative freedom is open to questions of moral commitments, ecological sustainability, social co-determination, and cultural sensitivity. From the perspective of quantitative freedom all those issues register as external limitations of private license until their utility is proven for the maintenance of the freedom of everyone. From the perspective of qualitative freedom, on the other hand, one has to consider whether and in which way these goals help us give meaningful contours to freedom; thus, these objectives appear not necessarily as external limits, but can also be understood as internal boundaries of self-determination through which the true content and actual form of freedom comes to the fore.

Open Access This chapter is licensed under the terms of the Creative Commons Attribution 4.0 International License (http://creativecommons.org/licenses/by/4.0/), which permits use, sharing, adaptation, distribution and reproduction in any medium or format, as long as you give appropriate credit to the original author(s) and the source, provide a link to the Creative Commons licence and indicate if changes were made.

The images or other third party material in this chapter are included in the chapter's Creative Commons licence, unless indicated otherwise in a credit line to the material. If material is not included in the chapter's Creative Commons licence and your intended use is not permitted by statutory regulation or exceeds the permitted use, you will need to obtain permission directly from the copyright holder.

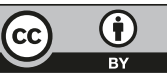




\section{Chapter 2 \\ Metaphysics of Freedom}

The history of the philosophy of freedom within the Continental European tradition is often treated as a historical and systematic development from Kant to Hegel (via Fichte and Schelling). In such presentations, Kant provides the intellectual point of departure for the construction of the idea of freedom. Fichte draws this point out into a line, with a theory of consciousness highlighting the subjective presupposition of the idea of freedom. In his philosophy of nature, Schelling adds to that picture a corresponding line, sketching its objective foundations. And Hegel transforms these two lines into a triangle by adding an absolute baseline that unites the subjective and objective angles. ${ }^{1}$ In drastically simplifying matters, this schema is both helpful and a hindrance.

What is helpful is the abstract demarcation of archetypal positions arising from an idea of freedom that critically examines itself. Actually, there is hardly any way of avoiding the questions which subjective and objective presuppositions freedom requires, as well as deliberation how they could be permanently reconciled. Accordingly, this triangular schema helps prevent us from either overlooking, or overemphasizing, certain perspectives. As the image correctly suggests, freedom as a whole is only in view when we look at the subjectively-inner and objectively-outer conditions together with the help of a theory that encompasses both aspects and relates them appropriately to one another.

Yet, this triangular illustration becomes a hindrance whenever it is held to be an accurate account of the philosophies it assimilates. In that regard, it caricatures those positions more than it characterizes them. The consistency of the schema suggests, for example, that the philosophical systems represented by its constitutive lines are one-sided and complete, whereas the attractiveness of the philosophies of Fichte, Schelling and Hegel up until today precisely consists in their many-sidedness and openness to alternative interpretations. For that reason alone, I am not following this conventional narrative sketch here.

${ }^{1}$ See Richard Kroner's classic Von Kant zu Hegel (Tübingen, 1921ff.). 
With my alternative selection of authors, I aim rather to open up that epoch of philosophy to questions demanded by contemporary thinking. Instead of expecting to find final answers in German Idealism, with the philosophies here collected, I wish to seek out the original questions to the problem of freedom. Therefore, I have not granted Georg Wilhelm Friedrich Hegel (1770-1832) the last word on metaphysical freedom, but rather given this to the less well-known philosopher, Karl Christian Friedrich Krause (1781-1832). In terms of both its methods and its content, Krause's philosophy offers more participatory and procedural openness than that of Hegel and his followers (as we shall see in Sect. 2.3.1). Its proximity to today's thought is thus greater. ${ }^{2}$

The investigation begins with Kant's philosophy, as it presents the central problem of a critically self-reflective theory of freedom. If freedom exempts itself from every external directive and questions all traditional values and commitments and is therefore ultimately only supported by itself, how can it be protected against its dissolution into arbitrariness and from a corresponding destruction of its own - e.g. cultural - presuppositions?

Fichte addressed this problem by first bringing before our eyes the abyss of freedom - its possibility of negating the whole world - and then trying to deduce all individual liberties from nothing but the idea freedom itself. Fichte will have us believe that freedom can only be protected from itself, by satisfying, in all of its manifestations, certain demands of rationality which are to regulate our lives down to the last detail. Hence the philosopher has to instruct the citizens how to use their freedoms correctly. The result is a directive liberalism.

A clear opposition against this position is formulated by the - even in Germany, unjustifiably forgotten - philosophy of Fichte's student, Karl Christian Friedrich Krause (1781-1832). Krause, whose philosophy is to this day widely honored in the Spanish and Portuguese speaking world for setting the standard of a cosmopolitan liberalism, relies on freedom as method: Liberty should be promoted by liberal means. Consequently, the forms of freedom's use ought to be defined less by the state, but rather determined by the citizens - through participatory and representative procedures. Instead of being freedom's recipients the individuals should become its producers. Krause advocates a participative liberalism. All manifestations of freedom - for example, democratic procedures - must always critically be evaluated and reformed in the light of the idea of freedom. Krause thereby lifts the discussion to a level from which today's philosophy of freedom must not slip.

\footnotetext{
${ }^{2}$ For a more detailed discussion see Claus Dierksmeier, Der Absolute Grund des Rechts: Karl Christian Friedrich Krause in Auseinandersetzung mit Fichte und Schelling (Stuttgart-Bad Cannstatt: Frommann-Holzboog, 2003).
} 


\subsection{Reflexive Freedom (Immanuel Kant)}

Kant's philosophy of freedom had an impact second to none. He provided the basis for a thoroughly modern philosophy reflecting critically upon its own boundaries. His philosophy throws the subject of modernity back upon itself and makes it aware of the foundational power of its own thinking. Kant refers to reason questions previously decided by tradition and authority. Not only in the sphere of the theoretical philosophy and in questions of knowledge, Kant invokes the self-enlightenment of human existence as "human being's emergence from his self-incurred minority [Unmündigkeit]" (AA VIII 35) ${ }^{3}$; he likewise makes freedom the basis of his practical philosophy. In questions of action, too, Kant demands autonomous selfdetermination, by instigating a metaphysics of freedom in which the idea of freedom, applied to itself, grounds but also bounds the freedoms to be founded upon it.

Kant thereby lays the foundation for liberalism's two opposing tendencies. Freedom as its own foundation - this notion is directed against the genuine opponents of liberal thinking, that is, against proponents of ethics who do not view freedom as the (highest) value. They learn from Kant's philosophy that those values to which freedom is supposedly subordinated only become valued by means of selfdetermined recognition, i.e. through freedom - and thus cannot reasonably be opposed to the idea of freedom. Freedom as its own boundary - that is directed against false friends of freedom who speak of a liberality that desires to respect no (other) values. They have to be taught that responsibility presents the flip side of freedom, and that therefore the observance of certain rules of moral, social, and ecological sustainability is a necessary consequence of each and every consistent liberalism.

\subsubsection{How Much Metaphysics Does Freedom Require?}

Kant's doctrine of freedom covers a broad thematic spectrum: For him freedom is a moment of theoretical philosophy (pondering the possibility of freedom in a world governed by laws of nature) as well as of aesthetic theory (reflecting how in the experience of beauty our mental faculties enter into a non-coercive convergence). It plays a role in observations concerning the philosophy of history and the philosophy of nature (for example in musings about how the unintended effects of natural as well as sociological forces contribute to the flourishing of individual as well as collective freedom), and the idea of freedom ultimately provides the foundations for Kant's ethics through a theory of moral autonomy. How are these diverse perspectives on human freedom united? Which aspects of these notions are most relevant for contemporary political and economic philosophy?

\footnotetext{
${ }^{3}$ Kant's works are cited according to the Akademic Ausgabe (AA) (i.e. Kant' Gesammelte Schriften) pagination. In all cases the Kant Camdridge Edition translations have been followed.
} 
A particularly appropriate perspective for this question arises from viewing his program of transcendental philosophy as that of a reason critically assuring itself about the conditions of its validity. To philosophize transcendentally means, according to Kant, to pay attention to the necessary conditions constituting selfconsciousness. We cannot understand anything about our environment and ourselves without recourse to certain fundamental assumptions. His project is to find out what these assumptions are and how they could be justified. Kant believes that the key to that lies in identifying structures that are "synthetic a priori." 4 By that, Kant means, above all, that no one lives self-sufficiently. Every person is dependent upon a natural as well as social environment. The subject thus co-determines the world of objects to which it is related, and which it - in Kant's words - "synthesizes." In this process, through the connection (synthesis) of appearances (i.e. of that which is "conditioned" by sensory perception) with spontaneous mental contributions (of the "unconditioned") a subject becomes self-aware.

When a subject orients itself in the world by laws inferred from experience Kant speaks of syntheses a posteriori, in other cases of syntheses a priori. Only a synthesis a priori, i.e. the process relating to the world based on nothing but mental structures, can generate timeless, certain knowledge. Those - and only those - fields of human practice (like morals and law), for which syntheses a priori can be constructed, allow norms that can be certified without recourse to personal experience; they alone generate universal directives for freedom. ${ }^{5}$

Subjectivity relies on contexts, as does personality on relations. Persons exist and experience themselves only within and by mean of relations with their fellow beings and environment. The theory of freedom must do justice to this fundamentally relational essence of human beings; when followed through consistently to its ultimate conclusions it will thus lead to a context-orientated ethics. ${ }^{6}$ - All-important is, of course, how a subject relates itself to its world. To that question, Kant's Critique of Practical Reason provides decisive directives. Kant wishes to establish commandments (synthetically practical propositions) a priori without recourse to specific experiences (AA V 31); more precisely, he wishes to establish their conditions of possibility, and even more precisely: that very structure of reason that facilitates a reasonable human being's ethical relation to self and other. He is searching for subjective universality as a form of interpersonally-universal validity.

The fundamentally decisive idea is as follows: Just as the theoretical cognizing of the true is no purely private matter, nor is the practical realizing of the good only a question of personal taste. We act freely, not arbitrarily; without outer compulsion, but not without inner directives. The true and the good are neither orientations that human beings simply fabricate nor orientations they simply find. Beyond subjective

\footnotetext{
${ }^{4}$ See Otfried Höffe, Immanuel Kant (München, 1983); translated as Otfried Höffe, Immanuel Kant (Albany: SUNY Press, 1983).

${ }^{5}$ See Claus Dierksmeier, Das Noumenon Religion: Eine Untersuchung zur Stellung der Religion im System der Praktischen Philosophie Kants (Berlin: de Gruyter, 1997).

${ }^{6}$ See Onora O’Neil, "Autonomy, Coherence, and Independence" in Milligan \& Miller, eds., Liberalism, Citizenship, and Autonomy (Aldershot: Avebury, 1992), 212-220.
} 
relativism and objective dogmatism, Kant locates a possible third way: a rulegoverned generation of the true as well as the good on the part of reason; leading to interpersonally valid subjective certainties.

By identifying a third class of possible statements about the world, Kant already moves beyond the dichotomy idiosyncratic of later analytic philosophy of either empirical (synthetic a posteriori) or analytic (tautological) propositions. This advance occurs by means of the categories of the understanding which structure our experience. A consensus with intersubjective validity about certain necessary and, at the same time, non-trivial (synthetic a priori theoretical) propositions becomes possible according to Kant through the convergence of (conditioned) intuition and (unconditioned) concept through categories (mediating both). A given situation is brought under general "categories" by determinate "schemata" and thus conceived as possessing a structurally warranted validity surpassing the particular situation. ${ }^{7}$

For example, our understanding automatically supplies regular successions of events with predicates of causality. Unaware of our own contribution, when observing regular sequences, we transform them into connections of cause and effect. Our mind thus constructs from a "previously-subsequently" a "because-therefore," and thereby claims something beyond what we observe with our eyes. We thus form a cognition which (synthetically) goes beyond the logical analysis of the elements causally connected here - with a claim to validity not only for us but for everyone. ${ }^{8}$ Such truth-claims are, therefore, not merely a private affair.

Just as in our theoretical apperception of the world we are afflicted by avoidable error, so in our practical relations to the world we encounter inappropriate actions. What can be done in order to avoid or correct either? One must examine whether that which in the process of the categorization of experiences (e.g. in succession) raises a claim to necessary and universal validity (e.g. as causality) rests on universally acceptable foundations. A claim to universal validity can legitimately only be made when the conditions of possibility of our experience can be demonstrated as necessary conditions of experience as such, when therefore that which individuals cognize here and now can be grasped correctly by everyone at every time and place.

A structural analogue occurs in Kant's practical philosophy. There, our references to the lifeworld (Lebenswelt) are informed by the categories of freedom, which provide the decisive formal directives. They mediate the (unconditioned) moral law with the (conditioned) sensible reality, by structuring it according to (mediating) laws of freedom. The idea of the good, just like the notion of truth, is not merely a private conception. Likewise, Kant proceeds in analogy to the insights of his theoretical philosophy when pondering how to correct fallibility in human practice. Everybody must examine whether the condition of possibility of their free action conforms to the conditions of free action as such, i.e. whether their individual

\footnotetext{
${ }^{7}$ See Hans Bussmann, "Eine Systemanalytische Betrachtung des Schematismuskapitels in der Kritik der reinen Vernunft," Kant-Studien 85:4 (1994), 396.

${ }^{8}$ See John R. Silber, "Der Schematismus der Praktischen Vernunft," Kant-Studien 56:3-4 (1965), 253-73, 257 and Rüdiger Bubner "Was heißt Synthesis?" in Gerold Prauss, ed., Handlungstheorie und Transzendentalphilosophie (Frankfurt am Main: Klostermann, 1986), 27-40.
} 
actions have a structure that is strictly universalizable (AA V 87). Thus Kant's categorical imperative proclaims: "act only in accordance with that maxim through which you can at the same time will that it become a universal law" (AA V 160). Kant identifies in this commandment the foundation of moral goodness as such, which is why, according to him, "all imperatives of duty can be derived from this single imperative as from their principle" (AA IV 421).

Categories of freedom determine an activity formally so that, regardless of what aim is pursued, we can say that it stands (or does not stand) in contradiction to the demand of universal validity. ${ }^{9}$ Thus reason makes possible the imputation of human actions on the one hand (imputatio facti) and their ethical direction on the other. Interestingly, with Kant the imputation is based upon the direction - and not vice versa. And precisely this is the essential point of the Kantian doctrine of freedom:

Since persons can ethically determine themselves, only thus do they have the option not to execute a particular action. It is only because human beings can act ethically, that they are in a position to rise above natural impulses and instincts, and only then imputably act (ethically or unethically). Practical reason does hence not only judge our free actions, in the first place it makes them possible. If we never could act in conformity with the categorical imperative, then it would be completely impossible to act with genuine freedom, according to Kant.

Certainly, most people always presuppose their own freedom and make nearly all of their decisions premised on that assumption. ${ }^{10}$ This self-image is, however confronted with the argument that, nevertheless, at times one may be compelled by inclinations or certain circumstances towards unethical actions. Such a lack of freedom is even loudly proclaimed every now and then; for example in order to excuse oneself from moral responsibility or to justify ethically repugnant behavior. Against this, Kant nevertheless maintains:

Suppose someone asserts of his lustful inclination that, when the desired object and the opportunity are present, it is quite irresistible to him; ask him whether, if gallows were erected in front of the house where he finds this opportunity and he would be hanged on it immediately after gratifying his lust, he would not then control his inclination”. (AA V 30)

Whoever beforehand maintained that he was thoroughly controlled by his inclinations would thus realize that he was nevertheless able to control them on at least this one occasion, thinks Kant. In such cases, persons ascribe to themselves a "negative freedom," i.e. a "freedom-from." Since, on this view, subjects can resist actions, they may legitimately be held accountable for them and juridical connections of freedom and responsibility between action and actor may be construed. Kant's legal and political philosophy operates on this foundation of an uncontentious

\footnotetext{
${ }^{9}$ See Gerhard Schönrich, "Die Kategorien der Freiheit als handlungstheoretische Elementarbegriffe" in Gerold Prauss, ed., Handlungstheore und Transzendentalphilosophie (Frankfurt am Main: Klostermann, 1986), 246-270 and Susanne Bobzien, "Die Kategorien der Freiheit bei Kant" in H. Oberer \& Seel, eds., Kant: Analyse, Probleme, Kritik (Würzburg: Könighausen \& Neumann, 1988).

${ }^{10}$ See Larry Krasnoff, "How Kantian is Constructivism?," Kant-Studien 90:4 (2009), 385-409.
} 
self-understanding - i.e., without intolerable metaphysical baggage; as we shall see, this is a significant intermediate result for modern liberalism. ${ }^{11}$

But does negatively-outer freedom of action suffice for moral-political concerns? To thematize questions of disposition and intention, does one not also need to talk about the freedom of the will to determine oneself ethically or unethically, i.e. about positively-inner freedom? Actually, one can object to Kant's argument so far that the form of freedom referred to in the example of the gallows could itself possibly rest upon an unfree will. One could for instance allege that mere inclination - and not ethical freedom - is directing things. Has merely one preference (for a satisfaction of certain wants) been replaced by another and stronger preference (to stay alive)? Perhaps, then, the human being only possesses the 'freedom' to follow what in any particular case is his strongest inclination and is however necessitated by his or her own nature.

Hence, Kant adds another example: If now however it should be demanded of the same man on pain of execution to destroy an honorable man through false testimony, then one would venture to assert that - whether he would do it or not - it would be possible for him to overcome his love of life for the sake of another's honor, although he certainly may not feel the slightest sensory (sinnliche) inclination or necessitation to do so. Who, Kant asks, does, however, not know about that ethical (sittliche) freedom that is morally proclaiming one should not slander the honorable man? And who would venture to predict with certainty in what way the person concerned would decide? Considering that for centuries human beings have again and again chosen martyrdom for moral reasons, one may here conclude: Reality proves possibility. We must theoretically realize that which those individuals realized practically so as not to underdetermine the idea of freedom.

In and for itself therefore negative freedom, that "freedom from," which we daily ascribe to ourselves, remains dubious. Only positive "freedom for," i.e. for the good - in the previously discussed example of the true testimony despite the threat of execution - proves unquestionably that we are free. The radical nature of everyday freedom becomes evident in heroic freedom. Thus it is only the reality and power of positive freedom that establishes the possibility and the radius of negative freedom. ${ }^{12}$ First appearances are hence deceptive: Negative freedom does not lead the way and then, as a kind of friendly encore, enable its positive orientation towards ethical values and other values. Rather, it is the other way around: The consciousness of being called to act in accord with the demands of positive freedom leads to an awareness of negative freedom. Freedom may hence in no way be equated with the realization of existing preferences. It includes also the possibility of critically

\footnotetext{
${ }^{11}$ That is above all to be noted in regard to the philosophy of John Rawls. He believed that he had to extricate himself from Kant because he set out from the mistaken assumption that Kant's concept of freedom as rational autonomy rested upon manifold presuppositions of his moral and metaphysical theories, which is why, according to Rawls, another foundation for the idea of freedom had to be sought for the concerns of contemporary liberalism - and this would have to be found in a rationalistic calculus of interests. More on this in Sect. 2.3.2.

${ }^{12}$ See Onora O'Neil, "Autonomy, Coherence and Independence" in Milligan \& Miller, Liberalism, eds., Citizenship and Autonomy (Aldershot: Avebury, 1992), 212-221, 213.
} 
relating oneself to one's own preferences, to reject some, to emphasize others, or, third, to develop yet others, etc.

With the example of the false testimony Kant shows that the concept of inner freedom required for moral philosophy is something familiar to everyone and not only the preserve of philosophically educated minds. One does not need complicated dialectical exercises in order to avail oneself of the concept of freedom employed in Kant's legal or moral philosophy. In both cases, Kant merely reconstructs foundational assumptions that our everyday consciousness inevitably already makes when it thinks of itself as free. On but these assumptions he establishes his ethics. Therefore, it does not at all depend upon, as is sometimes claimed, (possibly illegitimate) metaphysical foundations. Kant's ethics consequently also continues to be relevant for societies that conceive of themselves as post-metaphysical.

Let us pause here for a moment and consider the results of these reflections for liberal thinking. Kant shows how values can be liberating. The only faculty that we do not hold to be trounced by sensory stimuli is that power of ethical commitment in the latter example: to the duty to be truthful. Here, the ethical value (truthfulness) does not lead to a reduction, but rather to an awareness and increase of our freedom. At the same time, however, the value of truthfulness can only wield such a power since the former is an act of ethical self-commitment. As an imposed value, not shared by those concerned, the same commandment, not to lie, would be ineffective. According to Kant, just as the moral law lets us realize our freedom theoretically, our freedom in turn lets us realize the moral law practically. Therefore, to oppose freedom to ethical values (like some libertarians) is just as mistaken as it is to subordinate freedom to them (like many communitarians).

But how can we philosophically explain the very freedom presupposed by our everyday consciousness? It is only in order to answer this question that Kant has recourse to metaphysics. Since this groundwork is of subordinate importance for practical questions, it will here be discussed only briefly: Kant thinks of freedom of choice as merely a faculty of the empirical subject and not the transcendental subject. Freedom of choice comes about because the transcendental subject precisely does not have this capacity, but rather is merely free to follow and express the moral law. With this theorem, Kant explains his counter-intuitive claim that the human being is not at first simply free - and then, on top of that, takes on some normative orientation, but rather that we become free to choose as a result of ethical duty. This prima facie unwieldy thought is clarified by Kant's oft-cited distinction between "will and choice."13

The will, Kant says, is pure practical reason; reason, that is, which self-legislates and realizes its own concepts: radical ethical freedom. ${ }^{14}$ In contrast, choice (Willkür) denotes that psychophysical freedom of human beings, seemingly indeterminate, to opt for or to do this or that: the freedom to select (Wahlfreiheit). Freedom of choice

\footnotetext{
${ }^{13}$ See Hud Hudson, "Wille, Willkur, and the Imputability of Immoral Actions," Kant-Studien (1991), 179-196.

14 "We can therefore also explain reason by means of the faculty of judging and (in a practical regard) acting according to principles" (AA VII 199).
} 
however is only possible insofar as ethical freedom is actual, "for then it would itself be subject to the natural law of appearances, to the extent that this law determines causal series in time" (AA III, 373f.). The possibility of deciding for this or that expires precisely when a subject is without normative regulation and instead simply follows hedonistic or other preferential calculi. As a mechanism purely reacting to stimuli, his behavior would then resemble that of a robot; it would be both describable and predictable in terms of algorithms. Voluntary choice between alternatives would not take place (AA V 97). Rather, the conjunction of inner and outer circumstances would determine the subject's decisions. This resembles the 'freedom' of an hour-glass blessed with consciousness, foreseeing its running out, but at the same time itself 'deciding' in favor of precisely this and no other course of events for each and every grain of sand. ${ }^{15}$ Kant also derisively compares this form of liberty with the "freedom of a turnspit," which, "when once it is wound up, also accomplishes its movements of itself” (AA V 97).

This then is the core of the Kantian metaphysics of freedom: Because of its ethical faculty, the human being is able to act against the urges of interests and environmental influences. ${ }^{16}$ Morality makes free. Autonomy is experienced - but as obligation. As the example of the false testimony impressively demonstrates, even the threat of execution cannot extinguish our awareness of the possibility of deciding in accordance with the moral law. ${ }^{17}$ Unlike the outer, political-juridical freedom of action, the inner moral freedom of conscience is thus not always perceived to be a gift, but often rather as a burden. ${ }^{18}$ The consciousness of freedom does not resemble a passively-relished choice of the respectively most delightful option taken from a simply quantitatively assessed sphere of possibilities, but instead it is accompanied by uncertainty and angst. Since its qualitative aims are not already precisely given, they must above all be decided in responsibility before the particular conscience. The dignity (Würde) and the burden (Bürde) of freedom are one and the same. Consequently, freedom is less an objective fact (Tatsache) and more a continuous subjective project. Fichte will thus speak of an Act (Tathandlung), since freedom does not exist in itself, but rather for and through us.

Critics have reproached Kant for thus orientating human freedom - and thus ultimately also the human dignity resting upon it - to too great an extent around the very variable capacity for moral rationality. There are two things to say about that:

\footnotetext{
${ }^{15}$ Many contemporary philosophers are satisfied with a freedom of this kind (semi-compatibalism). Derek Parfit can in this respect be taken as representative here for a large part of the AngloAmerican discourse (Parfit, All That Matters [Oxford, 2009], 267). His critique of Kant is that we do not at all need to think of any superior form of freedom; to him, it is enough if we experience our decisions as our decisions in order to - whilst starting out from deterministic premises - not end up in fatalism. In other words: If the illusion of the freedom of the will is unavoidable and irrevocable then it is also harmless - for the experiencing and organizing of everyday liberties.

${ }^{16}$ See AA V 29. See also Lewis White Beck, Kants Kritik der Praktischen Vernunft: Ein Kommentar (München: Fink, 1995), 46.

${ }^{17}$ See AA V 31.

${ }^{18}$ See H. L. A Hart, Law, Liberty and Morality (Stanford: Stanford University Press, 1963), $8 \mathrm{ff}$.
} 
First, Kant actually often gives the impression that human freedom does not belong - but is rather opposed - to our animal nature. Accordingly, in Kantian thought, small children, senile and mentally handicapped persons - as a result of their reduced rational capacities - cannot enjoy a full compliment of rights, while animals would possess none at all; and there are some passages which in fact imply this. ${ }^{19}$ Here comes to light an essential problem with every theory of human rights based upon freedom; one which, as far as I am concerned, only K. C. F. Krause could adequately resolve (See Sect. 2.3.2).

Second, the particular appeal of Kant's theory lies precisely within the way in which it establishes human dignity in and through autonomy. ${ }^{20}$ By rejecting all material mobilization, it helps to prevent the estimation of human life only in terms of the utility it produces. According to Kant, human dignity can neither be given nor taken away. One of Kant's justifiably most cited passages proclaims: "What has a price can be replaced by something else as its equivalent; what on the other hand is raised above all price and therefore admits of no equivalent has a dignity" (AA IV, 434). That dignity and price are thus mutually exclusive for Kant precisely leads to the view that the value of human life may never be offset or discounted, but rather demands an absolute priority above all calculi concerning utility; a commandment that should be constantly revisited in business ethics. ${ }^{21}$

Nevertheless, even someone who might not accept Kant's transcendental explanation of freedom (i.e. his metaphysical interpretations of the implicit assumption of our everyday consciousness) can easily follow Kant's social philosophy. All of the determinations of the Kantian doctrine of freedom that now follow, which refer to outer actions (rights, politics, economics, etc.) do not depend upon Kant's explanation of morally-inner freedom. The previously discussed distinction between 'will' and 'choice' merely deals with the moral inner life. In contrast, the legal and political philosophy is based upon interpersonally manifest facts; it is, as we shall now see, concerned with freedom in the forum of society.

\footnotetext{
${ }^{19}$ Concerning the problem of Kant's conception of the dignity of the person with respect to disabled people and animals see Martha Nussbaum, Frontiers of Justice. She notes for instance that "for Kant, human dignity and our moral capacity, dignity's source, are radically separate from the natural world" (ibid. 131). That established an irrevocable separation (a "split") in the human being which hinders the creation of harmonious living conditions (in the human understanding as well as in our relation to the animal kingdom): "The split wrongly denies that animality can itself have a dignity. Thus it leads us to slight aspects of our own lives that have worth, and to distort our relation to other animals" (ibid. 132). See also Nussbaum, Creating Capabilities: The Human Development Approach, 85 \& 160.

${ }^{20}$ See Oliver Sensen, "Kant on Human Dignity," Kant-Studien (Ergänzungsheft) (2011), 166.

${ }^{21}$ For that see the unanimous contributions to Dennis Arnold \& Jared Harris, eds., Kantian Business Ethics (Northampton, MA, 2012).
} 


\subsubsection{Outer Freedom: The Good and the Law}

According to Kant there is a necessary object of pure practical reason, which describes an aim that we (without self-contradiction) cannot but strive after (AA V 119). He calls it the "highest good" and describes it as the ideal of ethics for an embodied self: as a life in which those experience happiness (Glückseligkeit) who are morally worthy of it (Glückswürdigkeit). ${ }^{22}$ Kant understands this as the ultimate objective every ethically relevant sphere of life must advance in its own way. Hence it is through this aim that Kant's diverse categorical imperatives arrive at a conceptual unity. For there is not only, as is often claimed, one categorical imperative in different formulations (an impression admittedly fueled by Kant's Groundwork of the Metaphysics of Morals), but rather (as a glance at his subsequent writings on moral philosophy reveals) there are many differing forms of that imperative. Within all of the subdivisions of Kant's practical philosophy (morals, rights, politics etc.) the categorical imperative assumes a form appropriate for each of these disciplines. And that respective form corresponds to the synthesis of this particular field of action with the universal concept of a rationally autonomous subject and its highest good. The synthesis of freedom and lifeworld (Lebenswelt) can thus principally be carried out in four ways. It will be self-related either to the actor (inner acting) or to others (outer acting) and at the same time can either be directed against or in favor of something. Ethical agency can thus refer to inner and outer actions: either ethically-negative ones (forbidding, excluding) or ethically-positive ones (commanding, electing). As a consequence, four central ethical arenas result: negativelyinner action (ethics of conscience) complemented by positively-inner acting (ethics of ends), as well as negatively outer-action (rights) complemented by positivelyouter action (politics). They all follow specific - yet complimentary - categorical imperatives. ${ }^{23}$ What connects them is that idea of practical reason (the highest good').

Kant's ethics culminates in the vision of a world in which individuals who do good (glückswürdig) also become happy in life (glückselig); a vision through which he morally and philosophically enobles the human interest in well-being: After all, a commandment to neglect the happiness of moral individuals stands in opposition to the idea of a harmonization of the worthiness and the attainment of happiness

\footnotetext{
${ }^{22}$ For this, Kant constantly uses symbolic, and at times, religious language. In the so-called 'Typic of Pure Practical Judgement' (AA V 67ff.) in the Critique of Practical Reason, Kant already textually anticipates the symbolic concept that would be unfolded later in his Critique of the Power of Judgement and makes it fruitful for his theory of moral practice. See Annemarie Pieper, "Kant und die Methode der Analogie" in Gerhard Schönrich \& Yasushi Kato, eds., Kant in der Diskussion der Moderne (Frankfurt am Main: Suhrkamp, 1996), 108-109. The decisive explanations about how it could be achieved that he who does good also participates in the good is something that Kant provides only in his late work, in the Critique of the Power of Judgement (1790), and in the theories it prepared concerning symbolic and figurative thinking which Kant unfolds thereafter in his Metaphysics of Morals (1797/98), and in a series of essays published around that time.

${ }^{23}$ See Claus Dierksmeier, Das Noumenon Religion: Eine Untersuchung zur Stellung der Religion im System der Praktischen Philosophie Kants (Berlin: de Gruyter, 1998).
} 
formulated by the "highest good." A world in which the good suffer and the evil rejoice would not only be unpleasant, it would moreover be judged as unjust. No one could consistently want such a world - i.e. from the standpoint of possible universalization; hence the categorical imperative demands its transformation. So, contrary to what one sometimes reads, Kant does not reject the "pursuit of happiness". He merely instructs humanity to pursue this goal via actions that make it 'worthy' of its happiness. This affirmation of an ethical pursuit of happiness is therefore not, as some have thought, Kant's belated attempt to soften his otherwise overly rigorous ethics. Instead from the outset the moral law is directed to abolishing anything hindering a harmony of the worthiness and the attainment of happiness.

In addition to this moral command, law and politics are tasked to resolve any outer ossification of ethical asymmetries, i.e. as far as is possible they are to make sure that society protects against systematic incentives for unethical action. ${ }^{24}$ The law does this by preventing illegal from going unpunished and appears profitable. Still, the law is only a very limited means for the dissolution of unjust states of affairs. For pragmatic motives (efficiency, feasibility, etc.) as well as for normative reasons (the protection of freedom) only a very small part of the ethical asymmetries pervading our lives can be resolved by lawful coercion. Could it therefore be the task of politics to promote the good beyond rules of compliance? May the state find modes of recognition (of a material as well as ideal kind) so as to encourage the ethical engagement of the citizens? Could politics be directed to this goal - and at the same time satisfy liberal standards of legal justice ${ }^{25}$ Should politics serve as the public landscape architect of the common good or should we, for the sake of freedom, leave the planting of moral seeds to the backyards of private self-sufficiency? $?^{26}$

What is at issue here is the view (of Hayek and others; see Chap. 3) that the freedom of open society either stands or falls according to whether politics abstains from visions and utopias of the good. This question touches upon a central point in the self-image of modern liberalism. Conservative liberal thinkers (like Hayek) as well as also more progressively liberal authors (like Rawls), set such great store by Kant's doctrine of law precisely because of its reputation for legitimating coercion only within strict liberal boundaries. ${ }^{27}$ So it is most instructive to observe how Kant seeks to find the path from his legal philosophy towards a theory of liberal politics. On closer examination, though, it becomes clear that in quite the same way that law

\footnotetext{
${ }^{24}$ Kant's moral philosophy and philosophy of religion rather deal extensively with the problem concerning how it is possible that a human being acts morally even if he believes that the conditions are and remain such that often precisely the moral deed will deprive him of the happiness he is entitled to. See Dierksmeier, Das Noumenon Religion, 58-61.

${ }^{25}$ See Katrin Flikschuh, Freedom: Contemporary Liberal Theory (Cambridge: Polity Press, 2007).

${ }^{26}$ See Claus Dierksmeier, "Zur systematischen Liberalität in Kants Politik- und Staatsbegriff” in Ottmann, ed., Kants Lehre von Staat und Frieden (Baden-Baden:Nomos, 2009), 42-63.

${ }^{27}$ See Michael Köhler, "Zur Begrundung des Rechtszwangs im Anschluss an Kant und Fichte" in Kahlo \& Zaczyk, eds., Fichtes Lehre vom Rechtsverhältnis (Frankfurt am Main, 1992), 93-125.
} 
confirms and complements morals, law in turn is paired and completed by a politics orientated by the idea of responsible freedom.

This move is a milestone in the development of liberalism and it takes its cue from Kant's parting with transcendent and naturalistic theories of moral value. Instead of deriving the principles of law and politics from external authorities (transcendence) or objective directives (naturalism), Kant appeals to reason. ${ }^{28}$ Autonomy instead of heteronomy, self-legislation instead of external-legislation, is his slogan. ${ }^{29}$ The idea of a freedom giving itself its own law in a rational manner functions as the highest principle. Kant thus wishes to develop legal philosophy in such a way that it identifies the principle of law as a rationally necessary upshot of the principle of freedom. ${ }^{30}$ Hence, before (metaphysically) unfolding the idea of law, Kant (transcendentally) construes it. That is to say, he first (transcendentally) demonstrates that something like law must be thought so that our consciousness of freedom can be completely clear and transparent to itself. Only subsequently does he (metaphysically) consider the extent to which the historically given laws correspond to the thus developed idea of law - or can approximate towards it through philosophical critique. ${ }^{31}$

Of that idea of law, Kant says:

There is only one innate right. Freedom (independence from being constrained by another's choice), insofar as it can coexist with the freedom of every other in accordance with a universal law, is the only original right belonging to every man by virtue of his humanity (AA VI, 237-238).

Unlike what Fichte will later have us believe (see Sect. 2.2), according to Kant, one cannot derive the specificity of legal rules from mere practical reason, i.e. deduce them by logical inference from said right to freedom. Kant rather sees that various concepts of law, according to historical and cultural contexts, can legitimately honor the one idea of law. Instead of promulgating from the lectern a particular set of laws as the philosophically only true ones, i.e. announcing only one possible interpretation of that innate right to freedom, Kant's thinking is open to diverse historical alternatives. While he himself interprets the statutes of one particular legal tradition (namely, the Prussian General Law of the Land of 1794) in the light of that idea of law, he does not exclude, but rather emphasizes the possibility, that at other places and at other times, other kinds of juridical institutions can also legitimately claim to realize the liberal idea of law.

\footnotetext{
${ }^{28}$ See Hariolf Seel \& Gerhard Oberer, Kant: Analysen, Probleme, Kritik (Würzburg: Königshausen \& Neumann, 1988), 218-224.

${ }^{29}$ See Friedrich Kaulbach, Das Prinzip Handlung in der Philosophie Kants (Berlin, 1978), 263-278.

${ }^{30}$ See Howard Williams, ed., Essays on Kant's Political Philosophy (University of Chicago Press, 1992), 24.

${ }^{31}$ See Friedrich Kaulbach, "Das transzendental-juridische Grundverhältnis im Vernunftbegriff Kants und der Bezug zwischen Recht und Gesellschaft" in Kaulbach \& Krawietz, eds., Recht und Gesellschaft: Festschrift für Helmut Schelsky zum 65 Geburtstag (Berlin, 1978), $263 \mathrm{ff}$.
} 
Kant thus separates the abstract deduction of the idea of law (for Kant: "transcendental deduction") from its concrete unfolding ("metaphysical deduction") in respect to particular legal orders. He thus separates the structural idea from substantial concepts of law. That distinction between concept and idea is something we will deal with below in more detail: First, in regard solely to Kant's political philosophy. It leads him to an approach of central significance for current liberalism; for there, in the political field, Kant separates a structural idea of liberal politics from concrete liberal conceptions of politics and shows how the idea of liberal politics differentiates itself into various political projects. Second, though, we will see that this very distinction between idea and concept plays a key role for the entire philosophy of liberalism. So much by way of anticipation.

But now let us return to Kant by asking: Must law exist at all? For what reason should there be a normative ethical concept for outward-directed behavior separate from moral criteria? Cannot morality simply serve as the principle of state action and enforcement? Could we not say that law is simply there to avenge especially egregious moral violations? Law - the ultima ratio of morality? To these questions the Kantian philosophy answers with a clear $\mathrm{No}$ - which resounds until today in the constitutions of liberal societies. Since not every good will entails also outer morality and, conversely, an evil will at times can lead to outer moral actions (AA VI 313ff.), Kant argues that it is indispensable to have laws distinguished from morals qualitatively (according to content) and not only quantitatively (according to grades of intensity). Intentions and deeds are twofold: they require independent ethical principles (AA VI 249). ${ }^{32}$

The right to property can serve as an example. Conflicts, e.g. concerning possession and usufruct of property, do not only occur among malicious people. Certain goods only allow for one use at a time. Whenever thus the moral usage of one person is incompatible with the ethical plans of the other, even well-meaning people may fall into conflict. ${ }^{33}$ Such a conflict about property marks, however, on the Kantian reading, a conflict between objects of freedom, i.e. a contradiction of reified freedom with itself. ${ }^{34}$ In the name of freedom, this should be resolved. Hence, according to Kant, all subjects who "cannot avoid living side by side with one another" (AA VI 307) have to get rid of every legal uncertainty and ambiguity about the use of their common lifeworld with the help of institutions that posit and protect rights. Laws of universal freedom should therefore limit all particular freedoms in such a way that they do not oppose and cancel one another out.

The idea of the freedom of all thus immanently regulates the freedoms of individuals. That is, Kant does not presuppose a concept of a first unlimited outer freedom, which afterwards would have to be cut back to make it socially compatible.

\footnotetext{
${ }^{32}$ See Wolfgang Bartuschat, "Apriorität und Empirie in Kants Rechtsphilosophie," Philosophische Rundschau 34:1/2 (1987), 31-49.

${ }^{33}$ See Otfried Höffe, Der Staat braucht selbst ein Volk von Teufeln: Philosophische Versuche zur Rechts- und Staatsethik (Stuttgart: Reclam, 1988), 56ff.

${ }^{34}$ See Rolf Gröschner et al., Rechts- und Staatsphilosophie: Ein Dogmenphilosophischer Dialog (Berlin: Springer, 2000), 223.
} 
Rather, he sees the right of individual freedom to manifest and reify itself in the world from the very beginning under the strict condition that it take place under forms accepted by everyone; within forms, that is, which concede equal rights to all. ${ }^{35}$ In contrast to the contractualist theory inspired by Thomas Hobbes (15881679), according to Kant's philosophy our outer freedom does not become restricted (by the state) to universalizable forms, but rather (by its idea) it is already so limited. The material limitation of freedom under the rule of law merely expresses its ideal limitation according to reason. In his eyes, conditions, which the state imposes in order to assure the compatibility of the liberties of all, do not not reduce but realize individual freedom. Interventions in our acts that conform to this principle of law, do not harm the citizens' freedom; they manifest it. A state under this rule of law is hence always a friend, and never a foe, to freedom. Anarchists may not appeal to Kant.

In short, where many thinkers observe the law as an outer limitation of freedom, Kant recognizes it as its inner boundary. Hence his definition of right as: "the sum of the conditions under which the choice of one can be united with the choice of another in accordance with a universal law of freedom" (AA VI 230). Law appears accordingly as a limitation of one's own actions to be decided rationally by everyone for themselves. The idea of freedom would consequently be incomplete were it not directed by the idea of law. In liberal law (freiheitlichen Recht) humanity finds the right freedom (rechten Freiheit). ${ }^{36}$ Hence the legal imperative: "so act externally that the free use of your choice can coexist with the freedom of everyone in accordance with a universal law" (AA VI 231).

In contrast to most libertarians and various neoliberal theorists of today (see Sect. 5.2) Kant declares: Law is not defined as the authority to coerce, but rather itself legitimates coercive authorities in the first place. ${ }^{37}$ Each and every act of coercion must result from the application of the principle of law to a finite subject and, importantly, it must be justified to the coerced subject in particular as conforming to and necessary for the principle of freedom, i.e. as "a hindering of a hindrance to freedom" (AA VI 231). If, for example, someone finds himself in court because of an accident resulting from drunk driving, he may not welcome the punishment he receives, but he cannot rationally characterize it as unjust. Persons are not negated by legal coercion, but rather confirmed in their status as mature subjects of freedom, insofar as from the point of view of the coerced subject, the legal coercion can be understood as an act of liberty-affirming self-constraint through others. ${ }^{38}$

\footnotetext{
${ }^{35}$ See Arthur Ripstein, Force and Freedom: Kant's Legal and Political Philosophy (Cambridge, M.A.: Harvard University Press, 2009), 223ff. See also Gregory Kavka, "Why Even Perfect People Would Need Government," Social Philosophy and Policy 12:1 (1995) 1-18.

${ }^{36}$ For example Kant writes that "when I draw up a penal law against myself as a criminal, it is pure reason in me (homo noumenon), legislating with regard to rights, which subjects me, as someone capable of crime and so as another person (homo phaenomenon), to the penal law, together with all others in a civil union" (AA VI 335).

${ }^{37}$ See Köhler, "Zur Begrundung des Rechtszwangs im Anschluss an Kant und Fichte," 105.

${ }^{38}$ See Peter Unruh, Die Herrschaft der Vernunft: Zur Staatsphilosophie Immanuel Kants (BadenBaden: Nomos, 1993), 44.
} 
If a state, though, uses coercion for purposes other than the protection of rights, it acts unjustly. In that regard, it is one and the same. No matter how noble the motives and how welcome the results might be, they cannot by any means justify that transgression. In questions concerning the inner determination of the will, that is, in the domains of morality and religion, the state should not interfere, according to Kant (see AA VI 219). Therein lies a decisive defense of personal liberty in the Kantian concept of legality, which protects the citizen from every usurpation on the part of the state, however well-meaning. In this regard, Kant's model is not only superior to utilitarian and other consequentialist doctrines, all of which legitimate the right to coerce for the sake of its effects and can therefore never be justified to those who doubt that in a given case these effects either occur or are desirable. It is superior as well to all theories of negative freedom, which aim to prove the compatibility of law and freedom by characterizing law as the sum of legitimate coercive acts and then founder, though, upon the question as to what actually legitimates coercion in the first place (See Sect. 5.2).

Translated into the terminology I brought into play, this notion could be expressed thus: While quantitatively directed liberalism generally seeks to protect the freedom of the individual through less, rather than more, state intervention, Kant subordinates the quantitative perspective to the question concerning the appropriate quality of state action, orientated by the need to promote the freedom of all. In short, one requires just as much state-intervention as is necessary to fulfil the aforementioned need: no more, but also no less. For Kant, the quality of the idea of freedom provides the measure of the quantity of the citizen's liberties. Kant therefore stands firmly not only against excessive state action, but also - all libertarians should take note - against insufficient state action.

\subsubsection{Social Rights?}

If freedom realizes itself in law and this presupposes a relation to objects, does there not also follow from the universal right of all persons to freedom a right to participate in the world at large and to have access to nature? Must the state of law also be a social state in order to enable everyone to be able to make use of the freedoms they are legally entitled to? Does the idea of freedom have a social side? Today, much seems to speak in favor of that idea.

The legal philosophies of the sixteenth to eighteenth centuries construed a fictional state of nature where all could take care of themselves through their own effort and wits, bringing food on the table, as it were, by the work of their hands. Between that imaginary world and our current lives, there is a stark - also philosophical - difference. Today, the access to freedom is societally mediated; no longer can individuals through an original appropriation of nature relate to ownerless goods and employ them to master their lives in isolation. ${ }^{39}$ Instead, the freedom of

${ }^{39}$ See G. W. F. Hegel, TWA 7, 388. 
the individual finds its relation to the objects of the world everywhere bounded by ownership rights, so that we require the legal consent of others for nearly every appropriation and use of the environment. Wherever this approval is lacking, then often - the best of will and brave diligence notwithstanding - individuals cannot sustain themselves. From the prohibition of appropriating other's property - as materially manifested freedom - unlawfully, might we not need to postulate to put every person in such a position that they do not need to act contrary to the law in order to survive? Must not hence everyone who wants to protect private property also ensure that the fundamental rights of human life can be realized without infringing upon the property rights of others? Should not the minimum presuppositions of maintaining one's existence and using one's freedom be construed and claimed as indispensable foundations of any individual's right to freedom $?^{40} \mathrm{~A}$ right to social participation as a result of a consistently thought liberalism - what is Kant's view on that?

At first glance it catches one's eye that in his 'Doctrine of Right' Kant converts the slogan of the French Revolution, i.e. liberté, egalité, fraternité, into the formula, freedom, equality, independence (see AA VI, 314). It may therefore seem as though he replaces the earlier apparently social-moral concept of fraternity with a category of law, and wants to demand the individual's participation in the economic and political sphere as a civil right.

A closer look, however, reveals that Kant's texts do not allow for this reading. In $\S 46$ of his 'Doctrine of Right' Kant defines the concept of the "citizens of the state" as containing three moments:

Lawful freedom, the attribute of obeying no other law than that to which he has given his consent; civil equality, that of not recognizing among the people any superior with the moral capacity to bind him as a matter of right in a way that he would not in turn bind the other; and third, the attribute of civil independence, or owing his existence and preservation to his rights and powers as a member of the commonwealth, not to the choice of another among the people. From his independence follows his civil personality, his attribute of not needing to be represented by another where rights are concerned. (AA VI 314)

Kant thus makes economic independence a presupposition of political independence. Distinguishing between "citizens of a state" and "associates in the state," he declares that human beings who do not reach economic independence also do not have a claim to political autonomy. In the paragraph in question, he expressly claims that:

not all persons qualify with equal right to vote within this constitution, that is, to be citizens and not mere associates in the state. For them their being able to demand that all others treat them in accordance with the laws of natural freedom and equality as passive parts of the state it does not follow that they also have the right to manage the state itself as active members of it, the right to organize it or to cooperate for introducing certain laws. (AA VI 315)

In other places Kant adds that those who do not enjoy independent employment also must lack the right to active citizenship. For instance, a barber with his own

\footnotetext{
${ }^{40}$ Michael Köhler, "Justitia distributive: Zum Begriff und zu den Formen der Gerechtigkeit," Archiv für Rechts- und Sozialphilosophie 79 (1993), 457-482.
} 
shop - this is Kant's own example - is to be looked upon as economically independent, whereas another barber who works based on home-visits is not. Women and children are from the outset degraded as merely passive "associates in the state".

How can we explain these - from our current perspective - abstruse restrictions on the right to political participation? Kant drew on a reality surpassed by his philosophical idea for its conceptual determination and thus mistakenly inferred norms from facts. Instead of celebrating this dip in his thinking as a libertarian curvature, ${ }^{41}$ we should rather recognize it as the embarrassing dent that it is. Something else would have been far more in accordance with his system, i.e. if the right of everyone to political representation would have given rise to a counterfactual claim to economic participation. Poverty does undermine active, intellectual as well as practical participation in political decision-making - that is correct! Consequently, however, it is not the political participation of the poor, which should be abolished, but their poverty. ${ }^{42}$

Such a reading would also correspond with the Kantian formula of freedom, equality, independence. Then, for this interpretation, one need only demand for "independence" what Kant's legal philosophy grants to the principles of freedom and equality as a matter of course, namely that they must also be counterfactually realized. Kant in no way maintains that all human beings are by nature legally free and equal, but declares that all human beings should be free within legal boundaries and equal before the law. The same thing ought to be true of independence too. Kant even seems to tend in this direction when he recommends that an "associate in the state" should at all times have the capacity to "work his way up from a passive condition to an active one" (ibid.). If, however, such a self-emancipation out of economic dependency is not possible for contingent reasons, then, one has to object: Why not then at least intervene by law? This, at any rate, was how Fichte and Krause saw the issue (for Fichte and Krause's development of this idea see, respectively, Sects. 2.2.2 and 2.3.3).

Moreover, insofar as the citizens themselves obviously have an interest in their economic emancipation, this very problem arises once again within the sphere of politics in a distinct way. Politics has the mandate to remove unjust living-conditions in accordance with the law. Perhaps then the overcoming of poverty and disadvantage could become the objective of politics. As we have already seen, Kant conceived of politics as a positively outer determination of action. Although this frees the political arena from an inquisition into inner motivations, it does not make questions concerning the ethical aims of political agendas in any way superfluous: Motivations and objectives are two different things; even the blackest soul can sometimes - for whatever reason - set something noble in motion. Not the secret intentions of politicians, but rather the recognizable aims of their politics ought to

\footnotetext{
${ }^{41}$ See Wolfgang Kersting, Wohlgeordnete Freiheit: Immanuel Kants Rechts- und Staatsphilosophie (Frankfurt am Main, 1993).

${ }^{42}$ Thus also Ripstein, Force, 282-285. Inspired by Kant he develops an obligation of the state to the needs of the poor through taxation of the rich and extracts from Kantian lines of thought the creation of a modern welfare state.
} 
be in the focus of philosophical attention: Is there a separate categorical imperative for politics? Can political philosophy achieve an independent a priori synthesis? The answer is provided by the liberal proceduralism of the Kantian ethic.

Kant's ethic typically proceeds formally at first and materially only thereafter. Initially, it turns away from the directives of traditional material values (happiness, enjoyment, utility, justice, well-being, charity, piety, etc.) towards formal procedures (avoidance of contradiction, universalizability) that are to uncover the morally obligatory aims and values. For this insistence on formality, up until today, Kant has been unjustly interpreted as culpable of a rigorous formalism allegedly repudiating all human striving for happiness and wellbeing. But such interpretations are erroneous. For as we have already seen, all the disciplines of Kantian ethics culminate in the concept of the "highest good" (AA V 108ff.). ${ }^{43}$ Politics, too, is directed towards this "highest good", in a yet to be characterized manner. Politics not only curates the law, it transforms it as well. Yet how are we able to determine, which political use of the legislative agrees with the liberal principle of law, and which contradicts it? ${ }^{44}$

Since Kant's idea of law is not constructed by pre-given ethical aims (common good, welfare, etc.), the criteria of politics must first be formally determined. Thus, still "the form of publicity, the possibility of which is involved in every claim to a right" (AA VIII 381) remains. Abstracting from all representations of the good, politics can realize the claim to conduct itself under the principle of freedom by examining as to their universalizability the way in which the political objectives are being established. The public, so to speak, is to run this universalizability-test. ${ }^{45}$ For, according to Kant, it is possible, through a republican "organization of the state," to arrange illicit political forces "in opposition to one another in such a way that one checks the destructive effect of the other or cancels it, so that the result for reason turns out as if neither of them existed at all and the human being is constrained to become a good citizen, even if not a morally good human being" (AA VIII 366).

By making political directives public, as soon as my directives are likely to impair the rights of others, there arises an "a priori foreseeable resistance of everyone to me" (AA VIII 381) ${ }^{46}$ The notion of publicity thus yields "a criterion to be found a priori in reason" with which "we can cognize at once, as if by an experiment of pure reason, the falsity (illegitimacy) of the claim in question (praetensio iuris)" (AA VIII 381). Therefore Kant issues the "transcendental formula of public right" (AA VIII, 381) that we should only engage in politics whose procedures can at all times be made public. Public action is thus structured by the principle of freedom (synthesis a priori) and the sphere of permissible politics bounded on principle, without recourse to material ends of politics.

\footnotetext{
${ }^{43}$ See Claus Dierksmeier, "Kant on Virtue," Journal of Business Ethics, 113:4 (2013), 597-629 and Robert B. Louden, "Kant's Virtue Ethics," Philosophy, 61:238 (1986) 473-489.

${ }^{44}$ See Ulrich Sassenbach, Der Begriff der Politischen bei Immanuel Kant (Würzburg, 1992) and Claudia Langer, Reform nach Prinzipien: Untersuchungen zur politischen Theorie Immanuel Kants (Stuttgart, 1986).

${ }^{45}$ See Howard Williams, Essays on Kant's Political Philosophy (1992), 34f.

${ }^{46}$ See also Reflexion 7687 in AA XIX, 491.
} 
Yet, up to this point, political reason is "only negative" (AA VIII, 382) in its operation. Still, the sphere of permissible directives so demarcated lacks an additional positive criterion for legislation. ${ }^{47}$ Not all measures passing the publicity-test are equally well-suited for organizing the political will of a society. Political reason must choose from the abstract quantity of permissible enterprises those whose concrete quality best promotes the citizens' cohabitation. To provide a genuine categorical imperative of politics, reason must therefore still substantially lead the community's will beyond the formal demand for legal structures. This necessary positive criterion is the pursuit of happiness (See AA VIII, 386ff.).

The rehabilitation of happiness (Glückseligkeit) within Kant's political theory has confused many a commentator, ${ }^{48}$ and, since Kant expressly excluded considerations about welfare from the justification of law and the state, this is quite understandable. With the oft-cited words - "welfare possesses no principle" (AA VII, 87n) - Kant had declared war on all state-paternalism. Kant did indeed dispute the central assumption of all utilitarian attempts at making commensurable and measuring individuals' happiness, pleasure, or utility so that technocratic governments could simply enhance everyone's wellbeing. The individuality and difference of human beings, intensified by their every free act, simply does not allow for a universally valid concept of material happiness. Accordingly, Kant determines "political freedom" in the following way: "This consists in each being able to pursue his welfare as he conceives it and also that he can never be used by another as a means for the end of his own happiness in conformity with the other's concept of happiness but only in conformity withhis own" (AA XXIII, 129). No single project could serve the happiness of absolutely everyone; making people feel comfy is not the job of the government. ${ }^{49}$

Still, Kant does champion a formal theory of happiness under the aegis of freedom. Projects that are in harmony with citizens' free choice of goals may be promoted as the object of politics. State action should create the necessary conditions -for example through the creation of economic prosperity - for enabling citizens to find happiness in the way they see fit. ${ }^{50}$ So Kant approves of pursuing the welfare of the community as a "means to secure their right and to place them in a condition to make themselves happy in every way" (AA XIX 560). He also contemplates measures where "to encourage silkworms, the sovereign offers a reward for planting mulberry bushes, or som other action" (AA XXVII 548). Today one would more likely think of the construction of structural and informational networks,

\footnotetext{
${ }^{47}$ See Joseph Knippenberg, “The Politics of Kant's Philosophy” in Beiner, ed., Kant and Political Philosophy: The Contemporary Legacy (New Haven, 1993), 155-172.

${ }^{48}$ Heinz-Gerhard Schmitz even sees here a - for him welcome - turn from Kant's entire concept of morality and its replacement with a concept of prudence. See Heinz-Gerhard Schmitz, "Moral oder Klugheit? Überlegungen zur Gestalt der Autonomie des Politischen in Denken Kants," KantStudien 81:1 (1990), 413-422.

${ }^{49}$ See Wolfgang Kersting, Kant über Recht (Paderborn, 2004).

${ }^{50}$ See Paul Guyer, Kant on Freedom, Law, and Happiness (2000), 285.
} 
administrative directives for the coordination of individual and collective pursuits, or state support for charity work and participation in NGOs.

The ends change; what remains is the method of protecting voluntariness through respect for citizen's individual interests. In politics it is permissible, often even commanded, to motivate citizens materially, ${ }^{51}$ as long as the advantages and incentives are being obtained in accordance with laws of liberty. Forms of recognition - ideal as well as financial - for helping political projects along are therefore not only pragmatically sensible, but - in the light of the idea of the "highest good" - also demanded: as a just support for those who further the political order and the public goods it promotes.

Kant opens up interesting possibilities through this dual determination that, on one hand, renounces every substantial concept of happiness, while it, on the other hand, marshals the structural conditions that enable the individual and collective search for happiness. This move facilitates a political philosophy that allows for a procedural instead of a substantial answer to the question which civil concerns should direct civic policy. Because individuals' ends and goals in life are infinitely variable, they cannot be directly promoted by state action without some being discriminated against for the benefit of others. Yet, individual welfare can certainly be supported indirectly; for instance, by the government enabling and capacitating citizens to pursue their own happiness individually as well as through voluntary cooperation. The state can and should adopt the goal of offering appropriate procedures, institutions, and infrastructure for this. Then one can reconcile the otherwise countervailing demands for freedom and wellbeing. Thus, orientated by the lodestar of a participatory self-determination on the part of the citizens, Kant steers his political concept of freedom between the Scylla of the libertarian refusal of all organized political activism and the Charybdis of illiberal paternalism. The aptness of Kant's theory for our times results precisely in his positioning himself both against the formalism of a merely "negative freedom" excluding all content, and in favor of a procedural, rather than substantial determination of "positive freedom".

\subsubsection{Societal Self-Regulation}

According to Kant, politics should refrain from coercion, but may introduce - monetary, material, informational, logistical as well as immaterial, for instance, reputational - incentives in order to promote its projects. Consequently, politics is not a mere amalgamation of the generality of lawful rules and aggregated special interests. Kant's concept of politics may not be reduced to state-prudence, ${ }^{52}$ the "doctrine of right put into practice" (AA VIII, 370), the promotion of progress toward justice

\footnotetext{
${ }^{51}$ The differentiation within the class of praemia auctorantia already worked out within Kant's earlier lectures on morality provides the foundation for this idea. See Hans Vaihinger, Kant-Studien (Berlin \& New York, 1942), 64ff.

${ }^{52}$ Although the contrary view is supported by Schmitz, "Moral oder Klugheit?" See 413ff.
} 
and/or the protection of peace. It certainly encompasses those dimensions ${ }^{53}$ but still aims at something higher: an ethically creative interpretation of the lifeworld (Lebenswelt). The political agent must ascertain which societal defects citizens conceive as unjust and which ideals provide suitable alternatives. ${ }^{54}$ Which accomplishments and norms are seen as particularly apt to help or hinder the promotion of the common good - and how is that fed back into our societal structures of incentivization and recognition?

Yet how do political actors ascertain the people's sense for socio-ethical problems to which they must cater? One answer popular in the secondary literature focuses upon certain reflections in Kant's Critique of the Power of Judgment that explain how individuals learn to assume the perspective of others in order to bring about a convergence of social judgements. ${ }^{55}$ Kant suggests one should judge as if directed by an "idea of a communal sense" i.e. oriented by a counterfactual ideal which can only be approximated towards (AA V, 293). He who judges must assume a perspective in which, as best one can, the view of all others is taken into account, by referring his particular judgment "as it were ... to human reason as a whole" (ibid.). ${ }^{56}$ Certainly, man does not possess a God's-eye view of the world. Nevertheless the practice of thinking "in the position of everyone else" (AA V 294) can be cultivated and optimized. The shadows our private perspectives cast on the world and the obscurity they produce can be lightened up by augmenting our range of vision with the perspectives of others.

Political theory here merges into the philosophy of culture. Can an "aesthetic education of man," like the one proposed by Friedrich Schiller (1759-1805) in allegiance to Kant, support a politics that is both liberal and at the same time orientated towards the common good? According to Schiller, by making us sensitive to the perspective of our fellow man, culture instigates in man, "a disposition which comprises in itself the wholeness of humanity." ${ }^{57}$ Cultural forms make us receptive to the feelings, points-of-view, and world-interpretations of others. ${ }^{58}$ Without such

\footnotetext{
${ }^{53}$ See Thomas Kater, Politik, Recht, Geschichte: Zur Einheit der politischen Philosophie Immanuel Kants (Würzburg, 1999).

${ }^{54}$ Jürgen Habermas, Strukturwandel der Offenlichkeit: Untersuchungen zu einer Kategorie der bürgerlichen Gesellschaft (Franfurt am Main, 1990), 190.

${ }^{55}$ See Ernst Vollrath, Grundlegung einer philosophische Theorie des Politischen (Würzburg, 1987) and Hannah Arendt, Lectures on Kant's Political Philosophy (Brighton, 1982). In their emphasis upon the political meaning of reflective judgement, the works of Hannah Arendt and Ernst Vollrath provide an important contribution to Kant-interpretation; but they err in according judgement too much independence over and above the sphere of practically normative theory as a whole. This aestheticizing of Kantian normativity is rejected within Patrick Riley, "Kant's Two Conceptions of the Will in their Political Context" in Williams, ed., Kant's Political Philosophy (Chicago, 1992), 309.

${ }^{56}$ See O'Neil in Williams, ed., Essays on Kant's Political Philosophy, 77.

${ }^{57}$ Friedrich Schiller, Sämtliche Werke V (München, 2004), 637; translated in Friedrich Schiller, On the Aesthetic Education of Man (Dover, 2004), 103.

${ }^{58}$ For contemporary reflection upon the contribution of aesthetic education to the project of a reflexively global politics see Martha Nussbaum, Not for Profit: Why Democracy Needs the Humanities (Princeton, 2010), 7 \& 103f.
} 
foundations promoting mankind's mutual respect and sensitivity towards one another, failure would threaten the project of a political reason autonomously deliberating about its goals. It would fall victim to the cold calculus of uncultivated thinking, like a man who - to quote Schiller once more - "self-seeking without being himself, unfettered without being free" - shrinks and sinks into gross egoism. ${ }^{59}$

Yet, no state can flourish that is comprised of individuals who absolutize their private ends and, wherever they can, assert themselves at the expense of all others. Society must control utility-maximizers who exploit every legal loophole. However, the tighter the straitjacket of incentives and rewards, and the more firmly tied the knot of surveillance, all the more difficult is it for freedom to breathe. Wherever it chokes, the putrid stench of opportunism engulfs us all the more. Without humanist culture, political liberalism cannot exist for long. Therefore the liberal state has a cultural mission. For this reason alone, culture is not merely a private matter; for without it the res publica cannot survive. ${ }^{60}$

Politics requires the symbolic worlds of culture in order to bring about a unifying interpretation of the social life and generate a plausible vision of its optimization. ${ }^{61}$ Politics cannot operate in a vacuum of abstract concepts. ${ }^{62}$ Without the concreteness of integrated symbols and convincing scenarios, politics cannot thrive. ${ }^{63}$ The intellectual lodestar for such a symbolic endeavor marks the command - formulated in Kant's concept of the highest good - to abolish step-by-step society's ethical asymmetries; a lodestar by which the respective political actors then are to navigate on the very path that, based on their own judgment, best fits the given situation. The regulative idea of the "highest good" provides the vision of a societal life where "freedom, partly moved and partly restricted by moral laws, would itself be the cause of the general happiness, and rational beings, under the guidance of such principles, would themselves be the authors of their own enduring welfare and at the same time that of others" (AA III, 525).

Although this may very much contradict the customary image of Kant: The pursuit of happiness becomes bound up with Kant's political liberalism and not at all in contradiction to its underlying principle of freedom - e.g. by Kant caving in to an otherwise overly restive human nature - but rather as its consistent expression. ${ }^{64} \mathrm{By}$ including conceptions of the 'highest good' in the sphere of politics the synthesis of practical reason with its lifeworld is completed. As reason is certainly autonomous, but not autarch, Kant coherently and consequently declares it the actual "task of

\footnotetext{
${ }^{59}$ Friedrich Schiller, Sämtliche Werke V, 646; translated in Friedrich Schiller, On the Aesthetic Education of Man, 113.

${ }^{60}$ See Wilhelm Humboldt, Ideen zu einem Versuch, die Grenzen der Wirksamkeit des Staats zu bestimmen (Stuttgart, 1967).

${ }^{61}$ See Dieter Henrich, ed. Über Theorie und Praxis (Frankfurt am Main, 1967), 35.

${ }^{62}$ See Heiner Bielefeldt, Symbolic Representation in Kant's Practical Philosophy (Cambridge, 2003).

${ }^{63}$ See Dierksmeier, Das Noumenon Religion, $148 \mathrm{f}$.

${ }^{64}$ See Schmitz, "Moral oder Klugheit," 413ff.
} 
politics" to make "the public satisfied with its condition" (AA VIII, 386). Accordingly, we cannot simply negatively protect the freedom of all, one must also - in the sphere demarcated and delimited by the principle of freedom - positively promote those projects from which citizens expect a better life. Hence results "another transcendental and affirmative principle of public right," which provides the systematic conclusion of the political theory of Kant's philosophy of freedom:

\footnotetext{
"All maxims which need publicity (in order not to fail in their end) harmonize with right and politics combined."

For if they can attain their end only through publicity, they must conform with the universal end of the public (happiness), and to be in accord with this (to make the public satisfied with its condition) is the proper task of politics. But if this end is to be attainable only through publicity, that is, by the removal of all distrust towards the maxims of politics, such maxims must also be in accord with the right of the public, since only in this is the union of the ends of all possible" (AA VIII, 386)
}

That which legally becomes the goal of politics in the sphere of publicity of a state governed under the rule of law, is consequently also legitimated in the name of liberty ${ }^{65}$ While philosophy does thus provide a procedural political goal, it leaves its substantial contents to the discretion of liberal republican processes. Kant thus connects the idea of a liberal order with that of a pluralistic public sphere. He furnishes politics with a normative idea, but does not lay down how specifically politics should be carried out in the light of this idea. On the contrary, he justifies the view that - and how - various societies could, according to their respective needs, come up with their own differing concepts of how the idea of liberal politics could be concretized and realized.

Kant thus identifies normatively correct politics as the path towards its empirically successful implementation. ${ }^{66}$ The political imperative, to only follow directives which require public agreement for their realization, refers politics to the participation of the population. Obviously, this procures the acceptance of the policies at hand. Instead of fantasizing about shattering private interest by a universal ethic imposed 'from above,' for Kant, it is all a question of the integration of the individual into the social - for the end of everyone's "moral happiness" (AA VII 277). Having the citizens' concrete concerns inform legislation is an outcome of the directive to bring politics into alignment with the free participation of citizens in order to pursue - within the boundaries of the rule of law - the conceptions of freedom they champion.${ }^{67}$ Kant therefore does not subordinate the citizens' understanding

\footnotetext{
${ }^{65} \mathrm{An}$ idea again appears here which is analogous to one that Kant already invoked in the ethicallyinner determination of ends. "What, in the relation of a human being to himself and others, can be an end is an end for pure practical reason; for, pure practical reason is a faculty of ends generally, and for it to be indifferent to ends, that is, to take no interest in them, would therefore be a contradiction, since then it would not determine maxims for actions either (because every maxim of action contains an end) and so would not be practical reason" (AA VI, 395).

${ }^{66}$ See Volker Gerhardt, Immanuel Kants Entwurf "Zum ewigen Frieden": Eine Theorie der Politik (Darmstadt, 1995).

${ }^{67}$ See Christopher Gohl, Prozedurale Politik am Beispiel organisierter Dialog: Wie politische Beteiligung professionell gestaltet werden kann - eine Grundlegung (2011)
} 
of freedom and politics - like Fichte and Marx (see Sect. 2.2.4.) - to the philosopher's supposedly better knowledge and to the political goals they formulate; he rather constitutively incorporates citizens' conceptions of themselves and the world into his political model.

Although Kant, as a citizen of his time, obviously took part in socio-political discourse and was savvy enough to ensure that the public attended to his opinions, in accordance with his own political philosophy he never claimed to speak with philosophical authority on daily politics. On the contrary, having established a universal idea of political freedom, he left its concretization through specific concepts of freedom to the citizens. As one such citizen Kant also allowed himself to express his views about current political affairs. Like everyone else, philosophers also have the right to add their voice to controversies concerning the optimization of laws and they may be outvoted, like everybody else, too. ${ }^{68}$

For this reason, Kant's political liberalism proves attractive beyond the circle of people convinced by Kantian philosophy as a whole. Kant did not proclaim for the political sphere the metaphysically-moral conception of a freedom obligated towards a determinate good, but rather merely proclaimed the outer-legal variant of a freedom generally orientated towards the good; consequently, his concept of the political can also integrate views privileging concepts of political freedoms other than the ones he favored. ${ }^{69}$ Kant regionalizes and temporalizes politics; it may, or rather, it should be different from place to place and from time to time, as he spurns the depiction of a philosophical perfect state, a perfectly rational legal and economic system or political model. In order to protect everyone's right to freedom and, at the same time, to arrive at adequately specific policy recommendations, two things are imperative: first, an informed public taking part in the development of political objectives and, second, an emphasis upon citizens' objections as prima facie indicators of possible violations of rights. Kant therefore expected the realization of his political theory from political freedom itself. Since philosophy does not only theoretically demand a plural public, but also practically promotes the public use of reason, it advances the factual recognition of its own liberal ideas.

Through constitutional arrangements regarding the appropriate organization of the state the public discourse about political directives must ensure that each law deliberated upon has to pass the publicity text. For this purpose, Kant stresses the importance of distinguishing between "the form of state" and "the kind of government" (AA VIII, 353). Although he looks upon democracy as the adequate contemporary expression of political freedom, he does not conceive of democracy as an end in itself. He speculates that in bygone times other forms of government may have

\footnotetext{
${ }^{68}$ See Volker Gerhardt, Partizipation: Das Princip der Politik (München, 2007).

${ }^{69}$ Kant thus begins a project of political philosophy which John Rawls similarly made the central program of his late philosophy. When Rawls ranks Kant among the proponents of that "comprehensive liberalism," against which he believes he has to demarcate his project of a "political not metaphysical" liberalism, then, in my opinion this is either owing to the will to brand only himself as the founder of that program and/or an imprecise interpretation of Kant. For more detailed information about this see Sect. 3.2.1.
} 
been more suitable for actualizing the liberal principle of law; and, furthermore, he points out that a democracy (demos/kratein) which turns into as a dictatorship of a 'tumultuously' gathered volition of the crowds is but "mob rule" (AA XXIII, 160ff.). Specific procedures must rather first transform the sheer will of the people into the legitimate will of the state. Liberty-protecting processes have to prevent the whims of the masses passing themselves off as acts of law and state - so that minorities can be protected and state action becomes uncoupled from private willfulness. ${ }^{70}$ Liberal processes are to ensure that politics does not lose its structural liberty during the determination and specification of civic freedoms.

Consequently, Kant does not champion merely procedural justice. Although, under the condition of modernity, he considers the democratic form of governance to be the most appropriate way of legislating public law (AA VIII, 353), he does not conflate the representative institutionalizing of political processes with the republican way of governing in the interest of freedom that, according to him, is the philosophical mission of politics. The right to freedom remains as ever the corrective ideal and the criterion for the critical evaluation and legitimation of all forms of legislation, including democratic ones. ${ }^{71}$ The democratic legislator may hence only work within the boundaries of a legal framework devoted to liberty and removed from popular discretion; that is, for instance, within the sphere of a constitution directed - procedurally and substantially - towards protecting the freedom of all (see AA XXIII, 160ff.). It is not the will of the majority in itself that should rule, but rather it is only the representation of a lawful will (expressing itself in majorities, but protecting the rights of minorities) that can legitimately organize citizens' freedom (see AA VI 313f.). Freedom acts thus not only as the basis of democratic legitimacy, but also as its boundary. If a democracy annuls its founding liberal principle - like, for example, through the Weimar 'Ermächtigungsgesetz' of March 24,1933 - it nullifies its own normative foundation.

With this turn to the liberal constitutional-state it becomes clear that, for Kant, the state's mission results from the specific measures of legal and political philosophy - and not vice versa. That makes his liberalism philosophically more attractive than that of many current Anglo-American thinkers who notably take their cues from a certain understanding of society and state (mostly multi-party democracy plus market-economy) when philosophizing about the contours of rights and politics. Kant's political philosophy thus transcends the cultural boundaries of the occidental context in which it arose and remains especially relevant for dialogue concerning human rights and constitutional law within the age of globality.

Moreover, the Kantian philosophy of law is neither primarily nor exclusively orientated towards the concept of the nation state. Kant does not legitimate the state in terms of ethnic particularity, but rather in terms of humanistic universality. Statehood results because everyone's innate right to an access to a world ruled by

\footnotetext{
${ }^{70}$ See also Reflexion 7687 (AA XIX 490) which is aimed at the idea of monarchy: "But this type of government or state constitution is certainly bad simply because the soundness of the government depends upon whether or not the will of an individual is good."

${ }^{71}$ See Langer, Reform nach Prinzipien, 87-95.
} 
laws of freedom cannot be realized without institutionalization. As Kant had showed, even most benevolent human beings cannot prevent themselves from coming into conflict with one another concerning that to which they respectively are legally entitled. So as not to be judge in their own affairs, they require institutions of arbitration. While this function is today mostly undertaken by nation states, from a philosophical perspective, this is insignificant; sub-state and super-state institutions could, with just the same claim to legitimacy, be entrusted with the protection of rights. What is indispensable is solely the provision of a monopoly of power within the respective sphere of regulation so as to guarantee the execution of the law. ${ }^{72}$ Kant, in short, is no nationalist, but rather a federalist and a cosmopolitan.

Yet, since the historical directive of Kant's time was the sovereign management of law by nation states, he concerned himself with accurately determining their lawful relations among one another. In the face of international conflicts, where states behave towards one another like individual subjects in a legally unregulated state of nature, one has to consider whether states also have a duty to submit to coercive lawful rules (AA VI, 354). ${ }^{73}$ Kant saw this to be the case. The absence of a generally binding world-order in the long run enables individuals and collectives to dodge the law, which, in his eyes, ultimately means that the lawful framework "of all the others is unavoidably undermined and must finally collapse" (AA VI 311). Kant thus strove for a lawful world order whose operations would result from universally recognized lawful principles and not merely from regional power relations. On one hand, this order should be so liberal and subsidiary that the individual states within it can protect their cultural idiosyncrasies and exist undisturbed - as long as they do not infringe upon the rights of other states or commit human rights violations. On the other hand, that global order should be able to address and regulate everything that communally concerns all world citizens.

The eventual name for this lawful representation of humanity is of only marginal significance. Kant juggles with the expressions "federal state [Bundesstaat]" verus "federation of states [Staatesbund]," in pretty much the same ways as today we debate concepts like Global Government versus Global Governance. ${ }^{74}$ More important are the criteria orienting such conceptions. These, however, were already clearly prescribed by Kant with the formulation of the legal and the political imperative. For that reason, Kant deserves to be honored as one of the first liberals both to identify the problems resulting from the global constellation of modern life and to contribute to their intercultural pacification.

All in all, Kant succeeded in navigating his philosophical liberalism safely between the equally unappealing extremes of a formalism of negative freedom and a dogmatism of positive freedom. For the quest for a consciously responsible liberalism that drives many thinkers today, Kant thus provided a solid intellectual point

\footnotetext{
${ }^{72}$ See Anna Stilz, Liberal Loyalty: Freedom, Objection and the State (Princeton, 2009).

${ }^{73}$ See Georg F. Cavallar, Kant and the Theory and Practice of International Right (Cardiff, 1999).

${ }^{74}$ See Antonio Franceshet, Kant and Liberal Internationalism: Sovereignty, Justice and Global Reform (2007) and Mark F. N. Franke, Global Limits: Immanuel Kant, International Relations, and Critique of World Politics (Albany, New York, 2001).
} 
of departure. Kant championed a reflexive, self-critical conception of a selfdetermining freedom, which allows, also on the global and intercultural level, the synthesis of diversity (concrete concepts of freedom) and unity (structural idea of freedom). Looking far beyond the affairs of his time, he developed conceptual foundations for a cosmopolitan liberalism that his successors, especially Karl Christian Friedrich Krause (see Sect. 2.3.4), made use of when developing plans for a European federation of states (Staatesbund) as well as for a worldwide league of nations. ${ }^{75}$

With Kant also begins the impulse to conceive of the relationship between individual autonomy and societal responsibility not as an unavoidable conflict, but rather as a necessary synthesis. Instead of engaging in a tug-of-war between the two respective parties - where a quantitative increase in freedom continually leads to a decrease in justice or responsibility and vice versa - Kant inspired people to examine how a reciprocal inclusion and qualitative reinforcement of either notion could take place. Kant thus became the catalyst for the social philosophy of German Idealism, which exerted a strong influence on the intellectual forefathers of socialism and social democracy. This very transition of the principle of freedom into its socio-political concretizations shall now be exemplified by two particularly distinctive representatives, Fichte and Krause. Both set out on the quest for a viable balance between individual freedom and social responsibility; a balance that is as precarious as it is necessary.

\subsection{Directive Freedom (Johann Gottlieb Fichte)}

In texts about the history of the idea of liberalism, Fichte is often overlooked. For many his work seems hardly accessible and its content mostly sublated and surpassed by Hegel's philosophy. Furthermore, the fact that Fichte promulgated socialism with a planned economy seems to suggest that his work should be classified as illiberal and passed over. But such a reading oversimplifies things. Fichte wished to grant freedom even greater importance than did Kant. He regretted that, with the exception of the practical philosophy, the idea of freedom does not always occupy the premier role in Kant's thinking. In Kant's theoretical philosophy it has merely a marginal function and in the Critique of the Power of Judgement its function, while certainly important, nonetheless remains in the background. In contrast, Fichte decided to make freedom the explicit basis of his entire philosophical system. He even addresses theoretical and aesthetic questions with reference to freedom. In aspiration and approach, philosophical liberalism cannot actually be any more radical.

\footnotetext{
${ }^{75}$ Karl Christian Friedrich Krause (1781-1832) filled the lacuna left over by Kant in his congenial engagement with him by producing a systematic theory of the rights of world citizens in which the peaceful and liberal establishment of supranational structures of order is the central theme (see Sect. 2.3).
} 
Nevertheless, Fichte's philosophy does not appear to be consistently liberal: In large parts of it, especially within his practical philosophy, directive coercion as opposed to freedom is the leitmotif. In the firm belief to be doing freedom a service, Fichte considers it right, for instance, to pass over or suspend liberal procedures of political decision-making in order to reach a final state of perfect freedom. Illiberal measures are sanctified as means towards freedom's end. Prominent examples are his outlines for a planned economy, his instrumentalist treatment of the environment, and his harsh contractualism - rejecting the rights of the disabled as well as gravely curtailing the freedoms of women and children: all proclaimed in the name of freedom. This paradox makes Fichte's philosophy an informative lesson, as it exemplifies the central problem concerning how, when, and where freedom may be advanced by coercion - by means of the decisive question: Whose idea of freedom actually tips the scales; that of the philosophers or that of the citizens?

In the work of all of the proponents of German Idealism, freedom is the philosophical principle par excellence, and Fichte's work should be seen in this context. ${ }^{76}$ In the eyes of the German Idealists, Kant had certainly uncovered the true, unconditioned character of freedom, but he did not provide a sufficient basis for it. According to Fichte, Schelling, Hegel and other thinkers of this epoch, one had to reconceive of reality itself as derivative of the principle of freedom, in order to demonstrate that, in truth, there is no valid alternative to freedom-based philosophy. Kant was therefore to be supplemented or surpassed by a philosophy which would be not hesitantly but emphatically, not partially but totally, dedicated and devoted to freedom.

In this context, lawful coercion is of particular interest, since it obviously limits individual freedom. ${ }^{77}$ To justify this, one can of course not, like English utilitarians, simply refer back to the benefits which legal coercion (in protecting and securing the individual) may provide. Reasons for compulsion, which are not essentially related to freedom, can be rejected in the name of freedom. Moral or religious considerations are therefore likewise problematic. The validity of subjecting to lawful coercion even those who do not share those very reasons cannot thus be derived. ${ }^{78}$ Although morality, religion, and a utility-conscious prudence provide numerous secondary reasons to behave lawfully, they do not capture what needs to be primarily identified here, a rationale for coercion that belongs to the principle of freedom itself. $^{79}$

\footnotetext{
${ }^{76}$ See Henry S. Richardson, Developments and Main Outlines in Rawls's Theory of Justice (New York: Garland, 1999).

${ }^{77}$ See Michael Köhler, "Zur Begründung des Rechtszwangs im Anschluss am Kant und Fichte" in Michael Kahlo, Ernst Amdeus-Wolff \& Rainer Zaczyk, Fichtes Lehre vom Rechtsverhältnis: Die Deduktion der [Paragraphen] 1-4 der Grundlage des Naturrechts und ihre Stellung in der Rechtsphilosophie (Frankfurt am Main, 1992), 93 \& 106.

${ }^{78}$ See ibid., 119.

${ }^{79}$ See Hans-Martin Pawlowski, Stefan Smid \& Rainer Specht, "Vorwort" in Die Praktische Philosophie Schellings und die gegenwärtige Rechtsphilosophie (Stuttgart: Bad Cannstatt, 1989), 9.
} 
The attempt merely to define coercion as the double negation of freedom, that is, as the nullification of a nullification of freedom, is just as unsatisfying. Kant had already considered the idea, taken up later anew by Friedrich August von Hayek and others (see Sect. 3.2.1) of a justification for coercion as "a hindering of a hindrance of freedom" (AA VI: 231). But Kant also immediately made it clear that the right to freedom could precisely not be explained by the authorization to coerce, but that rather the authorization to coerce always depends upon the rights it is to protect. The question concerning legitimate coercion therefore again leads immediately back to the question concerning a lawfully legitimated freedom. Whoever does not want to confound facts with norms and who does not want to equate the freedom that ought to exist with the freedom that does, has to indicate which freedom is supposed to be defended by the means of lawful coercion.

A philosophical clarification about to which freedom everyone has an inviolable right, must precede the definition and justification of coercion. Legal positivism therefore also fails in the attempt to define 'right' only in terms of that which the state declares to be right. The idea of law cannot of course be derived from the factual power of coercion in the cynical sense of the expression that "might makes right." The required self-sufficiency of the justification of lawful coercion however clearly means something completely different than a self-legitimation of legal facticity through value-relative decisionism.

Hence, Fichte concludes, freedom must limit itself. Whoever is coerced by me will hardly agree with my coercion if, as a result, only my freedom is excellently secured, while theirs is annihilated. I must rather make it clear that also their freedom is thereby defended. Consequently, not merely my purely private possession of freedom, but rather an interpersonally valid content of freedom, has to serve as a criterion. The principle that can acceptably limit anyone's freedom must therefore at the same time affirm everyone's freedom. Private freedom thus forever refers beyond itself to the horizon of societal freedom, without which it is theoretically null and practically void. To legitimate coercion one requires more than a contingent convergence of (conditioned) interests and concerns. Only (unconditioned) freedom itself can justify coercion.

Fichte now localizes that unconditioned, absolute freedom in the metaphysical freedom of the "Absolute," or, in other words, within the ultimate principle of being itself. ${ }^{80}$ Fichte believes that it is only insofar as freedom essentially holds the entire world together that it can constitute a uniting bond between individuals which transcends contextual contingencies. In his time, Fichte's speculative Idealist metaphysics of a cosmically unfolding freedom in no way stood alone; it was rather typical of early nineteenth century philosophy. Fichte's philosophy did, however, stand out from the thinking of his contemporaries because of its methodological rigor. $\mathrm{He}$ derives highly atypical consequences from the principle of freedom, which make us receptive to the systematic problems of the kind of liberalism he supports. At issue here is the aforementioned paradox, that Fichte's philosophy takes up freedom as its

\footnotetext{
${ }^{80}$ See Georg Römpp, Ethik des Selbstbewusstseins: Der Andere in der idealistischen Grundlegung der Philosophie: Kant, Fichte, Schelling, Hegel (Berlin, 1999), $274 \mathrm{f}$.
} 
goal and - as a means for its attainment - advocates a "system of coercion." 81 That and why - this paradox results from a methodological mistake with wide ramifications, should be more precisely discussed in the following; not least so that, in this context, the more perspicacious alternative found in Krause's procedural liberalism (Sect. 2.3) can be better appreciated.

\subsubsection{Epistemology and Metaphysics of Law}

From time immemorial, most philosophers have treated rights and law as a branch of practical philosophy distinct from morals. Kant did this (see Sect. 2.1.2) by distinguishing within the practical realm legal from moral norms (i.e. the ethics of good intentions and dispositions) according to their respective mode of sanctioning. In terms of substance, Kant sees law as concerned with outer freedom affecting others; in terms of sanctioning, legal norms allow coercion, while morality must be content with appeals to inner freedom. Consequently, law and morals both function as forms of ethical norms; they both formulate an ought, and not always also an is. Precisely this changes with Fichte. He believes one has to treat the theory of freedom-giving law in theoretical as opposed to practical philosophy, i.e. as part of the structure of what is as opposed to what ought to be. Fichte seeks a theory that not only makes an appeal for the establishment and maintenance of a system of rights serving freedom, but rather one which guarantees its own implementation. Fichte wishes not only to legitimate coercion within the legal system, but also to establish a coercion to it.

In a letter to Karl Leonhard Reinhold (1757-1823) in 1795, Fichte complained about how Kant would explain that an individual positing unethical maxims falls into self-contradiction once they are universalized. Yet Kant would not explain why individuals have to conceive of themselves in terms of precisely that universal perspective instead of, say, contenting themselves with a merely private - or selfcontradictory - positing of maxims. ${ }^{82}$ As a result, Fichte realizes that the actual task of the philosopher is to show, in contrast to Kant, that freedom can only be conceived as integrated within a kingdom of rational beings standing under universal

\footnotetext{
${ }^{81}$ See especially Manfred O. Hinz, Fichte's "System der Freiheit": Analyse eines widersprüchlichen Begriffs (Stuttgart, 1981).

${ }^{82}$ Letter from August 29, 1795 (GA III/2, 384, EPW 407). Fichte's works are, whenever possible, cited from Johann Gottlieb Fichte, Gesamtausgabe der Bayerischen Akademie der Wissenschaften, Reinhard Lauth \& Hans Gliwitsky, eds. (Stuttgart-Bad Canstatt, 1964): GA (with Roman numerals for the series, dash, Arabic numerals for the volume, comma and page numbers) for the Fichte Gesamtausgabe (e.g. GA I/3, 123). Otherwise, Immanuel Hermann Fichte's edition is followed (e.g.: FW II, 233). The following English translations of Fichte's works are followed and cited: Yolanda Estes \& Curtis Bowman, eds. J. G. Fichte and the Atheism Dispute (1798-1800) (Routledge, 2016): AD; Daniel Breazeale, ed. \& trans., Fichte: Early Philosophical Writings (Ithaca \& London, 1988): EPW; and J. G. Fichte, Foundations of Natural Right (Cambridge, 2000): FNR.
} 
laws. The solution to the problem is proclaimed one day later, concisely expressed in a letter to Friedrich Heinrich Jacobi (1743-1819):

the individual must be deduced from the absolute I ... A finite being (supposing that one can be deduced) can think of itself only as a physical being who is part of a realm of physical beings, of which a part (viz., that part which consists of those beings which are unable to initiate anything) is under its causal control, while it interacts reciprocally with the other part (viz., that part which consists of those beings to whom it attributes the concept of subject). (The conditions which make individuality possible are called "rights.") A finite being posits such a realm just as surely as it posits itself as an individual, for these are reciprocal concepts. (GA III/2, 391-392, EPW 411)

For the question of freedom, this means: Right would be derived, together with coercion, as a necessary expression of freedom, if no one could think of themselves as anything other than already connected within a lawful order universally protecting and structuring freedom. To make this point, Fichte wishes to engage in the deduction of the concept of right/law from the highest principle of philosophy so that "we can rely on this concept to answer all the questions common sense can raise concerning right" (GA I/3, 359; FNR 50). ${ }^{83}$

This claim clearly goes significantly further than the Kantian attempt merely to provide "metaphysical foundations" for the doctrine of law. In contrast to Kant, Fichte aims not only at a critical application of the idea of freedom to juridical themes. Rather, Fichte's doctrine of law assumes a foundational role in the theoretical-metaphysical derivation of the lifeworld. In it occurs the development of an, at first, still abstract subject into a concrete person by means of a deduction of the external world, of individuality, and of interpersonality. ${ }^{84}$ Fichte justifies the subjective assumption of an external world existing independently of individual consciousness not within the sphere of his theory of knowledge, but rather in his doctrine of law. ${ }^{85}$

The comparison with Kant (see Sect. 2.1.4) clarifies what is at stake: Kant had always carefully distinguished between critique and doctrine, i.e. between transcendental foundational work and metaphysical instantiation, that is, between the legitimation of an idea and of the concepts concretizing it. Fichte finds fault with how this does not lead to a unified philosophy. The idea of freedom would thus not be the sole principle of philosophy, but rather appears co-determined by worldly objects and themes. Fichte therefore nullifies that Kantian distinction (GA I/2, 159). With his Science of Knowledge (Wissenschaftslehre) he wishes to carry out transcendental philosophy and metaphysics - critique and doctrine - at one and the

\footnotetext{
${ }^{83}$ See Christian Maria Stadler, J. G. Fichtes Grundlegung des ethischen Idealismus, oder, Transcendentale Deduktion zwischen Wissen und Wollen (Cuxhaven, 1996), 129 and Hartmut Tietjen, Fichte und Husserl: Letztbegründung, Subjektivität und praktische Vernunft im transzendentalen Idealismus (Frankfurt am Main, 1980), 193-197.

${ }^{84}$ See Jacinto Rivera de Rosales, “Die Begrenzung. Von Anstoß zur Aufforderung," Fichte-Studien 16 (1999), 167-190 and Edith Düsing, "Das Problem der Individualität in Fichtes früher Ethik und Rechtslehre," Fichte-Studien 3 (1991), 29-50.

${ }^{85}$ See Wolfgang Schrader, Empirisches und absolutes Ich: Zur Geschichte des Begriffs Leben in der Philosophie J. G. Fichte (Stuttgart: Bad Cannstatt, 1972), 26ff.
} 
same time ${ }^{86}$ The aim is a unified metaphysics of freedom, which brings the derivation and the proof of validity of the principle of freedom together in one conclusively proven theorem (Letzbegründungstheorem) (GA I/2160f.). ${ }^{87}$ The idea of freedom and the actuality of freedom should melt into one.

The philosopher, Fichte holds, has to reconstruct all our knowledge from the ground up (GA I/3, 316n; FNR 7n) - as a necessary concept of the mind whose conceptual necessity extends to the specificity of its substantial determination and application in life (GA I/3, 319; FNR 8-9). The difference Kant established between transcendental and metaphysical deduction is collapsed - with grave consequences: As we saw (Sect. 2.1.2), Kant could simply fall back upon historical givens (like the Prussian General Law of the Land and the legal institutions outlined within it, like private property) as the object of his metaphysical deductions, without - unlike with objects of transcendental deduction - having to speculatively derive them. Fichte's method, on the other hand, forces him to deduce also these givens. ${ }^{88}$ The law is thus properly deduced only when it can exactly be identified in its whole concreteness as a necessary moment of human self-consciousness.

But since Fichte's legal philosophy would like to operate, not with representations of what ought to be, but rather as a doctrine of what is, it does not, as with Kant, aim to explain the normative necessity of the idea of law, but rather the factual necessity of law: as a strict "condition of self-consciousness [which] constitutes the deduction of that concept" (GA I/3, 319; FNR 9). ${ }^{89}$ Yet, wherever metaphysical and transcendental deductions - that is, proofs of content and the proofs of validity coincide, philosophy has to master all phenomena; it cannot leave anything unexplained, it must (be able to) trace all things to their ultimate foundation, and in this way first establish their respective significance (GA I/2, 146). That also includes the derivation of every object of consciousness with the result that "the necessity of all the particular objects in nature and their necessary classification" must be derived from that foundation (GA I/3, 348; FNR 38). ${ }^{90}$ All practical - for instance, economic - conditions, transforming, protecting, or hindering life under the rule of law should be derived in this way.

The effects of this methodological shift upon the theory of freedom are extreme. For example: It is one thing to explain the specific form of human freedom in terms

\footnotetext{
${ }^{86}$ See Christian Maria Stadler, J. G. Fichtes Grundlegung des ethischen Idealismus, oder, Transcendentale Deduktion zwischen Wissen und Wollen, 19.

${ }^{87}$ See Wolgang Schrader, "Konstruktion versus Unmittelbarkeit: Zum Verhältnis von Philosophie und Leben bei J. G. Fichte," Fichte-Studien 11 (1997), 367-377.

${ }^{88}$ See Ludwig Siep, Praktische Philosophie in Deutschen Idealismus (Frankfurt am Main, 1992) 65-80, especially $68 \mathrm{f}$.

${ }^{89}$ According to J. Brachtendorf, Fichte claims "too much when he pretends that the concept of law is a condition of self-consciousness and that he has deduced it from the I," since it is in no way the case "that rational beings must always stand in such a relation." Existing law is certainly a condition of possibility for society, yet "that society exists is not a condition of self-consciousness" (Johannes Brachtenorf, Fiche's Lehre von Sein: Eine kritische Darstellung der Wissenschaftslehre von 1794, 1798/99 und 1812 [Paderborn, 1995], 190f).
}

${ }^{90}$ See Schrader, Empirisches und absolutes Ich, 70 \& $77 \mathrm{ff}$. 
of the concept of a choice from manifold options; but it is quite another to "deduce" that "the manifold" exists in the world because it belongs to the structure of freedom to be able to choose from various options. ${ }^{91}$ Fichte thus makes the world as a whole dependent upon transcendental consciousness: The external world thus exists because freedom needs an object to toil with in order to become conscious of itself. Fichte maintains that certain materials exist because one requires them for ethical action - dense matter for bodily movement and self-articulation, subtle matter (i.e. air and light) for the ends of communication (GA I/3, 368; FNR 60-61). In the Wissenschaftslehre nova methodo, for example, space in its entirety is deduced as a "sphere of freedom" $" 92$ because only within it could the relative position of objects be changed and, consequently, only within it could freedom become practical.

Fichte's contemporaries already reproached him for treating nature as a whole merely as a substrate of ethical self-determination. ${ }^{93}$ Thus he appears guilty of a theoretical reductionism, which views the world merely as raw material for freedom, as well as of a moral rigorism, which only respects free agency. ${ }^{94}$ For a long time many Fichte scholars have taken pains to counter these objections by citing passages which, in contrast, evidence a less derivative valuation of nature. ${ }^{95}$ But such attempts are pointless. The claim that he would turn the world into a mere "material of our duty" (GA I/5 353; AD 25) is something that Fichte himself would not have understood as a reproach, but rather as a compliment (GA I/5, 349; AD 22-23). Fichte considered the instrumentalization of the entire world for the ends of freedom, not as an awkward blemish upon the face of his philosophy but rather as its badge of honor. ${ }^{96}$

The repeated comparison with the Kantian architectonic elucidates the explosiveness of Fichte's procedure: Kant had started out with a threefold philosophical structure (theoretical, practical, and aesthetic) and had established for his philosophical system a merely regulative unifying principle. He did not attempt to resolve the three independent basic mental faculties (understanding, reason, imagination) into one single principle. ${ }^{97}$ Rather, Kant purposefully distinguished three classes of phenomena: rational, irrational, and a-rational. A-rational phenomena - for instance objects and life forms of the natural environment - are in many cases not - or not fully - determined by ethical reason. Still, this does not justify deprecating them or

\footnotetext{
${ }^{91}$ See Fichte, Wissenschaftslehre nova methodo: Kollegnachschrift von K. Chr. Fr. Krause (179899), Erich Fuchs, ed. (Hamburg, 1982), 61.

${ }^{92}$ See ibid., 114.

${ }^{93}$ See Marco Ivaldo, "Die systematische Position der Ethik nach der Wissenschaftslehre nova method und der Sittenlehre 1798," Fichte-Studien 16 (1999), 237-254.

${ }^{94}$ See Hans Freyer, "Das Material der Pflichten: Eine Studie über Fichte's spätere Sittenlehre," Kant-Studien 25, 113-155.

${ }^{95}$ See Virginia López-Dominguez, "Die Idee des Leibes im Jenaer System," Fichte-Studien 16 (1999), 273-293.

${ }^{96}$ This original view is followed in: Christian Maria Stadler, Freiheit in Gemeinschaft: Zum transzendentalphilosophischen Rechtsbegriff Johann Gottlieb Fichtes (2000), 25ff. For the genealogy of these ideas, see Claus Dierksmeier, "Kant-Forberg-Fichte" (1999).

${ }^{97}$ See Klaus Düsing, Die Teleologie in Kants Weltbegriff (Bonn, 1968).
} 
treating them as opposed to reason. According to Kant, nature does not only exist for the ends of humanity. Our end-seeking (reflective) as well as end-giving (teleological) interpretation cannot determine nature in itself, but can at most determine it for us regulatively, and not constitutively, never totally, but forever only partially: "Teleology considers nature as a kingdom of ends, morals considers a possible kingdom of ends as a kingdom of nature" writes Kant (AA IV 436; italics, C.D.). Nature is therefore interpreted as, among other things, a medium of morality, but is not forcefully reduced to that role alone. For, in Kant, teleological thinking belongs "to no doctrine at all, but only the critique" of reason (AA V 417), a metaphysics placing the whole world in the service of freedom remains impossible. ${ }^{98}$

Fichte strives for the exact opposite. He first reduces our theoretical knowledge of the world to a fleeting dance of pictures whose true significance only ethics can pin down (GA I/5, 440; AD 114-115). He thus declares practical philosophy the "root" of all philosophy, one which penetrates into sovereign sphere of theoretical philosophy, thus making the latter subordinate to the former. Nature is, consequently, not to be studied in and for itself, but rather explained as - and thus transfigured into - a field of agency conforming to freedom; it is characterized as a world whose actual truth is only to be reached by the knowledge of its ethical purpose (GA I/5 158 \& 169f).${ }^{99}$ Contrary to his stated intentions, Fichte thus champions a conception of the world that it is not less, but rather more, intensively dualistic than the Kantian conception. Fichte knows only two classes of phenomena: valuably-rational versus worthlessly-irrational phenomena - tertium non datur. "Whatever is grounded in reason is absolutely necessary; and whatever is not necessary is precisely on that account contrary to reason" (GA I/5 348 AD 22). In this lies the crux of his metaphysics of freedom. ${ }^{100}$

Fichte radicalizes philosophy into a struggle between world-views, between nature (deterministic world-view) and freedom (perspective of autonomy). Instead of the mediation of both worlds (by a third dimension, that of the reflecting and symbolizing power of imagination) favored by Kant, Fichte's conception forces one to side with either one or the other point of view. And Fichte of course favors the moral conception of the world. What results is the dominance of a first-order (practico-ethical) world-view over a second order (theoretico-scientific) world-view

\footnotetext{
${ }^{98}$ For more details about this see Wolfgang Bartusschat, Zum systematischen Ort von Kants Kritik der Urteilskraft (Frankfurt am Main, 1972).

99 "The practical I and the theoretical I relate to one another like end and means. The theoretical I is the means with whose help the I can be practical" (Stadler, J. G. Fichtes Grundlegung des ethischen Idealismus, 356).

${ }^{100}$ See Günter Schulte, "Vernunft und Natur - Transzendentalphilosophie als Symptom" in Hammacher \& Muses, eds., Erneuerung der Transzendentalphilosophie im Anschluß an Kant und Fichte: Festschrift für Reinhard Lauth zum 60. Geburtstag (Stuttgart, Bad Cannstatt, 1979), 345359. C. M. Stadler attempts to absolve Fichte from this reproach with the peculiar argument that Fichte lacked "any sense of a disposition for the teleology of nature" because he, unlike Schelling, did not (falsely) claim that nature was "still unconscious spirit," but rather (correctly) that it existed "only as material of duty" and as a "value-free material for the realization" of morality (Stadler, Freiheit in Gemeinschaft, 73).
} 
(GA I/5, 349 AD 22-23). Quite consistently, therefore, Fichte writes that the kind of philosophy one has depends upon what kind of person one is and wishes to be (FW I 434f.). For an ethically committed consciousness there can only be Fichte's freedom-orientated world-view.

While Kant had declared the gradual harmonization of nature and freedom to be an ongoing, open project, Fichte champions a radical and total subordination of nature to freedom, and gives it top priority in his philosophy. All phenomena contrary to the moral law are labeled as insubstantial appearance or declared to be mere illusion (FW II, 298f.). For Fichte there exists no necessity to have a non-instrumental theoretical or practical approach to nature; to claim otherwise simply betrays the fact that one is beholden to a lower-order world-view. Only technical purposes warrant an interest in nature. A philosophical reconciliation of freedom with its natural contexts or even a recognition of the environment as intrinsically valuable are both absent - for systematic reasons. Since Fichte subordinates nature as a whole (ontologically) to the ethical sphere of human ends, i.e. freedom, everything within nature counts (ontically) as but a means at the arbitrary disposal of humans (GA I/3, 406407; FNR 104-105). ${ }^{101}$

Corresponding to that principal subordination of the sensible world to the consciousness of freedom (on the part of transcendental philosophy) we find in the everyday lifeworld (on the part of moral philosophy) the - no less problematic complete subordination of everything sensible to the rational (GA I/5 440; AD 114 $115)$ as well as the subordination of the body to the mind. ${ }^{102}$ Not unfairly, therefore, Fichte has been accused of metaphysical reductionism as well as of ethical rigorism. Hegel, for instance, characterized Fichte's concept of freedom - precisely for this reason -as purely 'negative. ${ }^{103}$ Hegel holds that the I's freedom from and against all limitations - so strongly promoted by Fichte - would, carried to conceptual extremes, be an attribute of death. ${ }^{104}$ Life, on the contrary, presupposes bonds of positive reference, which is why Hegel strove to promote a "concrete," "organic," "affirmative," and "substantive" freedom through which individuals become autonomous within their environment rather than against it. ${ }^{105}$

Like nature, Fichte also slips his interpretation of society into a freedomtheoretical straightjacket. Every I meets in the external world restricting resistance; as a result, the subject is in part impeded in its freedom, in part the resistance is such that the subject perceives itself to be free or as being called upon to be free because

\footnotetext{
${ }^{101}$ Concerning this, see Manfred Brocker, Arbeit und Eigentum: Der Paradigmenwechsel in der neuzeitlichen Eigentumstheorie (1992), $311 \mathrm{f}$.

${ }^{102}$ See Peter Rohs, Johann Gottlieb Fichte (2007), 106.

${ }^{103}$ Georg Wilhelm Hegel, TWA 2, 69-82. Translated in Hegel, The Difference Between The Fichtean and Schellingian Systems of Philosophy (Ridgeview Publishing Company, 1978).

104 "I can kill everything and abstract from everything. Thus the obstinacy is invincible and can in itself overcome everything. But the highest thing would be to overcome this freedom, this death itself" (Hegel, TWA 2, 547).

${ }^{105}$ See TWA 7, 298 \& 7, 406. Translated in Hegel's Philosophy of Right (London, Oxford \& New York, 1967), $107 \&$ 160. See also TWA 9, 66; 10, 333; 12, 58-66; 12, 417.
} 
of it - for instance through appeals to ethical action (GA I/3 343f.; FNR 33f.). Calls to a responsible use of freedom indicate a rational sender (GA I/3 344; FNR 34-35). Everyone, however, who cognizes the rationality of others must, logically speaking, also recognize them. For insofar as he understands autonomous reason to be the condition for the validity of his rights to freedom, for the sake of consistency he also has to see in the other's reason a foundation of equal validity. ${ }^{106}$ As the demand to recognize others thus proceeds from one's own reason it presents no external limitation of freedom (GA I/3 353; FNR 44).

Yet, its logical cogency notwithstanding, there still remains the possibility that this recognition will not ensue de facto (GA I/3 356; FNR 46). This, however, Fichte cannot tolerate; for otherwise, he fears it would not be "possible to point to an absolute reason why someone should make the formula of right - limit your freedom so that the other alongside you can also be free - into a law of his own will and action" (GA I/3 387; FNR 82). Why should one limit one's freedom if one cannot oneself be certain that others are doing the same? Consequently, Fichte devises means and ways to guarantee absolutely said reciprocal recognition - through state coercion ${ }^{107}$ and a complicated mechanism for the protection of rights. ${ }^{108}$

Herein again, Fichte proceeds contrary to Kant. Instead of leaving reciprocal recognition within the medium of the sphere of ought, Fichte is committed to the law's sphere of being and must thus transform the merely hypothetically-conditioned character of factual recognition into one categorically-unconditioned recognition which is assured by "certainly not the moral law" but rather "the law of thought" (GA I/3 356; FNR 47). Not recognizing the other as a subject entitled to rights, declares Fichte, presents a contradiction in transcendental consciousness which hinders the generation of free consciousness as such. In his Foundations of Natural Right (1796/1797) Fichte declares a direct reciprocal interaction (Wechselwirkung) between physical modification and volitional determination to be indispensable. He completely identifies (normative) liberty and (factual) physicality with one another (GA I/3 363; FNR 56). Physical action thus directly assumes a constitutive function for law. ${ }^{109}$

It is true that Fichte had already modified this position within his Vocation of Man of $1800 .{ }^{110}$ Yet, that change of course did not have a significant influence upon

\footnotetext{
${ }^{106}$ Rosales, "Die Begrenzung. Von Anstoß zur Aufforderung."

${ }^{107}$ See Michael Köhler, "Zur Begründung des Rechtszwangs im Anschluss am Kant und Fichte," $113 \mathrm{ff}$.

${ }^{108}$ For an exemplary discussion see Wolfgang Janke, "Anerkennung: Fichtes Grundlegungen des Rechtsgrundes," Kant-Studien 82:1 (1991), 197-218.

${ }^{109}$ For the variations upon the theory of recognition which follow on from the Foundations, see Düsing, Das Problem der Individualität; also Ivaldo, Die systematische Position der Ethik nach der Wissenschaftslehre nova methodo und der Sittenlehre 1798. For a critique of the Foundations of Natural Right's theorem of interpersonality see Eberhard Heller, Die Theorie der Interpersonalität im Spätwerk J. G. Fichtes: Dargest. in den "Thatsache des Bewusstseyns" von 1810/1811; eine kritische Analyse (1974), 59ff.

${ }^{110}$ In later years, Fichte promulgated the view that we reach the apperception of the other only by means of a supra-individual ground that we share with all others. The founding of recognition is
} 
the unfolding of his doctrine of law, politics, and economics. In most of his writings on social philosophy, Fichte outlines those ideas of a factually requisite, mechanically reciprocal recognition in such a way that in the case of failed or refused (factual) recognition it should be possible - or even ethically necessary - that the non-recognizer thus becomes (normatively) devoid of rights (GA I/3 355f.; FNR 45f.). ${ }^{111}$ In breaking the law, Fichte writes, the other provides the "sure proof" (GA I/3 387; FNR 83) that he did not bring his body completely under the control of his reason. Because of this infringement, one may now justly withdraw the recognition owed to his reason and withhold the concomitant respect for his dignity. Through unlawful action the wrongdoer loses his human dignity and, from then on, Fichte expressly says, one may consider him "as a merely sensible being" and treat him as a mere thing, i.e. as fundamentally devoid of rights (GA I/3 356; FNR 46). ${ }^{12}$

For the same reason Fichte refuses to acknowledge rights of all those persons who lack "a real reciprocal interaction" with us, as, for instance, in regard to "the rights of the dead." Real thus means physical: Rights concerning intellectual relations, for example concerning "freedom of thought, freedom of conscience" are flatly refused (GA I/3 360; FNR 51-52). We owe a relation of law only to such rational beings who can exact our recognition through physical influence. Fichte thereby touches upon a central problem of liberal philosophy as such: How do we deal with those who do not stand in reciprocal relations to us? Do we have obligations to future generations whose weal and woe we influence through our actions, but who, on their part, can yet neither benefit nor harm us? Does our freedom still deserve respect after death (the natural boundary of all chances for reciprocation)? May we, for instance, foil the testament of the deceased for the benefit of the living? And how does it stand with the freedom and dignity of mentally handicapped persons, whose behavior perhaps does not always clearly indicate a desire faultlessly in exact observance of the social contract - to toe the line of the law? Are they thus only to be considered as mere things devoid of rights?

Fichte answers these questions in a manner that crassly contradicts our moral intuitions. ${ }^{113}$ That results from that principal feature of his social philosophy to

able to be reconstructed in a way that does more justice to the phenomenon; the understanding of the call-to-recognition - now clearly empirico-factically conceived - requires a disposition towards supra-individual reason, whose possibility is derived from precisely that supra-individual ground (of being) which the Wissenschaftslehre nova methodo already engaged. See Makoto Takada, "Zum intersubjektiven Verständnis des Ich in der Wissenschaftslehre nova methodo," FichteStudien 35 (2010), 345-356. In passing it should be remarked that through engaging with this more mature position, Fichte's follower, Karl Christian Friedrich Krause, constructed his own theory of interpersonal (and also intercultural) recognition. More on that in the following chapter.

${ }^{111}$ For a critique of this see Ludwig Siep, "Naturrecht und Wissenschaftslehre" in Siep, ed., Praktische Philosophie in deutschen Idealismus (Frankfurt am Main, 1992), 38.

${ }^{112}$ For a critique of this idea see Rainer Zacsyk, Das Strafrecht in der Rechtslehre J. G. Fichtes (Berlin, 1981).

${ }^{113}$ For a twentieth-century critique see Ernst Bloch, Naturrecht und menschliche Würde (Frankfurt am Main, 1991) and Helmut Girndt "Über den Umgang mit der empfindungsfähige Natur nach J. G. Fichte" in Transzendentalphilosophie als System: Die Auseinandersetzung zwischen 1794 und 1806 (1989), 139ff. For K. C. F. Krause's contemporary critique of Fichte see Claus 
reproduce the entire system of rights in analogy with geometrically construing surfaces from lines and lines from points. Fichte gradually construes from reciprocal agreements (lines) between purely private subjects (points) the public relations of law (as a surface). ${ }^{114}$ Thus he anticipates many of the later conceptions of game theory and social contract theory. As a consequence, we can learn from his example a lot about their features: Fichte begins with two subjects who only wish to realize their private wills and recognize one another (for example, in their respective properties) through a reciprocal arrangement (GA I/4 5f.; FNR 165f.). Rational selfinterest produces the interest in the other. What arises next is a relation of reciprocal protection of rights and property of a still very fragile nature: "The smallest violation of another's property nullifies the entire contract and entitles the injured party to take everything from the transgressor, if he can" (GA I/4 9; FNR 169-170).

Upon the "surface of the earth," as a "sphere where everyone can exercise his efficacy," everyone's property can, in principle, always be endangered by everyone else. Consequently, no-one's property is absolutely secured through the mere agreement of two or more persons (GA I/4 9; FNR 170). Yet, according to Fichte, this in turn threatens to nullify the decisive condition under which one could at all consent to refrain categorically from appropriating the other's property. Something else must be added: The will (passively) to refrain from appropriating the other's property has to be reciprocally augmented by the decision (actively) to protect property: A reciprocal "protection contract" has to be established (GA I/4 10; FNR 171). Fichte reasons further that, just like the property contract, this "protection contract, like every other contract, is conditioned" (GA I/4 10; FNR 171): only under the condition of factually provided protection is one bound to protect the other against a third party. In order now to make that (theoretically) only hypothetical condition (practically) categorical, it must be assured that entry into that contract inevitably produces the fulfillment of the citizen's obligation through the requisite "contribution in the form of abilities, services ... or ... money" (GA I/4 16; FNR 178). Thus (in a manner similar to the later accounts of Robert Nozick and others) Fichte lets the state arise from the spirit of possessive individualism (Besitzindivialismus): The state first articulates itself as a protective association from an abstract pact of mutual assistance on the part of particular individuals after "the whole has come to exist as a result of contracts among individuals" (GA I/4 15: FNR 177). Its unifying end is but the individuals' interest in the protection of their safety and possessions. Where these interests, or the possibility of its timely fulfillment, are lacking, then so too the rationale for maintaining the community. ${ }^{115}$

Now, since, in the chosen mechanical picture of a static equilibrium of service and counter-service, even the smallest disruption to the balance would nullify the whole, the universal security of rights appears as strictly conditioned by the

Dierksmeier, "Fichtes kritischer Schüler: Zur Fichtekritik K. C. F. Krauses (1781-1832)," FichteStudien 21 (2003), 151-162.

${ }^{114}$ See Hans Jürgen Verweyen, Recht und Sittlichkeit in J. G. Fichtes Gesellschaftslehre (Freiburg, 1975), 124.

${ }^{115}$ See ibid., 132. 
service-contribution of each individual: "Thus the contract is cancelled as soon as the citizen does not contribute" (GA I/4 17; FNR 179). Then, the guilty party is liable with his entire existence; the state forcibly subjects this person to its law and treats him now like lifeless matter. For this reason, just as Fichte postulates, the contract actually guarantees its own fulfillment: "If someone exists apart from the contact, then he stands outside every rightful relation whatsoever"; whereas if he enters into the contract "then it binds him completely" (GA I/4 18; FNR 180). But since no government can afford to coerce its citizens incessantly, the order of law must be so constituted that violations of the social contract will not occur in the first place, and Fichte thus stipulates that "if an arrangement could be found that would operate with mechanical necessity to guarantee that any action contrary to right would result in the opposite of its intended end, such an arrangement would necessitate the will to will only what is rightful" (GA I/3 427; FNR 127).

As a result, for the execution of the law one would no longer depend upon a good will, ethical self-commitment, voluntarily assumed responsibility, etc. Once this kind of mechanical state apparatus exists, then a strict judiciary, with automatonjudges subsuming deeds under norms (GA I/3 398; FNR 95), will forever protect its order. And Fichte seriously believes that the idea of freedom commands the establishing of such a - totalitarian - state, as, in his reading, the liberal idea of law encompasses all the means for its complete realization (GA I/3 426f.; FNR 126f.).Fichte recognizes that it is just as impossible as it would be unethical to completely prevent human beings born free from carrying out actions contrary to law by means of physical precautions (GA I/3 425f.; FNR 125f.). Yet he sees no problem at all in thoroughly necessitating their wills to legality: For "this law of coercion does not infringe upon the freedom of the good will or its full dignity" (GA I/3 427; FNR 127 ; italics, C.D.). If it were clear to everyone that each volition contrary to the law necessarily resulted in "the opposite to what was intended" then, Fiche speculates, solely volitions in conformity with law would remain extant (GA I/3 426; FNR 126). Any volition contradicting law should thus become the reason for its own not improvement, but - negation, and this "proposition in its full synthetic rigor" would provide the unifying principle for all laws of coercion and punishment and a corresponding machinery of surveillance (GA I/3 426; FNR 126).

These ideas lead to a peculiar result: In order to secure the preservation of the mechanical equilibrium of law, every conflict of rights, even every unintentional conflict of rights, must be conceived as an intolerable disruption of the overall balance, which therefore must not only in retrospect be declared null and void as well as corrected (as is common in most constitutional states), but rather must ideally be prevented from the outset. ${ }^{116}$ In Fichte's time the technical possibilities for a complete surveillance and regulation of behavior were still lacking. Nowadays, since such tech-

\footnotetext{
116 "Coercion is the typical foundation of the Fichtean state: it enables the existence of the equilibrium of law because without the threat of punishments this equilibrium is unstable. Deterring activities contrary to law is the central element of the deduction of communal being in $\S \S 14 \mathrm{ff}$ of the Foundations" (Lucca Fonnescu, "Die Aufhebung des Staates bei Fichte," Fichte-Studien 11 (1997), 85-98). For criticism of that see Köhler, Begründung, 111.
} 
nologies are increasingly at our disposal, the illiberal menace encapsulated in these ideas is all the more salient. As far as possible, with the means available then, Fichte wanted to place the entire mechanism of the state - particularly socio-economic laws and regulations - in the service of the unavoidable fulfillment of the social contract. Allegedly for the sake of freedom, Fichte made coercion the principle of politics and economics, calling for directive paternalism on the part of the freedom-granting state. Starting from an almost libertarian position (with the state as merely an institution for protecting possessions) Fichte surprisingly ends up at a theory of law that is not libertarian at all (with a conception of a comprehensive nanny-state).

Fichte's philosophy of freedom is nevertheless not to be seen as but a eulogy for legal coercion. Fichte's works also contain an abundance of ideas that directly go against that mechanical concept and show another, more liberal Fichte. His socialphilosophical writings frequently contain biological metaphors giving expression to the notion of an organic self-organization of society. ${ }^{117}$ That, too, is typical of his time. In numerous philosophies of the early nineteenth century, the epithet organic gathers together many initially partly unarticulated and partly still unclear ideas with the common aim of escaping the rigid spirit of (Hobbes-inspired) socialcontract theory. ${ }^{118}$ Many thinkers felt that Kant's Critique of the Power of Judgment legitimated new and different ways of thinking through the relation of individual freedom and collective order oriented by the lodestar of a harmonization of nature and freedom achievable through culture. Fichte was no exception, and he enriched his social-philosophy with organic metaphors, too.

Occasionally Fichte declares that the human being is an "organization," a "consummate plant" (GA I/3 379; FNR 74). For, unlike machines, in the organism "the whole also exists for the sake of the parts, it has no purpose other than to produce these parts in a specific way" since "the product of nature ... continually produces itself, and maintains itself precisely insofar as it produces itself” (GA I/3 378; FNR 73). Fichte maintains that the human being represented in the image of the organism could only be conceived in terms of "the concept of freedom given to him by his own self-consciousness" (GA I/3 379; FNR 74). As beings whose concept is alone to be attained and interpreted by themselves, humans can truly realize their potential only when guided by their own aims. And all such passages obviously stand in recognizable tension with everything outlined earlier.

If, as it now seems, the "character of humanity" consists in "formability" towards freedom (ibid) then the vocation of the human being can hardly lie in a lawful order destructive of that freedom. As a consequence, it could be concluded that the citizens themselves ought to produce the law organizing their modes of socialization: in reflexive freedom and inspired by their own ideals. Instead of a philosophically deduced order, a socially construed order ought to arise, emerging from free civic agreement. And, in the light of that, would one then not also have to reconsider and redraft the objective of the law?

\footnotetext{
${ }^{117}$ See Manfred Riedel, "Fichtes zweideutige Umkehr der naturrechtlichen Begriffsbildung," Zeitschrift für philosophische Forschung 31:1 (1977), 5-18.

${ }^{118}$ About the mechanical versus organic distinction see Carla Amadio, "Aesthetik und Politik von der Grundlage der gesammten Wissenschaftslehre aus,” Fichte-Studien 11 (1997), 99-112.
} 
Some passages of Fichte's works, for instance in The System of Ethics, actually seem to warrant this reading: Freedom cannot be conceptualized as intrinsically vague, i.e. as non-conceptual. Freedom rather must know of itself and has to be committed to a concept of itself. Nevertheless, this concept cannot be gleaned from a purpose outside of freedom itself to which liberty would have to surrender: Human freedom must itself designate the ends that provide its orientation. But truly autonomous freedom can only remain in this process, however, if the goals it thus takes on in turn affirm freedom. Freedom is therefore that which posits itself as a universal end; freedom aims at freedom - otherwise it is not freedom. This is why individual freedom intrinsically refers to universal freedom. Personal freedom must be sought in the mode of universality. Otherwise the essence of individual freedom would become negated by its application, i.e. its idea would be negated by its realization.

Fichte hence confirms Kant's categorical imperative that individual subjective axioms of action (the maxims) should continually be able to be posited as an objective law. This, Fichte agrees, is the appropriate formula of the idea of freedom and its normative self-commitment. And since that categorical imperative demands that human beings be treated as ends in themselves and not instrumentalized, Fichte must also orientate the lawful order towards the aims autonomously formulated by the citizens and develop the law as the reflexive organization of their freedom. Throughout Fichte's writings we find numerous hints at such a more organic - rather than mechanical - conception of law. He thus recognizes for instance - refraining from all the negative restrictions which law imposes upon the pursuits of individuals - "the positive element in the concept of right" (GA I/3 356; FNR 47) as precisely lieing within the fact that everyone may be treated and judged only according to that lawful concept which he himself "must possess" (ibid).

But beware: Fichte is not referring to an idea of law empirically gleaned from historical reality. Rather, Fichte divines that this very concept of law is "contained within the essence of reason," since "no finite rational being is possible if this concept is not present within it ... in consequence of the being's rational nature" (GA I/3 358; FNR 49). He treats the factual conceptions of law entertained by real people with lofty disregard. He is similarly ambivalent when he describes the conception of conditions of the possibility for being "a person" as a "right" of said person, and calls all of these rights contained "in the mere concept of the person ... original rights" (GA I/3 390; FNR 87). In such contexts, he may well write that such rights belong to the essence of persons as such, thus unconditionally and not as a result of conditioned relations of recognition. ${ }^{119}$ Yet as soon as such declarations appear, they

\footnotetext{
${ }^{119}$ It is hence problematic that this revaluation of all individuals (including oneself) is with Fichte nevertheless ultimately only to be understood instrumentally on behalf of reason since all human beings are or should be means to the end of the universal reason; a position, which entails the immediate devaluation of all of those being or making them fit for this project. See Klaus Kodalle, "Der Stellenwert der Historiographie im Kontext des Fichteschen Gesichtsdenkens" in FichteStudien 11 (1997), 259-285. This is shown within, among other places, Fichte's formulation that the justification for the existence of human beings is contained in the work they do for the end of the species: "for that alone is he there, and if this should not occur, thus he does not at all need to be" (GA I/5 230).
} 
are retracted: "There is no condition in which original rights exists; and no original rights of human beings." Basic rights, i.e. human rights, are "a mere fiction ... for the sake of science" (GA I/3 403-404; FNR 102).

Doubts are appropriate. If the idea of law really follows as a necessary conception from the articulation of the free essence of human beings, then Fichte's claim that there is a natural law only within, and not before, the state, can hardly be maintained (GA I/3 395ff.; FNR 92). Certainly, the realization of the norms of natural law requires the state. But if the idea of law together with a limitation of everyone's freedom to the boundaries of the law belongs to the free essence of human beings, can - or indeed must - one not then speak of a minimum supply of pre-positive, rational normativity, i.e. natural law? ${ }^{120}$ Fichte seems now and then to concur when he declares that his concept of law is what legitimates positive laws in the first place. For instance, he argues: If one has an original right to personal liberties then one also has a claim to the adjudication of the rights which make this de facto possible: "Original right (Urrecht) returns back into itself and becomes a self-justifying, selfconstituting right, i.e. an absolute right" (GA I/3 409; FNR 108).

For its legitimation, an absolute right depends only on itself, not on empirically given laws. But if a right is valid for us as a person, then it is valid for every person (GA I/3 374; FNR 68-69). To demand rights to personal liberty means to claim a concept that interlinks the positing (of the rights) of one person with that (of the rights) of others. We can only expect freedom for ourselves in the name of reasons that at the same time obligate us to stand up for the freedom of all persons, of all world citizens. A foundation for intercultural human rights appears therefore to be the upshot of Fichte's concept of reason. If freedom is universally valid, should it not also be globally realized? Fichte, however, leaves that promising cosmopolitan path to become overgrown by the notional plants of the nationalism for which he was as famous at the beginning of the twentieth century as he has become infamous now after that century has come to an end. ${ }^{121}$ These potentials for a generously universal conception of freedom are, however, squandered. Fichte makes an astonishingly narrow-minded use of these intellectual foundations in order to secure a conception of perfect freedom through philosophical directives. Because the actual value of freedom consists for him in its rational use alone, Fichte subjugates all civil and civic freedoms to the philosophers' blueprint of freedom; and being without hope of enforcing this blueprint on a global scale, he limits his theory to national parameters.

\footnotetext{
${ }^{120}$ See Riedel, Fichtes zweideutige Umkehr der naturrechtlichen Begriffsbildung. The same applies to Fichte's central reflections concerning the "right of world citizens"; see Verweyen, Recht und Sittlichkeit, 98.

${ }^{121}$ For information concerning Fichte's reception in the philosophy of National Socialism, see Konrad Cramer, "Um einen nationalsozialistischen Fichte von Innen bittend: August Faust über Fichte im Jahr 1938" in Jürgen Stolzenberg, Oliver-Pierre Rudolph, eds., Wissen, Freiheit, Geschichte: Die Philosophie Fichtes im 19 und 20 Jahrhundert (Amsterdam, 2010). See also Christian Jansen, "The Formation of German Nationalism, 1740-1850" in The Oxford Handbook of Modern German History (2011), 234.
} 
Without hesitation, Fichte tells those who protest against his nationalist paternalism that they misunderstand themselves. That icy reproach of a false consciousness will later become a staple of Marx. Fichte, however, employs it even more rigorously. Marx at least allows the false consciousness (for him, at most times: capitalist ideology) to possess a partial historical truth, which, helped along by the philosopher, eventually can be transformed into complete truth (accordingly: communist theory). Fichte, instead, radicalizes the separation between true and false consciousness and situates it between the levels of the transcendental and everyday consciousness. The ordinary consciousness, insofar as it is philosophically reconstructed and guilty of mistaken assumptions, has no claim to validity at all. One must neither theoretically consider it, nor practically respect its proponents.

\subsubsection{Social Philosophy}

Fichte's social philosophy starts out from plausible, even congenial, concerns: All persons, according to Fichte, require a certain sphere to realize and symbolize their respective freedom: property (GA I/3 361; FNR 53). In property, freedom becomes materially graspable. The right to property functions, so to speak, as the grammar that regulates the communication of civic freedoms among one another. Whoever wishes to secure the semantics of freedom in inter-individual relations must know the syntax for the relation of individual and community. For example, in order to demarcate justly what does and does not belong to whom, the private must first be linguistically distinguished from the public. Fichte thus dedicates voluminous studies to the style of the legal prose of possession and property, interpreting the specific proclamations of civil rights, as it were, as public speech-acts of freedom itself. The poetic attraction of those considerations lies in how they describe the rights of others as manifestations, not negations, of the individual's freedom.

Fichte argues: Whenever I exclude others from my relationship to objects and wish to do so in a lawfully valid manner, I must acknowledge as legitimate the same behavior on part of every other rational being. In principle, therefore, my relation to any object entails the object-relations of all others (GA I/3 414-417; FNR 113116). Hence, the legal order's refusal to allow my appropriation of certain goods that belong to others is not merely the expression of an alien will (to possess) but also the manifestation of my own will (to possess) (GA I/3 416; FNR 115-116). Therefore, my right to property finds no alien limit in the property rights of others, but rather its very own boundary. That connection of everyone with everyone else is what constitutes the right to property: The social limits of property thus function, not as supplementary restrictions of an antecedently abstractly-universal right, but rather define all property radically (i.e. from the Latin radix, its root) as a common property prior to its subsequent private division. ${ }^{122}$ Everyone is entitled to freedom-

\footnotetext{
${ }^{122}$ For more information about the following, see Johann Braun, Freiheit, Gleichheit, Eigentum: Grundfragen des Rechts im Licht der Philosophie J. G. Fichtes (1991).
} 
enabling property. As a consequence, freedom should not only be protected by the rule of law (i.e. doubly negatively: as negation of negations of freedoms already established as a legal entitlements), but it has rather to be also (immediately positively and affirmatively) created (GA I/5 314). No-one may be animated (e.g. by destitution) to violate the law (e.g. towards theft) (GA I/3 459; FNR 163). ${ }^{123}$ The state under the rule of law must also be a social state.

Fichte is convincing when he demands us to see in the rights of others, not negative limitations, but positive bounds, which in the first place individuals into valid relations of mutual recognition. Consequently, the individual's lawful position is confirmed - or, where necessary, corrected - by society. ${ }^{124}$ It seems hardly surprising, therefore, that Fichte, unlike other philosophers of freedom, does not feel inspired towards a passionate hymn in favor of exclusive private possessions. Nevertheless, it remains surprising that he lets himself be carried away by an elegy on collective property. Although one finds his occasional approval for an intermediary, social-democratic position, he ultimately clearly joins the socialistic chorus about common property, in which the private at most chimes in as a softer counterpoint to the collective leitmotif. In an all too rapid series of chords, Fichte moves from his philosophically directive idea of freedom - via the interlude of a quasiorganic social utopia - to a brisk socialist oeuvre; orchestrated and announced, though, as an ode to freedom.

This is occasioned by his philosophical method, since it, directed by Fichte's speculative deduction alone, believes itself entitled to pay no attention at all to popular opinions. Fichte does not aspire to a politics by the people. His aim is the purest possible translation of the rational will of human beings into legislation and executive decisions (GA I/3 438f; FNR 139f). Only rational interests concerning the common good, and not the arbitrary opinions of the majority, should be politically decisive. Imitating Rousseau's distinction between the 'volonté de tous' and the 'volonté générale,' Fichte demands that the (factual) "communal will" (gemeinschaftlicher Wille) of the people must, in order to maintain political legitimacy, first be transformed into a (normatively acceptable) "unified will" (gemeinsamer Wille) (GA I/3 436; FNR 137). That requires an integrative representation of the common interests orientated towards a universally valid - and hence generally accepted - law (GA I/3 436; FNR 137). How can this succeed?

The most appropriate image for illustrating this concept is that of an organic product of nature. This image has frequently been used in recent times to describe the unity of the different branches of public power, but - so far as I know - it has not yet been used to explain the civil condition of the whole. [...] In the organic body, each part continually preserves the whole, and by doing so, is itself preserved; the citizen relates to the state in the very same way. And in fact, in the one case as well as in the other, this preservation of the whole does not require any special arrangement; each part, or each citizen, preserves only itself in

\footnotetext{
${ }^{123}$ For this "new motif in Fichte's thinking" which allows us to now grasp the rule of law "as something dynamic, as a system of interconnected rightful relations," see Nico Wallner, Fichte als politischer Denker: Werden und Wesen seiner Gedanken über den Staat (Halle/Saale, 1926), $107-110$.

${ }^{124}$ See Verweyen, Recht und Sittlichkeit, 107f.
} 
the place that has been determined for it by the whole, and in the very act of doing so, it preserves the whole in this particular part: and precisely because the whole preserves each part in its place, the whole returns into itself and preserves itself. (GA I/4 19; FNR 180-182)

Politics has accordingly to follow a concept of the common good, which harmoniously unites the particular interests and the needs of the political whole. For the specification of this abstract aim, Fichte makes use of the parallelism of natural product and social union: in numerous appeals to the "ordinary" and "sound judgment," which felicitously ascertains the "nature of the issue" (GA I/3 454f.; FNR 157). It is simply a question of "treating everything according to its final purpose", states Fichte. In this way, the required program could easily be "scientifically established" (GA I/5 150).

What is the origin of this remarkable optimism about divining with certainty and ease the respective necessities? Is such a teleological doctrine of the "final purposes" given by nature at all possible and admissible within the framework of a transcendentally directed philosophy? ${ }^{125}$ Certainly, it strays notably from the straight philosophical path pursued by Kant. For unlike Kant, Fichte presupposes not only a principal compatibility of nature with human ends, but rather - as for him the ought is the ultimate purpose of being - begins from a metaphysically founded (more precisely expressed: feigned) harmony of nature and freedom. Fichte ascribes a servitude to freedom even to such forms of life that in and of themselves do not display any such liberal tendencies. ${ }^{126}$ A procedure, whose general premises are just as questionable as its specific conclusions. Whoever takes Fichte at his word, has to ask at once: Why then does such an exquisitely arranged world still require means of coercion, when, as we are told now, some internal teleological necessity drives the cosmos toward the realization of the liberal utopia? What does one need compulsion for?

While in Fichte's Foundations of Natural Right it still looks as though (legal) coercion alone is needed to establish society, things sound quite different a little later in the System of Ethics (GA I/5, 253). And in Some Lectures concerning the Scholar's Vocation that followed shortly afterwards, one even reads that "upon the a priori prescribed course of the human species there lies a point where all statebased relations become superfluous" (FW VI 300). Fichte suddenly emphasizes that the state does not first socialize individuals by law, but already finds them embedded in ethical forms of community (FW VII 382). Numerous places, where Fichte even occasionally flirts with the complete dissolution of the state, ${ }^{127}$ suggest a theory of sociality established neither completely nor essentially by enforced laws, but rather by voluntariness.

At times one even seems to be hearing anarchic sounds when Fichte proclaims that clever politics could and should lead to a future state of affairs where individu-

\footnotetext{
${ }^{125}$ See the critique of Fichte already put forward by Albert Th. Van Krieken, Ueber die sogenannte organische Staatstheorie: Ein Beitrag zur Geschichte des Staatsbegriffs (Leipzig, 1873), 60-65.

${ }^{126}$ See Georges Gurvitch, Fichtes System der konkreten Ethik (Tübingen, 1924), 251.

${ }^{127}$ This is carefully documented and interpreted in Fonnesu, Die Aufhebung des Staates bei Fichte.
} 
als will conform to society's plans from ethical motivation such that gradually the lower forms of human behavior brought about through the sheer force of the law develop into a higher - more ethically than juridically established - compact for societal life. For, as is clearly repeated in later writings, the "life in the state does not belong among the absolute purposes of humanity." The state may then merely function as precursor of higher forms of fellowship; it serves as a useful means to an "art" - which will ultimately replace it - of "furnishing the entire relations of humanity according to the previously scientifically interpreted reason [...] until the species stands there as a complete expression of its eternal original image in reason" (FW VII 10f.).

Fichte surely never wishes to give up the state's role in economic planning and distribution, ${ }^{128}$ but, in later years, he wished to do away with precisely that apparatus of coercion which he had wanted to prove to be a logically absolutely required precondition for the possibility of a consistent idea of freedom. ${ }^{129}$ It remains unclear how the reason-directed social relations he strives after would have to be put into place (FW VII 161). On one hand, Fichte at times recommends the "absolute state" as "institution for coercion" (FW VII 143f.), as the most appropriate means for this purpose. Then again, on the other hand, he announces that, aside from their duties of citizenship, human beings should remain completely free of all political bounds ${ }^{130}$ : The state should only create the "outer conditions" with which human beings "could, with their own freedom, make themselves the apparent manifestation of reason" (FW VII 162) - for instance through indirect promotion of "religion, science, and virtue" (FW VII 166-168); a strikingly more restrained interpretation of the tasks of the state. ${ }^{131}$

Does Fichte's social-philosophy then ultimately follow a liberal or a totalitarian model? For Fichte, when it comes to freedom, is the path the goal? Or can the eminence of the ultimate end justify whichever choice of means? Fichte provides various and ambiguous answers to these questions. His thinking oscillates between (structural) ideas and (material) concepts of freedom and thereby exemplifies central questions for philosophical liberalism as a whole: How far is philosophy permitted to venture into the concrete? When and how do philosophically meaningful pointers deteriorate into pedantic dirigisme and illiberal dogmatism? The final answer to these queries lies in Fichte's economic philosophy. ${ }^{132}$ Long before Marx attempted to rescue human freedom from alienation and exploitation, Fichte had

\footnotetext{
${ }^{128}$ See Heinrich Rickert, "Die philosophische Grundlagen von Fichtes Sozialismus," Logos Internationale Zeitschrift der Philosphie der Kultur 9 (1923), 149-180.

${ }^{129}$ See Georg Geismann, "Fichtes "Aufhebung” des Rechtssaates," Fichte-Studien 3 (1991), 86-117.

${ }^{130}$ See Walker, Fichte als politischer Denker, 111.

${ }^{131}$ For more information about this conflicting interpretation see the contributions from Günter Zöller and Christoph Asmuth in Günter Zöller (ed.), Der Staat als Mittel zum Zweck: Fichte über Freiheit, Recht und Gesetz (Baden-Baden, 2011).

${ }^{132}$ See David James, Fichte's Social and Political Philosophy: Property and Virtue (Cambridge: New York, 2011), 22f.
} 
already seen the close connection between a liberally founded doctrine of law and a socially engaged philosophy of economics and thus worked upon their dovetailing. Fichte quite clearly recognizes and suggests that economic conditions in particular manifest human freedom in everyday life. Since for Fichte the universal right to freedom involves the particular presuppositions of a free life, economic questions (for example the allocation of goods as well as the distribution of costs and burdens in society) become the object of his doctrine of freedom.

\subsubsection{Economic Philosophy}

Fichte unequivocally demands: "everyone ought to be able live from his labor" (GA I/4 22; FNR 185). Whoever does his bit for the economic freedom of the whole, should receive his or her personal due - the material presuppositions of his or her individual freedom - on the part of the community. Every person should receive a private sphere of efficacy and property (GA I/3 361; FNR 53-54). Yet the market by and of itself will never guarantee that all obtain the goods they require for a free life. Fichte sees this as an unacceptable contravention of his idea of freedom that must be resolved by means of a national economy directed towards the freedom of all by regularly and reliably assigning everyone their fair share.

For this purpose, Fichte devises the model of The Closed Commercial State (1800) within which a cyclical exchange of goods and services takes place planned and overseen by the state. First of all, the state assigns to the proprietors their respective possessions and then establishes rules for their mutual exchange of commodities and services. According to these legally unchallengeable rules, thoroughly symmetrical relations of exchange should put an ordered cycle of allocation in place. This cycle is devised so that no one ever ends up positioned worse than they were upon the state's initial distribution. Fichte does not see the economy as able to process asymmetries productively. ${ }^{133}$ That is why he signs his readers up for a static model of mechanical order. ${ }^{134}$ For him stability cannot result from a dynamic balancing of economic inequalities. Consequently, Fichte fears foreigners. They are certainly not instituted into their property by the state. Their exchange behavior is thus much less malleable. So, they could disrupt the precious balance of the preestablished relationship between property and exchange.

Only a world-state could ultimately resolve this problem. Only when there are no more foreigners can property be guaranteed in a truly permanent and absolutely stable form recognized "by the present constitution of humankind" (GA I/3 418; FNR 118). In the absence of a world-state, the national economic system and nationstate must be "closed" so that, at least within their boundaries, the desired balance

\footnotetext{
${ }^{133}$ See Hinz, Fichtes "System der Freiheit."

${ }^{134}$ See Bernard Willms, "Zur Dialekik der Planung: Fichte als Theoretiker einer geplanten Gesellschaft" in Böckenförde (ed.) Säkularisation und Utopie (Stuttgart, 1967).
} 
of goods is not endangered from outside. ${ }^{135}$ Fichte accordingly severs the national society from the world-market in order to conduct undisturbed, within the so enclosed space, his politics of redistribution. The specific provisions for the execution of this plan within The Closed Commercial State are no longer of interest today. They do not penetrate into the essence of economics and attempt to bring Fichte's ethical ideals into play, not in the economic exchange process, but rather against it.

More interesting than that early outline for a planned economy (as a means) with a liberal agenda (as the end) is, however, the position Fichte presented 12 years later when reflecting upon his own subsequent studies of economic literature. ${ }^{136}$ Fichte took the topic of economics up again in lectures held in Berlin in 1812, but this time he wishes not only to cover and constrain the region of economics with juridical structures from the outside, but rather aims to transform it from within. He believes himself to be successful in this endeavor, and thus in a position to profess the very principles required for all future economic policy. This is shown by the following passage in which Fichte summarizes his mature philosophy of economics as follows:

\begin{abstract}
In Summa: Everything rests upon (1) that the state has a concept of human wellbeing and of the means to advance this and of the important consequences of this means. (2) That it in every moment knows precisely the actual and true condition of its nation and its standpoint in every respect. The first, as something a priori, is expected of it without doubt. The second arises from the constitution, since it always oversees the state of agriculture and business, and the results of that which its own action produces, and from time to time it is necessary to put aside precise accounts about it since it must establish the price of the commodities. It in no way lacks the power to give direction to the National-Industry since without its will no hand in the state stirs towards this end, and it continually has freely at its disposal a sum of forces which it can also arbitrarily increase or diminish. One should not fear the army of officials and their work and paperwork which would bring this about. (FW X 587)
\end{abstract}

The economic theory summarized in these words is bewilderingly heterodox. In it considerations about the state as a venture-capital-agent are united with socialist doctrines, and guild-thinking is united with physiocratic speculations and mercantile subtlety. Economically one can hardly find a common denominator for these ideas, but one might philosophically. Fichte ultimately presents his theory as the self-unfolding of metaphysical reason in economic matters. We must hence seek the conceptual key for deciphering the code of the true essence and value of commodities underlying all economic activity within precisely this philosophical enterprise.

Fichte desires to find reliable bases of value assessment for questions of social participation and redistribution. Real freedom manifests itself often as access to goods. Whoever wishes to promote a just allocation and fair distribution must make goods administrable and their value commensurable. Fichte hence strives to attribute to all commodities a fixed inner value, remaining stable in the face of every fluctuation of their so-called outer value, i.e. of their exchange value on markets.

\footnotetext{
${ }^{135}$ About this see the far-sighted critique given in Krieken, Ueber die sogenannte organische Staatstheorie, 641.

${ }^{136}$ See for instance Fichte's commentary to Theodor Schmalz's "Handbuch der Staatswissenschaft" of 1808 in GA II,/13, 9ff.
} 
His policy of redistribution requires as much. He seeks this "basic criterion of the value of all things" far away from the price of commodities, so as to not fall into that "bias towards money which disturbs all healthy insights into this matter" (FW X $558)$.

Fichte first posits the subsistence-costs of laborers as a necessary component of every commodity's value (FW X 559), below which nothing could be continuously produced. He then adds on the laborer's claim to "leisure," more precisely a claim to participation in the goods achieved macro-economically above the level of everyone's subsistence (FW X 544). Leisure is thereby defined as a span of the "ability to live without labor" (FW X 560), whereby it is not a question of free time alone, but also a question of a "release from all material purposes," secured by adequate material provision, during this time (FW X 539). In leisure time, one ought to be able to dedicate oneself to higher ends, for example, moral self-improvement.

Thus Fichte abruptly changes from a theoretical to an ethical perspective on economics. It is true, usually, laborers procure exchange-value, which exceeds simply covering the costs required for their continuing ability to work, and thus allows them some leisure. Nevertheless, this is not always the case. Therefore the state shall intervene. According to Fichte, every citizen who contributes towards society's wealth is entitled to claim adequate remuneration from society's total assets. If a laborer invests time, that is, if he puts in individual effort and leisure in order to establish subsistence and leisure for society, one must compensate this justly according to the proportion of the time employed by him to the time applied within the entire society and its total profit produced (FW X 561). The individual can thus multiply his applied hours with that economic performance ratio and may thus calculate what he is entitled to from the state (ibid).

All individuals are charged with being as economically successful as possible so that the community can secure the material freedom of each and everyone. Fichte, for instance, comments in the margins of his copy of Theodor Schmalz's Handbook of Political Science [Handbuch des Staatswissenschaft] of 1808 that prosperity "is not merely the means for another end, but rather the end of the whole is to be as great, cultivated, and wealthy as it can be. - The individual is not allowed to say: I wish to put up with being poor. You should and must be as rich as you can" (GA II/13, 9). Fichte's social-utopia needs economic growth.

But that alone does not yet solve the problem of (re)distributing value: While within the mental model of a static economy it is relatively comprehensible how the respective proportion of goods can be measured out for all, a dynamic order aiming towards growth brings along its very own econometric difficulties. In a constantly changing economy, how can one establish stable and lasting relations of property? How can one prevent the exchange-system producing ever-greater inequalities in private-property? Fichte deals with this problem with his usual tendency towards drastic solutions. He absolutely does not recognize any property prior to governmental assignment. Every position of property must, in the last instance, result from public distribution. As, however, public allocations have to proceed from equal rights for everyone, the government must assign everything to everyone in accordance with the same principles. 
Not only the abstract institution of private property, but also that of concrete private possessions, is thus turned by Fichte into a canvas for governmental designs. ${ }^{137}$ Accordingly, Fichte does not leave things to rest with a one-time allocation. He wishes also to ensure that every citizen "maintains the value of this property" through every further exchange of commodities and services that takes place even after that hypothetical original allocation (FW X 524). Fichte, that is, strives for nothing less than a lasting fixation of all relative assets. Unlike usual relations of exchange, where the cleverer individuals have an advantage over duller ones, the knowing over the unknowing, the independent over the dependent and - because of economies of scale and the conventional terms of trade - the rich have, in most cases, an advantage over the poor, from now on it ought to be so that "trading into infinity, no one will as a result become either richer or poorer" (ibid.).

What is heralded here is by no means merely the utopia of freely chosen communitarian socialism. Rather, according to Fichte, it is the "task of the state" to secure - and, if necessary, also by force - this "progress of humanity" through a firm control of all relations between commodities and prices (GA II/13, 10). The logical presupposition of that regulation of prices by the state constitutes a theory of the true value of commodities, formulated irrespective of any exchange relations. Its purpose is to enable the state to allocate to all precisely that to which they are entitled, and so Fichte strives for a metaphysically secured commensurability of the value of all commodities and services. His theory of money, doctrine of trade, and his idea of political economy all thoroughly depend upon this absolute dimension of value.

But what is that ultimate and highest criterion through which economic goods can be ascribed a completely market-independent value? For that role, mere working time does not seem to qualify since obviously equal working time does not always produce equal value - neither the same use value nor the same exchange value. In every competitive economy some lines of production certainly fair better than others and, even within one and the same profession, some producers attract more customers than others. Hence a market could hardly come to exist spontaneously in which everyone trades goods with everyone else simply for the amount of labor contained within them. ${ }^{138}$ Since the individual estimation of the utility of exchanged goods continually oscillates, the desired egalitarization of trade requires that one must politically fix value relations of the commodities' values.

That designation now may not be a forever fixed singular attribution. Otherwise it cannot adequately reflect the continual increase in production that Fichte demands from society (FN X 544). With a static principle of value the increase in individual

\footnotetext{
137 "The being of the freedom of the individual [...] is again completely lost by Fichte, since the empirical individual is, concerning the guarantee to property, exposed to the total grip of the administering community." Willms, Zur Dialektik der Planung, 121f.

${ }^{138}$ The trade on time in especially created trade-exchanges is something different. That is an exception, however, which confirms the rule, because in such exchanges one can only deal in units of time. The fact that one especially needs to create such artificial environments in order to facilitate 1:1 exchange in temporal units indicates that the exchange ratios that are protected by them could, in their absence, only rarely adjust themselves. Otherwise we would not require such exchanges.
} 
powers of production, for instance, would lead to an unequal distribution of the burdens between individual lines of production, as technology-driven growth in the economy hardly ever takes place in all sectors at the same time and in the same way. The upshot would be allocations running counter to the equal right of all citizens to their "due property" (FW X 530). Fichte thus looks for a dynamic medium that automatically reflects the societal progression in productive powers adequately:

It is to assign some kind of product of labor as continual criterion of all value, and to attribute the value to all remaining products of labor. That that product of labor must be a foodstuff, and certainly the most universal and most used foodstuff, e.g. a quantity of corn (a bushel) is obvious; for the possibility of life is precisely the ideal criterion of all value and labor. (FW X 563)

The quantification of all future economic production in terms of corn-bushels is not a self-evident proposition, however. Fichte's quantification of economic goods in terms of corn (albeit modeled most likely after the British economics of his time) proceeds - unlike that of, for instance, Fichte's contemporary David Ricardo (17721823) - in a physiocratic manner (FW X 565). Ricardo had established a corncalculation in order to show that, by leaving aside econometrically notoriously elusive fluctuations in the value of money, one is able to validate certain assessments of marginal and comparative value; especially about the relative relation of soilfertility to its annuity. ${ }^{139}$ Ricardo, that is to say, makes an exemplary regulative use of the calculation in terms of corn, but in no way assumes that corn is the actual constitutive criterion of all value. Fichte, on the other hand, seeks in corn an absolute measure of value: Every advance of productive powers ought to show in the corn-price, which - inasmuch as it is not calculated in money - always remains stable and consequently serves him as a reliable constant. Fichte believes that corn continually increases in price proportional to the cheapening of the production of other goods conditioned by growth (FW X 566). Therefore, the price of corn appears to be the sought-for dynamic third medium that can express the firm value-relation of all other goods standing in exchange-relations. With this criterion of value, the entire political economy is subsequently newly directed by Fichte:

The price of everything upon its surface is produced by the state, and it seeks out the products of labor which enter into commerce and declares them; and for this price everyone will be able to have every access at any time to the desired commodities against the equivalent which is to be found in his hands. Now how should the state secure this? There remains no other means than that it itself takes over commerce, to become the [...] third class, the trad-

\footnotetext{
${ }^{139}$ See David Ricardo, Miscellaneous Pamphlet Collection (Library of Congress) and Commercial Pamphlet Collection (Library of Congress), An Essay on the Influence of a Low Price of Corn on the Profits of Stock: Shewing the Inexpediency of Restrictions on Importation: With Remarks on Mr. Malthus' Two Last Publications: "An inquiry into the Nature and Progress of Rent" and "The Grounds of an Opinion on the Policy of Restricting the Importation of Foreign Coin" (1815) (taken from the printing in Works [London, 1821]). For Ricardo the meaning and purpose of the calculation in corn is to show how the rate of profit of a branch of the economy is oriented by the weakest marginal profit within it: In the case of agriculture: how the rate of yield of the soil poorest in profit also determines the measure for the yield of more fertile soils insofar as the surplus of productivity of these soils are absorbed by proportionally increasing rental costs (soil-annuity).
} 
ing class $[\ldots]$, that means merchants must be civil servants who buy on the state's account everything without exception that is offered to them at the fixed price, and thus sell on the state's account. (FW X 568f)

In terms of econometrics, Fichte's theory of the foundational corn-criterion falters. One reason is that the production of corn is not intertemporally stable; another is that even simultaneous corn-production requires different production-expenses in different places. There is consequently no fixed relation of applied labor and produced corn, not even when one neglects the time factor. ${ }^{140}$ As a result, Fichte's desire to reach social equality through a unitary taxation of all land-ownership is already thwarted at the outset. A land-tax of this kind would - because of the differing fertility of different soils - lead to an unfairly uniform burden and thus achieve the exact opposite of Fichte's egalitarian intentions; a difficulty later ever again faced by various "One-Tax" systems.

Another problem with the calculation in terms of corn is that the bringing about of exchange relations between corn and other commodities is only imaginable, if at all, in a strictly subsistence-orientated minimal economy. In no cases does this criterion allow the construction of meaningful relations of value for the innumerable non-material goods in complex service and communication-orientated societies. Goods can enter into a corn-calculation at best according to their relevance for the objectively general interest in survival (like basic nutrition). The more differentiated a society, however, the more it produces goods directed towards subjective individual preferences. Since the latter then can only be grasped by a generalizing economic calculation, economic planning based upon a central calculation must fail - not only accidentally, but also generally - to establish a stable relation of equivalence between corn and those differentiated economic goods.

Why these economic details? Because with Fichte's assumption of an a priori determinable value of commodities there topples a central-pillar of a distributive politics supposed to secure for citizens equal access to all life-goods relevant for freedom. Fichte overestimates the hermeneutic competence of the state and underestimates the heuristic potentials of the market. He does not even consider the contribution of fair, justly accessible and ordered markets for the establishment of value relations between goods and services. Compared with his ideal of an optimal ethical distribution, Fichte deems every market-constituted evaluation of goods and allocation of commodities to be pitifully deficient. He views market prices only as distortions of just exchange-ratios, but never as procedures achieving the latter approximately.

Fichte thus explains changes in price only in terms of the profit-motive of merchants to pass overpriced commodities on to consumers. Accordingly, he values the profits of trade as an illegitimate robbery from society's treasures and concludes that the state should rather place trade in its own hands (FW X 569f). Yet that is not all. As soon as domestic trade is value-metrically brought into line, the established

\footnotetext{
${ }^{140}$ See David Ricardo, Miscellaneous Pamphlet Collection (Library of Congress) and Commercial Pamphlet Collection (Library of Congress), On the Principles of Political Economy and Taxation (1817) (taken from the printing in Works [London, 1821], 121).
} 
price-relations must be protected from foreign trade. Fichte's more detailed considerations about this (FW X 587ff) are variations upon the selfsame theme of The Closed Commercial State. They follow the schema: The national economy presents an endangered order, which all too easily would be brought into disequilibrium by uncontrolled inner and outer commercial movements. The state thus requires unlimited powers of control and coercion. ${ }^{141}$ In essence, economic freedom cannot exist within or through the market, but only outside of it.

It would certainly not be fair to gauge Fichte in terms of knowledge reached only after the failure of 'Real-Existing Socialism' (real-existierender Sozialismus). But one should certainly compare Fichte's theory with the level of knowledge within the economics of his day. After all, that is what he wants to surpass. It is thus quite significant when Fichte ignores its insights. When he views commerce as nothing other than an exploitation of customers, he overlooks, for instance, the balances and allocations resulting from the merchant's counter-cyclical sale of commodities which commerce produces within society. Since commerce reacts to price-differentials and so gradually reduces these, it leads in the long term to a more efficient allocation of goods - and thereby to an increase in society's overall wealth. Profits obtained by merchants in this way are garnering otherwise unrealized returns and thus do not amount to a theft from society's assets. In that regard German national economics of the early nineteenth century thoroughly agreed with classical English economics. The same is true mutatis mutandis of commerce across borders. Trade imbalances in the roundabout commerce of an international exchange economy can lead to an increase in the prosperity of all parties. That had been previously recognized within classical economics since Hume and Smith, and Ricardo had begun to model such effect already, although still with fictional numerical values. ${ }^{142}$

Fichte, though, considers the appeals of English economics to spontaneous commercial balances as the evasions of a lazy reason refusing to engage with the construction of plans (FW X 554). He believes that before him one just did not yet seriously penetrate the concepts of property, trade, and exchange - and thus one had simply been unaware of the possibility of governing economic life by pure reason. Here, too, Fichte misjudges the state of the discussion back then. English economists had developed their theory of dynamic orders coping with inequalities productively as a reaction precisely to the failed hopes of mercantilists and physiocrats

\footnotetext{
${ }^{141}$ About this see Fichte's outline "Concerning Bonds [Pfandbriefe]," which probably came into being around 1809/10, especially his remarks there concerning the 'Durability of Value' (GA II/13, 11): "Only the state can secure the durability of this (we again insist upon a closed Commercial-State)."

${ }^{142}$ For the contemporary status of the discussion about the national economy, see the article "Political Economy" in the fourth edition of the Encyclopedia Britannica, Or, A Dictionary of Arts, Sciences, and Miscellaneous Literature (Edinburgh, 1810), vol. 17, 106-123, as well as the equally very instructive article of the same name in The Cyclopedia or: An Universal Dictionary of Arts, Sciences, and Literature (Philadelphia, New York, 1810). For the integration of Fichte's theory within the contemporary context of German philosophical theories of economics see also Tetsushi Harada, Politische Ökonomie des Idealismus und der Romantik: Korporatismus von Fichte, Müller und Hegel (Berlin, 1989).
} 
to devise an economy completely planned by the government; attempts in many ways resembling Fichte's. The British-Scottish economists had not simply overlooked, but rather rejected, the option of outlining rationalist models of closed cycles of goods and static commercial balances.

\subsubsection{Socialism Versus Social-Democracy}

A philosophical evaluation of Fichte's theory must obviously begin with the idea of freedom, around which revolves his outline for a socio-economic order directed by the state. In this regard, it is first of all to be recognized that Fichte very early on saw - and appropriately evaluated as challenges to freedom - some essential problems posed by the globalizing market and exchange economy. Fichte justifiably rails against conditions forcing human beings - out of economic necessity - to agree to contracts they would otherwise never enter. That is particularly pertinent wherever - as a result of historical injustice (colonialism, imperialism) - people end up in situations that render it impossible for them to reject the very conditions, defined by outer powers, for their own economic participation in the global market. Unjust commerce is illiberal.

Translated into the language of sport: Whoever has no other choice but to earn his living through boxing at fairs (Preisboxen), certainly recognizes - with every entrance in the ring - the fundamental rules of boxing as de facto binding, but not, for that mere reason, as fair. Something similar is true today of many developing countries. They cannot renounce participating within the global economy, but in no way find their legitimate interests appropriately addressed by the regulations of the World Trade Organization: Fichte clairvoyantly recognized this problem. Wherever there is no global government to govern the global economy, sheer power often defines the terms of trade: Trade agreements concluded by asymmetrically positioned partners, however, often perpetuate precisely the very economic unfreedom and indigence that bring the weaker party to the table. In this regard, Fichte's critique of an economic freedom naively seeking liberalism through laissez-faire economics certainly remains cogent. Free trade is only to be demanded in lockstep with the gradual developement of a global economic order that secures fair access to the global market for all world citizens.

Yet Fichte's recommendations for therapy appear to be just as erroneous as his diagnosis was sound. Whoever recognizes that decentralized transactions - under certain unfavorable presuppositions - create, or worsen, injustice, had better direct the wind of change to those unfavorable frameworks than attempt to nullify the free exchange of goods and services. His optimistic faith in a planned economy notwithstanding, Fichte anticipates that citizens might attempt to break out of his fixed exchange-schema. Hence he tries to foil such attempts by contriving multiple measures of police-control and supervision. But he thus throws into question why citizens would want to escape a system that grants them "property absolutely guaranteed by the state" (FW X 561) without any market risk? Why would they not 
simply want to wait obediently until the hand of the state doles out to them what they require for economic autonomy?

Fichte casually asks this question himself when investigating why human beings trade in and with variable currencies (FW X 575). No one can know what quantities of gold and silver are yet to be found upon earth, or which quantities of goods are to be acquired by them (FW X 575). Compare this to the quantity of corn-money controlled by his 'state of reason' (Vernunftstaat), which exactly represents one-to-one the available quantity of corn and thereby offers a stable foundation of value (FW X 571f.). For Fichte it thus appears to be completely unreasonable that citizens everywhere accept commerce in non-fixable - i.e. themselves traded - currencies (FW X 575). The aim of a generally balanced commercial transaction would thus always be endangered, and through disadvantageous trades one would constantly be in danger of reducing the level of property previously maintained. Fichte can thus understand the commerce in unstable currencies extant upon the world-market in no other way than as brought about "by the need" of the trade-partners (FW X 576). If they did not have to sell under conditions of uncertainty, they certainly would not; hence, if they do so, they are certainly coerced; and he concludes: "Here reigns force, certainly not right" (ibid.). "Who profits thereby ... ? Whoever understands well to calculate the needs of others. All commercial speculations, what else are they but presuppositions of such need" (ibid.).

The unintentional irony within Fichte's reasoning lies in his attempt to help out here with price-dirigism. Certainly, most human beings in no way wish to be diverted from the 'predicament' of a commercial or financial transaction resting upon their estimation of its personal benefit to them. One must rather force the 'blessings' of a planned economy upon them. ${ }^{143}$ Fichte fails to realize that, not only the criminal and crazy, but also everyday citizens tend to prefer their own judgment of the situation to benevolent state planning. ${ }^{144}$ Yet, in the firm possession of objective assessments of economic value, Fichte feels comfortable to disregard these subjective evaluations.

Which leads us to the question: If Fichte had not erroneously believed himself to possess an infallible criterion of value, would his economic theory then perhaps have turned out differently? Which form of economy would he have ended up with if he had renounced the assumption of a metaphysical omniscience in economic evaluations? How would his postulate of providing - for liberty's sake - an appropriate sphere of efficacy for all individuals be realized under conditions of informational uncertainty? Under this premise, might not the answer be found in forms of recursive freedom instead of in forms of directive freedom, therefore in forms which - instead of coercing - make the freedom of individuals the means for socioeconomic reform? With the impossibility of an absolute measure of value one

\footnotetext{
${ }^{143}$ In Fichte's state, money remains the only private property openly available, but also only within narrow boundaries, for it is significantly limited by political state-interventions as well as by the exclusion of all foreign money in its individually liberating effect. See Willms, Zur Dialektik der Planung, 123 n.560.

${ }^{144}$ See Karl Hahn, Staat, Erziehung und Wissenschaft bei J. G. Fichte (München, 1969), 109.
} 
should expect a renewed appreciation of subjective estimations of utility and a revaluation of market dynamics.

Once one no longer sees market transactions, like Fichte, merely as an economic state-of-nature to be corrected by the state (FW X 578), then market-based price formations appear in a new light. They now appear as interpersonal discussions about how much - in terms of money - citizens appreciate certain goods. That this conversation is comprised of verdicts about prices that differ and vary from one person to another as well as from one situation to another is, then, not only innocuous, but rather welcome. While such a free and fluctuating formation of prices certainly eludes all rational planning, it is, however, not necessarily contrary to all reason. Subsidiary allocations by the market are rather a-rational; they require a philosophical interpretation which does not force everything into that dual schema of rational versus irrational favored by Fichte. The exchange value of commodities and services established on the market is not inevitably a deceptive illusion (trügerischer Schein). Rather one might come to see it as a necessary appearance (notwendige Erscheinung) of the use value of goods and services which otherwise, i.e. in and of itself, remains ineffable: as a value, that is to say, which although not formed rationally might still - under determinate further presuppositions - be approved by reason.

Such a point of view also corresponds more closely with the liberal foundations of economic philosophy worked out by Kant, upon which Fichte believed himself to be building. Kant had, after all, defined the price of commodities: "the price (pretium) of a thing is the judgment of the public about its value (valor) in proportion to that which serves as the universal means to represent reciprocal exchange of industry (its circulation)" (AA 6:289). For Kant, inter-subjective judgments of value determine the price of commodities, and not - as with Fichte - objective costs of self-preservation. Consequently, and insofar as the prices the market establishes are not subject to the conditions of an illegitimate distortion (an - at that time as today unfortunately all too often counterfactual presupposition), they may provide information about what society actually values. Thus the economic freedom of citizens could be brought about through market-transactions, not merely against them.

For the functioning of such a price-based discourse on values the procedures of the market-economy must, however, be optimized in the interests of the freedom of all human beings. Still today, the path up to that destination remains long and toilsome. Only when access to the market is equitable and negotiations on all sides are carried out without coercion or manipulation, can there be a valid supposition of justice regarding commercial agreements. Only then may it be assumed that by means of formal fairness results of substantial justice are brought about. This aspect, therefore, i.e. the appropriate formal and procedural presuppositions of a free interpersonal discourse concerning economic value, would consequently be key to advance the Fichtean ideal of a universal participation in the goods of the earth. Fichte's socio-philosophical aims would more likely be served by a regulatory and fiscal law affirming and transforming market-freedoms, rather than with pricecontrols that abolish commercial freedom once and for all. Economic freedom, when universalized, demands social-democracy rather than socialism. 
Georg Wilhelm Friedrich Hegel (1770-1831) argued in a similar vein. He likewise saw in social grievances tangible hindrances to freedom that must be removed. He therefore came out in favor of provisions for the poor and a governmental surveillance of the economic order. He proceeded, though, from a general recognition of the historically formed views and pursuits of both individuals and institutions. Hegel, accordingly, sought freedom in tried and tested forms of sociality and in their further advancement, instead of attempting to design the essence of freedom completely anew from the philosophical drawing board. Not abstract philosophical planning is key, but rather the concrete appropriateness of a way of life for autonomous action. One has to ascertain where, and to what extent, institutions of concrete freedom (families, businesses, associations) are to be protected and strengthened and to what extent the state has the duty to criticize and correct these. Students of Hegel, not coincidentally, later expanded these ideas into a philosophical foundation for subsidiary social-state action. ${ }^{145}$

A short path leads from Hegel to Karl Marx (1818-1883). The bourgeois freedom Hegel aimed to protect was, Marx felt, ground down by capitalist conditions so that ultimately freedom was still only to be had in the forms of alienation (for capitalists) and exploitation (for the proletariat). Marx thus devalued as "negative," not only the Fichtean freedom which turns against its environment, but bourgeois freedom as a whole, including all of its traditional ties - as involuntary contributions towards the consolidation of an economic system which undermines all ethical commitments and is thereby deeply contrary to freedom. As a positive ideal, Marx introduced a freedom through which all human beings could realize - also economically - their true essence, i.e. their humanity. The essence of mankind to be realized thereby, according to Marx, does not rest on the back of history (golden age, paradise, primeval communities, etc.) or upon the deepest ground of human existence (nature of humankind, image of God), but rather in the future: it consists in reaching for still outstanding forms of economic and political freedom. In the name of such positive freedom, Marx ultimately calls for the violent destruction of certain forms of negative freedom: As with Fichte, with Marx, coercion is chosen as a means for realizing freedom, but no longer with paternalistic, but now rather with revolutionary force.

Some contemporaries attempted more moderate alternatives; such as Ferdinand Lasalle (1825-1864), who, for example, wished to transform capitalism from inside by supporting institutional balances like an organized workforce, or also Franz Hermann Schulze-Delitzsch (1808-1883), who aimed to tame it through cooperatives and consumer-cooperation. For them it was a question of strengthening individuals, who are weakened by isolation, through association, and thus of forming forces able to counterbalance the power of capital. These, and other cooperatively orientated groupings of the nineteenth century sought a 'Third Way' between the planning-dictate of totalizing collectives, on the one hand, and the opposed extreme

\footnotetext{
${ }^{145}$ See Stefan Koslowski, Die Geburt des Sozialstaats aus dem Geist des deutschen Idealismus: Person und Gemeinschaft bei Lorenz, von Stein (Weinheim, 1989).
} 
of the unregulated contingent decisions of atomistic individuals on the other; a path of mediation between individual freedom and social responsibility.

In my opinion, probably the purest philosophical formulation of that basic idea of a liberalism of responsible freedom is, however, found not with those well-known social-liberal and social-democratic figures, but rather in the work of philosopher, Karl Christian Friedrich Krause (1781-1832), who up until recently has rarely been discussed. According to him, the philosophical idea of freedom must be theoretically connected (verbinden) and practically allied (verbünden) with the citizens' consciousness of freedom in order to prove effective in society. Instead of writing in the style of Fichte and Marx against the false consciousness of the nation, Krause wishes to philosophize in a manner that begins with the worldview of his public. Economic justice is not to be forced through against the liberal market economy. Krause rather intends to support social justice by means of economic freedom and responsibility. For Krause, the means for freedom is not coercion, but rather freedom itself. He leads the idea of freedom through a critical reflection upon its presuppositions and aims toward a conception of a liberal order, which continuously reforms itself - and thus raises philosophical liberalism to a new methodological level.

\subsection{Participative Freedom (Karl Christian Friedrich Krause)}

Karl Christian Friedrich Krause (1781-1832), while hardly known within the Anglophone world, ${ }^{146}$ is remembered by many Spanish and Latin-American philosophers as the authentic progenitor of a sustainable and context-sensitive philosophy of freedom. ${ }^{147}$ Although Krause's philosophy was also neglected in Germany for a long time, since the 1980s, however, it has been receiving increasing attention among scholars. It has a key place in the history of ideas, insofar as Krause pioneered ideas which were later of formative importance for German Idealism as a whole. ${ }^{148}$ Moreover, slowly but surely the outdated caricature of Krause as a second-

\footnotetext{
${ }^{146}$ Apart from references to Krause in the work of Thomas Hill Green and James Lorimer, as far as I am aware, in the Anglophone world, one only finds real enthusiasm for Krause within the work of Clay MacCauley. MacCauley never fails to praise Krause, and describes him as "one of the best, wisest, most prescient and, in true manliness, one of the greatest of human kind" and considers it the greatest misfortune that Krause did not become Fichte's successor in Berlin, instead of "the compliant and complacent Hegel" (Clay MacCauley, "Krause's 1818 League of Peace," The Advocate of Peace 81:2 (1919), 43-44 \& 48; see also Clay MacCauley, Krause's League for Human Right and Thereby World Peace [Tokyo, 1917]).

${ }^{147}$ See Dierksmeier, "Krausism" in Nuccetelli, Schutte \& Bueno (eds.), A Companion to Latin American Philosophy (2010).

${ }^{148}$ See the studies by Enrique M. Ureña, K. C. F. Krause: Philosoph, Freimauerer, Weltbürger: Eine Biographie (Stuttgart-Bad Cannstatt: Frommann-Holzboog, 1991) and Enrique M. Ureña, Philosophie und Gesellschaftliche Praxis: Wirkungen der Philosophie K. C. F. Krauses in Deutschland, 1833-1881 (Stuttgart-Bad Cannstatt: Frommann-Holzboog, 2001) as well as Claus Dierksmeier, Der absolute Grund des Rechts: Karl Christian Friedrich Krause in
} 
rate philosopher yields to the portrait of a first-class thinker whose work was not only of relevance yesteryear, but also provides great inspiration for today.

Krause is particularly innovative as a result of his methodologically consistent implementation of the Kantian project of a philosophy focused upon freedom: dialogically, phenomenologically, and discursively. Krause thus arrives at a liberalism open to difference, which is highly suggestive for the current discussion. Directed to humanity in its entirety, his philosophy considers - at the outset of the nineteenth century - issues such as the legal representation of unborn children, minors, the disabled, distantly living peoples, and future generations. While promoting global governance structures for the peaceful resolution of international conflicts, he stresses the importance of sustainable conservation and pleads for the complete elimination of any kind of religious, sexual, and racial discrimination. And all of this was at a time when, as is well known, the prevailing tone favored the sounds of nationalistic and sexist chauvinism.

Such - in 1800 extremely unusual - postulates are not merely prophecies of a consciousness mystically communing with the future. They can rather consistently be derived from the fundamental convictions of Krause's methodology. As we have seen, Kant had already drawn attention to the self-reflexivity of the idea of freedom (see Sect. 2.1.1). Kant had specified the idea of freedom by referring to itself as regards its content. Krause goes one step further and appropriates that reflexive way of thinking in regard to the method of philosophy as well. Krause wishes to involve all persons in the generation of the rules under which they live; wherever possible in a direct and participatory manner, and wherever this is (still) impossible, at least in an indirect and representative way. From this approach, Krause develops a global ethics of freedom, the potential of which has up to now in no way been exhausted.

The proximity of Krause's doctrine to arguments currently championed by the proponents of 'capability theory' is particularly striking. Krause likewise bemoans how social contract theories fail in the face of asymmetrical living conditions: Whenever certain stakeholders (children, women, the disabled, or even animals) are so placed that the consideration of their interests is not in the self-interest of a rational utility-maximizer, the contractualist construction threatens to collapse. Krause thus suggests a revision of its fundamental assumptions (legitimating societal solidarity by the means of a contract for the sake of a reciprocally beneficial utilityexchange), and thereby he anticipates the critique of contractualism championed today by Martha Nussbaum and Amartya Sen.

These points of contact cannot be investigated in detail here. Yet, in especially striking cases I will highlight these parallels by referring in the footnotes to corresponding claims within Martha Nussbaum's work. In addition to Krause's pronounced systematic proximity to the "capabilities approach," there may also have been historical lines of connection, on one hand, by means of Thomas Hill Green

Auseinandersetzung mit Fichte und Schelling (Stuttgart-Bad Cannstatt: Frommann-Holzboog, 2003). 
and Ernest Baker ${ }^{149}$ and, on the other, by means of Friedrich Fröbel and John
Dewey. ${ }^{150}$
In what follows, I first situate Krause's thinking within the philosophical context
of 1800 . I then discuss how his relational concept of personality and qualitative

${ }^{149}$ Amartya Sen studied in Cambridge (UK) in an environment influenced by Ernest Baker; Baker was a student of Thomas Hill Green. The latter - a leading authority in German Idealism - was not only essentially closely connected to Krause's ideas (for instance, in regard to his capability-orientated concept of freedom, his panentheistic metaphysics, and his conception of cosmopolitanism), but rather, incidentally, also explicitly referred to Krause (for instance to his definition of rights, as entitlements enabling freedom and the presuppositions of reasonable self-determination); see Peter P. Nicolson \& Richard Lewis Nettleship, Works of Thomas Hill Green (Bristol: Thoemmes) II, 341.

${ }^{150}$ In questions of pedagogy, Martha Nussbaum aligns herself with John Dewey (e.g. in Martha Nussbaum, Not for Profit: Why Democracy Needs the Humanities [Princeton, NJ: Princeton University Press, 2010], 18 \& 60), who, for his part, (in John Dewey, Democracy and Education: An Introduction to the Philosophy of Education [New York: Macmillan, 1929], 207) explicitly and emphatically refers to the work of Friedrich Fröbel. Fröbel, however, was in direct contact with Krause. For the relationship between Fröbel and Krause see P. Hohlfed, "Über Krause und Fröbel" in Die Neue Zeit 3 (1874), 161-182; L. Kurze, Die pädagogischen Gedanken Karl Christian Friedrich Krauses in ihrem Zusammenhang mit seiner Philosophie dargestellt (Langensalza, 1911), 138-145, K. Giel, "Unvorgreifliche Gedanken über die Beziehung zwischen Krause und Fröbel," in: Kodalle \& Hofgeismar (eds.) Karl Christian Friedrich Krause (1781-1832): Studien zu seiner Philosophie und zum Krausismo (Hamburg, 1985), 112-123, and especially E. M. Ureña, Philosophie und gesellschaftliche Praxis: Wirkungen der Philosophie K.C.F. Krauses in Deutschland (1833-1881) (Stuttgart-Bad Cannstatt: Frommann-Holzboog, 2001), 215ff.: Krause and Fröbel became acquainted because Krause responded to one of Fröbel's essays in the magazine Isis with good-natured criticism - good-natured in respect of its pedagogical content, and critically because Fröbel presented his educational ideals as 'German,' whereas Krause advocated 'human' Ideals. Subsequently, a correspondence took place which intensified when Fröbel began to read Krause's works. Fröbel then attempted to acquaint himself personally with Krause. A meeting occurred between both teachers and some of their students that was both personally and professionally positive: The schools began to cooperate closely. Krause's son-in-law, Leonhardi, who sought to increasingly involve himself in the field of Fröbel's projects (especially in the Fröbelschool in Keilhau), became an essential link (see ibid. 298ff.). A close collaboration arose (from 1872 onwards) in, e.g., the General Education Association (Allgemeinen Erziehungsverein). Another connection could be the principle of cyclical education promoted on the part of the Krausist Institución Libre de Enseñanza. Cyclical education, as understood by the Krausists, rejects the separation of content by age groups and the compartmentalization of the disciplines. Instead, its standard model of education seeks progress through penetrating topics in accordance with the students' respective advances, deepening their grasp of them with each cyclical reoccurrence of the subject, and through clustering topics so that they meet the vital needs of the students and their societal contexts, see L. Esteban Mateo, El Krausismo, la Institución Libre de Enseñanza $y$ Valencia (Valencia, 1990), 56ff. A cursory glance reveals that those pedagogical considerations are very similar to the program of a life-affirming cultivation enabling democratic self-determination that was followed by John Dewey (and supported by Martha Nussbausm). Francisco Querol Fernández also stresses (in La filosofia del derecho de K. Ch. F. Krause: con un apéndice sobre su Proyecto europeista [Madrid, 2000], 395) the demand for a life-long cultivation closely associated with Krausism. For information about the dissemination of these and other widely exported educational principles from Krause's philosophy by the Institución Libre de Enseñanza, see Francisco Garrido Dominguez, Francisco Giner de los Ríos: Creador de la Institución Libre de Enseñanza (Granada: Editorial Comares, 2001), 59-64. In what follows we shall provide more information about the political aspects of Krausist pedagogy. 
understanding of freedom motivated his adoption of a methodology fundamentally different from those of his philosophical contemporaries and associates. I go on to discuss the central positions of Krause's socio-political and economic philosophy and finally return to considerations concerning its relevance for current problems of globalization. Throughout this reconstruction examples will illustrate how his philosophy of freedom was influential in Spain and Latin-America.

\subsubsection{Reception, Context, and Method}

In many Spanish speaking countries, Krause's philosophy found its practical expression in the political movement of Krausism or krausismo, a liberalism aiming at social harmony. ${ }^{151}$ Over half a century, from the middle of the 1860s until its suppression by Franco in the middle of the 1930s, krausismo shaped the constitutional life and political culture of Spain. ${ }^{152}$ The same is true of Argentina and Uruguay, where, since the 1870s, whole generations of presidents were committed to the Krausist thinking - until, in the second half of the twentieth century, dictators took over power and suppressed any kind of liberalism. Immediately after the end of those dictatorships, the first democratically elected presidents of those countries and the parties supporting them again avowed Krause's intellectual heritage. This applies both to the Argentinian President, Raúl Alfonsin, and Argentinia's liberal party, Unión Cívica Radical (UCR), which was very popular during his time in office, as well as to the Battle family in Uruguay, which since produced several heads of state. ${ }^{153}$

Up until the 1990s it was believed that the programmatic publications of Krausism were original creations of Iberian culture. Enrique Menendes Ureña's textual analyses have shown, however, that the writings that Julian Sanz del Río (the father of Spanish Krausism) distributed to his people were - contrary to what he made them believe - nothing but cleverly arranged translations of Krause's original

\footnotetext{
${ }^{151}$ For more information about the Krausist concept of "harmonious liberalism" see Juan José GilCremades, "Die politische Dimension des Krausismo in Spanien" in Klaus Kodalle (ed.), Karl Christain Freidrich Krause (1781-1832): Studien zu seiner Philosophie und zum Krausismo (Hamburg: Meiner, 1985), 221-223.

${ }^{152}$ Nicolás Salmerón, president of the first Spanish republic is known to most people as "exponent de la penetración krausista en la vida pública," see, for example, JuanTerradillos Basoco, "El Institucionalismo y el Nuevo Enfoque de la Doctrina Penal" in López Álvarez (ed.), La Institución Libre de Enseñanza: su influencia en la cultura española (Cádiz: Ronda, 1996), 80. Carlos Otto Stoetzer indicates (in Karl Christian Friedrich Krause and his Influence in the Hispanic World [1998] 98) that not only Salmerón, but also the third president of the Spanish republic, Castelar, were Krausists, which had an effect on the Spanish constitution of 1869 (see Stoetzer, 104). For the Krausist influence upon the genesis of the first Spanish republic see C. A. M. Hennessy, The Federal Republic in Spain: Pi y Margall and the Federal Republican Movement, 1868-1874 (Oxford, 1962) \& John Brande Trend, The Origins of Modern Spain (Cambridge, 1934), 30-49.

${ }^{153}$ See Enrique Ureña, "Krause hoy" in Jorge O. Casella (ed.), Las ideas filosóficas que influyeron en la formación del Uruguay contemporáneo (Montevideo, 1988), 19-27.
} 
texts. ${ }^{154}$ A few years ago, Ureña also presented extensive and meticulously researched studies which set the record straight in regard to Krause's impact on his homeland (where he was widely regarded as a "vergessener Privatdozent"). Ureña could show that there was, in a manner of speaking, something like a German Krausism at the end of the nineteenth century. The view that, within Germany, Krause's work never found any resonance, should thus be corrected. ${ }^{155}$

Krause deserves particular attention in the context of the philosophy of freedom of the early nineteenth century. At that time numerous thinkers strove to apply Kant's theory of freedom to social questions. In the competition to be Kant's official successor, Fichte first took the lead, by surpassing many of his competitors by virtue of the systematic rigor of his approach. Krause, although he was deemed to be Fichte's best student, ${ }^{156}$ nevertheless chose to endorse this view. At the tender age of 22 , he published a legal philosophy, which, in its structure and content, as well as its title, competed with Fichte's Foundations of Natural Right. In his "Foundations of Natural Right" of 1803, Krause explicitly accused Fichte's philosophy of grave structural and theoretical deficiencies. ${ }^{157}$ This critique allows us to reconstruct how Krause broke away from Fichte's directive liberalism to bring his own participative liberalism into being.

Fichte's deductions, Krause complains, attempt "by illusory teleological proofs" (NR 236) to feign a concreteness which can only be attained by a philosophy which - unlike Fichte's - does not merely pretend to engage with people's lives and ideas. ${ }^{158}$ Krause wanted to rehabilitate the everyday world-view - and its typical

\footnotetext{
${ }^{154}$ See Ureña, K. C. F. Krause: Philosoph, Freimaurer, Weltbürger.

${ }^{155}$ See all of Ureña, Philosophie und gesellschaftliche Praxis.

${ }^{156}$ See Rafael V. Orden Jiménez, El Sistema de la filosofia de Krause: Génesis y desarrollo del panenteísmo (Madrid: UPCo, 1998), 41-56.

${ }^{157}$ For the textual history and intellectual background of this work, see Wolfgang Forster, Karl Christian Friedrich Krauses frühe Rechtsphilosophie und ihr geistesgeschichtlicher Hintergrund (Ebelsbach, 2000).

${ }^{158}$ Krause's writings are referenced by means of the following abbreviations: (AR): Abriss des Systemes der Philosophie des Rechtes oder des Naturrechts (Göttingen, 1828); (ERB): Der Erdrechtsbund an sich selbst und in seinem Verhältnisse zum Ganzen und zu allen Einzeltheilen des Menschheitlebens, Georg Mollat, ed. (Weimar, 1893); (EU): Entwurf eine europäischen Staatenbundes als Basis des allgemeinen Friedens und als rechtliches Mittel gegen jeden Angriff wider die innere und äußere Freiheit Europas (1814) H. Reichel, ed. (Leipzig, 1920) (original edition 1814); (G): Grundlage des Naturrechts, oder philosophischer Grundriss des Ideales des Rechts. Erste Abteilung (Jena, 1803); (G II) Grundlage des Naturrechts oder philosophischer Grundriss des Ideales des Rechts. Zweite Abtheilung, G. Mollat, ed. (Weimar, 1890); (GW): Vorlesungen über Grundwahrheiten der Wissenschaft, zugleich in ihrer Beziehung zu dem Leben. Nebst einer kurzen Darstellung und Würdigung der bisherigen Systeme der Philosophie, vornehmlich der neuesten von Kant, Fichte, Schelling und Hegel, und der Lehre Jacobi's. Für Gebildete aus allen Ständen (Göttingen, 1828); (K): Erklärende Bemerkungen und Erläuterungen [Kommentar] zu J. G. Fichte's Grundlage des Naturrechts, Georg Mollat, ed. (Leipzig, 1893); (LL): Lebenlehre oder Philosophie der Geschichte zur Begründung der Lebenkunstwissenschaft (Leipzig, 1904); (Nph): Anleitung zur Naturphilosophie. I. Deduction der Natur, II. Anleitung zur Construction der Natur (Jena \& Leipzig, 1804); (NR): Vorlesungen über Naturrecht oder Philosophie des Rechts und des Staates, R. Mucke, ed. (Leipzig, 1892); (SL): System der Sittenlehre. I. Versuch einer wis-
} 
assumption of an independent external world (K 5). Unlike Fichte, Krause does not identify a world to which one - among other things - relates oneself morally with a world that actually exists only insofar as we can relate to it thusly; a world that, abstracted from the purposes of human freedom, possesses neither meaning nor intrinsic value. To follow Fichte's views invites thus an irrevocable dualism between the reasonable (freedom) and the unreasonable (necessity).

According to Krause, what is missing here is a medium indifferent to reason; a medium of neither reasonable nor unreasonable, but rather of reasonably determinable sensibility. As a consequence, Fichte's conception cannot productively synthesize the ' $I$ ' with nature. Free life inevitably comes into opposition with nature, and one ends up with "precisely that erroneous view of nature as inhibition and obstruction, but not real life" (K 5). In such a theory, free activity in nature must degenerate into the demand for radical actualization of freedom against everything that is not yet reasonable - and thus also against nature. According to Krause, this is the origin of Fichte's philosophical transformation of nature into nothing but a dead "material of duty" (GA 1/5, 353; AD 25) as well as of Fichte's advocacy of the devaluation of animals and plants as in themselves worthless things, which is strongly criticized by Krause (GW 455).

Krause's objections to Fichte' theory of intersubjectivity have a similar focus. ${ }^{159}$ As we have seen (Sect. 2.2.1), Fichte at times advocated that, so as to not forfeit its claim to recognition, freedom qua reasonable freedom has to be demonstrated through thoroughly ethical conduct. According to Krause, however, the recognition of human dignity is something that is neither won nor lost (K 11). Hence the forever conditioned reciprocity of factual recognition cannot justify the basic right of all human beings to be recognized as moral and reasonable. Rather, the unconditioned right to be respected as a reasonable being justifies an absolute legal obligation (Rechtspflicht) towards general recognition. In direct opposition to Fichte, Krause thus demands: "Treat as a reasonable being also one who treats you as an unreasonable being, who does not respect your reasonableness." Even "if no one respected me, this would not mean that I am no longer duty bound towards respect in general, not even legally" (K $13 \mathrm{f}$ italics in the original).

Fichte's doctrine that the foundation of law is the symmetry and reciprocity of legal acts (Rechtsleistungen) is rejected in favor of a rehabilitation of "original

senschaftliche Begründung der Sittenlehre. Zweite, vermehrte und verbesserte Auflage, II. Abhandlungen und Einzelgedanken zur Sittenlehre, P. Hohlfeld \& A. Wünsche, eds. (Weimar, 1888); (Sysl/II): Vorlesungen zum System der Philosophie, Siegfried Plegerl, ed. (Breitenfurt, 1981) (original edition, Göttingen, 1828); (U): Das Urbild der Menschheit (Göttingen, 1851) (original edition, 1811); (VR): Das System der Rechtsphilosophie - Vorlesungen für Gebildete aus allen Ständen, K. A. D. Röder, ed. (1874). Das Urbild der Menscheit is available in English translation as: K. C. F. Krause, The Ideal of Humanity and Universal Federation, W. Hastie (Edinburgh, 1900).

${ }^{159}$ These objections do not affect Fichte's later theory of intersubjectivity. Since Krause had intimate knowledge of the Wissenschaftslehre nova methodo (today's text is based upon his lecture notes) - and employed a similar approach within his own theory of intersubjectivity - it should also not be assumed that they were Krause's target. 
rights" (Urrechte) of personality (K 29). Consequently, the freedoms owed to every human being do not result from reciprocal exchange or contract. One is not only (hypothetically) obligated to enable the freedom of all persons if and insofar as one can expect symmetrical acts in return (Gegenleistungen). ${ }^{160}$ There is rather a (categorical) duty to enable everyone's freedom, and this duty also extends to thoroughly asymmetrical relations (such as, for example, the rights of future generations or of people with disabilities). The social contract does not result from the quantitativelymaximizing calculation of otherwise disconnected individuals haggling for rights and advantages. Rather a qualitatively-optimizing logic of human fellowship grants to all persons the right to a self-determined life, and this also entails, according to Krause, the entitlement to commit themselves autonomously to social contracts. ${ }^{161}$

Fichte's doctrine, according to which only strict reciprocity can justify claims to rights is, incidentally, rejected by Krause, even in cases where exchange and contract theories (Tausch- und Vertragstheorien) are by their very nature particularly strong, namely, in the sphere of civil-law contracts. In no instance, according to Krause, does right arise from contract alone. It is rather the case that everyone's right to personality produces a right to enter contracts with others: And this is why it is not the arbitrary will of the parties which is the basis of rights, but, in the first place, human rights that provide the necessary basis for private legal autonomy:

The validity of law can therefore not originally be based upon some kind of contract since
every contract presupposes an arbitrary determination of the will. Choice (Willkür), how-
ever, is any determination of inner freedom which derives its determining grounds merely
from the willing person as individual person. Law rather first gives to the free will the
sphere of its choice and justifies it to move arbitrarily within its limits. For any contract to
have legal force one has to presuppose the existence of rights in and through the state in
order to enter into such a contract. In short, in the already established state it is possible to
enter into rightfully binding contracts [...]. It is therefore a deep and dangerous misunder-
standing to ground all rights, even the state, and all legally binding powers, upon contracts,
upon so-called fundamental contracts, which have no legal force beyond said choice".
(ERB 39f.)

Even contracts within the realm of civil law and the obligations accompanying them do not always come to an end, as Fichte believed, as soon as just one party does not comply with the contract in some way (K 37). That is, reciprocity creates concrete rights only insofar as it itself is already abstractly justified and legally authorized for it - an insight, by the way, which accords with today's juridical practices and productively contradicts the reconstructions of law and society prof-

\footnotetext{
${ }^{160}$ To see what the "capability approach" has to offer for the same topic see Martha Nussbaum, Frontiers of Justice, 393f., e.g. the following quote: "We do not have to win the respect of others by being productive. [...] Productivity is necessary, and even good; but it is not the main end of social life" (ibid., 160). The search for reciprocal advantage would simply be a "wrong account of the primary basis for social cooperation" (ibid., 129).

${ }^{161}$ Compare with Martha Nussbaum's claim that "we acknowledge, as well, that the kind of sociability that is fully human includes symmetrical relations, ... but also relations of more or less extreme asymmetry; we insist that the nonsymmetrical relations can still contain reciprocity and truly human functioning" (Frontiers of Justice, 160).
} 
fered by game theory and utility theory that dominated the end of the twentieth century (about which there is more in Chap. 3). ${ }^{162}$

In the same context of a rejection of the mechanistically-reciprocal justification of rights, Krause also attacks Fichte's theory of excessive self-defense. If people harm us but slightly, one may not maltreat them ad libitum, since their actions cannot extinguish the constitutive legal relationship between us and them (K38). On the whole, Krause rejects what he sees as Fichte's "unlawfully determined" criminal law, which recognizes a barbarous penal power that, upon illicit conduct, would rob human beings of their right to dignity and henceforth treat them like beasts (VR 116). ${ }^{163}$ Succinctly and powerfully, Krause notes:

The thesis is false, for its condition [i.e. that the other acts illicitly] is in no way the foundation of legal status (Rechtswürdigkeit), but this is rather the reasonable nature [i.e. of the other]. It is impossible that the latter be stripped off by a single illicit action [...]. Therefore, Fichte's positing of rigid consequences [Fichtes Konsequenzenmacherei] is unjust. (K 46)

For Krause, freedom is an upshot of humanity's "reasonable nature". On this foundation rests the unconditioned dignity of human life, which is - even for the respective persons themselves - inviolable. ${ }^{164}$ Consequently, universal "rights for world citizen" (Weltbürgerrechte) are to be proclaimed, which guarantee certain freedoms to all human beings, not based on their specific citizenship, but in virtue of their general personhood. Concerning those cosmopolitan rights, Krause writes:

They belong to me not insofar as I am a citizen of this particular region and state, but insofar as I am a citizen of the world. I can thus call them, together with the rights to my body, as the proximate condition of their attainment, my rights as a world-citizen [Weltbürger], and call my possession of them my cosmopolitan property [weltbürgerliches Eigentum]; they rank higher than any positive form of coercion and are indelibly etched into the legal constitution of the world [Gesetzbuch der Welt]. (G 28)

Since the idea of freedom is not only the highest content of his philosophy, but serves also as its ultimate methodological principle, Krause has no desire to present his philosophy of freedom as ready-made before the public. He rather aims for the active contribution of the public. If a philosophy of freedom is to be liberating, freedom's ends and means must harmonize. Philosophy's path has to foreshadow its goal. Krause does not want to persuade his readers rhetorically, but rather aims to convince them truly. This is why he constantly refers back to pre-philosophical attitudes and everyday sensibilities and integrates them into his train of thought. He searches for a theory that does not dismiss as unscientific humanity's everyday con-

\footnotetext{
${ }^{162}$ See also Martha Nussbaum's intensive critique of "contractualism" as such: "our dominant theories of social contract give us the wrong message. For centuries they have been giving us a defective story about why people get together to form a society" (Frontiers of Justice, 222f.); see also Creating Capabilities, 87.

${ }^{163}$ See Michael Köhler, "Zur Begründung des Rechtszwangs im Anschluss an Kant und Fichte," 118.

${ }^{164}$ Compare with Martha Nussbaum's claim that "the approach espouses a principle of each person as an end. [...] The approach, however, considers each person worthy of equal respect and regard, even if people don't always take that view about themselves" (Creating Capabilities, 35).
} 
cerns and world-views. The goal must rather be to understand, reconstruct, and address these more clearly and coherently than they themselves can; where that succeeds, people will heed philosophy gladly and voluntarily. For that reason, Krause's focuses upon dialogical argumentation, comprehensible thoughtexperiments, and a theory formation - open to falsification - open to empirically testing its explanatory power. In short, he focuses upon methods which only later became widely adopted in academic philosophy. ${ }^{165}$

From 1803 onwards, there are therefore two strands to his philosophy. He develops his theory by means of a continually self-critical engagement between analytic and synthetic observations, which meadiates between scholarly ideas and everyday worldviews. The indispensable conceptual constructions serving all theoryformation should combine intellectual speculation and experience in a process of thinking in which "the deduction and the intuition of the object, as though holding hands, proceed together side-by-side into the depths" (SysIP 336). ${ }^{166}$ Two things are thereby avoided: The lack of contact with reality of those solely deductive methods which retreat into merely formal and conceptual worlds on the one hand, and the unimaginative blindness of purely inductive approaches and the analytical opaqueness of merely intuitive approaches on the other (SysIP 334f). In marked contrast to the speculative philosophies of the time, Krause makes clear that it is in no way as though "the constructing philosopher wishes to masquerade as the Creator; [...] or [that] the philosophizing spirit [Geist] ventures to scientifically deduce, demonstrate, and construct, as such, the infinitely determined temporal individuality of things" (SysIP 337). A philosophical construction should rather only be the link uniting the given intuitions, inductions, and deductions, which are required for this reciprocal critique and integration into a universal theory. Such construction, consequently, does not rest upon a mystical power of intuition or representation inaccessible to ordinary people.

Krause's philosophy thus contains presuppositions which enable it itself to be critically surpassed. The conceptual constructions of his philosophy result from free, creative mental activity (Geistestätigkeit): without blueprints and guarantees of success. Krause expressly underlines the capacity for error and revision of all philosophical speculation. Only thus can one avoid a philosophy like that of his teacher Fichte, which in extracting results from erroneous premises immunizes itself against any critique, only to fail all the more dramatically the more consistently it proceeds (SysIP 335f).

For this reason, too, Krause turns to his readers. In the light of their experience and insights, he examines, time and again, his constructions. While the German Idealists sometimes took to the lofty heights of a "transcendental" or "absolute consciousness" and, from this perspective, rebuffed the protestations of the "mundane" and "blind" consciousness of ordinary people as per se intellectually unsatisfactory, Krause takes them seriously. Although, Krause does not automati-

\footnotetext{
${ }^{165}$ For more detailed information about this see Dierksmeier, Der absolute Grund des Rechts, Chapter IV.

${ }^{166}$ See ibid., $322 \mathrm{ff}$.
} 
cally regard every critique as justified, he nevertheless takes up each objection and always tries to do justice to the concerns it conveys. No reasonable critique, he believes, can be completely off the mark; this is why their respectively applicable aspects must be recognized and acknowledged first. Only subsequently may one then proceed to a theory that integrates and surpasses these objections. ${ }^{167}$

Krause's theoretical philosophy takes a didactic path designed as a discourse that gradually leads his readers from their respective knowledge and level of insight to the requisite synthetically speculative topics of metaphysics. In his practical philosophy, that analytical approach develops out of the prevalent moral convictions of his contemporary citizens. Krause accepts their reservations as an indication that his philosophical constructions are yet imperfectly explained or still in need of revision (Nph 84). In this way, in Krause, the public is transferred from a passive object of philosophy into an actively participating subject. And just as with the establishment of truth in theoretical philosophy, Krause also involves the public within practical philosophy: By integrating their actual conceptions of freedom into the procedures of ethical argumentation.

\subsubsection{The Freedom of Nature and of Humanity}

In the philosophy of the nineteenth century, nature is often reduced to a mere object of human activity. Krause however looks for human freedom not so much in independence from, but rather in interdependency with, its environment. Human beings ultimately develop themselves and their freedom, not only in abstraction from their biological and social contexts, but rather mostly in and through them. ${ }^{168}$ Human beings live in and out of relations to their shared environment and posterity (Um-, Mit- und Nachwelt). From this relational understanding of the person there results a sustainability-orientated concept of freedom. Clearly, human beings must maintain the natural preconditions of their life if - in using their freedom - they do not want to negate its preconditions (VR 58). Since human freedom always depends on a context, every enlightened thinker will demand the "protection, maintenance and support of nature" (NR 135). Furthermore, Krause reasons that nature ought to be grasped according to its own laws and "in its inner freedom and absoluteness" (Nph 82).

Krause incorporates into his philosophy ontologically, as well as ethically, the degrees of freedom realized within all living beings, i.e. their self-organizing

\footnotetext{
${ }^{167}$ For more information about the development of Krause's philosophical system in reaction to Fichte's metaphysics see also Stefan Groß, Die Philosophie Karl Christian Friedrich Krauses im Kontext des Deutschen Idealismus: Vom Bild des Absoluten Krauses Lehre vom Göttlichen und Fichtes Wissenschaftslehre von 1804 (Berlin: Peter Lang, 2010).

${ }^{168}$ Compare with Martha Nussbaum's claim that "we insist that need and capacity, rationality and animality, are thoroughly interwoven, and that the dignity of the human being is the dignity of a needy enmattered being" (Frontiers of Justice, 278).
} 
capacities, ${ }^{169}$ and thereby departs from the trend of his time towards an anthropocentric devaluation of nature (ERB 36). ${ }^{170}$ Yet he does not lapse into the other extreme of biocentric thinking, but rather argues anthroporelationally: It is necessary to convey to the human consciousness, according to its categories, all natural boundaries it ought to recognize. ${ }^{171}$ Precisely this mediated conveyance is imperative, because nature does not immediately reveal its internal structures of intrinsic values at first glance.

In order to situate ourselves within nature as adequately as possible, we should strive to understand nature according to its own laws and strivings. Nevertheless, man, being situated within nature, cannot attain a God's-eye view. Nature must therefore be reflected upon in a twofold way: From the human perspective, and also with a critical glance upon this perspective. We are to recognize each living being as something not designed for mankind but living according to its own freedom (ERB 45), while also keeping in mind that, as far as we know, the human being is the only creature on earth aiming to evaluate accurately this intrinsic value of nature (ERB 36). ${ }^{172}$ That nature's intrinsic value (i.e. independent of our consciousness) cannot be assessed by anything other than our consciousness hinders the immediate derivation of normative commandments from facts. Biological facts can at times constrain, but never obligate us. ${ }^{173}$ For this reason, biocentric theories - be their motives as noble as those within the deep ecology movement or as ignoble as those of social Darwinism (survival of the fittest) - cannot claim immediate moral validity. Diagnoses are insufficient; we require valuations. ${ }^{174}$ Krause thereby questions that position which later on, since the time of George Edward Moore (1873-1958), has been called the naturalistic fallacy. ${ }^{175}$

Conversely, we must also not commit the obverse normative fallacy of teleologically ascribing moral purposes to nature (VR 104). Krause likewise strongly opposes the tendency, found within Antiquity and throughout the Middle Ages up until eighteenth century scholasticism, which metaphysically inscribed the respectively favored good as a supposedly inherent striving within the essence of human life. In

\footnotetext{
${ }^{169}$ Compare this with Martha Nussbaum's claim that "what is relevant to the harm of diminishing freedom is a capacity for freedom or autonomy. It would make no sense to complain that a worm is being deprived of autonomy, or a rabbit of the right to vote" (Frontiers of Justice, 360).

${ }^{170}$ Ernst Bloch even speaks of an "abolition of nature in German Idealist Natural Law" in "Naturrecht und menschliche Würde," 91 (see also ibid. 86).

${ }^{171}$ For Martha Nussbaum's position on this see Creating Capabilities, 161.

${ }^{172}$ See the similarly anthroporelational ethic of Martha Nussbaum in Frontiers of Justice, 355.

${ }^{173}$ A similar argument can be found in Otfried Höffe, "Naturrecht ohne naturalistischen Fehlschluss" in Höffe (ed.), Den Staat braucht auch ein Volk von Teufeln: Philosophische Versuche zur Rechtsund Staatsethik (Stuttgart, 1988), 35.

${ }^{174}$ Compare with Martha Nussbaum's claim that "the Capability Approach is not a theory of what human nature is, and it does not read norms off from innate human nature. Instead it is evaluative and ethical from the start" (Creating Capabilities, 28).

${ }^{175}$ See $\$ 12$ in George Edward Wisser Burkhard Moore, Principia Ethica (New York: Barnes \& Noble, 2005) and, for more detail, see William K Frankena, “The Naturalistic Fallacy," Mind 48 (1939), 464-477.
} 
searching for ethical norms, one cannot avoid the self-critical spirit of humanity and its freedom. ${ }^{176}$

The values and aims of freedom are not arbitrary, however. Whoever emphasizes freedom within ethics does not necessarily reduce morality to the contingent collusion between contractual parties negotiating their liberties, just as if human decision alone confers value upon the world. From the indispensability of human freedom for moral values it neither follows that freedom alone presents a good to be respected, nor, conversely, that our freedom is diminished only in respect to the values it facilitates. If, that is to say, freedom fulfills itself in the effort to relate properly to its world and contexts, then the construction of the inherent value of the natural environment may be neither arbitrary, partisan, nor unfree. A daunting task for philosophical construction.

Krause takes up this challenge by presenting and discussing different levels of freedom and consciousness of freedom in nature as a criterion for the relevance of non-human interests. Specifically, he distinguishes "three essentially different levels of finite reasonable personality" and the grades of freedom belonging to each (VR 245). The lowest form of freedom describes individuals whose self-direction is merely physical. The next level incorporates persons, whose behavior is orientated mentally but is only (pragmatically) rational (verständig) and not also (morally) reasonable (vernünftig), i.e. whose acts are only conditionally motivated and not based upon unconditional reasons. The third level of freedom describes those who, in addition, become self-conscious in a reflexively philosophical manner and from this standpoint critically evaluate their preferences. "As to these three levels of reasonableness, we find all three of them presented in certain ways by the human beings upon this earth" (VR 245).

In this way, Krause anticipated Ernst Häckel's (1834-1919) globally influential thesis of the recapitulation of the development of species (phylogeny) in the development of the individual (ontogeny): Every human being initially repeats in his personal development "certain periods" of vegetative and animalistic life (LL 18), within which he nevertheless would only remain as a result of a lack of education or disability. For most of their lives, most human beings act according to the second level of consciousness of freedom, i.e. in the mode of self-assertive finality. To a human being in the full sense there potentially belongs, however, also that highest level of consciousness - self-critical freedom - as well as, actually, a more or less conscious striving towards it.

The essential difference between animal and human being lies in the human I's ability to recognize itself as integrated by self-transcending rules and norms to which it is knowingly and willingly bound. Animals are not capable of that, since "they determine themselves only according to sensory finite impulses and not according to eternally infinite concepts [...]" (VR 172). Within "the sphere of our experience" we thus rightfully see the human being as the only form of life (LL 115) to whom belongs freedom in the all-embracing sense and, consequently, also a par-

\footnotetext{
${ }^{176}$ For the present state of the discussion see Hilary Putnam, Ethics without Ontology (Cambridge, MA: Harvard, 2004), 75.
} 
ticular responsibility as well as a certain ethical primacy (ASys 183). ${ }^{177}$ Krause hence neither endorses a biocentric view, seeing animals and human beings on one and the same level, nor an anthropocentric devaluation of all non-human life as mere stuff for arbitrary human use.

The special position of the human being in contrast to plants and animals is not grounded upon actual mental accomplishments. In contrast, Krause thinks, that often on the phenomenal level there is not such a huge difference between intelligent animals and human beings who (want to or must) live reduced to the realm of sensuality. What counts for the differentiation in species is rather the potential form of reflexive self-determination: An ethical freedom, to which only human beings (can) develop towards within the course of their lives. Humans and animals are not only gradually differentiated from one another, they differ also categorically. They are divided by precisely that difference which runs between purely technical ratiocination (which is environmentally conditioned and only free within limits) and moral reasoning (which is unconditionally free) (NR 136). And this constitutes a difference "in their entire essence" (LL 338). Unlike animals, mentally and/or physically limited human beings are reflectively-autonomous beings; their disability certainly inhibits the articulation of their human nature, but this does not signify a privation of it (LL 172). ${ }^{178}$

Hence, for Krause, disability in no way entails a loss of human dignity (VR 247). In this way, too, Krause represents a turning point within modern thinking. While numerous philosophers of the early nineteenth century demoted people with disabilities to a mere article of Sozialhygiene, for Krause, the disabled are never merely passive objects of law, but rather always active subjects with inextricable dignity. ${ }^{179}$ To enjoy humane freedom is the right of all human beings "however deformed and deficient, however stunted, however mentally or physically ill, however immersed in misery" they may be (LL 180). For the sake of their human dignity, society is

\footnotetext{
${ }^{177}$ Compare with Martha Nussbaum's claim that "The species norm is evaluative, as I have insisted; it does not simply read off norms from the way nature actually is. But once we have judged that a capability is essential for a life with human dignity, we have a very strong moral reason for promoting its flourishing and removing obstacles to it. The same attitude to natural powers that guides the approach in the case of human beings guides it in the case of other animals" (Frontiers of Justice, 347).

178 "A child with severe mental impairments is actually very different from a chimpanzee, though in certain respects some of her capacities may be comparable. Her life is lived as a member of the human community and not some other community; it is there that she will either flourish or not flourish. The possibilities of flourishing in that community are defined around species norms. [...] the fact, that their disabilities create impediments to species-typical ways of flourishing creates a moral imperative for society: such impediments should be treated and cured, where possible, even if the treatment is expensive" (Frontiers of Justice, 363f.).

${ }^{179}$ Compare this with Martha Nussbaum's claim that "a focus on dignity is quite different, for example, from a focus on satisfaction. Think about debates concerning education for people with severe cognitive disabilities. It certainly seems possible that satisfaction, for many such people, could be produced without education. [...] A focus on dignity will dictate policies that protect and support agency, rather than choices that infantilize people and treat them as passive recipients of benefit" (Creating Capabilities, 30).
} 
obligated to respect and care for disabled persons (G II, 189). ${ }^{180}$ The disabled have an entitlement to expect that others, i.e. the state, will help them make the best possible use of their freedom (G II 189). ${ }^{181}$

This entitlement to social support is not conditioned by returns. It belongs to the dignity of all human beings that their rights be unconditionally granted to them.

Insofar as the individual citizen is affected by one or more unavoidable limitations in body and soul, he can be incapable of naturally fulfilling some legitimate requirements or become incapable of this within the course of his life. To these belong those who are born without genius, those born blind, those born deaf and dumb, those who are naturally weak etc., as well as those who are weakened by sickness or mechanical damage to body or spirit or both. Now because, as is proven, the possession of the rights that are supposed to be awarded to him are in no way originally legally founded upon what he does in return, they are rather established by the constantly available demands of reason, so can the same unfortunate [person] [...] in no respect be or become legally incapacitated as a result of his misfortune. (G II 149)

By way of legal representation, society advocates that rights should also be enjoyed by individuals who do not (or are unable to) demand them. ${ }^{182}$ For this purpose, Krause promulgates a universal legal guardianship of humanity for all individuals. Instead of disenfranchising certain individuals or groups, this concept conversely serves as protection against creeping disenfranchisement (such as, of the child by the parents, the wife by the husband, the disabled by the healthy, of the uneducated by the educated, etc.). In contrast to many thinkers before him, Krause does not draw on factual dependency in order to legitimate legal dependency, but conversely forges - from the legal equality of all persons - an argument for the quickest possible improvement of degrading forms of life.

This legal guardianship, however, should - as much and as soon as possible render itself superfluous (VR 459). Representation is to be exercised in this emancipatory sense alone. Inasmuch as, for instance, a child can adequately handle its own freedom, it should no longer be kept in tutelage (bevormundet); the same is true, mutatis mutandis, of people with disabilities who always only partially, and never totally, fall under the management, care, and legal representation of others (VR 458f). Liberation towards autonomy is both the legitimation and limitation of all representation (NR 155).

Autonomy is also the guiding theme of Krause's treatment of the difference between the sexes, which, Krause declares, is anyway much exaggerated. But inso-

\footnotetext{
${ }^{180}$ Francisco Garrido shows that these Krausist ideas entered Spanish legal theory by means of F. Giner de los Rios' philosophy of law - the fundamental equality of the right to dignity of all human beings was explicitly extended to the "loco" and the "feto." See F. Garrido, Francisco Giner de los Ríos. Creador de la Institución Libre de Enseñanza (Granada, 2001) 88.

${ }^{181}$ Compare with Martha Nussbaum's claim that "we should bear in mind that any child born into a species has the dignity relevant to that species whether or not it seems to have the "basic capabilities" relevant to that species. For that reason, it should also have all the capabilities relevant to the species, either individually or through guardianship" (Frontiers of Justice, 347).

${ }^{182}$ See also James Lorimer (ed.), The Institutes of Law: A Treatise on the Principles of Jurisprudence as Determined by Nature (Edinburgh, 1872), 308.
} 
far as it actually exists, it in no way annuls "the universal human equality, rather it is only a further determination of it" (VR 471). Sexual differences can specify the universal human rights of women and men in respect of their implementation, but not reduce or violate them. Completely against the spirit of his time and society, Krause thus defends the rights of women in fiery words:

In contradiction to all spiritual, physical, and human empirical knowledge and history they wanted to claim that, spiritually and physically, the woman occupies a lower level of development, that women are only incomplete men [...]. Similarly averse to the nature and vocation of the human being is the claim that the whole vocation of woman is exhausted by her role as a mother and that the female half of mankind are not destined to participate in public life. The sexual function and its ethical and legal consequences (looking after the children and the household) annul neither for the man nor for the woman the demand for and the possibility of universally humane education and a satisfying career (in all aspects of the human vocation). And that which especially concerns the procreation, care, and upbringing of children is something that both sexes essentially and necessarily equally possess and, as the similarity of the bond with the children already shows, they possess the same intimate role and thus, as reasonable beings, an equally justified obligation, although the mother possesses the special duty towards the first nutrition and closest physical care in the womb and after birth. The whole life of the woman in itself must therefore, also in view of rights, be so determined that she can fulfill this duty which is only hers to fulfill [...]. (NR 272f)

Concerning the entire societal life and the participation in intellectual and material goods, Krause demands equal rights for both sexes. ${ }^{183}$ At the same time he advocates specific rules for the protection of mothers. ${ }^{184}$ Krause thus creates legal inequalities in order to enforce the fundamental equality of rights to autonomy in view of diverging conditions of its realization. ${ }^{185}$

The extent of Krause's originality at that time is also shown by his advocacy of an autonomous sexuality which may not be reduced to the reproductive function (ERB 138), in direct opposition to his contemporaries, Johann Gottlieb Fichte and Georg Wilhelm Hegel, who were completely impervious to ideas of sexual independence or any kind of legal emancipation of woman (see $\S 16$ of Fichte's Foundations of Natural Right and $\S 166$ of Hegel's Philosophy of Right). Krause’s

\footnotetext{
${ }^{183}$ For information about the influence of the women's rights advocate, Angelina Carnicer, and the Krausist "feminismo" see L. Esteban Mateo, El Krausismo, la Institución Libre de Enseñanza y Valencia (Valencia, 1990), 103ff. See ibid., 126ff for information about the Krausist Institución para la enseñanza de la mujer in Valencia, which prepared the adjustment of the educational differences between men and women in order to bring about concrete equal opportunities. See E. M. Ureña, "Algunas consequencias del panenteismo krausista: ecología y mujer" in El Basilisco, Segunda Epoca, 3:4 (1990), 51-58.

${ }^{184}$ See Christine Susanne Rabe, Gleichwertigkeit von Mann und Frau: Die Krause-Schule und die bürgerliche Frauenbewegung im 19. Jahrhundert (Böhlau Verlag: Köln Weimar, 2006).

${ }^{185}$ See also F. Querol Fernández: La filosofía del derecho de K. Ch. F. Krause, a.a.O.,S. 317. Similar contemporary arguments can be found in Susan Moller Okin \& Jane J. Mansbridge, Feminism (Aldershot \& Brookfield, 1994). Martha Nussbaum also argues that treating everyone schematically equally "proves an ally of the status quo. In order to put women and men in a similar position with respect to educational opportunity in a society that strongly devalues female education, we will have to spend more on female education than on male education" (Creating Capabilities, 57).
} 
remarks about the protection of the rights of underage children, ${ }^{186}$ whose freedom and dignity, if in doubt, must be defended against even their parents (G II 189), also far surpasses the horizon of his contemporaries. The family is subjected to the laws of society and is also controlled by it - especially with regard to the education of children. For a comparison one need only glance at the starkly illiberal views of Fichte ( $\$ 44 f$. of his Foundations of Natural Right) and Hegel ( $\$ 175$ of his Philosophy of Right). While the philosophy of his time callously declared children the property of their parents and wives the property of their husbands and - completely or partially - deprived them of their own rights to freedom, Krause campaigned for their autonomy.

Krause's theory of human sociality correlates the societal norms with grades of freedom. The various levels of maturity, which human freedom moves through, involve various forms of responsibility (LL 127ff.). ${ }^{187}$ Individual life begins with "sensory freedom," which takes its cues from context, follows habits, and customs (VR 441). On a next level of "rational freedom [verständiger Freiheit]" individuals set about making themselves more independent of their contexts - specifically through rational abstraction, and, for instance, emphasize their subjective characteristics in contradistinction to society (ibid.). That intellectual freedom leads to the productive liberation of individual capacities and energies, but - exclusively exerted - also to one-sidedness and isolation. It is rectified by a "reasonable freedom [vernünftige Freiheit]" (ibid). This highest level of freedom enables forms of coexistence surpassing connections concerning mere needs and interests by uniting human beings in the name of ethical aims (ibid.).

In the right to freedom lies the philosophical foundation of human rights. These are treated by Krause as subcategories of a more universal theory of personal rights, and thus not limited to, though exemplified by, homo sapiens. Life's essential grades of freedom are the main criterion. Plants, for instance, represent a form of unconscious life, which, internally as well as externally, certainly exhibits functional selforganization in space and time, but not conscious self-reflection. Yet the idea of freedom requires conscious life, and thus only comes into existence when an entity knows about itself and its environment. Plants are therefore not subjects of a freedom-oriented ethics, but only its objects. ${ }^{188}$ Hence biocentric theories propounding the ethical equality of human life with plant life cannot find support in Krause.

Yet, at the same time, Krause does not argue anthropocentrically, as his animal ethics show. All animals represent forms of conscious life. Some animals, moreover, possess more highly developed forms of self-conscious life and personality. ${ }^{189}$

\footnotetext{
${ }^{186}$ See Querol Fernández, La filosofía del derecho de K. Ch. F. Krause, 178-183.

${ }^{187}$ Krause's remarks in this connection anticipate the discoveries of Piaget and Kohlberg in their empirical investigations into the development of the moral consciousness of adolescents (see Lawrence Kohlberg, Child Psychology and Childhood Education: A Cognitive-Developmental View (New York: Longman, 1987).

${ }^{188}$ See Martha Nussbaum, Creating Capabilities, $158 \mathrm{f}$.

${ }^{189}$ In the same way Capability Theories define "animals as agents, not receptacles of pleasure or pain" (Creating Capabilities, 160).
} 
Krause declares that such animals hold a rank of particular relevance for an ontology of freedom, "because we assume that they know themselves in certain ways, sense themselves, and strive to maintain and perfect their selfhood according to sensory ends" (VR 172). A glance at our own pets, teaches us for example:

that these beings show all those idiosyncrasies which express the lowest level of the spiritual personality; they feel themselves, feel pleasure and pain, they have representations and fantasy, as is well known they determine themselves according to social concepts, since within various individuals of the same species they nevertheless recognize the same species, e.g. just as every man distinguishes himself as man, so every animal accordingly discerns its own species. They are therefore intellectual beings [geistige Wesen] [...]. (VR 246)

While the majority of the thinkers of his era thought anthropocentrically, viewing animals merely as instinctively driven automata and thus as mere things conveniently at hand for human purposes, Krause expressly recognizes animals as free beings. ${ }^{190}$ Because of their capacity for self-determination, Krause categorizes them as persons ${ }^{191}$ - and makes a plea for their protection; a position, which, in the historiography of animal ethics, still waits for its proper recognition. ${ }^{192}$

\footnotetext{
${ }^{190}$ In this way, also, Krause's position foreshadows Martha Nussbaum's, which likewise recognizes not only human beings, but rather "a wider range of types of beings who can be free" (Frontiers of Justice, 88).

191 "Right exists without regard to the person. No person has a privilege (no one anticipates the right of another), but every person has his or her right. This is just as true ... of the simplest (qui capere valet, capiat!) animals" (NR 114).

${ }^{192}$ In Krause's time there were certainly isolated ethical reflections on animals (for an overview see: Aaron Garrett, et al., Animal Rights and Soul in the 18th Century [Bristol \& Sterling, 2000]): The following authors, for instance, argue in favor of animal rights, or more precisely, the rightful duties of man to animals: Humphry Primatt, in A Dissertation on the Duty of Mercy and Sin of Cruelty to Brute Animals (London, 1776) argues with the golden rule, starting out from the animal's capacity for suffering: Wilhelm Dietlar (in: Gerechtigkeit gegen Tiere [Mainz: Schiller, 1787]) on the basis of an ontology of happiness for all life forms; Johann Georg Heinrich Feder (in "Über die Rechte der Menschen in Ansehung der unvernünftigen Tiere" in Neues hannovrisches Magazin 2 [1792], 945-960) based on a theory of perfection; and Lauritz Smith, Über die Natur und Bestimmung der Tiere wie auch von den Pflichten der Menschen gegen die Tiere (Copenhagen, 1790), with creationist theology. They also surpassed the characteristic style typical of their era, which merely limits, to some extent, human action towards animals out of an aversion towards cruelty. Nevertheless, it is only Krause who manages to integrate questions of animal ethics systematically into the modern philosophy of freedom (which was already noted at the end of the nineteenth-century by Ignaz Bregenzer in Thier-Ethik: Darstellung der sittlichen und rechtlichen Beziehungen zwischen Mensch und Thier [Bamberg 1894], 208). Krause's approach is phenomenologically more convincing than those theories interested merely in animals' capacity for suffering. His position portrays animals not only as passively capable of suffering, but also as actively capable of freedom, and in this way it also very much resembles the Capability Theories of today; compare the following observation of Martha Nussbaum that, "mere sentience is too simple a focus: it neglects the variety of animal capacities and activities, and thus certain areas of damage to flourishing that do not register as pain." For this reason, "uncritical nature-worship" is out of place and, and rather a "valuational exercise" is demanded (Frontiers of Justice, 94). Whoever today reaches back to Jeremy Bentham (cue: "capacity for suffering") and Arthur Schopenhauer ("animals are not things") for progenitors of current reflections on animal rights (see, for instance, Tom Regan, Animal Rights and Human Objections [Englewood Cliffs: New Jersey, 1989]) should therefore definitely enlist Krause in the trajectory of precursors.
} 
Yet, as we have seen, Krause does not view animals as on the same level with human life. Fully developed human beings are capable of reflexively orientating their basic faculties, i.e. they are capable of feeling their feelings, willing their willing, thinking their thinking, but also, feeling their thinking, willing their feeling, and reasoning their willing. By means of these reflexive faculties human beings are able autonomously to criticize and direct themselves (LL 115ff.). Unlike human beings, animals are, as far as we know, incapable of such self-reflective freedom and the genuinely ethical finality this enables (NR 149f.); therefore, they are deprived of such rights that specifically shape this third level of freedom.

\section{As soon as one considers the animal as a self-inward being possessing self-consciousness and self-feeling, one demands that man should also be just towards animals. But no one will talk about an animal justice which animals themselves practice. That is because one does not consider the animal capable of grasping the idea of justice in order to make justice its end. Thus one says: Man should be the guardian of all animals and man considers the entire animal kingdom as in need of legal reprensentation [unmündig] and rightly so. (VR 205)}

It is thus not because animals cannot themselves demand their rights - also children, minors, and the mentally ill are often unable to do so (NR 149f) - but because they ontologically exist upon a lower level of freedom that they have a different axiological ranking. Animals and humans possess different rights. Yet their rights are not any weaker. They belong directly to animals with the same binding force as human rights belong to human beings. Just as much as human rights, animal rights are unconditional. Just as little as human beings, do animals have to work for their specific rights; no reciprocity of rightful commissions and omissions is called for. ${ }^{193}$ Just as with human beings whose autonomy is limited (such as children, disabled and senile persons) a legal guardianship is thus to be applied to animals, so that "the temporally-free conditions of the completion of their purely animalistic life are guaranteed" (VR 246). Animals possess the right to a self-determined life insofar as they (unlike predators at times) do not violate the higher level, i.e. human rights (NR 136f). ${ }^{194}$

That which humans as the representatives of the highest degree of freedom and autonomy on earth may enforce upon others of the same standing, e.g. the elimination of unlawful violence, may also be enforced upon every being belonging to a lower level of freedom. If we are allowed to limit our shared environs - by enforceable laws - for the protection of everyone's freedom, then we are also allowed to limit that of animals insofar as their rightful interests are respected. If humans may industrially utilize their own organic waste products (hair, nails, etc.), then they may

\footnotetext{
${ }^{193}$ Today Martha Nussbaum makes similar arguments, see FJ 354-365.

${ }^{194}$ The right of animals to constitute themselves was also recognized in 1892 by Henry S. Salt in Animals' Rights Considered in Relation to Social Progress (1892) [New edition: London, 1980]. Like Krause, Salt also recognizes in the moral law the legitimate limit of animal behavior (to be enforced by humanity); so that a guardianship of humans over animals has to be realized (ibid., 46). However, Salt's position is based upon an implicit "anima" metaphysics which moves every natural kind (also flowers and crystals) into a position equal to the one of humanity in a quasicontractualist position; see Andreas Flury, Der moralische Status der Tiere: Henry Salt, Peter Singer und Tom Regan (Freiburg im Breisgau, 1999), 96ff.
} 
do the same with animal resources. ${ }^{195}$ Krause also thinks that it may be possible to use animal labor "for reasonable purposes" and thereby curtail the animals' natural freedom of movement (NR 137). Such a use does not automatically impinge upon the respective animal's right to freedom if it serves acceptable ends and does not distress the animal (VR 246), as we are wont to make similar use of human labor. ${ }^{196}$

More far-reaching rights are, however, problematic. May humans, who do not kill one another for the purpose of nourishment, eat animals? Only insofar, states Krause, as "without such killing humanity on earth could not exist, unless some other kind of nourishment were found" (LL 300n.). This theory does not provide a justification for the industrial exploitation of animals for gourmet purposes. For Krause believes that the justifying condition, i.e. that otherwise human life could not be guaranteed, only rarely occurs. Most people, after all, would have access to vegetarian food of adequate quantity and quality. And to destroy animal life without need cannot, according to Krause's theory, be justified at all, since one thus negates the natural freedom of animals without good reason.

Although Krause claims that animals "have a right to bodily well-being, to absence of pain, and to the requisite nutrition" (VR 246) he does not advocate that it is incumbent on humanity to assure a comfortable existence for all living beings of this earth. As a general rule, animals are quite capable themselves to take care of their own welfare, to obtain their own food, and avoid pain, etc. - They thus realize their natural rights as a result of their own capabilities and freedom. But human interference with the animal biospheres requires due diligence (LL 117). ${ }^{197}$ If one takes animals out of their original habitat, or limits it, and so impairs their capacity for self-care, then a duty to species-appropriate behavior and nutrition follows hot on the heels (NR 136n.). ${ }^{198}$ This conclusion, Krause optimistically believes, would concur with a pervasive "feeling favoring justice for animals," which "cannot be eradicated" from the human mind (NR 137).

\footnotetext{
${ }^{195}$ Martha Nussbaum brings up similar ideas in connection with education and cultivation: "A good education is sensitive to the individuality of the child, and is not rigid and above all not cruel or humiliating, but it does have goals and standards, and exacting through respectful discipline is often appropriate in leading children toward those goals. Why should we think differently about non-human animals?" (Frontiers of Justice, 377)

${ }^{196}$ Also see here Martha Nussbaum: "The analogue to work rights is the right of laboring animals to dignified and respectful labor conditions" (Frontiers of Justice, 400).

${ }^{197}$ Compare with Martha Nussbaum's claim that "large numbers of animals live under human's direct control: domestic animals, farm animals, and those members of wild species that are in zoos or other forms of captivity. Humans have direct responsibility for the nutrition and health care of these animals [...]. Animals in the "wild" appear to go their way unaffected by human beings. But of course that can hardly be so in many cases in today's world. Human beings pervasively affect the habitats of animals, [and] our pervasive involvement with the conditions of animal flourishing gives us such responsibilities now" (Frontiers of Justice, 373f.)

${ }^{198}$ Compare with Martha Nussbaum's claim that "As for the idea that we should leave animals alone when they live in "the wild," this naively romantic naturalism ought to be rejected for today's world. There is no habitat that is not pervasively affected by human action" (Creating Capabilities, 162).
} 
In dealing with animal persons as well as human persons, the aim is the same: To guarantee an optimum of freedom through lawful representation and protection. For both humans and animals, this implies a facilitation of the requisite space and opportunities for free individuation. With regard to human social relations, Krause, therefore, highly appreciates how the differentiation of modern society allows individuals to realize personal talents and preferences so as to play a part in society in their own unique way. But whoever supports the functional differentiation of society must also promote the sectorial specialization of ethics. A diversified society can no longer be directed by an ethic wholly alike for everyone and remaining the same for all times; it rather has to open itself up to regionally, professionally, culturally, and personally diverging representations of the good. The ethic of freedom is then to be so structured that it becomes receptive and adjusted to the peculiar logics of different societal subsystems.

A liberal society therefore cannot derive laws from a far-reaching metaphysics of the good, but rather justifies legal norms in and for themselves so that these enable human beings - all human beings - to strive for the good in their own way. Accordingly, Krause distinguishes, for example, an ethical concept of freedom from a legal concept of freedom. Krause declares that "the essential form of human life itself is ethical freedom, that is one's innermost [selbsteigne] choice of the individual good [...]" (NR 254). Legal freedom, in contrast, means freedom in which "everyone would have to possess a determinate outer sphere for the confirmation of his ethically free efficacy, in which sphere he can externally realize that which he internally cognizes with ethical freedom as good and thus decides to realize" (VR 452f.) Legal freedom protects the potential of reasonable freedom; ethical freedom realizes it. The freedom to be legally protected should enable, but not enforce, the ethical orientation of individuals.

The law is to grant opportunities, but not to lead mankind in shackles towards the good life (G II 166f.). The good should enter into the world through voluntary choices, not through coercion (VR 304). The law has consequently "to externally restrict the ethical freedom as little as possible" (NR 256), so that that ethical freedom can develop itself as much as possible. The first and foremost content of freedom's law is thus a "legal authorization [Erlaubnisgesetz]" of the ethical use of freedom, negatively as well as positively: "He who possesses jurisdiction may or may not avail himself of this right of his" (NR 256). The law does not only defend the reality and actuality of ethical freedom but also its possibility and conditions (LL 191); and, with that, also lots of immoral uses of freedom. Freedom cannot be had without this ambit. "This sphere of power (of outer freedom) must namely be greater than the sphere of its already constituted, reasonably-appropriate will, otherwise the free self-development cannot take place" (VR 304). Krause knows that morals only thrive by being tried and tested in and by freedom. "Every man and every society of men thus has the right to a determinate external sphere of freedom" (VR 453).

Consequently, Krause draws sharp boundaries of legal protection around the personal liberties of citizens. Whoever is morally troubled by the other's unethical use of freedom, he proclaims, should rather help to reduce the given motivations towards 
immorality and replace them with incentives towards the good, instead of limiting the freedom of choice of his or her fellow citizens (VR 317). For since freedom not only presents one good among many (i.e. a first-level good) but also - being frequently the only path towards these other goods - a good superior to them (i.e. a second-level good or meta-good), it may not be limited for the sake of these other goods alone, but rather its possible limitation must at the same time continually be carried out in accordance with its proper idea - i.e. in the sense of a reasonably, selflimiting freedom (VR 455).

Krause thus does not advocate a ("negative") concept of freedom without any relation at all to the good. He unambiguously claims rather that "freedom is not aimless choice [Willkür], not egotistic self-interest, not arbitrary lawlessness" (ERB 9). Yet Krause also does not champion a ("positive") concept of freedom, which makes a single, quite determinate morality the foundation of 'freedom's rights' (Freiheitsrechte). Krause can maintain this distance from either side since his idea of freedom is not committed to one materially-concrete concept of the good but directed to a structurally-abstract idea of the good. There thus arises neither a formal ("negative") under-determination nor a substantial ("positive") over-determination of the idea of freedom.

Certain (ethical) ends should direct but not dominate the freedom of the subject. In Krause's eyes, ends to which human freedom is autonomously committed do not corrupt but realize the idea of law. Thus, for him, law is something more and something different from a mere legitimation and limitation of coercion, namely a system of the outer conditions for responsible freedom (G 19f.). Therein consists the pronounced proximity of Krause's position to today's capability theories. The idea of law has not only a negative-protective side, but also positive-productive aspects: It aims not only to protect against the 'injury' (laesio) of factually given liberties, but also at contributions to the creation of capabilities and opportunities by forms of cooperation and life which promote the individual as well as the collective pursuit of goals. ${ }^{199}$

The shelters of private freedom that the law is to provide thus do not result from indifference towards the concrete differences of the ethical aims of individuals, but rather from respect for them. Thus, for Krause, the negative - restrictive - moment of freedom does not define, but rather articulates the idea of right. It is secondary to its primarily positive focus on affording chances for an autonomous existence. If individuals reasonably limit (in the sense of negative freedom) their freedom with and for one another, they can pursue their goals with less conflict and harmonize better (in the sense of positive freedom) with the interests of the general public. The bounds of the liberal law thus do not signify a quantitative minus, but rather a qualitative plus in freedom. Krause, that is, understands negative and positive dimensions of freedom as mutually reinforcing aspects of one and the same freedom. Freedom, since it develops successively from initial dependence, through levels of private

\footnotetext{
${ }^{199}$ See also Martha Nussbaum's characterization of her own theory: Capabilities "are not just abilities residing inside a person, but also the freedoms or opportunities created by a combination of personal abilities and the political, social, and economic environment" (Creating Capabilities, 20).
} 
independence, to forms of targeted interdependence, needs on all levels of its development (in always different degrees), both the negative liberation, without which it withers, and the positive orientation, without which it wilts.

The freedom for the good ('freedom-to') nevertheless possesses logical priority. No society should ever prevent its subjects from leading an ethical life, and to this belongs the voluntary dedication to the ethical. For the same reason society must not pervert the citizens' own ethical striving and compel them to good actions (G II 166f.). People must be allowed to pursue their own respective conception of the good and must therefore be safeguarded against well-meaning heteronomy. Hence individuals require negative freedom ('freedom-from'). Both freedoms, the positive freedom to commit and the negative freedom to refuse, thus present only two sides of one and the same qualitative freedom for moral autonomy. Not in isolation but only in unison do they articulate the essence of freedom.

Among the preconditions of personal freedom, which are to be legally protected, Krause includes, besides basic individual properties and capabilities, also an individual's capacity to enter into relationships with and towards other (natural as well as collective, i.e. juridical) persons. From this concept of relational personhood follows (as a first-level right) a set of basic personality rights. To these are related (as a second-level right) a 'right to right' and (as a third-level right) a claim on society for its promotion. The personality rights are therefore self-reflexively related to their realization. Krause calls this a "right to legal empowerment" (Rechtsbefähigungsrecht), which should guarantee that everyone "is capable of exercising his specific rights" (VR 260f.). ${ }^{200}$ Thereby Krause already anticipates much of the discussion about human rights at the end of the twentieth century: His concept of basic rights encompasses human rights of the first, second, and third generation, i.e. civic rights, rights to political participation, and to social as well as cultural inclusion. ${ }^{201}$

Since freedom degenerates without objectives, Krause also dedicates himself to the general conditions for the realization of personal ends - on the part of institutional infrastructure, as well as individual capabilities (VR 452f.). Much of what is today widely discussed in the spheres of capability theory was already anticipated by him ${ }^{202}$ : For Krause, the radius of any basic 'freedom right' (Freiheitsrecht) always also encompasses the right to cultivate oneself accordingly so as to be able to exert this respective freedom autonomously. The free cultivation and exertion of one's own body, for instance, requires certain presuppositions such as an intact liv-

\footnotetext{
${ }^{200}$ Today's Capability Theories see things quite similarly: "In other words, to secure a right to citizens in these areas is to put them in a position of capacity to function in that area." And for that it is not sufficient that one grants certain rights to citizens only on paper; one must enable them to seize these rights: "They really have been given right only if there are effective measures to make truly capable of political exercise." Thus, for instance, Martha Nussbaum formulates it and she further explains that "to do this involves affirmative material and institutional support" (Frontiers of Justice, 287).

${ }^{201}$ See Bard-Anders Andreassen \& Stephen P. Marks (eds.), Development as a Human Right: Legal, Political and Economic Dimensions (Antwep \& Portland: Intersentia, 2010).

${ }^{202}$ See all of Martha Nussbaum's Capabilities lists in Creating Capabilities, 34f.
} 
ing environment (VR 483). One must dwell in hygienic and unchallenging conditions (VR 498) or have access to care and treatment in the event of illness. Hence "the health of citizens" is, for Krause, a "public concern," because without it the corresponding individual freedom easily turns out to be a chimera (G II 169).

Similarly, rights to intellectual freedom protect people's intellectual cultivation and exertion. For what is the point of the freedom of thought "if one cannot concentrate and is unable to educate one's mind and learn scientific truth"? (LL 195) A right to free agency is also needed - e.g. a right to the intellectual activity of science and the physical activities of the arts (G II 125): "To deprive someone" of the realization of these rights "means to deny his human dignity" (G II 117). Without a minimal level of education, after all, intellectual freedom hardly ever arises, which is why Krause derives a secondary right to education from the primary right to intellectual freedom. Krause has in mind a pedagogy (U 230f) which gradually empowers the human being for mature self-control (U 231-235). In a third step, he considers whether, in order to secure the impartiality of educational contents, "public educational institutions" are required (G II 169), financed by the state (G II 136). On the other hand, private initiatives in education are also to be allowed, in order to guarantee a plurality of epistemic approaches, so as to help individuals form their own, mature judgment. Consequently, for the purpose of a real freedom of expression there also needs to be an uncensored media and free access to information (ibid.).

The example of the educational policy of the Institución Libre de Enseñanza (ILE), which exists until today, clearly illustrates Krause's basic concerns. The ILE was established in Madrid in 1876 by the Krausist Francisco Giner de los Rios in order to avoid the influence of church and state upon academic teaching and to develop Spanish citizens' political maturity. ${ }^{203}$ As Spain's first private institute of higher education this cultural and educational institution shaped Spain's educational elite over many decades (e.g. the famous "generación de 98"). ${ }^{204}$ Up until its closure during the Franco era, the ILE significantly influenced Spain's intellectual life - and also that of Latin America - by offering intellectual alternatives to the worldviews propagated by church and state. This initiative set precedents, for example, in Valencia in 1903. Based upon the free lectures of dedicated teachers, the Krausists founded there a Universidad Popular. Since the population was often insufficiently educated for taking up university courses, the Krausists created alternative offerings. They provided additional educational formats that made academic topics with relevance for daily life more broadly accessible. They especially attempted, by means of political education, to enable citizens to make use of their

\footnotetext{
${ }^{203}$ See J. F. Alemparte, “Aufnahme der deutschen Kultur in Spanien: Der Krausismo als Höhepunkt und sein Weiterwirken durch die Institución Libre de Enseñanza" in Kodalle (ed.), Karl Christian Friedrich Krause (1781-1832): Studien zu seiner Philosophie und zum Krausismo (Hamburg, 1985), 141 und J. J. Gil-Cremades, "Die politische Dimension des Krausismo in Spanien," in ibid., 235. For more information about the pedagogical conception followed by the Krausists see note 285 in this chapter.

${ }^{204}$ See Juan López-Morillas, El Krausismo Español: Perfil de una aventura intelectual (Madrid: Ediciones Fondo de Cultura Económica, 1980).
} 
freedom and motivate them towards the active participation in the fledgling Spanish democracy of that time..$^{205}$

The transition from the realm of intellectual education to the field of intellectual (often: political) activities, as shown in these practical examples, is indicative for Krause's theory. From the right to education there follow rights, which protect the freedom of conscience and the freedom of thought (VR 481), which safeguard the "acceptance or tolerance" of a critical public (VR 483) and which guarantee that all citizens can participate in the spiritual and cultural life of their society (VR 483). In this way, Krause gradually develops a catalog of human rights from the principle of freedom, which includes the rights of social life (VR 488; 491), a protection of the intimacy and exclusivity of private life (VR 484), forms of free economic activity, and of private autonomy (VR 491).

This is not the place for a more detailed presentation of the corresponding corollaries. But the decisive idea of these considerations should once again be pointed out: Krause qualifies the idea of freedom by a theory of relational personhood which stresses the interdependence of individuals with their social and natural environments more than it stresses independence. Accordingly, Krause also relates the fundamental right to a free cultivation of personality to the specific social and environmental preconditions of individual autonomy. Because of the central role of social spaces of interaction for the development of personal freedom, his theory of freedom thus ultimately leads to a sketch of a public order in the service of freedom. That order is to be structured by emancipatory forms of interaction so that the freedom of everyone is promoted by the freedom of all; this idea is the aim of Krause's legal and economic philosophy.

\subsubsection{Private and Public Interest}

In countless theories of freedom there is a conflict between private and public interest. The representatives of negative freedom usually fight on the side of private interest and employ the idea of freedom in the service of protecting that interest from public interference. They are, so to speak, concerned about the maximization of private goods. Conversely the representatives of positive theories of freedom are advocates of the common good and recognize in public freedom a liberty of higher value to which private freedom should subordinate itself. What about Krause's theory? What follows from Krause's conception of relational personhood and his concept of freedom focusing on interdependence for the ordering of the civic sphere and the rights belonging to it (property, possession, transfer, etc.)?

Concerning the animal environment, Krause had pleaded, as we have seen, for an ethics that recommends consideration in proportion to different levels of freedom. But what kind of ethics should we apply when the object of free activity is no longer a self-conscious animal (with his own liberties and rights), but rather an uncon-

${ }^{205}$ See L. Esteban Mateo, El Krausismo, $134 \mathrm{ff}$. 
scious plant, or even a nonliving thing without inherent freedom? Are boundaries then also still to be drawn or can human freedom now enjoy unhindered choice and exploit the world as it pleases? What liberties may human freedom take with unfree entities?

Nothing, according to Krause, can be absolutely worthless (ASys 182), because of the never to be excluded possibility of it serving somehow, someone, at some time, as a means towards freedom (NR 139). Sustainability protects future freedom. As a consequence, anyone disturbing or destroying the environment must justify their actions; it must plausibly be the case that they thus create more freedom than they annihilate. ${ }^{206}$ Unlike most liberal thinkers, Krause does not first abstractly allow the use of nature, only to then, subsequently, limit it as required. Rather, Krause prohibits from the outset every useless and purposeless destruction of nature as well as every excessive exploitation of nature: "Things are to be consumed, that is destroyed through their use, (a) only under the condition that they can promote higher living-being (a higher amount of the good or a higher good); and (b) only if the damage which they inflict on living beings could otherwise not be prevented" (NR 144n.). ${ }^{207}$ Against traditional philosophies of freedom, Krause thus shifts the burden of proof from the defendants of nature upon those who wish to instrumentalize it.

From these qualitative directives results the quantitative radius of the legitimate use of objects. Use without consumption or wear and tear can be granted without limit (NR 176). In regard to objects with multiple uses, an examination is due, which, e.g., with the use of wood, may reveal that one should give priority to "timber instead of firewood" (NR 176). It becomes more complicated if we move from natural products to manufactured objects. There is of course an important difference between "material goods dignified in themselves," i.e. such in which inheres the freedom they represent (artworks, etc.), and mere "utility goods" (NR 143). One may not only "use" pure "utility goods," but also "use them up" (NR 144), insofar as the rights of others and of society are not opposed to this (VR 292). Yet matters differ in respect of said "material goods dignified in themselves"; i.e. objects incorporating the 'freedom rights' of their creators that need to be respected, which is especially the case with intellectual property (as we shall see below).

Thus, although mere things can in principle be appropriated and used freely, this obviously surrenders neither their appropriation nor use to arbitrary and unlimited choice. Both are rather first to be regulated on the path of public, i.e. political, self-

\footnotetext{
${ }^{206}$ For more information about whether plants have rights, see the detailed discussion by Francisco Querol Fernández, La filosofía del derecho de K. Ch. F. Krause: Con un apéndice sobre su proyecto Europeísta (Madrid: Universidad Pontificia Comillas, 2000), 227-234. See Martha Nussbaum's position (Frontiers of Justice, 94) as well as, in regard to the differentiation between plants and animals, Creating Capabilities, $158 \mathrm{f}$.

${ }^{207}$ One can here catch sight of an answer to the later arising question about how man should adequately handle the "Promethean gap" lying between humanity's technical and prospective capabilities; already found in Günther Anders, Die Antiquiertheit des Menschen: Über die Seele im Zeitalter der Zweiten industriellen Revolution, (München: Beck, 1956), 267ff.
} 
determination. The notion of the originally communal human possession of the earth functions as a fundamental corrective to all appropriation and use of things.

Prior to public distribution, no individual possesses a legitimate right to some kind of useful thing except his own body, and only the public allocation according to just division is the form in order to obtain the rightful possession of something useful. Whoever wishes to take possession of something must first be entitled by everyone for this appropriation, just as is the case with whoever intends to work on something; [...] No individual can be placed by another individual in the rightful possession of some kind of useful thing or be driven out of such possession. (G II 191)

With these words, Krause rejects the acquisition of goods in the 'Wild West' manner as propounded by, for example, John Locke (1632-1704), according to which working on No-Mans-Land thus makes it one's own. The earth is neither infinite nor ever a no-man's-land; it belongs in principle to all of humanity. One must thus continually ensure that in all acts of appropriation the rights of others not to be excluded from global participation and to have a proper realm for their respective freedom - remain preserved. That, however, cannot at all be guaranteed by the individual, but only by a community representing everyone. All possessions up to date attained throughout history can thus only lay claim to provisional, and not eternal, validity. They are subject to the right to revision possessed by a future legally constituted humanity (ERB 108).

If one wants to grant everyone access to freedom, one must not necessarily call for an equality of goods (Gütergleichheit) (NR 142) like Fichte, but certainly for a uniformity (Gleichförmigkeit) of the right to acquisition (VR 253). The right to property has to balance the individual claim to the privatization of things with the public concern for open access to objects that are means to freedom (VR 511f.). For that is, following Krause, precisely the deeper, philosophical sense of private property, where "the outer becomes an inner, equivalent to the inner - being lawfully made dependent on the freedom of the entitled person" (NR 171). Just as all have a right to freedom, everyone also has a right to differentiate him-or herself from others (through merit and industry), i.e. to make his or her existence unequal from theirs. ${ }^{208}$ Nevertheless, not every inequality is now to be celebrated as an expression of freedom or praised for expressing the individual will to differentiation. Wherever an inequality exists because equal opportunities are lacking, there is a lack of freedom, and this must always be annulled. Thus commands freedom.

Krause gives the social dimension of property neither a prior nor posterior place in relation to its private dimension; he rather recognizes the former as being immanent within the latter, as an internal counterbalance of all private possession, without which it loses its principal legitimacy. In Krause's view, private property is not hindered but rather promoted by the demand of social responsibility. This demand does not burden the proprietors with excessive duties, but instead releases them

\footnotetext{
${ }^{208}$ The idea of communal ownership is for Krause in no way to be understood socialistically or as stressing collectivism, see Wolfgang Vester, Sozialphilosophie und Sozialpolitik der deutschen Rechtsphilosophie des XIX Jahrhunderts (Krause, Ahrens, Röder) (Cottbus: Grosse, 1935) 36. More on this below.
} 
from having to explain on a case-by-case basis their right to the exclusion of others which is bound up with the idea of private property. The concrete, socially adequate regulation of private proprietors supports the abstract institution of private property. The freedom of the owner is therefore not negated by social constraints in the name of everyone's freedom, but it is rather affirmed; laws and taxes that enable that freedom of everyone accordingly realize - and do not ruin - the freedom to property ownership.

Krause keeps his distance from both the extremes of individualism and collectivism. He neither narrows down freedom to private property, as was common in nineteenth century liberalism, nor does he strive for freedom by abolishing any and all property structures. He achieves this twofold distance by means of an innovative concept of property: Property, Krause notes, can always only bear upon functional characteristics. One can, to be precise, (legally) have ownership over something, but never (ontologically) be in possession of something. Thus "it cannot actually be said that this thing is property, one should rather say that this condition adhering to the thing is property" (NR 173). Not only does Krause thus distinguish possession and property as do the Roman and German traditions of jurisprudence, but also, what is more, an extremely consequential practical difference is thus also inscribed in the concept of property itself.

The point of this distinction between ontological and legal property is, according to Krause, to avoid the possible misunderstanding of "unconditional possession," including the heresy that the proprietor could do with a possession "whatever he likes and whatever he pleases" (VR 287). ${ }^{209}$ The everyday understanding of legal property as the holding of rights without regard for others, confuses the often granted, but also sometimes refused, exclusive legal relationship of a proprietor towards non-proprietors with the metaphysical relation of a subject towards things. An object can certainly belong to proprietors in certain legal respects, but it can never absolutely, ontologically be theirs. In short, rights to property are always valid functionally, never totally. And their function is freedom.

Although there is an unconditional right to possess some property in general for one's own free use, Krause recognizes only a conditioned right to specific properties and uses (NR 173). Properties and their employment are subjected to the discretion of their owners only within certain boundaries. Human beings should certainly also obtain some personal possessions to the "exclusion of all other persons" in order to win, for instance, a radius of free, undisturbed productivity. Nevertheless, the exclusion of others may never become a defining feature of the right to property. The

\footnotetext{
${ }^{209}$ With his critique of the conventional theories of property (see their presentation in Julius Weiske \& Franz Bopp, Rechtslexikon für Juristen aller teutschen Staaten enthaltend die gesammte Rechtswissenschaft [Leipzig: Wigand, 1839] 146f.), Krause is very much aware of the fact "that in the majority of states, as they are currently, in respect of the majority of assets an unconditional right to property is lawful. Here, however, we are not after teaching the legal status quo, but rather after seeing what reason considers as eternally right. It happens that, with the increasing education of peoples, this raw determination (Bestimmniss) of the absolute right to property becomes increasingly less feasible, that one limitation after the other must be added, and that one is thus gradually lead back to the reasonable principle of property, just as it was developed here" (VR 287f)
} 
validity of this or that exclusion rather stands and falls with its function of embodying freedom. Thus, also for Krause, the handling of everyday objects is mostly up to the liberty of the owners; but not because they may possess in and for themselves a (quantitatively) unlimited right to do to their things whatever pleases them, but because (qualitatively) to all individuals a determinate "sphere of freedom [Freiheitskreis]" must be granted, in which they freely define themselves (VR 452f.).

In terms of positive law, this means: The exclusion of others can only become effective as a secondary juridical consequence of a prior relation of the owner to a specific property, a relation that needs primarily to be approved by society (NR 173). ${ }^{210}$ The right to exclude others (in Latin privare $=$ to exclude, to deprive) does not constitute private property, rather, conversely, the right to property has as a consequence at times - but not always - certain rights to exclusions. This theoretical differentiation has tangible practical consequences. As we saw, things ought to be used according to their basic determination in the light of the reasonable freedom of all. From this there follows not only a specific proscription (Verbot) against senseless destruction, but also an unspecific prescription (Gebot) to use things sensibly and optimize their utility. Only a fundamentally socially obligated concept of property, which reciprocally qualifies the rights to freedom of the individual member and the social whole, can harmonize the "opposing demands of communal property on the one hand and the strict (absolute) private property" on the other hand (NR 173). ${ }^{211}$

Therefore, Krause believes that the material individualism of classical British liberalism sins against its own principle: freedom. When liberals, like Locke, attempted a justification of property in general, they typically enlisted the doctrine of the concrete types of acquisition in the service of a theory on the abstract right to ownership, and thus they confused the genesis and the validity of property: historical formation with systematic legitimacy. ${ }^{212}$ Whether unilateral actions (occupation, specification, and work) or multilateral actions (contract and law) lead to the acquisition of particular property, is, from a philosophical perspective, irrelevant to the question concerning whether anything like private, i.e. exclusive, property may exist at all (AF 174). This never follows from those actions themselves, but rather depends on a preceding justification of the institution of property. That universal right to property, however, can only be legitimated by the fundamental right to personal freedom (VR 512) and not, like particular properties, by specific forms of acquisition. Anything else would found the institution of property upon an insecure basis. Neither occupation and specification nor contract and law can legitimate

\footnotetext{
${ }^{210}$ See Francisco Querol Fernández, La filosofía del derecho de K. Ch. F. Krause, 378.

${ }^{211}$ For more information about the concept of "organic property" in Krause see: Julius Kautz, Theorie und Geschichte der National-Oekonomik (Wien, 1858). Kautz classifies Krause himself (62ff., 79) and his followers, Ahrens (83), as well as Leonhardi and Tiberghien as the earliest campaigners for a socially directed market economy (ibid. $170 \mathrm{f}$.). A similar judgment appears in Eugen von Philippovich, Die Entwicklung der wirtschaftlichen Ideen im 19. Jahrhundert (Tübingen: Mohr, 1910) and similarly Vester, Sozialphilosophie und Sozialpolitik, 46ff.

${ }^{212}$ See Rolf Gröschne et al. Rechts- und Staatsphilosophie, 131ff.
} 
property empirically in any and all cases, but, as merely hypothetical principles of validity, these legal forms do not suffice to derive the initial right to property.

Krause's follower, Ahrens, supplemented these considerations, with the remark that - contra the social-contract theory - the disadvantaged people in impoverished countries could not rationally accept conditions which prevent them from assuring their own subsistence, and that - against the theory of work and occupation - today property can no longer be attained only through industriousness, since hardly anywhere do 'ownerless things' present themselves to the potential appropriator for their occupation and work. Nowadays when non-propertied individuals seek untapped opportunities for their industry, they are typically dependent on being granted access to goods, which they then work upon or refine. Some such basic access to the world and its goods, however, is owed to everyone as a consequence of each person's entitlement to freedom, according to Krause. ${ }^{213}$ When, given appropriate procedural rules, the private property of some is employed to help others realize their basic personal right to acquire property, e.g. if the state taxes one's posessions to help others to some property, then we should not complain that this is an intervention into the freedom of private property, but rather welcome it as its appropriate regulation, according to its very own immanent principle. From the perspective of the principle of freedom, social securities and private property condition rather than combat one another.

The potency of conceptualizing property as, in principle, socially obligated comes especially to the fore with the problem of intellectual property. The question concerning the ownership in "intellectual things" or "objectified intellectual works" (VR 252) was already eagerly discussed in Krause's time with the example of the reprinting of books (AR 175n.). Krause's follower, Heinrich Ahrens, quite in the sense of his teacher's doctrine, offers the following solution to the dilemma about how society's interest in literature as a public good and the financial interests of the author can be reconciled. Since a book per se presents a common good, the author can possess no absolutely private, i.e. exclusive, right to it. In the rare event of an author without any countervailing interests, a text thus passes over immediately into the possession and use of the general public. But if, as in ordinary cases, such interests are to be recognized, these must be evaluated in light of the notion of freedomfunctional property. Unless and until society offers no other form of subsistence for the author other than book-sales, the financial interests of this 'intellectual worker' (Geistesarbeiter) are to be adequately respected. Without the prospect of profiting from sales the author might have, instead of the writing of the book, tried to procure his livelihood differently. As a consequence, for the duration of the author's life (and possibly also longer based on inheritance law) there must not be any reproduction without remuneration. Yet since the author never has an absolute right to the text, but rather a claim to income generated by it, compensatory interventions are always possible, for example, in the case of texts with particular societal relevance (research literature, etc.) (AR 175).

${ }^{213}$ See Heinrich Ahrens, Die Rechtsphilosophie, oder, das Naturrecht; auf philosophisch-anthropologischer Grundlage (Wien: C. Gerold, 1852), 462. 
Without going into further details, we can see clearly from the above example that Krause supports a relative and not absolute concept of property, which treats the right to possession, not from the singular perspective of the proprietor, but from the perspective of universal freedom. While other thinkers treat the social commitments of property rights as merely exceptions to a right conceived as without inherent limits, Krause can elegantly derive these legal qualifications from his principle of freedom-functional property (VR 287f). Thus the conflict between private and public interest (often driven to extremes by theories of negative freedom) loses much of its drama. Krause shows that what is at hand here is not a question of an ultimately irresolvable quantitative polarity between private and public concerns, but rather a question of their reconciliation by means of a qualitative criterion. To wit, in order to be protected, the exercise and employment of possessions must be socially acceptable. Property must never turn into an end in itself but has always to remain a means only - a legal attribution on behalf of freedom.

Generally, the state operates under the assumption that private possessions are put to appropriate use. This is, however, otherwise (preventatively) in the case of goods of extreme societal relevance. Krause is thinking of forestry and agriculture, whose undertakings should remain under public supervision because of their vital importance for the sustainability of life. Krause's disciple, Heinrich Ahrens, further ponders - based on the same principle of freedom-functional, socially-obligated property - how (reactively), in the cases of obvious adverse misuse detrimental to the common good, expropriations can be justified and compensated. ${ }^{214}$ What is more, Krause grants a right to permanent usufruct to non-proprietors, wherever this can increase the number of compatible utilizations of given goods for the benefit of the freedom of all. Certain claims on the property of another, like, for example, usufruct, occupancy, right of way, and easements, should open access to otherwise underused goods, their private possession notwithstanding. Last but not least: Forms of communal and societal property should be promoted (VR 291). The basic idea is always the same: Freedom not only legitimates private property, but also limits it.

What is true of the relationship between persons and things also characterizes the relationship between person and person, inspired, as it is, by an idea of freedom fulfilling itself in and through its societal embedding (LL 173). In Krause's thought, associations between persons do not have to be artificially added to individual existence, they are rather a natural form of how human freedom manifests itself. Families, associations, and society should not be secondarily derived (as today's game-theorists and contractualists care to do) from the interests of individuals primarily presumed to exist in isolation. Social contract theories thus falsely treat as emergent what is actually essential. In human beings, sociality is not contingent, however, but constitutive. For there is, Krause writes, "no ... possible sociality, unless they, as human beings as such, are already sociable" (U 79). ${ }^{215}$

\footnotetext{
${ }^{214}$ Ahrens, Die Rechtsphilosophie, $467 \mathrm{ff}$.

${ }^{215}$ Martha Nussbaum also champions a relational concept of the person which is constitutively characterized by sociality; just like Krause she differentiates it from the apolitical models of contractualism and determines the "idea of the human being as "by nature' political" (Frontiers of
} 
Unlike animals, humans can voluntarily enter and annul contracts. Human beings do not need one another merely for utility-enhancing exchanges and the reciprocal overcoming of deficiencies. They also come together for more noble ends. ${ }^{216}$ Beyond the mutual compensation of deficits, they strive to perfect themselves as well as to improve and ennoble their ecosystem into an ever-more freedom-enhancing environment (LL 149). ${ }^{217}$ Sociality arises not only through the inevitable coexistence of "characterless rational persons," but much rather - and contrary to the social contract theories of the time and the game theories of today - through freely chosen cooperation and collaboration of "persons full of character" (ERB 41). The theory of freedom should thus not reconstruct interpersonal relationships merely as institutions satisfying lower and urgent needs. It must also grasp them as interconnections for voluntary value creation. All aspects of societal life that display a desire for free sociality beyond assuring material survival are of particular dignity: The penchant for cultural self-advancement, symbolic communication, and spiritual contemplation, as well as the wish for joint ethical engagement in service to the freedom and dignity of others. ${ }^{218}$

Krause's social philosophy ascribes great importance to associations of persons. In their goals and through the forms of life they promote, certain institutions - like for example those dedicated to the cultivation of art, science, and religion (LL 198) - express the very idea of freedom. They provide society with patterns of nonoppressive community and responsible self-commitment. Even when some organizations, due to their mission, constrain and co-determine the use of their members' freedoms, this, too, can be grasped as a (qualitative) actualization of freedom and not as a (quantitative) constriction of it (U 318ff.) as long as, in their procedures and aims, these institutions are based upon personal freedom, offer inner and outer openness, and are democratically constituted, etc. - Krause's idea of freedom thus functions both recursively and procedurally at once. That which legitimates the interpersonal institutionalization of freedom limits it as well. Community-building is never an end in itself but should help individuals to realize and reinforce their freedom. Illiberal collectives are not Krause's cup of tea.

Beginning with the family, moving on to further and wider social relations (community and city), and concluding with sub-state and state, national and suprana-

\footnotetext{
Justice, 86) and explains that the concept of the person includes "the ideas of a fundamental sociability and of people's ends including shared ends" (ibid. 86) with the consequence that "the good of others is an important part of one's own scheme of goals and ends" (ibid. 91).

${ }^{216}$ In just the same way, Martha Nussbaum argues against the "very idea of classical liberalism, namely that the goal and raison d'être of social cooperation is mutual advantage" (Creating Capabilities, 150).

${ }^{217}$ Once again the comparison with Martha Nussbaum: She strives for "the gradual formation of an interdependent world in which all species will enjoy cooperation and mutually supportive relations. Nature is not that way and never has been. So it calls, in a very general way, for the gradual supplanting of the natural by the just" (Frontiers of Justice, 399f).

${ }^{218}$ Thus, Martha Nussbaum also states that that the end of "social cooperation is not to gain an advantage; it is to foster the dignity and well-being of each and every citizen" (Frontiers of Justice, 202).
} 
tional structures, even the entire world, Krause develops - with great attention to the sociological details - the theme of how individual freedom is complemented and completed by collective freedom. Said "inner sociability" ultimately leads, according to Krause, to the idea of but "one mankind," which - conforming to this very idea - comprises all persons, human beings far and near, and future generations just as much as present generations (U 72). The more that human beings are orientated by this idea in their thoughts and deeds, the more harmonious will they coexist and cooperate with others, Krause holds (U 72). In principle, human freedom has a cosmopolitan and intergenerational direction.

The government has to ensure the harmonious co-existence of the diverse social associations. To fulfill this task, the state has to relate to all sub-state associations "but only on the part of the law and for the sake of the law" (NR 226). It should not orchestrate communitarian life, but rather promote the subsidiarity and autonomy of associations (VR 84f). ${ }^{219}$ In this field, too, Krause's theory of freedom redirects customary lines of argumentation. Communitarian freedom has, like every other freedom as well, a pre-positive claim to legal recognition. While in the legal theories at that time, the state deigns to acknowledge social associations if these can adduce good reasons for it to do so, Krause demands the opposite. The state has to recognize as legitimate any and all associations aiming for the collective exercise of freedom, as long as no good reasons stand against this - like lack of liberality or failure to comply with the law (G II 134).

Already at the beginning of the nineteenth century Krause thus wrote a theory of civic engagement and intermediary organizations, ${ }^{220}$ which anticipates conceptually the later juridical doctrine of legal persons. ${ }^{221}$ In his time, taking subsidiarity as the bedrock for (legal) theories about sociality was a novelty (AR 171). Krause, after all, explained that processes of organized community building are always already

\footnotetext{
${ }^{219}$ E. Diaz praises (in Elias Diaz, "Krausismo e institución libre de enseñanza: pensamiento social y politico," jornadas homenaje a Giner de los Rios, 234) the Krausist "concepción organicista de la sociedad," because in it individual freedom as well as the social whole find their appropriate place. According to him, the Krausist insistence on "subsidiariedad" is not merely an expression of the desire for efficiency. Rather it expresses in a positive way the fellowship (Miteinander) of individually-personal and socially-personal freedom in an open "pluralism." Krause's societal doctrine thus prevents "la absorción y consecuente disolución del individuo en el todo social o en las plurales asociaciones" (ibid.).

${ }^{220}$ Concerning the importance of the intermediary organizations in Krause see G. Mollat, Lesebuch zur Geschichte der deutschen Staatswissenschaft von Kant bis Bluntschi (Osterwick: Harz, 1891) 97-104. Johannes-Michael Scholz's essay "Legitimationspraktiken krausistischer Dezentralisierungspolitik" in Ius Commune 12 (1984), 117-163 shows - orientated by Krause's leitmotif of "Lebenskreise" in vivid detail the influence of the Krausist body of thought concerning subsidiarity theory on the Spanish legal policy of the previous century. Equally instructive is Querol Fernández, La filosofia del derecho de K. Chr. F. Krause, 415ff.

${ }^{221}$ Krause's students were the first to employ the term "legal person [juristischen Person]" which is still common today. Krause speaks, on the other hand still within the Roman-law tradition of "societal persons [gesellschaftlichen Personen]," or with his own neologism of "associative-selfbeings [Vereinselbwesen]" (VR 241). Concerning Krause's treatment of the tension between natural persons and legal, general persons, see the writings of the Spanish Krausist: Francisco Giner de los Rios, La persona social: Estudios y Fragmentos (Madrid: V. Suárez, 1899).
} 
different from ephemeral legal relations (e.g. purchasing), purely functional partnerships for certain ends (e.g. trading companies), or rather conventional legal entities (e.g. the family). When social organizations are consciously and deliberately brought about, they also deserve a legal status sui generis. They are to be considered as manifestations of consciously collectivized freedom - and must not only be considered instrumentally, for instance, in respect of the goods and functions they realize. This theoretical insight must lead to their practical recognition. Where citizens' associations are understood in just this sense as forms of the development and organization of freedom, there immediately follows the anti-etatistic insight that wide fields within public order could and should emerge bottom-up, i.e. from private and voluntary cooperation, instead of having to be decreed in a top-down fashion. ${ }^{222}$

It did not remain unnoticed at the time that this approach allows rethinking the relationship between society and state entirely - based upon the notion of collective freedom. ${ }^{223}$ From the contemporary perspective, two things particularly stand out: First, how Krause distances himself from atomistic liberalisms by stressing that voluntary integration into collectives is an important expression of individual freedom. And second, how in regarding freedom as the raison d'être of those commitments, he also differentiates himself from positions labeled "Romantic" then and "communitarian" today. ${ }^{224}$ This is already shown by his terminology: Krause anticipated the differentiation, later popularized in German sociology, between "community" and "society" (U 62). ${ }^{225} \mathrm{He}$, however, values societies as desirable, since they

\footnotetext{
${ }^{222}$ See José Luis Malo Guillén, El Pensamiento Económico del Krausismo Español (1999).

${ }^{223}$ Heinrich Ahrens developed Krause's thinking - with the help of the distinction between "corporation" and "association" - into a theory of civil societies and trading companies; see Peter Landau, "Gesellschaftliches Recht und das Prinzip freier Körperschaftsbildung in der Rechtsphilosophie von Heinrich Ahrens" in Dilcher \& Distelkamp (eds.), Recht, Gericht, Genossenschaft und Policey Studien zu Grundbegriffen der germanistischen Rechtshistorie (Berlin, 1986). Also noteworthy is Krause's influence upon Lorenz von Stein and Robert von Mohl. Robert von Mohl himself positively acknowledged Krause's influence upon his thinking, see Robert von Mohl, Die Geschichte und Literatur der Staatswissenschaft in Monographien dargestellt (Graz: Akad. Dr.- \& Verl.-Anst, 1855), 245. Klaus Fischer sees "Lorenz von Stein as the intellectual successor of K. C. F. Krause" in Klaus H. Fischer, Die Wissenschaft der Gesellschaft: Gesellschaftsanalyse und Gesichtsphilosophie der Lorenz von Stein unter besonderer Berücksichtigung seines gesellschaftswissenschaflichen Entwurfs (Frankfurt am Main: Haag \& Herchen, 1990), 109.

${ }^{224}$ The influence of Krausist sociology upon the social philosophy of Spencer is regarded as certain in Spanish Krause research: "Spencer será deudor, ciertamente, de Krause, al retomar la idea de que la sociedad es un organismo y que la evolución es por esencia orgánica" (León Esteban Mateo, El Krausismo, la Institución Libre de Enseñanza y Valencia (Valencia, 1990) 35). In the same way there is a likely influence of Krausist doctrine upon Spanish sociology - above all in the work of Perez Pujol (1830-1894) - (see M. Núñez Encabo \& Manuel Sales y Ferré, Los origenes de la sociologia en España [Madrid: Editorial Cuadernos para el Diálogo, 1976]).

${ }^{225}$ One can trace a conceptual line of thought to Ferdinand Tönnies. The philosophical teacher of Tönnies - Rudolf Eucken - admired Krause's philosophy and dedicated intensive studies especially to his social philosophy, as one can learn from the research currently being conducted at the Eucken archive in Jena (I am grateful to Uwe Dathe for informing me about this). For many substantial agreements exist. It can be concluded that Tönnies' organic principle of sociology (see $\$ 2$ in Ferdinand Tönnies, Gemeinschaft und Gesellschaft: Der reinen Soziologie [Berlin: Kurt
} 
are liberal, namely, consciously and deliberately established forms of association. Community arises from coexistence, sometimes without free will. "Community but not society can be forced on us by fate." The latter, that is to say, presupposes deliberate association and thereby the conscious will towards self-integration in a higher unity.

Despite due respect to natural communities like the family, Krause clearly does not share the later prevalent pejorative outlook of Ferdinand Tönnies (1855-1936) and, afterwards above all, Werner Sombart (1863-1941), that societies are merely ethically thinned-out communities (U 62). "For society is a union of individual activity for communal achievement." Therefore, it is the "freely recognized and individually reciprocally enlivened community" that foremost deserves the title "society" (ERB 49). Krause thus does not champion a statist or popularist philosophy, but a civic, social philosophy; one that is founded neither on blood and soil nor on cold utility, but rather upon freedom and reason.

In this context, it must once again be emphasized just how explicitly Krause objects to the view that society and state could be grounded by reciprocity - by interest-oriented exchanges and thought-experiments aiming at utility. Remember: Even legal relationships based on reciprocal obligations do not, in his view, obtain their respective legal form and status from that reciprocity (NR 165). Mutual claims - constitutive as they are for commercial life - draw their legal force not only from the interests communicated within them. ${ }^{226}$ The private will of the subjects only establishes binding contracts if it lawfully determines itself (necessary condition) and can adduce legitimate reasons (sufficient condition). ${ }^{227}$

Krause therefore never simply reconstructs contracts from their negatoryrestrictive aspects. Contracts are not merely instruments to avoid or compensate damages or losses in exchange relations, for instance by contractual penalties, indemnification rules, etc., but rather fulfill integratively-positive functions. For the protection of these functions rather, and conditioned just as well as bounded by them, the negatory-compensatory aspects of contract law come into view. Contracts enable "individuals [...] to divide work" (VR 451). Contracts are thereby of a significant meaning, far beyond the utility they grant the parties concerned. They create stability, security, and trust within social transactions, they enable long-term economic planning, and thus constitute a central moment of civic self-sufficiency and collective freedom. Beyond emotional and family commitments, they allow for a reliable and constant allocation of goods and services through lawful, sanctioned agreements (U 218).

Curtius, 1912]) is clearly Krausist. And also Tönnies' reflections about the concepts "power of choice/choice of power [Willkür/Kürwille]" are also already anticipated by Krause (VR 317). Nevertheless - and this is decisive - Krause's valuation of community and society is thoroughly opposed to that of Tönnies.

${ }^{226}$ Again, Martha Nussbaum is of a similar view: "We acknowledge, as well, that the kind of sociability that is fully human including symmetrical relations ..., but also relations of more or less extreme asymmetry and truly human functioning" (Frontiers of Justice, 160).

${ }^{227}$ See Querol Fernández, La filosofia del derecho de K. Ch. F. Krause, 93. 
Private autonomy enjoys constitutional protection with Krause for the same reasons. Every single private contract, however, remains forever bound by and to the legal basis of all contracts, and can never replace this basis.

The contract is merely concerned with the allocation and individualization of right and of the legal claim, and not with the justification (nor the foundation) of law itself, that is why after the fulfillment of the contract the claim can still remain. Contract [sic!] is therefore only legitimately valid so far as the societally associated will could be seen as included (given) within the legal bases it relies on. (NR 198)

As the idea of law functions as the ultimate principle of legal legitimation, society is entitled to protect individuals who, from need or ignorance, might otherwise enter into contracts inimical to their autonomy. In contract law, the state regulates the individuals' sphere of action, not at all to eliminate their autonomy, but rather to safeguard it (NR 164). Thus Krause reconstructs, as inherent to the principle of freedom, those limitations of contractual autonomy that constitute the traditional canon of general contractual duties ("good faith" [Treu und Glauben]), of mutual contractual obligations (offer, acceptance), debtor's duties (notification, offer, specification, transfer), and the creditor's duties (demand, acceptance), including possible omissions (G II 170; NR 164ff.; VR 280ff).

Here too the strengths of Krause's conception directly catch one's eye, namely in view of the philosophical interpretation of the presuppositions of validity for establishing contracts: Capacity (no lack of understanding or maturity), absence of mental or physical coercion, presence of a 'permitted' subject matter of the contract (VR 342ff.). The agreement of the parties may be brought about neither by fraud or deception, nor can it include an error about the substance or essential characteristics of the object; and they must be explained reciprocally, correspondingly, and on time, etc. How are all of these restrictions justified? A clever maximizer of his or her own interests (which game theories or contractualist theories normally postulate) would accept these qualifications only as a necessary evil if and when they increase the average rate of returns: limitations of freedom in exchange for increased utility. Clearly, such reconstructions of contractual law fail to capture what Krause aims at, i.e. showcasing those qualifications as but conditions for enabling everyone's freedom. Krause advocates that these rules of fairness do not reduce the freedom of concluding contracts but rather secure this freedom in the first place.

For a contract to be valid, it need not only represent the interests of directly involved parties. It also has to conform to everyone's 'freedom rights' (VR 343). What holds true of contracts between individuals is all the more required of the social contract. The state can by no means simply be thought of (as libertarians would like) as a private contract extended to all citizens for the sake of the reciprocal protection of their interests. ${ }^{228}$ The various goals uniting people with each other are

\footnotetext{
${ }^{228}$ Similarly, Martha Nussbaum says "the capabilities approach denies that principles of justice have to secure mutual advantage [...]. Justice is about justice [...]. It is always very nice if one can show that that justice is compatible with mutual advantage, but the argument of principles of justice should not rest on this hope" (Frontiers of Justice, 89).
} 
by no means sufficient - in a generalized form - to ground a state of $l a w .{ }^{229}$ For every private contract is only ever valid provisionally and hypothetically, i.e. based upon the consenting volition and the persistent interest of the participants, and therefore can in no way provide peremptory and categorical validity (NR 133). On such shaky grounds, Krause feels, no stable state of law can be erected.

No. A communal entity is neither an agreement of private individuals nor a sideeffect of a reciprocally conditioned waiving and exchanging of rights. The community of rights exists unconditionally - for the right to freedom and through it. Social contract theories built solely upon the logic of bartering cannot, after all, include within the shelter of law human beings who can neither profit nor damage us (for instance members of future generations or the distantly located poor), since the nature of a utility-oriented exchange is to watch out for symmetry of commission and omission. Krause, however, does not have this problem. From the outset, his theory of society insists upon the unconditional protection of human rights, also and especially in cases of strictly asymmetric relations. ${ }^{230}$ A social contract (Staatsvertrag) laid down in the form of a constitution can therefore only be viewed as a historical manifestation of human rights, but not as their systematic ground of validity (AR 182). ${ }^{231}$ Likewise, the reverse applies: The universal human right to law justifies the right to formulate a national social contract or a constitution.

\subsubsection{Procedural Policy in Global Responsibility}

All human beings should, according to Krause, have the "same opportunity for the development of their spiritual and physical capacities" (NR 277f.); to create fair opportunities is the task of policy. The state helps those who cannot adequately support themselves by their own means (G II 149). The access to basic needs like nourishment, housing, and clothing must not only depend upon the market economy ( $\mathrm{G}$ II 149), since "the legal ground of useful possession does not lie in work, but rather in the need and, above all, in the reasonable nature itself" (G II 188). Everyone should be capacitated for a life in freedom and dignity.

Recall that Fichte still believed that whoever did not work and did not find anyone to provide him nourishment gratuitously, should "die of hunger, and rightfully so" (FW III/1, 119). Krause begs to differ. He rejects a reciprocally conditioned relationship between work and sustenance. The individuals are unconditionally

\footnotetext{
229 "The non-economic spheres of society cannot however develop their Logos from the logic of economic relations of exchange [...] The economy [...] cannot be the source code of society" (Udo di Fabio, Die Kultur der Freiheit (München: Beck, 2005), 122.

${ }^{230}$ Martha Nussbaum also sees things this way (Frontiers of Justice, 22). Like Krause, contrary to the basic logic of game theory and contractualist theories, she thinks that "A large asymmetry of power ... might make questions of justice more urgent than, as in contractarianism, taking them off the agenda" (ibid. 87).

${ }^{231}$ See Vester, Sozialphilosophie und Sozialpolitik, 15.
} 
obligated to work for their and the collective livelihood according to their abilities. Conversely, society owes to all the presuppositions for an existence in freedom also unconditionally. Both these commitments do not condition one another; they exist in and for themselves.

The physical and spiritual needs have to be provided for him [the worker], not because he works but because he is in need of them as a human being. If, although he is able to, he should not be working enough or properly, then he should thus be punished, but no right can be based upon taking away from him something other which he otherwise justly requires. (G II 198)

Since Krause does not conceive the legal order as a barter society, but rather a community for enabling all-round freedom (VR 531), he wants a dignified free human life for all, independently of social and biological contingencies (G II 152). Today, we may find analogous positions less within John Rawls' plea for a quantitatively-equal provision of "basic goods," and rather within Martha Nussbaum and Amartya Sen's qualitatively-differentiated "capability" approach (see Sect. 4.2.3). ${ }^{232}$ Similarly, i.e. with solidarity, one would have to deal also with natural catastrophes (and other disasters). "Natural damages on the common field of life" must not "be borne only by the person contingently affected, since, in contrast, this is a legal concern of the entire society" (VR 440).

On the whole, Krause wants to balance out through providential social policy the postulates of personal freedom, legal equality, and the citizens' economic independence. The historical experiments of krausismo illustrate this endeavour: Due to the "unidad intrínsica entre politica, filosofia y economia"233 in Krause's thinking, at the end of the nineteenth century leading Spanish Krausistas felt compelled to develop a social-liberal concept of economic policy that was said to balance out the diverging demands for social justice and individual freedom. The "libro más conocido de la corriente krausista," the "Estudios económicos y sociales" (Madrid 1876) of Gumersindo de Azcárate ${ }^{234}$ as well as the "Tratado de Hacienda pública y examen de la española" of J. M. Piernas Hurtado (which in the late nineteenth century was for several decades the standard textbook for economics at Spanish universities) were firmly dedicated to these intentions. ${ }^{235}$

\footnotetext{
${ }^{232}$ Peter Landau thus believes that a basic-income, differentiated according to divergent needs, as well as a basic supply of education and health care, would thus have been supported by Krause. See his "Karl Christian Friedrich Krauses Rechtsphilosophie" in Kodalle (ed.), Karl Christian Friedrich Krause (1781-1832): Studie zu seiner Philosophie und zum Krausismo (Hamburg, 1985), 92.

${ }^{233}$ See José Luis Malo Guillén, "La Institución Libre de Enseñanza y la ciencia económica," Sistema - Revista de Ciencias Sociales 157 (2000), 93-114, 99.

${ }^{234}$ For the realpolitik of Azcárate see ibid., 105ff.

${ }^{235}$ This Krausist economic theory first appearing in Madrid in 1884/85, went through several editions, and was widely used in academic economic instruction until the 1930s. According to its intellectual structure and train of thought, this treatise may be regarded as a true representation of the Krausist thinking of the time. See José Lusi Malo Guillén, krausismo económico español (2005).
} 
In foreign policy, the Krausists mostly fought for a policy of free trade, but regarding domestic policy they clearly distanced themselves from the economic thought of classical liberalism. Those economic and political differences result from philosophical divergences. A closer look at the latter leads us to some illuminating conceptual ideas - also for current debates. From the second half of the nineteenth century, economics both in its classical as well as its neoclassical (i.e. wedded with marginalism) form increasingly sought to feature mathematical methods. ${ }^{236}$ One wished to read the (optimal) economic activity by means of deductions from general economic laws - largely omitting social factors. ${ }^{237}$ Within that paradigm pursuing an equilibrium of market forces, every external intervention into the market is per definitionem viewed negatively as a disturbance of otherwise balancing forces. One was, consequently, against state intervention in economic life. Instead, such economists sought refuge alone with the "invisible hand" of the market - in a sometimes extremely selective reading of a crudely misunderstood Adam Smith. ${ }^{238}$ They, in short, defended an economic philosophy of negative freedom.

The social-liberals in Germany proceeded conversely. They backed the empirical investigation of historical conditions instead of abstractly-universal laws. Induction was their method of choice. The representatives of diverse "historical schools" wanted statistically to calculate which respective measures lead to desirable distributions of property, in order to derive recommendations for future economic policy and social welfare. ${ }^{239}$ They opposed the market's lottery with an unbridled trust in the planning capacity of society, which, when steered by correct insights, through the state's visible hand, would easily accomplish what the market's invisible hand grappled with so unsatisfactorily: a just distribution of welfare. They championed an economic philosophy of positive freedom.

The Krausist liberals criticized both approaches for being one-sided and - following Krause's philosophical methodology - sought the connection of induction

\footnotetext{
${ }^{236}$ See Claus Dierksmeier, "The Freedom-Responsibility Nexus in Management Philosophy and Business Ethics," Journal of Business Ethics, 101:2, 262-283.

${ }^{237}$ Here one should remember especially the works of William Stanley Jevons (1835-1882) and Carl Menger (1840-1921), in which it was announced that they wished to practice economics in the sense and in the form of mathematical mechanics. See Carl Menger, Untersuchungen über die Methode der Sozialwissenschaften und der politischen Ökonomie insbesondere (Leipzig, 1883) and William Stanley Jevons, The Theory of Political Economy (London \& New York: Macmillan, 1871) and his The Principles of Science: A Treatise on Logic and Scientific Method (London: Macmillan, 1874). For the contemporary debate see Samuel Bostaph, "The Methodological Debate between Carl Menger and the German Historicist," Atlantic Economic Journal 6:3 (1978), 3-16.

${ }^{238}$ For the argument against equating Smith's theory with laisser-faire economics, see Matthias Hühn \& Claus Dierksmeier, "Will the Real A. Smith Please Stand Up!," Journal of Business Ethics (2014), 1-14.

${ }^{239}$ See Gustav von Schmoller, Über Einige Grundfragen der Sozialpolitik und der Volkswirtschaften (Leipzig. Duncker \& Humblot, 1904) and Werner Sombart, Die drei Nationalokonomien: Geschichte und System; der Lehre von der Wirtschaft (München: Duncker \& Humblot, 1929). For the overall state of the discussion in his time, see Peter Koslowski, Methodology of the Social Sciences, Ethics and Economics in the Newer Historical School: From Max Weber and Rickert to Sombart and Rothacker (Berlin \& New York: Springer, 1997).
} 
and deduction in conceptual construction. ${ }^{240}$ That means, in the first instance, that neither reality should be dismissed as negligible for the benefit of pure theory, nor that the proper momentum of the economic sphere may be neglected in pursuit of noble ideals. Theory and practice should relate to one another through a common goal. Mediating concepts ought to be expressly construed, in order to integrate both spheres productively, instead of playing them off against one another. ${ }^{241}$

On the basis of frequent factual divergences between morals and the economy and, at the same time, because of their conviction regarding the (principal, freedom and responsibility based) commensurability of economic and ethical laws, the Krausists assigned to economists the task of scientifically investigating how market failures and social evils can be theoretically explained and practically corrected. They, so to speak, author the economic philosophy of a substantive idea of freedom, encompassing as well as socially reshaping both negative and positive aspects.

For the Krausists, the adequacy of society's influence upon economic life results not from a quantitative plea for either more state action (as on the part of the socialistic liberalism and the representatives of positive freedom) or less (as on the part of the Manchester liberalism and the supporters of negative freedom), but rather from the qualitative prescription to enable the freedom of all. ${ }^{242}$ From this then follows the stipulation to intervene by means of economic policy in free economic activity as much as is necessary and, at the same time, as little as is possible. The state's balancing activity must be subsidiary and thus secondary to the primary endeavors of individual self-reliance and charitable care for others. ${ }^{243}$ The state is the last guarantor of opportunities to a life in freedom, not their first producer. A free state requires a free economy; and where the latter fails, the former repairs it, but does not replace it. $^{244}$

In an ideal market (i.e. in a market not distorted by asymmetries from information, power, opportunities, transaction costs etc.) individual economic activity directs itself to where the greatest profits are expected. Thus production takes place wherever the greatest possible value can be attained by the least possible means; a

\footnotetext{
${ }^{240}$ For Krause's concept of construction see Claus Dierksmeier, Der absolute Grund des Rechts, Chapter 3.

${ }^{241}$ See José Manual Piernas y Hurtado, Tratado de Hacienda Pública y Examen de la Española (Madrid: Tip. De M. Ginés Hernández, 1891), 25ff.

${ }^{242}$ E. Diaz situates Krausist social-politics upon the golden mean between "abstencionismo" and "estatalismo" in his Krausismo e Institución Libre de Enseñanza: Pensamiento social y politico, $230 f$.

${ }^{243}$ In the first instance people should help one another upon a voluntary basis. Wherever this help is not enough to guarantee that each and all can live freely and self-determine themselves, the state should, according to Hurtado, compensate the "deficiencias de la caridad privada" by "beneficiencia publica” (Hurtado, Tratado de Hacienda Pública y Examen de la Española, 116).

${ }^{244}$ Hurtado thus writes that the state should not run and take into its own hands "la industria por via de especulación," but may exercise an influence only upon the economic processes necessary for freedom, law and security, "cuando la actividad privada no se sienta capaz o no se halle dispuesta a llevarlas a cabo por si misma" (Hurtado, Tratado de Hacienda Pública y Examen de la Española, 117f).
} 
process that optimizes the societal allocation of resources. As a consequence, private economic activity promotes the common good without having to directly intend this effect. Given these presuppositions (which, however, in such a pure form only exist on economists' blackboards), the government's direct and material intervention into the entrepreneurial calculations may damage the efficiency-enhancing allocations of the market. Then, "laissez faire" would make more sense, but not in order to bring about such ideal market conditions.

For real markets other considerations apply. From a Krausist point of view, one must insist upon a formal configuration of the market and certain guidelines for entrepreneurial action. A protection of public goods by regulations as well as performance-friendly taxation should continually broaden the opportunities for economic self-reliance and thus improve the presuppositions for fair transactions. Where this succeeds, a wage policy orientated by the market price, including a correspondingly unequal distribution of wealth can be accepted - not only in the name of economic efficiency, but also as an expression of the different extent of people's ambitions. This, however, only holds true if and where all have the chance to better themselves through their own accomplishments. Where this is not the case, the community must help out.

In elaborating the factual presuppositions required for a fairer market, the Spanish Krausists follow a three-level model of the individual (micro-level), intermediary associations (meso-level) and the state (macro-level). Piernas Hurtado, for instance, thus prescribes as a qualitative end that all economic life should provide everyone with appropriate conditions for life and freedom, by which the quantitative pursuit of profit is positioned at the level of a - legitimate and necessary means, but can no longer appear as an end in itself. Means and ends - technical and normative rationality - cannot be played off against one another within this model, but rather are constructively related to one another: Parameters and systems of recognition have to be found by which a state may attain welfare, companies can attain cooperative revenue, and individuals are able to make profit, each in a manner that helps rather than hurts the social, ecological, and moral contexts of the economy. ${ }^{245}$ The Krausist economic doctrine thereby already anticipated in the late nineteenth century attempts again undertaken in the late twentieth century to coordinate freedom, equality, and independence structurally with the internal logic of the economic sphere, so that the individuals' opportunities and the freedom of all are enhanced at one and the same time. The Spanish Krausists were thus well ahead of the Methodenstreit ("methodology controversy") and Werturteilstreit ("value-judgment controversy") in economics around the turn of the twentieth century - and formulated a philosophical standpoint which still contains much potential for our current debate (for the current state of economics see Sects. 4.1.3, 4.2.1, and 5.2). ${ }^{246}$

\footnotetext{
${ }^{245}$ See Stoetzer, Karl Christian Friedrich Krause, $311 \mathrm{ff}$.

${ }^{246}$ For the contemporary debate at the time see Jürgen Backhaus \& Reginald Hansen, "Methodenstreit der Nationalökonomie," Journal for General Philosophy of Science 31:2, 307336. For Amartya Sen's role in current economics see Steven Pressman and Gale Summerfield, "The Economic Contributions of Amartya Sen" in S. Pressman (ed.), Leading Contemporary
} 
Economic policy is promoted or impeded by the constitutional order. In the interests of everyone's freedom, Krause votes for a federal-subsidiary state constitution in which sovereignty is not handed to a single higher-level authority, but is rather collectively exerted by the legislative, executive, and judicative powers (VR 528). ${ }^{247}$ With freedom as his method, Krause strives for a political order that does not treat citizens as merely passive objects, but as active subjects, and so includes them in the state's decision-making. Freedom should be granted to the population in a procedural manner; the population is meant to participate in legislation. ${ }^{248}$

The Spanish Krausists put this mandate directly into practice, as may be illustrated by the 1883 referendum about the 'cuestion social' by Gumersindo de Azcárate (1840-1917). ${ }^{249}$ At that time, Spanish society threatened to fall apart because of the antagonism between labor and capital. To address blatant social inequality, monarchist forces recommended to Spanish society that it take a step into the past towards the violent restoration of the pre-modern social order. Conversely, socialist groups backed violent revolution leading to an egalitarian future. Against these two dirigistic alternatives, the Krausists put their entire trust in a participatory solution: Peaceful reform of the current state of affairs through the involvement of the population. Trusting the capacity for the enlightened selforganization of society, Azcárate initiated a countrywide 'Encuesta' about the social question, which documented sociopolitical demands. That brought about the resolution to the controversy and enabled the Krausists to defuse tensions by actualizing several sociopolitical demands, which previously were not implementable: A "proof of concept" for the Krausists's favored model of deliberative political governance and the harmonistic model of society underlying it.

The integration of the people's will into legislation may, though, never take place at the cost of the principle of law, according to Krause: "The fact that one or millions are deciding for an action in complete agreement makes it neither just nor

Economists: Economics at the Cutting Edge (London \& New York: Taylor and Francis, Routledge), 66-98.

${ }^{247}$ In respect of the regional structure of the state, Krause distinguishes between villages and provinces, i.e. tribal and national communities, and applies them to a separate, federal, and subsidiary ordered structure of administrative systems (VR 349). His follower Heinrich Ahrens develops Krause's thinking and wants to establish a federalism of the golden mean - between the extreme positions of the state being only the sum of the communities or the communities being the mere agents of the state - with the help of Krause's "life-philosophy" (Lebenlehre) according to which every higher form of life is characterized by a moderate transformation of its nevertheless autonomous members (Heinrich Ahrens, Die organische Staatslehre auf philosophisch-anthropologischer Grundlage [Wien, 1850], 221ff.). For the socio-political appropriation of these ideas in Krausismo see Johannes Michael Scholz, "Krausistische Staatskritik in der spanischen 'Restauración"” in Bergfeld (ed.), Aspekte europäischer Rechtsgeschichte: Festgabe für Helmut Coing zum 70. Geburtstag (Frankfurt, 1982), 335 and Scholz, Legitimationspraktiken krausistischer Dezentralisierungspolitik, 117-163.

${ }^{248}$ For the status of all democratic "cooperation of legal persons" in the legislation see also Landau, Karl Christian Friedrich Krauses Rechtsphilosophie, $90 \mathrm{f}$.

${ }^{249}$ See Johannes Michael Scholz, "La función sociopolitica del krausismo" in Ebert (ed.), Reinvindicación de Krause (Madrid, 1982), 87-99. 
unjust" (NR 228) Democracy must never degenerate into the tyranny of the majority (AR 192). Only the systematic mediation of the empirical will of the people with the normative idea of law can legitimately determine the state's activity. ${ }^{250}$ Freedom may never be surrendered to the sheer will of the state apparatus or the majority of the population. Citizens owe obedience only to a lawful regime.

A state can certainly not demand the blind obedience of its citizens, but can demand free obedience, that is, an obedience grounded upon their own recognition of the reasonableness of the laws; otherwise the state would make machines out of its citizens, would itself hinder reason and profane its own vocation. (G II 173)

The common good is for Krause not simply the smallest common denominator of all factual interests. The universal will is not the same as the will of the majority, but must be ascertained from instances of a legislation orientated around the principle of law (VR 523). The legitimate will of the people thus does not just exist before and beyond the constitutional procedures, but rather first emerges from them (VR 522). ${ }^{251}$ One cannot divide democratic substance from its constitutional form or play them off against one another. Procedures and principles require and condition each other.

Only insofar as they govern themselves in conformity with law "are the people themselves the sole administrator of law, sovereign, and autocrat" (LL 207); only then is there "a community, res publica, in the complete, genuine sense of the term" (LL 207). Under this strict and often unfulfilled precondition alone one could say "that what the community establishes as right is right in itself as well" (LL 211). Where this legal representation of the people's will succeeds, Krause prioritizes the idea of the parliamentary democracy over the then prevailing form of government, namely, constitutional monarchy (VR 541n.) Also and especially democracy remains subordinated to law and this, in turn, is subordinated to freedom, which is why Krause demands a transparent policy of "absolute publicity" [Publicität] (ERB 109). Legislative "decrees must have this disclosure, that is, they must be publicly decided, publicly announced, and accessible to everyone at all hours" (G II 167). Similar to Kant, Krause concludes that "the basis of the absolute disclosure of state authorities is positive, whereas mistrust and fear of suppression are not" (ERB 109). Publicity promotes participation. It lets individual and collective freedom find within each other a regulative body which enables them together to construct and thereby reciprocally optimize the democratic will.

\footnotetext{
${ }^{250}$ For a complete contrast, see the concept of right in the contemporaneous Rechtslexikon (Weiske und Bopp): "The national spirit [Volksgeist] collectively living and operating in every individual creates positive right" and "the foundation is the collective consciousness of the people; one recognizes this because it reveals itself in outer actions by emerging in practice, convention and custom; in the uniformity of a continuous, thus lasting conduct one recognizes the people's belief, which is a common root opposed to mere coincidence" (ibid., 152f.).

${ }^{251}$ This distinction between immediate people's sovereignty and lawfully, i.e. institutionally mediated national sovereignty is further developed by, above all, Krause's follower, Heinrich Ahrens. For an exemplary case, see Die organische Staatslehre auf philosophisch-anthropologischer Grundlage, $197 \mathrm{n}$.
} 
This turn towards a transparent, dialogue-orientated, and self-critical political model, too, was further developed by the Spanish Krausists. ${ }^{252}$ They did not want static and etatistic policy making, but rather one that was societal and dynamic, i.e. a policy constantly further developed by a discourse in the light of its own liberal leitmotif. Instead of, like many Continental European liberals, primarily defending acquired liberties, they continuously aimed at the conquest of new freedoms..$^{253}$

Freedom enhancing policy requires state institutions. That is why Krause was skeptical about the theories concerning the imminent death of the state that were emerging at the time. Injustice (and thus criminal state activity) could certainly diminish with a progressive improvement of living conditions (NR 230). But even if crime could one day be reduced to zero, "policing and punishment would be abolished, but law would not be" (VR 360). Anything else would mean mixing up (negating) administrative and criminal law with the whole of law and thus misunderstanding the (positively-affirmative) character of the constitutional state (NR 239); for "the state is not originally established to avoid and to destroy injustice, but rather it is the institution of society which is supposed to realize the idea of law" (LL 192f).

This vote in favor of the constitutional state is in no way the same as a sanctification of the national state. ${ }^{254}$ The "people's state [Volksstaat] which one customarily incorrectly only called the state" (AR 179), certainly takes a prominent position in the circles of institutions protecting rights but may never be made absolute (LL 203). For, contrary to the tendencies typical of the age, Krause ascribes no excessive significance to the people's ethnicity. For one thing he explains in detail how legal structures evolve underneath and outside of the sphere of the nation state. ${ }^{255}$ For another thing, his thought is strictly cosmopolitan and rejects every form of patrio-

\footnotetext{
${ }^{252}$ In an oft-cited study by López-Morillas it says that the Krausist "es liberal porque el liberalismo politico es un postulado necesario de la doctrina de Krause, ya que, al mantener que no hay más autoridad que la razón, el krausismo subraya que el libre ejercicio de ésta es imposible bajo un régimen político fundado en el cesarismo o la arbitrariedad. Decir liberalismo es [...] decir proyección política del racionalismo armónico y luchar en pro de aquél es coayudar a la implantación de éste. [...] El krausista no abrazaba el liberalismo por simple preferencia o capricho, sino que necesariamente tenía que ser liberal si quería mantenerse fiel al espíritu de la doctrina que profesaba" (Juan López-Morillas, El krausismo español. Perfil de una aventura intelectual [Madrid, 1980] 176).

${ }^{253}$ See Julián Sanz del Rio, "El derecho y el Estado según Krause" in Boletin de la Institutción Libre de Enseñanza 6 (1882), 269.

${ }^{254}$ It seems particularly important that Krause reached the idea of the dissolution of the national state as the theoretical model of social unification over a hundred years before it arose within subsequent social sciences. Teresa Rodriguez de Lecea in "Der spanische Krausismo als praktische Philosophie" in Kodalle (ed.), Karl Christian Friedrich Krause (1781-1832): Studien zu seiner Philosophie und zum Krausismo (Hamburg, 1985), 202. For a modern critique of "methodological nationalism" see Ulrich Beck \& Edgar Grande, Das kosmopolitische Europa: Gessellschaft und Politik in der zweiten Moderne (Frankfurt am Main: Suhrkamp, 2004).

${ }^{255}$ See Vester, Sozialphilosophie und Sozialpolitik, 11ff.; According to E. Diaz the fact that the Krausist doctrine does not contribute to the "exaltación hegelinana del Estado" and favors strictly separating state and society considerably contributed to its favorable reception in Spain, Diaz, Krausismo e Institución Libre de Enseñanza: Pensamiento social y politico, 64n.
} 
tism devaluing foreign countries. ${ }^{256}$ National law, for Krause, clearly does not legitimate itself by itself (as in legal positivism), but does so by its functional contribution to the freedom of all, i.e. concretely, in order to "provide" everyone with "his human rights" (VR 350) through the institutionalization of political autonomy. Krause explicitly says that national laws are supposed to be always constituted with regard to the possible "attunement of the whole of living humanity" (ibid). In his footsteps, Latin-American Krausists enshrined the cosmopolitan and intergenerational obligation of all national politics into constitutional law. ${ }^{257}$

A people is, for Krause, simply the cultural correlate of a legal community (LL 206). Only as representatives of humanity are nations authorized to enact and sanction legal norms. Therefore, the idea of a nationalistic liberalism is a non-starter (NR 230, VR 352). Krause rejects Fichte and Hegel's assumption that the Universal Spirit (Weltgeist) is biased towards certain nations and would realize itself supremely within the German people. Krause counters that "all currently living human beings taken together [must] be considered as representatives of reason itself" (G II 156f). With him there is therefore no Universal Spirit predetermining history (by making a grubby backroom deal with this or that nation). Krause is interested in humankind as a whole and its shared cosmopolitan reason..$^{258}$

History is the open-ended process of human freedom (LL 160). To the individual and collective freedom there corresponds the openness of human history. ${ }^{259}$ The freedom underlying human commerce and social life, although not randomly chaotic, is nevertheless unpredictable on both the individual as well as the general level (VR 200). Insofar as humanity wishes to survive, it must necessarily progress in its ethical development (LL 129), but precisely this survival is not guaranteed "for it could even be mankind's own misfortune to be extinguished in its prime" (LL 175). Whether that will happen can only be shown by experience (LL 213n.). Human beings, not chained to specific forms of being and behaving, can fail in their collective projects just as much as in their individual projects (LL 160). There is thus no speculatively predetermined world history for Krause.

\footnotetext{
${ }^{256}$ Thus, for instance, in November 1815 he explains to his father: "In order to respect and to love the German people, I do not need to hate another people in an unjust way" (Briefe 435).

${ }^{257}$ The Argentinian constitution of 1853 can in certain essential respects be identified as Krausist (see Julián Barraquerro, Espirit y Práctica de la ley Constitucional Argentina [1a Tribuna, 1878]); in that, for instance, it is directed towards all mankind and not only the Argentinian people, that the basic rights are derived from personal right, that sovereignty is conferred only upon the whole of society and that it intends to provide a thoroughly subsidiary and decentralized redistribution of power. See Otto Carlos Stoetzer, "Raices intelectuales de la Constitución Argentina de 1853," Jahrbuch für Geschichte von Staat, Wirtschaft und Gesellschaft Lateinamerikas (1985) 22, 295339. As well as Claus Dierksmeier, "Harmonischer Liberalismus am Rio de la Plata," Liberal, Vierteljahreshefte für Politik und Kultur (2008) 50, 46-49.

${ }^{258}$ See León Esteban Mateo, "El Krausismo en España: Teoria y Circunstancia (1)," Historia de la Educación 4 (1985), 97-118.

${ }^{259}$ See Alfred Theodor Schneider, Karl Christian Friedrich Krause als Geschichtsphilosoph (Leipzig: Druck von Bär \& Hermann, 1907), 37.
} 
Historical agency is influenced by one's respective understanding of history (LL 22f.). Whether human beings master their tasks depends upon their respective use of freedom - and this is in no small part a consequence of their understanding of freedom (NR 262). The intellectual and the practical realization of the idea of freedom thus influence one another (VR 200). A fatalistic view of the world can paralyze efforts towards social emancipation, a liberal theory, on the other hand, can have emancipatory effects (G II 119). The contemplation of cultural history is thus partially determined by the history of freedom both on the universal (species) level and on the particular (individual) level (LL 401ff.). We are accordingly able to, on the one hand, speak of a historical progress towards and within the consciousness of freedom, without nevertheless suggesting, on the other hand, that one can be certain about the future course of history, e.g. about the expansion of liberal systems (LL 160). ${ }^{260}$

To think historically, then, means to rely on interpretations and embrace ambiguity. Krause too undertakes such historical interpretations. For instance, he conceives of the Europe of his day as being in a gradual transition from a period of intensive national and cultural differentiation to a more integrative phase of regional cooperation (LL 376-396). He hopes one could soon progress from the still prevailing quasi-mechanical "system of mere political balancing" to a more organic international legal order (EU 9). ${ }^{261}$ Most European states do already recognize fundamental human rights, freedom of religion widely prevails, and technology helps to disseminate ideas to overcome national borders (LL 425). Moreover, one would find everywhere the seeds of a historically founded common European consciousness (LL 422). ${ }^{262}$ The epochal step towards a supranational legal order could thus first of all be demanded and expected from Europe. ${ }^{263}$ Krause even draws up a sample constitution for such a union of European peoples, in the hope that a successful European Union might serve as a model for the world and find emulation in various regions. ${ }^{264}$

\footnotetext{
${ }^{260}$ Tiberghien's history of philosophy explicates Krause's ideas by interpreting history as the normative history of freedom and judges it from the point of view of a strict prohibition of retrogression and from a soft precept towards development; see S. Monreal, Krausismo en el Uruguay: Alguno's fundamentos del Estado tutor (Montevideo: Universidad Católica del Uruguay Dámaso A. Larrañaga, 1993), 68.

${ }^{261}$ See Clay MacCauley, "Krause's Proposition for a European League of States," The Advocate of Peace (1894-1920), 79 (11), 337-39.

${ }^{262}$ Krause's pro-European thinking distinguishes him from his philosophical contemporaries. See Rolf Helmut Foerster, Europa: Geschichte einer politischen Idee (München: Nymphenburger Verlagshandlung, 1967), 240-243.

${ }^{263}$ See Lorimer, The Institutes of Law, 310.

${ }^{264}$ It was not by accident that Krause published his Entwurf eines europäischen Staatenbundes in 1814. It contained ideas which Krause wanted to explain within his text on Erdrechtsbund, but which remained fragmentary (see von Mollat, ed. Der Erdrechtsbund an sich selbst und in seinen Verhältnissen zu allen Einzelheiten des Menschheitlebens [Leipzig, 1893]).
} 
The world's citizens can only attain perpetual peace through a law-abiding league of nations - for which Krause draws up constitutional considerations, too. ${ }^{265}$ For as long as there exists no legal institution spanning the planet, in cases of conflict every country can insist upon its right to self-defense. But where every state acts as a judge in its own affairs arms races and spiraling violence are the consequence (VR 500). It is therefore to be hoped that the world's citizens will see this sooner or later and then one day "legally determine the relations of peoples as the whole of mankind and establish a higher organism of law, to which the peoples will relate themselves in the same way that every individual human being relates to his own people" (U 60). The required delegation of state sovereignty rights to higher regional, as well as global, unities is legitimate since, from the outset, Krause sees the nation state as just one - but in no way the only - form for institutionalizing the rights of freedom (LL 203f.). ${ }^{266}$

But since and so long as this condition of global law is still a long way off, the rights of individuals and peoples must be promoted in other ways. ${ }^{267}$ Provisional legal systems are to be established. A few states, acting from joint principles, may suffice for a start (U 142). And Europe ought to take the lead (EU 11). For example, a European Union could abolish all military conflicts within the European continent (SL 318) and ensure that, at least within its sphere, the "law of peoples [becomes] increasingly independent of fortune or misfortune, the size of the population, and any arbitrary decision-making" (EU 13). Krause thinks that it would be optimal if the earth were gradually to be transformed by such regional associations of peoples working together towards the task of establishing a fair world order (LL 201, U 149).

These cosmopolitan ideas are the result of the methodological principle of Krause's participative liberalism. Since the idea of 'right' imposes a duty of everyone to contribute to the acquisition and preservation of the rights of everyone else, one is to strive to put the world eventually in precisely such a state wherein "every citizen of the planet, wherever he may be heading, is granted his germane personal rights" (VR 467). In just the same way as one avails oneself of human rights, one must also help others to realize theirs, regardless of how far away (spatially or temporally) they live. ${ }^{268}$ The legal world order to which Krause aspires for the future would bring with it transformations of existing rights (VR 449f.) and modifications of the earlier (local, national, and regional) legal systems (LL 204). Should a "state of mankind [Menschheitsstaat] on this earth" (VR 348) ever arise then one has to reckon with a certain redistribution of legal positions, which in the light of that new

\footnotetext{
${ }^{265}$ For the cosmopolitan and pacifist character of Krause's philosophy see Veit Valentin, Geschichte des Völkerbundgedankens in Deutschland: Ein geistesgeschichtlicher Versuch (Berlin, 1920), 48f.; Hermann Hetzel, Die Humaniserung des Krieges in ihrer culturgeschichtlicher Entwicklung (Frankfurt an der Oder, 1889), 58 \& 157; MacCauley, Krause's League for Human Right, 458.

${ }^{266}$ See Karl Viktor Fricker, "Das Problem des Völkerrechts," Zeitschrift für die gesamte Staatswissenschaft 28 (1872), 91-144.

${ }^{267}$ For more about Krause's "splendid cosmopolitanism" see also Carl Fortlage, Genetische Geschichte der Philosophie seit Kant (Leipzig, 1852), 228.

${ }^{268}$ Compare with Martha Nussbaum's claim that "humanity is under a collective obligation to find ways of living and cooperating together so that all human beings have decent lives" (Frontiers of Justice, 280).
} 
alliance appear in need of reform (U 147). ${ }^{269}$ But since the earth is anyhow "the original external property of the entire whole of mankind" (VR 463) and certainly fundamentally belongs to "all and everyone who are at the same time counted as rational ends," ${ }^{270}$ this is philosophically unproblematic, howsoever controversial the concrete legal implementation could prove (VR 466).

Krause hereby provides an interesting, indeed provocative contribution to globalization ethics. He seeks to mediate between theoreticians who claim that no possession of rights is ever of permanent validity until the highest possible system of law is established and those who claim that every historically acquired right must be binding for all times. "In between these, decisively emerges the unpartisan truth that subordinate rights of subordinate legal persons have the authority to prevail" wherever they need not be "demoted by the novel higher ground of law into an inferior position, and [adjusted] accordingly to the now arising and emerging higher organism of rights" (VR 328). This transformation must not always entail the loss of acquired legal positions in favor of a modified return. For there will always exist particular areas of life in which individual "independence must be maintained" (NR $264 n$.). The accession of a state to a community of peoples will not change many of its local structures. But in respect to certain geographical sources of livelihood (Lebenschancen) a compensation in favor of disadvantaged peoples is to be expected. For the actual occupation of nature and its treasures has taken place as a result of power-relations. Thus it often ran counter to the "authority to take possession of the earth" (NR 262) which equally belongs to all human beings - on account of their common ownership of the earth. Therefore the first possession of land cannot also be the last (NR 262). ${ }^{271}$

Since every newly created legal entity is not only encouraged to quantitatively further the total extent of its freedoms through expansion or internal complexity, but rather also qualitatively to enhance them and thus to free itself from ethical contingency and asymmetry (NR 264), some of its internal legal positions are continually to be modified (ERB 108). Such a fairness-oriented transformation of global ownership presupposes the "insight" and "good, rightful will" (NR 264) of the global citizens, which is obviously not always a given. Instead often, wherever tensions are encountered, there prevails violence, destruction, and war, between individuals as well as peoples (NR 265). Krause nevertheless believes that the hope for a growing legal penetration of the areas of social conflict is justified. Culture and the sense of

\footnotetext{
${ }^{269}$ In the same way, Martha Nussbaum claims that "one might then doubt that domestic arrangements can be insulated from scrutiny, if they are such as to make it impossible for people in other nations to live decent lives" (Frontiers of Justice, 229).

${ }^{270}$ See Martha Nussbaum: “The capabilities approach is fully universal: the capabilities in question are held to be important for each and every citizen, in each and every nation, and each person is to be treated as an end" (Frontiers of Justice, 78).

${ }^{271}$ Martha Nussbaum similarly says that "even the concept of redistribution [...] needs to be called into question, since it rests on the prior determination that people own the unequal amounts they have." She thus argues against positions which claim "that the part of a person's holdings that is needed to support other members of a society (or world, [...]), are actually owned by the people who need them, not by the people who are holding on to them" (Frontiers of Justice, 373).
} 
justice, on the one hand, and people's prudent self-interest on the other, are significant driving forces for the global advance of law (NR 268). Long-term economic calculations of utility hand in hand with an appeal to "the conscience of mankind" (U 305) can definitely result in humanity increasingly directing itself towards the integrative regulation and protection of rights by means of global institutions. And once an order maintaining the interests and rights of all of earth's citizens arises, it would also - because of the economic advantages attained through membership be very likely to endure. ${ }^{272}$

Krause in no way wishes to level the diversity of civilizations and peoples in that envisioned global federation of law, but rather especially aims to protect diversity through the progress of cosmopolitan law. ${ }^{273}$ While, in a legally unregulated world, economic and military power raze traditional cultures ad libitum, their chances for a critically-affirmative preservation are far better in well-ordered relationships of cosmopolitan law. Precisely because, for Krause, the earth belongs to all people and peoples for the realization of individual freedom, the lifestyles of cultures may also manifest themselves in dissimilar ways of life. The basic right of all humans to a self-determined life may well lead to a multiplicity of divergent local and regional legal systems. These can continue to exist as, in essence, internal specifications of a globally networked system of rights and freedoms (VR 539f.).

\begin{abstract}
That implies that neither is justified the one claim which in recent times was fanatically claimed and striven for: that all men could have absolutely only identical equal rights. Nor is justified the other claim, which was just as fanatically taken up and enforced: that every man could have only his own quite individual right, and consequently one is unable to think about a universal (human) right possessed by all men. Both of these erroneous claims rather rest upon two basic truths, which were however at the same time misunderstood and comprehended in a one-sidedly exaggerated fashion. The universal, ever equal right of man is the eternal, unchangeable, and forever remaining foundation, but, on this foundation, rights must then be further determined. (LL 197)
\end{abstract}

Krause's cosmopolitan vision is astonishing. Two hundred years ago, he already showed the sociological as well as normative boundaries of the nation-state and took up the theme of globalization. While at the beginning of the nineteenth century most German philosophers inferred from the de facto marginalized role of colonialized peoples an inferior status for them in terms of rights and freedom, Krause boldly marches in the opposite direction. He campaigns for "the One indivisible human nature" (VR 469) which all individuals share in, and demands that it be respected vis-à-vis all persons regardless of where and how they live.

Krause strongly rejects all racial differentiations within the right to freedom. He disapproves of the reference to a supposed cultural gap between European and nonEuropean peoples, common at the time for the justification of colonialism. Back

\footnotetext{
${ }^{272}$ See Vester, Sozialphilosophie und Sozialpolitik, 11 as well as Siegfried Wollgast, "Karl Christian Friedrich Krause (1781-1832): Bemerkungen zu seinem Menschheitbund und Friedensplan" in Erhard Lange (ed.), Philosophie und Frieden: Beitrage zum Friedensgedanken in der deutschen Klassik (Weimar, 1985), 260-276.

${ }^{273}$ See Clay MacCauley, Karl Christian Friedrich Krause: Heroic Pioneer for Thought and Life (Gazette Press, 1925).
} 
then, Krause was already using arguments very similar to those used today by, for instance, Thomas Pogge. ${ }^{274}$ Those differences of cultivation and civilization, Krause holds, largely do not at all exist in the form and intensity claimed. But where they do exist, they have in many cases first been brought about by practices of colonialism in violation of international law. Therefore cultural and socio-economic differences may never be employed for the justification of relations of subordination, as legal grounds for (further) discrimination or even as proof of racial inferiority. Those asymmetries rather obligate us to support with solidarity those affected by them as well as to provide remediation for colonialized peoples (VR 464). ${ }^{275}$

Certainly, Krause did not believe that ideas alone could change the world, but he also never gave in to the opposing view that the world could manage without them. Human beings are, not in the least, what they become; and the latter results in part from what they strive for. Only a theory which also knows of the ideas and ideals of humanity is thus of practical value. And it was precisely the establishment of such a realistic idealism to which Karl Christian Friedrich Krause devoted his entire life.

Particularly interesting in Krause is the status of philosophical arguments and, especially, the status of metaphysics. Citizens instead of professors should ultimately decide whether and which metaphysical body of thought should influence humanity's public self-image. Therefore, instead of providing the world with a single overarching metaphysics, Krause advocates a world where the consensus regarding values and norms requisite for cosmopolitan coordination arises from the many minor metaphysics of the citizens. His philosophy of freedom is thus, so to speak, self-reflexive: Krause had initially (descriptively) characterized the idea of freedom as an unavoidable foundation of human self-determination. Its analysis showed that individually freedom can be consistently employed only if one attributes it to all human beings. That universal (ascriptive) dimension of the idea of freedom then (prescriptively) corresponds to a normative consequence; namely, the responsible exercise of one's own freedom in the interests of all human beings. Krause's idea of a globally responsible freedom results from a cosmopolitan ethics whose specifications derive from the influence of precisely those for whom it wishes to be valid. Therefore, Krause's philosophy of freedom is a participative liberalism par excellence.

Nevertheless, some readers will no doubt ask why - if all of this is true and if this Krause really philosophized with such balance and foresight - they have never heard of him before. Why do we not find - as with other far less interesting philosophers - statues of him, streets named after him, and busts portraying him? Why does his name not appear in most histories of philosophy? Indeed, within the German and English-speaking academic world, he is hardly known. And anyone

\footnotetext{
${ }^{274}$ See Thomas Pogge, World Poverty and Human Rights: Cosmopolitan Responsibilities and Reforms (Cambridge \& Malden, MA: Polity, 2002).

${ }^{275}$ Once again Martha Nussbaum's position is compatible: "Many of the problems of poorer nations were caused by colonial exploitation, which prevented them from industrializing and robbed them of natural resources, among other things. Redistribution in the present seems an appropriate form of remediation for the past" (Creating Capabilities, 115).
} 
who searches for him on the internet or within appropriate lexica often finds his work less favorably presented as here. Krause is condemned for abstruse language, fantastical ideas, and metaphysical preferences, and thus the impression may arise that he is justifiably forgotten.

Elsewhere I have endeavored to rebut these objections in detail. ${ }^{276}$ Hence I shall confine myself to but a few cursory observations here. That Krause was an enthusiastic utopian with obsolete metaphysics, would, in the light of the argumentation reconstructed here, appear doubtful. It is true however that Krause worked out his own technical terminology, which does indeed make the appropriation of some of his works more difficult. Although this was not always the case - some of his writings and also some of his posthumously published lectures are very clearly and, indeed, most elegantly written -, Krause's at times excessive recourse to his own terminology has certainly hindered the reception of his thought.

The external occasion for this move was the religiously and politically tense situation at the University of Jena. First, his teacher Fichte was forced to leave the university because of the so-called atheism controversy and, subsequently, also his colleague, Schelling, left in the wake of the so-called pantheism controversy. ${ }^{277}$ Krause, who had developed his own philosophy through critical engagement with theirs, did not wish to get into 'the cross-hairs' of questions about the philosophy of religion. Also, Krause wished to escape the ambiguities of quotidian concepts through a regularly constructed derivation of the required technical terms so as to bequeath to philosophy a logically unambiguous terminology. Other thinkers with similar aspirations, like, for instance, Leibniz (with his 'mathesis universalis') attained more recognition for such efforts than did Krause.

It seems to me that the actual reason for Krause's poor reception in his homeland was much rather his unfortunate academic career. In his time, only a few philosophers outside the university system were able to raise their work into public consciousness. Krause, though, never managed to get hold of a regular professorship. This had to do, for one thing, with envious chicaneries from political and academic opponents ${ }^{278}$ and, for another, certainly also with Krause himself. He neglected to promote either himself or his work. Tactical maneuvering was far removed from his nature. Trusting that his philosophy spoke for itself, he (all too?) peacefully acquiesced to inferior employment contracts and chose to apply his energies to the development and perfection of his system at the expense of its marketing. He had absolutely no desire to be a 'public intellectual.' Therefore, the true responsibility for the lack of prominence of his philosophy lies more within his personality than in his works, whose rediscovery is very much to be hoped for. Facing enormous cosmopolitan challenges and searching for a healthy mean between an irresponsible

\footnotetext{
${ }^{276}$ See Dierksmeier, Der absolute Grund des Rechts.

${ }^{277}$ For more information about this see Klaus Kodalle \& Michael Ohst Martin, Fichtes Entlassung: Die Atheismusstreit vor 200 Jahren (Würzburg: Königshausen \& Neumann, 1999).

${ }^{278}$ For a more detailed discussion see Enrique M. Vierhaus Rudolf Ureña, K. C. F. Krause: Philosoph, Freimaurer, Weltbürger: Eine Biographie (Stuttgart-Bad Cannstatt: FrommannHolzboog, 1991).
} 
libertinism on the one hand, and the equally unappealing alternatives of socialist or religious command economies as well as virtue- or eco-dictatorships (Tugend- oder Ökodiktaturen) on the other, the global community today can discover in Karl Christian Friedrich Krause an instructive precursor of the project of a liberal world ethos (Weltethos).

\subsection{Results and Implications}

In this section, as in later sections under the same heading (Sects. 3.3 and 4.3), we pause in order to see what systematic results our trawl through history has yielded, and what consequences can be derived from them for contemporary work on a theory of freedom.

Immanuel Kant showed: Only through the freedom to act morally can we make our own (also immoral) decisions. Without this ethical freedom enabling us to opt against our inclinations, we would be mere automatons weighing up quanta of pleasure, impelled by advantage-maximizing algorithms programing our very existence. Our freedom would be neither unconditioned nor spontaneous; it could not make us the authors of our actions.

Our real employment of that radical freedom is obviously also conditioned by the circumstances of life, by education and cultivation, by access to resources, both material and informational, and political as well as cultural. Not only a lack of rights diminishes freedom. Not only the legal, but also the social and cultural buttresses of freedom should therefore be strengthened by liberal politics. But since Kant also maintains, in harmony with classical liberalism, that coercing state interventions should be limited to the narrow sphere of the administration of rights, other noncoercive forms of politics must be found. To further the radius of an empowering and capacitating politics enabling an autonomous life for everyone, it must be open to the interests and opinions of the population.

Yet Kant does not only legitimate - he also limits - the democratic self-regulation of the open society according to the principle of a freedom self-consciously shaping itself. He thereby prepares a bridge towards conceptions of the 'common good' considered off limits by many other liberal theories. Freedom, he declares, can only be consistently conceived as directed toward a notion of a "highest good," albeit one open to different interpretations. Freedom's highest good does not lie ready-made waiting to be found. It only arises as a result of a communal searching and striving: as the result of free political deliberation. Against the false alternative - fostered by many of liberalism's friends and enemies - of either a theory of freedom averse to values or one consumed by ethical commitments, he opens a third way. Kant shows that freedom always already has a resolve towards values, without dissolving itself in them.

Culture is required for values to be realized in a liberal manner; so that the state is not lead into attempting to violently counter moral anomie, ethical pathologies, and social atomization; and so that ethical impulses (ethischer Drang) instead of 
governmental impositions (staatlicher Zwang) create the required commitments and institutions which enable individuals and institutions to tolerate freedom. A liberal society needs the state to promote culture (Kulturstaat); not to establish a dominant culture, but certainly to place into the citizens' hands the necessary means of communication for peacefully and liberally developing a shared political will. The more the representation of minds and the collaboration of spirits succeed, the easier becomes the coordination of body and things. Culture improves governance. Wherever it facilitates identification with others and empathy for their situation, people find it easier to act from consideration and self-restraint, for instance by improving the livelihood of strangers. Especially in the era of globality and evermore pluralistic societies, a cosmopolitan culture that promotes sympathy for the fate of foreign human beings is of increasing significance.

Fichte reassesses the Kantain attempt at making freedom the foundation of all modern, self-reflexive, and self-critical philosophy. He points out: One cannot philosophize about freedom without considering its, above all, social presuppositions. But how are these to be integrated into philosophical liberalism? Fichte wishes to achieve this through a theory of reasonable freedom. Only a thoroughly rational concept of freedom could identify what precisely state and society have to provide for individuals' autonomous lives. Since only (his) philosophy can legitimately indicate the freedoms truly worthy of promotion, only the philosophically directed state - but not the freely constituted citizens' will - is granted the right to define and concretize the right to freedom.

Fichte thus commits an instructive error: Whoever, like Fichte, views the world as either material conforming to reason or as mere resistance contrary to reason, will treat it in just the same way. The same is true of our fellow human beings. Alterity is valuable to Fichte only when in service of his philosophical model; in all other cases it is seen as a hindrance to be abolished. In the realm of such thoughts there is no room for shades of grey. Everything within nature and society is clearly separated into black and white according to how serviceable it is to freedom. With Fichte, the normative force of freedom thus has theoretically and practically excessive effects. This leads to an exaggerated concept - as well as to an over-bearing reality - of legal coercion. Fichte's insistence that freedom is essentially ethically orientated is just as convincing as his wish to protect only ethically realized freedom appears bizarre. His correct view that coercion may only be legitimated through the logic of freedom, however, in no way justifies Fichte's erroneous belief that coercion also presents the correct means for every advance towards freedom.

For Fichte, coercion is advanced from a means to enable a state of law to a means to realize reason's ideal state. And therein lies the decisive problem. A notable example is Fichte's social-contract doctrine. In order to motivate the individual towards law-abiding behavior by means of a machinery of incentives and punishments, Fichte contrives a mechanism of legal and economic relations resting upon strict reciprocity. Wherever that symmetrical reciprocity is absent, no legal relationship - and, as a result, also, no protection of freedom - is achieved. This model cannot process asymmetries. It supports a closed social space that continually safeguards a static equilibrium through strict (legal and economic) surveillance. 
Human beings are entirely prevented from politically or economically exercising their freedom in ways Fichte views as unreasonable.

The result is, in many respects, a dictatorship of reason in the name of freedom. Since Fichte believes himself able to derive most precisely what and how much every human being needs to live freely, he embarks upon, for instance, planning an optimal economic system. Therein the state features as that which is reasonable and the market as that which is contrary to reason. Since the market only disturbs the well-planned distribution of goods it is eliminated. Fichte overestimates the possibility of the state to establish freedom-conducive relations between goods and services. At the same time, he underestimates the contribution market-structures can provide to this endeavor. It would have been more appropriate to conceive of the market as an a-reasonable process; one that - dependent on its political and cultural framing and direction - can be more or less reasonably shaped.

In Fichte's philosophy of freedom, liberal and totalitarian motives are thus fighting for predominance. At the same time, cosmopolitan and national motives battle one another. On the one hand, Fichte behaves universally and ascribes to every person an original right (Urrecht) to freedom. Still, he does not advance towards a globally-oriented liberalism. Because Fichte supposes that the reasonable order he strives for can only be secured in small, controllable spaces, he restricts his political perspective to the German people. And since global markets can disturb national equilibriums, the unstable world had better remain outside. Instead of devising procedures with which the challenges of globalization could be surmounted in a liberal manner, Fichte advocates national unilateralism. It is no wonder, therefore, that later populist thinkers chose him as their philosophical hero.

Karl Christian Friedrich Krause undertook to even out the socialistic-totalitarian and ethnic-nationalistic imbalances in Fichte's thinking. His critique of Fichte goes to the root of the matter, being directed against the false dichotomy between nature and reason. In truth, according to Krause, the relations between natural necessity and moral freedom are far more complex. Krause presents them in a multi-level order of forms of freedom interlaced with one another instead of in a model of opposed polarities. This order then provides a differentiated foundation for the conferral of rights and obligations. Krause can thus espouse ecological sustainability and the protection of animals for example - not as limitations, but as consequences of the liberal principle.

Krause seeks the foundations of ethics beyond the logic of reciprocity. Against the Fichtean social-contract theory (and contemporary game-theory) he establishes a foundation for the principle of freedom that encompasses not merely symmetrical exchanges but also asymmetrical situations in life. This allows him to guarantee human dignity unconditionally: Unborn lives, the severely disabled, members of future generations, and the senile must be protected by the legal and societal order even though their contribution to it might not be economically equivalent to what they receive. For Krause wishes to formulate the rights of all persons so that people become effective about what affects them; wherever possible through participation, and otherwise through representation. With Krause, humanity as a whole is promoted to the overall corrective of all legal claims. Consideration for other human 
beings' rights to freedom appear, from this perspective, not as subsequent curtailments of an originally infinite freedom, but rather as the outer expression of the inner structure of freedom. For Krause, freedom goes in hand with responsibility for the freedom of others.

Especially in regard to the right to property it becomes clear how this different groundwork leads to an innovative liberalism. Property and possession are to be cherished for promoting freedom, according to Krause. Certain - absolute - forms of property, however, often prove less conducive to the freedom of all than other relative - forms. The liberal support for private property must correspondingly prevent property from being never communally and always exclusively possessed. In contrast: The enabling of an autonomous life for all functions as regulator of the order of possession; and therefore the human claim to just participation is globalized by Krause. Our commitment to help others attain freedom does not end at the front door, customs-barriers, or national boundaries.

Krause's cosmopolitanism outshines the work of his predecessors. He holds a subsidiary federal order to be the best protection of freedom inside the nation as well as outside of it, in the international and intercultural space. Just as on the domestic front Krause pleads for the civil-societal development of institutional orders, he makes similar pleas in foreign (and global) affairs. He opposes a globalization 'from above' with his model of a cosmopolitanism 'from within.' Krause wants freedom's commitments to be established by the global citizens themselves. As a result his preferred procedure is a subsidiary political self-determination arising from civil-society organizations and movements, and not the plebiscite; one finds contemporary equivalents of these ideas in, for instance, the concept of Network Governance and Stakeholder Democracy. By differentiating the idea of freedom in the medium of freedom in various concepts of freedom, Krause's philosophy returns to its methodological principle, already sketched by Kant. It frees human beings for the formation and implementation of their own representations of freedom.

We here witness a historically as well as systematically fascinating trajectory of thought in three steps: Kant had turned the idea of freedom back upon itself, by showing that the basis for the legitimation of individual freedom is the freedom of all. Correctly understood, the freedom of others and its promotion must hence be recast as an objective for individual freedom. Fichte further develops this consequence, albeit in a manner often running contrary to its liberal core concern. From the task established by Kant and the overblown Fichtean solutions, Krause extracts the appropriate consequence: To elevate the realization of the idea of freedom not merely as the aim of individual liberties, but rather to make liberty also the means for its pursuit.

Correspondingly, these three thinkers present the relationship between metaphysics and freedom very differently. In Kant, metaphysics serves to enable the self-questioning of everyday conceptions of freedom. Fichte employs it in order to give a definitive answer to those questions. And Krause in turn uses metaphysical thinking as a horizon of orientation before which human beings can individually as well as institutionally answer the conundrums being produced by the radical nature 
of their freedom. In short, with Kant, metaphysics leads us to the big questions how freedom should relate itself to its lifeworld. Fichte's metaphysics provides but one big answer, whereas Krause uses his metaphysics in order to combine Kant's big question with the global citizens' many small answers.

Open Access This chapter is licensed under the terms of the Creative Commons Attribution 4.0 International License (http://creativecommons.org/licenses/by/4.0/), which permits use, sharing, adaptation, distribution and reproduction in any medium or format, as long as you give appropriate credit to the original author(s) and the source, provide a link to the Creative Commons licence and indicate if changes were made.

The images or other third party material in this chapter are included in the chapter's Creative Commons licence, unless indicated otherwise in a credit line to the material. If material is not included in the chapter's Creative Commons licence and your intended use is not permitted by statutory regulation or exceeds the permitted use, you will need to obtain permission directly from the copyright holder.

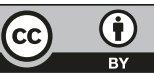




\section{Chapter 3 \\ Quantitative Freedom}

Despite all of their particular differences, the metaphysics of freedom of Kant, Fichte, and Krause have a common guiding thread: They characterize freedom according to its inner essence before setting to work on the outer delimitation of individual freedoms. They differentiate between essential and inessential, meaningful and meaningless options, and first designate which freedoms are in question before indicating how many of these respective freedoms are to be granted respectively. That consensus about the priority of the qualitative nature of freedom and its merely subordinate quantitative contours is due to the fact that Kant, Fichte, and Krause philosophize about freedom essentially from the consciousness of freedom. This fundamentally qualitatively and normatively evaluative consciousness serves them as a decisive test for the cogency of their theories of freedom. Since the era of German Idealism, however, the willingness to employ metaphysical arguments for the philosophical investigation of the consciousness of freedom has noticeably decreased.

In the face of a world where, in the shadows and security of theological dogmas, freedom of thought and civil liberties were curtailed for centuries, the wish for more theoretical and practical license grew. To some a frontal assault upon the ancient walls of metaphysics seemed necessary. With David Hume (1711-1776), an alternative philosophical program gradually began to gain acceptance. From now on, truth was in no way seen to be gleaned from mere conceptual speculation or cognitive intuition, but should rather be gained either analytically by means of the logical examination of "relations of ideas" or synthetically by means of interpersonally accessible "matters of fact." In the first case a priori knowledge is possible, in the second case only knowledge a posteriori; the former can be unconditional, while the latter only lays claim to conditional validity. With some modifications, the majority of positivist and analytic philosophers of the nineteenth and twentieth centuries retained this two-source theory. They refused to search for a third font of knowledge, i.e. for cognitions necessary for consciousness and independent of

${ }^{1}$ David Hume, Philosophical Essays Concerning Human Understanding (London: Cooper, 1801). 
experience, which nonetheless structure the latter - like, for example, Kant's a priori synthetic judgments or the dialectics of Fichte, Schelling, Krause, or Hegel. ${ }^{2}$

What does this methodological presupposition mean for the theory of freedom? Whoever accepts as true only that for which either logic or experience provides compelling grounds must establish the essence of freedom through either logical analysis or empirically locate it: Voilà, the theoretical program of large parts of the Anglo-American philosophy of freedom in the twentieth century.

Let us first turn to the empiricist attempt. Its positivist investment restricts freedom to phenomena that can be observed through the five senses; primarily to freedom of movement. The forefather of such attempts is Thomas Hobbes with his physicalist concept of freedom (which we already encountered in Sect. 1.3.2). The advantage hoped for by such an undertaking is a value-free, purely descriptive concept of freedom that first defines the permissible linguistic field upon which later questions of a normative nature can be cultivated - for example, who owes to whom, and how, the (re-)production of which freedoms. ${ }^{3}$

One nowadays no longer follows Hobbes, who includes in his definition of the boundaries of freedom also physical constraints and natural hindrances. Rather, most side with Jeremy Bentham (1748-1832) who only accepts boundaries other human beings could be held causally responsible for. The particular aim of this demarcation is to delimit clearly from one another "freedom as normative condition and freedom as physical fact"; the physical freedom resting upon "modal categories of possibility and impossibility" is to be separated from normative questions orientated towards "deontic categories of permissibility and impermissibility."

At first glance, that appears convincing: What one can and what one may often differs. But not always. The mere fact that we can clearly distinguish conceptually between ability and authorization does not mean that also in reality there could be "no necessary connection between instances of normative freedom and instances of non-normative freedom." If, for instance, libertarians advocate that the same freedoms that are open to the rich are also open to the poor, they nevertheless base their claim upon precisely this assumption: The poor may (normatively) ultimately aspire to the same thing as the rich, but merely often can not (physically) attain it. Their (prescriptive) freedom nevertheless is said to remain untouched by this (descriptive) incapacity and to resemble the freedom of affluent people. Poverty thus does not seem to be a problem for the philosophy of freedom. This is countered with the well-known objection on the part of social-liberal thinkers that the "freedom to sleep under bridges," 6 for instance, nevertheless appears very different to the poor

\footnotetext{
${ }^{2}$ See Alfred Jules Ayer, Language, Truth and Logic (London, 1936)

${ }^{3}$ Felix Oppenheimer, for instance, is a representative of this position. He writes: "An agreed descriptive language is a prerequisite for a fruitful discussion of normative issues" (Felix Oppenheimer, “'Constraints on Freedom' as a Descriptive Concept,” Ethics 95:2 (1985), 309).

${ }^{4}$ Kramer, The Quality of Freedom, 59.

${ }^{5}$ Ibid., 61.

${ }^{6}$ This formulation is, as far as I am aware, found for the first time in Anatole France, Le lys rouge (Paris, 1984).
} 
than it does to the rich. Since the rich can also sleep somewhere else, it is all the same to them whether they may sleep under bridges. Rendering the separation from facts and norms absolute could consequently lead to a suspect theory and a cynical practice. Yet, against this objection libertarians maintain: Even if one is poor, there would nevertheless be a marked difference between a society in which the poor, like the rich, could avail themselves of this very freedom and one in which the police cordon off all bridges. ${ }^{7}$

Who is right? Let us scrutinize this: Can one really describe what people 'can' do in purely physicalist terms before dealing normatively with what they 'may' and 'must' do? Is this truly the smallest common denominator, agreeable to all, from which any controversy in the philosophy of freedom can be untangled and solved? Can we measure, enumerate, and calculate freedoms? Is this the key that opens the door to comparing and distributing freedoms interpersonally? ${ }^{8}$ Doubts seem appropriate.

Even physical ability arises in the context of authorization. Someone, for example, suffering from a tetanus infection in the leg will experience a quantitative reduction of his abilities: His initial set of physical freedoms to walk and/or to limp is numerically reduced to the 'freedom' to limp. ${ }^{9}$ Yet that does not have to be the case. Most societies prevent such cases with tetanus injections - or treat them with penicillin. Access to tetanus and penicillin, functional for one's physical freedom (to walk), is socially provided: through a legal authorization, i.e. by the consent to appropriate the requisite medicines (hitherto in the possession of others). Whoever does not receive such consent (by lacking means of payment for instance) must limp. Ability and authorization are, consequently, in this case in no way absolutely separable from one another. Their relationship - and thereby our real freedom - varies from society to society and, also within certain societies, from one point in time to the next. ${ }^{10}$ In a communist society, access to medicine should be for either everyone or no one. In a consistently libertarian-capitalist society, however, it may be available only through sufficient private financial means. Whoever would want to obtain the required medicine otherwise would be stopped by the long arm of the law: a physical coercion par excellence. The physical freedom (to be able to walk again) encounters its limit in physical coercion (of the police's protection of possessions), yet only because those affected lack normatively legitimated options (legally to acquire medicine). Decreased authorization reduces physical ability; a lack of normative freedom reduces factual freedom.

What follows? The quantity of our descriptively describable freedoms ultimately depends upon the quality of the freedoms normatively ascribed to us, like, for example, the societally granted or refused freedom for basic medical care regardless of wealth. Therefore, the physicalist-quantitative concept of freedom is devoid of

\footnotetext{
${ }^{7}$ See Hillel Steiner, An Essay on Rights (Cambridge, MA, 1994).

${ }^{8}$ See Christopher Megone, "One Concept of Liberty," Political Studies 35:4 (1987), 621ff.

${ }^{9}$ I have borrowed this example from Philippe van Parijs, see Parijs, Real Freedom for All, 14.

${ }^{10}$ See Nussbaum, Frontiers of Justice, 165, 182.
} 
meaning without normatively-qualitative background assumptions (who possesses what and who owes what to whom). The oasis of semantic clarity luring us towards the positivist concept of freedom evaporates upon closer inspection into a Fata Morgana.

If freedom really only consisted in moving our body as we like, how could one then explain the emphasis and moral pathos with which political and philosophical discussions about freedom are conducted? Why do human beings desperately cling to certain freedoms, while nonchalantly renouncing others? ${ }^{11}$ That shows: If we completely separate the question concerning what actually makes a freedom valuable from the idea of freedom, then we subjectivize something that actually objectively belongs to the matter at stake. Wherever normative aspects belong to the freedom in question, a limitation to only descriptive judgments and a shift of the normative into the private leads us astray; it sacrifices truth to method. ${ }^{12}$

Whoever shuts themselves off from this insight - of freedom being normatively conditioned and socially constructed - must accommodate themselves to strange stances: In order to remain true to the program of mere description even something like coercion would have to be grasped purely materialistically: as physical necessitation. For lack of physical causality, mere omissions would not count. Coercion would require that an agent be physically prevented from acting. But that leads to bizarre consequences, because, on the view of those positivist-empirical stipulations, even a death threat does not coerce anyone to anything. In regard to the slogan: 'Your money or your life!' we could, after all, decide for the option of forsaking the latter. One may not voluntarily want to make such a decision, but many believe that such a decision nonetheless remains a free one. ${ }^{13}$ Nevertheless, whoever still blithely speaks of freedom even in regard to an acute death threat, may hardly present themselves as an analytic philosopher obligated to the customary use of language. Since, in everyday language, a pistol to the head stands, quite to the contrary, for a bitter loss of freedom.

What do we learn from this? A certain value (to allocate one's money free from intimidation) enters into the description of the facticity of the freedom to be discussed. The meaning of the expression 'Your money or your life!' is not quantitatively measured by the recipient against a factual benchmark ('How many options does that expression create or leave open?'). Rather this command is qualitatively interpreted in front of a normative horizon of interpretation ('How does this change the existence I cherish?'). Instead of celebrating that, quantitatively viewed, an additional option - to be shot dead - is now on offer for selection, the affected party may well lament losing an alternative of qualitatively higher value - to remain unin-

\footnotetext{
11 "If we view [...] agency as nothing but the pursuit of preference, or freedom as nothing by the absence of constraint, how are we to explain how some acts can be more central than others to the self, agency, freedom, identity or integrity [...]?" (Onora O'Neil, Constructions of Reason: Explorations of Kant's Practical Philosophy [Cambridge, 1989], 205).

${ }^{12}$ See William E. Connolly, The Terms of Political Discourse (Oxford, 1993), 139-143.

${ }^{13}$ See Serena Olsaretti, Liberty, Desert and the Market: A Philosophical Study (Cambridge, 2004), 148 .
} 
jured in possession of one's purse. One correctly understands this expression only as a necessitating threat to which one better comply by relinquishing the wallet: as coercion. ${ }^{14}$

The suggestion, therefore, that one could - first - decide upon the factual level whether a threatening situation implies a physically-causal coercion so that it could - then - be meticulously separated from all value-judgments (whether or not such coercion be legitimate), ${ }^{15}$ contradicts our experience, goes against our moral intuition, and is contradicted by the natural use of language. We also describe as unfree such people who, albeit not because of physical influence, but rather due to a credible threat, lose the chance to act autonomously. ${ }^{16}$ (The same is true - about which there is more to be said later - of the absence of physical causality in cases of failure to render assistance or of an unalleviated lack of the means of livelihood: here, too, freedom is curtailed.)

Coercion can thus be present in the absence of direct physical influence and whether this is the case has to be ascertained by value judgments. The positivist separation of fact and value does not succeed, therefore, neither with the idea of freedom itself, nor in the attempt to define freedom supposedly quite value-free - as the negation of coercion. The quantitative program to explain freedom through the formula 'less (value-free) coercion $=$ more (valuable) freedom' fails. We require an evaluative concept of freedom as well as coercion. In the last decades, analytic philosophy has therefore gradually distanced itself from the attempt to define freedom by purely concentrating upon visible, physical components. In an appeal to everyday pre-reflexive understandings of freedom, and their linguistic reflections, 'invisible' dimensions are now ever more often taken into account, for instance moral aspects of the idea of freedom. This, too, indicates that the immanent normativity of the idea of freedom presents the true basis for the controversies about freedom. ${ }^{17}$

That today's philosophy admits and examines the richer forms of meaning which our everyday language ascribes to the idea of freedom is surely a positive development. But is that enough? The analytic approach must, nonetheless, ultimately renounce every interpretation of the idea of freedom transcending the factual customs and boundaries of the linguistic community. This hampers the appropriate perception of counterfactual aspects, for instance when the idea of freedom confronts us as a normative demand to change our dominant ways of talking and acting. Consequently, one should ask more fundamental questions: Does it make sense to merely (extensionally) pin freedom upon its semantic or other expressions? Or should we not also (intensionally) investigate the idea of freedom according to its possible meaning beyond all previous manifestations? After all, were we to forget that the image of freedom, arising from an externally-objectivizing observation

\footnotetext{
${ }^{14}$ See Swanton, Freedom, 109-113.

${ }^{15}$ See Felix E. Oppenheim, Political Concepts: A Reconstruction (Chicago, 1981), 53, 160.

${ }^{16}$ See Jeremy Waldron, Liberal Rights: Collected Papers, 1981-1991 (Cambridge, 1993).

${ }^{17}$ In my opinion William Connolly is correct to declare that the idea of freedom is thus "contested partly because of the way it bridges a positivist dichotomy between descriptive and normative concepts" ("Liberty as an "essentially contested concept,"” in Cramer (ed.) Freedom, 200).
} 
alone, severed from its inner sense and purpose, was at best a replica of its worldly manifestation and never its original image, then we could unintentionally end up taking a distorted picture of freedom for its accurate portrait. Freedom then would shrink to (nothing other than) the mass of existing options, and all normative questions suddenly would be settled by the basic and base expression "the more, the better."

For this, too, David Hume provided the blueprint. Like Hobbes, he defined freedom as unhindered movement according to discretion. The space for the articulation of such movement itself has to be limited, since no individual freedom can be infinite, if space for the freedom of others is to remain. According to this model, there is an unavoidable competition between the individual's desire for freedom and interpersonal requirements for coordination. This is the Achilles' heel of many Anglo-American theories of freedom: their geometrical image, representing freedom via mutually exclusive shapes on bounded surfaces. This schema reduces freedom to a quasi-spatial conflict of distribution between incompatible circles of freedom. Accordingly, the relationship between law and freedom appears to Hume to be a tragic conflict: "In all governments, there is a perpetual intestine struggle, open or secret, between authority and liberty, and neither of them can ever absolutely prevail in the contest. A great sacrifice of liberty must necessarily be made in every government." ${ }^{18}$ Peaceful order costs much freedom, and thus establishes the false choice between quantitatively enlarging either the individuals' spheres of freedom and action or that of the state. Tertium non datur.

The opposed idea that individual and collective freedom could reciprocally aid and include one another, cherished and celebrated within the Continental-European tradition, cannot be expressed within this matrix. This is due to the classical perceptual angles of quantitative logic - geometry and arithmetic. It is geometrically true that two bodies cannot occupy the same space. Therefore, wherever freedom is represented through a parallelogram of physical forces, the societal gestalt of personal freedoms can only be interpreted as loss or limitation of their original impetus. The same result arises arithmetically. Society is conceived - in terms of game theory and social contract theory - as a thought-experiment in which individuals aim to maximize their own freedom and minimize the interventions of others. The crux of the purely quantitative approach to the subject of freedom is, as the following sections will illustrate in more detail, to perceive the societal balance and synchronization of conceptions of value merely as an antagonistic zero-sum-game. According to this logic, gains in freedom on the one side, must produce losses in freedom on the other.

According to the quantitative logic, individuals only accept the state, for example, insofar as they foresee that under the rule of law they are able to catch hold of more advantages for themselves than in anarchic settings. In order for this costbenefit-calculation to work, in their hypothetical exchange of rights and duties, individuals must get out something of at least equal value to what they put in. And here - in this demand for symmetry - lies the snag: What about people who are

${ }^{18}$ David Hume, Theory of Knowledge: Containing the Enquiry Concerning Human Understanding (Austin, 1953), 156ff. 
clearly not in a position to help or hurt others, and thus appear as unattractive partners for such an exchange? How are they to be integrated into society? ${ }^{19}$ This problem arises, for instance, in regard to the needs, interests, and rights of disabled people.

Let us think of a teenager who, because of being physically disabled, cannot travel to school by his or her own means. According to theories of quantitative freedom, one would only have to guarantee that no one hindered him or her through physical coercion on the way to school. Then their freedom would not be damaged and there would be no duty on the part of the state to intervene to help them. Everyone else can go on maximizing their private options; they do not have a social, political, or legal responsibility to help the teenager. The case would be delegated to individual morality and left to charity stemming from private compassion - which of course also often fails to materialize, and makes the recipient dependent upon the benevolence of the provider. The case looks quite different from the perspective of qualitative freedom. It evaluates a freedom that cannot be exercised as a deficiency; as a consequence, society has to empower the teenager to make use of his or her freedom of education through appropriate measures. Therefore, even if no one has actively produced the teenager's quantitative 'minus' in freedom, a society orientated by qualitative freedom would recognize the qualitative 'malus' of impairment and remedy it.

Proponents of quantitative theories have at times attempted to ward off such outcomes, by stating, for instance, that citizens could certainly have an interest in enabling the education of disabled people. One would only have to consider the required expenditure as an investment in their later economic productivity. The necessary expenditure would then prove financially worthwhile, as a contribution to a later increase of the gross-domestic-product (as the material proxy for aggregated individual options). Thus the symmetry of services and returns demanded by the proponents of the contractarian utility exchange could somehow be established. But is this argument convincing? In the case of some disabled people, such a calculation might succeed; but it hardly works out for all, above all hardly for the most severely mentally handicapped persons. ${ }^{20}$ Moreover, in each and every case, the right of impaired individuals, recognized as unconditional from the perspective of qualitative freedom, would thus be devalued as merely conditionally conceded opportunities for freedom - i.e. under the condition of their prospective economic profitableness. Society's support would then no longer be the expression of the inalienable (unveräußerlichen) dignity of humankind, but rather would become speculation about its alienable (veräußerbaren) economic value. In cases of a blatant asymmetry of service and return, it would be consistent if society's assistance would not come forth; in all other cases it would be the result of base motives.

\footnotetext{
${ }^{19}$ See Nussbaum, Creating Capabilities: The Human Development Approach, 87.

20 "Such cases strip contractarianism bare, so to speak, and reveal a face often concealed by the moralized elements present in the strongest such doctrines" (Nussbaum, Frontiers of Justice, 128f).
} 
The difficulties at which quantitatively orientated theories of freedom arrive when confronted with the problem of such - and other - asymmetries (for instance in regard to global and intergenerational justice) are now examined more closely, by scrutinizing the work of Friedrich August von Hayek and John Rawls. Both thinkers were - and are - popular: Rawls, as a progenitor for social-liberal and progressive liberals, and Hayek as patron of conservative and economic-liberal groups. In political direction, they differ. They are nevertheless united in the undertaking to speak of freedom free of metaphysics. Both philosophize from the premise of a rationally pursued self-interest. Both advertise that the most liberal of all worlds would follow from their respectively favored institutions for the maximization of private options. They each thus pay homage to the quantitative paradigm of freedom - and their doctrines throw light upon its plausibility. In respect of strongly asymmetrical social relations, for instance, both Hayek and Rawls furtively amend their quantitative models in order to produce the desired socio-political and redistributive results. They thereby shift - unintentionally, but patently - freedom's quantitative paradigm into a qualitative one.

\subsection{Liberal Allocation (Friedrich August von Hayek)}

Friedrich August von Hayek (1899-1992) was originally trained as an economist, but his interests ultimately included all of social philosophy. Accordingly, Hayek attempted to integrate his economic theory within a larger philosophical architecture presented as a comprehensive analysis of the modern consciousness of freedom. In The Constitution of Liberty he makes explicit this connection between questions of economic order and the philosophy of freedom. He aspired to produce ultimate and conclusive proof that freedom was the true basis and boundary of all state action.

Throughout his life, confronted by the violent excesses of systems of state regulation (from the right as well as from the left), Hayek sought principles which could both justify and effectively limit the exercise of coercion, and found these within the individual's consciousness of freedom. In this endeavor, Hayek played the part, not only of the academic, but also of the polemicist. Many remember him less as an author of subtle theoretical treatises, but rather as a strongman sporting confrontative theses and combative postures. Thus one knows him, for instance, as the grandmaster of a noteworthy paradox: of liberal thought-police. Just as fiercely as he campaigned for freedom, he fought against all who differed in their understanding of freedom. Ideas that he loathed, such as those of positive freedom and social justice, Hayek brusquely declared as anathema for liberals.

Where, previously, there prevailed still fluid crossovers between ordo-liberal, social-liberal, and neo-liberal positions, Hayek introduces a radical either-or; either freedom or the social: "Liberty does not mean all good things or the absence of all 
evils. It is true that to be free may mean freedom to starve (...)." ${ }^{21}$ That was a clear pronouncement. Together with his mentor, Ludwig von Mises, and his follower, Milton Friedman, Hayek saw to it that from that time on the triumvirate of classical liberalism (in the shape of Hume, Smith, Kant, Humboldt, etc.), new liberalism (Green, Hobhouse, Hobson, etc.) and neo-liberalism (Eucken, Müller-Armack, Rüstow, etc.) no longer presented a harmonious trinity. Since Hayek's adepts championed - with the furor of the orthodox - his doctrinal views as dogmatic insights, behind which no future liberals may hark back, liberal theology has been embroiled in disputes about heresy. However, his adherents nonchalantly overlook that many of Hayek's political positions covertly contradict his proclaimed philosophical principles and can in truth only be legitimated by assumptions transcending his theoretical program. This very problem - the transition from quantitative to qualitative models of thought - is at the heart of what follows.

\subsubsection{Genesis of the Neo-Liberal Concept of Freedom}

In one fell swoop, Friedrich August von Hayek became both famous and infamous through the publication of his controversial pamphlet "The Road to Serfdom" in 1944. Therein he declared that Great Britain was on the way to transforming itself into a second Weimar Republic. The German state could only have been conquered by Hitler because it had already been undermined by social-democratic thinkers. They had anaesthetized the spirit of individual freedom and responsibility in the suffocating embrace of total nurture, having thus prepared citizens' minds for National Socialist collectivism and the drowning of individual liberty in the intoxicating waters of totalitarianism. Insofar as England was now attempting socialdemocratic experiments of its own, it but repeated the error of underestimating the corrupting force of the Left's ideals. Whoever flirts with social-democracy ends up in an involuntary marriage to socialism; hence, proclaimed Hayek, such experiments must be nipped in the bud!

Hayek felt that Europe had been truly liberal only before the First World War; in an era, it should be recalled, when power was chiefly held by monarchies. At that time, individuals could still call a sizeable sphere of freedom their own, while the collective hand only put in an appearance on the margins. But since then, everywhere a drastic increase in state-quotas has been observable, and people became increasingly spoonfed by the nanny state. Freedom's case is everywhere failing, because democracy allows the masses to raze the liberal ramparts that protect the community from falling into the temptations of collectivism. - Even today, neoliberals and libertarians still relish citing this pamphlet. It supplies them with powerful quotations accusing their opponents - whether from the camps of the left, the right, or that of social liberalism - of deliberately or carelessly encouraging

\footnotetext{
${ }^{21}$ Hayek, Constitution of Liberty, 19.
} 
totalitarianism. For his image of being a libertarian populist, Hayek must therefore take some of the blame.

In his later years, however, Hayek attempted to tread more lightly and add more nuance. And these attempts deserve our attention. As Hayek further developed his theory over the decades he provided the public with a vivid lesson on both the strengths and weaknesses of a quantitatively directed liberalism. Hayek's theory is a textbook example of what a formal theory of freedom geared to private options can provide - and where it fails, which is why at long last it dialectically turns towards qualitative categories.

In the theater of his mind, there are qualitative liberal motives, which, albeit in the background, forever vie for control over the play's storyline with the more visible, purely quantitatively-oriented protagonists, and which drive the latter to some thoroughly surprising theatrical twists and turns, which make his dramatic texts an instructive characterpiece on liberty. Let us hence first look a little more closely at the dramatis personae populating Hayek's philosophical stage. Hayek names those Old Whigs, responsible for plotting England's Glorious Revolution of 1688, as the intellectual progenitors of his position. ${ }^{22}$ Aligning himself with this tradition, he propagates a British concept of liberalism as the paragon for his own philosophizing. That model, presented more as a conceptual archetype than a historical reconstruction, ${ }^{23}$ stands for an empirically-inductive position. In questions of societal organization, the contingencies of historical developments are stressed and procedures of cultural trial and error are glorified as the greatest political wisdom. Enter into Hayek's drama of ideas, opposed to the heroic Whig, the villain of the piece: a French concept of liberalism tracking Jacobin doctrines of freedom. The gaudy garb of this quite sketchily scripted antagonist makes him out as a tragic fool beholden to rational deductionism and all-too-optimistic planning. Hayek then sharpens that conceptual comparison into a political opposition and comes down on the side of the British model. He opts for a politics orientated towards experience and experimenting, which ever so wisely forsakes the outlining of perfect societal systems through rational scenario techniques. ${ }^{24}$

Hayek epistemologically underlines this position with the cybernetic argument that one can completely comprehend only systems of lower orders of complexity and never systems of the same or much higher complexity. ${ }^{25}$ Individuals should not therefore dictate to others what their highest good is supposed to be because they are unable to know this with certainty. All political teleologies aiming at materially concrete ideas of the good necessarily fail, according to Hayek, because of freedom's unique unpredictability and dynamic. Subordinating societal life to a general plan means to undercut the developmental potentials inherent within the

\footnotetext{
${ }^{22}$ Hayek, Constitution of Liberty, $407 \mathrm{ff}$.

${ }^{23}$ See William P. Baumgarth, "Hayek and Political Order: The Rule of Law," Journal of Libertarian Studies 2 (1978), 11-28.

${ }^{24}$ See Hayek, Constitution of Liberty, $54 \mathrm{f}$.

${ }^{25}$ See Morris M. Wilhelm, "The Political Thought of Friedrich A. Hayek," POST Political Studies 20:2 (1972), 169-184.
} 
self-determined cooperation of individuals who can always congregate into new, spontaneous orders. And it would be illiberal to boot.

With these arguments, Hayek casts about 2000 years worth of philosophical doctrines about the essence, value, and vocation of human life into the trash can of history. Instead of planned orders, Hayek promotes the market as the paradigm of societal relations. For one thing, the market helps pursue and counterbalance conflicting interests peacefully. For another thing, markets promote social productivity by employing and trading on the differences of personal interests. Decentralized market-activities use resources more efficiently than social-technocrats and societalplanners ever might. ${ }^{26}$ This superiority of unplanned market activity over planned economies causes Hayek to advise against rational constructions in the political arena as well. But - to raise an obvious objection - are not precisely our complex political institutions proof of the capacity of the politically planning intellect to mold and improve the world we live in?

Hayek sees this differently. One ought to understand the effects of political reason historically; as the product of social evolution. Historically developed social structures are often less the result of purposeful planning, but rather have gradually arisen; at times contingently or even contrary to expectations, yet finally they proved themselves reliable. Our political institutions function sometimes rather in spite of, instead of because of, the ideas people once had about their tasks and purposes. Nothing is more mistaken, therefore, than to absolutize a single, social or political model (via a supposed highest social goal, for instance, or through a fictional or real social contract) and thereby block the way towards further social evolution - as has, according to Hayek, the French constructivist type of liberalism.

Hayek's statements about the German philosophy of freedom complete the picture. ${ }^{27}$ Against German Idealism he notes that one may not postulate an identity of freedom and the moral law so as not to curtail the freedom to act morally wrong. ${ }^{28}$ Such remarks, however, say clearly more about Hayek's strategic motives than about the tradition devalued here: Each and every substantive definition of freedom de facto would lead to an erosion of freedom through ethical pressure to conform, which, Hayek believes, only a concept of strictly negative freedom could prevent. $^{29}$

\footnotetext{
${ }^{26}$ Werner Keck, Zwischen evolutionärer und gesellschaftsvertraglicher Fundierung des Staates: Eine vergleichende Analyse der Staatsauffassungen von Rawls, Buchanan, Hayek un Nozick (Berlin, 1998), 212.

${ }^{27}$ See Hayek, Constitution of Liberty, 16, 20.

${ }^{28}$ See ibid., 79.

${ }^{29}$ See ibid., 31.
} 


\subsubsection{Validity of the Neo-Liberal Concept of Freedom}

Anyone who defines freedom negatively has no other alternative but to opt - ceteris paribus - for those competing alternative actions and arrangements which promise more options. Quantitatively directed liberalism therefore often stands in tension with religion because every form of spirituality reduces liberality through the commitments it commends. Hayek thus claims that, for instance, a "Jesuit who lives up to the ideals of the founder of his order" has to be counted as unfree, since his spiritual dedication bars him from numerous options. ${ }^{30}$ Is that true?

Now, if a Jesuit renounced certain freedoms, he would have at his disposal, not necessarily fewer options, but rather, in the first instance, others: such as those arising only from intensive dedication and concentration upon spiritual goals, which perhaps are less frequent in a thoroughly secular life. Could the gains and losses in options possibly offset one another even quantitatively? Some managers who, following a burnout, flee into the next best monastery for a spiritual retreat may perhaps entertain such ideas at times. Yet even if that Jesuit has a lesser number of choices at his command, his freedom could thrive nonetheless, namely if the remaining quantity contains options that to him are especially desirable. But this insight is not gained arithmetically; it can only be captured by a qualitatively oriented way of thinking.

Precisely that difficulty - of distinguishing between options of higher and lower value - continuously troubles Hayek. Despite his own rhetoric that only a social order demanding the quantitative maximizing of the individual realm of choice may count as liberal, one finds in Hayek no plea for a total laissez-faire. Hayek does not support a position that knows no kind of commitments to the social environment or only accepts such restrictions as can result from utility-exchange models in minimal states, i.e. as strategies of reciprocal maximization. ${ }^{31}$ Rather he defends - in contrast to what many of both his supporters and opponents believe - a freedom that is not only limited by moral laws but also oriented at ethical values.

Concerning ethical values Hayek's insistence that he would support only a "merely negative" concept of freedom is hence misleading. ${ }^{32}$ Hayek wishes to protect not freedom as libertinism, but freedom precisely as the source of ethical values, when he postulates it as society's "overriding principle." ${ }^{33}$ This principle should prevent us from employing means contrary to freedom in order to realize ethical values. A coercion towards the good - for instance towards engagement in civilsociety - could rob that good of its ethical quality. Individual freedom must be spared morally motivated coercion, not because Hayek would renounce all ethical

\footnotetext{
${ }^{30}$ See Hayek, Constitution of Liberty, 14.

${ }^{31}$ This is according to the interpretation in H. B. Falkena, "On Hayek's Philosophy of Limited Government and the Economic Order," South African Journal of Economics 53:4 (1985), 235-243.

${ }^{32}$ Hayek, The Constitution of Liberty, 19.

${ }^{33}$ See ibid., 68.
} 
orientation, but rather because he wishes to liberate people to engage freely in genuine commitments. Ethical aims ennoble the freedom they arise from. Among other things, freedom should thus not be sacrificed to moral values since a virtue coerced is a virtue lost.

Hayek defends the legal limitation of freedom by disassociating himself from Jeremy Bentham (1748-1832) ${ }^{34}$ who (see Sect. 1.3.2) had supported the view that "every law is an evil for every law is an infraction on liberty." ${ }^{35}$ In contrast, Hayek stands in solidarity with the idea of law as a form of freedom prominent in the Kantian tradition. Like Kant, Hayek demands boundaries for individual freedom of action which constitute the presuppositions of the freedom of all. ${ }^{36}$ While the proximity of his thinking to Kant's, which the later Hayek likes to stress, ${ }^{37}$ certainly does not always exist, ${ }^{38}$ in this respect it is patent: He battles only against arbitrary coercion, but never one in conformity with laws of freedom. Arbitrary coercion reduces individuals to mere instruments, yet they desire and shall be ends in themselves, forming and directing themselves free of coercion.

Freedom from arbitrary coercion requires the state to have a monopoly on coercive practices which it then employs only in the service of freedom. State action should therefore be directed by the principle that coercion may befall no one "unless he has placed himself in a position where he knows he will be coerced." ${ }^{39}$ So far as the exercise of coercion is depersonalized, subject to abstractly general and publicized laws, all individuals can adjust their behavior to avoid coercion. Legal norms are then hypothetically and instrumentally present for individuals, just like laws of nature. Just as one knows that lighting a fire in the living room can lead to burning down the house, one likewise knows that the deliberate burning down of a house can put one in prison..$^{40}$ This spells the end of arbitrary coercion, as now only coercion deliberately or negligently provoked by individuals is administered. The rules of law indicate the juridical admissibility of certain means, yet entrust the determination of ends to free moral choice alone. The basic pattern of the state's coercive rules are conditional codes (like the if/then regulations of penal law), according to which all can make an informed decision about whether they wish to put themselves in a situation invoking state coercion. ${ }^{41}$

\footnotetext{
${ }^{34}$ See ibid., 60.

${ }^{35}$ Jeremy Bentham, Étienne Dumont \& Richard Hildreth, Theory of Legislation (London, 1887), 48.

${ }^{36}$ For the theoretical connection with Kant (concerning freedom) and the remaining differences between both thinkers see Michael Kläver, Die Verfassung des Marktes: Friedrich August von Hayeks Lehre von Staat und Markt im Spiegel grundgesetzlicher Staats- und Verfassungsrechtslehre (Stuttgart, 2000), 18-31.

${ }^{37}$ Friedrich August von Hayek, Law, Legislation and Liberty: A New Statement of the Liberal Principles of Justice and Political Economy (London, 1976), 166 n.24.

${ }^{38}$ For more about Hayek's reckless and, at times, clumsy Kantian musings see Hans Jörg Hennecke, Friedrich August von Hayek: Die Tradition der Freiheit (Düsseldorf, 2000), 287-294.

${ }^{39}$ Hayek, Constitution, 21.

${ }^{40}$ See ibid., 153.

${ }^{41}$ See ibid., $142 \mathrm{ff}$.
} 
Obviously, the state cannot establish such conditional rules capriciously. Citizens must never be degraded into mere means for the realization of political ends they do not share; not even from paternalistic concern for the sake of their assumed welfare, let alone for the benefit of contingent aims. Hayek only sanctions rules of coercion that help individuals pursue their own ends in a manner that excludes collisions with the freedom of others. Just like with Kant, with Hayek, the real coercion of the legal order is, therefore, legitimated and - in accordane with the former principle - limited by functioning as ideal support for those coerced by it, i.e. by protecting their freedom from themselves.

Yet precisely that tinge of transcendental philosophy within his ideas suggests that we should challenge Hayek's claim that he merely follows a negatively formal, externally quantitative concept of freedom. ${ }^{42}$ Hayek certainly maintains that his concept of law pays homage to purely procedural criteria. ${ }^{43}$ However, many of the convictions supported by him cannot be justified with procedural criteria alone, but instead require for their support more far-reaching substantial premises, like, for instance, the Kantian idea of autonomy. ${ }^{44}$ Lawgivers could certainly formally act without reproach and, say, unanimously place on the satute book universal laws to which they themselves would be subject, which, however, Hayek would nonetheless materially reject. ${ }^{45}$ He would surely not brook, for example, a society which legislated to safeguard the orthodoxy of its members (including those in government) with the aid of floggings and stonings. Against all who aim to realize their freedom in such a way, Hayek draws a clear red line.

Hayek thus dodges the consequences of his own formalisms and brings instead an essentially qualitative concept of freedom into play. ${ }^{46}$ That typically occurs with recourse to the previous conceptions of the British legal tradition. Hayek expressly does not surrender the rule of law (for instance established legal principles like nulla poena sine $\operatorname{leg} e^{47}$ ) to social evolution. ${ }^{48}$ He proclaims this to be common-law

\footnotetext{
${ }^{42}$ Christoph Zeitler in any case doubts Hayek's self-assessment that he is only committed to a negative concept of freedom in Spontane Ordnung, Freiheit und Recht: Zur politischen Philosophie von Friedrich August von Hayek (Frankfurt am Main, 1995), 147ff.

${ }^{43}$ See Hayek, Law, Legislation and Liberty, 43.

${ }^{44}$ See Nikolas Roos, "Hayek's Kantian Heritage and National Law" in Birner \& van Zijp (eds.), Hayek, Co-ordination and Evolution: His Legacy in Philosophy, Politics, Economics and the History of Ideas (London \& New York, 1994), 294.

${ }^{45}$ See Lionel Lord Robbins, "Hayek on Liberty," Economica 28:109 (1961), 66-81.

${ }^{46}$ See Hayek, Law, Legislation and Liberty, 58ff. This contradicts Aimar Thierry, who establishes the thesis that Hayek's normativity is purely hypothetically-universal in its nature - since it rests upon the subordinate survival interests of everyone, from which everyone's interest in a productive socioeconomic order is derived - because it merely deals with a normativity "without prescriptions." See his "Coordination, Survival and Normativity: A Hayekian Perspective Revisited" in Birner et al. (eds.), F. A. Hayek as a Political Economist: Economic Analysis and Values (2002), 225f., 230.

${ }^{47}$ In English: No penalty without a law. Further such common principles are, for instance, in dubio pro reo (in doubt, for the accused) and actori incumbat probatio (the onus of proof is incumbent on the plaintiff).

${ }^{48}$ See Hardy Bouillon, Ordnung, Evolution und Erkenntnis: Hayeks Sozialphilosophie und ihre erkenntnistheoretische Grundlage (Tübingen, 1991), 59ff.
} 
traditionalism. It is not, though, because this particular tradition of the rule of law itself is in no way up for discussion. ${ }^{49}$ The rule of law is the liberal rock in the social surf upon which all waves of illiberal plans for change should break. While all other institutions are seen as fluid, Hayek ascribes to the rule of law a rock-solid a priori validity - which however he does not really admit, neither to himself, nor to his readers..$^{50}$

Holding fast to legal principles that must never be relinquished clearly collides with the program of social evolution otherwise so thoroughly supported by Hayek. Some interpreters have therefore advised Hayek also to relativize the rule of law instead of treating it as though it were, so to speak, a natural right. ${ }^{51}$ Others, on the other hand, come out against Hayek's evolutionary subjectivism for undercutting the logic of argumentation he otherwise employs. This second interpretation seems more plausible: By highlighting the conditions that make universal freedom possible, Hayek put himself in a good position to clarify that not every adherence to basic rights and rules of interpersonal recognition is but a contingent postulate by construction-loving theorists. ${ }^{52}$

For example, Hayek writes: Not only physical violence hinders a self-determined life. Fraud and deception present interventions in personal freedom quite comparable to coercion. Through them the individual is robbed of the access to reality required for living an autonomous life. ${ }^{53}$ Deception and fraud thereby deny de facto the claims to freedom of the deceived and turn them into mere means subordinate to the ends of the deceiving. This sort of thing cannot be the upshot of universalization and mutual agreement. Accordingly, any law dedicated to the protection of freedom must protect liberty not only from violence, but also from fraud and deception. With similar arguments - transcendentally seeking the presuppositions of universal freedom - Hayek gradually reconstructs a canon of formal legal principles (like, for example, pacta sunt servanda) and material legal tenets (for the protection of property, for instance).

Hayek is thus not merely retelling the story of one particular legal tradition, which cultural evolution contingently treated with especial kindness. These reflections are rather presented as self-evident elements of the idea of freedom. Here deduction reigns supreme - not induction. Speculation orients the compass of historical experience - and not vice versa. Since Hayek loathes the tradition of legal positivism and accordingly demarcates his theory of evolutionary development of

\footnotetext{
${ }^{49}$ See John Gray, Hayek on Liberty (Oxford \& New York, 1986), $31 \mathrm{ff.}$

${ }^{50} \mathrm{See}$ also the differentiation from communitarianism with Barbara M. Rowland, Ordered Liberty and the Constitutional Framework: The Political Thought of Friedrich A. Hayek (Westport, 1987), $119 \mathrm{ff}$.

${ }^{51}$ See Theodore A. Burczak, "The Contradictions between Hayek's Subjectivism and His Liberal Legal Theory" in Birner et al. (eds) in F. A. Hayek as a Political Economist: Economic Analysis and Values (London, 2002), 201.

${ }^{52}$ See Ross, Hayek's Kantian Heritage, 289.

${ }^{53}$ See Hayek, Constitution of Liberty, $143 \mathrm{f}$.
} 
law sharply from it, he cannot but endorse the idea of justice as a meta-legal ideal. ${ }^{54}$ That is why the rule of law has such a key-function within his theory. ${ }^{55}$ Without this counterfactual orientation, Hayek's descriptive use of social-evolutionism would quickly turn into the normative. That however would, in political theory, lead to a type of fatalism akin to the legal positivism Hayek rejects. Hayek's version of the rule of law thus has roughly the status of a regulative ideal in Kant's philosophy. ${ }^{56}$ For instead of renouncing his own ideal of justice in favor of social evolution, Hayek rather wishes to evaluate the latter against the former. ${ }^{57}$

Speaking metaphorically: For many sea miles, Hayek's ship of ideas follows a fairway that traverses the ocean of liberty along the societal enabling conditions of freedom. Only as he, upon this journey, comes in sight of the continent of social justice, does he abruptly change course. Suddenly he makes for the high seas of distributive arbitrariness, where he commits his theory and its practical results, afar from all normative lighthouses, to the high waves of the market. Hayek keeps insisting that the concept of freedom he employs is merely negative, ${ }^{58}$ and this certainly seems true of that ultimate nautical maneuver; yet, in respect of the overall course of his journey, one must view this statement as the yarn of an old seadog. By means of qualitative coordinates, Hayek first carefully navigates the ship of freedom around the shallows of relativism and past the sandbanks of positivism. Only when these are passed by, does he loosen his grip on the rudder and entrust his vessel to the currents of social evolution and the eddies of economic deregulation.

\subsubsection{Legal and Political Philosophy}

Hayek expressly recognizes that, to every social evolution there also belong conscious and planned systematic reforms which in turn are based upon orientations that do not simply reflect the historical status quo, but rather wish to change it. $\mathrm{He}$ merely demands that only such steps towards justice should be taken that ensure the equal right of all and do not block a further evolution beyond the current state of knowledge. The commitment of all positive right to the directive of the rule of law that allows freedom to be curtailed for the sake of freedom alone leads therefore to one normative demand: to structure the state in such a way that it could only promote ends whose realization conform with freedom. That postulate, however, in no

\footnotetext{
${ }^{54}$ See Hayek, Constitution, 205ff., and Law, Legislation and Liberty, 44-60.

${ }^{55}$ Zeitler, on the other hand, interprets the rule of law as a merely procedural criterion, ibid., 213.

${ }^{56}$ For Kant's concept of a regulative idea see Dietmar Köveker, Grenzverhältnisse: Kant und das "Regulative Prinzip" in Wissenschaft und Philosophie (1996).

${ }^{57}$ Yet as Jacob Viner writes: "I do not see how this doctrine can be distinguished from "Social Darwinism" ("Review. Hayek on Freedom and Coercion," Southern Economic Journal 27:3 [1961], 233).

${ }^{58}$ See Hayek, Constitution, 12.
} 
way resembles the "rigid position" of the libertarian who limits the state to only coercive administration. ${ }^{59}$ Rather, Hayek does accept that the state act as a "service agent" assisting in society's "achievement of desirable aims," i.e. the qualitative transformation of the collective sphere of liberty. This social-democratic and cultural aspect of his theory must not be obfuscated. Hayek does insist, however, that, from accepting something as a goal promoting the common good, it does not automatically follow that all means leading to this goal are permissible: Often one must content oneself only with second-best, yet, freedom-conforming solutions, in cases in which the situation could only otherwise be improved by coercion and dirigisme ${ }^{60}$ While a "dogmatic democrat" would subordinate anything and everything to the judgment and goals of the majority, ${ }^{61}$ Hayek places politics from the outset within firm legal boundaries. Certain realms of reality are taboo.

To wit, the protection of minorities: The majority may only decide upon such principles "which the minorities also accept." ${ }^{2}$ Yet how does one justify devaluing the votes of the majority, so that differences enter into a legal framework, which should, in principle, nevertheless serve all legal subjects in one and the same way? Hayek declares: Equality before the law should not mean measuring everything with the same yardstick, but rather treating that, which is unequal, unequally. ${ }^{63}$ Agreed. Yet, how does one find out in a particular case what is essentially equal and what essentially unequal? Hayek certainly wishes to elevate certain phenomenal differences to the rank of conceptual distinctions and thereby classify certain differences between people - but not others - as legally relevant or, respectively, irrelevant; and yet other differences he wishes to treat counterfactually. With a quantitative logic, viewing all options as basically of the same kind, this cannot be had. Must one therefore qualitatively ground the principle of freedom?

In The Constitution of Liberty Hayek is still looking for a pragmatic solution to the problem: "So long as, for instance, the distinction is favored by the majority both inside and outside the group, there is a strong presumption that it serves the ends of both. When, however, only those inside the group favor the distinction, it is clearly privilege; while if only those outside favor it, it is discrimination." ${ }^{64}$ Even disregarding the fact that this answer contains no kind of theoretical criteria to prefer normatively just this discursive process over alternative procedures for the selection of politically operative values, there remains the practical difficulty of introducing a consensus about the "generality and equality" of a settlement on the

\footnotetext{
${ }^{59}$ See ibid., 258.

${ }^{60}$ See ibid., 261.

${ }^{61}$ See ibid., 106.

${ }^{62}$ See ibid., 107.

${ }^{63}$ See ibid., 153.

${ }^{64}$ See ibid., 154.
} 
part of all affected. ${ }^{65}$ What is to be done, if the most that is achievable are highly controversial majority judgments?

Not before the three volumes of Law, Legislation and Liberty (1973-1979), which appeared after the Constitution of Liberty, did Hayek present an answer to this question. Here he elaborates how to conceptualize an appropriate political selfregulation that adequately deals with differences of public opinion. ${ }^{66}$ Through their personal - not least financial - interests those in government may be influenced, which can noticeably impair the logic of their decision-making. The calamity of modern democracies, results not predominantly from the lack of intelligence and willingness of the politicians, but rather in the fact that they are systematically exposed to lobbying and corruption: "So long as the present form of democracy persists, decent government cannot exist, even if the politicians are angels ... because ... we ... place them in a position in which they can obtain power ... only if they commit themselves to secure special benefits for various groups." ${ }^{67}$ The better certain societal interests are organized, the greater is the peril to the political representation of unorganized interests. ${ }^{68}$ Therefore the modern state should, for its own good, constrain its own ability to cater to groups whose interests do not align with the common good.

The remedy shall be provided by a two-chamber-system, which makes interference in politics unattractive to lobbyists. Accordingly, the functional difference between the legislative and the executive should be tightened: "the legislative one is to represent the opinion of the people about which sorts of government actions are just and which are not, and the other governmental assembly were to be guided by the will of the people on the particular measures to be taken within the frame of rules laid down by the first." ${ }^{\prime 9}$ Bribery is thus impeded. One would have to corrupt both houses coordinately; and, consequently, it becomes far less probable that the legislative issue precisely those laws which suit the executive, but also that both houses unproductively inhibit one another like in the continual dispute between the American congress and the US president.

The further specification of the rule of law in concrete laws would then be incumbent upon a legislative assembly independent of popular influence since, according to Hayek, the application of the laws issued by it are in turn entrusted to an executive assembly orientated towards the will of the people. And a constitu-

\footnotetext{
${ }^{65}$ See ibid., 210.

${ }^{66}$ Calvin Hoy believes that Hayek gives up the theory of consensus in Law, Legislation and Liberty because it is no longer explicitly mentioned there (see A Philosophy of Individual Freedom: The Political Thought of F. A. Hayek [Westport, Connecticut, 1984], 86); in my opinion it rather looks like Hayek feels that the two-level concept of democracy he worked-out in the meantime can deliver what his previous idea of a consensus legitimating unequal social distribution demanded; an interpretation supported also by the characteristic style of the treatment of public opinion as an additional criterion for political legitimacy in the first volume of Law, Legislation and Liberty.

${ }^{67}$ See Friedrich A. von Hayek, Law, Legislation and Liberty: A New Statement of the Liberal Principles of Justice and Political Economy (London, 1979), 135.

${ }^{68}$ See ibid., $99 \mathrm{f}$.

${ }^{69}$ See ibid., 104.
} 
tional court should settle their respective quarrels. ${ }^{70}$ This model was criticized for being artificial and impractical. ${ }^{71}$ However, Hayek did not at all intend "to propose a constitutional scheme for present application." 72 What is more, he even advised established democracies against replacing their historically proven constitutions with that model - and only talked about it as a normative lodestar for future constitutional developments.

The technical details of this model per se are less interesting than what they reveal about Hayek's understanding of democratic freedoms: Hayek looks for a new, institutional solution to the traditional idea that democracy should act within the boundaries of the will of the majority. Rather than taking the - for modern constitutions - routine step of curtailing the decisions of parliament through, for instance, certain inflexible rules about human rights, Hayek aspires to a more malleable system. He wishes to secure government in conformity with the rule of law in a manner that at the same time affords the legal system an openness to change. ${ }^{73}$ The dualism of the chambers shall lead to a political self-limitation assuring that everyone can freely agree to the resultant political decisions due to the complete transparency about how they come to pass. ${ }^{74}$

So, after Hayek had first dispatched every rational constructivism through the front door of his system, the idea of a universal acceptability now enters again through the backdoor. ${ }^{75}$ This result does not mesh well with a concept of freedom of ostensibly only negative and quantitative characteristics. For Hayek thus makes the presence of specific qualitative presuppositions - like the feasibility conditions of a free reconstruction of the respective political decisions on the part of rational subjects - into the criterion of the lawfulness of precisely those decisions. This is, after all, why he orientates politics towards decision-making procedures removed from populist and lobbyist pressure. Nevertheless, this only makes sense if one understands the rule of law, not as a mere formality, but rather as a normatively and qualitatively determined manifestation of the principle of autonomy. Otherwise, each and every traditionally tested procedure would suffice for the production of law.

These ways of guaranteeing the desired impartiality of the parliamentarian decision-makers (e.g., by stipulating that the members of the legislature can be neither voted-out nor re-elected) clearly limit the immediate execution of the political

\footnotetext{
${ }^{70}$ See ibid., $103-127$.

${ }^{71}$ For an example of this see Roald Hamowy's critique in "The Hayekian Model of Government in an Open Society," Journal of Libertarian Economics 6 (1982), 137-144.

${ }^{72}$ Hayek, Law, Legislation and Liberty, 107.

${ }^{73}$ See ibid., 109.

${ }^{74}$ In this connection, I agree with Keck's criticism that Hayek merely insufficiently worked out that part of his theory - without which it can win no normative independence; see Keck, Zwischen evoltionärer und gesellschaftsvertraglicher Fundierung des Staates, $239 \mathrm{f}$.

${ }^{75}$ For more information about the tension between Hayek's historical evolutionism and the constructivist approach of his own constitutional model see Viktor Vanberg \& James Buchanan, Liberaler Evolutionismus oder vertragstheoretischer Konstitutionalismus? Zum Problem institutioneller Reformen bei F. A. von Hayek and J. M. Buchanan (Tübingen, 1981), $35 \mathrm{ff}$.
} 
will of the population. ${ }^{76}$ Hayek thus aims to accomplish through a rearrangement of the internal organization of the state what elsewhere - also binding the will of the majority - constitutional texts aim to achieve through catalogues of basic rights and declarations of the state's prime objectives, i.e. a liberal self-limitation of the democratic decision-making. Given this reorganization, he holds an enumeration of basic rights within the constitution as dispensable. ${ }^{77}$ This, however, might not convince everyone. It could just as well be argued that a catalogue of decisively formulated constitutional rights would be rather desirable, especially for the public, selflegitimation of the constitutional court and thereby for its assertiveness in respect of deciding formal disputes over authority between the two bodies as well as in respect of a material condemnation of certain laws. Be that as it may, the main point is that, time and again, when it comes to mapping out the political results of his philosophy of freedom, certain qualitative considerations in the background of his conception consistently prove to be more impactful than the procedures rhetorically placed into the foreground by Hayek. A system of quantitative freedom only leads to a liberal society insofar as its political processes are conceptualized with regard to qualitative ideals of freedom. In short, Hayek's political theory disguises the very qualitative presuppositions which it needs to succeed.

\subsubsection{Economic and Social Philosophy}

Although quantitatively-liberal positions typically seek proximity to laissez faire thinking, Hayek quite expressly rejects the hands off-approach of the early nineteenth century as a misguided maxim. ${ }^{78}$ The aim of liberal economic politics is for Hayek - unlike the views of many of his followers - in no way "that government should never concern itself with any economic matter." 79 It is not defined by "absence of all government action," but rather concerned with the fact that the "freedom of economic activity" should only be limited according to liberty-protecting laws. ${ }^{80}$ The economic order is to be pre-structured by the legal order in such a way that certain means of state action (like, e.g., arbitrary coercion) are principally deemed inadmissible. Thereby the state refuses to realize such ends (for instance a strictly equal distribution of assets) which are only reachable by such means. ${ }^{81}$

\footnotetext{
${ }^{76}$ See Hoy, A Philosophy of Individual Freedom, 110.

${ }^{77}$ The decisive passage runs: "The enumeration of certain rights in this Constitution shall not be construed to deny or disparage others retained by the people"; see Hayek, Law, Legislation and Liberty, 111; see also 185 f.

${ }^{78}$ See G. R. Steele, The Economics of Friedrich Hayek (New York, 1993), 47.

${ }^{79}$ Hayek, The Constitution of Liberty, 231.

${ }^{80}$ See ibid.

${ }^{81}$ See ibid., $221 f$.
} 
Hayek's economic policy focuses upon structural measures. No economic order can flourish without "certain activities on the part of the state." 82 That applies both to the formal preconditions of market activity - monetary system, weights, units of measure etc. - and to the material preconditions of the same: for instance measures designed for risk-prevention (building regulations, workplace design), infrastructure, for the creation of public goods, and for national defense. ${ }^{83}$ In that respect, dimensions of the common good can clearly be found in Hayek. ${ }^{84}$ And in this instance, again, he does not appear concentrated on quantitatively minimizing all state-action in the economy, but rather on its qualitative optimizing through a concentration upon certain indispensable tasks.

Hayek's economics wishes to empower citizens. Individuals' knowledge and ability, decentrally allocated throughout society, presents the actual human and social capital of a national economy, which is used for better or for worse - depending upon the respective economic system. To Hayek, market prices appear as an especially fast and fluid medium of communication necessary for shared collaboration. In them, citizens communicate with one another in an impersonal, honest, and efficient way about the value of certain goods and services. Production follows the individuals' willingness to pay presented in the fluctuation of prices. For the sake of their own economic advantage, by allocating resources where these promise the highest possible yields, citizens will engage in many socially useful activities. Thus the market indicates and coordinates supply and demand in a decentralized and reciprocal manner. Information about shortages and surpluses must therefore not take the circuitous route via a governmental center. Goods are therefore more efficiently distributed and, due to their thereby increased relative and individual utility, the aggregated absolute benefit to society increases.

While in the language of economic valuation prices constitute the vocabulary, the state has to provide the grammar for this language game. Through structural measures (rules, taxes) it must ensure that individual competition releases as few negative externalities (public evils) as possible and as many positive externalities (public goods) as possible. ${ }^{85}$ But the state may also, in certain situations, add its own voice, in order, for instance, to create public goods the market does not produce. For such operations Hayek recommends a multi-level assessment: Are the economic and political measures to be taken legally permissible? If they are, one must then examine "whether the benefits are worth the cost." ${ }^{16}$ Wherever this, too, is affirmed, the examination passes from formal, quantitative gauges to qualitative criteria. For instance, the state may never place in the world such monopolies that could exclude the possibility that, in the future, the goods currently procured by state-ventures are produced by private hands.

\footnotetext{
${ }^{82}$ See ibid., 220.

${ }^{83}$ See ibid., $220-223$.

${ }^{84}$ See Steve Fleetwood, Hayek's Political Economy: The Socioeconomics of Order (London \& New York, 1995).

${ }^{85}$ See Hayek, Law, Legislation and Liberty, $44 \mathrm{f}$.

${ }^{86}$ See Hayek, The Constitution of Liberty, 222.
} 
A mix of quantitative and qualitative ideas of freedom is also found in Hayek's discussion of tax legislation. The crux of every tax lies in the fact that, from the quantitatively liberal perspective, it presents a means of state coercion: If the individual would prefer not to pay it and views it as a minus for personal freedom, it is nevertheless forcibly collected. One must therefore clearly justify this coercive intervention into individuals' means for freedom. Since the state is generally entitled to raise money through taxes for community tasks, Hayek believes, one merely needs a majority vote in order to legitimate the subsequent distribution of this money. As long as the elementary private rights of individuals are not infringed upon, the corresponding expenses would already be legitimated through the universal acceptance of the democratic system: a surprisingly social-democratic pivot within his thinking.

Interestingly, here a qualitatively liberal approach might lead to stronger protections for individuals. Since, in tax legislation as anywhere, only freedom can legitimate coercion, a qualitative perspective suggests the viewpoint that unavoidable taxes may only be applied to unavoidable tasks securing citizens' capacity for freedom. Consequently, one would have to concentrate, for example, all direct taxes upon the essential tasks of the state (judicature, national defense, securing the subsistence and basic education of the citizens). ${ }^{87}$ Other tasks of the state would have to be financed by indirect taxes maintaining the citizen's freedom, i.e. by means of of the possibility of alternative consumer choices. If one were to follow these ideas a few steps further, then one ought to demand moreover that payment and expenditure strictly match each other. One should therefore not collect moneys from an ecologically legitimated gas-tax, and then spend its revenue on "old-age provisions." Hayek, however, completely overlooks this qualitatively-liberal constraint. ${ }^{88}$

All the more radical are Hayek's postures in regard to questions of redistribution. For a progression of taxes according to income, he complains, no just criterion can be provided for lack of universal agreement about such differentiations. No tax must alter the relative wealth of economic actors, ${ }^{89}$ for ethical reasons as well as also for reasons of efficiency, i.e. first in favor of an equal right for all and second because otherwise one would create incentives towards unproductive economic activity. ${ }^{90}$ As individuals or occupational groups are automatically urged towards the most efficient use of resources by the market and its price-incentives, since in a competitive marketplace the most productive activities are remunerated with more money and therefore increased, every disproportional tax cannot but skew this matrix of pay-

\footnotetext{
${ }^{87}$ Morris Wilhelm for instance questions where the criterial boundary for a quite generally compulsorily ordered state-culture could lie if the state took the step of financing some selected cultural interests (building of theatres, etc.) in The Political Thought of Friedrich A Hayek, 171f.

${ }^{88}$ See Keck, Zwischen evolutionärer und gesellschaftsvertraglicher Fundierung des Staates, 216.

${ }^{89}$ See Hayek, The Constitution of Liberty, 316.

${ }^{90}$ See Hayek, Law, Legislation and Liberty, $95 \mathrm{f}$.
} 
ment and thereby produce misguided encouragements and discouragements. ${ }^{91}$ The advantage of the beneficiaries would thus be purchased by the disadvantage of all. ${ }^{92}$

Something similar had already been proposed by Hayek's mentor Ludwig von Mises (1881-1973).$^{93}$ In the 1930s, Mises had undertaken the reconstruction of economic doctrines, like that of marginal utility and marginal profit, in philosophical terms and as components of a universal praxeology. ${ }^{94}$ This was intended to provide an analysis of the behavior of rational actors detached from all human ends, and thus provide insights relevant for all practical sciences. That praxeology should do without value judgments, since, according to Mises, "the aims and ends lie beyond the rational sphere. They are deprived of verification and evaluation by reason and by thought." ${ }^{95}$ Praxeology prepares such evaluations, however, by calling attention to problems of implementation and operational costs of certain projects. It thus sharpens the view of the effects intentionally or unintentionally implicated in pursuing a certain end.

With that, Mises laid intellectual foundations for the game theory later established by Oskar Morgenstern (1902-1977). It too shuns normativity. Decisionmakers are not told (geraten) what to do but merely informed (beraten) what consequences their alternative options entail, which must impact their decision - if this is supposed to be perfectly rational. That meshes well methodologically with quantitative liberalism, which, allegedly featuring greater scientific rigor, renounces all qualitative objectives. Not incidentally, therefore, we find such a strong permeation of the hypotheses of game theory within quantitative liberalisms - for instance by way of agent-based modeling based on the homo oeconomicus.

Hayek did not go along with all the steps of this deliberately reductionist program; one occasionally finds value-judgments within his work, but never attempts at the mathematization of economics. Nevertheless, in central political questions he does apply the praxeological method. For instance, in regard to subsidies and price and wage guarantees by the state, Hayek shows that these entail determined and probably unwanted secondary effects. This, Hayek believes, is especially the case with the deviation from proportional tax rates in favor of progressive ones. For progressive taxes were only able to be politically supported by principles which "most people would not approve if they were stated abstractly. That a majority should be free to impose a discriminatory tax burden on a minority; that, in consequence, equal service should be remunerated differently; and that for a whole class, merely because its incomes are not in line with those of the rest, the normal incentives

\footnotetext{
${ }^{91}$ See Hayek, Constitution, 317.

${ }^{92}$ See Hayek, Law, Legislation and Liberty, $67 \mathrm{ff}$.

${ }^{93}$ For information about Hayek's conception of market-freedom see Kläver, Die Verfassung des Marktes, $165 \mathrm{ff}$.

${ }^{94}$ See Ludwig von Mises, Nationalökonomie: Theorie des Handelns und Wirtschaften (München, 1980), 89ff.

${ }^{95}$ Von Mises, Nationalökonomie, 44f.
} 
should be practically made ineffective - all these are principles which cannot be defended on grounds of justice." ${ }^{96}$

Hayek wishes to limit all redistributive taxes to the quantitively smallest possible degree. First, he rejects the aim of an artificially balanced societal distribution of wealth. It would allocate the available resources contrary to the laws of productivity and thus damage all in the attempt to benefit some. ${ }^{97}$ Second, he shields himself against the, as he believes, illiberal means with which alone such an asset policy could be realized..$^{98}$ Hayek dramatizes such measures as the beginning of a socialdemocratic descent, which ends in a socialistic valley of tears: Initially, an assessment-authority would disregard the individual judgments - i.e. payments - of citizens concerning what they value economically: a first assault on citizens' choices. ${ }^{99}$ Then, a redistribution-authority would interfere with the citizens' property rights according to socio-political discretion: a second infraction upon their freedom. Finally, because the market-system would eventually be so impaired that it could ever less meet people's needs, a work-and-production-authority would have to mitigate the self-produced market failures. By decree that institution would then have to coerce people towards producing the requisite output. The initially merely incidental break with the principle of freedom thus develops into a system of allconsuming coercion: a dictatorial planned economy. ${ }^{100}$

How much truth is there in this horror scenario? Hayek's argument that, whoever wants a liberal political order, should principally also stand up for a liberal economic order seems plausible. ${ }^{101}$ Therefore, under the aegis of freedom, individual legal positions, like, for example, private dispositions over property, are to be recognized as a rule. A liberal government will consequently prefer to exert influence on future asset distribution - by abstractly general laws, while renouncing, wherever possible, specific interventions into current assets. In contrast to what Hayek will have us believe, however, his view that each progressive taxation would inevitably lead to the ultimate demise of the occident, neither follows conceptually nor corresponds with historical experience. Rhetoric rules over realism here. ${ }^{102}$

Did not Hayek propose that essential inequalities may - or rather must - be treated unequally? Where extreme quantitative distinctions between rich and poor lead to a qualitative difference of living-conditions, an inequality calling for unequal treatment might thus be given. That is to say, a qualitatively liberal appropriation

\footnotetext{
${ }^{96}$ See Hayek, The Constitution of Liberty, 332.

${ }^{97}$ See Gerhard Wegner, Wohlfahrtsaspekte evolutorischen Marktgeschehens: Neoklassisches Fortschrittsverständnis und Innovationspolitik aus ordnungstheoretischer Sicht (Tübingen, 1991), $103 \mathrm{ff}$.

${ }^{98}$ See Hayek, The Constitution of Liberty, 87.

${ }^{99}$ See Hayek, Law, Legislation and Liberty, 72, 75.

${ }^{100}$ See ibid., 82.

${ }^{101}$ See Hayek, Constitution of Liberty, 192.

${ }^{102}$ See Reinhard Zintl, Individualistische Theorien und die Ordnung der Gesellschaft: Untersuchungen zur Politische Theorie von James M. Buchanan und Friedrich A. V. Hayek (Berlin, 1983), 226.
} 
can accept a progressive tax and the limitation of individual possessive freedom it entails: as a quantitative expression of a reciprocal self-limitation of the state's citizens through universal rules, which grants all citizens the chance for a life in freedom. In contrast, proponents of quantitative freedom obscure how this minus of pecuniary choice on the part of the taxed benefits the freedom of society at large. Quantitative schemas distort the qualitative issue at hand.

Hayek tenaciously maintains that what, in his view, must not be, cannot take place: a harmony of freedom and social justice. For Hayek, the idea of social justice is simply absurd. Justice is only suitable as a concept of individual behavior, and not as a measure of societal relations. ${ }^{103}$ With that position, however, he stands in opposition to natural language as well as his own theory. What about procedural and structural justice then? Hayek certainly recognizes those forms of justice beyond individual justice, which, for example, are inherent in the procedures and rules of the state of law. He is therefore guilty of double standards: Should what he deems perfectly legitimate in regard to the formal procedures of law, now be illegitimate in respect to material aspects of justice? How could that stance be justified?

Looking for intellectual support, Hayek likes to quote Immanuel Kant. With Kant's critique of the material indeterminacy of the concept of "welfare" Hayek wants to beef up his own critique of the concept of social justice. Nevertheless, Hayek's lesson about the impossibility of social justice was already completed before his encounter with the Kantian philosophy of law. ${ }^{104}$ Hayek did not heed Kant, but rather fitted the Kantian philosophy into his own doctrines. ${ }^{105}$ And thus Hayek undermines the socio-critical impulse of the Kantian position. For Hayek, the categorical imperative merely acts as a negative universalizability-test, which functions solely against the background of a traditional and undisputed legal culture, trying to ascertain whether certain plans of action harmoniously conform with this accepted context of law and property. ${ }^{106}$ Hayek thus turns the essential critical point of Kantian theory on its head, though. ${ }^{107}$ Kant had set out from a pre-positive share of everyone in the communal possession of the earth: Therefore all property includes societal obligation from the outset, ${ }^{108}$ an extremely unfavorable startingpoint for the possessive individualism cherished by Hayek.

\footnotetext{
${ }^{103}$ See Hayek, Law, Legislation and Liberty, $96 \mathrm{f}$.

${ }^{104}$ The work which most significantly influenced Hayek was - according to his own statements Mary Gregor's Laws of Freedom: A Study of Kant's Method of Applying the Categorical Imperative in the Metaphysik der Sitten (Oxford \& New York, 1963), which only appeared three years after the publication of his Constitution of Liberty.

${ }^{105}$ This is also reflected within the literature on Hayek. Bernhard Erning's otherwise very informative and balanced portrayal of the positions of Kant and Hayek, for instance, overlooks the dimension of distributive justice in Kant, see: Hayek's Moralphilosophie: Freiheit und Gerechtigkeit in der Grossen Gesellschaft (1993), 107-132.

${ }^{106}$ See Hayek, Law, Legislation and Liberty, 42.

${ }^{107}$ About this see also Kläver, Die Verfassung des Marktes, 59-76.

${ }^{108}$ See Köhler, Iustitia distributiva, 457ff; for a corresponding criticism of Hayek, see also Stephan Rothlin, Gerechtigkeit in Freiheit: Darstellung und kritische Würdigung des Begriffs der Gerechtigkeit im Denken von Friedrich August von Hayek (Frankfurt am Main, 1992), 188.
} 
Kant certainly declares himself against arbitrary distributions, but for participative justice, while Hayek lacks the conceptual possibilities for said differentiation. Hayek's kneejerk rejection of the concept of social justice therefore forces him to reclassify all assistance given to the indigent as means to protect social peace and societal harmony. ${ }^{109}$ With deliberately drastic formulations, Hayek creates an unresolved conflict between the rather balanced social policies of this theory and the one-sided rhetoric it is couched in. He thus writes, for instance, that social justice is as unthinkable as, for example, a "moral stone," or also that supporting social justice is comparable to believing in "witches and ghosts." 110 On one hand, he firmly declares that according to his theory the state has no mandate at all to look after individual assets. On the other hand, however, he relativizes this stance in practice, by standing up for contributions securing the subsistence of those who lack property, for access to education for all, for help towards self-help, and even for a partial share of the innocently unemployed in the increase of overall prosperity. ${ }^{111}$ Theoretical inconsistence forces him into practical inconherence. ${ }^{112}$

A further example underscores this point. From the strict inactivity of the state his theory demands in regard to all things economic, he expressly exempts action against monopolies. If someone has a monopoly on goods vital for life (his example: through possession of an oasis in the desert ${ }^{113}$ ), then he must respect the legitimate needs of his customers or he could be coerced by the law to respect them. Thus, however, Hayek again contradicts his claim that the state should act only to protect negative freedom. Whoever watches idly as others die of thirst is guilty of all sorts of things, but not in violation of the concept of negative or quantitative freedom; he neither damages the physical sphere of freedom of the thirsty, nor does he actively reduce their available options. Hayek's plea for state intervention can therefore only consistently be maintained through qualitative criteria - like, for example, a normative, counterfactual entitlement to nutrition. ${ }^{114}$

We now see the enormous price Hayek has paid for persisting in determining the idea of freedom only negatively and quantitatively. Since he characterized freedom as but a collection of non-coercive options, his right hand may not know what the left one does. While, with the right hand, he rejects any form of progressively liberal engagement, with the left hand, he secretly escorts it back into his palace of ideas again. That makes him appear hardly consistent from a neoliberal perspective and hardly trustworthy from a social-liberal perspective. For instance, Hayek's criticism of class envy and of the lobbyist organization of particular egoism, ${ }^{115}$ in no way takes the side of the propertied. This stance is even maintained when it would entail

\footnotetext{
${ }^{109}$ See Hayek, The Constitution of Liberty, 202.

${ }^{110}$ See Hayek, Law, Legislation and Liberty, 66.

${ }^{111}$ See Hayek, The Constitution of Liberty, 257.

${ }^{112}$ See also the (equally Kantian) criticism of Kläver in Die Verfassung des Marktes, 246ff., 299f.

${ }^{113}$ See Hayek, Constitution, 135.

${ }^{114}$ See David Miller, "Constraints on Freedom," Ethics 94:1 (1983), 66-86 and John Gray, "Hayek on Liberty, Rights and Justice," Ethics 92:1 (1981), 73-84.

${ }^{115}$ See Hayek 1976, 98.
} 
a loss of privileges and assets. In this manner, Hayek rejects, for example, any social isolationism against impoverished immigrants in the interests of the propertied classes. ${ }^{116}$ For Hayek, the principle of freedom does not end when it begins to cost something. On the contrary, since, for him the freedom of individuals constitutes the legitimating principle of politics, Hayek holds that it is wrong to always grant primacy to national interests instead of the concerns of other peoples. Hence Hayek's support for a liberal, global governance order, which - obligated to the rule of law should serve the freedom of all the citizens of the world.

As a result, it can be said: Contrary to popular belief, Hayek does not always insist upon a minimal state, but rather provides some positive tasks which the state, serving society as a whole, should undertake. For the arrangement of these statetasks, his theory provides important criteria and unique ideas about constitutional theory. Nevertheless, Hayek cannot gather up these results on the path proposed by him en route to a purely negative conception of freedom. His theory of the lawful state and the economic system concomitant to its legal order are infused with numerous positive postulates. In all, Hayek clearly gives his theory of freedom a direction which implicitly points beyond its explicit quantitative foundations - in the direction of qualitative freedom.

\subsection{Liberal Distribution (John Rawls)}

At the end of the twentieth century, hardly any philosopher was quoted as much as John Rawls (1921-2002). Now, at the beginning of the twenty-first century, hardly any other philosophical conception is criticized as much as his. In the 1970s, his work seemed to provide a welcome answer to the question concerning how the modern nation-state could harmonize the tension between the ideals of freedom and social justice. Today, in the era of globality, this answer appears less satisfactory. The burden of global and intertemporal problems revealed many fissures within Rawls' conception, which, while manifest already in its architectural plans, had initially been overlooked.

John Rawls intended to establish a new home for liberalism that would perfectly situate it within the theoretical landscape of the present. For that purpose, he wished to build on the content of Kant's theory of freedom, while leaving behind its method. Liberalism without the metaphysics of freedom: This attempt to appropriate Kant selectively motivates and connects the various levels of Rawls' work and, within it, the gradual development of his own theory of freedom. Rawls, for instance, does not wish to derive the social order he favors from substantial directives, but rather wishes to let it arise by means of formal procedures alone - from theoretical thoughtexperiments and practical political representation. The liberal order should be justified by reflections undertaken and accepted on the part of citizens themselves; a project, which, in his time, was also advanced by other thinkers, like Charles

${ }^{116}$ See Wilhelm, The Political Thought of Friedrich A. Hayek, 168. 
Larmore, and which today continues to be pursued by otherwise harsh opponents of the Rawlsian approach, like Martha Nussbaum.

The crux is Rawls' attempt to get exactly the kind of a fair social order he wants through a social contract resulting supposedly from nothing but a purely descriptive concept of interests, processed by the instrumental logic of rational exchanges, and governed by structural directives alone. However, the preference-theoretical concept of freedom as the quantity of all privately available options, which John Rawls overtly declares to be the foundation of his philosophical work, does not harmonize with his covert understanding of freedom. Rather, that quantitative theory of freedom endangers the very conception of freedom that is close to Rawls's heart.

\subsubsection{Approach and Method}

Rawls never leaves any doubt about what kind of social order he favors and wishes to promote with his philosophy: a liberal order in which human rights are inviolable and where no citizen can prescribe to another which ideas of the good he or she should employ to direct his or her life. The human being should be able to live freely and only be limited in this freedom insofar as this is required for the protection of the freedom of others, or serves to enable the freedom of fellow human beings. The leitmotifs of the Rawlsian Theory of Justice ${ }^{117}$ are built upon this classically liberal basic chord. In order to fulfill customary expectations about contemporary compositions, Rawls nevertheless rearranges the harmonic sequence of his - in melody and rhythm - strongly Kantian liberal work. But since Rawls (incorrectly) assumes that Kant lets his harmonics of freedom resound from a metaphysically monophonic cadence of moral-legal-political ideas of freedom, he commits himself to another program. His aim is to unfold the desired liberal melody from the dissonant notes of musicians only obligated to their own self-interest. Therefore, Rawls mixes Kantian chords with contractualist sounds. Rawls, in short, suggests that Kant is attached to a metaphysical composition no longer suitable for post-metaphysical times. ${ }^{118}$

As a passage from his Theory of Justice makes clear, ${ }^{119}$ Rawls bases this interpretation of the Kantian opus (attractive melodies, unattractive basso continuo), which is quite common in the English-language literature, upon Henry Sidgwick's The Kantian Conception of Free Will. ${ }^{120}$ This text provides a decisive key to Rawls' Kant reception, as well as to his understanding of freedom as a whole. Sidgwick, discuss-

\footnotetext{
${ }^{117}$ First edition 1971. Quotations are from the following edition: John Rawls, A Theory of Justice (Cambridge, MA, 1999).

${ }^{118}$ About this see Onora O’Neill, “Autonomy, Coherence, and Independence” in Milligan \& Miller (eds.), Liberalism, Citizenship and Autonomy, 214.

${ }^{119}$ See John Rawls, A Theory of Justice, 224.

${ }^{120}$ See Henry Sidgwick, The Methods of Ethics (Indianapolis, 1981), 511ff. Rawls found this study so significant that he attached it as an appendix to his edition of Sidgwick's main work, The Methods of Ethics.
} 
ing Kant's theory, distinguishes three concepts of freedom: first, freedom as chaotically unregulated determination of the will; second, freedom as freedom of choice; and, third, freedom as conformity with the moral law. The first is then immediately ruled out again. For Sidgwick, a chaotic determination of the will can neither be thought along with Kant nor in and out of itself: Wherever mere chance rules, there is no responsibility. The question therefore arises concerning which of the two remaining concepts of freedom Kant favors. Both frequently surface in the Kantian oeuvre, and yet are, according to Sidgwick, incompatible with one another.

According to Sidgwick, the conformity theory entangles us in the spider's webs of shadowy metaphysics. One thus remains without any information concerning how evil comes into the world since - on one hand - the purely free, i.e. the autonomous, enforcement of the moral-law is never evil, and - on the other hand - the purely natural will, lacking freedom, cannot actually be called evil. There, consequently, remains only the concept of freedom of choice. Yet, if one stakes everything upon that, one loses the rigorous potentials of the Kantian moral doctrine - which continually and unconditionally demands that the moral law be followed. Eventually, the somewhat awkward question arises: Why be moral at all? For, according to Sidgwick, without recourse to the conformity thesis, with Kantian means no kind of rational preference between the maxims of the saint and the scoundrel can be justified. Either could be universalized; and one could therefore consistently (i.e. universalizably) choose both as systems of preference directing action.

Having highlighted this difficulty, Sidgwick believes the Kantian position to be finished. But not Rawls: He certainly follows Sidgwick in turning away from the metaphysics of freedom. He also agrees with him that Kant's theory could not possibly explain why a free subject should actually decide upon a moral course of life. But Rawls believes that it is possible to remedy this supposed "defect" of the Kantian theory. ${ }^{121}$ It is precisely a question of indicating good reasons for why one should freely choose ethical options. If one could show that to do so is based upon the well-understood self-interest of every agent, then a plausible motive for decent behavior would exist. One could then hold on to the results of the Kantian doctrine of freedom without the burden of metaphysical thinking. To this end, Rawls recommends his own conception of the original position (about which there is more below):

The original position may be viewed then, as a procedural interpretation of Kant's conception of autonomy and the categorical imperative within the framework of an empirical theory. [...] No longer are these notions purely transcendent and lacking explicable connections with human conduct, for the procedural conception of the original position allows us to make these ties. ${ }^{122}$

This position provides the source-code for Rawls' Theory of Justice: the derivation of substantial positions from procedural postulates. In analogy with classical

\footnotetext{
${ }^{121}$ See ibid.

${ }^{122}$ Ibid., 226.
} 
German philosophy, Rawls distinguishes between rationality in the narrow sense, as a prudent adaption of means to given ends, and reasonableness in the broader sense, as a wise consideration of the meaning and purpose of our intentions. Yet, unlike the philosophers of German Idealism, Rawls attempts to prove that the reasonableness (Vernünftigkeit) of ethical action is the expression of appropriate proceduralized rationality (Verständigkeit). He wishes to defend the content of a good number of Kant's positions, yet replace the form of the arguments defending them with calculations from rational-choice theories. ${ }^{123}$ Nothing but recourse to formal, procedural criteria (like consistency, reciprocity, etc.) would be required for the necessary limitation of individual freedom (i.e. so as to discriminate between legally licit and illicit options). Rawls wishes, as it were, to protect political liberalism from metaphysics and morality.

Via the intermediate step of a hypothetical situation in which rational decisionmakers - shielded by a 'veil of ignorance' from knowing specifics about their life discuss the foundations of their social order, this idea of a purely formal representation of the citizens' political will leads Rawls to a dual conception of freedom characterized by the following distinction: "liberty is represented by the complete system of the liberties of equal citizenship, while the worth of liberty to persons and groups depends upon their capacity to advance their ends within the framework the system defines." 124 This differentiation between liberty and the worth of liberty reflects the difference between liberal and utilitarian argumentation in favor of freedom. On the one hand, freedom (deontologically) presents a value in itself: "Freedom as equal liberty is the same for all." ${ }^{125}$ On the other hand, Rawls (consequentialistically) recognizes that a liberal regime is more beneficial for some than for others. For instance, the rich typically profit from a liberal order more than the poor; in short, "the worth of liberty is not the same for everyone."126

Since Rawls suspects all material criteria for evaluating freedom of metaphysics, there remains for individuals only a formal logic for the comparative evaluation of their options: In the absence of qualitative measures they must orientate themselves quantitatively. They will therefore (have to) decide upon rules that promise to them "more" rather than "less" utility. Consequently both - freedom in itself and its utility for us - should be maximized. Rawls expressly aspires to "the most extensive scheme of liberties" for all, as well as also a distribution-technique which is able "to maximize the worth of liberty" for those most poorly positioned. ${ }^{127}$ Extending the radius of freedom and maximizing the options contained therein - these quantitative leitmotifs are characteristic of the Rawlsian endeavor.

Such an approach, though, comprises difficulties. Two can already be addressed. First, there arises the problem that now both targeted values - freedom as well as its utility - are made measurable and commensurable; a quite problematic directive.

\footnotetext{
${ }^{123}$ See ibid., $14 \mathrm{f}$.

${ }^{124}$ Ibid., 178.

${ }^{125}$ Ibid.

${ }^{126}$ Ibid.

${ }^{127}$ Ibid.
} 
How does one count or gauge freedom? Is there a yardstick with which even aspects of freedom not extant in the physical world could be accurately measured? ${ }^{128}$ Second, a difficulty arises in guaranteeing that the quantitative calculations and procedures recommended by Rawls eventually produce what is qualitatively acceptable to him - namely a liberalism directed also towards social fairness. Rawls attempts to guarantee this outcome through certain procedural rules. To rescue some positions especially dear to him (for instance, distributive justice), Rawls must however again free himself strenuously from precisely that quantitative straitjacket he had earlier put on.

Referring back to Kant assists us in outlining Rawls' project more precisely. As we have seen (Sect. 2.1.1), Kant requires for his philosophy of law only a concept of freedom that makes possible the ascription of outer actions to subjective actors. Only for moral philosophy does Kant aspire to a concept of freedom which also thematizes the inner life (AA VI 223f). It should therefore be asked: From what exactly does Rawls actually detach himself when he distances himself from the Kantian metaphysics of freedom? Rawls follows Sidgwick in the assumption "that the noumenal self can choose any consistent set of principles," ${ }^{129}$ as long as one does not attribute to this self some fixed "desires" like the "desire to express their nature as rational and equal members of the intelligible realm." ${ }^{30}$ Now, Rawls believes he has to remedy that (erroneously) assumed lack of direction in Kant's concept of personality: by an ad hoc introduction of certain natural needs for morality, due to, namely, a "desire to act justly" and a "desire to express most fully what we are or can be, namely free and equal beings." "131 A philosophical Münchhausen trick: To free himself from basic metaphysics, Rawls thus flees into baseless speculation.

Yet, Kant's theory of the noumenal self is neither an indispensable nor characteristic feature of his liberalism. ${ }^{132}$ Kant's theory of the subject is part of his critical philosophy, not his applied ethics. ${ }^{133}$ Kant's liberalism must therefore be neither freed nor protected from metaphysics. Rawls would not have gone so far astray had he remained closer to Kant and followed his distinction between a phenomenally parsimonious (as well as non-metaphysical) concept of the legal person on the one hand and a comprehensive concept of moral personality on the other (see AA VI 214). As we have already seen (Sect. 2.1.1): Metaphysics in no way provides the foundation for Kant's political philosophy, which refers purely to the sphere of outer-factual, legally enforceable actions between persons (AA VI 230). Whoever admits outer freedom of action does not at all need to further engage with Kant's

\footnotetext{
${ }^{128}$ See Onora O'Neill, “The Most Extensive Liberty” in Proceedings of the Aristotelean Society 80 (1979), 45-59.

${ }^{129}$ Rawls, A Theory of Justice, 224.

${ }^{130}$ Ibid., 225.

${ }^{131}$ Ibid.

${ }^{132}$ See Larry Krasnoff, "How Kantian is Constructivism," Kant-Studien 90:4 (1999), 385-409.

${ }^{133}$ See Otfried Höffe, "Öffentliche oder politische Vernunft? Zu Rawls II," Zeitschrift für Philosophische Forschung (1994), 259-269.
} 
transcendental philosophy for questions of political, legal, and economic ethics. ${ }^{134}$ Kant's political liberalism therefore - contra Rawls' interpretation - in no way depends upon his metaphysics and moral theory. ${ }^{135}$ It rests upon an argument sui generis in favor of external freedom, ${ }^{136}$ which is why the construction of a system of rights could occur, as Kant writes, even in "a nation of devils," i.e. a society of not at all morally or metaphysically motivated subjects (AA VIII 366). And hardly anyone would, after all, ascribe to devils a natural 'desire' to be well-behaved.

But Rawls proceeds differently: To prevent the inclination "to act as a free rider" from being lived out in the well-ordered society he aspires to, Rawls declares that it must be held in check by an "effective sense of justice," which presents, as it were, the natural correlate of those natural "desires" under conditions of institutionalized justice. ${ }^{137}$ With this hefty anthropological thesis Rawls also undermines his own supposedly metaphysics-free approach. Rawls introduces those assumptions, after all, not via an empirically validated theory, but rather posits them ad hoc.

Rawls apparently wishes to pay off a debt that Kant never actually incurred; and Rawls does this by indebting himself to rational choice theory. He accepts the liability of thoroughly redeeming his arguments in the currency of enlightened selfinterest. With that charge, however, his project becomes excessively burdened. For the repayment of a credit supposedly drawn down by Kant, Rawls turns to a philosophical policy of austerity: both, in terms of content, "by posing more limited questions" and, in terms of method, "by substituting prudential for moral judgment." 138 Rawls thus renounces the entire purchasing power of ethical currencies: Theories of the good life are rejected for being illegitimate means of payment. Normative bills should no longer be paid off with genuinely moral reasoning but rather be redeemed by "a judgment of rational prudence." 139 Even the solvency of the "principles of justice," which Rawls so desires, no longer lie within their reasonableness, as they still did with Kant. Criteria for justice receive their "justification" now only through the contingent fact "that they would be chosen." 140 Philosophical values with formally unconditional validity are thus depreciated to a currency whose purchasing power results solely from its factual acceptance in circulation.

Rawls perceives this as a gain. The burden of norm-conforming behavior would consequently be drastically reduced since everyone could now recognize social "obligations" as "self-imposed," which would provide a good "basis for the public acceptance of the corresponding principles of justice." ${ }^{141}$ However this kind of una-

\footnotetext{
${ }^{134}$ See Marcus Willaschek, "Right and Coercion: Can Kant's Conception of Right be Derived from his Moral Theory," International Journal of Philosophical Studies 17:1 (2009), 49-70.

${ }^{135}$ See Thomas Pogge, "Is Kant's Rechtslehre Comprehensive?," Southern Journal of Philosophy 36:1 (1998), 149.

${ }^{136}$ See Gregor, Laws of Freedom, 67.

${ }^{137}$ Rawls, A Theory of Justice, 499.

${ }^{138}$ See ibid., 39.

${ }^{139}$ Ibid.

${ }^{140}$ Ibid., 37.

${ }^{141}$ Ibid., 12 .
} 
nimity is only possible on the assumption that the way people understand themselves is free from complication and controversy. One should, Rawls holds, start out from starkly reduced features of human existence; from individual self-interest and the capacity for logical thinking in particular. In the light of these premises, Rawls believes that, in a "hypothetical situation," a social order would be able to be negotiated in which enlightened self-interest would drive everyone to the recognition of precisely such rules that enable fair cohabitation for all. ${ }^{142}$ In short, Kant's categorical imperative that justice is unconditionally to be done is transformed into the conditional commandment of a hypothetical imperative that justice is to be aspired to since (and insofar as) it serves rationally pursued self-interest. ${ }^{143}$

It is difficult to see how this is an improvement upon Kant. ${ }^{144}$ According to Kant, the person's ethical commitment does not arise as a result of insight into certain amoral grounds for morality or through the wish to respond to certain amoral needs for morality. Rather it plainly results from the reasonable insight and the concomitant emotional recognition ('respect') of the salience of moral commandments. ${ }^{145}$ Kant's approach is therefore more consistent and far-reaching than that of Rawls since, from the beginning - and not only by way of secondary derivations - it always included cases where ethical action would be contrary to self-interest. The Kantian construction thus appears to me to be simpler and more parsimonious than the Rawlsian variant. ${ }^{146}$

\subsubsection{Transcendental or Transactional Freedom?}

An idiosyncrasy of Rawls' philosophy of freedom is the enormous tension between the plea for a transactionally generated order of freedom on the one hand and, on the other, the extensive limits imposed on the very constructions rendered by the quantitative computations of self-interest:

Among the essential features of this situation is that no one knows his place in society, his class position or social status, nor does anyone know his fortune in the distribution of natural assets and abilities, his intelligence, strength, and the like. I shall even assume that the parties do not know their conception of the good or their special psychological propensities. The principles of justice are chosen behind a veil of ignorance. ... Since all are similarly

\footnotetext{
${ }^{142}$ Ibid., 11.

${ }^{143}$ See John Martin Gillroy, "Making Public Choices: Kant's Justice from Autonomy as an Alternative to Rawls' Justice as Fairness," Kant-Studien 91:1 (2009), 44-72.

${ }^{144}$ Concerning the following, see Robert S. Taylor, Reconstructing Rawls: The Kantian Foundations of Justice and Fairness (2011), 280ff.

${ }^{145}$ See Dieter Schönecker, "Das gefühlte Faktum der Vernunft: Skizze einer Interpretation und Verteidigung," Deutsche Zeitschrift für Philosophie (2013) 1, 91-107.

146 "For Kant ... the theory simply defends the principles that ordinary agents accept. But for ... Rawls, theory claims to construct the principles for society as a whole" (Krasnoff, How Kantian is Constructivism?, 409).
} 
situated and no one is able to design principles to favor his particular condition, the principles of justice are the result of a fair agreement or bargain. ${ }^{147}$

Behind that oft-referenced 'veil of ignorance' subjects are robbed of all opportunities to generate tactical advantages for themselves, for instance by choosing rules which are in their own interest, while socially damaging. According to these limitations they can then actually increase their own utility only by nolens volens enhancing the utility of all. No one wants to cut their own finger; and if, behind the 'veil of ignorance,' one does not know into whose finger one is about to cut, one likely wields the blade gently.

As is well known, Rawls explains that a deviation from an initial "benchmark" of original equality of assets will be universally accepted in the "original position" when this indirectly also favors those who do not directly profit from the admission of differences in incomes. There thus arises Rawls' (in)famous "principle of difference" in favor of the economically weakest: If after a hypothetical redistribution society as a whole has absolutely more, this should also satisfy those who unlike others possess relatively less than previously. Reformulated in terms of economic policy: Insofar as even the smallest piece of a capitalist cake turns out to be bigger than each piece of an all-in-all smaller socialist cake sliced into rather equal parts, a capitalist confectionary would nevertheless certainly be preferred to a socialist one, wouldn't it? Therefore, one must move away from the idea of a completely deregulated libertarian pastry-product-market and, through a regulation of the bakingbusiness, see to it that a sufficient part of the total production is supplied to the hungriest; that is more-or-less the basic idea.

The indirect character of this concept of solidarity immediately catches our eye. Why does this social redistribution not occur from a direct commitment in favor of the economically disadvantaged? Instead of reflecting upon the quantitative aggregate (for all taxed individuals), it might be more appropriate to inspect directly the qualitative results (for the needy). ${ }^{148}$ Why not - in order to remain in the picture lay down lower boundaries of minimal-satisfaction, which every pastry-product has to reach which wants to be just? Surely, by means of the "principle of difference," distributions of assets can incontestably be worked out which appear to societies to be both pragmatically and normatively acceptable; which is the main reason for the enduring popularity of the Rawlsian model. Nevertheless, in extreme cases situations may arise where its foundational concerns lead ad absurdum and reveal their theoretical weaknesses.

Imagine, for example, an extremely rich society in which everyone would be a millionaire, some however - with no limits put up against increasing inequality have made the leap to billionaires. Even in a society of this kind there would still be continuous redistribution according to Rawls. The principle of difference certainly cannot issue a qualitatively motivated call like "It is enough!"; from every quantita-

\footnotetext{
${ }^{147}$ Rawls, A Theory of Justice, 11.

${ }^{148}$ See for example Martha Nussbaum's counter-project: "My theory speaks only of a social minimum and does not address inequalities above that (very ample) social floor" (Frontiers of Justice, 178).
} 
tively enlarging delta it will rather derive an appeal for the relative improvement of the "least benefitted." Conversely, in a society where large sections languish below subsistence-level, one would only be allowed to redistribute in strict quantitative proportion to the respective growth of the difference in societal assets overall, but not beyond this proportion. There could arise drastic emergencies - through famines produced by natural catastrophes for instance - in which the state would have to remain passive because it would not believe itself legitimated to redistribute more radically (accessing, for instance, the substance, and not just the growth of assets). For, without a qualitative criterion for basic needs, how could one even begin to justify (stronger) egalitarian redistributions within Rawls' model?

Rawls' attempt to procure universal qualitative justice from quantitativelyreciprocal utility exchanges not only fails in extreme situations, however. The actual problem lies deeper: in the idea that (only) the self-interest of individuals constitutes the basis of universal agreement with the social contract. Rational agents will grasp that their enlightened self-interest comprises entering into social relations only if and insofar as society is arranged as "a cooperative venture for mutual advantage."149 The readiness of individuals for "social cooperation" is purchased at the price that this proves to be to the benefit of all. ${ }^{150}$ Where everyone has access to more resources and consequently also more numerous options in a rule-based society than in imagined isolation or in unregulated living conditions, the establishment of a state of law is but an upshot of the quantitative logic of self-interest.

This rationally pursued interest, however, stands and falls with the precise knowledge of the specific situation one respectively finds oneself in. People from privileged backgrounds benefit from different political rules than persons with a background of migration. For example: Without knowledge of one's own abounding private assets, one will perhaps assume to profit from certain regulations (like, for instance, a strong progressive taxation of assets and income), which would also and especially better position the most poorly situated. Yet as soon as one already knows that one will inherit millions, this deliberation becomes meaningless - in the naked ratio of quantitative maximization. This shows that, behind a 'veil of ignorance' and without information about their personal position in life, individuals can therefore only very moderately serve their actual interests, which is precisely also Rawls' declared intention. ${ }^{151}$ But why would human beings at all then venture upon the thought-experiment of the original position? Why should they make decisions under the constraints of a hypothetical situation in which the successful maximizing of their own benefit is de facto impossible? That appears highly implausible, since, according to Rawls' model, the only characteristic all decision-makers possess is precisely the rational pursuit of their self-interest. And right here resides a considerable problem for the Rawlsian theory.

\footnotetext{
${ }^{149}$ Rawls, Theory of Justice, 4. In contrast, Martha Nussbaum argues that this fixation with reciprocal advantage simply presents a "wrong account of the primary basis for social cooperation" (Frontiers of Justice, 129). In the following I will present arguments agreeing with this judgment.

${ }^{150}$ Rawls, Theory of Justice, 126.

${ }^{151}$ Ibid., 148.
} 
Whereas Rawls is concerned to show that the principles of justice he establishes (the principle of freedom and the principle of difference) present a rational choice for all participants within the original position, he can hardly explain how it should occur to someone from outside this perspective to impose its restraining knowledgelimitations upon themselves. A quantitatively orientated self-interest would in no way command that. Applied to economics: A homo oeconomicus who robbed himself of the presuppositions for being an efficient homo oeconomicus is not really an effective homo oeconomicus - or, more precisely, is not one at all. Only a consciousness always already qualitatively directed to duty may urge us to accept the Rawlsian intellectual restrictions in order to generate distributive results that serve the cause of justice rather than maximization. Whoever is not already ethically motivated will hardly involve themselves with that little game with the 'veil of ignorance.' Whoever is, however, might instead prefer to look directly in the face of justice as opposed to observing only its silhouette reflecting the image of self-interested rationality refracted by those complicated procedures.

These objections lead back to the Kantian formulation of the problem of explicating the normative form of the consciousness of freedom in and for itself (see Sect. 2.1). And it is thoroughly questionable whether for this purpose one must at all make use of the model of a social contract advantageous for all participatory parties. ${ }^{152}$ Rawls advocates this because he assumes that only through inadmissible metaphysics might one otherwise be able to identify the good and the just. Therefore, due to the peril of endless metaphysical dispute, the direct path to justice must not be taken. Society should head for that sublime goal only indirectly. And the social contract model provides the sought-after detour.

Yet can substantial justice be reached via forms of procedural fairness alone? Rawls believes "there is a correct or fair procedure such that the outcome is likewise correct or fair, whatever it is, provided that the procedure has been properly followed." ${ }^{153}$ Nothing more than rationally pursued self-interest need be presupposed. However, Rawls must then restrict this interest by many procedural tricks so as to achieve a quasi-identity between decision-makers and those affected by the decisions. ${ }^{154}$ Ultimately, no one deliberately harms themselves, therefore prudent decision-makers will - in the correct procedural framework - always act in everyone's interest. Only thus does the model function.

At first glance, it seems that not all that much is demanded of the decisionmakers; only a general capacity "to take part in and to act in accordance with the public understanding of the initial situation." ${ }^{155}$ For instance, whoever can grasp the rules of a typical strategy game is already deemed appropriate for Rawls' thoughtexperiment; towering intelligence appears unnecessary. It is enough if the capacity for thinking exists "within the normal range." ${ }^{156}$ Consequently, Rawls wants his

\footnotetext{
${ }^{152}$ See Brian Barry, Justice as Impartiality (Oxford \& New York, 1995).

${ }^{153}$ Rawls, Theory of Justice, 86.

${ }^{154}$ See Martha Nussbaum, Frontiers of Justice, $16 \mathrm{f}$.

${ }^{155}$ Rawls, Theory of Justice, 505.

${ }^{156}$ Ibid., 25.
} 
self-given guideline, "to assume as little as possible,"157 to be sufficient. Most people actually possess precisely this instrumental rationality which is here in question. "Only scattered individuals are without this capacity, or its realization to the minimum degree." 158

Does that, however, suffice? Rawls suggests that a society structured according to the framework of the principles he supports establishes more utility for all participants than an unjustly structured social order and is consequently to be desired out of purely rational self-interest. But perhaps that applies only for some, or in the best-case scenario for most, but never for all. Only when one hypostatizes the fiction of the "original position" into reality - thus assuming that people actually do not know who they are and what is most of all useful for them in their specific position do the principle of difference and rational choice theory provide equal results. ${ }^{159} \mathrm{In}$ real life, however, it is not always - and not for everyone - advantageous to join together with others within a society that redistributes private assets.

How is it, for example, with those "scattered individuals," of which we were talking a moment ago, who lack even the lowest degree of strategic rationality? Severely mentally handicapped people, for instance, may not fit in with such a calculation, in at least two respects ${ }^{160}$ : First, they cannot engage in the required cognitive processes of abstraction which Rawls outlined for working-out their long-term advantage. Second, other people among the prudent advantage-seekers may not at all wish to include people with such limited capacities within the social contract because they view their contribution to social net utility as too small. Highly explosive questions immediately surface: How then should the rights and interests of these persons be satisfied? Are they to be declared wards of the law and second-class citizens? That shows: Strongly asymmetrical living-conditions can implode a social model orientated around the idea of reciprocal symmetry.

Yet doubts concerning the model of the 'veil of ignorance' and the original position do not of course only arise from the perspective of a self-interest potentially thwarted by the Rawlsian procedural requirements. What should we think of a conception of freedom concretized by means of the fiction of people without qualities? If we follow Rawls to the point where we have a naked maximizer of preferences before our eyes, then we have already stripped the subject in question of two decisive dimensions. First, we find not a word here about reasonableness taking precedence over instrumental rationality. Yet where no ethical reason directs the technical ratio, decisions are made as automatically as in software-based expert systems. Is that already freedom? Second, behind the "veil," these subjects lack every sensible, bodily, or spiritual dimension, which could give their decisions a genuinely individual or private aspect. These decision-makers are therefore, strictly speaking, not themselves at all, but rather merely masks of the universal. Is that still freedom?

\footnotetext{
${ }^{157}$ Ibid., 129.

${ }^{158}$ Ibid., 506.

${ }^{159}$ See Fred D’Agostino, Free Public Reason: Making it up as we go (New York, 1996), $40-44$. ${ }^{160}$ About the following, see Martha Nussbaum, Frontiers of Justice, 135-145.
} 
These considerations are especially pertinent in regard to moral or religious life goals. As long as I, as a result of the 'veil of ignorance,' do not know whether I entertain religious sentiments, and if so which, it may be prudent to promote a form of society where I do not end up suffering the tyranny of fundamentalists. But, if one ponders the matter at hand from a firm, religious perspective, what then? Many religious people, from their own theological standpoint, certainly demand open societies with institutionalized religious pluralism. Yet intellectual honesty compels us to admit that the opposite will also be maintained. Some believers already feel that the hypothetical entrance into that situation of theological amnesia postulated by the 'veil of ignorance' is absurd or blasphemous, and so they reject the demands for secular political institutions and comprehensive civil tolerance resulting from it as heretical. Only those already motivated to overcome their own (here: religious) interests in favor of a concept of universally-acceptable (here: tolerant) living conditions - concretely: only those who already have a liberal understanding of religion as instructing tolerance (about which there is more in Sect. 5.1) - will gladly accept the preconditions for reflection Rawls establishes. Nevertheless, for its part, this qualitative motivation will hardly be derived from a quantitatively maximizing rationality. ${ }^{161}$

Rawls had sensed this problem. It appears highly questionable whether people wish to continually and necessarily serve his idea of procedural justice more than their own, not infrequently, countervailing ideas of the good or of God. This explains, in my opinion, why Rawls had recourse to that already mentioned "desire for justice" which was introduced ad hoc and assumed of everyone. Rawls assures us that "the desire to express our nature as a free and equal rational being can be fulfilled only by acting on the principles of right and justice as having first priority." But how exactly does he know this if not from a metaphysical theory or moral intuition? Is this prioritizing of justice convincing - and what price do we have to pay for it?

For the argumentative support of that "desire for justice" Rawls enlists some theses far from every metaphysical restraint. Without hesitation he declares: "the self is prior to the ends which are affirmed by it." 162 That means: The philosophical consciousness of axioms of justice belongs to the inner kernel of the person. Religious ends, however, are a matter for the outer shell; a definitely controversial view. The priority of the self over its attributes and aims maintained here, certainly looks back towards a venerable tradition, and it may also appear prima facie plausible to many. But that is not the point. In Rawls' anti-metaphysical theoretical framework, this position can be neither deduced nor defended. ${ }^{163}$ Therefore, whether Rawls' take on the issue is correct is unimportant, since he cannot justify those emphatic declarations with his own methodological directives.

\footnotetext{
${ }^{161}$ See Bernard P. Dauenhauer, "Response to Rawls" in Cohen \& Marsh (ed.), Ricoeur as Another: The Ethics of Subjectivity (New York, 2002), 208ff.

${ }^{162}$ Rawls, A Theory of Justice, 491.

${ }^{163}$ See Michael J. Sandel, "Review of John Rawls: Political Liberalism," Harvard Law Review 107: 7 (1994), $1780 \mathrm{ff}$.
} 
Rawls' critics reliably located and admonished these metaphysical remainders in the Theory of Justice. Communitarians and theologians dislike Rawls' preference of rights over the good; utilitarians and game-theorists point towards the indecisiveness of a calculation that does not use knowledge of one's situation; pragmatists and relativists want to reject Rawls' massive claim to normativity; and positivists as well as neoliberals are against the sociopolitical aims of his theory of justice: But they all agree that Rawls' arguments in favor of freedom and justice are far less free from metaphysics and presuppositions than he professed. Furthermore, his critics concur that Rawls only apparently follows an abstractly-maximizing concept of materially neutral freedom, but in truth pays homage to a (very) concretely determined doctrine of freedom. Rawls could have responded to these criticisms in two ways: either by defending the qualitative presuppositions he had already enlisted or by retreating to the quantitative realm. ${ }^{164}$ Which alternative did he opt for?

\subsubsection{Relativist Versus Dogmatic Liberalism}

Rawls answers his critics in Political Liberalism ${ }^{165}$ and The Laws of Peoples, ${ }^{166}$ as well as in Justice and Fairness: A Restatement. ${ }^{167}$ He thereby makes use of both of the previously mentioned strategies - the tactical flight forward as well as the strategic retreat - which makes it difficult to interpret his late work properly. It is, however, generally agreed that in later years, Rawls distanced himself from the quantitatively maximizing directives of his original theory ("the most extensive scheme"; "to maximize the worth of liberty"; "mutual advantage"), ${ }^{168}$ but without completely relinquishing the contractualist model. ${ }^{169}$ He turns his back on the originally intended quantitative measuring of a single type of freedom and its always commensurable value and frankly admits "that the idea of the extent of basic liberty is useful only in the least important cases." ${ }^{170}$ Instead of that he now also recommends a theory qualitatively orientated towards the sufficiency and optimization of freedom.

In Political Liberalism, the emphasis now lies rather on "society as a fair system of cooperation over time." ${ }^{171}$ Occasionally, Rawls even seems to set aside the struc-

\footnotetext{
${ }^{164}$ See William A. Galston, “Two Concepts of Liberalism,” Ethics 105:3 (1995), 516-534.

${ }^{165}$ First edition, 1993. Quotations are from the second edition: John Rawls, Political Liberalism (New York, 1996).

${ }^{166}$ First edition, 1999. Quotations are from the fourth edition: John Rawls, The Law of People: With 'The Idea of Public Reason Revisited' (Cambridge, MA, 2002).

${ }^{167}$ John Rawls, Justice and Fairness: A Restatement (Cambridge, MA, 2001).

${ }^{168}$ Ibid., 112-114.

${ }^{169}$ Martha Nussbaum pronounces: "However, at the end of the day Rawls was unwilling to drop the social contract structure in favour of a more Kantian theory" (Creating Capabilities, 85).

${ }^{170}$ Rawls, Justice and Fairness: A Restatement, 112-114.

${ }^{171}$ Rawls, Political Liberalism, 14.
} 
ture of symmetrical exchange-relations; for instance, when he declares that "the idea of reciprocity is not the idea of mutual advantage." ${ }^{172}$ Instead of that, two "moral powers" of humanity henceforth become the normative directives of his liberalism: the capacities, on the one hand, to settle on principles of social justice and, on the other hand, to develop an idea of the good for one's own life. With their help, in his later work, Rawls qualitatively weighs up the options of freedom as more or less "significant":

a liberty is more or less significant depending on whether it is more or less essentially involved in, or is a more or less necessary institutional means to protect, the full and informed exercise of the moral powers in one (or both) of the two fundamental cases. The more significant liberties mark out the central range of application of a particular basic liberty; and in cases of conflict we look for a way to accommodate the more significant liberties within the central range of each. ${ }^{173}$

The example of freedom of speech explains the meaning and purpose of this distinction. In respect to the proclamation of political opinion, freedom of speech is unconditionally to be protected, Rawls believes, but perhaps not for the ends of private defamation. The justification of the difference lies in their respective contribution (present in the first case, lacking in the second) to the actualization of the two moral powers. ${ }^{174}$

All of that is of course transparently qualitative thinking, which - once more enlists full-bodied anthropological pronouncements about the nature of human beings and their "moral powers." Nevertheless, Rawls now also freely admits that he thereby sets out from materially loaded assumptions, like, for instance, from a normative concept of free and equal persons who are already orientated towards justice and the good; furthermore, from a two-level concept of reasonableness, which ethically transforms the purely technical end-means-rationality; as well as also from a concept of political community as an order aiming, from the outset, for fair cooperation.

Nevertheless, the status of conceptual construction in Rawls' theory thereby changes. It is no longer a question of justifying the liberal society in general but of specifying its particular features:

We start with the fundamental idea of a well-ordered society as a fair system of cooperation between reasonable and rational citizens regarded as free and equal. We then lay out a procedure that exhibits reasonable conditions to impose on the parties, who as rational representatives are to select public principles of justice for the basic structure of such a society. ${ }^{175}$

Oddly, Rawls refuses materially to defend these substantial foundational presuppositions (for example, the assumption that "reasonable and rational citizens [be]

\footnotetext{
${ }^{172}$ Ibid. In the light of that, Martha Nussbaum rightly criticises Rawls for nonchalantly skating around the thereby produced contradiction with his earlier work: "He is simply silent about the apparent contradiction" (Frontiers of Justice, 59).

${ }^{173}$ Rawls, Justice and Fairness: A Restatement, 112-114.

${ }^{174}$ Ibid., 114.

${ }^{175}$ Rawls, Political Liberalism, 103.
} 
regarded as free and equal"). He rather returns to the unorthodox argument that such a defense would run contrary to the liberal interests of his theory. ${ }^{176} \mathrm{He}$ has thus been derided for being ready to defend the basic liberal order with arms, but not with words. ${ }^{177}$

Rawls justified renouncing argumentation by claiming that, under conditions of pluralistic publicity, disagreements about ultimate truths, even on the part of wellmeaning as well as intellectually competent judges, cannot be avoided. If one does not wish to dictate some kind of position, then one must just accept the fact of plural worldviews. No political ideology relying upon but a single one of the extant worldviews, philosophies, or other 'comprehensive doctrines' can enjoy universal acceptance. For pragmatic reasons, therefore, only an 'overlapping consensus' of as many of such doctrines as possible should be aspired to. ${ }^{178}$

According to Rawls, this consensus shall not be comprised of all extant views, but only of those that are already characterized by reasonableness. For Rawls, this reasonableness means not to impose one's own principles of moral reasoning (religion, morality, tradition, etc.) onto one's discussion partners. One must address one's interlocutors solely with such arguments that they, too, can share - merely as fellow-citizens. Instead of subsuming others into one's own moral or metaphysical paradigm, one is to address them as fellow citizens of the state. Only justifications corresponding to this condition of reciprocity should be considered by public reason, i.e. concretely: in the legislative and judicative institutions of the state. ${ }^{179}$

But how do all citizens agree upon premises as tolerant as, for instance, that every fellow citizen is to be recognized as free and equal, and therefore as a fellow decision-maker? Rawls' answer is surprising: One must, in short, have the fortune already to live in a liberally constituted society. If this is the case then everything required for that step (a generally accepted concept of the basic rights of free, equal personality, as well as the idea of society as a fair cooperative order emerging from reciprocal agreement) is already anchored in the political culture and constitutional reality.

Surely: Wherever one can hark back to an already culturally embedded 'overlapping consensus' of tolerant convictions, such as in open societies, one can normally rely on that broad support for liberal principles that is required to get the implicitly already affirmed values of Rawls' ideas of consensus explicitly realized in politics also. Therefore, the task of political philosophy would no longer consist in deriving a liberal canon of values, but rather in applying it, for example by further differen-

\footnotetext{
${ }^{176}$ See Patrick Neal, "Does He Mean What He Says? (Mis)Understanding Rawls' Practical Turn," Polity 27:1, 77ff. especially 87.

177 "Political liberals will, one assumes, defend liberalism with arms, but they will not do so with words" (J. Judd Owen, Religion and the Demise of Liberal Rationalism: The Foundational Crisis of the Separation of Church and State (Chicago, 2001), 120.

${ }^{178}$ Rawls, Political Liberalism, 38.

${ }^{179}$ For Habermas' critique of Rawls' concept of public reason, see Jürgen Habermas, "Reconciliation Through the Public Use of Reason: Remarks on John Rawls' Political Liberalism," The Journal of Philosophy 92:3 (1995), 119ff.; and Cristina Lafont, "Political Justice? Implications of the RawlsHabermas Debate for Discourse Ethics," Philosophy of Social Criticism 29:2 (2003), 171ff.
} 
tiating already shared basic values through the thought-experiment of the "veil of ignorance' and by applying them to concrete problems. Instead of a philosophizing about the foundations of liberal orders and constitutions, the program of Rawls' revised liberalism is rather a philosophizing based on their foundation.

The contextual relativity of that program is as peculiar (auffällig) as it is perilous (anfällig). Does it realize or ruin Rawls' normative demands? It is certainly no accident that Richard Rorty attempted to appropriate Rawls' new doctrine for himself, i.e. for his own, expressly relativist liberalism. ${ }^{180} \mathrm{He}$ joyfully recognizes within Rawls an unexpected partisan of his view that indeed liberalism offers no universal truth, but rather merely reformulates the agreeable customs of the West. Yet Rorty thereby clearly overlooks Rawls' own claim to offer more than merely a copy of the political comme-il-faut of occidental democracies. ${ }^{181}$ Rawls rather seeks a theory, which, while independent of philosophical, religious, or moral presuppositions, still does not operate merely descriptively.

Rawls looks for this intermediary position on the path of a renewed engagement with Kant's philosophy, which he characterizes as a "comprehensive liberalism." In contrast, he himself wishes to make do with a narrower "political liberalism." $\mathrm{He}$ makes the same pronouncement about John Stuart Mill, who in Rawls' later works feature far less than in his earlier ones. Rawls means that Kant, and similarly also Mill, provide a theory that employs not purely political, but also rather moral and/ or metaphysical reasons in favor of defending political freedom. ${ }^{182}$ That, however, would resemble arguments based upon religious faith; and these are useless for a political theory obligated to the pluralism of the moderns. Moral and metaphysical arguments, according to Rawls, are appealing to those who share their premises; yet - wherever inquisitions and forced philosophical conversions are considered unfashionable - this never includes everyone. ${ }^{183}$ It is certainly good and honorable to commit oneself as a moral individual to the tenets of Kantian ethics, but this sort of thing may not be elevated to the principle of political action. In the same way, Rawls again denies that a metaphysical belief may be made into the criterion of state action.

In this argumentation, Rawls from now on also includes the "belief" in freedom in the Kantian sense. Hence Rawls now formulates - against his earlier conceptions - that one may not make the Kantian concept of a person, transcendentally hovering above its interests and aims, the foundation of the political/legal understanding of persons. ${ }^{184} \mathrm{We}$ can concede this point, as long as we are clear that, with these arguments, Rawls does not put Kant out of commission, but only his own, deficient Kant-interpretation, which depends upon the erroneous assumption that

\footnotetext{
${ }^{180}$ See Richard Rorty, Contingency, Irony and Solidarity (New York, 1989), 57.

${ }^{181}$ See Farid Abdel-Nour, "Liberalism and Ethnocentricism," Journal of Political Philosophy 8:2 (2000), 213.

${ }^{182}$ See Rawls, The Laws of Peoples, 156.

${ }^{183}$ See Thomas Nagel, "Rawls and Liberalism" in Freeman (ed.), The Cambridge Companion to Rawls (Cambridge, 2003), 83ff.

${ }^{184}$ See Rawls, Political Liberalism, 100.
} 
Kant transferred his metaphysical and moral concept of freedom to the political arena. Kant, however, had supported neither the one nor the other (see Sect. 2.1.2). ${ }^{185}$ Kant did not at all demand that one make the obligation to obey the law also the inner, i.e. moral ground of the determination of one's will. ${ }^{186}$ For Kant, the outer legal coercion functions as an analytic moment of the principle of law, precisely because legal norms must be able to be enforced independently of morality or other convictions. Therefore, Kant's doctrine of right, keeps moral theory - and, even more, metaphysics - strictly separated from the realm of rights. Only within the doctrine of virtue does Kant declare the fulfillment of legal commitments also to be an inner concern of an ethical life; but this is clearly an issue within the ambit of morals and without any claims to political validity.

There is, to be sure, nothing objectionable about Rawls' plan to found rights independently of morality and metaphysics. It would just have been better to carry out this plan, not against Kant, but rather with him. From giving lectures about Kant's practical philosophy for many years, Rawls actually should have most precisely recognized the systematic foundations in Kant's system that demand precisely such a separation of the moral and the legal realm. ${ }^{187}$ But, with his identification of Kant's legal freedom with the principle of moral autonomy, Rawls nevertheless follows an interpretation that overlooks that differentiation. At any rate, de facto Kant's Doctrine of Right can be understood, just as Rawls claims about his own theory, ${ }^{188}$ as a module whose reduced concept of freedom can be incorporated in the most varied wider theories (of a "comprehensive liberalism") ${ }^{189}$

This point is expressly stressed here, since the definition of the legal/political medium in question concerns something both delicate and central for liberalism as a whole: the justification of legitimate coercive force. ${ }^{190}$ How can a legitimation of coercion on the part of the state be implemented without damaging the demanding liberal aims of the Rawlsian approach? Because Rawls relegated each and every fundamental theoretical determination for concrete political decisions to the discussion of the procedural framework-conditions of his theory, the question concerning the potential validity of his approach leads to the following consideration: What must occur when those prior clarifications about a valid procedure for arriving at

\footnotetext{
${ }^{185}$ See Pogge, Is Kants Rechtslehre Comprehensive?

${ }^{186}$ See Marcus Willaschek, "Which Imperatives for Right? On the Non-Prescriptive Character of Juridical Laws in Kant's Metaphysics of Morals" in Kant's Metaphysics of Morals: Interpretative Essays (Oxford, 2002), 68.

${ }^{187}$ See Beate Rössler, "Kongenial und aufmerksam. Rezension zu John Rawls: Geschichte der Moralphilosophie," Deutsche Zeitschrift für Philosophie 51:2 (2003), 325-329.

${ }^{188}$ See Rawls, Political Liberalism, 144.

189 "Rather than presuppose much more than Rawls does ... he in fact presupposes much less. He makes no appeal to fundamental ideas prevalent in the public culture of his society, nor does he insist that persons have certain moral powers and matching higher-order interests in their development and exercise, nor does he seek to identify all-purpose means needed for realizing the conceptions of the good that citizens of a society like his own are likely to have (Pogge, Is Kants Rechtslehre Comprehensive?, 149).
}

${ }^{190}$ See Rawls, Political Liberalism, 567. 
political decisions are just not shared by all participants? How, for instance, are we to deal with individuals or whole societies, for whom the political common good in no way consists in seeking a fair cooperation between the free and the equal in conscious contrast to their own ideas of the good and well-being respectively? Or, how are those individuals (like feminists, for example), who do not strictly separate the private and the public, to be dealt with? Or those (like, for example, certain religious groups) who reject drawing a clear line between the holy and profane, the religious and the political arena? With people, therefore, who do not wish to roll back and limit their ultimate and deepest convictions for the sake of penultimate pragmatic deliberations? ${ }^{191}$ After all, in the eyes of many people the mere demand for such lines of separation is already a liberal dogma - and an implausible one to boot. They feel imposed upon not only by what results from the limitation of discourse decreed by Rawls, but rather already by the structural and materially restrictive preconditions that thus enter into the political discourse. ${ }^{192}$

How then can Rawls' liberal proceduralism defend itself against illiberal convictions? How can he counter, for instance, the argument that human beings are in no way equal, but rather that a deity has purposefully created differences between men and women, between one's kin and those of another caste, between those of one and another skin color, between those of one and another faith, which must also be correspondingly taken into account in the procedures developing the political will - for example through a differentiated suffrage? How does Rawls defend his approach against the belief that it is sacrilege to consciously bracket one's commitment to individual and collective salvation, or that one's faith-based knowledge justifies the practices of the inquisition in the name of the soul's salvation? How can Rawls answer someone who, in all seriousness, declares that the meaning and purpose of the political order is the most radical realization of theocratic ideals - including the repression of those of other faiths? And what is to be said when entire states devote themselves to such views and therefore completely or partially reject the provision of human rights? ${ }^{193}$

Rawls' answer to these questions is surprising to put it mildly. He refrains from a substantial rejoinder to such conceptions and rejects mobilizing his own philosophical convictions to battle fanaticism. ${ }^{194}$ Yet he in no way pretends to be a relativist willing to tolerate fundamentalism either. As long as he knows that a sufficient "overlapping consensus" is backing him within his own society, Rawls intends to take no notice of such views. Rather, he excludes them from the outset from the ranks of theorems worthy of political consideration: Whoever does not comply with the presuppositions of argumentative reciprocity and secular tolerance, simply dis-

\footnotetext{
${ }^{191}$ See Banu Kilan, 'J. Rawls' Idea of an 'Overlapping Consensus' and the Complexity of 'Comprehensive Doctrines,'” Ethical Perspectives 16:1 (2009), 21-60.

${ }^{192}$ See William Arthur Galston, Liberal Pluralism: The Implications of Value Pluralism for Political Theory and Practice (2002).

${ }^{193}$ See Steven J. Kautz, Liberalism and Community (Ithaca, 1995), 179f.

${ }^{194}$ See Owen, Religion and the Demise of Liberal Rationalism, 120.
} 
qualifies himself as "unreasonable" and is therefore not allowed to participate in the legitimacy-generating deliberations of public reason.

Rawls operates with a strikingly narrow understanding of "reasonable" though; even "perfectly rational" arguing subjects are, for him, only "reasonable" insofar as they are not led by their particular ideas of the good. They must rather document a "desire to engage in fair cooperation as such" 195 and aspire "for its own sake" to a world "in which they, as free and equal, can cooperate with others on terms all can accept." 196 Now, this indeed very specific concept of reasonableness surely reflects accurately the central content of Rawlsian liberalism: Namely, to position the consensus produced by reciprocal argumentation above every other objective and value in politics. Yet this is in no way merely a formal position, but also a material one. Under the watch of procedural value-neutrality, a highest value is smuggled in: consensus. There appears to be no value resulting from these considerations that would deserve giving up the quest for consensus and conflict-free cooperation. ${ }^{197}$ In comparison with that, however, every other value is consequently reduced and thus robbed of its potential unconditionality, although nothing at all about values is explicitly discussed! $!^{198}$

This background adds poignancy to the question how to deal with persons who do not accept such a secular depotentialization - and consequent political restriction - of their values, because they, for instance, believe "that certain questions are so fundamental that to insure their being rightly settled justifies civil strife?"199 Confronted with this question Rawls takes off all his masks and speaks bluntly. If, from belief in other highest values, like, e.g. "the salvation of a whole people," there arises a resistance against the conditions of liberal discourse, Rawls declares without hesitation that, "At this point we have no alternative but to deny this, or to imply its denial." ${ }^{200}$ Evidently, in order to politically devalue their values, for him it is enough to prove to such believers that their doctrine is incompatible with the fact of plural worldviews. It would surely be preferable to strengthen tendencies or groupings within the respective religious communities that already pursue the pluralistic openness of society. Yet if these kinds of tolerant tendencies, which Rawls detects predominantly within Christianity and - in a few isolated cases - also within Islam, are too weak to find broad acceptance, there remains only the exclusion of religious speech from political discourse.

In this way, however, Rawls' talk of the state's value-neutrality degenerates into lip service. Reducing the radius of the space of public reason so drastically, Rawls

\footnotetext{
${ }^{195}$ Rawls, Political Liberalism, 51.

${ }^{196}$ Ibid., 50.

${ }^{197}$ See Owen, Religion and the Demise of Liberal Rationalism, $113 \mathrm{f}$.

198 "Rawls seems to suppose that a fundamentalist can believe in the unambiguity of God's commandments for human life ... while nevertheless putting these commandments aside politically." That however demands "a change in ones beliefs concerning God's will. One must come to believe that it is consistent with God's will that it be set aside in politics" (ibid., 117).

${ }^{199}$ Rawls, Political Liberalism, 152.

${ }^{200}$ Ibid.
} 
robs political dispute of essential depth. The suggestion that the propositional contents of respective (often religious) background-theorems are, even without including their ultimate grounds, translatable into the political medium without losses, does not convince precisely those whose ultimate convictions demand a dedication without compromise in opposition to the principles of consensus and tolerance..$^{201}$ Against this backdrop, it becomes clear that Rawls' project of not at all including certain justifications within the process of political decision-making has in no way neutral, but rather partisan, consequences: His model procedurally invalidates all of those convictions which aspire to a good superior to every conceivable consensus. His supposed tolerance towards the religious consciousness thus reveals itself as its poorly concealed rejection; which Rawls also tersely vouches: "Of course, we do not believe the doctrine believers here assert, and this is shown in what we do."202

These considerations draw attention to a systematic weakness of Rawlsian liberalism. First, Rawls claims to refrain from all qualitative (moral and metaphysical) valuations and, with downright positivism, let all rationally pursued preferences be quantitatively equal. Yet he then recoils from the ultimate consequence of this move. Whenever the going gets tough, because the actually expressed preferences are pushing towards undesirable forms of society, Rawls applies the emergency brake; the quantitative freedom (of all) to political free speech and participation is thus cut back to the qualitative concept (of some) of what reasonable political arguments are supposed to be.

Nevertheless, without agreeing with Rawls' conclusions, one can still support the panegyric of a 'political liberalism' and the search for an 'overlapping consensus' shared by all social groupings. ${ }^{203}$ Treating political problems as penultimate questions whose solutions are not to be deduced from the ultimate grounds of human existence, but rather to be worked on by the respective political community in a debate considering the reflections of all citizens, does appear compelling. Indeed, metaphysics is not the raison d'état. ${ }^{204}$ Yet this consideration in no way automatically compels us to conclude that one may never question the premises of freedom and equality, or thematize their validity from, respectively, their own world-views. Sending metaphysics into political exile appears to me to be neither feasible nor desirable (about which there is more in Sects. 5.2 and 5.3).

Rawls is knitting a common pattern of quantitatively liberal needlework: the presumption of a value-neutral concept of freedom laced with the thread of mere quantity. Yet because those principles, which liberals actually favor, cannot be secured, qualitative criteria are subsequently woven into the quantitative yarn in order to attach the postulates of, for example, cosmopolitan tolerance and restrained citizenship. Truly laborious needlework!

\footnotetext{
${ }^{201}$ See Stephen Macedo, "Liberal Civic Education and Religious Fundamentalism: The Case of God v. John Rawls?," Ethics 105:3 (1995), 482ff.

${ }^{202}$ Rawls, Political Liberalism, $152 \mathrm{f}$.

${ }^{203}$ See Martha Nussbaum, Frontiers of Justice, 6.

${ }^{204}$ See Charles E. Larmore, The Morals of Modernity (Cambridge \& New York, 1996).
} 
Compare that to Kant's weaving-technique: Just as sharply as Rawls, he rejected all attempts at curtailing the freedom of others for religious or moral reasons. Yet, to do so, he did not have to distinguish between politically permissible and political impermissible opinions. His concept of law prohibits from the outset projects violating the individual's right to freedom from entering into the political decisionmaking. Kant, however, deduces that result directly from a qualitatively outlined idea of lawful freedom. It does not indirectly have to be derived via the supposed protection of self-interest. This strict determination has liberating, not limiting, consequences for the liberal cause. Kant appears to be thus a more orthodox and, at the same time, a more tolerant liberal than Rawls. He is more orthodox because he materially defends the doctrine of freedom, for which he also makes use of his basic philosophical convictions, for instance, of the priority of freedom over the political goods to be established by it. Yet Kant also shows himself to be more tolerant since he does not wish to exclude the victory of unpleasant opinions through delegitimizing political procedures, but rather places confidence in public reason's ability to cope with illiberal demands in and by means of democratic processes. ${ }^{205}$ While Kant, of course, can also not prevent a people from revolting against the religious appropriation of the political sphere and/or their individual rights to freedom, at least, in contrast to Rawls, his philosophy allows him to reject that as normatively inappropriate. $^{206}$

Rawls, on the other hand, is impeded from the possibility of opposing ethically or religiously motivated relativizations of political freedoms by anything other than an authoritative dictum, since he, under postmodern conditions, rejects as inadmissible every substantial argumentation for freedom as a political principle. Yet, by prescribing, without further substantiation, the West's liberal political procedures, he performatively contradicts his own basic liberal concerns. He presupposes what should be justified; namely, that in entering procedures of legal/political decisionmaking something occurs over and above the enforcement of a liberal creed against other systems of conviction. Enforcing freedom in this way dogmatizes liberalism. At the same time, it relativizes it, since one would consequently also have to make friends with illiberal political procedures as soon as social indicators change; a conclusion which Rawls, personally, certainly would not have wanted to draw.

\footnotetext{
${ }^{205}$ See Gillroy, Making Public Choices.

206 “Unlike Rawls' original position ... the principle of publicity is not a hypothetical choice situation in which ordinary citizens will place or imagine themselves. The substantive work of Kant's political philosophy is done not by the constructive procedure of the social contract, but by the constructed ideas of publicity and possible political agency. ... Kant is not a hypothetical proceduralist" (Krasnoff, How Kantian Is Constructivism?, 405).
} 


\subsubsection{Whose Freedom?}

In my opinion, the vacillation between a dogmatic and relativist understanding of freedom in Rawls' work is no mere gaffe. Rather, it is characteristic of the unclear relation between qualitative and quantitative criteria in his conception. This feature not only shows itself - as the last section has argued - when one asks about which options, opportunities, or capacities should be maximized in the name of freedom. It also emerges when one looks more closely into whose freedoms a Rawlsian society concerns itself with. Rawls' answer to this qualitative question likewise remains unsatisfactory.

The problem of appropriately thematizing the rights of the disabled or of future generations already shows up within A Theory of Justice. The reason: Within the framework of the "original position," the decisive moves are ascribed to rational maximizers of self-interest. Obligations to others must be reconstructed as exchange of quantities of private utility or freedom. Under such presuppositions, all parties will aim at symmetrical reciprocity, and only provide their due share in cases where they can obtain something of a quantitatively equal value. The emergence of fair results from exchange is only conceivable insofar as the trading partners act as contemporaneous and equally strong subjects "who can play the role of fully cooperative members." 207 But when the benefitting other is an as of yet unborn subject or someone severely handicapped, of which one expects nothing or only little in return, then - in a calculation of sheer quantitative advantage - granting services makes no sense. ${ }^{208}$ As a result, in the framework of his theory, Rawls could professedly not grant animals the status of subjects with rights. ${ }^{209}$ People with disabilities are an analogous case. Perhaps this is why Rawls forever postponed dealing with the rights of people with disabilities. ${ }^{210}$

The rights of future generations, however, had already been addressed within Rawls' Theory of Justice. ${ }^{211}$ In order to obtain the desired results (a sustainabilityoriented environmental and financial policy), Rawls first introduced additional anthropological assumptions, like, for instance, the assumption of the contract partners' emotional concern for their own offspring. He thus invites us to think of a sequence of interlinked generations. Then, from step to step, a more or less sym-

\footnotetext{
${ }^{207}$ Rawls, Justice as Fairness: A Restatement, 24.

${ }^{208}$ See Brian Barry, The Liberal Theory of Justice: A Critical Examination of the Principal Doctrines in 'A Theory of Justice' by John Rawls (Oxford, 1973); see also Barry, Justice as Impartiality.

${ }^{209}$ See Rawls, A Theory of Justice, 504-512.

${ }^{210}$ Martha Nussbaum's Frontiers of Justice contains a detailed discussion of that difficulty in Rawls' work. She shows that Rawls could only have solved the problem of an equal consideration of the human rights of people with disabilities if he were ready to resign himself to modifying the essential foundations of his contractualist theory; which he, however, was, as is well known, not ready to do. I have nothing to add to this analysis.

${ }^{211}$ See Claus Dierksmeier, "John Rawls on the Rights of Future Generations" in Jörg Tremmel (ed.), Handbook of Intergenerational Justice (Cheltenham \& Northampton, MA, 2006), 73-85.
} 
metrical utility-exchange could take place as long as one ascribes to the rational decision-makers an interest in the wellbeing of their descendants. ${ }^{212}$ In so doing, however, Rawls still owes us a proof of why a policy should not be content to still benefit the first, second, and, eventually, third subsequent generation (i.e. those who may be born within one's own lifetime), but not at all consider the interests of the seventh and eighth generations (which are not included in that construct).

Moreover, in the eyes of his critics, Rawls is once again guilty of ad hoc metaphysics: For concern for one's offspring is certainly not analytically contained in the concept of a rational advantage-seeker. But equally unsatisfactory are his attempts to protect the legal interests of future generations, without those ad hoc assumptions. Rawls, for instance, declares that each generation must sense that it lies within its interest to commit itself to axioms of action which it wishes would have been considered by earlier generations. ${ }^{213}$ If we nevertheless concentrate upon a purely quantitative exchange of freedom and utility, then current decision-makers will certainly joyfully welcome that previous generations carefully and sparingly dealt with their environment. But why should it enhance their utility to likewise decide in favor of a consideration (necessarily remaining unrequited) for those born posthumously? Rawls thus proclaims something which de facto is not true: Rational egoism and the interests of future generations very often do not coincide - which is exactly why the rights of posthumous generations are so often trampled underfoot. ${ }^{214}$

What is needed is therefore more decency and morality than self-interest and advantage-seeking. Whoever sees himself, from unconditional respect for subsequent persons, as obliged to treat the planet earth sustainably, follows no utilityexchange calculation conditioned by quantitatively symmetrical exchange, but rather acknowledges a commitment to another notion of freedom. Only from the perspective of a qualitative conception that does not ascribe the same quantitative value to each employment of freedom - destroying freedom the same as protecting freedom, for instance - can responsibility also for the seventh or eighth subsequent generation plausibly be justified.

Rawls' laborious constructions of intergenerational justice thus unintentionally reveal the inconveniences of a theory shielding its qualitative premises: In A Theory of Justice he had - in favor of intuitively recognized qualitative and asymmetrically directed duties - still engaged in correcting the clockwork of quantitatively symmetrical exchange with contingent additional assumptions. After demoting the - in A Theory of Justice still serviceable - speculations about the freedom and equality of all persons from the status of prescriptive metaphysical universals to that of merely descriptive generalizations about liberal societies, such an escape from the

\footnotetext{
${ }^{212}$ See Jörg Tremmel, "Welche Prinzipien der Generationengerechtigkeit würden Vertreter aller Generationen unter dem Rawls'schen Schleier der Unwissenheit festlegen?," Zeitschrift für politische Philosophie (2009).

${ }^{213}$ See Rawls, Political Liberalism, 271ff. and Rawls, The Law of Peoples, $159 \mathrm{ff}$.

${ }^{214}$ See Mark Anderson, Mario Teisl \& Caroline Noblet, "Giving Voice to the Future in Sustainability: Retrospective Assessment to Learn Prospective Stakeholder Engagement," Ecological Economics 84 (2012), 1-6.
} 
logic of symmetrical reciprocity is no longer possible. With quantitative means alone, Rawls cannot justify why in certain fields of the political administration of law a purely quantitative ratio of the exchange calculi should no longer or not solely dominate.

Rawls is lacking qualitative guidelines that secure affected subjects their due irrespective of symmetrical relations. Since he refuses to transcend hypotheticallyreciprocal layers of interest in the direction of categorically-unconditional demands for recognition, he must - strictly speaking - refuse to grant rights whenever and wherever symmetrical relations cannot be construed, or at the very least accept that their actual rejection conforms with his theory. Rawls accordingly acknowledged that the rights of future generations and people with disabilities, or even animals, could only be integrated with difficulty into his theoretical framework: "While we would like eventually to answer all these questions, I very much doubt whether that is possible within the scope of justice as fairness as a political conception."215

This diagnosis may surprise us; it seems to oppose the large amount of liberal pathos one finds throughout Rawls' late work: for instance, an emphatic concept of persons, who, grasping themselves and one another to be free and equal, examine and, if the occasion arises, transform the rules of the rationality guiding their interest in the light of ethical reason. Indeed: When, at the altar of Rawls' theory, aspects of personality are negotiated and transformed, thick swathes of humanistic incense pervade the cold cathedral of his thinking. Yet we should not be deceived into thinking that this is anything more than a pleasantly fragranced smoke screen. What does not take place is a genuine transubstantiation of symmetry-orientated utilitycalculations into appropriate normative correctives in favor of inviolable human rights.

Rawls in no way counterfactually substantiates his concepts of personality - that would all too closely resemble the Kantian metaphysics he desperately avoids - but rather only historically, as it is distilled by him from the factually applied principles of practical reason at the heart of the liberal state. Rawls only declares that, insofar as those principles (recognizing other persons as free and equal individuals as such) are historically discoverable, the reason articulating itself within them will encounter subjects for whom those principles mean something. In that case then there are persons furnished with the capacity to distinguish between the (less important) good and the (more important) just. ${ }^{216}$ The two-level ethical orientation his theory requires to enable a critique of the private ideas of the good in the light of universal forms of justice, thus already exists in practice. This argument is as circular as it is unproductive. It establishes the validity (Geltung) of these principles only within communities where they already possess historical authority (Gültigkeit). A concept of personality acquired in this way can, however, exert no normative force beyond liberal societies. The result is: In attempting to unburden his liberalism theoretically,

\footnotetext{
${ }^{215}$ Rawls, Political Liberalism, 21.

${ }^{216}$ See Rawls, Justice as Fairness: A Restatement, 107.
} 
Rawls robs it of precisely the argumentative foundations that a philosophy of freedom requires in order to defend its normative demands. ${ }^{217}$

This point becomes striking in regard to the marginalization of certain people and groups from the protected sphere of the social contract in Rawls' theory of international law. From the logic of his earlier theory one may have speculated that in international settings he would seek to extend the normative measures of his Theory of Justice to the global level, defending postulates of international social justice and a global catalogue of personal rights to freedom. But instead, in the Laws of Peoples, Rawls proclaims a different policy. He recommends a federation of states - largely inactive in questions of distributive justice - in which even nations not especially strict on human rights may participate. ${ }^{218}$

Rawls' position is: As long as in their external relations illiberal states keep to axioms offered by a second order original position of international law, their partial non-compliance with demands developed on the part of the first order original position in inner relations should be accepted. ${ }^{219}$ Insofar as these states grant to everyone at least "a special class of urgent rights," like, for example, "freedom from slavery and serfdom," 220 they are acceptable allies within a global federation. One should, after all, not force basic convictions of a "Western individualism" 221 onto other nations. Therefore one would regrettably have to recognize from nation to nation also some inequalities in the attribution and protection of human rights. ${ }^{222}$ Though forcefully demanded on the part of the first order original position, from the second order original position certain liberal rights to protection (especially, it seems, of women) may now apparently be infringed upon, which should be accepted within international law out of respect for the internal sovereignty of those states.

We see: The ultimate source of all normativity is and remains for Rawls the national community, which Rawls conceives as "a closed system isolated from other societies." ${ }^{223}$ To it alone, i.e. to the nation state, individuals have to adhere to claim their human rights. To prevent an ugly theoretical lacuna here, nations must be conceived as though they one and all provided the presuppositions to satisfy their citizens' claims to human rights. Yet, with a glance at the reality, one must certainly question whether all nation states have at their disposal the necessary (economic) and sufficient (political) means to distribute fairly to all people what they are respectively due.

\footnotetext{
${ }^{217}$ See Stephen Macedo, Diversity and Distrust (Cambridge, MA, 2000), 183.

${ }^{218}$ See David Ingram, "Between Political Liberalism and Postnational Cosmopolitanism: Toward an Alternative Theory of Human Rights," Political Theory 31:3 (2003), 359-391; Charles R. Beitz, "Human Rights as a Common Concern," American Political Science 95:2 (2001), 269. In contrast, an extended defense of Rawls' position is to be found in David A. Reidy, "Rawls on International Justice: A Defense," Political Theory 32:3 (2004), 291-319.

${ }^{219}$ See Rawls, Justice as Fairness: A Restatement, 70.

${ }^{220}$ Ibid., 79.

${ }^{221}$ Rawls, The Law of Peoples, 69.

${ }^{222}$ See ibid., 65-71.

${ }^{223}$ Rawls, A Theory of Justice, 8.
} 
That attracted the attention of renowned critics. If a certain polis does not give a whit about the effects of its policies on foreigners or on the subtleties of human rights, then, as Amartya Sen, for instance, complains, the Rawlsian theory knows "no systematic way of opening up the reflections in the original position to the eyes of mankind." 224 Martha Nussbaum also criticizes the assumption that states always fairly represent their populations - in terms of domestic and international policy as "idealism carried to a point at which it loses useful contact with reality." 225 There are, after all, governments for whom violations of human rights are not the exception, but rather the rule, since they are part of their political program. Nussbaum poses the eminently important question: Who stands up for the repressed? Who protects citizens from (unlawful) states? ${ }^{226}$ These are concerns to be discussed in more detail in the following chapter (Sect. 4.2.4) in connection with Sen's criticism that Rawls provided no "procedural barricade against susceptibility to local prejudices" and thus was himself guilty of just such a narrow-minded and petty "parochialism.",227

Rawls thus not only disappointed hopes for the construction of a convincing cosmopolitan liberalism. ${ }^{228}$ With the international limitation of his basic liberal concerns, he also damaged political liberalism on the national level. Ultimately Rawls throws into doubt even the prescriptive character of the original position of the first order, and thus his tools of justification par excellence. If, as A Theory of Justice suggests, the original position is really an illustration of human reason's normative capacity, then its rules must be valid universally - and therefore be binding for every state in the world. But if one accepts that only some states meet the criteria established in the first order original position, what then? Insofar as (with the late Rawls) one recognizes as valid for other states also the procedures of political representation that, for example, through hierarchical representation lead to the exclusion of marginalized strata and women, one thus retroactively devalues the status of the original position in liberal societies as well. It consequently becomes downgraded

\footnotetext{
${ }^{224}$ Amartya Sen, The Idea of Justice, 127.

${ }^{225}$ Nussbaum, Frontiers of Justice, 233.

${ }^{226}$ In Frontiers of Justice Martha Nussbaum thus remarks that "Rawls seems to accord legitimacy to the status quo, even when it is not fully accountable to people. One of the things people themselves might want out of international relations is to help in overthrowing an unjust regime, or winning full inclusion in one that excludes them" (ibid., 234).

${ }^{227}$ Amartya Sen, The Idea of Justice, 127.

${ }^{228}$ See: Charles R. Beitz, "Rawls' "Law of Peoples,"' Ethics 110:4 (2000), 669; Allen Edward Buchanan, "Rawls' Laws of Peoples: Rules for a Vanished Westphalian World," Ethics 110:4 (2000), 697; Simon Caney, "Cosmopolitanism and the Law of Peoples," Journal of Political Philosophy 10:1 (2002), 95-123; Andreas Føllesdal \& Thomas Pogge, Real World Justice: Grounds, Principals, Human Rights, and Social Institutions (Dordrecht, 2005); Andrew Kuper, "Rawlsian Global Justice: Beyond the Law of Peoples to a Cosmopolitan Law of Persons," Political Theory 28:5 (2000), 640-674; Kok-Chor Tan, "Review of The Law of Peoples: With 'The Idea of Public Reason Revisited,"' Canadian Journal of Philosophy 31:1 (2001), 113. A - in my opinion - unconvincing defense of the Rawlsian standpoint in regard to globalization ethics is to be found in Huw Lloyd Williams, On Rawls, Development and Global Justice: The Freedom of Peoples (Basingstoke \& New York, 2011).
} 
from a transcendental condition of legitimation for all dominion into merely a description of some political conceptions. ${ }^{229}$ Just as in Rorty then, the liberalism in the West is diminished into merely the liberalism of the West. ${ }^{230}$

The practice of global solidarity thus falls victim to theoretical predilections. Instead of - as was suggested by Kant ${ }^{231}$ and carried into execution by Krause (see Sect. 2.3.4) - positioning humanity as a whole as the terminus a quo and ad quem of global justice, Rawls remains attached to a methodological nationalism. Beyond national states, he does not at all attempt to give the idea of distributive justice a place within political practice. In the face of blatant global poverty, Rawls has not much more to offer impoverished nations than to shift the essential responsibility for their unfortunate position upon themselves:

I believe that the causes of the wealth of people and the forms it takes lie in their political culture and in the religious, philosophical, and moral traditions that support the basic structure of their political and social institutions, as well as in the industriousness and cooperative talents of its members, all supported by their political virtues. ${ }^{232}$

The paralyzing consequence is clear: If it lies in the hands of every one nation to protect its citizens from poverty, then it is also the responsibility of nobody else. ${ }^{233}$

An astonishing result both in regard to the past (colonialism, imperialism) and the present or future (for example in respect of structural injustices in worldtrade) ${ }^{234}$ For, do we really live in a world in which nation states can haggle amongst themselves as 'rough equals' for economic advantage and political design so that the interests and rights of their citizens are adequately protected? Or, is that quasisymmetry not completely fictional in the face of a world that can be unbalanced militarily by individual states, economically by a few nations and firms, and financially by numerous hedge funds and investment bankers? ${ }^{235}$ The global governance system, largely formed by the affluent nations of the world, and the past and present economic disadvantages for poorer countries resulting from it, have rather created a

${ }^{229}$ For a defense of the modifications in the concept of the original position see Terence Kelly, "Sociological not Political: Rawls and the Reconstructive Social Sciences," Philosophy and the Social Sciences 31:1 (2001), 3.

${ }^{230}$ See Martha Nussbaum's critique of this in Frontiers of Justice, 235ff. and especially $301 \mathrm{ff}$.

${ }^{231}$ See Brian J. Shaw, "Rawls, Kant's Doctrine of Right, and Global Distributive Justice," The Journal of Politics 67:1 (2005), 220-249.

${ }^{232}$ Rawls, The Law of Peoples, 108.

${ }^{233}$ Martha Nussbaum quite rightly notes in regard to Rawls that one can in no way cover up questions of global justice with appeals to "thrift and virtue" (Frontiers of Justice, 240). Rawls, on the other hand, "ratified philosophically what the powerful nations of the world, especially the United States, like to do anyway: they pretend their system is fixed and final, and resist with might and main any demand that they change internally, whether in matters of human rights or in environmental matters of economic policy, either in response to the situation of the rest of the world or in response to international treaties and agreements [...] In the real world, however, we see this tactic for what it is: an arrogant mentality that is culpably unresponsive to grave problems. One should not grant it philosophical respectability" (ibid., 236).

${ }^{234}$ See ibid., 20f.

${ }^{235}$ See ibid., $262 \mathrm{ff}$. 
world which for the foreseeable future will be characterized by asymmetries rather than symmetries.

Therefore, we must agree with the trenchant analysis of Martha Nussbaum, that: "To assume a rough equality between parties is to assume something so grossly false of the world as to make the resulting theory unable to address the world's most urgent problems." 236 In contrast, Martha Nussbaum states that "We live in a world in which it is simply not true that cooperating with others on fair terms will be advantageous to all." ${ }^{237}$ Affluent institutions and states have one-sided duties for the creation of a more just global (legal and economic) order according to Nussbaum. She of course knows: The powerful and affluent of this world "pretend their system is fixed and final, and resist with might and main any demand that they change internally, whether in matters of human rights or in environmental matters or in matters of economic policy, either in response to the situation of the rest of the world or in response to international treatises and agreements." ${ }^{238}$ This kind of thing is to be taken seriously politically, but not philosophically. It merely involves an "arrogant mentality that is culpably unresponsive to grave problems." Therefore, with a swipe at Rawls, Nussbaum tells us that the only consistent consequence is that: "One should not grant it philosophical respectability."239

This critique emphasizes a general weakness of theories of sociality based on the logic of quantitative maximization. Some states on this earth are so indigent that self-interest does not drive richer nations to enter into equitable commercial exchange with them. Here fails the logic - insisted on by game theories and contractualism - of a cooperation for the sake of reciprocal advantage. Whoever recognizes this also considers neither cosmopolitan anarchy nor a global system of victor's justice to be acceptable and must therefore transform those quantitative calculations by qualitative criteria for a fellowship of all world citizens. ${ }^{240}$ For cosmopolitan rights and duties will certainly often lead to living-conditions which immediately also benefit the world citizens respecting them, although not always. Quantitative exchange-calculations can thus underscore global and intertemporal demands for justice but not justify or establish them. They require an independent foundation upon the basis of qualitative freedom: In order to defend a consistent liberalism, one has to materially and not only formally, qualitatively and not only quantitatively, support the principle of freedom. One would have to show, for instance, that and why liberalism's respect extends to the human person as such - and not only the members of certain groups, classes, ethnicities, or trading communities. Only in this way can the normative force of the ideal of freedom equally relate to all human beings and establish a universal ethos of responsibility.

\footnotetext{
${ }^{236}$ Ibid., 235.

${ }^{237}$ Ibid., 273.

${ }^{238}$ Ibid., 236.

${ }^{239}$ Ibid.

${ }^{240}$ Martha Nussbaum likewise pronounces the following verdict upon Rawls" approach: "So we must have a richer account of the purposes these very different nations pursue together" (ibid. 249).
} 


\subsection{Results and Implications}

Rawls and Hayek are thinkers typically located at opposite extremes of the liberal spectrum. This manner of evaluation is orientated, rather superficially, by the political tendencies of their doctrines and thereby overlooks the structural similarity of both approaches. Both attempt to support a philosophical liberalism without talking about the content of freedom: Rawls, because he fears metaphysics, and Hayek, because he resists theories of positive freedom. Their premises and aims are different, but their methodological approaches are not. Rawls operates from the assumption of a fictional negotiation, Hayek backs real processes of historical development. Both, however, mistrust their sources. Rawls keeps his hypothetical decision-makers in check by redirecting their maximizing logic through procedural directives, wherever their choices do not suit him. Hayek, in contrast, rejects actual decisions as illegitimate, whenever they run contrary to his substantial concerns. Although Rawls' social liberalism and Hayek's Whig liberalism clearly differ politically, they resemble one another in their methodological inconsistency. Both consequently ended up in a cross-fire between false friends and genuine opponents: While the former prompt them to provide more methodological consistency in undesired directions, the latter call for them to revoke their methods in the name of their basic convictions. Thus critics and fans agree in rejecting the obvious contradictions within the respective approaches.

The studies of Rawls and Hayek thus highlight: In order not to lack all content, quantitative thinking must borrow from qualitative presuppositions. Problems emerge wherever this borrowing is not admitted openly. Either this undermines the consistency and the consequences of the theoretical approach. Then a truly qualitative program is sold as a quantitative one, an essentially positive concept of freedom as a negative one, a material understanding of freedom as a formal one, a substantial issue as a merely procedural one. The result then is a theory standing in frequently unacknowledged contradiction with its premises. Or quantity - despite all inner intuitions and outer observations - is raised to a qualitative category und thus the quantifiable is made the sole theme of the philosophy of freedom. Then the result is a theory permanently in marked contradiction to reality. Both alternatives damage the concerns and reputation of the idea of freedom.

We must therefore move away from the stupefying poverty of option counting, in order to be receptive to the stupendous diversity of freedoms. To ward off such a move, tenacious followers of quantitative approaches declare that their model would indeed be able to reproduce all necessary qualitative differentiations within its quantitative matrix. One would merely have to value options in respect of their quantitative fecundity. ${ }^{241}$ If one simply counted the resulting options (second order), which a certain option (first order) opens up or forecloses, one would have at hand the multiplying factor with which every option of the first order can be assessed against competing (only seemingly qualitative) alternatives (of the first order). One

\footnotetext{
${ }^{241}$ See Feinberg, Freedom and Fulfillment.
} 
could thus confidently adhere to the quantitative matrix and at the same time take into account qualitative differences in the value of certain options.

Yet, along with Charles Taylor, we can reject this argument as "either vacuous or false." ${ }^{42}$ The statement that (qualitatively) more valuable freedom is continually to be also (quantitatively) estimated more highly, is vacuous and counterproductive; that does not strengthen quantitative approaches, but rather expresses the essence of qualitative theories of freedom: the conceptual priority of the qualitative. False, however, would be the assumption that more quantitative options necessarily imply a qualitatively higher-grade freedom. For example, the customary penal laws for theft and fraud constrict the room for manoeuver of countless people in many spheres of life. Laws against radical political freedom of expression and "fringe political activity" 243 instead affect far fewer people in more narrowly circumscribed fields of action. Nevertheless, we judge the latter, and not the former, to be especially dangerous for freedom. Here, the quality, and not the quantity, of those options clearly tips the scales.

Martha Nussbaum therefore urges us finally to recognize unambiguously "that some freedoms are central for political purposes, and some are distinctly not [...]. Some lie at the heart of a view of political justice, and others do not. Among the ones that do not lie at the core, some are simply less important, but others may be positively bad." 244 As an example of the latter variant she invokes "the freedom to harass women in the workplace"245; as an example of the former "the freedom of motorcyclists to drive without helmets." ${ }^{246}$ In short, some freedoms mean more than others: This elementary as well as essential insight forces the rethinking of the fundamentals of precisely these quantitative theories of freedom blurring this distinction.

The materialist and positivist foundations of quantitative theories of freedom must be especially scrutinized. For a concept of freedom only aiming at the number of easily realizable preferences all too easily enables one to overlook that freedom quite essentially consists in the - idealistically and normatively motivated - reflection upon, criticism, and change of our preferences. A few (second order) preferences can critically evaluate and, in the long term, transform innumerable (first order) preferences. One thinks, for example, of elementary ethical maxims that keep in check a multiplicity of hedonistic predilections. Would our freedom be helped for instance if, because of the predominance of the latter, the former would suddenly be nullified? Do people, whose capacity for moral reflection is sabotaged, perhaps experience in the satisfaction of their then unreflected wants a maximum degree of freedom?

\footnotetext{
${ }^{242}$ See Charles Taylor, "What's Wrong with Negative Liberty? in Philosophical Papers, vol. 2 (Cambridge, 1985), 211-229.

${ }^{243}$ See Ronald Dworkin, Taking Rights Seriously (London, 1977), 268.

${ }^{244}$ Nussbaum, Creating Capabilities, 72.

${ }^{245}$ Ibid.

${ }^{246}$ Ibid., 73 .
} 
To clarify this objection, one must not at all fall back on the shrill thoughtexperiments cherished by today's philosophers (hallucination machines, happiness drugs, parallel existences, etc.). We only need think of a society which increasingly renounces public media and culture and thus increasingly leaves the cultivation of intelligence and taste to the private sector. This could give us citizens conditioned by commercial manipulation, who fritter-away their lives by politely conforming to consumer madness, and who vote for policies devoted to the permanent extension of consumer options. Now, according to the quantitative understanding of freedom these people would, however, have to be freer than citizens of other liberal societies, who, although autonomously informed and cultivated (plus 1) would have fewer consumer options (minus $n+1$ ) to choose from. ${ }^{247}$ Does anyone seriously wish to maintain this?

We must, therefore, avoid turning the freedom of choice into a fetish. And certainly not only because of the everyday experience that occasionally a little less quantitative freedom is quite agreeable since, for instance, before overflowing supermarket shelves, there creeps up upon us a longing for a "freedom from decision." 248 The critique would also not be primarily psychological and directed by the idea that a superfluity of possible choices pressurizing people to be ever more individualistic and authentic can make some poor souls depressed. ${ }^{249}$ No, we should quite fundamentally investigate whether it is prudent to reduce freedom to freedom of choice and to conceive it as an enumerable commodity. ${ }^{250}$

So as not to be misunderstood here: That quantitative theories reify freedom into a commodity is no innuendo but rather the credo of their proponents. Apologists for quantitative approaches present this argument as an ultimate defense of their position: Freedom, which from a qualitative perspective appears to be an end in itself, $i s$ in truth only a means to an end (see the Introduction in this chapter). While our freedom of choice is no concrete means (for predefined ends), it is an abstract instrument. And this abstraction constitutes its charm. Like money, freedom thus also presents a means to all ends, of which one can never have enough, regardless of what one intends to do with it. Therefore, freedom is wrongly held to be intrinsically more valuable than the goods it brings. Actually, its value is just as extrinsic as the value of the former; only - this is the point - quantitatively unequally greater,

\footnotetext{
${ }^{247}$ See Dworkin, The Theory and Practice of Autonomy, 15.

${ }^{248}$ Quine thus already points out that we occasionally long for a "freedom of second order: freedom from decision" (William van Orman Quine, Quiddities: An Intermittently Philosophical Dictionary [Cambridge, MA, 1987], 68). Alain Ehrenberg, Das erschöpfte Selbst: Depression und Gesellschaft in der Gegenwart (Frankfurt am Main, 2008) treats in detail the psychological dimensions of such an escape from the excessive demands of autonomous life.

${ }^{249}$ See Axel Honneth, "Organized Self-Realization," European Journal of Social Theory 7:4 (2004), 463-478 and Anders Petersen, "Authentic Self-Realization and Depression," International Sociology 26:1 (2011), 5-24.

${ }^{250}$ See Dworkin, Taking Rights Seriously, 268: "It is very difficult to think of liberty as a commodity." See also Will Kymlicka, Liberalism, Community and Culture (Oxford, 1989).
} 
since through said abstractness this commodity also encompasses future - currently still indeterminate - uses. ${ }^{251}$

Whoever thinks of freedom as like - or directly as - money fetishizes it, however, since, in the glorification of its quantitative exchange-value, its qualitative usevalue is neglected. Furthermore, in order to satisfy the postulated commensurability, the commodity-value of freedom is to be budgeted by a reduction to purely material options. Yet, in order to be able to measure and make freedom comparable in this way, we must, we are being told, conceive of the entire world, including ourselves and our freedom, mechanically: "we need to think of space and time as granular in order to produce measurements of 'the extensiveness of available action."' ${ }^{252}$ Then alone could all qualitative value judgments be completely reduced to quantitatively exactly ascertainable spatiotemporal relations.

What twisted logic: One first commits oneself to viewing freedom purely quantitatively. As a consequence, its commensurability - and thus also its measurability - has to be postulated. The latter, however, demands a physicalist view of the world as well as of ourselves. That worldview, for its part, now allows only quantitative analyses and no qualitative appraisals. Finally, all qualitative aspects of freedom are thus passed off as inessential, and it is maintained that, without any losses, these can be reduced to quantitative differences. A circulus vitiosus.

The same is true of the concept of coercion which the quantitative tradition would also like to grasp in purely physical terms. Earlier (see the Introduction in this chapter), I already expressed doubt as to whether a normatively rich concept of freedom could be picked out from a purely physical definition of coercion. Usually the experience of coercion is "emphatically and technically contextual"; in real life, descriptive and prescriptive aspects are typically intertwined ${ }^{253}$ Everyday experiences, normative behavioral-expectations, and situational preconceptions - and not only physical aspects - define what are freedom-infracting, coercing acts.

Whoever, for example, breaks into a house and takes possession of someone else's things negates the owner's freedom of possession. Violent, physical causality is present. But that those things were first of all bounded from the appropriation of others by fences and walls, likewise presents a physical causality which limits their freedom of movement and freedom of appropriation. ${ }^{254}$ Whoever criticizes the former causality (criminally directed against private property) must legitimate the latter causality (effecting protection for private property). Without such legitimation there prevails a stalemate between the physical freedoms, i.e. between the coercions of the homeowner and those of the intruder: That which the one experiences as a minus in freedom, i.e. coercion, the other registers as a plus. Whoever does not want to content themselves with this almost Proudhonian stalemate ("property is theft"255)

\footnotetext{
${ }^{251}$ See Ian Carter, A Measure of Freedom (Oxford, 1999), 50-52.

${ }^{252}$ Ibid., 174.

${ }^{253}$ See Wertheimer, "Social Theory and the Assessment of Social Freedom," Polity 7:3 (1975), 334-360.

${ }^{254}$ See Cohen, Self-Ownership.

${ }^{255}$ Proudhon, Traité du domaine de propriété, ou de la distinction des biens; considérés principalement par rapport au domaine privé (Paris, 1862), 37.
} 
has the burden of proof and must justify the legitimacy of the privation of objects due to their privatization. But that is clearly not achievable physicalistically, but only ethically: through a theory of qualitative freedom.

The theory of quantitative freedom pretends to be value-neutral, but it is not. There is, rather, a hidden valuation in its physicalist limitation to the empirically enumerable: against, namely, all quantitatively inestimable but nonetheless relevant aspects of freedom. ${ }^{256}$ With what right is it established that only causal effects count as limitations of freedom, but not also omissions of services, which could be imperative for the protection or materialization of the freedom of others ${ }^{257}$ Can we at all define that which is injurious to freedom before we have come to an agreement about what our duties in regard to one another are? ${ }^{258}$ In short, questions of value belong to the perception of freedom. Unless they are answered, the radius of freedom cannot be outlined, and we cannot specify what we may lawfully defend against others and what we are justified in demanding of them. ${ }^{259}$ A theory of the Ought, and not only of the Is, must inform therefore the content of the idea of freedom. ${ }^{260}$

The quantitative imprecision which the turn towards the qualitative entails at times is not a loss in acuity, but rather a gain in proximity to the issue at hand. To paraphrase Aristotle: One should never be more precise than the topic allows. ${ }^{261}$ Otherwise, one exchanges uncertain truths for precise falsities. Whoever investigates an essentially humanistic phenomenon using the methods of the natural sciences should not be surprised if aspects residing outside the material and physical realm thereby evaporate. The theory of quantitative freedom is, however, lacking in precisely this critical self-reflection. It gives far too much currency to its reductionist picture of freedom as a commensurable commodity.

Yet, wherever freedom is perceived to be a naturally given capacity, fellow human beings appear first and foremost to be possible intruders. ${ }^{262}$ The social construction of freedom is overlooked ${ }^{263}$ and so the absurd practical consequence ensues that, the less individual freedom is socially influenced or co-determined the

\footnotetext{
${ }^{256}$ See Connolly, The Terms of Political Discourse, 141: "Without the normative point of view from which the concept is formed we would have no basis for deciding what 'descriptive terms' to include or exclude in the definition."

${ }^{257}$ See David Miller, "Reply to Oppenheim,” Ethics 95:2 (1985), 313.

${ }^{258}$ See Connolly, The Terms of Political Discourse, 142: "To refuse to bring these considerations into one's deliberations about 'freedom' is to deny oneself access to the very consideration that can inform judgment about the concept or to delude oneself by tacitly invoking the very considerations formally eschewed."

${ }^{259}$ See Kristján Kristjánnson, Social Freedom: The Responsibility View (Cambridge \& New York, 1996), 32.

${ }^{260}$ See Richard E. Flathman, The Philosophy and Politics of Freedom (Chicago, 1987), 105.

${ }^{261}$ Aristotle, Nichomachean Ethics I, 3 1094b.

262 "That individual freedom enables every human being to find in other human beings not the manifestation, but rather the limits of his own freedom (Karl Marx, Werke [Berlin, 1988], 365).

${ }^{263}$ See Guido de Ruggiero, The History of European Liberalism (London \& New York, 1927).
} 
better. Freedom must consequently be sought in sovereign independence and every regulation of private freedom will be perceived as its potential negation. ${ }^{264}$ Accordingly, theories resting upon the logic of quantitative freedom regularly exhibit a tendency to push back, as far as possible, the limits of private freedom of choice. It is therefore no accident that the conception of a minimal state - caricatured in other places as a 'night-watchman-state' - enjoys great popularity amongst proponents of quantitative freedom. ${ }^{265}$

Quantitative theories of freedom typically only protect freedoms which one already (factually) possesses, and not those to which one perhaps (counterfactually) could have a right. ${ }^{266}$ They orientate themselves (extensionally) towards a freedom in its material formation - ownership of the individual's body and possessions - not (intensionally) towards its ideal conceptual meaning. It does not optimize concrete opportunities, but rather maximizes abstract options - embodied in enforceable property-rights. ${ }^{267}$ The political community thus evaporates into a society obsessed with property and entitlements which, instead of enabling all-round freedom, is committed and obligated to the reciprocal protection of possessions and entitlements. ${ }^{268}$ Thus, in quantitative liberalism, society loses solidarity with regrettable consistency, as became clear with Hayek's invective against social policy and the Rawlsian failure in the face of the challenges of global and intergenerational justice.

Yet, from a contractualist viewpoint such outcomes sadly appear logical. Why should we take into consideration human beings from whom we expect neither advantages nor disadvantages? Consequently, it would appear only consistent to limit solidarity within national boundaries, whenever disadvantageous repercussions (e.g. regarding economics or security) are not to be expected, and, conversely, no robust advantages are achievable. Therefore, in the framework of quantitativelyliberal theories, questions of global and intergenerational socioeconomic participation are willingly avoided or dealt with unwillingly and unkindly.

Nevertheless, on the horizon we can glimpse a change. While yesterday's demigods of quantitative liberalism still pray for the transubstantiation of the earthy, everyday bread of economic contracts into the sanctified body of freedom, ${ }^{269}$ based on a magic supposedly dwelling within the Roman rule of the market that volenti non fit inuria (to a willing person, injury is not done), the symbols of this sacramental transformation are presently subjected to a sober critique. Obviously, only where

\footnotetext{
${ }^{264}$ See John Stuart Mill, On Liberty and Other Essays (Oxford \& New York, 1991), 8.

${ }^{265}$ See Macpherson, Democratic Theory, 91.

${ }^{266}$ See Cohen, Self-Ownership.

267 "In the profoundest sense there are no rights but property rights. [...] Each individual, as a natural fact, is the owner of himself, the rule of his own person. Then, "human" rights of the person ... are, in effect, each man's property right in his own being, from this right stems his right to the material goods he has produced" (Narveson, The Libertarian Idea, 175); see also Murray Newton Rothbard, Government and the Economy (Kansas City, 1977), 238.

${ }^{268}$ See Harold Laski, The Rise of European Liberalism (London, 1962), 105.

${ }^{269}$ See Robert Nozick, Anarchy, State, and Utopia (Oxford, 1975), $262 \mathrm{ff.}$
} 
no "asymmetries of power" distort the interests of the contractual partner can we say, that, actually, to a willing person, no injury is done. Genuine economic freedom for contracts presupposes "the absence of domination, not just the absence of interference"; otherwise it all too quickly befits "appalling contractual arrangements," to which we, precisely in the interest and name of freedom, must refuse to agree to. ${ }^{270}$ Increasingly, therefore, even the proponents of quantitative theories resist the "libertarian thesis that only coercion undermines voluntariness." ${ }^{271}$ From the long overdue confession that need can necessitate, there now grows, also in the positions of quantitative theories of freedom, a critical reflection upon the nature of economic freedom. It is now said that freedom in business in particular may not counter the idea of freedom in general; and therefore some Anglo-American liberals even demand "that no one may so acquire goods that others suffer severe loss of liberty as a result." 272

In the last decades, the idea of the admission of sociopolitical concerns into the concept of freedom itself, first introduced into positivist groundwater by Gerald MacCallum, found its way into the strata of Anglo-American philosophy. Analytic theories became infiltrated by the idea of conceptualizing freedom, not from the starting-point of unhindered actions, but rather from the finishing-line of available options. Freedom would then need to be measured less by means of the volume of the inlets or outlets, but rather by the whole reservoir of liquid options available to all. Thus, however, the flow of quantitative liberalism turns against the formerly dominant stream of libertarian market-idolatry and thus creates dangerous shallows for possessive individualism. While, until recently, the quantitatively-liberal waters coolly and quietly flowed past the sandbanks of poverty, some now produce, from inlets fed from left-libertarian estuaries, an inverse undercurrent, becoming increasingly stronger, which swirls asunder the once straight conservative alignment of quantitative freedom theories.

Perplexed, conservative libertarians find themselves confronted with cheeky questions, like, for example: "How is libertarian capitalism libertarian if it erodes the liberty of a large class of people?"273 Suddenly, there is talk of a universal empowerment to autonomy, ${ }^{274}$ in accordance with the insight that "a society is as free as its underdogs are." ${ }^{275}$ This shakes the silent alliance between libertarian thinking and a politics directed against social justice. Hillel Steiner, for instance, washes down the libertarian assumption that freedom primarily manifests itself

\footnotetext{
${ }^{270}$ See Philip Pettit, Republicanism: A Theory of Freedom and Government (Oxford \& New York, 1997), $65 f$.

${ }^{271}$ See Olsaretti, Liberty, Desert and the Market, 149.

${ }^{272}$ Cohen, Self-Ownership, 37.

${ }^{273}$ Cohen, ibid.

${ }^{274}$ If we see "freedom as the non-restriction of options, rather than the absence of impediments" (Stanley Benn \& W. L. Weinstein, "Being Free to Act and Being a Free Man," Mind 80 (1971), 201) then it is also clear that social assistance for the acquisition of freedom belongs to a liberal philosophy just as much as the defense of freedoms against impediments.

${ }^{275}$ Bay, The Structure of Freedom, 7.
} 
through rights to possession and disposal - with a shot of socialist logic. If everyone has an equal right to object-related freedom, then this right should also be due to all of them in more or less equal quantity. Everyone must therefore be able to start out in life from a quantitatively comparable starting-point. Since such an allocation of goods is unable to come about by itself, corresponding redistributions must be seen as producing freedom and accordingly demanded, according to Steiner. ${ }^{276}$

The prescriptive demand for support for solidarity born out by such arguments however clearly contradicts the descriptive methodological ideal of the quantitative logic which professedly aims to operate from the negation of the negation of already extant freedom-positions. Yet, the thinkers of "left-libertarianism" no longer consider solely the quantitative extension of factually given freedoms, but rather demand the establishment of counterfactual freedoms. With that, however, the matrix is covertly exchanged. The quality of the freedoms to which all are entitled assumes priority over the quantitative logic and consequently demands quantitative egality. Thus the plateau changes and - as we have already seen with Hayek and Rawls - we suddenly exchange a factual-quantitative framing for a counterfactual-qualitative one, which examines not only the number, but also the nature of our options. ${ }^{277}$ Covertly, the discourse has moved to qualitative premises.

This objection also affects the now fashionable attempts of libertarian paternal$i s m^{278}$ to deflect the anti-libertarian critique through the integration of especially popular (social and environmental) policy demands. What is intended thereby is to understand the actual interests of individuals better than they themselves. Libertarian paternalist believe themeselves justified - until explicitly revoked on the part of those affected - even obligated, to bolster through state action the supposed interests of people (by means of the homo oeconomicus models). Allegedly, one thus secures more freedoms for individuals in the long run. Left to themselves, individuals would make too many (false) decisions running contrary to their true rationallyselfish interests, and thus over time unduly reduce the sphere of their options. Observed from this foil of 'true' interests orientated towards economic rationality, many familiar ways of life end up looking suspiciously 'irrational.' These, therefore, should in no way be maximized. Implicitly, however, even the explicit conceptions of freedom, upon which these lives are built, are devalued too. So, whoever, like the libertarian paternalists, prescribes the maxims of a rational maximization

\footnotetext{
${ }^{276}$ See Steiner, An Essay on Rights, 28.

${ }^{277}$ See Cohen, Self-Ownership, 53.

${ }^{278}$ About libertarian paternalism see Richard Thaler \& Cass Sustein, "Libertarian Paternalism," The American Economic Review 93:2 (2003), 175-179. For the current discussion, see Nick Gill \& Mathew Gill, "The Limits to Libertarian Paternalism: Two New Critiques and Seven Best Practice Imperatives," Environment and Planning, $30: 5$ (2012), 924-940; Riccardo Rebonato, Taking Liberties: A Critical Examination of Libertarian Paternalism (2012); Mozaffar Qizilbash, "Sugden's Critique of Sen's Capability Approach and the Dangers of Libertarian Paternalism," International Review of Economics 58:1 (2011), 21-42; Jessica Pykett et al., "Interventions in the Political Geography of 'Libertarian Paternalism,'” Political Geography 20:6 (2011), 301-310; Jennifer Prah Ruger, Health and Social Justice (Oxford \& New York, 2010).
} 
of self-interest as an outvotable default position also pursues value-orientated metaphysics - only secretly.

Dressed up as a qualitative algorithm, there consequently takes place on the part of the "left-libertarianism" as well as on the side of the "libertarian paternalism" a qualitative selection of supposedly more or less 'good' forms of freedom. Howsoever one twists and turns the matter, one cannot avoid therefore a substantial discussion of what should serve as freedom. The theory of freedom must be qualitatively orientated before it can devote itself to quantitative questions.

Open Access This chapter is licensed under the terms of the Creative Commons Attribution 4.0 International License (http://creativecommons.org/licenses/by/4.0/), which permits use, sharing, adaptation, distribution and reproduction in any medium or format, as long as you give appropriate credit to the original author(s) and the source, provide a link to the Creative Commons licence and indicate if changes were made.

The images or other third party material in this chapter are included in the chapter's Creative Commons licence, unless indicated otherwise in a credit line to the material. If material is not included in the chapter's Creative Commons licence and your intended use is not permitted by statutory regulation or exceeds the permitted use, you will need to obtain permission directly from the copyright holder.

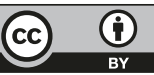




\section{Chapter 4 \\ Qualitative Freedom}

Our previous studies have shown: Freedom cannot be analyzed from a value-neutral standpoint. Whereas the options of robots can be adequately described in purely quantitative terms, the freedom of humans requires that we transcend talk of "overall amounts," i.e., the sheer "quantity of freedom."1 This is increasingly recognized today, and the importance of qualitative considerations is thus evermore frequently acknowledged. ${ }^{2}$ Yet, often only as a small concession by a still predominantly quantitative way of thinking, according to the motto that one could privately live out qualitative moments in that space opened up by a policy orientated by the quantitative conception of freedom. ${ }^{3}$ One only needs to create enough space for variety to let a thousand flowers bloom, including the flower of qualitative freedom. But manifoldness is not a quantitative concept. Multiplicity (Vielzahl) is quantitative. Variety (Vielfalt), in contrast, aims at diversity in the multiplicity: at a multitude qualitatively classified.

This can be illustrated by the example of the relation between public and private transport. Whenever, for instance, someone in the USA is thinking about commuting to work, in most cases they only have a choice between different cars; the possibility of cycling or taking the train frequently does not exist for lack of bike paths or efficient public transport options; often simply because the only connection between two places is a highway. Assuming that the automobile market in the USA is flooded with considerably more brands and models than in Europe, purely quantitatively (in the sense of sheer multiplicity), the multitude of options for the freedom of private transport would be greater. Qualitatively, on the other hand (in the sense of significant variation), the choice appears deplorably narrow. In many places there is no real choice between different means of transport. The morale of the story:

\footnotetext{
${ }^{1}$ Miller, Constraints on Freedom, 83.

${ }^{2}$ The idea of "qualitative freedom" has already been taken up in the political discourse. See, for instance, the introduction by Christian Linder in Philipp Rösler \& Christian Lindner (eds), Freiheit: geführt-gedacht - gelebt: Liberale Beiträge zu einer Wertediskussion (Wiesbaden, 2009).

${ }^{3}$ See Eric Nelson, “Liberty: One Concept Too Many?," Political Theory 33:1 (2005), 58-78.
} 
Whoever wishes for a genuine variety of opportunities is demanding qualitative, not just quantitative, freedom. Only the qualitative difference makes colorful variety out of colorless multiplicity.

But which freedoms belong within that sphere of possibilities worth protecting? All of them? Even destructive ones? There must be a choice ${ }^{4}$; therefore - as the previous chapter has shown - even theories expressly committed to a quantitative model of thinking ultimately fall back upon qualitative distinctions. Something similar also occurs in the opposed case. Every qualitatively directed theory must also pick out certain freedoms which should first be realized from a set of competing alternatives, and then indicate the extent to which these should be protected and the point at which other freedoms should be given a chance. Qualitative freedom has therefore to quantify the freedoms with which it deals. Quantitative and qualitative conceptions of freedom therefore both complement one another, albeit in different ways.

In quantitative thinking one must, without fail, always pick out from competing freedoms that one which leads to more options now and in the future. It is a question of an absolute measure between options and their assumed consequences. The highest numerical value of options is automatically awarded the highest freedom value. Yet wherever quality results from quantity alone, the former is ultimately reduced to the latter. In the framework of quantitative theories of freedom, quantity turns out to be the (only accepted) quality of freedom.

Not so in qualitatively orientated theories. They recommend giving priority to those options that fulfill certain material criteria, like, for example, human dignity, reasonableness, reciprocity, universalizability, autonomy, promotion of capabilities, etc. ${ }^{5}$ For such a comparison, relative relations of rank suffice. A proponent of a qualitative theory must therefore not precisely weigh (abwiegen) the liberty content of certain options to the nearest gram; he will, however, weight (abwägen) the attractiveness of different possibilities. One can, for instance, meaningfully say that the freedom to express a certain opinion is more essential than the freedom to drive upon a certain side of the motorway, yet without measuring exactly how much better the first option is than the second.

In terms of econometrics, quantitative freedom demands cardinal scales with commensurable measures, whereas qualitative freedom establishes ordinal taxonomies which also allow for comparisons between incommensurable goods. This theoretical difference has noticeable practical consequences. For example (and to anticipate the following chapter), while, in the framework of quantitatively directed types of freedom, an increase in private options - for instance within a free market economy - is to be approved per se, qualitatively directed liberalisms are more discerning and can also take account of the nature of those options (as well as their opportunity costs). Mass is not class, and freedom is therefore also not to be simply equated with market freedom. ${ }^{6}$ While theories directed towards quantitative

\footnotetext{
${ }^{4}$ See John Christman, “Saving Positive Freedom,” Political Theory 33:1 (2005), 79-88.

${ }^{5}$ See Martha Nussbaum, Creating Capabilities, 32.

${ }^{6}$ See Eric MacGilvray, The Invention of Market Freedom (2011).
} 
freedom, for instance, normally paint the market as a paradise of economic freedom, since it, according to their definition, is nothing other than the location and aggregate of voluntary acts of exchange, ${ }^{7}$ there is something decidedly more terrestrial about theories of qualitative freedom. They ask about the quality of market transactions and investigate how free those 'voluntary' acts of commercial exchange really were. Was necessity in play or did manipulation take place ${ }^{8}$ Are we also to accept voluntary transactions that undermine human dignity? ${ }^{9}$ How, moreover, do things stand with unethical and dishonorable deals?

Because of such reflections, qualitative freedom will not approve of every increase of options and will not consistently define economic aims in the sense of a purely quantitative growth. ${ }^{10}$ Rather, a balance between freedoms ought to be found: certainly, between economic freedom on the one hand, and political and cultural freedoms on the other. Yet also between the economic freedom of this and that citizen, as well as, of course, likewise between different forms of economic freedom, for example between economic aims that are short-term or long-term, or are more or less ecologically and socially sustainable (see Sect. 5.2). When, accordingly, tendencies of economic maximization are being curtailed, we are not - in contrast to common neoliberal and libertarian stereotypes - witnessing an assault upon freedom, ${ }^{11}$ but rather - as we will presently show from the theories of freedom of John Kenneth Galbraith and Amartya Sen - different forms of freedom competing with one another.

Qualitatively oriented liberalism demands a primacy of the political and the societal debate about which targets our economic freedom should satisfy. It thus reestablishes upon a liberal foundation the deference of economics to politics and of politics to ethics, recognized as mandatory from Aristotle to Adam Smith, but subsequently noticeably displaced in economic thinking. Of course, economic freedom is not to be abolished in the name of political freedom. ${ }^{12}$ Yet, conversely, as Galbraith and Sen stress, the freedom of some to engage in wild transactions may also not undermine the freedom of all to participate in economic life and sociopolitical cooperation. Freedom will only be defended by all, if it fends for the liberty of all.

So, indeed: "Freedom does not only belong to the rich."13 Some may sleep under the open sky, possibly because they are admirers of the firmament, or perhaps also because they lack the means for providing a roof over their head. The former have the freedom to make use of shelter, the latter not. Therefore, since freedom de facto

\footnotetext{
${ }^{7}$ See John Thrasher, "John Tomasi: Free Market Fairness," Public Choice 159:1-2 (2014), 309-311.

${ }^{8}$ See Richard Arneson, "Meaningful Work and Market Socialism Revisited," Analyse und KritikZeitschrift für Sozialwissenschaften 31:1 (2009), 139.

${ }^{9}$ See Martha Nussbaum, Creating Capabilities, 35.

${ }^{10}$ See Philip Mirowski \& Esther-Mirjam Sent (eds.), Science Bought and Sold: Essays in the Economics of Science (Chicago \& London, 2002).

${ }^{11}$ See Colin Crouch, The Strange Non-death of Neo-liberalism (Cambridge, 2011).

${ }^{12}$ See Parijs, Real Freedom for All.

${ }^{13}$ See Herzog, Freiheit gehört nicht nur den Reichen.
} 
depends upon conditions - whoever involuntarily sleeps outside is unfree - the theory of qualitative freedom shifts attention towards the enabling conditions of real freedoms and socio-economic capabilities. The philosophy of qualitative freedom therefore reformulates the concept of economic freedom so that it comprises not only the transactional freedom of some, but rather the participatory freedom of all.

\subsection{Fair Freedom (John Kenneth Galbraith)}

With Milton Friedman (1912-2006) and John Kenneth Galbraith (1908-2006) there passed away, a decade ago, the two most influential U.S. American economists of the twentieth century. Although, in the German perception, Milton Friedman played a greater role, internationally the title "most widely known American economist of the twentieth century" is typically being awarded to his intellectual antagonist, Galbraith. ${ }^{14}$ With his theoretical writings and socio-critical novels, Galbraith acquired worldwide fame, from Russia, through India, to Latin America. In public life in the USA, he took up the glove for Keynsianism. In the academic world, Galbraith made a name for himself through modifying Keynesian doctrine with regard to applied economics and organized politics. Furthermore, as US-Ambassador to India as well as John F. Kennedy's ghostwriter and personal as well as political advisor, he exerted significant influence upon American politics.

In the last few years, research on Galbraith has been revived..$^{15}$ Particularly as a result of his crystal-clear studies concerning the nature of global financial crises, the economic aspects of his works have received the most attention. Galbraith's contributions to the socio-political philosophy of the present and the relevance of his economic theory for the philosophy of freedom have, up to now, been studied less. Yet, here too he has much to offer. John Kenneth Galbraith connected economics to the discourse on individual freedom and social justice, developing a qualitatively directed concept of freedom; not via reflections on abstract philosophical principles, but rather by means of an analysis of concrete socio-economic issues.

Galbraith's theory of freedom takes its departure from a critique of the prevailing methodology in economics. His core thesis is that economics could far better grasp and employ the potential for economic emancipation if it were only to proceed with more self-reflexivity. Neoclassical axioms are to be questioned, in order to scrutinize the recommendations for political action of a neoliberal conservative nature

\footnotetext{
${ }^{14}$ Richard Parker's biography (John Kenneth Galbraith: His Life, His Politics, His Economics [New York, 2005]) surpasses in precision and detail all the other presentations of Galbraith's life and work provided up to now; its particular merit lies in its competent arrangement of Galbraith's intellectual biography in connection with recent economic and political history.

${ }^{15}$ See Stephen P. Dunn, The Economics of John Kenneth Galbraith: Introduction, Persuasion and Rehabilitation (New York, 2010); Blandine Laperche, James K. Galbraith \& Dimitri Uzunidis (eds.), Innovation, Evolution and Economic Change: New Ideas in the Tradition of Galbraith (Cheltenham \& Northampton, MA, 2006); Kevin Mattson, When America was Great: The Fighting Faith of Postwar Liberalism (New York, 2004).
} 
resting upon them. It is imperative to confront those doctrines with a concept of economic and political freedom that relates affirmatively to its legal preconditions, to its social and ecological obligations, and to its cultural presuppositions, thus aiming to harmonize personal autonomy with economic reality. Galbraith strives for an economics, not of quantitative maximization, but of qualitative optimization, which orientates the economy not only towards material aims, but also towards aesthetic, moral, social, cultural, and ecological goals.

\subsubsection{Democratized Economics}

According to Galbraith, economics has the noble goal of emancipating citizens so that they may autonomously co-determine their economic environment. To that end, economics, the doctrine of the economy, must be conducted in such a way that the public can form an informed judgment about decisive political and economic questions. Yet it is precisely with this demand, Galbraith complains, that economics does not comply. Instead of providing enlightenment about reality and transparency about what's truly decisive, within the economic guild theorizing often tends towards the trivial or fictional. In the constant rehashing of conventional wisdoms, academic economics constructs theories, whose popularity can be explained less objectively than subjectively, i.e. as resulting less from relevant disclosures than from the "vested interest in painfully acquired error" accepted within them. Academic economists, Galbraith notes derisively, have been all too willing to pay homage to "what is closest in belief and method to the scholarly tendency of the people who already have tenure in the subject" (AAL 135). ${ }^{16}$ Instead of serving the truth, they prefer to serve their own careers.

How could this happen? When and where did economics lose its compass? In search of an explanation, Galbraith tracks the history of economic thinking and shows that, in the endeavor to become more scientific, in the eighteenth and nineteenth centuries, economics separated from moral philosophy and the social sciences. Economics, which, formerly, as political economy or national economy dealt with concrete economic conditions and their legal directives, has, according to

\footnotetext{
${ }^{16}$ The quotations follow the following scribal abbreviations: AAL: Annals of an Abiding Liberal (New York, 1979); AC: American Capitalism: The Countervailing Power (New York, 1993); AP: The Anatomy of Power (New York, 1985); AS: The Affluent Society (New York, 1958); AU: The Age of Uncertainty: Points of Departure (New York, 1978); CC: The Culture of Contentment (New York, 1993); CCC: Capitalism, Communism, Coexistence: From the Bitter Past to a Better Prospect (New York, 1988); ED: Economic Development (Cambridge, 1964); EIF: The Economics of Innocent Fraud: Truth for our Time (New York, 2004); EPL: A Contemporary Guide to Economics, Peace and Laughter (New York, 1971); EPP: Economics and the Public Purpose (New York, 1973); GC: The Great Crash 1929 (New York, 1954); GS: The Good Society: The Humane Agenda (New York, 1996); LT: Life in our Times: Memoirs (New York, 1983); M: Money, Whence it Came, Where it Went (New York, 1975); NIS: The New Industrial State (New York, 1986); VS: A View from the Stands: Of People, Politics, Military Power, and the Arts (New York, 1986).
} 
Galbraith, restricted itself to increasingly abstract questions. The goal of this undertaking - to work on economic problems free from values and experience, and to find universally valid solutions for them - was, however, never achieved, according to Galbraith. The reason: Economists followed the wrong paradigm, a scientific model inappropriate for their epistemic object, "the economy," as it abstracts the economic life from its historical and socio-political contexts.

In being orientated by a formally quantitative ideal of science borrowed from physics, especially mechanics, economics increasingly proceeded to measure the scientific status of theories against the ability to quantify their elements and to mathematicise their discoveries. ${ }^{17}$ Yet, this orientation can cloud the view of descriptive findings as well as of normative arguments. Certain realities can only be grasped qualitatively, and not quantitatively - and yet, in the end, they are no less real or meaningful. Some arguments will only be formalized late in the day and others perhaps never - notwithstanding being just as significant. Nevertheless, within established economics, as a rule, everything offered in "oral rather than mathematical" presentation becomes "readily dismissed by the men of scientific reputation or pretension" (EPL 96). And that, Galbraith explains, leads to a questionable selfimmunization against all information that does not fit with prevailing convictions.

In particular, in the face of drastic social changes, the mechanical paradigm of conventional economics obscures the view: "Thus does a scientific or pseudoscientific posture direct economics away from accommodation to underlying social institutional change. And it does so with the blessing of presumptively scientific attitude, method and conscience" (EPL 96). Galbraith explicates this by means of the basic model of neoclassical economics: The competition of multiple suppliers. While instructive for the period from 1750 to 1850 , this model unsatisfactorily reflects the modern reality of large oligopolies with influence on macroeconomic frameworks. Yet Galbraith is keenly interested in those structures of modern industrial society and their historical formation, because they led to a transfer of economic power with far-reaching consequences for the moral evaluation and political coordination of economic relations.

Galbraith's critique of academic economics: Instead of being orientated by contemporary facts, until far into the 1970s, economic theories preferred to be orientated at bygone constellations, for instance, small agrarian family businesses, which, because of their tiny size, are in no position to distort the equilibrium prices (postulated by neoclassicism) on the job market (NIS 411). Yet the marked pressure that, in their agreements about collective pay, unions and large corporations exerted upon societal price developments, was, for a long time, not studied in detail, or even dismissed as theoretically irrelevant. Thus economics denied itself the possibility of

\footnotetext{
${ }^{17}$ See George Lennox Sharman Shackle, Epistemics and Economics: A Critique of Economic Doctrines (Cambridge, 1972), 360; Deidre McCloskey, Knowledge and Persuasion in Economics (Cambridge \& New York, 1994), 9ff.; David Colander \& Arjo Klamer, "The Making of an Economist," The Journal of Economic Perspectives 1:2 (1987), 95-111; Lawrence Summers, Nils Gottfries \& Birgit Grodal, "The Scientific Illusion in Empirical Macroeconomics," The Scandinavian Journal of Economics 93:2 (1991), 129-148; Robert M. Solow, "How Did Economics Get That Way and What Way Did It Get?," Daedalus 126:1 (1997), 39-58.
} 
appropriately describing the actual trends in wages and prices. This adversely manifested itself in the stagflation crisis of the 1970s, when stagnation and inflation appeared together, although this was 'theoretically impossible.' As a result, this crisis intensified as academic economics, guided by unrealistic models, formulated policy recommendations highly inappropriate for the actual conditions.

Such clumsy treatment of historical change and political contexts, is, Galbraith believes, largely the fault of economics' aping the epistemic model of the natural sciences. The object of physics remains the same; scientific advance thus results from an increasingly exact and evermore specialized description of the given. By emulating this model, academic economics hoped for a better comprehension of its object and sought to force this through by means of an ever-further specialization and ever-finer division into sub-disciplines (NIS 411). In the event, however, this simply produced an inoculation of the economic disciplines against important information from surrounding fields, inside as well as outside economics, and consequently increasingly estranged economists from the facts and facets of real life. Quantitative calculations displaced qualitative thinking and mathematical constructs supplanted phenomenological reconstructions.

Yet, of course, 'the economy' nowhere exists as a timeless and forever established entity. In all places, economic activity appears in different forms, subjected to manifold, often simultaneously emerging, cultural and political influences. Trains of economic events are, furthermore, reciprocal and reflexive in the highest degree. Abstracting from all of that is a source of inevitable error (NIS 403). If, for example, social change appears at the same time in many economic subsystems, the application of ceteris paribus rules must yield to a more comprehensive perspective, which, as far as possible, includes all entities undergoing change. If that is not done, the actually causal factors become obfuscated and causality is instead ascribed to - in and for themselves - irrelevant phenomena. This then results in doubly erroneous recommendations for action: Initially, one recommends that factors be acted upon which do not at all causally influence events in the hoped-for sense. Finally, from the failure of such measures, one concludes that they were not enforced strongly enough: moderate measures are intensified; thus producing dramatically accumulating failures (NIS 405).

A case in point is market theory: A market, where trade takes place under fair competitive conditions, does not fall from the sky, but rather is often the result of centuries of cultural efforts and legal policies to eradicate individual or organizational free-rider behavior. ${ }^{18}$ A theory that, for methodological reasons, obscures all such social and cultural influences, however, must make the market appear as a quasi-natural phenomenon producing its own equilibrium. When such a market is disrupted, one will tend to attribute this to undue interference on the part of society and thus seek to optimize the market through deregulation. When this fails to work,

\footnotetext{
${ }^{18}$ See Marshall David Sahlins, Stone Age Economics (Hawthorne: New York, 1972), 85f.; S. Todd. Lowry, The Archaeology of Economic Ideas: The Classical Greek Tradition (Durham, 1987); Karl Menninger, Number Words and Number Symbols: A Cultural History of Numbers (Cambridge, MA, 1969), 212f.
} 
one must conclude that the market was not yet deregulated enough; and that is then repeated, until the previously still partially intact market collapses completely. The blame for this is consequently (ex post) attributed to grave asymmetries of power and information (for example, oligopolies), whose fateful effect, however, was first of all (ex ante) made possible by massive deregulation.

Whoever, on the other hand, like Galbraith, includes the market's social and cultural conditions into the analysis, would not strive to reestablish that (at any rate, fictional) natural condition of the market. Rather, a socially and culturally embedded economics would demand an adjusting of the framework and environmental conditions of markets so that free and fair relations of exchange prevail. Such an economics would thus bid rather than forbid economic policies aiming at market design.

\subsubsection{Democratic Economy}

John Kenneth Galbraith wishes to liberate economics from its self-induced alienation from politics. He sees and shows that the mathematical narrowness of economic theory is in no way simply a matter of innocent academic abstraction. Whenever non-quantitative factors drive economic activity, their theoretical occlusion leads to erroneous conclusions. An economics, for instance, which, through its methodological commitments (for instance to the homo oeconomicus as a strictly rational pursuer of given preferences) is prevented from understanding how and from whom (through advertising, marketing, etc.) citizens are influenced in their (often irrational) decisions, does not serve the common interest. It serves, as Galbraith never tires of reminding us, identifiable - yet thus far unidentified - special interests.

Similarly, the conventional exclusion of the topic of 'power' from economics lets the influence of organized interests upon economic regulation and redistribution vanish only from theory, but not from practice (AL 136). Wherever this influence takes place without being thematized, economics does not present - but rather veils - reality. Consequently, economics easily becomes the ideology of the establishment, or - as Galbraith sharply formulates it - the "influential and invaluable ally of those whose exercise of power depends on an acquiescent public" (AAL 151). Only where economists identify economic power - and the dangers it may pose for freedom - can politicians regulate it.

Whoever deceives, robs freedom. False information makes subjects capable of autonomy into heteronomously controllable objects. People can effectively pursue their own ends only on the basis of a sufficiently adequate picture of reality. Whoever manipulates this picture, subsumes persons - as mere means - under the aims of others. Illusion is damaging (schädlich), deception disgraceful (schändlich), for the first instrumentalizes people unwittingly, whereas the second does so wittingly. Scholars therefore have an important societal responsibility whose evasion is morally culpable. 
This flies in the face of the customary refusal of economists even to recognize that the object of their investigation is co-created by themselves through conceptual constructions. ${ }^{19}$ The real influence of economics upon the economy and society is strengthened through that denial, according to Galbraith, as it leads to economics being subjected to far too little skepticism, first by its proponents and consequently also on the part of society. Their recommendations, when presented as solely 'scientific,' appear unpartisan. That is awkward for the social responsibility of economists: The less economics takes itself to be shaping reality, all the more indifferently to the societal consequences of its counsels will it proceed. Economists like to let themselves and others believe that they merely describe, never prescribe, economic 'laws.'

Yet since recommendations for economic and political action are supported by the theoretical descriptions of economics, it is, according to Galbraith, imperative to recast economics as a self-critical social science so as to make it democratically accountable. ${ }^{20}$ Many economists object that they would - and could - not be doing normative scientific work. In the course of the Werturteilsstreits at the beginning of the twentieth century, the majority of economists embarked on a positivist course. They sided with the view that economics did not have to consider the aims of economic activity, but only served to explain the most intelligent employment of multiply usable, scarce means for given ends. ${ }^{21}$ Until today, many economists refuse to discuss the appropriate (individual and societal) ends of economic action. This they mostly legitimate by an outwardly modest abstinence from ultimate justifications and/or a resolute reference to the non-quantifiable nature of the qualitative valuations inevitably involved within determining aims.

According to Galbraith, economics thereby pulls the wool over its own eyes. Even if it avoids explicit (categorical) orientations, economics nevertheless must at least implicitly (hypothetically) align itself with certain aims and measurements in order to make even the simplest strategic recommendations as well as to formulate a research perspective integrating its sub-disciplines. That indeed occurs, of course, and thus economics opts in general for "more" (in questions concerning supply of goods, production, employment, etc.) rather than "less" (NIS 408). After all, it is not so long ago that microeconomic success was evaluated predominantly by means of the gross domestic product and macroeconomic success measured merely by means of a plus in the 'bottom line.'

\footnotetext{
${ }^{19}$ Galbraith is not alone in holding this view: "In natural science, what is thought is built upon what is seen; but in economics, what is seen is built upon what is thought" (Shackle, Epistemics and Economics, 66); for more detailed information about this thesis see Warren J. Samuels, "Galbraith on Economics as a System of Professional Belief," Journal of Post Keynesian Economics 7:1 (1984), 67-76.

${ }^{20}$ Similarly also: Kenneth E. Balding, "Economics as a Moral Science," The American Economic Review 59:1 (1969), 1-12.

${ }^{21} \mathrm{See}$, for instance, Lionel Robbin's classic formulation: "Economics is the science which studies human behavior as a relationship between ends and scarce means which have alternative uses" (Lionel Robbins, An Essay on the Nature and Significance of Economic Science [New York, 1984], 16). See Milton Friedman (ed.), Essays in Positive Economics (Chicago, 1953), 3-43.
} 
Hiding behind the claim that economics would merely guarantee that society has available sufficient means for the ends it pursues, the growth of production was advanced as the stealthy aim of economic theory and practice. Thus was an overt working hypothesis surreptitiously transformed into a covert economic and political imperative. The quantitative premise, however, that lies at the bottom of that approach, i.e. the assumption that without exception, human ends are served by a 'more' rather than a 'less' in material goods, is tantamount to a qualitative devaluation of all alternative aims. Economists subject political options, for instance, to a cost/benefit analysis and typically advise against everything which costs more than it accrues. Nevertheless, as only aspects that are quantitatively measurable enter into the economic evaluation, these kinds of decision-making processes tend to a materialist bias. Ideal entities are generally far more difficult to quantify than physical things. The sense and meaning of non-instrumentalized natural and cultural spheres enter only ever so partially into economic value-calculations. They consequently receive less consideration. For this reason alone, society should be wary to proclaim the economist the "highest arbiter of social policy" (NIS 408).

The focus upon more and more production and, consequently, in order to sell it, upon more extensive and intensive consumption, represses alternative life-plans. Aims like "more sharing of work," "more relaxed conditions of toil or less air and water pollution," "a large amount of leisure," etc., which, among other things, would depend upon a slowing down of the growth of production (NIS 408), automatically fall victim to this commitment. For, through the lens of the gross domestic product, a gain in leisure cannot be measured, while an increase in privately possessed goods can. Thus, econometrically, the private purchase and maintenance of an automobile is equated with a gain in social welfare. Even an absurdly high density of private vehicles leads, through the resulting tasks of regulation (administration, trafficsafety), the necessary infrastructure (road-building, automatic control technology), and the increased consumption of raw materials and measures to overcome damages (cost of accidents, environmental damage) to an increased gross domestic product (EPL 100). But what for?

The abstraction of the economy from its humane objective therefore leads to a "progress toward the wrong goals" (NS 409). Galbraith thus pleads that, in the interest of its moral, aesthetic, and political values, society should sacrifice some of its economic prosperity (EPL 104). Certainly, in very poor countries, the more narrowly defined economic aims are also the politically most important; every society has ultimately to secure the sustenance of its members. But the more affluent a society, the less it should surrender its politics and culture to the imperative for endless economic growth. Questions concerning the quality of life must increasingly retain primacy in the face of the positing of purely quantitative ends (EPL 98). Ultimately, the human being is the end of economic activity - and not vice versa (EPL 101). Hence Galbraith pleads that economics be open to societal discourse about the good life, and develop an economics related to values and the environment (NIS 407).

The economic guild still demurs. A depotentialization of purely economic goals within societies' priorities inevitably results in economists' knowledge losing its 
significance. But economists do not want to become obsolete (EPL 93) and perhaps for that very reason, Galbraith surmises, they obstinately hold on to the paradigm of growth (EPL 95); a trend which is further reinforced by the increasing privatization of the academic sector. Many economists today receive their bread - or, at least, very lavish entremets - from the private economy (NIS 373). In addition to the tendency, observable in all sciences, of granting superiority to conventional wisdom as opposed to awkward innovations, many economists still tend to repress the expression of inconvenient truths in order not to bite the hand that feeds them (AP 130).

The greatest chance for a turn away from the idolization of production growth thus lies in a general realization of the failure of the prevailing paradigm. Insofar as, in the long run, economics is measured by the feasibility of its practical recommendations, it cannot survive a glaring distance from reality and blatant governance failures unscathed. If the course of the world would belie the discipline's "conventional wisdoms" so drastically that an academic career could be made from a call for reform, more and more economists might eventually warm to a paradigm shift. The "march of events" (AS 13) could thus ultimately compel that which hitherto was not to be had by way of collegial criticism and good words: The supersession of the neoclassical evangelism of the market.

\subsubsection{Critique of Neoclassical Economics}

The customer is king! - thus reads the fundamental thesis of those economists who believe that the course of commercial events always and only is controlled "from below," i.e. from the free choice of consumers, and, hence, quasi-democratically (NIS 210). The philosophical foundations of this view originate with Jeremy Bentham (1748-1832) and James Mill (1773-1836). Their economic elaboration begins with David Ricardo (1772-1823). It receives canonical form with Ludwig von Mises (1881-1973) and, subsequently, protection against contradictory experience by means of the revealed preference theory with Paul Samuelson (1915-2009). One must have this intellectual movement before one's eyes in order to understand precisely why Galbraith deals so severely with neoclassical economics. In nuce, it concerns the basic philosophical decision to exclude long-standing debates concerning the (objectively) good from the research field of economics. According to British utilitarianism and the subsequently arising Austrian marginalist school, the good is that which one (subjectively) holds to be so. End of debate. In Bentham's famous words: "Prejudice apart, the game of push-pin is of equal value with the arts and sciences of music and poetry. If the game of push-pin furnish more pleasure, it is more valuable than either." 22

What follows? Since no one knows his ideas of the good as well as the subject in question, every externally arising behavioral control must necessarily provoke suboptimal results. Insofar as one, like Bentham and his followers, equates without

${ }^{22}$ Jeremy Bentham and John Bowring, The Works of Jeremy Bentham (New York, 1962), II, $253 \mathrm{f}$. 
hesitation the common good with the sum of the pleasure of all individuals, any such interventions must impair the common good. The paradoxical result: Whoever wishes to promote the common good will damage it; it can only be advanced by whoever refers individuals back to their own interests. Under this presupposition, any limitations of individual license can only be legitimated insofar as one makes the affected subjects appreciate that these are merely clever detours on the path to their pleasure - like, for example, legal coordination rules, which, although occasionally burdensome, nevertheless without a doubt aid the avoidance of conflicts. Politics, in the sense of wise statecraft, has had its day. It only has to be ensured that individuals can direct political actors with their votes so that they, or rather their preferences, can play the part of the true sovereign. Accordingly, the best policy would be one which reaches the conceivable maximum of freedom of choice through a minimum of arbitrary limitations. Voilá, the theory of quantitative freedom upon a utilitarian foundation. ${ }^{23}$

In parallel with this concept of politics, modern economics formulates its theory of "consumer sovereignty," according to which the economy is directed solely by consumers through their purchasing decisions (NIS 211). In pursuit of individual utility individuals purchase that which pleases them (most, in relative terms) - and in so doing inform the market which needs are (most pressing, relatively speaking) to be fulfilled. Only consumers have intimate knowledge of the catalogue of their needs. Therefore, only they will optimally mobilize their financial means and, certainly, always in such a way that the marginal utility of all acquired goods is the same. For example, one will therefore not be so irrational as to buy an extra quantity of salt if an increase in the domestic sugar reserves would produce greater happiness. Every intervention in the purchasing decisions of individuals on the part of the government must distort that formula of marginal utility and will therefore per definitionem distribute the resources of individuals less efficiently, consequently reducing their happiness and the welfare of society, which is defined as the sum of everyone's happiness (NIS 213). One should thus simply leave the economy alone (laissez faire) and not politically interfere with the market.

Following the model a few steps further: Businesses are 'coerced' by the return of information communicated in prices to attend to fulfilling society's needs. Suppliers compete with one another, after all. In order to survive, they strive after the constant improvement and increase in what they can offer. Businesses consequently reinvest their profits in more modern and efficient production-technology. And since the competition does not abate, it is a question of maximizing profits in order to come out on top in the race towards the best technologies. Unit-costs hence continually sink and this saving is, as a further result of the competition among suppliers, given back to consumers in the form of price reductions. The ultimate consequence is that the market therefore always offers for sale at what, at the time, is the cheapest feasible price, that which consumers want most of all, and everyone thus attains the highest possible maximum of utility. Uninhibited capitalism creates the best of all possible worlds.

${ }^{23}$ See Conrad Waligorski, The Political Theory of Conservative Economists (Lawrence, Kansas, 1990). 
This model certainly functions on occasions, for instance, if businesses appear in the style of late eighteenth century manufacturers working with their own capital. Market competition then confirms "Say's Law of Markets"24: If a commodity is overproduced, nothing remains for the producers to do than to constantly reduce its price until it again finds purchasers. The falling price informs other producers that investing in this commodity is not worthwhile. Overproduction is reduced; and soon there prevails a renewed equilibrium between supply and demand (NIS 220). Everyone is satisfied.

Similarly, monetary policy can steer entrepreneurial activity in the public interest. If the state artificially reduces the amount of money to cool down overheated speculation, entrepreneurs receive capital investment on the financial market only against higher prices because of raised interest rates. Many previously marginally profitable investments no longer pay their way and are thus abandoned. The market cools down. Harmony prevails anew.

Galbraith does not dispute that, even today, there are markets like this: the communal vegetable market of local suppliers for instance. He maintains, however, that the "accepted sequence" of "economic control from below" does not at all take place in the sphere of industrial and post-industrial production. A "revised sequence" is rather to be observed, where the essential control does not lie with consumers, but with corporations (NIS 212ff). No longer the isolated choice of consumers, but rather the organized power of suppliers, proves decisive, which obviously changes the assessment as to whether politics should handle commercial freedom with kidgloves or not. For it is certainly now no longer a question of an increase or decrease in economic freedom as such, but rather one of an evaluation of whether either the freedom of consumers or the freedom of business is granted priority.

The reasons for the historical shift in market power from consumers to producers are practical in nature: With continual modernization, both the production and sale of industrial commodities have radically changed in the past decades. The intensified application of technology has led to a sharply growing need for capital and qualified personnel. At the same time, production time and planning requirements have considerably increased. An airline carrier, for instance, will produce with an incomparably higher, technical, personnel, and financial expenditure than a manufacturer of horse-drawn carriages. That brings along important consequences for the industrial and political economy, which have to be addressed by economic policy (AP 141).

Businesses have reacted to the increasing complexity in the production-sector with an internal, functional differentiation. In the place of the private capital provider who, as a business proprietor, at once acts as founder and director, today the financial burden is the responsibility of the shareholders, the technical construction the responsibility of a specialist staff, and the leadership of the personnel the responsibility of management. The directors of modern large corporations are subject to far less financial coercion than a private capitalist. They are not - or are only

\footnotetext{
${ }^{24}$ See Jean-Baptiste Say, Traité d'économie politique, ou simple exposition de la manière don't se forment, se distribuent, et se composent les richesses (Paris, 1803), $138 \mathrm{f}$.
} 
slightly - liable for the corporation, and that alone already changes their attitude towards profit-maximization and leadership (EPP 266). The management can thus often and with impunity deviate from the neoclassical postulate of proportionally adjusting its wages in proportion to profits, and instead simply decide upon their level and composition discretely for themselves (EIF 27). Galbraith believes that this helps explain the much-discussed phenomenon that, as a rule, the salaries of CEOs still increase, even when their businesses hang in the balance (CC 74).

The shareholders, to whom legally speaking the business belongs, may well be frustrated, but are generally powerless. ${ }^{25}$ That forces a reevaluation of the concept of free enterprise (EIF 31). If, in contrast to neoclassical assumptions, their pay cannot necessitate managers to specific actions, how are they to be influenced? Outside of the ideal worlds of mathematics, managers have very real practical leeway, ${ }^{26}$ which, according to Galbraith, they use in order to fulfil expectations of corporate as well as societal roles (identification), or also to adapt the business to their own interests (adaption). ${ }^{27}$

For a long time, the neoclassical theory neglected such phenomena. On the one hand, such maxims are "not easily adapted to the simplifications of mathematics and symbolic logic" (NIS 146). On the other hand, they upset the argument that businesses cannot assume any moral responsibility for their actions, since (pressured by the market and shareholders) they are lacking in freedom. Recognizing, however, that management is very much in the position to pursue its own interests, not only means to throw into question the neoclassical dogma that private businesses always provide their consumers with an optimum of quality for a minimum of societal costs. Moreover, one must concede: Wherever there exists the freedom to detract from the logic of maximization egoistically, there is also a freedom for socially orientated commerce. In short: Freedom establishes the obligation towards its responsible use.

The demand for Corporate Social Responsibility is thus not - as Milton Friedman still wanted us to believe ${ }^{28}$ - an unruly attack upon the profitability of business and, by extension, upon the rights of its shareholders and the interests of its consumers, but, rather simply an expression of the socially responsible nature of corporate freedom. Management itself often shares this view, Galbraith shows. The corporate

\footnotetext{
${ }^{25}$ See Richard Michael Cyert and James G. March, A Behavioral Theory of the Firm (Cambridge, MA, 1992); Robin Lapthorn Marris, The Economic Theory of "Managerial" Capitalism (London, 1964); Michael Useem, Investor Capitalism: How Money Managers are Changing the Face of Corporate America (New York, 1996).

${ }^{26}$ See Stephen A. Marglin, "John Kenneth Galbraith and the Myths of Economics" in Helen Sasson, Derek Curtis Bok and Andrea D. Williams, eds., Between Friends: Perspectives on John Kenneth Galbraith (Boston, 1999), 114-138, especially 134.

${ }^{27}$ See Oliver E. Williamson, Corporate Control and Business Behavior: An Enquiry into the Effects of Organization Form on Enterprise Behavior (Englewood Cliffs, New Jersey, 1970); Adrian Wood, A Theory of Profits (Cambridge, England, 1975); Harvey Leibenstein, Inside the Firm: The Inefficiencies of Hierarchy (Cambridge, MA, 1987).

${ }^{28}$ See Milton Friedman, "The Social Responsibility of Business Is to Increase Its Profits" in New York Times Magazine, 33, September 13, 1970.
} 
bureaucracy of modern large corporations is interested in the stability of their jobs and, therefore, in their societal acceptance. An enlightened management will hence not always maximize profits. ${ }^{29}$ For the all too radical pursuit of profit gets business into hot water in three different ways: First, it can introduce a perilous price war with the competition. Second, an all too aggressive wage-policy (to keep down costs) leads to conflict with the (often organized and quarrelsome) workforce. Third, if the business all too rabidly sacrifices stakeholder interests for the benefit of the balance sheet, it ultimately brings together both legislature and society against it. Much to the detriment of long-term business activity and, hence, the job security of managers.

Yet, if the corporation pursues profits with more moderation, it can quietly grow without fierce competition, street-protests, and clashes with society. Mergers and acquisitions secure managers' professional positions; their personnel increase alongside their salary and prestige. Furthermore: Wherever the management considers the incentives and aims of its stakeholders, it can reduce legal costs, avoid reputation costs, and increase the benefits of its employers and suppliers. Social recognition also creates a greater inflow of capital. The success of modern management is thus evaluated on capital markets not in the least by the extent to which corporate practices mesh with prevalent values. All of this has effects on the balance sheet. Ethics, in short, can be profitable. ${ }^{30}$ Accordingly, management-lead businesses thus find themselves in no way always in opposition with the workforce and the public. Within the management-lead firm, freedom of business has, consequently, not ceased to exist but merely altered its form and appearance. With this theory of corporate behavior, Galbraith provides important theoretical foundations for current debates about Corporate Social Responsibility, Corporate Citizenship, Social Entrepreneurship, etc., since he explains why it can be viable for firms to move away from the axiom of short-term profit maximization in favor of socially as well as ecologically sustainable strategies. ${ }^{31}$

Yet, all is not well. The spheres of activity of management can also be less civilly employed - for which the current state of the economy provides many incentives. Say's Law, that with decreasing prices every commodity ultimately finds buyers, may still be true of scarce essential commodities. But what today takes place is evermore a trade in commodities the consumer does not urgently need, like prestige goods, branded products, and home electronics. The subjective opinions of consumers about their assets and the world in general noticeably influences the demand for

\footnotetext{
${ }^{29}$ Upon its publication, this thesis provoked fierce resistance. See Marris, The Economic Theory of "Managerial" Capitalism, 37-45; as well as Eli Goldston \& Harold Demsetz, "Discussion," The American Economic Review 60:2 (1970), 479-484. A little later it was, however, empirically and analytically supported: See Williamson, Corporate Control and Business Behavior, 93ff.

${ }^{30}$ See Geoffrey M. Heal, When Principles Pay: Corporate Social Responsibility and the Bottom Line (New York, 2008) and Simon More Elise Webley, Does Business Ethics Pay? Ethics and Financial Performance (London, 2003).

${ }^{31}$ See Stephen Dunn, "John Kenneth Galbraith and the Multinational Corporation (The New Industrial State)," Challenge 48:2 (2005), 90-112 and John Adams, "Galbraith on Economic Development," Journal of Post Keynesian Economics 7:1 (1984), 91-102.
} 
such commodities and thus constitutes a share of their objective market value. Because of a liquidity preference one sometimes does not purchase even when - and often precisely when - prices sink. At the same time, it is incomparably more difficult for modern corporations to adapt to fluctuations in demand than it was for their early capitalist predecessors. Unlike in the pre-industrial era, fluctuations in demand for planning-intensive and capital-intensive commodities (like cars for example) cannot be controlled by either drastic changes in the quantity or mode of production, or by radical price reductions. The obedience to the market postulated by Say is, as a result, defied by businesses as well as consumers.

Yet wherever businesses prefer to back a stabilization of demand to maximum profits, they must influence the purchasing decisions of individuals as well as the whole of society. It is in the systematic interests of businesses to manipulate the individual's 'free' purchases, and so to undermine the very consumer sovereignty neoclassicism places on a pedestal. We would not have advertising if it were completely ineffective. Whoever nonetheless wishes to uphold the thesis of 'consumer sovereignty,' must consequently maintain that advertising is merely informative - for instance by increasing the rationality of purchasing-decisions by providing relevant information about products (for a better calculation of their utility). But does not the advertising industry boast of suggestively appealing to our irrational motivational forces, in order to intensify existing wants, as well as to create new ones (EIF 35)?

Consumer-sovereignty is thus undermined twice; first, overtly, in regard to the individual purchasing-decision: If, for instance, poorly paid citizens decide to invest their limited financial means on a pair of designer sunglasses in preference to a healthy diet, they satisfy an artificially created want to the cost of a natural need. Neoclassical economics finds that unproblematic. Because of its abstraction from questions concerning qualitative values, it equates artificially generated demand with all other preferences. ${ }^{32}$ Yet, even in societies massively overrun with advertising, consumption of luxury goods only rarely produces the same satisfaction curves as the satisfaction of basic needs. And even if, once upon a time, it were otherwise, descriptively, the normative question would still remain, as to whether society then should equate the one with the other; especially if the satisfaction with luxury goods comes at the cost of public goods or brings with it further opportunity costs (AS 128). Products that are marketable only through advertising ultimately have a sharply decreasing marginal utility, for "since the demand [...] would not exist, were it not contrived, its utility or urgency, ex contrivance, is zero" (AS 131). The production of ultimately 'useless' goods nevertheless stands in stark contrast to the neoclassical postulate that deregulated economic activity automatically leads to maximal efficiency in the use of society's resources (AS 129). It squanders otherwise useful means and consequently reduces the economic freedom of the population as a whole..$^{33}$

\footnotetext{
${ }^{32}$ See George J. Stigler \& Gary S. Becker, "De Gustibus non est. et disputandum," American Economic Review 67:2 (1977), 76-90. For an opposing view see Kenneth E. Boulding, "The Economics of Pride and Shame," Atlantic Economic Journal 15 (1987), 10-19.

${ }^{33}$ For this reason, I consider Jean Baudrillard's critique of Galbraith off the mark, according to which Galbraith follows a naively naturalistic and/or an equally naively idealistic concept of value
} 
Yet - defenders of the status quo argue - can we not emancipate ourselves from marketing and refuse to purchase so many advertised products? Occasionally, yes. It remains, however, still the case that upon another subtle level, the unrestrained effect of suggestive advertising impairs the autonomy of individuals and society, insofar as it assaults the social presuppositions of reasonable self-orientation. The capacity critically to evaluate one's own preferences is not innate, but the outcome of the formation of mature subjects that can be culturally favored or impaired. Now, since preciously little truth can be expressed about the rise in quality of life through an ever-larger quantity of products, advertising subservient to the stimulation of ever more purchases has much to lie about. "Social distinction must be associated with ... a swimming pool, sexual fulfilment with a particular shape of automobile, social acceptance with a hair oil or mouthwash, improved health with a hand lotion ..." (EPL 104).

In a society in which all public spaces are flooded with messages promising that consumption is the answer to all questions in life, a truthful discourse about the good life becomes more difficult. This undermines the cultural presuppositions of moral and political autonomy. ${ }^{34}$ Moreover, the obstruction of all natural and artificial spaces with appeals to consume ruin the chances of an environment with a humane aesthetic. The more we subject our lifeworld to the dictates of commercial interests, comfortable consumptions, and effective product-advertising, the uglier it becomes (EPL 104); a horrible troll prancing around in the garb of economic freedom.

Certainly, people clamor ever louder to be protected from unwanted influences, dangerous products, avoidable environmental damage, and the toil of unnecessary production-processes. Yet, ironically, that is ignored by an economics that is methodologically premised entirely upon the individual. Neoclassicism reinterprets the citizen's explicit demand for protection as a wish for paternalism, to concede to which would mean - according to Mises, Hayek, Friedman, Stigler, Becker, and many more - an inadmissible turn away from the principle of freedom. The conscious use which citizens make of their qualitative freedom of expression is thus

(see Jean Baudrillard, La société de consommation: ses mythes, ses structures [Paris, 1970], 17-26). In his role as advisor to a discursively construed political public, Galbraith recommended that which he considered good and correct - in this case a dependence upon biologically provided or rationally justified needs. In the ordering of economic priorities to be decided by society, he championed relief from hunger and need, recognizing that the satisfaction of such needs had priority over the desire for luxury goods. This appeal to nature and reason is, however, not naturalistic, but rather political. Galbraith recommends such an orientation for societal debates, but does not prescribe it metaphysically, while, on the other hand, the neoclassical and neoliberal doctrine refuses such a discourse about the quality of freedom by making quantitative freedom absolute. A concept of basic human needs that is very similar to Galbraith's was already employed by, among others, John Maynard Keynes in Essays in Persuasion (London, 1931), 358-373.

${ }^{34}$ See Richard L. Lippke, "Advertising and the Social Conditions of Autonomy," Business \& Professional Ethics Journal 8:4 (1989), 35-58. Lippke agrees with Galbraith's argument and expands upon it; so does Roger Crisp and Vance Packard: See Roger Crisp, "Persuasive Advertising, Autonomy, and the Creation of Desire," Journal of Business Ethics 6:5, 413-418 and Vance Packard, The Hidden Persuaders (Brooklyn, New York, 2007). 
devalued in the name of a merely assumed (and, by many, very consciously contested) unconscious desire for quantitatively unbounded consumer freedom. Honi soit qui mal y pense.

Paul Samuelson's theory of "revealed preferences," for instance, proclaims (as we shall see later in the subsequent chapter on Amartya Sen) that our purchasingbehavior always exposes what we mostly aspire to, otherwise we would - as, by definition, rational consumers - certainly acquire something else. Nevertheless, it is foolish to say that with their purchasing decisions citizens give their blessing to the consumerism they are talked into, solely because, with these, they react affirmatively to advertising-messages. Galbraith objects that one could just as well fell a man with an axe and then maintain that this was quite obviously something which he had longed for: ultimately, he has, after all, clearly reacted to the impulse visited upon him (NIS 349).

We should prefer to dispel the myth that our current economic system rests completely upon consumer sovereignty (NIS 218). As long as there persists the illusion that the market-economic system merely neutrally expresses the free decisions of all affected individuals, a pseudo-liberal pseudo-legitimacy is granted to the prevailing conditions. This, however, stands in the way of political reform; to the disadvantage of the common good - as well as to the advantage of a privileged few. Galbraith's critique of neoclassical microeconomics thus culminates in the demand for society's economic and philosophical self-enlightenment, which should pave the way for an autonomous political qualification of its societal freedoms.

\subsubsection{Critique of Neoliberal Economic Policy}

The modern corporation pursues certain systemic interests which do not automatically converge with the common good. Instead of fantasizing within mathematical ideal-worlds about a fictional compulsion towards profit-maximization, Galbraith believes economics should give preference to studying the real displays of entrepreneurial freedom. Contra neoclassicism, businesses are certainly not machines run by algorithms, which can be analyzed and optimized from the outside. Businesses are, rather, self-reflexive, idea-driven decision-making systems. To the extent to which it is present in the minds of managers, the idea of entrepreneurial freedom can affect their actions. So, since economics determines to what degree freedom and responsibility are a part of economic theory-construction and pedagogy, it influences the impact of those ideas upon managerial practice.

That can be illustrated with the example of the entrepreneurial endeavor to minimize planning-uncertainties by the manipulation of demand. Marketing is not only geared at individual customers, it is also often aimed at the state and the society as a whole as guarantors of aggregate demand. For many firms, erosion of societal demand through recession, inflation, etc., is more dangerous than a fluctuation in the purchasing tendencies of isolated market participants. It is therefore essential to influence the overall societal purchasing power and, by implication, the state's economic policies 
as well. Corporations, especially those in technology-intensive industries, seek proximity to the state. If capital-investments are high and sales opportunities uncertain as, for instance, with new armament technologies - the producer hardly likes to accept the risk of failing demand. For instance, whoever produces a complex missilelaunching system must - on pain of bankruptcy - know that they have definite buyers for it. The producer will therefore ensure through all licit (and, occasionally, illicit) means that the state will take up in the long-term a foreseeable and possibly growing number of goods (CC 136). The upshot is an intricate entwinement of heavy industry and armament producers with politics, culminating in co-authoring international policy on the part of the industrial decision-makers (EIF 54).

But if politics already extensively cooperates with the economy - as mutatis mutandis is also to be observed in other capital-intensive sectors (aeronautical industry, construction) - what, asks Galbraith, are we to make of the neoclassical and neoliberal demand that politics should keep out of the economy? Why should the visible hand of democracy be denied access to an economy which is already shaped and molded at pleasure by the invisible hands of lobbyists? Whose freedom and which freedom does this actually protect, and why? Contra neoclassicism, which categorically separates state and private-economy and likes to close its eyes to their factual approximation, Galbraith views the overlapping of the public and private sectors as the rule, not the exception, within modern economic practice, and thus would not release firms into a policy-free arena (CC 75).

Let us consider the economic background of this argument more closely: Cyclical crises constitute an inverted image of the transformed structural conditions of the modern economy. On the one hand, it is necessary for every technology-intensive production that much is saved on the part of business so that the sums kept aside can be handed over by the credit market to corporations and cost-intensive investments can be undertaken. Yet, the more that is saved, all the greater is the leverage upon economic events, if that money is for once not fed back into the economic cycle.

Only within narrow limits, can large corporations react to falling demand with price elasticity. Apart from the already described intricacies of production technology, there is also the fact that the stock market as a rule punishes a reduction in the rate of profit; consequently, businesses lose investment capital and equity proportional to the amount of shares they hold in themselves. In order to raise its equity quota, management will be induced to cut down on operating costs. That can be achieved through reducing production as well as redundancies. Rational microeconomic action then leads, however, to a suboptimal allocation of resources and thus to manifestly disadvantageous macro-economic outcomes: With unemployment and wage cuts the purchasing power of society is further reduced, which intensifies even more the trends giving rise to the problems. Underemployment equilibria result. ${ }^{35}$

Galbraith thus champions an anticyclical economic policy. Unlike John Maynard Keynes (1883-1946), he does not, however, believe that job-creation programs are

${ }^{35}$ See N. Gregory Romer David Mankiw (ed.), New Keynesian Economics (Cambridge, MA, 1991), 412. 
a blessing. They work too slowly, and once called into life cannot so easily be removed from the world. Yet Keynes precisely presupposed just that: in the case of high inflation the state was to slow down the economic cycle artificially. If that does not happen, then, in the long-term, stagflation results. Galbraith thinks the state fares better when operating with the more flexible system of taxation. As long as taxes are progressive, they tend to auto-correct the economic situation. Whenever especially large profits appear, progressive taxation siphons off a disproportionate share for the state; an overheating of the economy through continuing reinvestments becomes, consequently, less likely. If profits fail to appear, on the other hand, then the burden of taxation placed upon entrepreneurs is, conversely, disproportionately reduced, partially balancing out their loss in investment capacity.

To enable the fruits of taxation to return into the economic cycle, a public sector is needed. Galbraith underlines that the times in the twentieth century when the public hand intensively interfered in American economic life (during the two worldwars and during the moon-race) were also the very epochs when the American economy most intensively prospered. Nowadays, he notes, that economic stabilization effect falls to the American weapons industry (EPP 284f.). One should, therefore, give up the neoclassical illusion that government's intimate linkage to weapon producers and heavy industry would merely constitute a somewhat (too) large form of private entrepreneurship with incidentally always filled order-books (AP 142). Together with that illusion would then also evaporate the conclusion that the state may in no way intervene (EIF 54ff.). If in truth economic policy is made via the USA's military budget, it should also be subject to democratic controls. In this way one could then gradually reduce the military budget in favor of investments in civil demands, which are just as suitable for stabilizing the economy, yet entail fewer questionable results in the arena of international politics.

In general, according to Galbraith, it is a question of translating the abstract quantitative freedom of a virtual consumer state (preached in the textbooks) into the concrete qualitative freedoms of the real civil society. The economic scandals of the previous decades illustrate, however, that quite the opposite occurs. The close cooperation of creative bookkeepers, careless private economic auditors, and indulgent public supervising committees could only take place because it operated in the dark shadows of neoliberal politics and neoclassical economic theory (EIF 50), which rejects regulation and control, in principle, as contrary to freedom and detrimental to efficiency (EIF 8). The striking coincidence between the deregulation of the American security sector and the consequent savings-and-loans debacle, between the deregulation of investment banking and the following WorldCom-bankruptcy, as well as that between the deregulation of accounting law and the Enron/Arthur Andersen scandal, suggest the following lesson ${ }^{36}$ : Government and administration

\footnotetext{
${ }^{36}$ See David Bailey, George Harte \& Roger Sugden, "Corporate Disclosure and the Deregulation of International Investment," Accounting, Auditing and Accountability 13:2 (2000), 197-218; Gerald Vinten, "The Corporate Governance Lessons of Enron," Corporate Governance: The International Journal of Business in Society 2:4 (2002), 4-9; C. Richard Baker, "Investigating Enron As a Public Private Partnership," Accounting, Auditing and Accountability 16:3 (2003), 446-466.
} 
in no way proceed inefficiently per se, and, conversely, businesses do not per se present productive entities which one must thus spare from all societal oversight. But since, for the proponents of neoclassicism, the free market is "a semireligious totem" (CC 135) they close their eyes to the fact that businesses only operate productively and in support of the common good under certain conditions, which are by no means always a given, says Galbraith.

The conflict between the concept of freedom supported by Galbraith, which examines the qualitative value of socially constructed freedoms, and the merely quantitatively directed neoclassical concept of freedom, comes especially to the fore in the dispute between fiscalism and monetarism. Instead of an anti-cyclical fiscal policy which is directly of benefit to citizens and only indirectly (by way of strengthening demand) of benefit to businesses, ${ }^{37}$ a quantitatively liberal agenda prefers economic policy favoring monetary measures which directly serve solely business (planning security) whose increased profits reach, if at all, the citizens indirectly (trickle-down economics) ${ }^{38}$ In economics lead by monetarism, the poorer strata not only continually lose out on relative income, they also thereby gradually lose sociopolitical weight in the contest for public opinion as against the active financing of politicians and opinion makers on the part of business (EPP 255).

It is therefore especially cynical when - like on the part of the Chicago School economists - monetary policies are attacking fiscal social policy in the name of economic freedom. The opposite is much closer to the truth: "Income rising above the level of mere subsistence is [...] a liberating force. [...] It is one of the curiosities of much social comment that such welfare measures are regularly seen as limitations on freedom - the freedom presumptively inherent in the free enterprise system" (AP 51). Serious liberalism especially protects the freedom of the economically weak (CCC 151).

When "countervailing powers" (CCC 128) like trade unions, associations, cooperative ventures, charitable organizations, etc. do not succeed in assuring an economy catering to basic human needs, the law, creating entitlement to a minimum wage (EPP 262) and social-security measures, has to support the poor (AP 187). Failing that, the "social balance" is forfeited; "private opulence" and "public squalor," i.e. "public penury and private affluence" come into ever-starker contrast, and the community disintegrates, ultimately even politically (EPL 93). ${ }^{39}$ Nothing damages capitalism's sustainable success and outlook, Galbraith concludes, as much as the regency of its apologists (M 312). Still, the class of the "contented and [...] comfortable" constantly opposes the crucial reforms (CC 144). Galbraith thus sees himself forced towards the following grim prognosis: "The past age of contentment will come to an end only when and if the adverse developments that it fosters

\footnotetext{
${ }^{37}$ About this, see also: Giovanni Andrea Cornia, Inequality, Growth and Poverty in an Era of Liberalization and Globalization (2004), 3-26.

${ }^{38}$ See James Bradford De Long, "The Triumph of Monetarism?," The Journal of Economic Perspectives 14:1 (2000), 83-94.

${ }^{39}$ See Thomas Karier, “The Heresies of John Kenneth Galbraith,” Challenge 36:4 (1993), 23-28.
} 
challenge the sense of comfortable well-being." This, though, is only to be expected of an economic catastrophe (CC 156f.).

What would apt alternatives look like? Certainly, at times policy can ensure that businesses internalize the negative external effects they produce. That is successful when the legal order - through taxes on expenditure and duties on emissions, for instance - brings it about that businesses include the public cost of their productionprocesses in their balance-sheets and are thus urged towards a more careful engagement with the environment. Nevertheless, one must not lose sight of the fact that the language-game of the internalization of externalities does not cover one particular issue. If society's only allocation mechanism is merely the market, then that negatively affects all of those commodities that cannot be sold on the market even under optimal frameworks. Local environmental damages can be quantified only to some extent, and at high taxonomic costs to boot, being implemented in entrepreneurial cost-calculations then only via political pressure. Things look even worse for, e.g., aesthetic and moral goods, the qualitative nature of which far less allow of quantitative accounting. The hasty answer that these kinds of goods have then instead to be procured by society is as correct as it is insufficient. The potential of national laws and regulations lags noticeably behind the reality of the world economy. Globalized economic-practice over-strains domestic politics' governance competency, not merely selectively but rather structurally.

The formative power for a kind of 'World Domestic Policy' (Weltinnenpolitik) today no longer lies solely with the world's states. Rather, a global public engaged in all political and economic niches plays an ever more important role. This planetary public operates not at all solely against firms, but also together with a growing number of businesses, which in evident seriousness and with striking success try to live up to their responsibilities as corporate citizens and are, for that reason, preferred in the market by mature consumers and selective investors. Which corroborates Galbraith's thesis that businesses, when adequately directed, do indeed have the requisite space for decision-making and forms of commerce corresponding to the responsibility growing out of their economic freedom.

Nevertheless, civil-society initiatives and economic initiatives (e.g. the $U N$ Global Compact) cannot completely replace state action. Galbraith believes that the enormous inequalities in the global distribution of wealth require a coordinated initiative on the part of all nations. An alliance of public opinion and enlightened commercial self-interest cannot make state-controlled global economic policy superfluous, since, as ultima ratio, they lack the means of legal coercion. Yet, wherever policy has created the conditions for poverty by destroying embedded structures of governance, it must also accept responsibility for the reestablishment of rights. This is true of large parts of the developing world, where previous colonial injustice and the accompanying destruction of a formerly autochthonous community enabled the subsequent dictatorship of large corporations. The fact that industrialized nations now point to the limited possibilities of national politics in regard to the very lawless conditions they themselves caused, is, in Galbraith's eyes, but a hollow "formula for selfishness" (GS 131). In order to assist the economically disadvan- 
taged on this earth, the wealthy must ultimately be prepared to establish a socially and ecologically well-balanced global economic order.

Galbraith thus provides important building-blocks for a timely theory of responsible freedom: His economic philosophy enables the reconceptualization of the demands for social and ecological sustainability as qualitative increases as opposed to quantitative reductions of our economic freedom. From the perspective of a critique of its physicalist self-understanding, Galbraith pleads for an economics qua self-critical social science. Since the economic sciences directly (via economic policy recommendations) and indirectly (by forming opinion) contribute to the realization of their conceptions, they must open up to society's discourse on values. Yet, as long as economics does not reflect upon its practical influence, its effects will be, in the best-case scenario, conservative - insofar as it is oriented towards present phenomena - and in the worst case, reactionary - when oriented by superannuated premises. To correctly grasp and measure the actuality to which it needs to react, a change in the prevailing materialistic economic paradigm is required.

In the face of corporations' organized power to distort the market and to influence public decision-making - and the correspondingly weakened position of both the individual and the state - many of the axioms of neoclassical economics can no longer be honestly maintained. An economics doing justice to the real structural changes of today can, for instance, no longer trust the market to be a panacea and guarantor of freedom. In the structures of economic activity and decision-making transformed by multinational corporations, economics finds, though, a new arena for the analysis of economic freedom and responsibility. From now on, through targeted economic policy and prudent Corporate Social Responsibility, it ought to aim at dismantling those conditions which, supposedly in the name of freedom, rob humanity - against its express will - slowly but surely of the foundations of a life worth living. Therefore, economists should no longer only conceive of freedom as the "maximum range of choice" (NIS 217) but rather recognize freedom as reasonable autonomy. Yet our freedom can only be reasonably orientated when it does not methodologically deprive itself of its anthropological perspectives, its psychological insights, and its moral views. Therefore, in order to enable an emancipative and sustainable economy, Galbraith wishes to advance an economics established upon qualitatively orientated freedom. ${ }^{40}$

\subsection{Responsible Freedom (Amartya Sen)}

Amartya Sen (1933-) developed his theory of freedom over many years in close collaboration with Martha Nussbaum (1947-). Both criticized the inadequacy of the current state of liberal political philosophy, looked for alternatives, and thus

\footnotetext{
${ }^{40}$ See the assessment of Sen, Heilbronner, and Marglin in Helen Sasson, Derek Curtis Bok and Andrea D. Williams (eds.), Between Friends: Perspectives in John Kenneth Galbraith (Boston, 1999).
} 
proposed the capability approach, which today enjoys worldwide reception. Although the historical development of Sen's work is closely connected with Nussbaum's, I have primarily concentrated upon the former, indicating parallel positions in Nussbaum's work in the footnotes. ${ }^{41}$ This occurs for two reasons: First, for Martha Nussbaum, the idea of freedom is not as significant as it is for Sen. Second, in contrast to Nussbaum's much broader works, Sen's texts concentrate far more upon the very questions of the philosophy of economics that are pivotal for our investigation. I thus only examine the relationship between Nussbaum and Sen in more detail when dealing with their dispute about how the idea of freedom should be specified into concrete concepts of freedom.

Sen's works seamlessly connect with those of John Kenneth Galbraith. First, Sen reinforces Galbraith's view that economics is not able to be limited to contents and questions amenable to quantitative formalization. The object should determine the method and not vice versa: Mathematics and logic have to be the servants and not the masters of economics. ${ }^{42}$ Second, Sen, too, is concerned with the economic and political emancipation of the public. Like Galbraith, he endeavors to make the structural contexts of economics so transparent that they can be shaped democratically. Third, Sen also wishes to forge a path leading away from an abstractly quantitative concept of freedom towards a theory of freedom ("substantive freedom"), which investigates the concretely qualitative opportunities of citizens.

Yet Amartya Sen deals with these concerns in a different manner than John Kenneth Galbraith. Whereas Galbraith tracks economic upheavals and is led to theoretical problems from practical ones, Sen frequently inverts that sequence, concentrating, time and again, on the axiomatics of economics. The high practical relevance of his works notwithstanding, on the whole Sen's works focus predominantly on theoretical principles. Where Galbraith historicizes, contextualizes, and personalizes, Sen generalizes and formalizes.

I reconstruct Sen's notion of freedom by showing how he developed it in critical contrast to traditional economic theories and their underlying concepts of rationality. I then move on to extract the practical consequences of his theory of freedom for economics and politics. This sequence follows the system of Sen's thinking: In the course of his academic career, Sen reached a point where he could no longer carry out his intended research program without finding a new, freedom-oriented criterion for evaluating current economics. His desire to eliminate blind spots from the methodology of the economic sciences ultimately forced him to analyze the economic lens as a whole. Sen recognized the intimate relation between a liberal economy and a critically self-reflexive economics freely choosing its own methods and themes. Whoever demands liberal economic practices must promote a freedombased economic theory. For the image of the economy arises in our minds. It is there

\footnotetext{
${ }^{41}$ For more detail about the similarities and differences of both conceptions, see Nussbaum, Creating Capabilities.

${ }^{42}$ See Amartya Sen, "Galbraith and the Art of Description" in Helen Sasson, Derek Curtis Bok \& Andrea D. Williams (eds.), Between Friends: Perspectives on John Kenneth Galbraith (Boston, 1999), 139-146, for the advantages of Galbraith's qualitatively described economics.
} 
that economic experiences are selected, sorted, and sequenced. Our thinking directs the lenses of economics, and economics should make and employ this very choice of perspectives consciously. Economics is not a passive product of its object, but rather a construct of active subjects. And as such - as the work of human freedom it should also be studied and practiced, lest it fall victim to the dictatorship of supposed inevitabilities.

\subsubsection{Critique of the Neoclassical Paradigm}

Many utilitarian and welfarist economists of the nineteenth and twentieth centuries attempted to replace the forever contentious debates about the qualitative aim of the economy with a quantitative decision-making logic. Sen is skeptical of these undertakings, since the hereby envisioned maximization of utility stands and falls with the functionality of utility-comparisons. From the 1920s on, it became, after all, increasingly apparent to an increasing number of leading economists, like e.g. Alfred Marshall (1842-1924), Arthur Cecil Pigou (1877-1959), and John Hicks (19041989), that, strictly speaking, personal utility does not allow for inter-subjective comparisons. Therefore, one has since rather defended the postulate of utilitymaximization analytically (RF 364). ${ }^{43}$ Paul Samuelson's (1915-2009) attempt to establish on solely conceptual grounds the usefulness of the utility focus through his revealed preferences theory (which we already touched upon in the chapter on Galbraith, see Sect. 4.1.3) was particularly important. ${ }^{44}$ Samuelson simply turned the tables. Instead of proving that market choices optimally realize the preferences of market participants, he postulated it. If it is true by definition that all purchasers are rigorously rational decision-makers according to the homo oeconomicus model, then their purchasing decisions must reveal and realize their respective preferences. Accordingly, Samuelson promoted his theory as being "freed from any vestigial traces of the utility concept." 45

The methodological program "to explain behavior without reference to anything other than behavior" is, however, according to Sen, comparable to the attempt "to get an empirical rabbit out of a definitional hat" (RF 364). People who receive what they choose do not always thereby obtain what they desire. The inference from choices to desires overlooks that one always has to choose from a set of extant options, whereas what is desired may often be outside that set. One must thus consider - in James

\footnotetext{
${ }^{43}$ Amartya Sen's works are referenced according to the following abbreviations: (DF) Development as Freedom (New York, 1999); (IV) Identity and Violence: The Illusion of Destiny (New York \& London, 2007); (CWB) "Capability and Well-Being" in Martha Nussbaum \& Amartya Sen, The Quality of Life (Oxford, 1993); (RF) Rationality and Freedom (Cambridge, MA \& London, 2002); (IJ) The Idea of Justice (Cambridge, MA, 2009).

${ }^{44}$ See Paul A. Samuelson, "A Note on the Pure Theory of Consumer's Behavior," Economica 5:17 (1938), 61-71.

${ }^{45}$ Ibid., 71.
} 
Buchanan's formulation - not only the choice within constraints, but also the choice of constraints. ${ }^{46}$ If the latter (trans-systemic, i.e. meta-systemic) choice is conflated with the former (inter-systemic) choice it becomes difficult to question the status $q u o$; it is consequently presumed that everyone who participates in market activity therefore eo ipso finds happiness and prosperity. The trick with the "revealed preferences," designed as an obsequious theoretical service, thus surreptitiously turns into an obnoxious defense of established practice. Just as John Kenneth Galbraith had already noticed and denounced (see Sect. 4.1.3).

Besides, the value of options not only lies in their realization, it also consists in the fact that they exist at all: they provide people with alternatives ${ }^{47}$ Freedom is, consequently, in no way exhausted by the sum of manifested choices, but rather also encompasses "spurned options" (RF 593n.) and "options forgone" (RF 608). Merely measuring the utility of instantiated choices does thus not suffice to attain the true value of freedom.

Amartya Sen criticizes furthermore the assumption that subjective perceptions of happiness present a necessary and sufficient criterion for objective well-being. The poor who accept their lot; the sick who are uninformed about their condition, the uneducated who are unable to picture a better life and so accept what fate grants them all reconcile themselves to the manner of their existence, perhaps even finding modest personal happiness therein (DF 62). But subjective accommodation establishes neither objective well-being nor genuine autonomy (FR 90f.). The measure of "pleasure and desire" is thus "too malleable to be a firm guide to deprivation and disadvantage" (DF 63) ${ }^{48}$ Whoever views individual perceptions of happiness as the only measure for welfare-provision, must, consequently, also be ready to reject donations to the modest poor, in order to slip them into the hands of the greedy rich; people who are unhappy solely because they cannot get enough (RF 82).

According to Sen, one does not escape this objection by combining utilitarianism with egalitarianism. Certainly, one can conceive of granting everyone the same entitlement to money as an all-purpose means so that everyone could attain their respectively desired utility. One would acquire bread, the other a mink coat; would not the happiness of all thus be served? Could this rescue the old utilitarian and welfarist axioms?

Hardly. Welfare-egalitiarianism is frustrated by the "diversity of human beings," says Sen. "Differences in age, gender, special talents, disability, proneness to illness and so on can make two different persons have quite divergent opportunities and quality of life even when they share exactly the same commodity bundle" (DF 69). Disability makes life costlier. The same is true of age and sickness. Furthermore, disadvantages are often felt twice, not only from the perspective of costs, but also

\footnotetext{
${ }^{46}$ See James Buchanan, "The Domain of Constitutional Economics," in Constitutional Political Economy 1:1 (1990), 1-18.

${ }^{47}$ See Martha Nussbaum: "Thus the Capabilities Approach departs from a tradition in economics that measures the real value of a set of options by the best use that can be made of them. Options are freedoms, and freedom has intrinsic value" (Creating Capabilities, 25).

${ }^{48}$ See Martha Nussbaum, Creating Capabilities, 54f.
} 
from the perspective of income. Because of limited possibilities for employment, a disabled person has, as a rule, a lower income. This "coupling of disadvantages" (DF 70ff.) must be legally accounted for in distributive processes. Equal distribution fails here. To assume that all are the same rather means to treat unequals equally. It violates precisely that demand for fairness that egalitarian theories wish to satisfy (IJ, 255-259). ${ }^{49}$

People with disabilities therefore present a special case of a universally valid assessment: Individuals are, objectively, too unequally constituted and, subjectively, too unequally oriented for measuring them all with the same economic yardstick. A humane economics is therefore one which accounts precisely for that difference in objective want and subjective need. Hence one has to free oneself of the fixation with the distributional aspect of economic means and rather consider which capabilities and life-chances these create for the persons in question; a perspective that cannot be attained without recourse to values and norms.

This critique of the foundations of utilitarianism and egalitarianism shakes the welfarist superstructure of neoclassical economics which rests on these two pillars. For while German economists at the turn of the nineteenth century still allowed a Methodenstreit (methodology dispute) as well as a Werturteilsstreit (value-judgment dispute), about the status that moral norms and empirically inductive (historical, statistical) knowledge should have in economics, Anglo-American economists were by the middle of the twentieth century almost unanimously conforming to the program of a purely descriptive as well as primarily deductive economics. ${ }^{50}$ This positivistic economics was said to operate from a few, clearly defined axioms and thereby - it was claimed - describe and make predictable economic behavior in accordance with laws similar to those paramount in the natural sciences.

The homo oeconomicus model is at the heart of these aspirations. ${ }^{51}$ In order to be able to construct algorithms it reduces economic behavior to the simplest elements: rationality and self-interest. From this foundation, neoclassical economics proceeds to explain the economic world at large. Sen has no objection to the axiom of rationality as a scientific hypothesis, but he does object to its connection with a "presumption of ubiquitous selfishness" (DF 118). Either this prescription does far too little and is prognostically unproductive, if one - as in Paul Samuelsson's "revealed preferences theory" - conflates it with actual market behavior. Or it does much too much; i.e. whenever it ventures towards the "highly restrictive and thoroughly dubious empirical assumption that people, in fact, choose entirely according to their respective personal interests and well-beings" (RF 589). The belief that pure

\footnotetext{
${ }^{49}$ Authors who insist on egalitarianism, like Thomas Pogge, have of course already reacted to this objection by appropriate differentiations and modifications of their "basic goods" theories: for a critique of these differentiated positions (and a strengthening of Sen's core-argument) see Johnathan Wolff and Avner De-Shalit, Disadvantage (Oxford \& New York, 2007).

${ }^{50}$ For more information, see Claus Dierksmeier, "The Freedom-Responsibility Nexus in Management Philosophy."

${ }^{51}$ For a description and defense of the model see Gebhard Kirchgässner, Homo Oeconomicus: The Economic Model of Individual Behavior and Its Application in Economics and Other Social Sciences (New York, 2008).
} 
egoism governs the economic world is, empirically, just as untenable as the converse presumption that human beings act only from altruism. Whoever rejects the latter view of things as "high-minded sentimentality," must also, Sen declares, disown the former as a mirror-inverted "low-minded sentimentality" (RF 26).

While contractualists and game-theorists stubbornly attempt "to make us accept the peculiar understanding that rational choice consists only in clever promotion of self-interest," phenomenologically there is little to be said in favor of this "remarkably alienating belief" (IJ 32). ${ }^{52}$ Whoever reduces the rationality of the homo oeconomicus to self-interest, construes a "rational fool," i.e. someone who in the most rational manner acts deeply unreasonably. Because this commits the individual decision makers to selfish preferences alone, it reduces without need the radius of their legitimately "rational" choices. Being self-interested need not be foolish, but not to have the freedom to consider whether to be self-interested (and to what extent) is a serious limitation of rationality" ( $\mathrm{RF} 7 \mathrm{n}$.). The axiom of self-interest therefore does not present a harmless working hypothesis, but rather a misleading "a priori prejudice" (RF 26).

Against it, Sen champions a model of economic rationality which includes our critically reflexive freedom "to reason about what we should pursue" (RF 46). Sen thus takes a position against Lionel Robbins' almost canonical formulation of economics as a "science which studies human behavior as a relationship between ends and scarce means which have alternate uses." ${ }^{33}$ That economic positivism which focuses only upon the appropriateness of the chosen means, but not upon their goals, is characterized and caricatured by Sen by means of the following image: A man who zealously works at cutting off his toes with a blunt knife hardly behaves more rationally as soon as he - after analyzing the relative inefficiency of the chosen means - finally reaches for a sharp knife (RF 39). He wishes to illustrate that one cannot meaningfully talk about economic rationality while avoiding the debate about its appropriate goals and ends.

Sen intends "to reclaim for humanity the ground that has been taken from it by various arbitrarily narrow formulations of the demands of rationality" (RF 51). He holds onto the postulate of rationality but shows that it is thoroughly compatible with an ethical reflection upon economic ends: "a selfless person who wants to maximize, say, the aggregate social welfare, or some feature of equity or social justice, need not, for that reason, depart from maximizing behavior" (RF 37). The rationality of human behavior does not depend upon utilitarian or egoistic premises but rather could also be retained among other - e.g. moral - indicators.

\footnotetext{
${ }^{52}$ See also Hilary Putnam, The Collapse of the Fact/Value Dichotomy and Other Essays (Cambridge, MA, 2002).

${ }^{53}$ See Lionel Robbins, An Essay on the Nature and Significance of Economic Science (London \& New York, 1932), 16. A (critical) evaluation of Robbins' contribution to the development of positivistic theories within current economics as well as an (affirmative) appreciation of Sen's opposing contribution can be found in Pressman \& Summerfield, The Economic Contributions of Amartya Sen.
} 
Sen's example: At a garden party, we would perhaps prefer to sit in the most comfortable seat and snatch the last fruit from the fruit bowl (RF 161). Yet, we often hold back out of consideration for others. We not only consider the situation from the point of view of our interests, but rather plan our behavior with reference to the social context (RF 161). Defenders of the homo oeconomicus model object that such considerations might still proceed from self-interest, because, for instance, one always has one's mind set upon one's own image in the eyes of the other. That is possible but misses the point of Sen's critique. According to him, we commonly want something for ourselves only if, in so doing, we do not thereby improperly violate the interests of others. According to Sen we thus leave the best chair and the last fruit in the bowl to others, not only because we indirectly care about our own interests, but rather at least at times also because we take a direct interest in the preferences of others (RF 161).

Authors like Gary Becker have also sought to ward off this objection: by postulating some other-orientated, yet nevertheless egotistic, joy in the well-being of others. The everyday experience that we are glad about making others happy is thereby reinterpreted such as that, first, we wish to be pleased with ourselves and, then, mindful of our charitable form of self-enjoyment, are ready to do good for others. Self-advantage remains - quod erat demonstrandum - the decisive factor. Sen, however, counters that sportsmen often only wish to emerge victorious from a game insofar as they have fairly won it, regardless of whether they are lauded for this self-commitment to fairness or not. Although our desires do not always heed a normative logic and pursue private benefit solely in forms of decent agency (RF 12), often they do, ${ }^{54}$ and occasionally - and here the logic of self-interest ultimately collapses - even to our own disadvantage. ${ }^{55}$ We strive for what is normatively correct not exclusively because of its advantages for $u s$, but also because we aspired to it in itself. The rational agent postulated by economics thus in truth behaves - at the very least occasionally - as a reasonable person with moral orientations. ${ }^{56}$

This has important consequences for economists' understanding of rationality and science:

The first and most direct use of rationality, it can be argued, must be normative: we want to think and act wisely and judiciously, rather than stupidly and impulsively. If the understanding of rationality is firmly tied to the systematic use of reason, the normative use of rationality is easily placed aqt the center of the stage. (RF 42)

\footnotetext{
${ }^{54}$ Sen follows the view of Thomas Scanlon that, in general, we (should) be orientated by principles "that others could not reasonably reject" (Thomas Scanlon, What We Owe to Each Other [Cambridge, MA, 1998]) in that, along with Scanlon, he localizes the descriptive and normative core of current decisions (DF 92).

${ }^{55}$ See Paul J. Zak, "Neuroeconomics," Biological Sciences 359:1451 (2004), 1737-1748; Timothy Killingback \& Etienne Studer, "Spatial Ultimatum Games, Collaborations and the Evolution of Fairness," Biological Sciences 268:1478 (2001), 1797-1801; Peter A. Ubel, Free Market Madness: Why Human Nature is at Odds with Economics - and Why It Matters (Boston, MA, 2009).

${ }^{56}$ See Vivian Walsh, Rationality, Allocation, and Reproduction (Oxford \& New York, 1996).
} 
For the justification of this demand, Sen appeals to the work of Hilary Putnam. ${ }^{57}$ The latter had - for his part building upon Willard van Orman Quine's (1908-2000) critique of the fact/theory distinction, a staid dogma of analytic philosophy ${ }^{58}$ - critically scrutinized the fact/norm dichotomy in economics. According to Putnam, physicalism within economics fails, first because of its unsophisticated understanding of physics. The clean separation - still instructive in the late eighteenth and early nineteenth centuries - of empirical observation and analytic statement can hardly be maintained today. Witness the not directly observable, but merely indirectly inferred, negatively curved time-space continuum (on a large scale) or quantum dynamics (on a small scale). As a close study of the wave-particle duality of electrons reveals, that which one perceives depends in each case upon how one observes. And results from how the respective object is conceptualized. Experience follows observation, and this, for its part, is orientated - consciously or unconsciously, willingly or not by theory. In the same way as how in contemporary physics one can seldom speak of theory-free events, economics often lacks value-free actions. ${ }^{59}$ Just as in physics, theory (all the more so, the more sophisticated physics becomes) defines what serves as a datum, so in economics (implicit rather than explicit) values define what counts as a fact.

Those who, overlooking this, attempt to give economic realities a purely positivistic interpretation confuse the hall of mirrors of their own projections with the world. The economic positivists see themselves compelled to deprive people of motives they possess, and instead to substitute these with preferences that they lack. Normativity belongs to the theory of economic facticity, simply because normativity belongs to the facticity of what economic theory is about. Normative values and ego-ideals orientate our life. The Ought has an $I s-$ in our aspirations. It is therefore to be objected against the homo oeconomicus that it is not realistic enough, since it does not speak idealistically enough about people.

To reiterate: If human rationality were to consist only in cost-benefit calculations, how is it that we sometimes let our morality cost us something? ${ }^{60}$ Some economists, it is true, reinterpret peoples' moral expenditure as refined forms of care for oneself - set upon social recognition or transcendent salvation. ${ }^{61}$ With the

\footnotetext{
${ }^{57}$ See Hilary Putnam, The Collapse of the Fact/Value Dichotomy, 7-45 and Hilary Putnam, "For Ethics and Economics without the Dichotomies," Review of Political Economy 15:3 (2003), 397.

${ }^{58}$ See Willard van Orman Quine, "Main Trends in Recent Philosophy: Two Dogmas of Empiricism," The Philosophical Review 60:1 (1951), 20-43.

${ }^{59}$ See also Vivian Walsh, "Fact/Value Dichotomy" in Jan Peil \& Irene van Staveren (eds.), Handbook of Economics and Ethics (Cheltenham, UK \& Northampton, MA, 2009).

${ }^{60}$ See Paul Pecorino \& Mark Van Boening, "Fairness in an Embedded Ultimatum Game," Journal of Law and Economics 53:2 (2010), 263-287. Francesco Guala, "Paradigmatic Experiments: The Ultimatum Game from Testing to Measurement Device," Philosophy of Science 75:5 (2008), 658669. Catherine Eckel, Martin Johnson and Rick K. Wilson, "Fairness and Rejection in the Ultimatum Bargaining Game," Political Analysis 10:4 (2002), 376-393; Killingback \& Struder, Spatial Ultimatum Games.

${ }^{61}$ See Gary S. Becker, The Economic Approach to Human Behavior (Chicago, 1976); Gary S. Becker, Accounting for Tastes (Cambridge, MA, 1996); Gary S. Becker \& Richard A. Posner, Uncommon Sense: Economic Insights, from Marriage to Terrorism (Chicago \& London, 2009).
} 
help of secret motives unknown to the agents, usual altruism is reconstructed as unusual egotism. But if such scientifically questionable ad-hoc assumptions are required in order to not simply dismiss moral action to one's own disadvantage as irrational, what does that say about the theory employed here? What, asks Sen, are we to make of an economics that declares "Ghandi, Martin Luther King Jr., Mother Theresa and Nelson Mandela" to be "huge idiots" (IV 21)?

With the dogma of self-interest collapses an essential buttress of neoclassical economics. Another stands and falls with the mathematization of all economically relevant phenomena. The program of quantitative maximization requires the commensurability of all utility functions. This, in turn, presupposes the exchangeability of all goods and services; and that, according to Sen, does not exist. At one and the same time people constantly aim for different kinds of - and often incommensurable (hedonistic and moral, material and ideal, practical and aesthetic, etc.) - goods, and flexibly evaluate, in each case, which should have priority. This consideration, for its part, leads to qualitative questions of value, which, not only in part but in principle, transgress the quantitative logic of conventional economics.

Even one and the same person often cannot reduce all relevant aspects of one and the same object to a single nominal value. The value of a car, for instance, cannot be measured only in terms of either its top speed, or its comfort and safety functions, or its environmental friendliness, or its design, look, or brand-status. The different criteria of evaluation can also not always be reduced to a common denominator. Nevertheless, without fulfilling these conditions of rationality presumed by the homo oeconomicus model, we can make more-or-less reasonable purchasingdecisions on the automobile market. ${ }^{62}$ But if individuals do not even make onedimensional benefit-assessments in respect of particular objects, how does it stand then with the oveall societal assessment of multiple - intersubjectively relevant and independently assessed - goods? Who still seriously believes that, in such scenarios, society could simply adhere to simple cost-benefit comparisons?

The idea of an ultimate incommensurability of economic goods certainly provokes "anxiety and panic among some valuational experts," who would prefer to live in a world which is "agreeably trivial" so that all-important decisions could be evaluated "simply by quantity" (IJ 240). Sen objects, though, that in our everyday actions - when shopping for instance - we handle this incommensurability of various goods pretty well (IJ 241). To reduce complex societal decisions to simple costbenefit analyses is hence equivalent to a "daydream," he believes, which one had better dismiss with waking eyes: "To insist on the mechanical comfort of having just one homogenous 'good thing' would be to deny our humanity as reasoning creatures" (DF 77). We should therefore break away from the, in any case, mythical maximization of one-dimensional goods in favor of a more realistic balancing of multi-dimensional values. Since the economic "cost-benefit-analysis" subjects all options to the quantitative dictate "more is better than less," it has, for its part, to be hedged in by "social choice judgments." Political reason must bring the wayward economic ratio to heel.

\footnotetext{
${ }^{62}$ See Nicholas Rescher, Ethical Idealism: An Inquiry into the Nature and Function of Ideals (Berkeley, 1987), 55ff.
} 
The societal role and appreciation of the market is a case in point. The market serves well as a discovery process of scarcity and preferences, but only with regard to commensurable goods. If the part is taken for the whole here, and the market as well as the Pareto-efficient ${ }^{63}$ it promotes are declared the arbiter of everything, the extolled informational capacity of the market founders. It produces misallocations. In Sen's sharp and terse words: "a Pareto efficient outcome may well be thoroughly unequal and nasty" (RF 524). Moreover, even within the vocabulary of commensurability the market splutters, when only a select few are getting a say. As indicators, markets function the better the more citizens participate through payments in the societal discourse about prices. But no pareto-efficient equilibrium achieved by unregulated markets can establish the ideally requisite economic capacity of strictly all citizens to take part in that communication. ${ }^{64}$ Left to its own devices, the market can neither create nor reproduce its own efficiency-conditions. ${ }^{65}$

Sen demands the demystification of the market; it should come down from heaven to the earth. The "oddly common presumption that there is such a thing as 'the market outcome,' no matter what rules of private operation, public initiatives, and nonmarket institutions are combined with the existence of markets" (IV 136) must yield to a recognition of the social construction of market-economics. The (free) market does not exist; there only are various forms of a socially regulated exchange of goods, growing out of a reciprocal play of interests and values. Markets and the options they offer are creations of the values inherent in their arrangement and environments; without the latter the former could not exist. Markets ought to be designed in such a way as to not undermine their own social, cultural, moral, and ecological presuppositions. For this market-design, however, purely quantitative imperatives are insufficient.

In order to evaluate the pros and cons of markets qualitatively, pre-modern economics had recourse to the ethics of theological and metaphysical providence. But that avenue is barred, factually and normatively, by today's plurality of individual and social self-conceptions. The fundamentals of our social reality must conform to everyone's free decision about the merits or demerits of their options. Also, in economics, there must be no regress behind the idea of freedom (DF 30). The consequence of Sen's approach is to decide questions of economic orientation through a

\footnotetext{
${ }^{63}$ The concept 'Pareto-efficient' designates (following the economist Vilfredo Pareto) a condition of the allocation of goods in which the welfare of some people cannot be improved through redistribution without, at the same time, reducing the welfare of others. A condition beneath this level expresses a lack of allocational efficiency (some goods are distributed in such a way that they generate less than the maximal aggregated utility and could therefore be substituted with others so that some persons are put in a better position, but no one is put in a worse one). Pareto efficiency fulfills a minimal demand of technical rationality but says nothing about substantial questions (beyond technical efficiency); about this see E. J. Mishan, "The Futility of Pareto-Efficient Distributions," The American Economic Review 62:5 (1972), 971-976.

${ }^{64}$ See Partha Dasgupta, "Positive Freedom, Markets and the Welfare State," Oxford Review of Economic Policy 2 (1986).

${ }^{65}$ See Jens Beckert, Beyond the Market the Social Foundations of Economic Efficiency (Princeton, NJ, 2002).
} 
“"social choice' exercise" by means of "public discussion" (DF 78f). Economics owes citizens the possibility "to discuss and debate - and to participate in the selection of - values in the choice of priorities" (DF 30). Economics should therefore be open to "public scrutiny and criticism" (ibid.). Everyone must be concerned with what concerns everyone.

Democratically agreed upon aims should lead to econometric benchmarks instead of, conversely, letting technocratic benchmarks dictate economic policy (ibid.). The values and aims which should guide policy are not given a priori but must be negotiated anew from society to society, from place to place, and from time to time. The search for a mix of broadly agreeable values is, Sen admits, sometimes "extremely messy." And he knows that "many technocrats are sufficiently disgusted by its messiness to pine for some wonderful formula that would simply give us ready-made weights that are "just right"' (DF 79). But unfortunately, there exists no such "magic formula" which would absolve us from the dispute about the values guiding our (economic) life; that's a matter of "judgment," not for "some impersonal technology" (DF 79). The freedom of individuals to actively co-design the conditions influencing their life-chances must be protected against all the tendencies of economics to hermetically seal itself off and - through "cultivated opaqueness" - to hide its indwelling "choice of values and weights," in the interests of simpler procedures of calculation and decision-making (DF 110).

Thus, instead of hiding economic standards of value in the premises and axioms of econometrics, they should be debated through "public participation" so as to be endorsed or rejected by the society through "responsible social choice" (DF 110). ${ }^{66}$ Because these procedures make explicit the implicit values of the discourse's participants (DF 80), this process enables at the same time also their public critique (DF 81). It is the burden of freedom that such "social choice"-procedures only produce workable results when purposes are found or formed which appear acceptable to all concerned (DF 79). In this weight (Bürde) nevertheless lies precisely the worth (Würde) of those procedures (RF 526). For by means of them one might bridge, Sen speculates, the unsightly chasm between the abstract "freedom-invoking rhetoric" of some economists and their disinterest in the concrete emancipation of indigent individuals (DF 26).

Before economics can successfully remove motes from reality, it must be conscious of the beam in its own eye. Since, for the sake of the economy's targets, those of economics are also at issue, economics must free itself from the quantitative paradigm of physics and reestablish itself as a social and humanist science in which qualitative "value judgments" neither can nor should be avoided (DF 110). And, in order to offer - with the turn from the previous one-dimensional economic targets to a multidimensional idea of freedom - precisely that democratic transparency he finds lacking in his colleagues, Sen neither wishes nor allows himself simply to impose his own set of values. He instead has to justify to everyone the concept of freedom his economic theory employs: through a critique of competing concepts of freedom.

${ }^{66}$ See Tapas Majumdar, "Amartya Sen in Search of Impure Welfare Economics: Finding New Space," Economic and Political Weekly 33:45 (1998), 2860-2862. 


\subsubsection{Critique of Reductionist Concepts of Freedom}

Sen worked out his own understanding of freedom in joint seminars and discussions with Nozick, Rawls, and Scanlon. At first, he merely wanted to counterbalance the one-sidedness of prevailing theories. He set about this, however, so thoroughly that out of the sum and unity of those critical strivings a new theory of freedom grew which Sen also declared as such in 1998, in his seminal book Development and Freedom. ${ }^{67}$ This theory primarily gains its contours from its opposition to the utilitarian and libertarian positions.

Against utilitarian theories of freedom, completely determining the value of freedom according to its utility, Sen argues that, although freedom is not the only value, it is a value in itself. On one hand, freedom certainly has to relate to objectives, but, on the other hand, it is not consumed by them. The respect for freedom as an endin-itself is to be distinguished from its value as a means to reach the goods it can achieve (CWB 39). The intrinsic and the instrumental appreciation of freedom are to be distinguished. ${ }^{68}$

Furthermore, freedom extends not only to given first order preferences (like, for example, the desire to smoke), but also to "second order preferences," like, for example, the meta-preference "not to have the preference for smoking" (RF 18). Instead of robotically pursuing an order of preferences fixed according to the strength of desires it comprises, freedom can critically ask, "what preference should I have" (RF 619). True freedom does not uncritically maximize what certain desires demand, but rather evaluates and optimizes how they ought be consummated.

The idea of freedom thus encompasses two distinctive aspects. First, the internal conditionality of preferences. The mere wish to have no craving to smoke cigarettes does certainly not immediately extinguish the latter. Second, this very reflection throws light also upon the external conditions influencing our preferences: an environment, for instance, which portrays smoking as particularly attractive or especially repulsive. Therefore, from the direct demand for freedom, there follows an indirect desire to influence freedom's contexts.

Freedom is, consequently, political from the outset. It manifests itself not merely in a choice between (given) alternatives, but rather also always in opting and searching for (better) alternatives. ${ }^{69}$ For this reason Sen thinks highly of the tradition of theories of "positive freedom" (for the genealogy of "positive freedom" in Thomas Hill Green and German Idealism see Sect. 1.2.1). ${ }^{70}$ These contain an - always

\footnotetext{
${ }^{67}$ See Malcolm Bush, “Amartya Sen, Development as Freedom," Social Service Review 75:3 (2001), 514-517.

${ }^{68}$ Martha Nussbaum also agrees with this: "Freedom to choose and to act, however, is an end as well as a means, and it is this aspect that the standard utilitarian position cannot capture." As a result, very much like Sen, she thus concludes: "In short, the utilitarian approach undervalues freedom" (Creating Capabilities, 56).

${ }^{69}$ See Paul Streeten, "Amartya Sen: Rationality and Freedom," Economic Development and Change 52:4 (2004), 889-891.

${ }^{70}$ Sen very approvingly refers to Thomas Hill Green (see RF 586 etc.). Sen's citation-praxis clearly reveals his sympathy for proponents of theories of positive freedom; he often approvingly
} 
implicit, sometimes explicit - commentary on the value of given options, and consider the societal presuppositions of a life in liberty. In agreement with this tradition, Sen does not doubt that social policies securing fair opportunities for all belong to freedom in the full sense of the word. After all, the abstract right to the ("negative") defense of property is unhelpful to those who do not possess anything valuable to begin with. ${ }^{71}$ In such cases, curtailing the freedom to property of some in favor of the ("positive") participatory freedom of all would surely be advisable. ${ }^{72}$

Hence Sen's demarcation from libertarian positions: Theories of negative freedom, Sen holds, misunderstand that the private control over our life's settings is often far less essential than their design. ${ }^{73}$ Whereas libertarians believe that every quantitative increase in state control necessarily propagates a decrease in individual freedom, exactly the opposite can be the case. Contrary to the conventional wisdoms of libertarians, the private autonomy of citizens is surely better protected in a district where police patrol than one where citizens, wielding private fire arms, try to take care of peace and quiet themselves (RF 397) ${ }^{74}$ This example illustrates that in Sen's eyes the primary distinction of relevance for freedom does not turn out to be quantitative (a plus or minus in state authority), but is rather qualitative: It depends upon how and for what that authority is established. Only secondarily to this evaluation can one plausibly discuss its quantitative dimensions.

Both demarcations - the one from utilitarian positions just as much as the one from libertarian conceptions of freedom - must be kept in view. Against the utilitarian standard of "cumulation outcomes," i.e. measuring summarily material endstates, Sen proposes a concept of "comprehensive outcomes," which holds on to the liberality of the formal procedures leading to the respective results. In this regard, then, Sen enters a coalition with defenders of negative freedom, when he, like them, denies any eudemonistic dictatorship that grants people opportunities at the expense of their civic freedoms (RF 510). Nevertheless, Sen does not wish to thoroughly

mentions, for instance: Ronald Dworkin, Taking Rights Seriously (London, 1977); Partha Dasgupta, The Control of Resources (Oxford, 1982); Partha Dasgupta, "Positive Freedom, Markets and the Welfare State," Oxford Review of Economic Policy 2 (1986); Alan P. Hamlin \& Philip Pettit, The Good Polity: Normative Analysis of the State (Oxford, 1989); Dieter Helm (ed.), The Economic Borders of the State (Oxford, 1989).

${ }^{71}$ See Ann Nevile, “Amartya K. Sen and Social Exclusion,” Development in Practice 17:2 (2007), $249-255$.

72 "This is a curtailment of a certain kind of freedom of control. But it is motivated by considerations of freedom of another kind: freedom to achieve things" (Partha Dasgupta, "Power and Control in the Good Polity" in Alan P. Hamlin \& Philip Pettit (eds.), The Good Polity: Normative Analysis of the State (Oxford, 1989), 191).

${ }^{73}$ See Skinner, Liberty Before Liberalism, 86.

74 "If, as libertarians believe, every individual has the right to own his person and property, it then follows that he has the right to employ violence to defend himself against the violence of criminal aggressors [...] Gun prohibition is the brainchild of white middle-class liberals [...]. If we wish to encourage a society where citizens come to the aid of neighbors in distress, we must not strip them of the actual power to do something about crime" (Murray Newton Rothbard, For a New Liberty [New York, 1973], 86-88). 
reduce the idea of freedom to that procedural dimension. Attention to the procedures in which rights and commitments are to be spelled out is in no way to be equated with an inattentiveness in respect of the foreseeable consequences of those procedures (IJ 232f): "Even if [procedural, C.D.] liberty is given a special status, it is highly implausible to claim that it would have as absolute and relentless a priority as libertarian theories insist it must have" (DF 67).

The right to property and ownership, for example, "must not necessarily be taken as being just as momentous as my right not be tortured and killed" (RF 636). Precisely such differentiations are refused, however, when libertarians treat both rights on the same level as "side constraints" of liberty (RF 636). Absolute insistence upon the formal dimension of rights to freedom can lead to material losses in freedom (RF 511). Against Nozick and Gauthier, ${ }^{75}$ Sen points out that "institutional fundamentalism" (IJ 83), i.e. a protection of freedom which only pays attention to the procedure and never the end-results can produce counterintuitive results: "even gigantic famines can result without anyone's libertarian rights (including property rights) being violated. The destitute such as the unemployed or the impoverished may starve precisely because their 'entitlements' - legitimate as they are - do not give them enough food" (DF 66).

Yet, who would dare to maintain that individuals who are starving are not losing out on freedom, when they are lacking the most elementary of all freedoms, namely, the "basic freedom to survive" (DF 15)? Such "sledgehammer reasoning" (RF 561) heedless of consequences should thus be thrown into doubt. Robert Nozick perceived the force of this objection. In a (not only by Sen) much-noticed footnote of a later edition of his work, Anarchy, State, and Utopia, he qualifies his theory of freedom as the sum of all legitimate "entitlements". To avoid "catastrophic moral horrors," perhaps sometimes limitations of those "entitlements" might nevertheless be legitimate. ${ }^{76}$ Nozick does not, however, enlighten us about what this exception to the rule says about the validity precisely of that rule of a purely procedural protection of freedom. Sen comments: "But once such an exception is made, it is not clear what remains of the basic priorities in his theory of justice" (IJ 85). For Nozick's statement either marks a genuinely intended relativization of his hitherto absolute notion of negative freedom (but then one can confidently pass over his theory and turn towards conceptions which - like Sen's own contribution - attempt from the outset to balance out the formal and material aspects of freedom); or - and this certainly seems more probable - Nozick installs this statement only as a valve within his theory so that social pressure cannot explode it. Then this statement

\footnotetext{
${ }^{75}$ See Nozick, Anarchy, State, and Utopia; David P. Gauthier, Morals by Agreement (Oxford \& New York, 1986).

${ }^{76}$ Nozick writes "The question of whether these side constraints reflecting rights are absolute, or whether they may be violated in order to avoid catastrophic moral horror, and if the latter, what the resulting structure might look like, is one I hope largely to avoid" (Robert Nozick, Anarchy, State, and Utopia, 30). In a personal discussion on April 22, 2008, Sen pointed out that before he had had no personal contract with Nozick that might have provoked this concession; and, then, clearly and concisely sketched his own position once again with the words: "I am no big fan of property rights. Property must be justified by what it does."
} 
would be as objectively injurious as it appears subjectively ignominious. In both cases, however, the conception of negative freedom turns out to be unsatisfactory.

Why then is the theory of negative freedom, despite its striking flaws, nevertheless still so widespread? Like Galbraith (see Sect. 4.1.3) Sen attributes this to exogenous grounds. A purely formal concept of freedom is easier to quantify and adjust to a mathematicised economics. If one simply enumerates options and identifies their increase with a gain in freedom, then one already finds oneself in the familiar fields of maximization logic. But one is thus kidding oneself (see also the introduction to Chap. 3). Whoever views freedom "as a matter of the size of the set from which one can choose" overlooks to their own detriment that the extent of individual freedom cannot be meaningfully judged "without reference to the person's values and preferences" (RF 514). A choice must be judged "not just in terms of the number of options one has, but with adequate sensitivity to the attractiveness of the available options" (DF 117). The quantity of options attains meaning only secondarily: in terms of the primarily to be evaluated quality of the same (CWB 33f).

A purely formal theory of freedom gets us nowhere. Not only are a few good options to be preferred to a choice of innumerable horrible possibilities (RF 13). Often only a quantitative reduction of options leads to qualitative improvements (RF 602). Autonomously enacted limitations of the "freedom to act" can, for instance, produce a gain in the "freedom to achieve" (RF 597). By more people coming to coordinate their actions, it becomes possible for all to reach certain common targets. Collective forms of action and social structures do not only bound individual freedom, they also broaden it, by instantiating some possibilities which otherwise would not exist. Having access to meaningful options clearly stands and falls with the possibility of evaluating one's own preferences and opportunities in coordination with others and of changing them in collaboration with them (RF 12).

Sen maintains that positions solely oriented by negative freedom - the right to fend off all interventions into property rights and entitlements - are not sophisticated enough. He instead holds that "both negative and positive freedom can be simultaneously valued" (RF 12n.). Still, a clear hierarchy is a presupposition of this agreeable harmony. Sen does subordinate the concept of negative freedom to the concept of positive freedom instead of merely coordinating it with it - let alone, allowing the latter to reign above the former. We should protect negative freedom precisely because we respect positive freedom (RF 646).

I have found it more useful to see "positive freedom" as the person's ability to do the things in question taking everything in account (including external restraints as well as internal limitations). In this interpretation, a violation of negative freedom must also be - unless compensated by some other factor - a violation of positive freedom, but not vice versa. (RF 596)

A complete conception of freedom should encompass all socially conditioned "capabilities to do things that a person has reason to value" (DF 56). But since the twofold distinction between "negative" and "positive" freedom makes the articulation of this idea more difficult, Sen ultimately replaces it with his own threefold model. The latter distinguishes an "opportunity aspect," directed towards our opportunities, from a "process aspect," which investigates how these come about. Both 
aspects are subsequently brought together and conjoined in the concept of a "substantive freedom." As a result of this conception, individual and collective freedoms inseparably refer to one another. Institutions codetermine the preferences and opportunities of individuals. We must therefore also evaluate and reform these institutions "in the light of their contributions to our freedom" (DF 142). Whoever makes use of socially imputed freedom must not refuse collaborating in the social construction of the freedom of others: "we have to see individual freedom as a social commitment" (DF XII). ${ }^{77}$

John Rawls is a thinker who had insisted upon just that. The emancipatory moment of his theory of justice consists in the social-liberal preoccupation with giving everyone the "basic goods" they require in order to be capable of a real use of freedom, both materially and ideally. As was discussed in the previous chapter, this attempt was undertaken in Rawls' Theory of Justice, which is supposed to outline how much (quantitatively), within ideal societal institutions, everyone owes everyone else so that everyone can live in freedom. But in Sen's judgement this approach fails because Rawls attempts to tie up the idea of freedom with his own Rawlsian concept of justice. Sen, however, maintains that Rawls' search for a perfect norm of justice is "neither necessary, nor sufficient" (IJ 15). It is not required because - not only an absolute, but rather - a comparative concept of justice suffices to address glaring "capacity deficits." And it is insufficient because even a concept of optimal justice does not enable us to evaluate concrete grievances. Sen illustrates this critique with vivid examples. Even if one could agree, say, on Leonardo's Mona Lisa being the best painting in the world, that alone would still provide us with no appropriate criterion to evaluate the work of, for instance, Picasso and Dalí. ${ }^{78}$ Applied to questions of social justice that means: Rawls' attempt to find a single fixed criterion of justice overlooks the fact that different systems of distribution can rest upon diverging measures of value - and legitimately so. While differences in political forms of justice from society to society will certainly not always express legitimate divergences over values, quite often they may (IJ 52ff.).

Freedom is recursive, according to Sen; it must liberate people - also and especially for finding new and innovative answers to what constitutes or what enables freedom (e.g., by means of distributive justice) in any given scenario (IJ 232ff.). The capacity and readiness of individuals to examine their values critically from the perspective of an unbiased observer (IJ 108, 125, 138) is thus of decisive importance. It allows the replacement of the rational choice theory Rawls employs with a social choice practice. Instead of, like the former, reconstructing the reasonableness of the chosen options merely quantitatively, namely "simply as smart maximization of self-interest" (IJ 179), the latter can also process qualitative criteria.

\footnotetext{
${ }^{77}$ Just like Martha Nussbaum, Creating Capabilities, 22.

${ }^{78}$ In the same way, Sen also rejects the Platonic doctrine of "methexis" ( = participation) (IJ 16) for determining justice, with the following example: Whether one now views white or red wine as the ideal, a wine-connoisseur will always prefer his or her second choice to a fusion of the two, although as a mixture, it is closer to the ideal. Therefore, it is not always the best method for reaching optimal results to reduce different standards to but one metric.
} 
Broadening the perspective to encompass qualitative viewpoints is of decisive importance. As previously demonstrated (in the Rawls-chapter) in regard to people who can never benefit or harm us, the models of quantitatively symmetrical reciprocity fail. What obligates us is not an abstract thought-experiment in which we contractually negotiate conduct advantageous to everyone with all persons concerned. It is rather the very concrete fact that we seriously influence the life of future generations (RF 535). We feel obliged to take account of the needs of those people, not only in the sense of a "benign humanitarianism," but rather for reasons of fairness (IJ 129). But neither as "social contractor" nor as "utilitarian in camouflage" (IJ 138) can we explain why we imagine ourselves as having such unilateral responsibility.

The shipwreck of symmetry-fixated social-philosophies upon the rock of temporary or geographical asymmetries is a secret blessing for further advances in theory (IJ 129, 145ff.). ${ }^{79}$ It helps us recognize that the idea of freedom requires a normative vanishing point lying beyond the "limited - and limiting - framework of social contract" (IJ XI). And that prompts us to also pay attention to asymmetrical interests. Distantly dwelling peoples, or those who have yet to be born, do not qualify as contractual partners for interactions based solely on quantitative advantage-seeking, but they do qualify as claimants from a qualitative concern for fairness. In the place of commercial reciprocity there enters ethical mutuality.

But what remains of conventional socioeconomic philosophy if, as Sen demands, the self-interest orientated axiomatic of the rational-choice model is extended to moral dimensions (IJ 32) and the preference-formalism (and the accompanying instrumentalist reduction of freedom to choice) is rejected (IJ 83)? The postulate of rationality, i.e. the irrevocable "interdependence of rationality and freedom" (RF 52 ), according to which the true quality of freedom can only be outlined in communal, political quests for its reasonable direction (IJ 232ff.). The step from the calculations of symmetrical reciprocity to theories of unilateral and asymmetrical commitments is, after all, meant to express and not negate reasonable freedom. The formulation of such a theory of responsible freedom - by means of which, correctly understood, individual freedom when contributing to the emancipation of others is not reduced but realized, and not contradicted but completed - requires, however, according to Sen, the capabilities approach.

\subsubsection{Freedom Through "Capabilities"}

Sen complains that libertarians, utilitarians, and Rawlsians have all inappropriately conceptualized the "freedom to achieve actual livings that one can have reason to value," which is so decisive for people's real lives (DF 73). Only Martha Nussbaum has achieved this (ibid.). Taking her departure from Aristotle, Nussbaum had closely

\footnotetext{
${ }^{79}$ See Harry Brighouse \& Ingrid Robeyns, Measuring Justice: Primary Goods and Capabilities (Cambridge \& New York, 2010).
} 
scrutinized the various human "capabilities to function" (CWB 32) and investigated their respective contribution to an empirically complete and philosophically coherent conception of freedom. ${ }^{80}$ In this "capabilities approach," established by Nussbaum, Sen welcomes the opportunity to reclaim "some of the old heritage of professional economics" (DF 25) in order to reassess the tradition of qualitatively directed economy neglected since the end of the eighteenth century (DF 24f.).

Sen explains that: "A person's 'capability' refers to the alternative combinations of functionings that are feasible for her or him to achieve. Capability is thus a kind of freedom: the substantive freedom to achieve alternative functioning combinations (or, less formally put, the freedom to achieve various lifestyles)" (DF 75). Rich people who fast, for example, may well endure the same privations as poor people who are starving. Yet, despite the same "functionings," both groups clearly have a different "capability set"; the former choose that condition, the latter do not (DF 75). The distinction between "functionings" and "capabilities" is, first of all, epistemic: "The two give different types of information - the former about the things a person does and the latter about the things a person is substantively free to do" (DF 75). Second, that distinction is employed to differentiate the "value of choosing" (DF 76) from the options between which one chooses. "While the combination of a person's functionings reflect her actual achievements, the capability set represents the freedom to achieve: the alternative functioning combinations from which this person can choose" (DF 75).

Important is not only the abstract quantity of formally and universally granted possibilities, but rather primarily the concrete quality of the life-chances people can realize here and now, i.e. the "substantive freedoms - the capabilities - to choose a life one has a reason to value" (DF 74). And the question concerning which kind of increase in freedom certain "functionings" achieve, leads, according to Sen, to different answers in different cases: On one hand because persons with distinct objective needs draw different benefits from the same goods, but on the other hand because, as a result of subjective preferences, even needs-based allocations of goods mean something different to different individuals. ${ }^{81}$

The "substantive freedom" Sen is striving for is characterized by multiple components and their interaction. His conception includes "(1) political freedoms, (2) economic facilities, (3) social opportunities, (4) transparency guarantees, and (5) protective security" (DF 38ff.). Sen thus not only demands traditional rights to freedom, he rather at the same time says that these will only come into effect when, for example, there exists protection from corruption and fraud (4) and individuals have effective access to the economic (2), pedagogical, and medicinal (3) as well as

\footnotetext{
${ }^{80}$ See Giovanola, Re-Thinking the Anthropological and Ethical Foundation of Economics and Business: Human Richness and Capabilities Enhancement; Paul Anhand, Graham Hunter and Smith Ron, "Capabilities and Well-Being: Evidence Based on the Sen-Nussbaum Approach to Welfare," Social Indicators Research 74:1 (2005), 9-55.

${ }^{81}$ See Douglas A. Hicks, "Gender, Discrimination, and Capability: Insights from Amartya Sen," The Journal of Religious Ethics 30:1 (2002), 137-154; David A. Clark, "Sen's capability approach and the many spaces of human well-being," The Journal of Development Studies 41:8 (2005), 1339-1368.
} 
social (5) conditions necessary for reflexively critical self-determination (ibid.). The different aspects of this "substantive freedom" strengthen and reinforce one another. The more political freedom a community possesses, the more effectively it can, for instance, democratically organize its economic institutions and enable social participation. Conversely, a high degree of institutional transparency, for example, serves to free the functioning of economic transactions and political deliberations from corruption. The various moments of "substantive freedom" are therefore not only intrinsically but also instrumentally important (DF 37).

So far, Sen and Nussbaum are in complete agreement. Their views diverge, however, concerning the status of procedural freedom within those "substantive freedoms." For in Aristotle, the spiritual father of her approach, Nussbaum makes out "just one list of functionings [...] that do in fact constitute human good living" (NFC 152). ${ }^{82}$ Similarly today one would also have to define this one basic set as exactly as possible. Nussbaum consequently finds that Sen lacks an "objective normative account of human functioning." She criticizes his model for lacking a "procedure for objective evaluation by which functionings can be assessed for their contribution to the good human life" (NFC 176).

Martha Nussbaum views her own approach to capabilities-theory essentially in terms of a Rawlsian "commitment to political liberalism" (CC 75); like Rawls she wishes to make use only of arguments that she may assume are already backed by the "overlapping consensus" of the actual community: "my capability-based theory of justice refrains from offering a comprehensive assessment of the quality of life in a society, even for comparative purposes, because of the role of political liberalism in my theory requires me to prescind from offering any comprehensive account of value" (CC 19). She, therefore, on the one hand, finds that Sen's liberalism goes too far in vigorously professing the necessity of "capability fulfilment as freedom," as though it were a self-contained "comprehensive doctrine" (ibid.). On the other hand, according to her, Sen does not go far enough, since he does not establish a list of the irrevocable basic capabilities (CC 76).

The "capabilities approach," Nussbaum explains, deals with "substantial freedoms" (CC 18). It is therefore incumbent upon it to state precisely which these are. (Nota bene: As we will later discuss, she does not talk about "substantive freedoms," like Sen, but rather of "substantial freedoms"). According to Nussbaum, Sen simply never gives us an answer to the question, "Which capabilities are the most important?" (CC 27) Rather than providing one, he simply contents himself with suggestions: "Sen takes a stand on the valuational issue by emphasis, choice of examples, but he does not attempt anything like a systematic answer" (CC 27). One gets the impression that, although Sen had set off in the right direction, he ultimately failed to jump as far as required.

\footnotetext{
${ }^{82}$ Martha Nussbaum's writings are cited in accordance with following abbreviations: (NFC): Martha Craven Nussbaum, Nature, Function, and Capability: Aristotle on Political Distribution (Oxford Studies in Ancient Philosophy, 1988); (FJ): Martha Craven Nussbaum, Frontiers of Justice: Disability, Nationality, Species Membership (Cambridge, MA, 2006); (CC): Martha Craven Nussbaum, Creating Capabilities: The Human Development Approach (Cambridge, MA, 2011).
} 
Sen, conversely, is disturbed by Nussbaum's elimination of interpretative leeway in favor of a fixed conception of "well-being" (CWB 47). For Sen conceives of his concept of "substantive freedom" as embracing not only the material results of freedom, but also its procedural dimensions. For the sake of this "process aspect" Sen wishes to keep the "capability approach" open to diverging answers to the question concerning which freedoms deserve priority (CWB 47). The last word about this should be had by neither economists nor philosophers, but rather by all concerned. Instead of one single answer to the question concerning which "capabilities" place people in the position of possessing "substantive freedom," there should be just as many answers as there are political communities: here and now they are possibly quite different ones from those at different places and different times. Sen thus defends the openness of his approach as one of "deliberate incompleteness" (CWB 47, italics, CD).

It is certainly not the case, as Sen sometimes suggests, that Martha Nussbaum simply sits in an ivory tower drafting a "blueprint" (IJ 232) which once and for all declares what every person at every time and place requires to be free - and that's that. But although Nussbaum certainly does establish a list with ten "capabilities" (CC 33f) that she claims are essential for any living human being, her approach also aims at a certain openness to the respective political and cultural contexts of human life: First, she conceives of her list as "open ended" and open to "ongoing revision"; second, she is decidedly open to differentiated concretization within different societies; third, she draws up a "modular" conception which can be applied to the most varied "comprehensive doctrines"; fourth, she grants individuals important scope for decision-making by typically demanding only that "capabilities," but not the realisation of "functionings," be safeguarded; and, fifth, she integrates flexible classical civil-liberties into the list, as well as, sixth, clarifying that she aims more at a "justification" of the capability concept than at a blueprint for its "implementation" (see FJ 296ff.).

This displays significant flexibility and dynamism. Nonetheless, it cannot satisfy Sen's demand that each and every polis must always be able to opt out of individual points on the list and place quite different ones on the agenda. In my view, this constitutes the decisive difference between both thinkers. In Sen's conceptualization, freedom is quite clearly a good through which the basic capabilities enabling it are transcended and integrated. Contra Nussbaum, Sen does not see this prioritizing of freedom above its conditions of realization as a weakness of his theory, but rather as its particular strength. Hence the radical procedurality of his approach: The procedural freedom defining the concrete freedoms established by a community indispensably belongs to the idea of freedom. And that in turn explains why Amartya Sen partout does not write up a definitive list of inviolable basic capabilities.

It is from methodological as well as material considerations, therefore, that Sen refuses Nussbaum's attempt "to move on relentlessly until one [...] arrives at exactly one interpretation of the metaphysics of value" (CWB 48). Methodologically much speaks against deciding questions of value before "an agreement is reached on the choice of an evaluative space" (ibid.), i.e. before it is clear who has the right to make decisions or mistakes. And, in Sen's eyes, this systematically antecedent question in 
turn has to be decided democratically, not technocratically. This argument goes hand in hand with the material consideration that freedom of choice surely presents a good in itself - and certainly not only for liberals, but rather also for teleological theorists of "well-being," for, strictly speaking, the "freedom to choose our life can make a significant contribution to our well-being" (IJ 18). Therefore, instead of specifying an absolutely optimal canon of substantial freedoms from an ivory tower, Sen wishes to ensure that citizens themselves can decide this sort of thing. Only the population as a whole is called upon both to determine the procedures by means of which they will negotiate and then settle that issue. Sen believes that both decisions - the procedural decision as well as the substantial decision about the manner and prioritization of substantial freedoms - must ultimately be decided by the people and not by professors.

This indirect access to capability-promotion wishes to ensure that freedom is not reduced to one single good and its maximization, but rather is respected as "an inherently diverse concept" (DF 298). ${ }^{83}$ Sen's idea of freedom allows - even demands - that differences of a social, cultural, political, and institutional nature are inscribed into it. This is why Sen does not demand equality in the actual operationalization of the idea of freedom, but rather that this be entrusted to liberal, i.e. participative procedures. In Sen's conception, that is, the "capability perspective" remains "inescapably pluralist" (DF 76). Sen leaves the concretization of the "capabilities" entirely to the actual political communities (IJ 232). Here, then, lies the parting of the ways between the liberal Aristotelianism of Nussbaum and the Aristotelian liberalism of Sen.

Sen's theory consequently operates (in substance, if not in name) with the distinction, employed within our study, between an (abstractly universal) idea and (concretely situated) concepts of qualitative freedom. Yet precisely for that reason Sen's terminology appears unfortunate. The adjective "substantive" certainly abstracts more important from less significant aspects, and thus passably serves, looked at from a merely lexical angle, to call for a qualitatively differentiated treatment of freedom. But the word is so dangerously close to the word "substantial" as to be potentially confused with it or its meaning. For example, as previously observed, one finds in Nussbaum's critique a description of Sen's position as a theory of "substantial freedoms" (CC 18). Yet, the adjective "substantial" connotes independent attributes enduring throughout change. That is to say, it very precisely highlights what is at issue with the "capabilities approach" for Martha Nussbaum but less so for Amartya Sen: the establishment of a definite core of basic faculties. Formulated differently: Semantically "substantial" is a diametrically opposed concept to "procedural." The whole point of Sen's "substantive freedom" was, however, to assign the procedural moment a central instead of marginal role.

\footnotetext{
${ }^{83}$ In my view, therefore, Nussbaum's objection does not ring true: "Sen sometimes speaks as if all capabilities were valuable zones of freedom and as if the overall social task might be to maximize freedom. He speaks of a 'perspective of freedom' - as if freedom were a general, all-purpose social good of which the valued capabilities were simply instances" (Creating Capabilities, 70).
} 
On this reading, it would probably be more expedient to call the idea of liberty sketched by Sen qualitative freedom and to contrast it with quantitative approaches. The attribute "qualitative," after all, only evokes a general concern for the content of options, yet not certain specific qualities (quiddities). It has, moreover, the connotation of goodness, without the undertone of that being unique and unchangeable (as is, however, suggested by the concept of substance). In short, the expression "qualitative freedom" achieves what, according to Sen, the "capability approach" was meant to provide: insisting upon a meaningful direction of freedom on the one hand without, on the other hand, predetermining it once and for all. "Qualitative freedom" thus appears to me to be both a simpler and more accurate appellation for what Sen means by "substantive freedom."

Be that as it may, in any case Sen's approach entails that liberal economics does not ontologically deal with goods, but rather axiologically negotiates opinions about goods. Its subject matter is not values in themselves, but rather values for us. We are to investigate not the economy, but rather our economic activities in this political community ${ }^{84}$ An economics doing justice to this idea must work with diverse and for the most part incomparable information, and therefore stands in express contradiction to the methodological ideal orientated by the analytic mechanics of the early nineteenth century. ${ }^{85}$ It has to deviate from the aim of an absolute commensurability of all values in favor of a more pragmatic view, and, where necessary, has to exchange abstract precision for concrete relevance. As a consequence, economics should not strive for the status of a discipline with universal and eternal variables and target-figures to the detriment of cultural and historical differences. Rather, economics must learn to perceive the change of societal values and institutions in freedom.

Such a discipline would arrive at the "conceptualization of "needs" (DF 148) democratically, not technocratically. Accordingly, Sen rejects as a "significant mistake" the attempt to see the "capacity approach" as expressing or continuing "methodological individualism" (IJ 244). For this overlooks that individuals constitute themselves in and through society. Social institutions and collectives make up an integral part of the individual's conception of self and of liberty (IJ 246). Instead of atomistic holders of private rights constituting society by negotiating a social contract promoting their respective and unconnected interests, the opposite is the case: Subjects find their identity through social roles and political deliberation; only in and through society do they develop and articulate their personal interests.

The Other is the interpretative horizon of the Self. "Individual freedom is quintessentially a social product" (DF 31). Through the "interactive formation of public perceptions and collaborative comprehension of problems and remedies" the privately-individual sphere and the politically-general realm reciprocally constitute themselves. Hence Sen's theory of freedom culminates in questions concerning how much social justice open societies owe themselves and others. That is to say, Sen's philosophical liberalism requires a cosmopolitan culmination. In the commitment of

\footnotetext{
${ }^{84}$ See Pressman \& Summerfield, The Economic Contributions of Amartya Sen.

${ }^{85}$ See Dierksmeier, "The Freedom-Responsibility Nexus in Management Philosophy."
} 
helping all global citizens to substantial freedom, the idea of freedom rids itself of all false arbitrariness and determines itself in and by global responsibility (IJ 138, 248ff.).

\subsubsection{Cosmopolitan Freedom}

In an increasingly borderless and networked world, ethical theories that only function under the premise of geographical isolation lose plausibility. This is why Sen criticizes Rawls' premise of a "closed society: [...] self-contained and [...] having no relations with other societies [...]" (IJ 151). He counters Rawls' defense of methodological nationalism - as a device supposedly indispensable for concentrating philosophically on the essential - simply with the question, "whether considering ideas and experiences from elsewhere are matters of 'distracting details' that are somehow to be shunned" (IJ 151)? ${ }^{86}$ Would one not rather have to say that whoever lives in a globalized world must also think and act globally?

The undifferentiated universalism of a "gigantic global social contract" (IJ 71) espoused by some of Rawls' disciples is just as unhelpful as globalization-blind nationalism. Sen regards the vision of a world-state established by global social contract as "deeply unrealistic - now or in the foreseeable future" (IJ 140). Sen, that is, rejects globalism just as much as he dismisses local chauvinism, and, in place of both, he strives for a cosmopolitanism open to difference. In place of that golden mean, however, Sen admits, there is thus far, merely a wide lacuna: theoretically and practically (IJ 141). How is it to be filled? Which form of Global Governance should humanity strive for? Based on which philosophy?

Sen has doubts about all philosophizing that is not self-critically situated. Questions of Global Governance are able to be answered neither simply within local parameters nor from a utopian perspective - for instance in the sense of Thomas Nagel's demand for "position independence" through a "view from nowhere." 87 Sen declares himself rather for a middle way, for a theory of "positional objectivity," which proceeds "person-invariant but position-relative" (IJ 157). This alternative takes account of the relativity of the respective standpoint in historical time and cultural space, without taking it to the extreme of an ethical relativism. Although through their integration in roles, geographical locations, and physical conditions, people will never be able to gain an absolute, ultimate perception of the world, Sen believes a sufficiently nonpartisan thinking for all practical purposes is well within reach. Positionality must be distinguished from partisanship; conditionality must be differentiated from arbitrariness. The latter always ruins fair judgments, but the former does not. ${ }^{88}$

Quite the opposite: Sometimes it is precisely concrete positions (cultural regions, climatic zones) and stations in life (parenthood, offices, roles, etc.) which make us

\footnotetext{
${ }^{86}$ See also Rawls, Political Liberalism, 12.

${ }^{87}$ See Thomas Nagel, The View from Nowhere (New York, 1986), 5.

${ }^{88}$ See Streeten, Amartya Sen, Rationality and Freedom.
} 
perceptive and competent for certain questions. One has thus to differentiate between legitimate (nonpartisan and general) and illegitimate (privately contingent) influences upon our value-judgments. The former survive the critical challenge of reciprocity and generalizability tests, whereas the latter do not. Schematic universalism overlooks the former; ethical relativism ignores the latter (RF 469-471). A self-critically liberal reason will therefore plead for a kind of globalization which does not flatten all local and regional particularities, but rather allows legitimate culturally-specific differentiations (DF 18). ${ }^{89}$

Sen therefore engages his globalization ethics on two fronts: on the one hand against the "identity disregard" of crude universalists, but also, on the other hand, against cliquish communitarians who think that salvation lies in turning their backs on all things global, since they suffer, as he believes, from a "singular affiliation" neurosis (IV 20). Their models tend to bleach the colorfulness of human life "in a single-minded celebration of only one community" (IV 38). Yet people are "diversely different" (IV XIV); they distinguish themselves according to religion, career, sex, taste, political convictions, hobbies, etc. That is why the human lifeworld is also "diversely divisive" and the classification of the "global population into distinct "nations' or 'peoples"' (IJ 141) is neither the only one possible, nor the most important category for our thinking about global affairs. ${ }^{90}$ The philosophy of freedom must not reduce the global attachments of peoples only to one single - national or religious - affiliation. It ought to remain open to multiple roles and dynamic identities.

One should not, like "many communitarian thinkers," consider cultural and religious identity to be static, "as if it were a purely natural phenomenon" (ibid.). Instead, Sen stresses the dynamic malleability of our "different affiliations and associations" (IV 5). Our passport is not our destiny, our nationality is not our vocation, for "the preservation of something with which a person is stamped, simply because of birth, can hardly be, in itself, an exercise of freedom" (IV 116f.). People are not firmly stuck in their cultures and contexts like sausages in their skin, but rather encounter "choices that continue to exist in any encumbered position one happens to occupy" (IV 35). To the idea of freedom there also belongs the dimension of a "cultural liberty [...] to preserve or to change our priorities" (IV 113). That means: The value of cultural differences results from an (affirmative or negative) evaluation on the part of cultural freedom and not vice versa (IV 116). Because of this cultural liberty, we should reject any form of diversity that can only be secured against the freedom to question the "cogency and relevance" of particular identities (IV 4). Difference does not have dignity in itself; rather the dignity of human freedom bestows value on difference.

\footnotetext{
${ }^{89}$ In this connection Sen approvingly quotes the pleas for reasonably justified differences in Bernard Arthur Owen Williams, Ethics and the Limits of Philosophy (Cambridge, MA, 1985), 133 and John Gray, Two Faces of Liberalism (New York, 2000), 139.

${ }^{90}$ See also David A. Crocker, Ethics of Global Development: Agency, Capability and Deliberative Democracy (Cambridge \& New York, 2008); Kwame Anthony Appiah, "Sen's Identities" in Kaushik Basu \& Ravi Kanbur (eds.), Arguments for a Better World: Essays in Honor of Amartya Sen, vol.1 (Oxford \& New York, 2009), 488.
} 
Strictly speaking, therefore, cultural relativism contradicts itself (RF 477). In every society there are eventually "dissenters," "skeptics," and "minorities" (RF 476). Whose cultural specificity does the cultural relativist advise us to respect, that of the majority or that of the minorities? Which freedom is decisive, the dominating or the dissenting one? Whoever does not simply want to battle on the side of supremacy must make sure that the tolerance to let the other be other does not transform itself into indolence in the face of their possible intolerance against a third (RF 477). If cultural relativism is prepared to become a tolerance of militant intolerance, it sins against precisely that cultural freedom it promises to defend. Outright skepticism against all "global ideas (such as democracy and personal liberty)" as supposedly purely Western creations gets us nowhere (IV 89). A turn from the idea of universal human rights, i.e. of rights, which precisely address not the regional-particular aspects but rather the transpersonal-universal side of human existence (IJ 143), gives expression to the very intellectual provinciality and partiality the cultural relativists sought to evade. For the universality of human rights arises from the personality and not the particularity of individuals serving as the basis for their rights.

For this reason, too, Sen pits a cultural history of his own against narratives about an alleged schism between Asian and European, i.e. Eastern and Western values (IJ 227f.). ${ }^{91}$ "Valuing liberty or defending public reasoning" is not "exclusively "Western"” (IV 84). In a penetrating excursion through intellectual history, Sen shows that both values are rather "part of our global past" (IV 84). Instead of succumbing to the "temptation of solitary identities and priorities" and - from this point of departure - musing about a "clash of civilizations" (IV 99), one should rather extricate oneself from this homespun 'intellectual straitjacket' (IV 11). Otherwise one stands to advance the social entrenchments of such rubrics and the antagonisms they feed on (IV 27). Reductionism in the airy heights of philosophy can thus aid and abet violent demarcations in the political lowlands (IV XVI). For "theories of civilizational clash" - unintentionally perhaps, but no less effectively still - do the preliminary work for those who have an interest in "cultural bigotry and political tyranny" (IV 105). When academic theories provide ammunition for world-views charged with resentment, they share in the guilt of those who extract ideological ammunition from them. Hence the "extraordinary naiveté" of monolithic cultural associations "must at once come to an end" in a world of obviously plural affiliations (IV 175).

Sen opposes all provinciality of thinking with a plea for its planetary expansion. In step with the growing worldwide commerce and encounters, we should strive for a globalization of the mind (IV 99) and our sense of justice (IV147). Sen does not tire, therefore to take ethical relativism to task, denouncing it, not only theoretically, as the "lazy resolution" of a reason in decline (IJ X), but also for being practically dangerous. The fatalism of cultural relativism weakens our sense for our duties to humanity and thus ushers in a spurious self-righteousness: For instance, starving people are not free. It is cynical to interpret their situation as an expression of cultural

\footnotetext{
${ }^{91}$ See Emanuela Fornari, Modernity Out of Joint: Global Democracy and Asian Values in Jürgen Habermas and Amartya K. Sen (Aurora, Colorado, 2007).
} 
specificity (RF 88). Instead of construing poverty as a form of cultural selfdetermination, its systematic causes - deficiencies in structural justice and the failure of global institutions - must be fought.

The impoverished of this world seldom get to taste the carrot of a deregulation of financial markets, but they are familiar with the stick of wildly fluctuating speculation (IV 139-141).$^{92}$ Here lies the decisive problem to be solved, according to Sen. And it would be hypocritical to hide behind the argument that, through the past course of globalization, the poor would still economically be better off now than they were before. Whereas authors like Thomas Pogge question the empirical premises of this argument based on sound statistical analyses, ${ }^{93}$ Sen criticizes its logic. What is at issue is not whether globalized collaboration brings about better results than economic isolation. The decisive question is rather whether, from all the extant possibilities for global cooperation, those most appropriate for the poorest have been chosen (IV 135). And since the answer to that is an embarrassed No, one may in no way content oneself with the status quo:

The consideration on which many of the debates on globalization have concentrated, to wit, whether the poor too benefit from the established economic order, is an entirely inadequate focus for assessing what has to be assessed. What must be asked instead is whether they can feasibly get a better - and fairer - deal with less disparities of economic, social, and political opportunities, and if so, through what international and domestic rearrangements this could be brought about. This is where the engagement lies. (IV 136)

A truly consistent philosophy of freedom thus leads to the mandate to work for fairer conditions of Global Governance. According to Sen, this does not require a world-state but certainly a thoroughgoing reform of our global institutions (IV 184). So that on the global level the "vexation without representation" comes to an end, we must follow up on economic globalization with a political globalization, reckons Sen. In particular, an honest democratization of the global decision-making bodies is called for (IJ 139). That demand goes along with the hope that, in the future, under more favorable geopolitical auspices, global citizens will enter into firmer legal connections with one another. ${ }^{94}$ But at any rate, even within the context of the current institutional global governance structures, we must do everything possible

\footnotetext{
${ }^{92}$ See Nevile, Amartya Sen and Social Exclusion; David B. Grusky, S. M. Ravi Kanbur \& Amartya Sen, Poverty and Inequality (Stanford, CA, 2006).

${ }^{93}$ See Thomas Pogge (ed.), Freedom from Poverty as a Human Right: Who Owes What to the Very Poor? (New York, Oxford \& Paris, 2007). Pogge shows that intentional or unintentional erroneous assessments as well as unjustified changes in assessment standards (undertaken over time) has led to an incorrect, disproportionately positive presentation of the development of global poverty in the last decades; see also: Brighouse \& Robeyns, Measuring Justice.

${ }^{94}$ In his publications, Sen is very cautious about questions concerning a possible future global government. In a personal conversation (in summer 2008), he nevertheless revealed a preference for the ideas of a democratically constituted global government operating federally and subsidiary, but at the same time laid down that it is currently more prudent to only speak in favor of more global governance instead of a global government, for: (1) one thus concentrates upon something achievable and (2) one would endanger such achievable advances in regard to more global governance with a too open advocacy of the idea of global government, thus inviting conceivable fears of a global Moloch.
} 
to make a life in substantive freedom possible for every person upon this earth (IV 136). And Sen declares this the responsibility of absolutely all (individuals, institutions, states) that can help - unilaterally, simply since and inasmuch they can. No one may argue their way out of this duty to humanity. ${ }^{95}$

Sen finds it intolerable that we live in a world in which "unprecedented opulence" and "remarkable deprivation, destitution and oppression" exist side by side (DF XI). With "constructive impatience" he observes how we do not make full use of our technical and political possibilities to alleviate human suffering (DF 11). Worldwide misery is not the fault of globalization itself, though, but rather due to its mismanagement (IV 121). And the latter is, according to Sen, not least the result of misunderstandings about the meaning and end of economic activity. We ought to exchange our material concepts of well-being for conceptions directed towards the substantial freedom of all people. " 96 "Freedom - rather than well-being" must assume the "foundational role" (RF 9) in socioeconomic philosophy.

The individual and institutional demands of freedom must be brought into a cosmopolitan balance so that the freedom of one does not hinder - but rather promotes - the liberation of the other. Although, or perhaps precisely because, freedom is universally desired and experienced (DF 118), one cannot, therefore, simply like in the case of the "Washington Consensus" - globalize one particular concept

\footnotetext{
${ }^{95}$ What this means in practice becomes clear(er) in the work of Martha Nussbaum. Worldwide people vote with their feet against their respective political and economic systems and direct their hopes upon the global community. "One of the things people themselves might want out of international relations is help in overthrowing an unjust regime, or winning full inclusion in one that excludes them" (FJ 234). We should therefore not let a false relativism delude us into believing that we only have moral obligations towards our fellow citizens. Streams of refugees compel the affluent world to adopt a cosmopolitan perspective. One cannot practically treat them with fairness without being theoretically fair to their human rights. For Nussbaum that entails renouncing the naïve belief (fueled by Rawls among others) that every nation is the architect of its own well-being. For even when states continue to strive for good governance, they are not always successful. Other forces contribute towards their destiny. "The global economic order and the disadvantages it imposes upon poorer nations" (FJ 262), for instance, are to be born in mind, according to Nussbaum. Global trade federations and the powers standing behind them change and curtail the possibilities of national politics. Thus even states adequately governed on the inside, when from the outside afflicted by severe economic disadvantages, may fail to provide their citizens with sufficient chances to flourish economically. In addition, there is the influence of powerful "multinational corporations" (FJ 225), whose logistic and financial power outranks many state institutions, without being subject to procedures of political legitimation. On a global scale, therefore, the contractualist hypothesis that an intelligent striving of all nations for their "mutual advantage" alone will suffice to bring about acceptable socioeconomic conditions for all world citizens thus fails (FJ 270). Ultimately some states are "just too poor for the richer nations to gain anything from treating them as rough equals" (FJ 249). But what should the global community do with societies which - observed from a purely economic perspective - appear as a "drag on the whole system?" She agrees with Sen about the fact that "different principles will have to be chosen to deal with them" (FJ 249). Instead of reciprocal advantage, the principle of global justice should be found in mutual recognition, "human fellowship and human respect" (FJ 270).

${ }^{96}$ See George Mavrotas, Anthony F. Shorrocks and World Institute for Development Economics Research, Advancing Development: Core Themes in Global Economics (Basingstoke \& New York, 2007).
} 
of freedom and mold all local politics in its image. If one does not wish to circumvent methodologically the core concerns of liberal thinking, then one must rather always keep in mind that "freedom is an irreducibly plural concept" (RF 585). As much as consistent liberalism requires a theory of those "capabilities," the presence or lack of which indicates the degree of substantive freedom a person can access, just as little may said theory be simply decreed top-down. It is essential that the "capabilities" in question are determined by citizens' democratic will - and not from the lectern. And with this turn, Sen's approach subjects itself to precisely that reflexive recursivity it demands of others. Sen's theory thus survives its critical selfapplication and thereby, in form as well as substance, conclusively lives up to its claim to be a philosophy of and for freedom.

\subsection{Results and Implications}

Whereas the previous studies of Hayek and Rawls showed that philosophies based on models of quantitative freedom are insufficient and necessarily drift into qualitative distinctions, Galbraith and Sen demonstrate how a modern theory of qualitative freedom can be brought into being. Both focus upon the social lifeworld: People are dependent upon the help and support of their fellows. Their freedom requires sociality in ideal as well as in material dimensions: ideally, in order to ascertain what are the true needs and interests of human life - and materially, in order to fulfill these. Whereas quantitatively orientated freedom aims to maximize autonomy (Selbstbestimmung) and minimize heteronomy (Fremdbestimmung), qualitative freedom sets out to optimize personal autonomy through social co-determination (Mitbestimmung). It views others and society as spheres rather than limitations of individual freedom. It reads the world of societal coordination as the eulogy of socially mediated freedom, and not as an elegy about conditions of unavoidable coercion.

Galbraith and Sen insist upon a just differentiation of personal and political freedom; from this angle, they develop their critique of prevailing neoliberal fashions in economics and politics as well as of the libertarian models in economic and political theory that buttress them. Galbraith and Sen demonstrate that our practices are always already both construed and polarized by theories of freedom. Both stress that our socioeconomic realities are not natural constants but vary under the direct influence of individual as well as institutional liberties, and thereby, indirectly, also from the various theories of freedom determining these. For this reason, it would be too simplistic merely to thematize distributive conflicts between factual instantiations of freedom. Rather, counterfactual considerations must also be factored in: We need to ask, for example, which alternative freedoms are thwarted by the current economic and political status quo and which alternative conceptions of freedom are blocked by the intellectual status quo. 
Communitarianism and feminism formulate similar objections against the quantitative paradigm of liberal theory. As expressions of the philosophy of the present, which take kindly to the idea of freedom while being critical of modern liberalism, they too are informative for our project. Both camps criticize liberalism for soaring into the airy heights of conceptual abstraction, far beyond the specific concerns of the subjects it affects. According to a typical objection, liberal politics often disregards the concrete lifeworlds of those individuals whose freedom it supposedly furthers. ${ }^{97}$ If regional ways of life, the cultural practices of traditional communities, as well as certain behavioral patterns colored by, e.g. gender roles, are illuminated in the cold light of a merely functional, quantitatively maximizing rationality, then what follows? Does not such abstraction, with its chilly cost-benefit analyses, shock-freeze the fluid support of personal freedom and social autonomy (like, for instance, through "care" and "community") ordinarily provided in socially embedded forms of life?

Such concerns mostly attach to the homo oeconomicus-theorem, the central figure of quantitatively orientated theories like game-theory and contractualism: According to feminist critique, under the cover of value-free science, this model of a rational utility-maximizer encourages behavioral expectations along a certain, selfish line. ${ }^{98}$ Conversely, it brands socially directed behavior as a "moral failure," 99 for instance, by depreciating "participation in nonreciprocal relationships; low privacy needs; a greater willingness to seek the approval of the group, [...] and irrationality (defined as a failure to seek utility maximization; in other words, extraordinary and even ordinary acts of altruism and benevolence)." ${ }^{100}$ Feminists therefore support the thesis that the homo oeconomicus-doctrine impedes women's self-assertion "with their unchosen dependency relationships with children and others in need, their alleged proclivity towards moral decisions based on partial and contextual grounds, their putative lack of respect for rights in the face of needs, and their supposed tendency to define identity through relationships with others rather than through the values of separation and self-realization."101

\footnotetext{
${ }^{97}$ See Debra Satz \& Rob Reich (eds.), Toward a Humanist Justice: The Political Philosophy of Susan Moller Okin (Oxford \& New York, 2009); Onora O'Neill, “Justice, Gender, and International Boundaries" in Pablo Greiff \& Ciaran Cronin (eds.), Global Justice and Transnational Politics: Essays on the Moral and Political Challenges of Globalization (Cambridge, MA, 2002), 303-323.

${ }^{98}$ See the debate in Ann E. Cudd \& Nancy Holmstrom, Capitalism: For and Against (Cambridge, 2011).

${ }^{99}$ See Riane Eisler \& Daniel Loye, “The 'Failure' of Liberalism: A Reassessment of Ideology from a New Feminine-Masculine Perspective," Political Psychology 4:2 (1983), 375-391 for further evidence.

${ }^{100}$ See Lisa Cohen Elliot D. Hill, "Homo Economicus, Different Voices, and the Liberal Psyche," International Journal of Applied Philosophy 13:1 (1999), 21-46.

${ }^{101}$ Ibid.
} 
Yet, according to the critique, in quantitative thinking, men also would be locked into clockwork behavioral patterns through stereotypical role-models. ${ }^{102}$ For, in a society directed by this model all who do not comply with the maximization imperative will ultimately have access to fewer resources; and according the logic of the model of inherent self-interest, they will then also have to blame themselves for this outcome to boot. ${ }^{103}$ Whether people do not want to conform to that rationality or whether they are not able to conform to it, the logic of selfish maximization - even where tempered by the welfare state - in effect disadvantages them just the same.

For those unable to play along, it is in no way simply a question of physical disabilities. Mind and character also be factored in. Industriousness does not fall from the heavens but is rather acquired upon earth. Its cultivation depends upon social and cultural preconditions among other things, to which not everyone has the same access. Not only ability but also attitude is in large part a cultural construct. Theories suppressing cultural contexts consequently invite a misreading of socially construed distinctions, together with the privileges and discriminations they entail, as but natural delimitations. Thanks to this blunder, inequality easily acquires a Social Darwinist alibi - according to the motto: "The secret of success is hard work!" When deliberately ignoring, though, that in a deregulated market-driven society not everyone is equipped and positioned to deliver such hard work, the fact becomes obfuscated that therefore people do not always deserve what they earn. Economic liberalism thus fails its very own ideal of meritocracy. ${ }^{104}$

The systematic reason for these distorted outcomes lies in the matrix of quantitative thinking. For quantitative freedom aspires towards the maximal realization of subjective preferences, i.e. the minimization of their restrictions; and those preferences are viewed as naturally given. But that is short-sighted according to communitarians and feminists. ${ }^{105}$ What applies, for example, if a person's preferences have been developed under oppressive conditions? A woman born into a culture that degrades her, so that after decades of socialization she reacts to maltreatment with servility, may perceive her situation as hopeless, perhaps even as just. ${ }^{106}$ Even if (for instance, through a move into a society which fosters equality) there is a change in her physical options (in the sense of quantitative freedom) for an emanci-

\footnotetext{
${ }^{102}$ See also Okin \& Mansbridge, Feminism; Martha Fineman \& Terence Dougherty, Feminism Confronts Homo Economicus: Gender, Law and Society (Ithaca, NY, 2005).

${ }^{103}$ See Jennifer Chan, "Between Efficiency, Capability and Recognition: Competing Epistemes in Global Governance Reforms," Comparative Education 43:3 (2007), 359-376.

${ }^{104}$ See Herzog, Freedom gehört nicht nur den Reichen.

${ }^{105}$ See Nancy J. Hirschmann, The Subject of Liberty: Toward a Feminist Theory of Freedom (Princeton, NJ, 2003), $236 \mathrm{f}$.

${ }^{106}$ For the discussion about "adaptive preferences" forced by Sen and Nussbaum see Ann E. Cudd, "Oppression by Choice," Journal of Social Philosophy 25 (2005), 20-49 and Serene J. Khader, Adaptive Preferences and Women's Empowerment (Oxford, 2011).
} 
pated life, she may not necessarily realize, theoretically or practically, the (qualitative) freedom to use these increased options.

Communitarians argue likewise: What applies if the individual's preferences are characterized by corrupt contexts, e.g. in an unlawful state like that of the Third Reich? Are such preferences to be respected in the same way as those developed in a community characterized by mutual respect and responsibility? Are both types to be measured as quantitatively equal? Or is one not forced to switch to a logic that can qualitatively differentiate between the formative conditions of subjective preferences (for example, as helping or hindering autonomy). ${ }^{107}$

That at least is the argument of the American philosopher, Joseph Raz, who evaluates freedom according to its contribution to the development of reasonable selfdetermination. ${ }^{108}$ Against the assumption of a normatively empty world - prevailing in quantitative models of freedom - into which our choices alone first inscribe values, Raz proposes that the "ability to respond appropriately to (perceived) normative aspects of the world" essentially belongs to freedom. ${ }^{109}$ Freedom does not flourish by unleashing individualist caprice, but by acting appropriately to the situation, and responding justly to the respective 'nature of things.' The latter statements are as metaphysically intended as they are worded. Yet that should not startle us; these arguments were not formulated as policy papers, but rather as philosophical contributions to the civil discourse concerning their shared freedoms. According to Raz, government ultimately cannot and should not decide which options are "valuable or valueless." ${ }^{110}$ For that it usually lacks the competence and always lacks the legitimacy. It is rather incumbent on society to lead a pluralistic debate from which the government can learn which forms of public life more than others strengthen the cultivation of individual and institutional autonomy.

At times, after all, it is precisely state coercion and interference with individual freedom which grants citizens genuine liberty for "some options one is better off not having." 111 Also the deselection of unwanted possibilities contributes to personal and political autonomy and its development. The polis has little reason "to provide, nor any reason to protect, worthless let alone bad options," if these do not make anyone capable of autonomy (ibid.). For that reason, philosophical liberalism must give up its "blind obsession with the avoidance of coercion" (ibid.) as well as the quantitative fixation on a content-neutral maximization of options. State action on behalf of cultural and regulatory frameworks must obviously respect the freedom and autonomy of the individuals they are to foster. Raz therefore limits the state's activity to securing the "background conditions which enable a person to be autono-

\footnotetext{
${ }^{107}$ See Christman, Saving Positive Freedom.

${ }^{108}$ See Raz, Morality, 407ff.

${ }^{109}$ See Raz, Engaging Reason: On the Theory of Value and Action (Oxford \& New York, 1999), 77.

${ }^{110}$ Raz, Morality, 410.

${ }^{111}$ Raz, Morality, ibid.
} 
mous." Since these are of an intellectual and cultural, pedagogical and medicinal, as well as social and material nature the state must, however, many a time be active "far beyond the negative duties of non-interference." "In this respect, government's role on behalf of freedom is definitely "extensive and important," while in all cases "confined to maintaining framework conditions conducive to pluralism and autonomy" (ibid.).

Such liberalism based on qualitative distinctions leads neither to a conception of a minimal state nor to the vision of maximal statehood. These quantitative specifications rather take a backseat in favor of the qualitative deliberation concerning the extent of the citizens' consensus about their obligations to one another and to the common good. The state should promote individual autonomy only by measures already endorsed by "a large measure of social consensus." Whoever has freedom as a goal must desist from using "coercive and of greatly conforming measures" as a means, and thus find "gentler measures," according to Raz (ibid.). Citizens with a zest for political change thus ought to develop a theory of non-coercive forms of motivation and recognition, graduated according to the intensity and relevance of the freedoms respectively to be promoted; something already demanded by Kant (Sect. 2.1.4) and Krause (Sect. 2.3.4) as the culmination of liberal political culture.

Qualitative liberalism is both sensitized to and reliant on the assimilation of contextual differences. As a result, it can treat traditional forms of culture and ethical communities in a rather relaxed fashion. A qualitative conception of freedom must not per se combat communitarian limitations of individual agency. Some of them it can affirm - in the form of voluntary qualifications. To quantitative liberalism, though, this sort of thing is anathema. Objections from virtue ethicists and advocates of the common good are devalued in most cases as but expressions of misplaced sensitivities or even as narrow-minded attempts to blunt the edge of the sword of universalism. But this misjudges the liberal concerns articulated in that critique. As we had learned from Kant, freedom consists quite centrally also in evaluating and transforming one's own preferences (see Sect. 2.1.1).

To repeat: Not only first-order preferences, but also their transformation by second-order preferences, belong to freedom. Therefore we also have to recognize as a genuine object of liberal thinking the social and cultural contexts among which such reflexive appeals as well as the capacity for self-criticism and self-control are shaped. ${ }^{113}$ But wherever the inner freedom for self-legislation becomes a theme, its descriptive chronicling inevitably also involves prescriptive elements. In order to correctly describe freedom, we must understand what we always already prescribe to ourselves in the name of freedom. Ultimately, the actuality of freedom can only

\footnotetext{
${ }^{112}$ All following quotes from Raz, ibid. 407-429.

${ }^{113}$ See Dworkin, The Theory and Practice of Autonomy, 15.
} 
be conceived of from culturally mediated normative goals. Our ideals belong to the reality of our freedom.

Whereas the model of quantitative freedom arises from a freedom appealing to independence and indifference, which can isolate itself from social, moral, or religious commitments at discretion, ${ }^{114}$ from the perspective of qualitative freedom, autonomy can also be spotted in dependent as well as interdependent lifecircumstances. ${ }^{115}$ That makes a huge practical difference. Questions concerning a liberal formation of life-circumstances can consequently no longer be answered by the simple qualitative equation: more independence $=$ less dependence $=$ more freedom. They rather demand a qualitative answer regarding which forms of dependence and interdependence most aptly promote our autonomy. Some directives may curtail permissiveness and yet thereby enable freedom by catering to the integrity of our civilization as well as the values and virtues supporting it.

The philosophy of qualitative freedom, consequently, better captures the phenomenon of religious dedication. Instead of a purely quantitative and entirely exterior observation of the options of religious people, the theory of qualitative freedom takes seriously the phenomenon of religious self-commitment. Moreover, it views the religious urge towards "responsible freedom" as a valuable ally. ${ }^{116}$ People conceiving of freedom as a gift from above perhaps tend less to measure the value and being of freedom solely with the calculi of utility-maximization ${ }^{117}$ and might find themselves ready to promote the freedom of others wherever possible, even when and where this appears detrimental to their own self-interest. ${ }^{118}$ And whoever thus conceives of freedom as an obligating mission may wish to help others attain the same kind of freedom, as illustrated by the example of Latin American liberation theology. ${ }^{119}$

\footnotetext{
${ }^{114}$ See Christman, Saving Positive Freedom, 123 \& 143.

${ }^{115}$ See O'Neill, Autonomy, Coherence, and Independence, 212-221, especially 220.

${ }^{116}$ See Benedict XVI, Charity in Truth - Caritas In Veritate: Encyclical Letter (San Francisco, 2009).

${ }^{117}$ See Karl Rahner, Freiheit und Manipulation in Gesellschaft und Kirche (München, 1970).

${ }^{118}$ See Karl Lehmann, Frei vor Gott: Glauben in öffentlicher Verantwortung (Freiburg i.Br.), 2003.

${ }^{119}$ Departing from the works of Thomas Aquinas (1225-1274), who appealed to the reasonable capability of all human beings, even non-believers and those of other faiths, at the beginning of the sixteenth century the theologians of the "Escuela de Salamanca" developed a cosmopolitan philosophy and globalization ethics with a view to indigenous peoples. The writing of Francisco de Vitoria (1483-1546) and Domingo de Soto (1494-1560) were above all decisive for further theory development. Vitoria defended the political freedom and autonomy of the Latin American population (Francisco de Vitoria, Luciano Pereña \& C. Baciero, Relectio De indis. Carta Magna de los Indios: 450 aniversario, 1539-1989 [Madrid, 1989]); de Soto also addressed questions of personal property and of economic freedom (Domingo de Soto \& Venancio Diego Carro, De Iustitia et lure [De la justicia Frontiydel derecho] [Madrid, 1967]). Their writings first served as the foundation of a critique of political suppression and economic exploitation of the native population. Bartolomé de las Casas (1484-1566) and Alonso de la Vera Cruz (1507-1548), who both campaigned against colonial injustice and for the right to liberal self-determination of the Latin Americans with philosophical as
} 
Moreover, when resolving societal problems and conflicts of interest, a spiritual hermeneutic often turns out to be a helpful heuristic device even for secular problems. For since religious conceptions of self and world often declare even the furthest to be the nearest and treat the whole world with a respect grounded by a theory of being or creation, they have already for a long time anticipated the present cosmopolitan extension of our perspectives compelled by globalized economic relations and environmental crises. Even politics committed to ideological neutrality can derive inspiration from the spiritual answers to questions about the orientation of human life. ${ }^{120}$

Meanwhile, qualitative liberalism adopts a critical stance whenever opportunities are canceled for supposedly religious reasons. Religious communities must, for instance, tolerate divergent world-views and forms of life so as not to negate the very freedom they claim for themselves. The perspective of qualitative freedom therefore allows a differentiated treatment of spirituality. While quantitative freedom fosters suspicion of religions in principle since and inasmuch as they reject some options and plead for certain forms of individual or collective self-commitment, qualitative freedom only excludes fundamentalist forces aiming to allow freedom merely for their own message, but not for that of competing denominations and faiths. ${ }^{121}$ Qualitative liberalism does not pose as a secular judge of religious wisdom and belief, but it does examine the procedures of religious decision-making and self-articulation according to their compatibility with society's freedom. Thus religions are, for instance, obligated to respect that people are free to educate themselves and decide about spiritual things for themselves, also and especially where this involves that people inform themselves about alternative - not least, irreligious - world-views, and follow them.

well as political arguments, stand out above all others (see Bartolomé de las Casas, An Account, Much Abbreviated, of the Destruction of the Indies, with Related Texts [Indianapolis, 2003] and Alonso de la Vera Cruz, De dominio infidelium et iusto bello, I-II [Mexico, 2000]). In the twentieth century the liberation movement in Latin America appealed once again to the intellectual heritage of a tradition (theologically) viewing human freedom as a gift from God, i.e. (philosophically) encouraging all persons to employ their own reason and freedom. That is especially true of the writings on liberation theology of Gustavo Gutierrez (Gustavo Gutierrez, A Theology of Liberation: History, Politics, and Salvation [Maryknoll, NY, 1973]) and Ignacio Ellacuria (Ignacio Lee Michael Edward Ellacuria, Ignacio Ellacuria: Essays on History, Liberation, and Salvation [2013]), as well as of the works on liberation pedagogy by Paulo Freire (Paulo Freire \& Antonio Fernandez, Learning to Question: A Pedagogy of Liberation [Geneva, 1989]) and last but not least the liberation philosophy of Enrique Dussel (Enrique D. Dussel, Philosophy of Liberation [Maryknoll, NY, 1985]).

${ }^{120}$ See Guilherme Baraúna \& Viktor Schurr, Die Kirche in der Welt von heute: Untersuchungen und Kommentare zur Pastoralkonstitution "Gaudium et spes" des 2. Vatikanischen Konzils (Salzburg, 1967). There are similar arguments in Jörg Dierken, Selbstbewusstsein individueller Freiheit: Religionstheoretische Erkundungen in protestantischer Perspektive (Tübingen, 2005).

${ }^{121}$ See Claus Dierksmeier, Noumenon Religion. A similar standpoint in championed in Martha Nussbaum, Frontiers of Justice, 182-185. 
Conversely, it belongs to freedom to grant a hearing also to "disparate voices, even those who endorse traditional and authoritarian values." ${ }^{122}$ But where is the limit? Up to what point, does a tolerance of religious forms of life correspond to the ideological neutrality of the state, and when does it contradict it? In terms of a qualitative liberalism, the answer must run: As long as the formation and expression of religious opinions remains free from "hypnotic suggestions, manipulation, coercive persuasion, subliminal influence, etc., we have no reason to maintain that people with spiritual commitments are less free or more in need of protection than atheists and agnostics. ${ }^{123}$ Liberalism's mandate to take care of peaceful plurality in the political sphere is thus not the same as an imperative to secularization. Liberalism has to protect freedom of religion, just as much as it has to protect freedom from religion. The theory of qualitative freedom is, consequently, in harmony with self-enlightened forms of religiosity. ${ }^{124}$ Not only secular but also some spiritual self-conceptions, after all, demand the ideological neutrality of the state: as an expression of a respect for the inviolability of personal convictions. ${ }^{25}$

Quantitative liberalism, on the other hand, lacks an adequate criterion for such a careful demarcation. Quantitative liberalism treats all commitments of a spiritual and traditional kind generally with mistrust. For, strictly speaking, quantitative thinking allows no differentiation in regard to the application of the idea of freedom. More options must be preferred always and everywhere. ${ }^{126}$ But where cultural or religious communities oppose this imperative of maximization with a profile of their own comprising fewer options, sooner or later there will be friction. Qualitative freedom is more liberal. It limits tolerance only in regard to the tolerance of intolerance. It evaluates the use of freedom according to whether and how it protects and increases the disparate but uniform freedoms of others. The criterion for the examination of religious freedom thus concerns whether and how its respective use leads to alternative forms of spirituality being accepted or attacked.

Metaphorically speaking: Quantitative liberalism identifies itself solely with the white light of freedom and spots political opponents in each and all other hues of the

\footnotetext{
${ }^{122}$ See John Philip Christman, The Politics of Persons: Individual Autonomy and Socio-historical Selves (Cambridge \& New York, 2009), 173.

${ }^{123}$ See Dworkin, The Theory and Practice of Autonomy, 19.

${ }^{124}$ See Claus Dierksmeier, "Bundesrepublikanisches Staatskirchenrecht aus kantische Perspektive," Rechtstheorie - Zeitschrift für Logik und Juristische Methodenlehre, Rechtsinformatik, Kommunikationsforschung, Normen- und Handlungstheorie, Soziologie und Philosophie des Rechts 30:1 (1999), 110-112.

${ }^{125}$ See Jon Kabat-Zinn and Richard Davidson, The Mind's Own Physician: A Scientific Dialogue with the Dalai Lama on the Healing Power of Meditation (Oakland, 2012); Dierken, Selbstbewusstsein individueller Freiheit.

${ }^{126}$ See Flathman, The Philosophy and Politics of Freedom, 92: "It makes good sense to talk of more and less freedom, but the notion of complete, or full, or perfect freedom is a misunderstanding."
} 
color spectrum. Qualitative liberalism recognizes that these spectral colors are but aspects of the white light of freedom in the prism of everyday specificity and symbols. While quantitative freedom combats the colorfulness which qualitative freedom celebrates, qualitative freedom directs itself merely against the black of fundamentalists.

Open Access This chapter is licensed under the terms of the Creative Commons Attribution 4.0 International License (http://creativecommons.org/licenses/by/4.0/), which permits use, sharing, adaptation, distribution and reproduction in any medium or format, as long as you give appropriate credit to the original author(s) and the source, provide a link to the Creative Commons licence and indicate if changes were made.

The images or other third party material in this chapter are included in the chapter's Creative Commons licence, unless indicated otherwise in a credit line to the material. If material is not included in the chapter's Creative Commons licence and your intended use is not permitted by statutory regulation or exceeds the permitted use, you will need to obtain permission directly from the copyright holder.

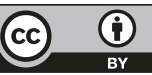




\section{Chapter 5 \\ Conclusion}

Talking about liberalism makes one quite a killjoy these days. Not only liberal politics is met with increasing skepticism, doubts abound also about the philosophy of freedom itself. The political and the philosophical problems are connected. The incapacity of political liberalism to clearly take a position on urgent social and political challenges also has something to do with the confusion about the actual content of the idea of freedom. Since the traditional concepts (especially those of negative versus positive freedom) do not get us any further (see Sect. 1.2), I suggested a new terminology. In my opinion, the distinction between quantitative and qualitative freedom that was developed and tested in the previous chapters provides more conceptual clarity than all previously employed terminologies.

While quantitatively conceived freedom amounts to a "the more, the better" in the choice of options, qualitatively orientated freedom emphasizes, "the better, the more." Quantitative freedom describes a fundamental concern with maximizing, towards the highest possible number or the greatest possible expansion of individual options. The idea of qualitative freedom wishes to sensitize us to the necessary assessment, creation, and alteration of those possibilities: We should especially promote some more than others. While quantitative freedom reflects upon how much freedom to grant the individual, qualitative freedom attends to which freedoms we grant to one another and whose freedom we enable. Metaphorically speaking, quantitative theories of freedom consider freedom to be like a sheet of paper that becomes smaller the more it is shared out to other persons. It seems therefore in individuals' interests to exclude other people from this scarce good in order to increase their own share of it. Qualitative freedom, in contrast, tends to see freedom as a light, the luminosity of which becomes all the more intense, the more persons that it shines upon.

Yet, we are not simply concerned here with conceptualizations, we are also concerned with a new architectonic of liberal thinking that can integrate philosophical liberalism's variant conceptions of freedom. This is achieved by distinguishing divergent concepts of freedom (what a community values and defends as freedoms) from the idea of qualitative freedom (that this concretization is instantiated). Since 
the idea of qualitative freedom can combine structural equality with substantive diversity in the concepts of freedom, the liberalism underpinned by it is able to maintain the unity of its principle alongside plurality in the manifestations.

Both can be safeguarded when in our reflection upon freedom we sharply differentiate between a contribution from philosophers to the idea of freedom and what emerges from the discourse of citizens as to the concepts - conceptions and programs - of freedom. This differentiation should especially be observed in questions concerning the practical consequences of liberal theory. It makes an important difference whether authors (at the level of the polity) employ philosophical reflections when addressing constitutional or procedural questions, or whether, against the background of such considerations, they express themselves as citizens in questions of political programs (policy) and processes (politics). The former allows more certainty and precision; the latter rather demands concreteness and realism. I maintain that a decisive advantage of my theory over and above earlier schemes is that it enables and defends this differentiation. It can thus prevent political differences leading to philosophical oppositions and vice versa.

The house of freedom has many rooms; the liberal idea can offer a home to various liberalisms. Consequently, divergent kinds of liberal thinking that have arisen at different points in history or in different cultures should not be pitted against one another but should rather be reconciled by means of their shared fundamental concern. I wish accordingly to expressly draw attention here to the different voices I use in the following. While, next, in the review of the previously reconstructed theories (Sect. 5.1) I systematize the scholarly results of this investigation, afterwards I will speak less as an academic philosopher and more as a citizen and global citizen. By inspecting the current problems in economics and politics (Sect. 5.2) as well as also in giving a prospectus of future discussions of a cosmopolitan nature (Sect. 5.3), I express my own liberal convictions.

This change from the earlier monochrome prose of philosophy towards the vernacular of multicolored life occurs in order to emphasize the practical relevance of the previous studies and to encourage interest in the previously studied mental models. To facilitate the coloration of the academically grey constructions of the philosophy of freedom, I will insert my own economic, ethical, and political views into the theoretical frameworks prepared here; not to impose them or to trigger political reflexes, but rather in order to stimulate philosophical reflections about political and economic affairs.

\subsection{Review}

In order to account for the idea of freedom's universal nature, one must demonstrate its cosmopolitan suitability - not only in the production of those social, economic, as well as ecological and cultural conditions needed to make its global actualization durable, but also in respect of its proceduralization. The globality of freedom demands that all human beings - persons living near and far, present and future 
generations - directly or through representation - participate in the concretization of the idea of freedom: Without participation there is no codetermination, without procedural distinction there is no substantive differentiation of freedom!

For this very reason, discourse about freedom must be open to the values individuals seek in and from freedom. Freedom is an end in itself, but not the only aim of human life. Therefore, in the chapters of this book, we constantly dwelt upon the following questions: How can freedom gain in quality through autonomous commitments and self-imposed boundaries? How can we thus leave behind the schema of a quantitative maximization versus minimization of options to enable a construction of the qualitative optimization of freedom? And how can the thinking of freedom consequently extricate itself from that scale upon which earlier theories constantly moved back and forth between the poles of autonomy and heteronomy, without nevertheless ever reaching a generally satisfying unity of self-determination and codetermination?

For this purpose, Kant's philosophy developed a theory of a self-determining publicity. In a political imperative, which calls for the public self-critique and transformation of political freedom, Kant presents an early defense of reflexive democracy and procedural politics. Kant questions what empowers individuals to participate actively in the public development of societal freedom and to advance a politics of freedom. Thus he bequeathed his successors the challenging task of clarifying the indispensable cultural, pedagogical, and economic conditions citizens require in order to participate in this project of liberal politics.

Kant stresses that freedom entitles and empowers us to be diverse and to manifest the unifying liberal principle differently. The fundamental idea of autonomy encourages the most divergent ways of living. That is, Kant aims for a synthesis of unity and difference: Unity in respect of the structure of freedom; difference in respect of the substantive lifestyles, not predefined by, but certainly able to be evaluated by, the principle of freedom. Our separation between the idea of freedom and its procedural restructuring in diverging concepts is inspired by this distinction. Kant thereby provides a notion of extreme relevance for intercultural questions. His theory can explain and justify human beings obtaining varying understandings of freedom according to context and realizing freedom divergently. For the objectives of his theory to be accomplished, Kant must therefore not depend on turning everyone into a disciple of his very own vision of what makes liberal sociality thrive. That sets him pleasantly apart from many of his intellectual successors.

Fichte wished to improve upon Kant's philosophy of freedom. Philosophy is called upon to deduce also the specific prerequisites needed for a life in freedom, and to dictate to the state how, in the name of true freedom, to realize these - if necessary against citizens' own conceptions of freedom. Fichte's fundamental thought is that freedom requires preconditions. Whoever wants the former must create the latter. For him it is above all a question of rescuing freedom from its devaluation through need and dependency. Fichte recognizes that severely asymmetrical economic conditions can make a mockery of political and cultural freedom, and that liberalism must guard against, not just governmental abuses, but also economic power. Even those who disagree with the concrete conclusions Fichte draws should 
familiarize themselves with this perspective of a socially engaged liberalism. For it is hard to keep the center of the political spectrum in focus when one's left eye is blinded.

At the same time, it is striking that, by campaigning under the banner of freedom, Fichte ends up with an oppressive model of state and politics. Where, therefore, lies the misstep leading from the coherent insight that all freedom has preconditions onto the precipitous path of leftist paternalism? When Fichte deduced, in the most minute details, the tasks and procedures of a model state of freedom, he meant - but did not achieve - merely to draw the socio-philosophical conclusions which Kant's approach overlooked. In the interests of a monolithic metaphysics of freedom, Fichte departed from Kant's distinction between idea and concept of freedom and thus squandered the opportunity of accommodating both unity and difference within liberalism. Whereas metaphysics was the foundation (Grund) of freedom in Kant, for Fichte it is its abyss (Abgrund). In failing to see that one can both defend the structural universality of the idea of freedom and entrust its concrete everyday implementation to the citizens' will, Fichte believes that one must choose between the rational freedom and democratic self-determination - and ultimately sacrifices civil liberties.

In this regard he was followed by Karl Marx (1818-1883) and Friedrich Engels (1820-1895), with political consequences that often let us forget that they themselves also saw their theories as philosophies of freedom. After they - with good reason - rejected every theory only advocating "negative" freedom, they ended up without good reason - on the side of a communist version of "positive" freedom. Even though anyone who today reflects upon the regimes invocating Marx and Engels as their intellectual forefathers hardly ever translates the socialism legitimated by the - rarely authentic - reference to their works into the grammar of liberalism, the philosophical roots of their socialist systems nevertheless lay within the struggle for the freedom of all citizens. As long as we do not understand this and fail to grasp what went wrong here conceptually, we are ill-equipped to resist a repetition of this historical mistake.

These mistakes ultimately result from an insufficiently sophisticated theory of freedom which does not clearly enough distinguish between the principle of freedom and the forms in which it is cashed out. For, ultimately, it is irrelevant whether one thinks of freedom from the left or from the right and loads it with communist or communitarian meaning. What is important is that the step beyond conceptions of "negative" freedom does not come down to simply writing up philosophical wishlists. It is no accident that in most cases conceptions of "positive" freedom fully accord with the societal aims of their respective authors, which are then immunized against all critique and solemnly promulgated as the constitutional objectives of the state. Only when we grasp that this problem is systemic and not merely due to specific authors - namely, a structural deficit in the terminology of "negative" versus "positive" freedom (see Sect. 1.2) - can we systematically obviate it.

The theory of Karl Christian Friedrich Krause (1781-1832), which poses the question about which procedure best does justice politically to the distinction between idea and concept, helps us with precisely this differentiation. Thus Krause also can 
steer clear from Fichte's socialism: Freedom's ends and means must harmonize. Whoever wants freedom should employ coercion only under clearly defined (qualitative) conditions and even then (quantitatively) only as little as possible. Freedom's preconditions are to be established through, not against, the freedom of citizens. Philosophy should not simply force-feed people templates of liberal lives. Freedom must be the method of philosophy. Citizens are consequently raised from passive objects of theory to active participants in the program of a progressively self-determining reflexive freedom. Krause thus completes Kant's fundamental thought that freedom is its own project, and convincingly explains why freedom is directed towards societal aims without itself being completely dissolved within them.

According to Krause, freedom should be both an end in itself and the means to this end. Its superordinate intrinsic value does not exclude, but rather includes, its subordinate instrumental significance; an idea which has returned today, especially in capability-theories (see Sect. 4.2): Capabilities should enable - but not compel functionings. The former find an aim in the latter, but not their raison d'être, which is and remains the freedom of citizens. People should not be coerced into liberal conditions, but rather should bring them about. The innumerable fascinating innovations of Krause's liberalism (like, for example, demands for intergenerational justice, ethics of sustainability, etc.) grow out of this understanding of freedom. As much as is possible, Krause bets on participation and involves citizens directly in the decision-making process concerning them. Wherever this is (still) impossible, for instance in global contexts, he places emphasis upon their indirect participation by means of representation. Active world citizenship is the focal point from which Krause reorients politics, and so he strictly revokes Fichte's nationalism while directing his philosophical liberalism in a decidedly cosmopolitan manner.

The potential of this self-reflexive philosophy of freedom for transforming the lifeworld becomes especially clear when focusing on the development of the concept of property in Kant, Fichte, and Krause. It is no accident that the question concerning the legitimation and limitation of private property provides a decisive key for understanding what type of liberal thinking one is dealing with. Whereas economic liberals enjoy emphasizing how private property enables the freedom of the one, social liberals stress how it often hinders the freedom of the other. Whoever restricts something to themselves typically excludes others from it. It thus makes little sense to declare private property per se as favorable or unfavorable to freedom. One ought to make it neither the embodiment of freedom in a libertarian fashion nor freedom's antipode in a communist fashion. The interesting question rather concerns how one reconciles the competing demands which people make on the assets of this world.

In response to this question, Kant sought to derive the right to property from the right to freedom. Only the human right to freedom is inborn, permanent, and unconditional. Property, on the other hand, is merely one of its many forms and presuppositions. Since freedom is therefore always positioned higher than property it follows that all human beings have an absolute claim to share the world and manifest themselves within it in a protected manner - to some kind of property therefore. However, in all cases human beings only have relative rights to the free use of cer- 
tain properties; rights, that is, which must be placed in relation to the higher-ranking human right of all other global citizens to participate in the world. A world in which the few possess practically everything and the many possess almost nothing would be difficult to justify upon this foundation. In Kant, however, it remains uncertain to what extent, with which means, and by which rules, the political communities may correct the existing property-distribution.

On this issue, Fichte believed that only the state could lawfully establish and legitimate the universal institution of private property as well as particular private possessions. Private property thereby becomes entirely subject to political action. But since, for Fichte, the state does not look at the concrete individuals, but rather respects them as subjects of rights only in their abstract capacity as persons, he allows little room for distinctions within property rights. If only abstract persons, and not this or that concrete human being are considered, then all individuals are equal. If anyone's right to property rests on one and same foundation, then the distribution of property must also be more or less the same, according to Fichte. While the individualist liberalism of the nineteenth century always let the freedom of the poor come to an end at the railings of the rich, Fichte does the precise opposite: for him the poor's right to freedom prevents private riches. Therefore, while Manchester Liberalism sees private property as the bulwark of freedom, for Fichte it is communal property. While the former accepts the social at best as a substitute and safetynet of the private, Fichte defines the private as a derivation and subset of the universal.

Krause seeks a moderate mean between these extremes. The central concern for him is not the quantitative maximization of either individual or collective options but instead the qualitative optimizing of concrete opportunities - for each and everyone. Following Kant, Krause wishes to grant everyone access to freedom through property and usage rights. Yet it is also clear to him that human beings and their lifeworlds are different: The disabled, for example, depend upon assistance in order to live a life of dignified freedom. One may not paint, therefore, all global citizens with a single quantitative brush, but ought to respect the qualitative difference of their respective circumstances. Moreover, the procedural freedom of all, and not a single philosophical doctrine, should define the prerequisites of what makes for a free society. Therefore, political procedures are to be devised and justified which, through legal norms and solidary action, help everyone attain a materially mediated freedom. - Truly everyone? Yes, as the right to property follows from the right to freedom of all persons, its regulation falls, strictly speaking, into the remit of humanity as a whole. Even the most far-reaching political order can, within the reach of its sanctioning powers, introduce only temporary redistributive measures. The ultimate say, though, remains the preserve of a future lawful global community acting with a view to the rights of coming generations. With this argument Krause achieves two things: In local, national, and regional communities one may already reform yesterday's legal conditions in the name of the freedom of all participants, without thereby standing in the way of a future transformation in the name of all affected. 
The philosophies of freedom of Kant, Fichte, and Krause thus examine the opportunities and threats of metaphysical liberalisms encompassing a sphere of questions and concerns bearing upon absolutely all persons. In the face of our largely globalized world, it becomes increasingly clear that this globality of metaphysical constructs signifies a welcome opportunity for contemporary philosophizing. Metaphysical thinking encourages us to transcend narrow spatio-temporal horizons and can open up an intellectual eye for perceiving aspects which often remain hidden to the naked eye. Not nationalism, but cosmopolitanism, is the "default option" of the metaphysics of freedom.

At the same time, metaphysics harbors risks. Fichte's claim to sole representation for the practical realization of freedom highlights how quickly the inclusivity of a metaphysical idea sometimes turns into the exclusivity of a certain style of life and politics. Metaphysics - in the supposed possession of ultimate speculative truths can be misused to devalue alternative perspectives and ward off experimental thinking. And since thinkers like Fichte and Hegel became influential especially through this doctrinaire strand in their thinking, many subsequent philosophers - once the historical and sociological limitations of these doctrines showed - wanted to have nothing more to do with metaphysics.

Yet even open metaphysical projects, like Krause's, unjustifiably fell victim to that critique, which, from 1870 onwards, became increasingly intense. One thus overlooked how metaphysical thinking, in forever transcending the status quo, can make a genuinely liberal contribution. For Krause already illustrated what many later thinkers like Popper and Dewey would stress once again: Metaphysical ideas and falsificationism, philosophical speculation and pragmatic action, can go hand in hand - and thus serve the freedom of all. Instead of establishing our conceptions with recourse to certain speculative presuppositions, metaphysics may also keep these conceptions open to change - in anticipation of as yet uncertain developments. Instead of prohibiting conceptual and practical experiments in the name of a higher reality, metaphysics ought to demand these in the interest of a reality always capable of improvement.

What prevailed in that era, especially in German universities, were however not open, dynamic constellations but closed, static systems of thought. In reaction to them, since the end of the nineteenth century, philosophers tried out mainly three alternatives. First, a pronounced metaphysical - albeit no longer system-bound philosophy (as, for instance, in Nietzsche and Kierkegaard). Second, a radical - yet just as metaphysical - materialism (from, for instance, Feuerbach, Marx, and Lenin). And third, analytical, logical, and empirical approaches. The latter especially have increasingly set the agenda since the beginning of the twentieth century - with patent consequences for the theory of freedom. In the course of this historical development, the obviously social and cultural idea of freedom became increasingly maltreated as though it were but a numerically measurable and algorithmically maximizable entity. The spiritual essence of freedom thus shrank into the contours of physical freedom of movement. Humanistic reflections about the ideality of freedom were replaced with the mechanistic models of materialism. To better understand this new paradigm in the theory of freedom and to analyze the 
immanent problems of its quantitative methodology we have focused upon two thinkers for whom precisely the choice of this methodological guidepost proved to be a programatic pitfall.

Friedrich August von Hayek (1889-1992) personifies a central concern of the quantitative philosophy of freedom: The state should establish a maximum of individual freedom though a minimum of statehood. Since no one can guess the vocation of the other, teleological master plans must be renounced. Hayek thus demands something akin to a life-long learning program for politics, backed by social evolutionism, decentralized flows of information, subsidiary decision-making procedures, federal structures, and the promotion of responsible liberty through the widest possible range of private autonomy: Institutions may not be absolutized, but rather must continually remain transformable and capable of improvement. One should not delude oneself into thinking that people's behavior is ever capable of being predicted once and for all. The same holds for the economy. Hayek demands a modest economic theory and moderate economic policy. The former should not deceive itself into thinking that free economic activity can be captured by mathematical or scientific formulas; the latter ought to dispel the illusion that economic freedom can be mapped out by perfect plans.

Hayek maintains that it is an expression of our ethical vocation, as well as being in our own well-understood self-interest, to politically establish and legally protect an order of free economic competition and of liberal communality. People should only be coerced in predictable ways; if they willfully or recklessly violate the rules coordinating communality laid down by the constitutional state, but not in order to extort a certain good conduct from them. Still, for Hayek, freedom is also always a principle directed to its ethical use. In contrast to the opinions of many libertarians, Hayek calls for the defense of freedom not only against theories which start out with much solidarity pathos and end up suffocating individual spontaneity and selfreliance. It must also, he holds, be defended against approaches which, in the interest of serving egotistically-material concerns, misunderstand the value of freedom as being purely instrumental.

Hayek, therefore, sees himself as more than simply the advocate of the freedom of the rich. In Hayek's philosophy of law, a concept of freedom manifests itself which focuses upon the capacity of all persons to make use of the law and to participate in politics. This is also reflected in Hayek's economic philosophy, which argues that it is incumbent on the state to create the social preconditions for the independent economic activity of all citizens. Both demands nevertheless transcend the ideological content of negative freedom and a purely quantitative theoretical utility calculus. Wherever it appears necessary or desirable to him, Hayek thus reduces the freedom of some in order to optimize the freedom of others. Yet, that contradicts the minimalism of his basic assumptions. That is, in Hayek, qualitative leitmotifs (especially those of Immanuel Kant's philosophy) are directing the show behind the scenes, even though, upon the stage, there is a superficial pretense of the mere quantitative maximization of freedom. In contrast to the still prevailing neoliberal interpretation of Hayek's theory - against which it is not entirely, but in large parts, to be defended - the latter provides in the final analysis, not so much a particularly 
conclusive construction of a quantitative concept of freedom, as, rather (see Sect. 3.1.2), an agreeable, if somewhat unintentional, contribution to its deconstruction.

John Rawls (1921-2002) also has an ambiguous relationship with Immanuel Kant. He wanted to inherit some of the contents, but not the methodology, of Kant's doctrine of freedom. In order to avoid metaphysical arguments, he attempted to legitimate his qualitatively pursued boundaries of private freedom with quantitatively directed utility-calculi. Nevertheless, Rawls' critics soon informed him that his Theory of Justice still made extensive use of a series of unacknowledged metaphysical assumptions. In his later works, he thus aimed at presenting a justification for the liberal social order entirely free of metaphysics. That required renouncing any and all substantial directives concerning the nature and vocation of man. Yet, at the same time, Rawls did not wish to end up jeopardizing the tolerant, open society he envisaged. He therefore employed certain procedural rules in an attempt to condition the choices made by the persons deliberating on the social contract. He curbed the citizens' rational exchange logic in such a manner that eventually, from their negotiations about the political framework, only ethically acceptable results could turn out to be formally admissible.

This trick of smuggling in content-related qualifications through procedural framework-directives is of course already questionable in and of itself. Furthermore, it only works for as long as the contractual parties stand together in constant reciprocal relationships. Prudent utility-maximizers engage in fair negotiating conditions only if they themselves also occasionally require such conditions. Everything therefore depends upon an approximate symmetry of the cost-benefit potentials between those involved in the exchange. Severely asymmetrically situated subjects - for instance future generations or severly disable people - are, despite Rawls' countervailing attempts, not convincingly given a chance within such agreements; their interests can therefore be neglected with impunity. Yet that runs counter to the gist of Rawls' universally-liberal concerns.

Rawls undermines the binding force of his own Political Liberalism with the attempt to rid himself of all substantial foundations - even those from the philosophy of freedom. Within already liberally constituted societies, Rawls wishes to deny fundamentalist voices the political ear; conversely, when confronted by fundamentalist regimes, he advocates a policy of nonintervention. That produces, as a consequence, an explosive mixture of ethical relativism (in international policy) and dogmatic liberalism (in domestic policy). Which shows: Quantitatively and rational freedom finds its necessary measure in Rawls not in and out of itself, but rather in all cases through implicit qualitative directives which on its own principle it can neither make explicit nor affirm.

In regard to the critique of liberalism, the theories of Rawls and Hayek thus oscillate back and forth between acceptance and denial; and in that they reflect a characteristic of quantitatively orientated liberalism as a whole. The quantitative approach - left to its own devices - does not work and is continually driven beyond itself towards qualitative conceptions. The latter are introduced into theories of quantitative freedom mostly either as (procedural) side-restrictions (as in Rawls) or as (material) exceptions (as in Hayek). This shows that with the means of quantitative 
analysis - on the scale of everything, something, or nothing - alone, an answer to the challenges of the critique cannot be found. A liberalism, however, that recognizes no critique is dogmatic; one which accepts them all relativizes itself; and a liberalism which meanders between these poles at the discretion of its respective author remains theoretically unclear and practically ineffective.

On the basis of these observations, we conclude that the theory of quantitative freedom is not self-sufficient; it requires qualitative completion and foundation. What in any given case promotes or hinders freedom cannot be solely derived from the vectors of an imaginary world reduced to physically-quantitative aspects. That rather needs to be negotiated time and time again against the backdrop of our respective worldviews. Hermeneutics and heuristics go hand in hand. Depending on how we interpret our lifeworld, we either spot or overlook certain opportunities, and we understand certain commitments either as liberalizing ligatures ${ }^{1}$ or as freedom's fetters. This very interpretation of life will of course be different for different persons in different places and at different times; and that gives metaphysics its appropriate role in liberalism.

False fears of metaphysics and its methods (of introspection and intuition for instance) have gradually reduced philosophical liberalism into a positivistic physicalism, in whose wastelands only the thorny branches of prickly choice can thrive. Yet instead of banishing the substantial-normative side of freedom into the filthy swamp of supposed "metaphysical pseudo-questions," this aspect must be spruced up, so that liberalism can shine once again. ${ }^{2}$ Rather than (with Fichte) answering once and for all the question how to shape our lifeworld with but one single "big metaphysics," we should sooner, with more modesty and more humanity, engage with the many "small" metaphysics emanating from the most varied systems of ultimate justification spanning the entire range from folk knowledge to spiritual and secular traditions of practical wisdom. If citizens, from their ideas about the good life formulate, certain implorations (Anmutungen) to employ freedom on behalf of social and environmental responsibility, then, from a qualitative (as opposed to quantitative) perspective, these will thus not be understood to be illiberal impositions (Zumutungen), but rather as suggestions to develop and ready liberal thinking for the tasks that lie ahead.

That is corroborated by the last part of our investigation, which underscores that freedom cannot simply be identified with the sheer number of possible choices. In the same way that every individual always prefers a small number of attractive options to a large quantity of unwelcome choices, the political community must evaluate the content of freedom's options. This is especially evident when they conflict, like, for instance, the freedom of smokers and non-smokers in enclosed spaces. We require legitimate evaluation-criteria which by reflecting on the quality of freedom determine their quantitative radius. Thus, correctly understood, the idea of quantitative freedom results from the idea of qualitative freedom; the former is to be

\footnotetext{
${ }^{1}$ See Ralf Dahrendorf, The Modern Social Conflict: The Politics of Liberty (New Brunswick, NJ, 2008).

${ }^{2}$ Charles Taylor, What's Wrong with Negative Liberty?, 218.
} 
dialectically classified and subordinated to the latter as a moment of its fully developed notion. Quantitative freedom finds its foundation in qualitative freedom; qualitative freedom reveals its measure in quantitative freedom.

Section 4.1 reconstructed the theory of freedom of John Kenneth Galbraith (1908-2006), as an exemplar of economic and political thinking in the light of qualitative freedom. He sought to connect his economics to the social sciences and to a practical philosophy focusing on freedom and justice. By pointing to the societal malleability of the economy in view of its historical changes, Galbraith wishes to provide a public interested in the liberal reform of its lifeworld with conceptual tools: Citizens should learn to identify economic power in order to be able to modify it. Based upon a critique of neoclassical axioms (homo oeconomicus, perfect competition, etc.) and the neoliberal theories of politics and economics (equilibriumpostulate, market efficiency, laissez faire, etc.) Galbraith campaigns for a democratization of the economy by means of a reflexively self-critical economics. Galbraith strips economics of the vestiges of value-free (natural-)science, which conceal its implicit normativity. By contrast he champions disclosing the values guiding both the economy and economics. Only thus can we all freely codetermine the economic parameters and institutions that shape our lives.

Whoever, with an eye to the relations between individual and state, insists that the law secure personal freedom, should also consider the potential of businesses, banks, and stock-exchanges to increase or decrease the freedom of global citizens. Galbraith shows the powerful role played by economic entrepreneurs in the formation of opinions, powers, and markets. So that our freedom is not reduced to its commercial aspects, Galbraith initiates a debate about the qualitative dimensions of freedom (quality of life, etc.) and demands a democratization of economic policy. Galbraith thus wishes to balance out with countervailing societal powers the economic tendencies one-sidedly directed towards maximizing material goods. The latter should serve everyone's freedom by enabling a life beyond economic costbenefit analyses and strengthening the presence of public goods.

Amartya Sen (1933-) approaches the self-same question about the quality of freedom in another way: by reflecting upon individuals' capabilities. Since Sen is less concerned about abstract options, and more concerned with concrete chances, i.e. those comprehensive outcomes that result from given economic and political institutions for the life of citizens, he declares himself in favor of a concept of substantive freedom. This aims to gather the intellectual light of other theories of freedom in a lens focused upon individual opportunities. Sen's conception of political autonomy is directed towards harmonizing the choice of economic aims and criteria of success with formally-procedural demands of liberty. Formal and material dimensions of freedom should not be played off against one another, but rather balanced out. For, according to Sen, no society is excluded from the liberal debate about the preferred qualities of freedoms to be politically promoted. A genuine liberalization of our lifeworld presupposes a procedural emancipation of the economy and of the aims materially guiding economic policy. After all, only what is qualitatively defined can quantitatively be maximized. Yet that definition should take place democratically according to qualitative criteria, not technocratically according to quantitative scales. 
Galbraith and Sen's theories of qualitative freedom thus confirm an insight already familiar from our studies of the metaphysics of freedom (Chap. 2). Freedom, while pursued for its own sake, is not self-sufficient; it must be free in order to be able to commit itself, and it must be committed in order to remain genuinely free. ${ }^{3}$ That is not as paradoxical as it may sound. The tension between the two pronouncements resolves itself, as we have shown, in the distinction between the idea and concept of qualitative freedom. What the idea of qualitative freedom protects (schützt) as an end in itself one prizes (schätzt) in the light of concrete concepts of freedom for the sake of the aims which one (only) achieves in freedom. Whoever has succeeded for instance - to quote Schiller - "to be the friend of a friend"4 will pursue in that friendship, not so much the abstract manifestation of his freedom as the concrete wellbeing of this friend and this friendship. Wherever friendship takes roots it also individually strengthens the friends by granting them new, deeper, and stronger relations: It reinforces individuals' autonomy in relation to themselves, to one another, and to the world. Successful friendship can nevertheless not be coerced, it is only thinkable in terms of a voluntary commitment. What freedom and friendship can do for us we only get to experience when we learn to appreciate them in themselves. The instrumental value of freedom cannot be severed from its intrinsic dignity.

The fact that freedom as such (i.e. the universal idea of qualitative freedom) must have its content determined, still does not decide what (i.e. the particular concept of freedom) should be demanded and promoted in the name of this idea. Since the theory of qualitative freedom differentiates between its unified vision and the manifold manifestations, it can integrate the most varied concepts of freedom (negative, positive, substantial, emancipative, republican, procedural, etc.). The idea of qualitative freedom consequently does not have in mind a "one size fits all" model of substantially liberal conditions. In comparison: While quantitative approaches prompt everyone to maximize options, the idea of qualitative freedom recommends openness and diversity. It allows, for instance, preference to be granted to a smaller but variegated set of options than an only numerically impressive but less differentiated quantity of options. Qualitative considerations must therefore precede the quantitative measuring of individual and social spheres of freedom and instruct the latter. Thus does qualitative freedom implement and adjust quantitative concerns.

A qualitative liberalism strives for a variety of opportunities. And because variety - as opposed to plurality - already is a qualitative concept the question, "Which freedom?", cannot be avoided. Even libertarians pose this question, albeit confident that only their answer is blessed. Such dogmatism constitutes a central problem of today's liberalism. Intellectuals argue against one another about freedom, and not alongside one another for freedom; with the result that various groups, while each

\footnotetext{
${ }^{3}$ This is an idea often found in Catholic social theology since the time of Thomas Aquinas. The selecting freedom of choice is dependent upon - and derived from - the ethical freedom of the will, i.e. the "freedom of indifference" is dependent upon - and derived from - the "freedom for excellence"; for more details about this see Leo XIII, Human Liberty, Encyclical Letter (New York, 1941) and Servais Pinckaers, The Sources of Christian Ethics (Washington D.C., 1995).

${ }^{4}$ Schiller, Werke I, 133 (Ode an die Freude).
} 
and all celebrating themselves as friends of freedom, condemn one another as enemies of freedom. By avoiding uniformity and encouraging us to try our differing conceptions according to the situation and context, the idea of qualitative freedom provides a remedy here. For the general postulate of the idea of freedom that the quality of freedom must be debated permits various pleas for which freedoms are to be striven for within given religious, cultural, and geographical contexts.

Qualitatively conceived, the idea of freedom can relate to its environments as critically as it can constructively. The idea of qualitative freedom is relationally conceived. For a qualitatively orientated liberalism, therefore, the contextualization of freedoms is not an exception to the rule, but rather an expression of its principle. For example, to take up an example from Martha Nussbaum, in Germany the constitutional right to freedom of expression does not extend to "holocaust denial." But, conversely, in the face of the persecution of the so-called "degenerate art" in the 1930s and 1940s, the constitutional right to artistic expression is protected without restriction. Against the background of Germany's experiences with the Third Reich both are understandable; and in just the same way it is also understandable that other liberal communities have different priorities. ${ }^{5}$

Consequently, the political dispute about both the meaning of freedom and about concrete freedoms is to be welcomed, not bemoaned. It mediatizes and ameliorates the normative claims of all societal forces. Through its procedural implementation, political freedom thus constitutes and construes itself. Instead of being racked by the dispute about the best conception of freedom and its appropriate aims, the political community is time and again communicatively regenerated by it. ${ }^{6}$ Liberal thinking thus stands to benefit a lot from the dispute over different versions of freedom. Far from continually sensing an attack upon liberal positions, the theory of qualitative freedom encourages the interpretation, where possible, of even conservative, ecological, or social demands as efforts on behalf of the sustainability conditions of liberal societies. Thus, when politics moves to the 'middle of the road,' this may often be the most direct route to a freedom conscious of its own natural and societal presuppositions, rather than an illiberal detour.

For this very reason, the theory of freedom should not only look towards the state and the parties, when aiming at the concretization of freedom. Without civil-society being an incubator of new developments - be it in the cooperative agency of the citizenry, through competitive innovation in business, or in the quest for scientific truth - politics would lack the experiences and insights requisite for prudently pursuing its goals. What society does not get, politics cannot grasp.

Of course, not every concept of freedom can legitimately concretize the idea of qualitative freedom. Every liberalism must defend itself against totalitarian definitions. But how? With which procedures should the step from the idea to the concepts of qualitative freedom be taken? Clearly the proceduralization, too, must take

\footnotetext{
${ }^{5}$ See Claus Dierksmeier, "Die Würde der Kunst - Überlegungen zu Schutzbereich und Schranken eines schrankenlosen Grundrechts," Juristenzeitung 18:55 (2000), 883-889.

${ }^{6}$ See Volker Gerhardt, ed., Der Begriff der Politik: Bedingungen und Gründe politischen Handelns (Stuttgart, 1990).
} 
place in the light of the idea of qualitative freedom; philosophers tend to speak in this regard about the iteration of the idea in its application: The idea of freedom demands liberal procedures for its self-concretization. Only procedures open to the participation of all whose freedom is in question satisfy this requirement. While the fact that freedom is being qualitatively conceived does not establish what is to be regarded as qualitative freedom, it does clarify how a society should (not) determine this. Inadmissible under the terms of the idea of qualitative freedom are decisionmaking procedures which discriminate against individuals or groups and prevent that the minorities of today can peaceably become the majorities of tomorrow.

The idea of qualitative freedom has to remain structurally identifiable in all of its concretizations. To test for that, as we learned from our review of the political version of Kant's categorical imperative (see Sect. 2.1.4) as well as from Krause's outline for participatory liberalism (see Sect. 2.3.4), an intellectual "role reversal" may be an appropriate procedure: Those who wish, for instance, to exercise their physical freedom through the suppression of the physical freedom of others, undermine the freedom they employ. Those who realize their freedom in such a way that, if the roles were reversed, would lose their freedom, contradict themselves and thus undermine the legitimacy of their own claim on freedom. Only such a concept of freedom, which withstands its critical universalization and self-application, ${ }^{7}$ can be accepted as a translation of the idea of qualitative freedom. Human selfdetermination, ground and goal of the idea of qualitative freedom, is also the measure of all concrete concepts of qualitative freedom.

Freedom therefore always also means the freedom of those who live differently. A use of freedom that creates hardly reversible path-dependencies requires far more justification than one whose effects are easily alterable. Economists have long since recognized that whoever uses a temporary monopoly to permanently prevent others from market access inadmissibly uses their freedom to the detriment of the freedom of others. Does this also hold ecologically? Whoever, for the sake of economic ends, ruins the Wadden Sea, for instance, thereby eliminates the countless freedoms to other uses of these tidelands, now and in the future. Should such acts be equated with actions which encourage or empower the freedoms of others? Surely not.

Since, in its commitment to the right to self-determination of all persons, a clear parameter is available for the concretization of qualitative freedom, one need not fear that it facilitates a contextual watering down of fundamental liberal concerns. In line with this parameter, qualitative freedom can selectively differentiate between meaningful criticisms of today's liberalism and the uncritical adaption of fundamental liberal values to changing fashions and tastes. Qualitative freedom therefore provides precisely that liberal protection of fundamental rights which many pursue with conceptions of quantitative freedom; yet without the burdens hidden within the theoretical thickets of quantitative thinking.

\footnotetext{
${ }^{7}$ For the genealogy of this idea from the spirit of the "golden rule" and in respect to a global ethic connecting the people of all regions see Martin Bauschke, Die Goldene Regel: Staunen Verstehen - Handeln (Berlin, 2010).
} 
Of course, there is no cure against some parading around illiberal plans in the name of the idea of qualitative freedom. Nevertheless, the attempt to prevent that by hiding behind a minimalistic quantitative concept of freedom is pointless. Whoever believes they best protect their friends from attacks by burying them alive make just as fatal an error as those on the side of negative and quantitative conceptions of freedom who religiously shun all discussion. Freedom needs air to breathe. Whoever cuts off this air through all too narrowly negatively-libertarian or quantitativelyliberal constrictions, does not strengthen but weakens the power of freedom. Whoever from the outset resists a debate about the qualitative aims and preconditions of freedom suffocates the liberal spirit and denies that it proves itself within the forum of public discussion. The opposite path promises more success: the opening up of the idea of freedom to people's concrete aims and needs. Freedoms do not only want to be defended, they need to be conquered too. Options for an autonomous life must not only be protected, they must also, in many cases, be created for the first time and continually acquired again. Quite like deeds, omissions can reduce our opportunities. People require the political community not only for the reduction of threats, but just as much to pave new avenues for a life in liberty. We should, that is to say, not think of liberalism as Atlas, miserably bearing the ever-same burden for all eternity, but rather as a happy Sisyphus, for whom the continually new ascent towards freedom appears as the best of all goals, as the most beautiful of all paths.

The eventual question, though, concerning which particular political procedures are most suitable for which societal and political tasks, should not be answered by metaphysicians from a lectern. The directive goal of a politics campaigning in the name of freedom shall be to become popular but not populist, striving for as much civil-participation as possible and accepting as much statehood as necessary. To get this project off the ground is a political - not a philosophical - task, for whose accomplishment numerous means may be considered: legal proceedings, civilsociety deliberation, direct democracy, public dialogue, think tanks, focus groups, surveys, procedures of mediation, etc. ${ }^{8}$ In fact, precisely with a view to the appropriate means, there currently still exists a great need for improvement and a gaping lacuna in research - namely regarding the most apt forms of codetermination in regard to the increasing globalization and virtualization of our lifeworld and problems. For the forms of political freedom must advance with the times. Technical and civilizational innovations obviously alter the experience of freedom and therefore also change the demands placed upon its political use. ${ }^{9}$ If one understands democracy as "humanity's self-determination"10 it follows that: Where societal concerns overtax the competencies of national rights, one has to look for answers beyond the

\footnotetext{
${ }^{8}$ See Raban D. Fuhrmann, Der Bürger der Bürgergesellschaft: »Bürgergutachten« aufgrund von fünf »Bürgergutachtenzellen «nach dem Verfahren »Planungszelle» (Berlin, 1999).

${ }^{9}$ See Jürgen Howaldt \& Michael Schwartz, »Soziale Innovation« im Fokus: Skizze eines gesellschaftstheoretisch inspirierten Forschungskonzepts (Bielefeld, 2010).

10 "Democracy works towards mankind's self-determination, and only when the latter actually exists is the former true. Political participation will then be identical with self-determination" (Jürgen Habermas, Über den Begriff der politischen Beteiligung [Neuwied am Rhein, 1961], 15).
} 
conceptual framework of the state. As a result of the increasing fluidity of conventional patterns of responsibility, policy today can no longer solely depend upon the state, within firmly determined geographical boundaries, to be the solution to any and all problems. ${ }^{11}$

A line of thought running from Kant (publicity) via Krause (participation) to Sen (procedurality) clearly emphasizes that for a timely realization of the idea of freedom we require a democratic policy which supplies participative and/or representative procedures wherever life demands communal decisions and actions; increasingly far from parliamentary spheres dominated by party politics; above and below, as well as alongside, the decision-making bodies of nation states and - ever more often - also within the digital lifeworld. ${ }^{12}$

The idea of qualitative freedom does not resist every codetermination and external determination. Yet wherever the defensive function of qualitative freedom is employed, it appears with full force. The correct and important concern of negative theories of freedom with providing individuals with a certain refuge for experiencing and developing their own autonomy finds unassailable protection in the framework of the philosophy of qualitative freedom. But qualitatively orientated freedom philosophy also extends - and this is an important advantage - to asymmetrical relations. ${ }^{13}$ As we have learned, above all from Karl Christian Friedrich Krause (Sect. 2.3) and Amartya Sen (Sect. 4.2), it is not contractually conditioned reciprocity that is crucial, but rather morally unconditional universality. We owe protection and security also to the rights of people from whom we (could) receive nothing in return. Qualitative freedom thus obligates us to a temporal (intergenerational) and spatial (global) extension of freedom's commitments to responsibility as well as to their internal differentiation: Demands for morally, socially, and ecologically sustainable economic activity are, from the perspective of qualitative freedom, readily respected: as theory-conforming engagements in favor of the chances of present as well as future generations for a life in freedom.

But do we not confuse or overburden the idea of freedom with this extension of its responsibility dimension? From the quantitative perspective, i.e. according to the directive of reaching for a maximum of private options, that may appear to be the case. Yet, the theory of qualitative freedom does not at all flirt with the fiction of unlimited leeway. It continually scrutinizes the individual range of options in order to harmonize it with everyone's freedom. ${ }^{14}$ Burdens and boundaries that serve this end are thus not looked upon (as in the quantitative logic) as unpopular if indispensable limitations of freedom. They should (upon qualitative evaluation) rather be

\footnotetext{
${ }^{11}$ See Xavier de Sousa Briggs, Democracy as Problem Solving: Civic Capacity in Communities across the Globe (Cambridge, MA, 2008), 13.

${ }^{12}$ See Hildegard Hamm-Brücher, Und dennoch.... Nachdenken über Zeitgeschichte, Erinnern für die Zukunft (München, 2011), 106f.

${ }^{13}$ In this it is in my opinion sufficient to follow Brian Barry (Theories of Justice: A Treatise on Social Justice [Berkeley, 1989], 163): Justice must be successful under precisely asymmetrical conditions; purely symmetrical justice is not justice.

${ }^{14}$ See Glenn E. Tinder, Liberty: Rethinking an Imperiled Ideal (Grand Rapids, MI, 2007).
} 
affirmed as forms for enabling universal freedom: as acts through which freedom commits and restricts itself. Qualitative liberalism does not conceive of demands for responsibility per se as negative limitations, but rather considers whether these could rather be positive determinations of freedom. Often, after all, the options we are called to renounce are - sometimes quantitatively, but in all cases qualitatively compensated by opportunities only thus attained. A case in point is the sustainability of the presently much imperiled environmental conditions for a life in freedom.

The qualitative viewpoint allows the intellectual and institutional break with stereotypes. For far too long the schemata of quantitative thinking have dried up the liberal imagination and insisted upon dichotomies far removed from real life (freedom versus coercion, individual versus state, private versus public, etc.). Their theoretical paucity and practical insufficiency are obvious. For day-to-day politics these antipodes are of little help. Politics rather refrains, for instance, from pursuing its goals by way of physical coercion, even if only so as not to lose support in the short term and its mandate in the long term. Instead, politics plays ever so subtly on a finely-tuned keyboard of varied forms of recognition and encouragement so that citizens eventually do on their own accord what is in the general interest. Successful societal cooperation within political projects results hardly ever from coercive pressure. It rather arises as a result of the appealing and motivational power of attractive concepts and symbols. Accordingly, political liberalism should participate in the quest for forms of codetermination and societal coordination with strong appeal. Herein lies, in my opinion, a major task for a liberal philosophy of the cosmopolitan society of the future. ${ }^{15}$

The means of liberal politics should - as we saw above all in Krause and Sen correspond to their goals, so that freedom is, wherever possible, attained by freedom itself. Substantive and procedural freedom therefore firmly belong together. Every society must not only decide for itself about what legal protection, which opportunities, and what kind of support it wishes to grant its citizens. It must also autonomously establish the procedures for such decision-making. The theory of qualitative freedom does not, therefore, like many strands of earlier economic and political theory, ask technocratically: "Who is right?", but rather democratically asks "Who has the right to decide?" and thus of course also "Who has the right to err?"

The mission of the idea of qualitative freedom, the concern with reconciling individual and societal liberties in such a way that everyone can live in freedom, thus leads to the concept of democracy - and qualifies it at the same time. Kant already summoned democracy from the throne of an end-in-itself and assigned a functional place to it as a means to the end of the autonomous life of all world citizens. That is, democracy attains its sovereignty from its tasks. It should provide procedures enabling those affected by political decision-making to participate within it. It must accomplish no less, but also no more, than the communal tackling of shared problems upon the foundation of a deliberative participation and political representation of the freedom of all. The idea of qualitative freedom does not there-

\footnotetext{
${ }^{15}$ See Christopher Gohl, "Beyond Strategy: Prozedurale Politik," Zeitschrift für Politikberatung 1:2 (2008), 191-212.
} 
fore obligate us outright to push through the parliamentary system everywhere else. It does, however, argumentatively insist upon a fair representation (including the protection of minorities) of all global citizens; not least in their respective national communities.

Parliamentary systems are obviously particularly fitted for that purpose. Yet this is a procedural concern on the conceptual level, not a substantial directive upon the level of principles. Many communities that differ from the Anglo-American model of politics and society in no way compete against the idea of freedom, but rather stand up for freedom, if nonetheless in alternate forms. One should not - in overzealous liberal imperialism and from supposedly privileged insight into the true essence of freedom - brew a 'liberalization cocktail' that everyone merely needs to down. True liberals must not turn into paternalistically-liberal nannies. Against the schematic liberalism of a quantitative type, from the perspective of qualitative freedom, we are to recognize that divergence in practice does not have to mean difference in principle. The procedural model of qualitative liberalism rather has the respective civil-societies themselves define in what form they wish to practice their political freedom.

With qualitative freedom, therefore, the official pronouncements of philosophy end where we transition from idea to concept. When confronted by freedom's concrete concepts, philosophers speak only as citizens, who lack definite certainties and are often out-voted in elections. Political debates are not to be replaced by philosophical formulas. We must all engage in interpreting the idea of qualitative freedom - time and again. In this process, academic philosophy cannot claim privileged knowledge; it may insist, however, upon participating in the societal dialogue. ${ }^{16}$ For wherever within the mass of all politically legitimate options we are to select some as preferable to others, concrete judgment, and not knowledge of abstract principles, is what tips the balance. Politics must - as Gerald Dworkin put it colorfully employ arguments understandable not only by academics, but also by farmers who, if without theoretical education, are certainly not lacking in practical experience. ${ }^{17}$

In political dialogue about the appropriate contours of the freedom within society, it is not only liberals and libertarians who speak to one another; rather the appropriate arguments are examined from every conceivable political and ideological camp. Liberal concerns therefore require an additional justification; one that transcends their own argumentative canon. That is a blessing in disguise. After all, upon the political stage we rarely find authority-free discourses about lofty principles, but rather people with 'skin in the game' disputing about mundane practices. ${ }^{18}$ Freedom's friends must therefore make their projects appealing to the proponents of other ideals and ideologies. And this will only be successful if they can clarify the contribution of liberal ways of life to other (conservative, social-democratic, ecological, etc.) conceptions of value. (An instructive example of this is the discussion about the reciprocal relation between freedom and social justice promoted by

\footnotetext{
${ }^{16}$ See Gerhardt, Partizipation. See also Pettit, Republicanism, 57, 59.

${ }^{17}$ See Dworkin, The Theory and Practice of Autonomy, 17.

${ }^{18}$ See Michael Walzer, Thinking Politically: Essays in Political Theory (New Haven, 2007).
} 
Amartya Sen, see Sect. 4.2). Precisely for this reason, political liberalism cannot avoid the question about more or less meaningful freedom, superior or inferior, and more or less beneficial freedoms. Liberals should accordingly not, in the name of quantitative freedom, avoid such conversations, but are well-advised rather themselves to lead such discussions under the banner of qualitative freedom.

As upon the psychological-pedagogical level, in politics too freedom ripens and flourishes by assuming responsibility and being held accountable. Activity and liability belong together - for liberal reasons. If society complains, for instance, that on the part of the finance industry profits are privatized and losses socialized, then liberals must therein recognize their own concern: that single individuals and institutions do not internalize the opportunities of their actions while externalizing their risks. Personal as well as organizational freedom finds the criterion of its evaluation - and limitation - within the quality of its contribution to universal freedom.

The idea of qualitative freedom thus openly aims at particularly valuable and sustainable options. Yet it would be completely wrong to believe that individual and collective choice were to be restricted to such options only. Qualitative liberalism rejects, on the one hand, the view of the quantitative dogma that to the philosophy of freedom all options must appear equivalent. But, on the other hand, qualitative freedom also discards the belief cherished by some religious and metaphysical systems that freedom only manifests itself in certain - say, especially ethical - practices. Qualitative freedom wishes to encourage and empower persons as well as communities to take care of the common good in responsible freedom, without wishing to enforce this. Even though freedom is directed towards qualitatively valuable goods and activities, the value of freedom nevertheless transcends (as Kant, Krause, and Sen teach us especially) the sum total of the projects it realizes.

Qualitative liberalism therefore views freedom neither as a finished being (as does the theory of quantitative freedom) nor as a fixed ought (as do some metaphysical doctrines and religious dogmas). In the perspective of qualitative freedom, freedom is and forever remains a fluid becoming. Freedom must experiment, fail, and begin afresh. Just like its being, its ought, too, always requires active design and ongoing development. Freedom thrives and survives only when enacted. Freedom grasps its mission only by reflecting upon itself: What freedom essentially is and ought to be, can only be identified in and through freedom itself. The dispute about freedom and its true understanding must therefore be conducted in the midst of society: via the dialogue of everyone with everyone else.

On the basis of the previously presented approaches, the conclusion can be drawn that quantitative and qualitative freedom do not present equivalent, but instead hierarchically-dialectical concepts. Although in most cases theories of quantitative freedom explicitly reject qualitative considerations, they cannot function without making use of them implicitly. Their reconstruction thus amounts to their deconstruction - i.e. their dialectical transference into the category of quality. Conversely, the idea of qualitative freedom is from the outset directed at the integration of quantities. Qualitative values wish appropriately and proportionately to employ quantitative measures, not replace them. Qualitative freedom does not eliminate quantitative freedom, just its absoluteness. While quantitative thinking negates and externalizes 
all qualitative demands, the quantitative dimension is affirmed and integrated by the qualitative approach. The idea of qualitative freedom thus proves itself to be more capable of integration and therefore deserves categorical priority.

\subsection{Insights}

In the last decades, the criticism of liberalism has considerably deepened and widened. As a result, there is a serious menace to the liberality practiced in open societies. This menace, as well as the continuing and - in the age of globality - still increasing meaning of the ideal of freedom, prompted me to write this study. Of course, I could not respond to all the branches of said critique, such as those arising from epistemological sources (John Henry Newman, George Santayana), as well as those arising from theological (Karl Barth, Carl Schmitt), communitarian (Charles Taylor, Martin Walzer, Michael Sandel), ecological (Hans Jonas, Franz Josef Radermacher), cultural (Herbert Marcuse, Slavoy Žižek, Roger Scruton), postmodern (Jean Baudrillard, George Bataille) and feminist (Nancy Fraser, Susan Moller Otkin) directions. ${ }^{19}$

In the face of the breadth and depth of this critique, two things, though, are to be emphasized. First, that this critique is often only applicable to quantitatively orientated theories of freedom. For, it is true that a liberalism without qualitative musicality is deaf to life's subtler melodies and stomps along to a monotonous rhythm - to the detriment, not least, of freedom itself and its differentiated inner harmonies. Second, it is also the case that this critique largely misses a qualitatively orientated liberalism. For the latter attends to the concerns of such critique, not just for tactical and pragmatic considerations, but rather for strategical and principled reasons. With a view to the current recommendations of liberal thinkers for economics and politics, either claim shall now be discussed and illustrated with reference to the different anthropological models the respective theories of freedom employ. In the case of quantitative thinking, the homo oeconomicus model predominant in economic, political, and social theory will be drawn on, and, conversely, I will tap into conceptions of human dignity and the conditio humana for qualitatively orientated liberalism. Unsurprisingly, both approaches lead to fundamentally different treatments of economic and political institutions.

Already in Sect. 4.2. on Amartya Sen, we dealt in detail with the basic assumption underlying the homo oeconomicus model of a utility-maximizer forever rationally striving to increase options for the fulfilment of individual preferences. Branches of academic economics still continue to defend the homo oeconomicus theorem; with the argument, for instance, that it should not serve to describe realities but to build models, and not bring about certain applications but merely to prepare them. In the end, science must always generalize, abstract, and simplify. So, if

\footnotetext{
${ }^{19}$ For more details see Ronald Beiner, What's the Matter with Liberalism? (Berkeley, CA \& London, 1992).
} 
this theorem still serves as a helpful tool for exact science and the generation of accurate predictions, what's the problem?

Increasingly, though, social psychology, behavioral economics and neuroeconomics are raising doubts as to whether the model provides useful predictions at all. ${ }^{20}$ Behavioral observations, decision-making tests, as well as numerous anthropological, psychological, evolutionary-economic, and neuro-economic studies conclusively show that real people rarely act in accordance with the model. ${ }^{21}$ They conduct their business according to alternate criteria, they expect as well as honor behavior contrary to the model, and make investments in pursuit of different objectives. Actual economic behavior rather has the characteristics of "bounded rationality,"22 "bounded will power," 23 and "bounded self-interest." ${ }^{24}$ Social researchers today describe people not as pure utility-calculators, but instead as persons concerned about their community, environment, and posterity, who have an intense interest in moral behavior and - as fMRI-Scans of the reward-centers in the brain colorfully illustrate - even gladly (!) make sacrifices in its pursuit. ${ }^{25}$

The homo oeconomicus model reduces human behavior so much that it fails, more often than not, to make sound prognoses. Nevertheless, it still is a hallmark of economic pedagogy. According to its proponents, moral behavior and social emotions are not valid objections against it: They view them as exceptions to the rule of self-interested rationality and then add them as modifiable variables to the enduring constant of rational self-interest. The data nevertheless suggest the exact opposite: Fundamentally, human behavior seems socially embedded and morally grounded; exceptionally it takes on atomistic and egoistic traits. (By the way, this is exactly the way pre-modern philosophy of economics, up to and including Adam Smith, had always seen it. ${ }^{26}$ ).

No matter, some apologists say that neither description nor prediction are important! Even if the model neither explains what happened yesterday nor foresees what will happen tomorrow, it could nevertheless suggest what is to be done today. The logic of self-interest allows us to find loopholes in our legal and social institutions handing out rewards and sanctions. Because of the pressure of competition, these loopholes will be exploited at first by some - but soon increasingly more - persons, until eventually the last remaining honest person will be the hindmost taken by the

\footnotetext{
${ }^{20}$ See Jennifer Arlen \& Eric L. Talley, Experimental Law Economics (Cheltenham, UK \& Northamption, MA, 2008).

${ }^{21}$ See Daniel McFadden, "Free Markets and Fettered Consumers," The American Economic Review 96:1 (2006).

${ }^{22}$ See Herbert A. Simon, Models of Thought (New Haven, CT, 1979).

${ }^{23}$ See Richard H. Thaler, Quasi Rational Economics (New York, 1991) and Thomas C. Schelling, Choice and Consequence (Cambridge, MA, 1984).

${ }^{24}$ See Christine Jolls, Cass R. Sunstein \& Richard Thaler, "A Behavioral Approach to Law and Economics," Stanford Law Review 50:5 (1998).

${ }^{25}$ See Ernst Fehr \& Antonio Rangel, "Neuroeconomic Foundations of Economic Choice - Recent Advances," The Journal of Economic Perspectives 25:4 (2011).

${ }^{26}$ See Hühn \& Dierksmeier, "Will the Real A. Smith Please Stand Up!"
} 
devil. Ultimately, our societal institutions are destined to collapse as a result of progressive undermining. The homo oeconomicus model can thus function as a useful sensor for precisely such a fraying of the social fabric, alerting us to abuses of the system. $^{27}$

At times, that might work indeed. But beware: This mental model does not really behave passively like a merely observing sensor, but rather actively like an aggressive acid. In laboratory tests, acids reliably expose certain inorganic structures, but only by dissolving all other materials. Analogously, the homo oeconomicus model disintegrates all conceptions of the human being dissimilar to it, for example those characterized by ethical criteria and values. For a long time, there have been alarming reports that students of business and economics display less moral responsibility than their peers. ${ }^{28}$ For one thing, they rate the chances of success for moral behavior as lower and tend stronger towards materialistic and hedonistic goals than those who are graduating in other disciplines. That also affects their behavior. For example, such students allow themselves more "free-riding," are less ready to share, more likely to deceive others, and cheat more in exams. Also, later in their professional life, they more often display opportunistic - through to criminal - behavior. They circumvent, for instance, standards of health and safety more frequently, and accept bribes more often, etc. Conversely, they display less readiness to invest in public goods or to operate philanthropically. ${ }^{29}$

Students of business and economics differ from students of other disciplines both theoretically in terms of their conception of the human being and practically in terms of their behavior. Are they less attached to morality first and then sign up for economics courses (self-selection effect) or is it the economic teachings which entice them away from morality (indoctrination effect)? The gathered empirical data evinces a small self-selection effect; to a far greater extent, however, these test results can be traced back to indoctrination through their studies. ${ }^{30}$ What does that

\footnotetext{
${ }^{27}$ See Karl Blome-Drees Franz Homann, Wirtschafts- und Unternehmensethik (Göttingen, 1992).

${ }^{28}$ An excellent survey of these studies is provided in Juan Elegido, Business Education and Erosion of Character (2009)

${ }^{29}$ See Gerald Marwell \& Ruth E. Ames, "Economists Free Ride, Does Anyone Else? Experiments on the Provision of Public Goods, IV," Journal of Public Economics 15:3 (1981); John R. Carter \& Michael D. Irons, "Are Economists Different, and If So, Why?," Journal of Economic Perspectives 5:2 (1991); Robert H. Frank, Thomas Gilovich and Dennis T. Regan, "Does Studying Economics Inhibit Cooperation?,” The Journal of Economic Perspectives 7:2 (1993); Charles Bram Cadsby \& Elizabeth Maynes, "Choosing between a Socially Efficient and Free-riding Equilibrium: Nurses Versus Economics and Business Students," Journal of Economic Behavior \& Organization 37:2 (1998); Bruno S. Frey \& Stephan Meier, "Are Political Economists Selfish and Indoctrinated? Evidence from a Natural Experiment," Economic Inquiry 41:3 (2003); Ariel Rubinstein, "A Sceptic's Comments in the Study of Economics," The Economic Journal 116:510 (2006); Donald L. McCabe, Kenneth D. Butterfield \& Linda Klebe Treviño, "Academic Dishonesty in Graduate Business Programs: Prevalence, Causes, and Proposed Action," Academy of Management Learning \& Education 5:3 (2006).

${ }^{30}$ See Neil Gandal et al., "Personal Value Priorities of Economists," Human Relations 58:10 (2005); Sumantra Ghosal, "Bad Management Theories Are Destroying Good Management Practices," Academy of Management Learning \& Education (4/2005).
} 
tell us? For one thing that economics affects practice; for another thing that it does so in a hardly desirable manner - which is not even desired by the management and economics professors themselves ${ }^{31}$ : The students of economic disciplines are more skeptical in their judgment and much more cynical in their behavior. That is to say, attitudes not conforming to the cold rationality of self-interest are weakened by the prevailing economic pedagogy. This impedes the assertion of a morally, socially, and ecologically responsible economic theory and a humane economic practice based upon it. ${ }^{32}$

An important cause for that finding lies, in my opinion, in the quantitative manner of thinking of the homo oeconomicus anthropology. Why? Between moral philosophers and moral psychologists the consensus prevails that self-images influence self-assertion. ${ }^{33}$ People who believe they are free and able to act morally sooner succeed than those doubting their creative possibilities. ${ }^{34}$ When one models this freedom, however, in accordance with assumptions derived from the (highly unrealistic because extremely reductive and, yet, for that very reason, readily mathematicizable) homo oeconomicus theory, things look quite different; like for instance in the principal/agent-theory still popular in management theory. ${ }^{35}$ Students are then deceived into thinking that people also behave in accordance with the model (i.e. opportunistically) outside of those model worlds. ${ }^{36}$ But what happens if one recognizes in the "agent" a thoroughly self-interested, only financially driven, but otherwise unwilling contractual partner of the "principal." Do not the sanctions (within the corporation: complete surveillance, conditioning, incentivizing, etc., - and outside of it: strict disciplining through quarterly reports for the financial markets) demanded and pursued by such theory inexorably lead us into a downward spiral? Do they not consistently intensify and provoke the presupposed opportunistic behavior in practice $?^{37}$ Experience shows just that ${ }^{38}$; which, incidentally, prompted

\footnotetext{
${ }^{31}$ See Dirk C. Moosmayer, Die Intention betriebswirtschaftlicher Hochschullehrer zur Beeinflussung von Werten: Konzeptionelle Entwicklung und globale empirische Überprüfung (Frankfurt am Main, 2013).

${ }^{32}$ See Henry Mintzberg, Managers not MBAs: A Hard Look at the Soft Practice of Management Development (San Francisco, 2004); Henry Mintzberg, Robert Simons \& Kunal Basu, "Beyond Selfishness," MIT Sloan Management Review 44:1 (2002); Ghoshal, Bad Management Theories Are Destroying Good Management Practices.

${ }^{33}$ See John Dewey, Democracy and Education: Freedom and Culture (Denver, 2009).

${ }^{34}$ See Dierksmeier, "The Freedom-Responsibility Nexus in Management Philosophy" and Michael von Grundherr, "Selbstwirksamkeitserwartung und die Rolle von Vorbilden in der Ordnungsethik," Zeitschrift für Wirtschafts- und Unternehmensethik 15:3 (2014).

${ }^{35}$ See Michael C. Jensen \& William H. Meckling, "Theory of the Firm: Managerial Behavior, Agency Costs and Ownership Structure," Journal of Financial Economics 3:4 (1976).

${ }^{36}$ See Arne Manzeschke, Veronika Drews-Galle \& Marburger Arbeitskreis Theologische Wirtschafts- und Technikethik, Sei ökonomisch! Prägende Menschenbilder zwischen Modellbildung und Wirkmächtigkeit (Berlin, 2010).

${ }^{37}$ See Chris Argyris, Increasing Leadership Effectiveness (Malabar, Fla, 1984).

${ }^{38}$ For the influence of the financial markets upon the decision-making processes in business see John R. Graham, Campbell R. Harvey \& Shiva Rajgopal, “The Economic Implications of Corporate Financial Reporting," Journal of Accounting and Economics 40:1-3 (2005).
} 
the father of the principal/agent-theory, Michael Jensen, to depart from his own model - unlike, unfortunately, the majority of his guild - and to now, conversely, direct all his pedagogical energy towards theories of integrity and authenticity. ${ }^{39}$

Also, society as a whole incurs collateral damage wherever the homo oeconomicus is viewed as an image of economic rationality and the spirit of the model is translated into a directive (or excuse) for selfish behavior. ${ }^{40}$ If one replaces real people with the fictional homo oeconomicus and lets the latter romp around in imaginary perfect markets - i.e., excluding power-asymmetries, access-barriers, and path dependencies, but including information that is complete and free of charge - then the pursuit of maximum efficiency may suggest: Wherever everyone takes care of themselves, all are taken care of. On the chalkboards of economics that may be feasible; but in the real world this produces dissatisfied cynics en masse. Honest persons, for fear of being duped, then perpetuate what in game theory is called "preventative defection." ${ }^{41}$ That is, they prefer to break with the precepts of decency themselves before others - eventually - can do the same. But they thus encourage others to follow and emulate them. The phantom created by a dubious theory thus turns into a phenomenon masquerading as the theory's indubitable illustration - and announces that, in order to survive in this world, one must behave selfishly: Quod erat demonstrandum?

Yet experience follows observation, and the latter is - consciously or unconsciously, willingly or unwillingly - influenced by theoretical models. There is no practice without theory because actuality is never perceived independently of mental models. Whoever does not wish to be tormented by homespun fantasies must learn to grasp their own personal contribution to their own worldviews and the constructions guiding their lives. That is especially true in economics. The socioeconomic anthropology which up to now has been wholly focused on quantitative maximization sees its object - human commerce - through a grossly distorted lens constantly providing skewed pictures. Whoever does not take that into account, confuses the projections generated within their own hall of mirrors with the world. As long as people orient themselves according to distorted models, their models' theoretical deficiencies will translate into real-life practical deficits.

A false theory taken to be true deceives us into systematically acting without reference to reality. Included therein is, for instance, the widespread and powerful belief that one must simply accept egoism as a fact about reality, whereas altruism is but an idealistic fiction. What an optical illusion! Egocentric as well as altrocentric interests are both values as well as facts, even if their normative evaluation and their empirical allocation differ. Yet their difference does not consist in the fact that self-

\footnotetext{
${ }^{39}$ An especially striking text in this regard is Werner Erhard, Michael C. Jensen and Kari L. Granger's working paper, "Creating Leaders: An Ontological Model” (2010): http://hbswk.hbs. edu/item6570.html

${ }^{40}$ See Wolfgang Amann et al. (eds.), Business Schools under Fire: Humanistic Management Education as the Way Forward (Basingstoke, U.K., 2011).

${ }^{41}$ See K. Sridhar Moorthy, "Using Game Theory to Model Competition," Journal of Marketing Research 22:3 (1985).
} 
ishness dwells in the world of being, from which the love of one's neighbor would be per definitionen excluded. One is in no way more realistic the more selfishly one thinks and acts, one rather thus just drops one - contestable - value judgement!

The homo oeconomicus model thus resembles a badly done-up zipper. It suggests temporary closure but will split open under pressure from real conditions. Even though we do not only pursue private utility in forms of morally correct action, we often do; and sometimes we even do so to our own disadvantage. ${ }^{42}$ The good is in no way striven for simply because of its advantages for us - as the proponents of the homo oeconomicus model like to suggest ${ }^{43}$ - it is rather sometimes also striven for in itself. That must not be overlooked by any anthropology to be operationalized economically or politically. Otherwise it is ideology and not science, spreading illusions rather than producing knowledge.

Conventional economics suggests, for instance, that one can count upon no interest in morality from one's fellows (customers, coworkers, stakeholders), where this is not to their immediate financial advantage. This theoretical approach conceals important opportunities for successful action beyond self-interested calculation. That is not just academically deplorable, it is also economically unprofitable. Unseen opportunities remain unexplored. A business case which is overlooked as a result of the homo oeconomicus model can have no positive impact. ${ }^{44}$ We can see this clearly in regard to the presently perhaps most exciting proponents of innovative business: the social entrepreneurs, who strategically let themselves be guided by moral values, ${ }^{45}$ and their twin brothers in conventional firms, the social intrapreneurs. ${ }^{46}$ Both groups direct, not only certain areas of their business-policy, but their entire business model ecologically, socially, and/or morally - and in so doing earn good money in both senses of the word, and as a result obtain access to sustainability-orientated financial capital. ${ }^{47}$ What works out for these innovators is, in principle, open to all. Reality proves possibility. That principles can lead to profits and that businesses catering to the natural and cultural environment can be thor-

\footnotetext{
${ }^{42}$ See Zak, Neuroeconomics; as well as Killiongback \& Studer, Spatial Ultimatum Games.

${ }^{43}$ See Gary S. Becker, Economic Theory (New Brunswick, NJ, 2007); Gary S. Becker, Accounting for Tastes; as well as Gary S. Becker, Human Capital: A Theoretical and Empirical Analysis, with Special Reference to Education (Chicago, 1993).

${ }^{44}$ See Dierksmeier, "The Freedom-Responsibility Nexus in Management Philosophy."

${ }^{45}$ See André Habisch, "Gesellschaftliches Unternehmertum - Blinder Fleck wirtschafts- und sozialwissenschaftlicher Gemeinwhohltheorien," in Helga Hackenberg \& Stefan Empter (eds.), Social Entrepreneurship - Social Business: Für die Gesellschaft unternehmen (Wiesbaden, 2011); John Elkington \& Pamela Hartigan, The Power of Unreasonable People: How Social Entrepreneurs Create Markets that Change the World (Boston, MA, 2008).

${ }^{46}$ See Ronald Venn \& Nicola Berg, "Building Competitive Advantage through Social Intrapreneurship,” South Asian Journal of Global Business Research 2:1 (2013); Walter Baets \& Erna Baets-Oldenboom, Rethinking Growth: Social Intrapreneurship for Sustainable Performance (Basingstoke, 2009); David Grayson, Heiko Spitzeck et al., Social Intrapreneurism and All That Jazz (Sheffield, 2014).

${ }^{47}$ See Heiko Spitzeck, Michael Pirson \& Claus Dierksmeier, Banking with Integrity: The Winners of the Financial Crisis? (Basingstoke \& New York, 2011).
} 
oughly profitable is shown by many "case studies," even from conventional firms, within many industries and economic sectors from all over the world. ${ }^{48}$

Precisely for this reason, moral theories should be accepted and not rejected by economic theory, and brought into the center of research as opposed to being pushed into the margins of curricula. Instead of continually bypassing reality with the homo oeconomicus model, a more appropriate alternative would be to analyze the actual conditio humana oeconomica. Realism creates relevance! We have to reconstruct the essence of the human being in terms of the symbolic systems that constitute its world: Religion, science, art, morality, etc. ${ }^{49}$ What human beings are becomes visible in that which they create and achieve. ${ }^{50}$ The moral ought has its being in our endeavors and is reflected in our ethics, religions, codes of conduct, customs, and conventions. An unabridged doctrine of humankind therefore also looks at these symbolic worlds. It understands that ideal, spiritual, and metaphysical architectures likewise belong to being human and to housing humanity. A successful long-term business strategy is consequently best built upon an anthropology informed by all including ethical - human drives.

Economic value creation (Wertschöpfung) grows not least from human appreciation (Wertschätzung) and moral commitment (Wertbindung). While to many practitioners this might sound obvious, for economically informed, or rather deformed, academics it is still news. For up until a few years ago, the haute couture of economic ethics was designed for the narrow walkway of the homo oeconomicus. The results were those extremely narrow-cut corsets of compliance management, plus a corporate social responsibility doctrine painstakingly wedged between carrot and stick. Can one really blame the many entrepreneurs eager to rid themselves of these costumes restricting their every freedom of movement? Is it any wonder that these programs often failed to be successful?

Slowly but surely, however, the prevailing design is changing to allow firms more leeway for moral motion. The rigid stays of the quantitative corset eventually give way to rather loosely woven threads that allow the fabric to incorporate patterns qualitatively desired by customers. The recent fashion of business ethics at the moment introduces a procedural design which more closely corresponds with the contours of qualitative freedom.

Customers and the public increasingly expect from business a behavior that can lead to a race to the top ${ }^{51}$; especially when NGOs (non-governmental organizations) cooperate as competent intermediary trustees. ${ }^{52}$ In the last few years, much

\footnotetext{
${ }^{48}$ See Ernst von Kimakowitz et al. (ed.), Humanistic Management in Practice (New York, 2010).

${ }^{49}$ See Ernst Cassirer, The Philosophy of Symbolic Forms (New Haven, 1953); Donald Phillip Verene, The Origins of the Philosophy of Symbolic Forms: Kant, Hegel, and Cassirer (Evanston, 2011).

${ }^{50}$ See Helmuth Plessner, Conditio humana (Frankfurt am Main, 1983).

${ }^{51}$ See Sebastiaan Princen, "Trading up in the Transatlantic Relationship," Journal of Public Policy 24:1 (2004).

${ }^{52}$ See Shaomlin Li et al., "Corporate social responsibility in emerging markets," Management International Review 50:5 (2010).
} 
was achieved through sector-specific programs (like the Kimberly Process in the diamond industry or EITI in the extractive industries), through industry-spanning institutions (for example Transparency International and the World Wildlife Fund), as well as through institutions with a cosmopolitan mandate (UN Global Compact), by means of soft sanctions (organized publicity, reputational damages, rejection of cooperation) despite the lack of lawful sanctions on a global level. ${ }^{53}$ Similar steering effects come from ethically directed cash injections on the part of private investors (from Socially Responsible Investing to Impact Investing and Venture Philanthropy) as well as national and international public institutions (like, for instance, the Government Pension Fund of Norway and the World Bank).

From numerous firms backing social, moral, and ecological sustainability, it can easily be seen that businesses increasingly work with differentiated criteria of success. Success is already ever more often defined via a triple bottom line directed towards the harmonization of social, ecological, and financial interests (people, planet, profit). ${ }^{54}$ It also appears that in management circles concepts like "network governance" and "stakeholder management" 55 are finding more and more acceptance. All this is qualitative freedom in application: a firm will only allow itself to be co-governed by its network if it understands that as a gain rather than a loss in freedom. And stakeholder-dialogues can only be productively conducted if one does not believe one already knows all about the antagonists' concerns. Unlike the fictional homo oeconomicus one's fellow human beings are irreducible to algorithms. One must engage in an open dialogue with them and one's stakeholders must wherever possible also participate in the strategic corporate responsibility - if they are not to mistake such parleys as mere PR stunts. ${ }^{56}$

I abandon this fashion show of business ethics here: The business models of Social Entrepreneurs and Social Intrapreneurs in all cases clearly demonstrate that theories are in error, which - orientated by the premises of the homo oeconomicus model and quantitative freedom - conclude that ethical business is unprofitable. In practice, an entrepreneur must by no means choose between the Scylla of a relativist "anything goes" and the Charybdis of a negotiation logic based solely on selfish

\footnotetext{
${ }^{53}$ For example, in the last years, the effect of Transparency International has broken the international dominance of bribery as an acceptable means of initial business contact. On the basis of exemplary data research, Transparency International provided reliable information about the level of national corruption. This information was used by both public and private sponsors for investment-decisions and thus provides incentives for economic integrity. See Michel van Hulten (ed.), Transparency International (Leiden, 2009). For information about the global compact see Klaus M. Leisinger, Aron Cramer \& Faris Natour, "Making Sense of the United Nations Global Compact Human Rights Principles," in Andreas Rasche \& Georg Kell (eds.), The United Nations Global Compact: Achievements, Trends and Challenges (Cambridge, New York, 2010).

${ }^{54}$ See Klaus M. Leisinger, "Capitalism with a Human Face,” Journal of Corporate Citizenship 28 (2007).

${ }^{55}$ See R. Edward Freeman, “The Stakeholder Approach Revisited," Zeitschrift für Wirtschafts- und Unternehmensethik 5:3 (2004).

${ }^{56}$ See Jon Burchell \& Joanne Cook, "Stakeholder Dialogue and Organizational Learning: Changing Relationships between Companies and NGOs," Business Ethics: A European Review 17:1 (2008).
} 
maximization. Both approaches allow, in the best case, sub-equilibria of cooperation, and lead, in the worst case, to the erosion of the social, cultural, and natural foundations of economic collaboration. That is why, for a long time already, the connection between ethics and success is the daily bread of many - especially medium-sized - firms and family-businesses, and by no means only a matter for the Social Business sector. In the real economy and in the financial economy there are plenty of business models reconciling principles with profit. ${ }^{57}$ The goal of economic pedagogy should be to explain and demonstrate their success, which occasionally even exceeds that of conventional business models, so as to teach how and why "decent business" 58 works.

The fulfilment of this directive, however, first requires a management-theory which places real people at the center of economic doctrine. Economics must eventually grant moral potentials the same status in theory that, because of their impact, they have in practice. Morality reduces the costs of conflicts and transactions, helps firms through the voluntary unremunerated support on the part of their stakeholders, and inspires entrepreneurs towards strategic innovation. Economic training must no longer obfuscate the actual opportunities which make possible a strategically directed Corporate (Social) Responsibility. One cannot shape, after all, what one cannot see. Only when the idea of freedom constitutes the foundation of economics will responsibility unmistakably appear to be the natural correlate of all economic activity instead of its burdensome "side constraint." ${ }^{59}$ We must no longer educate generations of economists who by permanently staring at theoretical fictions become blind to the practically necessary perception of the factuality of morally, socially, and sustainable economic activity.$^{60}$ In business curricula the modelling of dead, mechanical production factors must be replaced by the fundamental principle of all economic activity: vibrant and free human activity. Instead of mechanistic economics we need humanistic management. ${ }^{61}$

What holds for the microeconomic level, also applies to macroeconomic theory. Although, for a homo oeconomicus, the rational goal of economic policy may well be quantitative growth of the gross domestic product, for flesh-and-blood human beings that is not necessarily the case. They can and must qualitatively consider whether ever more production and consumption actually helps them attain a freer and more dignified life. ${ }^{62}$ It is thus to be welcomed that in macroeconomic debates people now begin to distance themselves from one-dimensional quantitative standards like GDP

\footnotetext{
${ }^{57}$ See Heiko Spitzeck, Michael Pirson \& Claus Dierksmeier, Banking with Integrity.

${ }^{58}$ See Hans Küng, Anständig wirtschafen: Warum Ökonomie Moral braucht (München, 2010).

${ }^{59}$ See Dierksmeier \& Pirson, "The Modern Corporation."

${ }^{60}$ See Dierksmeier, "The Freedom-Responsibility Nexus in Management Philosophy."

${ }^{61}$ For the history and theory of "humanistic management" as well as the publications on this topic see: http://humanisticmanagement.org/.

${ }^{62}$ See Domènec Melé \& Claus Dierksmeier (eds.), Human Development in Business: Values and Humanistic Management in the Encyclical in Veritate (New York, 2012).
} 
and draw on a range of alternative parameters for orientation. ${ }^{63}$ The quantitative conception of economic freedom that has predominated up to now (namely that of the Chicago School of Economics) is gradually giving way to a conception of economic freedom qualitatively orientated by the social, moral, and ecological conditions of its own sustainability. To strengthen economic responsibility in practice requires this turn in theory; especially when trying to inspire successful collaboration within unfamiliar constellations across cultural boundaries. ${ }^{64}$

The same is true of political theory. Here also, in the last decades, much havoc has been wrought by the decontextualized modelling of human behavior via the axiom of a rational maximization of self-interest; here, too, this lens's focus upon the isolated individual has provided a distorted picture of reality. Aspects which only appear from a perspective open to the natural environment and the social fellowship of human life, systematically ended up out of view. Thus, it is also in the interest of a more realistic and for that reason more relevant political theory to support another anthropology and to show that humans are beings essentially directed to alterity. ${ }^{65}$ Being free presupposes being integrated. Freedom is not an isolated faculty. Fellowships, customs, conventions, lifestyles - they all support or constrain individuals' opportunities in life. Freedom not only thrives in exclusive privacy, but flourishes also and especially in the inclusivity of autonomous commitments and communities. Consequently, the social bond - the friend, the family, the association, the firm, the federation, etc. - does not artificially have to be bolted on to the individual's existence, it is rather always already a natural form of how human freedom manifests itself. ${ }^{66}$

Unlike in contractualist theories, real life is not always strictly functional, but replete with spontaneous value creation and non-instrumental self-expression.

\footnotetext{
${ }^{63}$ Here is a small selection of such criteria (including, in brackets, the administering institutions): Human Development Index (The United Nations Development Program), The Global Gender Gap Report (The World Economic Forum), The Index of Social Health (Fordham University), American Human Development Report (The Social Science Research Council), The Calvert-Henderson Quality of Life Index; Child Development Index (Save the Children), The Child and Youth WealthBeing Report (The Foundation for Child Development), State of the World Population Report (United Nations Population Fund) System of National Accounts (The United Nations), The Civic Health Index (The National Council on Citizenship), Commission on the Measurement of Economic Performance and Social Progress Counting on Care Work (University of Massachusetts), The Gender Equity and Quality of Life Report (The Center for Partnership Studies), Genuine Progress Indicator (Redefining Progress), Levy Institute Measure of Economic Well-Being (Bard College), Missing Dimensions of Poverty Data (Oxford Poverty and Human Development Initiative), National Accounts of Well-Being (The New Economics Foundation), Organization for Economic Co-operation and Development Index of Statistical Variables Real Wealth Indicators (The Center for Partnership Studies), The (Un)Happy Planet Index 2.0 (The New Economics Foundation).

${ }^{64}$ See Claus Dierksmeier \& Anthony Celano, "Thomas Aquinas on Justice as a Global Virtue in Business," Business Ethics Quarterly 22:2 (2012).

${ }^{65}$ See José Ortega y Gasset \& Helene Weyl, Concord and Liberty (New York, 1946).

${ }^{66}$ "What, indeed, could be less scientific than to construct the notion of man, in abstraction from society, and then to explain society in terms of his desires?" (John Petrov Plamenatz, English Utilitarians [Oxford, 1958], 152).
} 
Human beings in no way only require and use one another in order to reciprocally remedy defects, they also unite together for more noble ends. Beyond compensating for deficiencies, individuals also aspire to perfect themselves and their environment. Sociability does not only arise as a result of the contingency of coexistence, but rather - as Krause in particular shows (Sect. 2.3.3) - also as a result of voluntarily chosen cooperation and collaboration in the free pursuit of aims that are considered to be of particular qualitative value. Such dimensions of sociability transcending any quantitative utility-calculus are particularly accentuated by the theory of qualitative freedom. Instead of - like contractualists and game-theorists - rationally reconstructing all personal commitments, qualitative liberalism focuses on the human desire for sociability in and for itself, i.e. upon the human propensity for cultural exchanges, symbolic communication, spiritual contemplation, and the freedom for ethical commitment.

Let us ascertain and retain the following: Individual freedom is in many cases complemented and completed by collective action. Although liberalism will never be collectivism, it need not end up in privatism and libertinism. ${ }^{67}$ In contrast, since human beings are relational life forms and voluntarily integrate themselves within certain social associations, these and their norms possess a special status in philosophical liberalism: They explicitly give expression to the implicit sociality of freedom - as forms and functions of the manifestation of freedom. ${ }^{68}$ For example, someone marooned upon an uninhabited planet, even if plentifully supplied with food and drink, will hardly experience themselves as being especially free, although they can pursue the fulfilment of their preferences physically unhindered as well as socially and morally unconstrained. The libertarian's dream of unhindered and quantitatively unlimited freedom proves to be, if radically fulfilled, nothing but a nightmare.

Integration is indispensable to the unfolding of personal freedom. ${ }^{69}$ Society has forever privileged certain forms of freedom and for the most part subordinated the freedom for destruction to the freedom for creation or the freedom for protection. And for good reason: Without symbolic forms and their norms, human beings degenerate and their freedom decays. Yet, by taking responsibility for its contexts, freedom furthers and fulfils itself. Freedom only survives within cultures which affirm and support it and should therefore contribute to their flourishing. ${ }^{70}$

In this sense, a qualitatively conceived liberalism respects and reinforces that everyone must be employed in ensuring that each and everyone can be free: whether in standing up for education and training, in defending private - yet socially-

\footnotetext{
${ }^{67}$ See Leonhard Trelawny Hobhouse, Liberalism (New York, 1911); Hobson, The Crisis of Liberalism: New Issues of Democracy (London, 1909).

${ }^{68}$ See Dahrendorf, The Modern Social Conflict; Avital Simhony \& D. Weinstein, The New Liberalism: Reconciling Liberty and Community (Cambridge, 2001).

${ }^{69}$ See Benn, A Theory of Freedom, 181: "Someone who had escaped such a socialization process would not be free, unconstrained, able to make anything of himself that he chose; he would be able to make nothing of himself, being hardly a person at all."

${ }^{70}$ See Di Fabio, Kultur, 75.
} 
obligated - property as the foundation for self-subsistent living, or in charitably caring for others; whether in engaging in the protecting of the natural resources enabling future generations to live freely, or in working in solidarity with the poor and socially-excluded of today. Just as our freedom is enabled by others, we are to enable the freedom of others.

Freedom has necessary preconditions. On that all of the thinkers analyzed in this study concur. On one hand, that means the removal of barriers. It lies within the idea of freedom to battle any discrimination which (based upon race, sex, class, religion, etc.) privileges the liberties of some above the freedom of others. Thus, from time immemorial, liberalism was a bastion of protective rights (Abwehrrechte). Nevertheless - as all the liberalisms treated here also agree - that is clearly not enough. On the other hand, the preconditions for personal autonomy must be actively promoted by the community since neither market nor nature ensure that everyone attains the economic or educational preconditions of autonomy. The demand of individual responsibility and the promotion of its prerequisites must accompany one another to ensure that people's destiny is not sealed merely by the location of their cradle.

The idea of qualitative freedom therefore imposes tasks on both the individual and the community: To free oneself from self-incurred dependency (selbstverschuldete Unmündigkeit) - as Kant showed paradigmatically - is something everyone owes to themselves. But - according to Fichte and Krause, and, later, Galbraith and Sen - the liberation from outwardly imposed dependency (unverschuldete Unmündigkeit) is something everyone owes to each other, both materially and ideally. It is cynical to demand respect for private property from the starving, and utopian to expect entrepreneurial prowess from the illiterate. Only those who grant everyone genuine opportunities are defending a fair freedom. Instead of viewing society as a contract for the reciprocal insurance of having, we should understand it as a covenant for the all-round enabling of being.

Freedom does not grow on trees, but flourishes in society. Without a social subtext, we may but theoretically refer back to a reservoir of metaphysical freedom, but without serious opportunities for its practical cultivation in life. Freedom therefore requires not only the absence of the violation of rights, but also the presence of certain conditions: For instance, freedom needs a socially active state empowering everyone's autonomy as well as effective environmental protection, an attentive civil-society, and a cultural community for the dissemination of values. For acts of freedom, the adage holds that what goes around comes around. How societies treat nature and culture, space and time, shapes customs: who or what merits attention; whether people are more or less willing to take on responsibilities; to what extent unwritten as well as legal rules are observed willingly or only in view of threatened sanctions. ${ }^{71}$ The practice of freedom rests upon preconditions that it can influence. Care for our social and natural surroundings is liberal, because freedom is relational.

\footnotetext{
${ }^{71}$ See Robert Levine, A Geography of Time - On Tempo, Culture and the Pace of Life: The Temporal Misadventures of a Social Psychologist, or: How Culture Keeps Time Just a Little Bit Differently? (New York, 1997).
} 
Qualitatively orientated freedom therefore proceeds economically and ecologically with caution. Precisely because liberal thinking imposes upon no-one the ultimate goals of their lives, it must - in the face of finite resources and the infinity of present and future human aims - advise us towards a precautionary use of our shared lifeworld and the Global Commons.

In my view, a liberalism appealing to the idea of qualitative freedom should also demand a humane provision of and universal access to public goods, like education, health, culture, and transport. Liberals should strive for a balanced allocation of assets - not directly and motivated from an interest in material equality, but rather indirectly and interested in an equitable access to the presuppositions and conditions of autonomy. Neither the secession of the rich nor the exclusion of the poor (accompanying extreme material inequality) can be tolerated by an idea of freedom which campaigns for a (global) society in which everyone contributes to the dignified life of all. ${ }^{72}$

Unlike some theories of positive freedom, however, the idea of qualitative freedom - like the "capability theory" championed by Amartya Sen - establishes an important procedural boundary when it comes to the implementation of this notion. While the universal enabling of qualitative freedom is legitimately a high priority of the social and cultural state (Sozial- und Kulturstaat), the specific organization of that dimension of freedom remains exclusively a matter for the citizens themselves. There is also a right to distinguish oneself from others through one's own work. Performance should be rewarded if and inasmuch as doing so honors everyone's equal right to unequal advancements.

Applied to current political circumstances, qualitative freedom demands not only the social embedding and cushioning of market-activities, but also - presupposing the latter - their free operation. Fair liberalism is therefore neither market-obsessed nor market-repressed. It respects the results of the free market economy as the expression of individuals' evaluations and aspirations insofar as the market - a condition never to be forgotten and often violated - is organized so as to heed the voices of the many instead of merely the valuables of a few. ${ }^{73}$ Consequently, the idea of qualitative freedom straddles the usual left-right schematizations germane to the logic of quantitative thinking and their blunt assertion that more equality/solidarity $=$ less freedom. Normally, social democrats show up upon the left side of that spectrum together with their alleged quest for achieving, with as much freedom as necessary, as much equality as possible. At the right end of the spectrum then reside neoliberals and libertarians trying to achieve, with as much equality as necessary, as much freedom as possible. Somewhere in between classical liberalism scuffles with new liberalism for the sovereignty over the definition of the golden mean. ${ }^{74}$

\footnotetext{
${ }^{72}$ See Parijs, Real Freedom for All.

${ }^{73}$ That is, especially in regard to the global market, unfortunately a condition that is all too often violated, which makes the economic policy of free-trade - which (under ideal conditions) is potentially a blessing - a (when under real conditions) scourge of the poor, see Agus Pakpahan, Freedom for Farmers, Freedom for All (Bogor, 2007).

${ }^{74}$ See Thomas Nagel, "Review: Libertarianism without Foundations," The Yale Law Journal, 85:1 (1975), 136-149.
} 
Underlying this quantitative scheme is the superstition of a fundamental conflict between equality and freedom, according to which gains upon the one side are registered as loses on the other: a zero-sum game. ${ }^{75}$

It is not only in extreme cases that this model fails: Wherever no kind of equality prevails there is typically just as little freedom and vice versa. Anarchic and tyrannical conditions for the most part deny citizens both freedom and equality. This practical deficiency has its ground in the theoretical deficit of concise categories. The "alleged conflict between equality and liberality" is in truth "a category mistake." ${ }^{76}$ Even libertarians want equality, albeit limited to formal and procedural aspects. Socialists also want freedom, albeit through plan-based economic redistribution. Consequently, the ideas of freedom and equality do not at all find themselves in an insurmountable tug-of-war; merely some concepts of freedom need to be reconciled with demands for material equality. ${ }^{77}$ So, wherever quantitative freedom declaims an abstract stalemate of ideas, the question concerning the concrete quality of respective freedoms finds a way forward: The integration of certain aspects of equality as genuine demands of the liberal idea. While, from the quantitative perspective, liberals view social-democrats as arch-enemies, from the qualitative perspective one sees them both as struggling for forms of equality which support and conform with freedom.

The same is true of liberalism's ecological focus. For many years, upon both sides, a false antagonism between liberal and green movements was paraded around. Today it becomes obvious, though, to ever more people, that the idea of freedom includes the principle of sustainability. As soon as liberalism turns its back upon the quantitative fixation with utility-calculi and, in aiming to protect the rights of future freedom, opens itself up to the qualitative notion of an obligation also committed to strictly asymmetrical relations, imperatives of sustainability will immediately be recognized as indispensable components of a liberal program. Conversely, it should be obvious just how much green politics profits from liberal axioms. A credible demarcation from eco-dictatorial positions will only succeed by means of a marked commitment to freedom as the primordial foundation for the evaluation of all lifestyles. Only as freedom's devisee can a politics of sustainability accept its bourgeois inheritance.

The philosophy of qualitative freedom does not define the spectrum of liberalism between the abstract antitheses of left and right, but rather in accordance with the actual tension between freedom's prerequisites and freedom's goals. Politics, in the sense of qualitative freedom, must continually mediate between freedom's particular intentions and its universal conditions - through a constant back and forth between the dimensions of responsible and fair freedom. Responsible freedom honors worthwhile goals, while fair freedom preserves the presuppositions of personal autonomy. A qualitatively orientated liberalism can thus, for example, call upon cooperation between both progressive and conservative forces. In the name of responsible freedom, one might suggest the ("conservative") cultivation of family

\footnotetext{
${ }^{75}$ See Harry Frankfurt, "Equality as a Moral Ideal,” Ethics 98:1 (1987).

${ }^{76}$ See Amartya Sen, Inequality Reexamined (Cambridge, MA, 1992), 23.

${ }^{77}$ See Dworkin, Taking Rights Seriously, 270-273.
} 
values which give the freedom of individuals meaning and direction, but also - and for the same reason - the ("progressive") defense of non-traditional lifestyles in which individuals likewise develop into authors of their biographies.

Never in isolation, but always in dialectical unity only, must fair and responsible freedoms express the idea of qualitative freedom. Social policy, for instance, must aspire towards a balance between subsidiary responsibility on the one hand and solidary fairness on the other. Whoever only backs solidarity in social policy quickly turns it into the paternalism of comprehensive welfare. Conversely, sheer subsidiarity makes the opportunities of the poor dependent upon the privatism of donors. Neither paternalism nor privatism is liberal. The idea of qualitative liberalism is not shaped by the one-sided - but by the unified - use of responsible and fair freedom. Solidarity can be responsibly handled only in subsidiary form, and subsidiarity is only fair when solidary. Subsidiary solidarity and solidary subsidiarity should therefore be the lodestars of liberal social policy.

A society that wants freedom must forgive mistakes. Just as we, in private relations, continually give people second and third chances so that their (and our) freedom can forge new paths instead of grinding to a halt in the cul-de-sacs of the past ${ }^{78}$ so we should also do so in economic affairs. Everyone requires opportunities to work and participate in the economy in order to be able to take care of themselves and their own. Whoever - by their own fault or otherwise - becomes unemployed must receive new chances to said participation. The state of qualitative freedom does not hand out alms, but it does provide opportunities. In an economic order which, in the interest of the common good, depends on individual risk-taking, the state has the duty to ensure that individuals always retain the capacity to contribute to the whole. Freedom for economic risks has to be accompanied with freedom from the risk of social exclusion. People grasp economic opportunities much more readily when the state helps them to a new beginning in cases of failure. ${ }^{79}$ The state can count on the efforts of individuals if they can rely on social security by the state. Taxation to finance this backstop does not ruin our economic freedom, but rather enables and conditions it. ${ }^{80}$ Whoever preaches responsibility must empower people to take on responsibilites.

On the flip side, it needs to be reiterated that freedom obligates. Today's liberalism would benefit from the ancient insight that freedom manifests and enriches itself as virtue. The encomium of freedom should not sound like a hymn to baser instincts and the lowest common denominator. But precisely in this - in the qualitative distinction between the true face of freedom and the false grimace of the permissiveness of hedonistic consumerism - the West's politics has recently shown itself to be just as ignorant as inept. In the drunken belief in the redeeming power of unlimited growth, it was overlooked that a freedom, which only thrives quantitatively, gradually loses its qualitative determination as well as its orientation towards the common good. It was premature to reject, as an allegedly improper curtailment of the private sphere, the res publica as the true focus of freedom.

\footnotetext{
${ }^{78}$ See Klaus-Michael Kodalle, Annäherungen an eine Theorie des Verzeihens (Stuttgart, 2006).

${ }^{79}$ See Parijs, Real Freedom for All, 28.

${ }^{80}$ See Pettit, Republicanism, 66, 110 \& 273.
} 
Freedom depends more on the class than on the mass of our options. ${ }^{81}$ Selfreflective liberalism philosophically is thus not only bent upon the quantitative enumeration of abstract options but focuses in the first instance rather on the qualitative evaluation of concrete opportunities. For, when quantitative thinking treats all freedoms without differentiation, liberalism leaves people indifferent. For that reason, it is to be stressed that, the more essential a freedom, the more strongly should we - as against alternative possibilities - promote it. The qualitative evaluation therefore precedes the quantitative enumeration; for, in some cases (for example, in regard to unsustainable practices), less can actually be better. On occasions, freedom shows itself in the reduction of options. ${ }^{82}$ This holds especially for liberalism's ethical orientation. ${ }^{83}$ Because the idea of qualitative freedom links individuals' freedom with universal freedom it sees the acceptance of responsibility for others as not an external negation but rather an internal manifestation of freedom.

From a qualitative perspective, then, liberalism has to take up much unfinished business of emancipation and ought to take on long-overlooked dimensions of responsibility. We everywhere need a more inclusive liberalism than the one provided by the symmetry-fixated hypotheses of contractualism and game-theory. To achieve fair and responsible freedom, a shift within liberal discourse is necessary: a turn away from the neoliberal and libertarian concepts of freedom and back towards the forever qualitatively orientated progressive roots of the Anglo-American liberalism as well as the qualitatively orientated ordo-liberal tradition of German liberalism.

Today's liberalism requires, in nuce, a philosophy of freedom in the genetivus objectivus - as a philosophy for freedom; as well as also in the genetivus subjectivus - as a freely self-developing philosophy. We find this philosophy arising from the idea of qualitative freedom. In regard to the tension between the aims of individuals and of communities, qualitative freedom wishes to reconcile them (to preserve freedom), to coordinate them (to shape freedom), and to inspire people to use their personal freedom on behalf of the autonomy of others (to spread freedom).

\subsection{Outlook}

The freedom of the other not only defines the boundary of our own, but also determines one of its noblest goals. Not only do we demand freedom but also freedom makes demands on us. It calls for liberation: internally, for the emancipation of ourselves, but also externally, for the liberation of everyone else. Since neither market nor nature can ensure that everyone can lead an autonomous life, the demand of individual freedom and the promotion of its general presuppositions must go hand in hand. Consequently, liberals should not only defend possessions already held and

\footnotetext{
${ }^{81}$ See Claudia Mills, “Choice and Circumstance," Ethics 109:1 (1998).

${ }^{82}$ See Robert Young, Personal Autonomy: Beyond Negative and Positive Liberty (New York, 1986); Dworkin, The Theory and Practice of Autonomy.

${ }^{83}$ See Brian Morris, Bakunin: The Philosophy of Freedom (New York, 1993).
} 
liberties already secured, but also everyone's claim to receive access to property and rights. Personal property secures participation in the world; and there is a human right to such participation. Since we are entitled to freedom only as a result of reasons applying to everyone, it follows that, as long as there is but one single human being who lacks freedom, everyone's freedom is imperfect.

The idea of qualitative freedom is thus per se neither local, nor national, but global; it does not exclude anyone, yet includes everyone. Race, sex, and religion, but also spatial-temporal distance, in no way diminish the validity of a demand for freedom. The citizens of distant countries and members of future generations have just as much a human right to the conditions enabling a free life as persons with whom we interact or trade directly. A consistently realized idea of freedom extends, therefore, not only its protective dimension to asymmetrical spatial and temporal relations but also the obligation towards capability building. Only a globally solidary liberalism is a consistent liberalism.

Our work has demonstrated that a liberalism arising from a theory of qualitative freedom must reflect upon precisely this obligation towards worldwide solidarity. Freedom revealed itself as an ongoing task for humanity charged always to transcend its historical achievements anew. Yet this mandate does not provide liberal thinking with an instruction manual for its world-historical mission. The precise way in which a cosmopolitan liberalism operating in the name of qualitative freedom is to develop can ultimately only be decided by the global citizenry and not academic philosophy.

Precisely because the claim to freedom extends to all persons, there will be differences from place to place, not only in the manner freedom is lived, but also in the way it is conceptualized - and that includes the respective interpretation of its global responsibility. The unity of freedom must be realized, not through uniformity, but in multiplicity. At the same time, the global claim of the idea of freedom as universal entitlement to the presuppositions and conditions required for an autonomous life helps every liberalism 'on the ground' to establish the locally appropriate forms of freedom qualitatively (for example by the prioritization of competing claims) and quantitatively (for example in respect to the magnitude of individual versus institutional freedoms, the extent of societal codetermination, etc.). This is not the place to anticipate this worldwide dialogue about the future shapes and forms of freedom, but solely to prepare for it. Instead of drafting that impending form of qualitative freedom, I would like to conclude by outlining the questions and challenges that such discourse about the globality of freedom must confront.

In the face of the severely tattered global image of the idea of freedom, it seems more than doubtful at the moment that the people and peoples of this world will want to unite under the liberal banner. There is skepticism and mistrust against freedom. And not without reason. After the collapse of the 'real-existing socialism' it was loudly proclaimed that finally the idea of freedom had been victorious and that now the history of the human species was about to fulfil its destiny. ${ }^{84}$ Today, though,

${ }^{84}$ See Christopher Bertram \& Andrew Chitty (eds.), Has History Ended? Fukuyama, Marx, Modernity (Aldershot, UK \& Brookfield, VT, 1994); Timothy Burns, After History? Francis 
this interpretation of history, which repeated Hegel's fulminant thesis that "the History of the World is nothing but the development of the Idea of Freedom," 85 has lost much of its luster.

Two decades ago, however, the course of history seemed to justify such liberal optimism. The revolutions in Eastern Europe were indeed characterized by a desire for civil liberties. With the sweeping victory of democratic freedoms over socialist commando-economies, the world appeared to exit from a centuries-old labyrinth of political and economic confusions. Intellectual interpreters like Samuel Huntingdon or Francis Fukuyama proclaimed in unison with less intellectual politicians like George W. Bush that under the banner of freedom the world could and should be mended. ${ }^{86}$ The way towards a better future, to a world of affluence and peace, towards a second Garden of Eden, would, it seemed, be paved by freedom, i.e. the individual freedom to activate personal potentials and their economic power as well as the collective freedom for cooperative corporative and democratic-participative organization.

This optimism soon fell flat. The champagne of democratic autonomy of the 1990s quickly lost its fizz right after the turn of the century. Fermented by corruption on the inside and heated by crises from the outside, in Eastern and Central Europe, the sparkling wine of liberal self-government soon fermented into the vinegar of bitter systematic constraints. And especially the most recent global economic crises had a sobering influence upon liberals across the world. The intoxication of rapidly globalizing freedom was followed by the stubborn hangover of cosmopolitan responsibility and global sustainability problems.

On the part of the West, military violations of international law and economic incursions into sovereign national spheres - cynically, stupidly, or perfidiously perpetrated in the name of freedom - have considerably damaged the liberal idea. ${ }^{87}$ The 'liberalization' of markets pushed through as a result of, for instance, the Washington Consensus ${ }^{88}$ visited severe economic dependency upon many people and peoples. Certainly, this program of deregulation originated within the camp of

Fukuyama and his Critics (Lanham, MD, 1994); Francis Fukuyama, The End of History and the Last Man (New York, 1992).

${ }^{85}$ Georg Wilhelm Hegel, TWA 12, 539f. Translated in Georg Wilhelm Hegel, The Philosophy of History (New York, 1956), 456.

${ }^{86}$ See Samuel P. Huntington, The Clash of Civilizations and the Remaking of World Order (New York, 1996); Fukuyama, The End of History and the Last Man; George W. Bush, Our Mission and Our Moment: Speeches since the Attacks of September 11. (Washington D.C., 2001).

${ }^{87}$ See Carl Mirra, Enduring Freedom or Enduring War? Prospects and Costs of the New American 21st Century (Washington, D.C., 2005); Aziz Rana, The Two Faces of American Freedom (Cambridge, MA, 2010); Anthony Bogues, Empire of Liberty: Power, Desire, and Freedom (Hanover, NH, 2010).

${ }^{88}$ See Shahid Javed Burki \& Guillermo Perry, Beyond the Washington Consensus: Institutions Matter (Washington, D.C., 1998); Ben Fine, Costas Lapavisas and Jonathan Pincus, Development Policy in the 21st Century: Beyond the Post-Washington Consensus (New York, 2001); A. K. N. Ahmed, Washington Consensus: How and Why It Failed the Poor (Dhaka, 2004); Narcis Serra and Joseph E. Stiglitz (eds.), The Washington Consensus Reconsidered: Towards a New Global Governance (New York, 2008). 
the libertarians ${ }^{89}$ and neoliberals, ${ }^{90}$ and only rarely finds support by liberalism's classical authors or the German ordo-liberals, and not at all by the progressive liberals in the USA or the new liberalism in Britain. Nonetheless, the idea of freedom as a whole suffered collateral damage. Many blamed not only the actual actors, like the International Monetary Fund (IMF) and the World Trade Organization (WTO), for the mistakes of these programs, but the liberal ideology as such. Many, who were stretched upon the rack of economic liberalization in the last few decades, blame the dislocations they suffered on the notion of freedom itself and not only on its libertarian overextension.

What is more, there is a widespread perception that the recently experienced economic crises are not only economic but also societal, not only financial but also moral, and not really accidental but rather inevitable. ${ }^{91}$ As a result, the call for systemic reform and - prior to that - systematic reflection becomes ever louder. The economic crisis smoldering since 2008 significantly contributed to a worldwide shift in consciousness by devaluing as outdated many of the old-fashioned prescriptions of liberal politics - less state, laissez faire, deregulation, monetarization, and incentivization. ${ }^{92}$ Accordingly, the liberal camp currently sings the credo of liberalization more quietly.

This must unsettle neoliberals and libertarians, since for quite a long time they have directly connected the striving for freedom and the striving for profit: The racing car welded together from the axioms of neoclassical economics and neoliberal political theories, after all, has had a good run a while! That vehicle of deregulated quantitative freedom accelerated by Thatcher, Reagan, and their successors, with

\footnotetext{
${ }^{89}$ For information about the terminology of varying libertarian [libertärer und libertarischer] positions in philosophy and political science see footnote 115 . A concise comparison between liberal and libertarian thinking is provided by Samuel Freeman, "Illiberal Libertarians: Why Libertarianism is Not a Liberal View," Philosophy and Public Affairs 30:2 (2001).

${ }^{90}$ A short note about the use of the concept "neoliberal": The appellation "neoliberal" first surfaced amongst ordoliberal thinkers (Eucken, Röpcke, Müller-Armack). In the journal "Ordo" they above all criticized as "paleoliberal" almost exactly those minimal-state attitudes (radical privatization, deregulation, laissez faire, etc.), which one today often writes off with the label "neoliberal." In contrast, they supported under the rubric "neoliberal" an ordoliberalism also vigilant in regard to social concerns. The use of the concept "neoliberal" based upon German etymology today, however, hardly finds any imitators, since, internationally, this fact is still largely unknown. In global discourse, the concept "neoliberal" thus rather outlines the - Mises and Hayek inspired - Chicago School of Economics' (and the political theories inspired by it) turn away from the moral as well as social and democratic elements of the classical liberalism of Hume and Smith in favor of an advancing deregulation and privatization. "Neoliberal" is also used here in this far more usual sense. For this "deutschen Sonderweg" in etymology see Viktor Vanberg, "Ordnungstheorie' as Constitutional Economics: The German Conception of a "Social Market Economy" in Walter Eucken (ed.), ORDO: Jahrbuch für die Ordnung von Wirtschaft und Gesellschaft 39, 1988.

${ }^{91}$ See Rowan Williams \& Larry Elliott, Crisis and Recovery: Ethics, Economics, and Justice (New York, 2010); Kean Birch \& Vlad Mykhnenko (eds.), The Rise and Fall of Neoliberalism: The Collapse of an Economic Order? (New York, 2010).

${ }^{92}$ See Olivier J. Blanchard et al., In the Wake of the Crisis: Leading Economists Reassess Economic Policy, 2012; Adair Turner, Economics after the Crisis: Objectives and Means, 2012.
} 
the gas of deregulated economies seemed to glide almost effortlessly over political burdens, cultural barriers, ecological problems, and religious sensitivities. But upon the home straight towards a state-bereft global society, the sleek sports car lost traction, ended up skidding on the oil of speculative finance, and crashed into the brick wall of reality. Now that it is only fit for scrap metal, no one admits to having had their hands on the wheel.

Libertarians (like Hillel Steiner) smarten-up leftist cantilevers; economic liberals return to shock-absorbers from moral philosophy (like those in Adam Smith); and in the camp of ordo-liberalism tools critical of the market (of, for instance, Wilhem Röpke) are brought out of storage. At home and abroad one suddenly remembers the insight of classical liberalism that the selfish cruising of the few needs to be slowed down by making basic provisions for the many and ethical rules for all. Admirable though these insights are - above all as indirect admissions of guilt on the part of those who negligently or deliberately forgot all this for far too long - they do not suffice to set things in gear again. The crash was ultimately not an accident but due to the fact that the unfortunate liberal-economic vehicle was controlled by an understanding of freedom that systematically obstructed sideways glances upon the ecological, social, and moral crash barriers of the economic route. In order to make freedom's vehicle road-worthy again, the cause of the crash - the quantitative tunnel-vision - must above all be remedied. Otherwise future accidents are already predestined.

Against the idolization of the market on the part of quantitative liberals (in their talk of 'market society', etc.) a qualitative basic principle should be adhered to: The freedom for self-determination should be realized, and not undermined, by the market. The market has to serve people and their freedom - not vice versa. ${ }^{93}$ Qualitatively thinking liberals therefore promote a global trade that gives everyone the chance to develop autonomously. We must maintain that, only fair trade is truly free trade. Only when all parties to an economic transaction are so positioned that they can refrain from "humanly intolerable exchanges" may one conclude that formal voluntariness implies the material legitimacy of transactions. ${ }^{94}$ To ensure a fair and square deal for all parties, it is advisable to differentiate, as in sports, between weight categories. Small states and weak economies sometimes need protective rules; liberal solidarity demands that we help them obtain these. For equally treating the unequal is quite as unjust as unequally treating the equal. ${ }^{95}$

Some liberals falsely see critics of globalization per se as opponents of their cause. However, those (like the proponents of the Washington Consensus) who prescribe that freedom is only to be quantitatively understood, i.e. as the maximization

\footnotetext{
${ }^{93}$ See Ronald Dworkin, Sovereign Virtue: The Theory and the Practice of Equality (Cambridge, MA, 2000).

${ }^{94}$ See Vivian Walsh, “Amartya Sen on Rationality and Freedom," Science and Society 71:1 (2007), 63.

${ }^{95}$ See Mark R. Reiff, Exploitation and Economic Justice in the Liberal Capitalist State (Oxford, 2013).
} 
of - especially economic - options, themselves violate that very freedom for civic self-determination held aloft by all liberals. It is rather the profoundly liberal concern - political autonomy for all - which is recognized by the critics of globalization who avowedly struggle for the freedom for regional and local self-determination. Accordingly, a qualitatively orientated liberalism may not stand idly by when forms of economic activity are internationalized, while the legal and political means for influencing it remain limited nationally. For otherwise ecological, cultural, and social liberties soon become the victims of economic freedom.

Whose freedom is served if the profits of international business primarily go to rich nations and large corporations while the negative externalities chiefly haunt poor countries and smaller civic and economic units? ${ }^{96}$ Here, not only the principle of justice, but also the cosmopolitan dimension of the idea of freedom, is violated. Liberals should therefore protest when the postulates of free-trade and competition are asserted only if and inasmuch they coincide with the interests of affluent nations. Qualitatively directed freedom not only campaigns against discriminations contrary to human rights where such advocacy may bring political or other advantages (the opening of markets, new alliances, etc.). To loosen the grip of economic power through rule-governed competition was forever the concern and pride of the ordoliberal school ${ }^{97}$; a notion we must return to today on a global scale.

Qualitative liberalism has to engage itself also and especially where this means coming into conflict with today's centers of power - dictatorial, hegemonic, oligarchic, and plutocratic structures. Under the flag of quantitative freedom, however, such battles were rarely fought. And, in my opinion, that explains a good part of the worldwide unease about the idea of freedom. Today many harm the banners of cosmopolitanism because of disingenuous and dishonorable campaigns in the name of universalism. Since the ideas of human rights and of freedom were often defended too one-sidedly, they are now challenged from every side. The idea of freedom therefore urgently requires new strategists (strategoi) and more successful qualitatively orientated - strategies. We must rethink freedom from the ground up, in order to leave behind the division of the world into friends and foes of freedom for being erroneous on the part of either perspective.

While quantitative theories tend to outsource into the realm of private morality all forms of global responsibility that contribute to the augmentation of their respective options, the idea of qualitative freedom fundamentally comprises and insists

\footnotetext{
${ }^{96}$ See J. Timmons Roberts \& Bradley C. Parks, A Climate of Injustice: Global Inequality, NorthSouth Politics and Climate Policy (Cambridge, MA, 2007); Stephen M. Gardiner, "Ethics and Global Climate Change," Ethics 114:3 (2004); JoAnn Carmin \& Julian Agyeman (ed.), Environmental Inequalities beyond Borders: Local Perspectives on Global Injustices (Cambridge, MA, 2011); Flavio Comim, "Climate Injustice and Development: A Capability Perspective," Development 51:3 (2008).

${ }^{97}$ See for example the contributions in Walter Eucken et al., (eds.), Freiheit und wettbewerbliche Ordnung: Gedenkband zur Erinnerung an Walter Eucken (Freiburg, 2000) as well as in Eucken's original: Walter Eucken, Grundsätze der Wirtschaftspolitik (Bern, 1952).
} 
upon a responsibility for the whole. As individuals' rights to freedom are not rooted in their subjective particularity, but rather in their personality, a qualitatively orientated philosophy of freedom necessarily culminates in cosmopolitanism: with the task of helping everyone achieve autonomy. Qualitative freedom begins and ends with global citizens and their actual opportunities in life. Nationalistic egotism is thus foreign to a qualitatively directed liberalism. Instead of being on the defensive, liberals are proactively to advance the free self-determination of everyone and stand up for the emancipation of all global citizens.

But who is this global citizen? Just as in the search for the essence of the human being, this question cannot simply be answered materialistically or empirically. Neither the human being as such nor the global citizen as such can be laid down naked upon a spectrometer so that we can then precisely read off their anthropologicalmetaphysical mass. Of course not; since humans are relational beings, one cannot analyze them in abstraction from their relations. At issue is less the biological skeleton and more the symbolic framework of the human lifeworld. The worlds created artificially from science and religion, morality and law, economics and politics, within which human beings develop their future selves, demonstrate that it is in the nature of human freedom to be at work; and its works are not only material but also ideal. Metaphysics belongs to the human condition just as much as monuments do; humanity gives expression to its ideals through edifices of the spirit just as much as by way of physical buildings. Before the eternal background of religion's and metaphysics' ultimate questions, humanity ever anew ponders what, in its time and day, might be adequate answers to the penultimate questions of politics and economics, law and morality. It is therefore not very modern but rather very naive to expect or desire that human beings at long last renounce metaphysics, religion, and spirituality.

Principles so comprehensive that, even in cases of conflicting interests, the global community still turns to them for normative orientation never can be externally, i.e. heteronomously, imposed on people. They must rather be suggested to people from within their own worldviews and made plausible by means of their own reason. I am thus skeptical about the attempts of academic philosophy to solve the problems of global ecology, global economy, and global politics by reinventing the moral wheel. One does not have to be a gourmet to find unappetizing the idea of a 'global dish' to feed all people everywhere. And the notion of a 'global ethics' (Weltethik), which once and for all, down to the smallest detail, would prescribe to everyone everywhere what they should do, seems to me to be just as unattractive. I believe it more plausible, as well as more in keeping with freedom's procedural guidelines, to rather seek a convergence of those values global citizens already espouse.

The philosophy of freedom must thus leave the ivory tower and make its way within the streets of this world and pick up on what forms of responsible freedom find respect in the various cultural communities. ${ }^{98}$ Thus it will encounter people as constantly self-interpreting and morally self-examining persons. Yet only a few

\footnotetext{
${ }^{98}$ A similar argument can be found in: Ganesh Nathan, Social Freedom in a Multicultural State, 2014.
} 
people orientate their normative ideals of self solely by means of secular mental models. Most people abundantly supplement their cognitive diet with spiritual accoutrements. A liberalism unable to digest this side-dish will thus sooner or later become enfeebled. ${ }^{99}$ Unlike theories of quantitative freedom (see Sect. 4.3), any liberalism concerned with the actual homo sapiens must therefore also be able to understand spiritual and metaphysical orientations and relate these to its own values and tenets. And only within the framework of a theory of qualitative freedom can this be accomplished; albeit - as the philosophies of Kant and Krause clarified never in a manner that imposes more - or other - forms of reflection upon ultimate questions than the citizens themselves request.

Qualitatively orientated liberalism thus inherits selectively - and critically humanity's metaphysical and spiritual traditions. If religious citizens formulate political maxims as a result of their spiritual convictions, such arguments are not suspect simply because they are guided by spiritual premises. Nevertheless, whenever these religious convictions make the claim immediately to instruct collective action and political decision-making, one must examine the extent to which those arguments could also convince non-believers or those of other faiths. ${ }^{100}$ Therefore, in a qualitatively liberal political system, religiously or metaphysically founded truths do not directly carry weight, but at most do so indirectly: when and insofar as they formulate values affirmable also by alternative world-views.

The latter is all the more the case the more precisely the respectively mobilized values agree with fundamental convictions of all human beings, like, for instance, the Golden Rule. ${ }^{101}$ With such principles, the transformation of spiritual wisdom into secular validity easily succeeds; with other values (for instance when looking at certain sexual norms) that is far less the case. Yet, wherever a stable, intercultural agreement in certain fundamental values does result, it can work in the background of political discourse as a subtle filter for the proposals being foregrounded. For instance, political projects of religious (as well as secular) interest groups and communities that move within that intersection of globally converging values, may thus enjoy greater approval and thereby better chances of being realized than others.

But is there at all such a humane consensus and wherein could it consist? In the last years, this question was intensively pursued within spiritual, ${ }^{102}$ agnostic, ${ }^{103}$ and secular ${ }^{104}$ contexts, especially under the auspices of the Global Ethos Project

\footnotetext{
${ }^{99}$ See Di Fabio, Kultur, 8.

${ }^{100}$ See Todd Hedrick, Rawls and Habermas: Reason, Pluralism, and the Claims of Political Philosophy (Stanford, CA, 2010).

${ }^{101}$ See Bauschke, Die Goldene Regel.

${ }^{102}$ See Fethullah Gülen, Toward a Global Civilization of Love \& Tolerance (Somerset, NJ, 2004).

${ }^{103}$ In this regard we must above all think of the recent publications of the Dalai Lama, for instance: Beyond Religion; Ethics for a Whole World (Boston, 2011).

${ }^{104} \mathrm{~A}$ collection of secular approaches can be found in: Dierksmeier, Humanistic Ethics in the Age of Globality.
} 
(Projekt Weltethos) founded in 1990 at the University of Tübingen. ${ }^{105}$ Over the last 25 years, scholars there have undertaken research into the fundamental values which interconnect people of all nations and regions and have produced a body of scholarship encompassing thousands of pages. As well as comprehensive monographs on the common ethical values of Judaism, ${ }^{106}$ Christianity, ${ }^{107}$ Islam, ${ }^{108}$ in Daoism and Confucianism, ${ }^{109}$ and in the spiritual life of Hinduism, Buddhism, and Jainism, ${ }^{110}$ Hans Küng and his team also traced this convergence of values in the field of intercultural literature ${ }^{111}$ and philosophy. ${ }^{112}$

The central result of these studies was that two formal principles and four substantial values were recognized - although, of course, not always observed - to be morally binding by humanity across all spatio-temporal boundaries. ${ }^{13}$ First, the Golden Rule of reciprocity (known through directives like "Do unto others what you would have them do unto you!') and the principle of humanity, to treat human beings humanely, i.e. to not treat subjects like objects. Second, when applied to the everyday lifeworld these two formal principles lead to four substantial basic values which likewise enjoy worldwide approval: truthfulness, justice, partnership, and peacefulness. Together, these rules and values constitute the kernel of an ethical attitude which has always and everywhere inspired people towards ethical behavior, precisely a global ethos.

Since these values have always found comparable expression in incomparable cultural contexts, that is to say, because the global ethos (Weltethos) ${ }^{114}$ belongs to the foundations of human self-orientation, one can view it as the kernel of a realistically idealistic anthropology. It represents the legacy of all human traditions: Thus, within and throughout the concrete plurality of cultures, we find a reflection of the

\footnotetext{
${ }^{105}$ See Hans Küng, Projekt Weltethos (München, 1990).

${ }^{106}$ See Hans Küng, Das Judentum: Die religiöse Situation der Zeit (München, 1991).

${ }^{107}$ See Hans Küng, Das Christentum: Wesen und Geschichte (Zürich, 2007).

${ }^{108}$ See Hans Küng, Der Islam: Wesen und Geschichte (Zürich, 2007).

${ }^{109}$ See Hans Küng, Tracing the Way: Spiritual Dimensions of the World Religions (London, 2002).

${ }^{110}$ See Stephan Schlensog \& Hans Küng, Der Hinduismus: Glaube, Geschichte, Ethos (München, 2006).

${ }^{111}$ See Karl-Josef Kuschel, Im Ringen um den wahren Ring: Lessings "Nathan der Weise" - eine Herausforderung der Religionen (Ostfildern, 2011); Karl-Josef Kuschel, Jesus im Spiegel der Weltliteratur: Eine Jahrhundertbilanz und Einführungen (Düsseldorf, 1999).

${ }^{112}$ See Hans-Martin Schönherr-Mann, Globale Normen und individuelles Handeln: Die Idee des Weltethos aus emanzipatorischer Perspektive (Würzburg, 2010); Hans-Martin Schönherr-Mann \& Hans Küng, Miteinander leben lernen: Die Philosophie und der Kampf der Kulturen (Zürich, 2008).

${ }^{113} \mathrm{~A}$ good overview of this and what follows is provided in: Küng, Gebhardt \& Schlensog, Handbuch Weltethos.

${ }^{114}$ See Hans Küng \& Karl-Josef Kuschel, Wissenschaft und Weltethos (München, 1998); Helmut Reinalter, Projekt Weltethos: Herausforderungen und Chancen für eine neue Weltpolitik und Weltordnung (Innsbruck, 2006); Schönherr-Mann, Globale Normen und individuelles Handeln: die Idee des Welthethos aus emanzipatorischer Perspektive.
} 
conceptual unity of the ethical nature of humanity. The global ethos thus resembles an invisible union of all civilization and cultures. That union cannot of course supplant the visible efforts on its behalf. Yet it instructs people of all backgrounds about how they can theoretically unite and practically cooperate. The key idea of the Global Ethos Project is that, as a result of the convergence of elementary values, persons of the most diverse backgrounds can, through dialogue, develop shared ideas and meaningfully cooperate. ${ }^{115}$

Clearly, for them to have obligatory power, the values of the global ethos need not only spiritual but also secular foundations. Secular reasons must be adduced so that they can bring together both believers and unbelievers beyond all spiritual foundations. These can be of historical as well as of systematic nature. One may perhaps more easily reach agnostics and atheists with the historical argument that conceptions of an ethically self-committed freedom, along with the values identified by the Global Ethos Project, have constantly arisen over the centuries. Across all historical and geographical spheres, people have time and again agreed on these basic norms of coexistence; in different forms, of course, from place to place and from time to time: in the spritual teachings of China and India, in the philosophies of northern Europe and South America, as well as in the poetry and reflections of African culture. ${ }^{116}$ Systematically, though, it needs to be shown furthermore why a way of life orientated by those values expresses the reasonable self-commitment of human freedom consistently and coherently.

Although people differ about what they celebrate as the highest quality of freedom, our study could demonstrate that they can very well agree that and about how human freedom should be ethically orientated. From this perspective, the values of the global ethos can be seen to manifest qualitative freedom via the mandate to take on responsibility for the dignified autonomy of all fellow humans. The perpetual quest of the world's cultures for a good, true, and meaningful life, viewed through the lens of a qualitative conception of freedom, appears to be as essential for a fulfilled human existence: as an expression of our freedom's ethical autonomy. This is why a qualitative liberalism must treat the traditions of all peoples, both spiritual and secular, with respect.

Of course, the rules garnered by the Global Ethos Project are of an expressly general nature and must, according to the context of their application, be further determined. The Global Ethos Foundation (Stiftung Weltethos) set about concretizing the meaning of these values and norms for questions of, for example, global

\footnotetext{
${ }^{115}$ See Hans Küng, "We Need Bridge-Builders - No Survival for the World Without a Global Ethic" in East-West Divan in Memory of Werner Mark Linz (London, 2014).

${ }^{116}$ See Christel Hasselmann, Hans Küngs Projekt Weltethos interkulturell gelesen (Nordhausen, 2005); Hans Küng, Ein Weltethos für die neue Weltepoche (1998); Hans Küng, Weltordnung braucht Weltethos - Interkultureller Dialog als Schlüssel zu friedlicher Koexistenz. (1997); Dierksmeier, Humanistic Ethics in the Age of Globality.
} 
politics, ${ }^{117}$ rights, ${ }^{118}$ economy, ${ }^{119}$ science, ${ }^{120}$ culture, ${ }^{121}$ pedagogy, ${ }^{122}$ sport, ${ }^{123}$ sustainability, ${ }^{124}$ etc. The shared goal of both the Global Ethos Foundation as well as the Global Ethos Institute (Weltethos-Instituts), which was founded at the University of Tübingen in 2012, is to continue and develop this work in the most inter-culturally inclusive manner possible. ${ }^{125}$ Nevertheless, the Global Ethos Project neither can nor wishes to issue exact instructions for all actions (Handlungen) through a universally binding "global ethic," it rather uncovers the shared ethical attitudes (Haltungen) behind humanity's divergent systems of morals. The goal is the orientation and coordination, not the equalization and standardization, of behavior so that, in the light of their basic convictions, people in all places together find appropriate solutions, for their respective time and context, to the problems they share.

The "global ethos," inductively derived from humanity's greatest ethical repositories, is not only to be pragmatically preferred to a philosophically deduced "global ethics" for departing from people's beliefs rather than sending them on an arduous intellectual path towards abstract philosophical ratiocination. Its most decisive advantage is in terms of principle. While a "global ethics" can all too easily understand itself as an ultimate answer to all questions, the Global Ethos Project stands for the precise opposite: for the beginning of an intercultural conversation that, in light of those shared attitudes and convictions, allows people to address what separates them as well as to cope with conflicts and problems. In the light of the global ethos, culturally conditioned differences in values are likely to be discussed and

\footnotetext{
${ }^{117}$ See Hans Küng, "Weltpolitik und Weltethos," Evangelische Akademie Bad Boll: Aktuelle Gespräche 43:4 (1995), 30-35; Hans Küng, "Zur Problematik von Weltpolitik, Weltstaat und Weltethos" in Stefan Gosepath \& J. C. Merle (eds.), Weltrepublik Globalisierung und Demokratie (München, 2002).

${ }^{118}$ Hans Küng, "Menschen-Rechte und Menschen-Verantwortlichkeiten" in Hans Küng (eds), Dokumentation zum Weltethos (München, 2002).

${ }^{119}$ See Hans Küng, Klaus M. Leisinger \& Josef Wieland, Manifest Globales Wirtschaftsethos: Konsequenzen und Herausforderungen für die Weltwirtschaft (München, 2010); Hans Küng, "Weltethos und globale Führungsverantwortung," in Uto Meier \& Bernhard Still (ed.), Führung. Macht. Sinn: Ethos und Ethik für Entscheider in Wirtschaft, Gesellschaft und Kirche (Regensburg, 2010).

${ }^{120}$ See Küng \& Kuschel, Wissenschaft und Weltethos.

${ }^{121}$ See Hans Küng, "Weltmusik - Weltreligionen - Weltethos. Interkulturelle Kommunikation durch Musik" in Christine Büchner et al. (ed.), Kommunikation ist möglich theologische, ökumenische und interreligiöse Lernprozesse, Festschrift für Bernd Jochen Hilberath (Ostfildern, 2013).

${ }^{122}$ See Stephan Schlensog \& Walter Lange (eds.), Weltethos in der Schule: Unterrichtsmaterialien der Stiftung Weltethos (Tübingen, 2008).

${ }^{123}$ See Hans Küng, "Welt - Sport - Ethos. Weltethos" in Eckhard Nagel (ed.), Deutscher Evangelischer Kirchentag Hannover 2005 (Gütersloh, 2005).

${ }^{124}$ See Hans Küng, "Nachhaltige Entwicklung und Weltethos" in Heidi Bohnet-von der Thüsen (ed.), Dekanstöße '99 Ein Lesebuch aus Philosophie, Natur- und Humanwissenschaften (München, 1998).

${ }^{125}$ More information about the institute's work can be found at www.weltethos-institut.org/.
} 
resolved, instead of - as is to be feared of the perspective of a global ethics - being silenced and repressed.

Qualitative liberalism and the Global Ethos Project converge in the basic insight that freedom will flourish insofar as it helps people overcome worldwide ethical challenges. Thus, when the Global Ethos Project demands cosmopolitan responsibility from individuals' freedom, the image that should come to mind is not that of a prison cell, but that of a body's skin. Said responsibility is a boundary conferring shape and individuality on freedom, not a limit hindering it. Our investigation has shown: Values - and the global dialogue concerning them - belong in the center of the liberal self-image. In the face of the spatial globality of our lifeworld and in the time-spanning countenance of generations to come, from care for our natural and social surroundings, as well as from concern for what we leave behind, both with a view towards the ideal of the integrative tolerance and faced with the reality of exclusionary intolerance, mindful of the material foundations of life as well as of its spiritual transcendence, a freedom finding its measure and mean in the global ethos brings people together in calling upon the freedom of each and every person to advance the freedom of all the world's citizens.

Attempting to navigate by the light of its lodestar, a qualitatively orientated philosophy of freedom finds in the Global Ethos Project an ethical inspiration of kindred spirit. A philosophically crafted theory of qualitative freedom likewise provides important secular support to the Global Ethos Project. A qualitatively oriented liberalism can explain why the spiritual traditions detailed in the Global Ethos Project may also inform secular perspectives. For human beings are what they become, and people become what they strive for; and thus the cultural and spiritual aspirations of humanity- of all human beings - belong to the definition of homo sapiens. ${ }^{126}$ Human beings are cultural by nature insofar as they realize themselves by means of the symbolic worlds and meanings they themselves create. As beings seeking for meaning they essentially live in a world of values. Thus considered, moral commandments and the vast cosmos of contemplative or meditative practices and religious symbols belong to humanity just like the flora and fauna which populate our biological environment. ${ }^{127}$ Instead of having to create out of nothing the values for the orientation of human freedom within daily life, they can be picked up from the wealth of spiritual and secular designs and historically developed practices. ${ }^{128}$

With the critical sampling of values and with the selection of programs suitable for the problems of the future, it is as ever the task of philosophy to analytically examine the (metaphysical, moral, political, and religious) concepts introduced by its interlocutors, and to square them with the demands of reason. The procedural dimension of qualitative liberalism - as worked out especially in the chapters on Karl Christian Friedrich Krause and Amartya Sen - ensures that this return to tradi-

\footnotetext{
${ }^{126}$ See Ernst Cassirer, Freiheit und Form: Studien zur deutschen Geistesgeschichte (Berlin, 1916).

${ }^{127}$ See Helmuth Plessner, Die Stufen des Organischen und der Mensch: Einleitung in die philosophische Anthropologie (Berlin, 1965).

${ }^{128}$ See Arnold Gehlen, Anthropologische Forschung (Reinbek bei Hamburg, 1967).
} 
tion, via a lively exchange of religious and philosophical, spiritual, and secular arguments, remains within the confines of a wholesome pluralism. For, after all, only those values may be put into practice which both survive their critical selfapplication (see Sect. 4.3) and are honored by the citizens as a liberal form of collective self-commitment. Through liberal procedures, freedom can thus be reclaimed as a morally appealing and aspirational ideal without, however, restricting the idea of freedom to but a single set of ethical goals.

This optimistic vision of a reciprocal self-examination of freedom's demands taking place in the public sphere with the aid of values broadly affirmed by humanity, and, proceeding by means of a "cosmopolitan conversation" ${ }^{129}$ about the collective mastery of the problems besetting global citizens, does not find applause with secular and spiritual fundamentalists. The former dislike the notion of spiritual foundations penetrating into public judgments. The latter are displeased about their religious fundamentals being subjected to critical examination - that would be to faithlessly enthrone reason as a judge over God. The religious fanatic is never satisfied with the demand for tolerance - i.e., with maintaining one's faith as true internally, while externally neither representing it as absolute nor imposing it ruthlessly on others. ${ }^{130}$

We have already (see Sect. 4.3) rebutted the secular fundamentalism (for instance of Rawls). The spiritual fundamentalism must of course be countered as well. Certainly, in plural societies, the views of religious fundamentalists are nowadays modernized and mediatized as a rule. Yet even where the stability of civil tolerance is not in peril, it exists against the will of the fundamentalists and is often only the eventual result of century-long bloody confrontations. ${ }^{131}$ For inner-societal and inter-societal peace, it is therefore important to indicate to religious fanatics that an absolutization of their own viewpoint is contrary to that very stance - and not just contrary to the liberal procedures of open societies. The true strength of the pluralistic worldview lies in this argument: Religious fundamentalism contradicts the true essence of religion; fanaticism is irreligious. ${ }^{132}$

Whoever views religious proclamations as signs with binary indicators - here the sign, there the signified - misunderstands them. Holy texts do not function as signposts equally valid for and equally indifferent to every observer. Religion rather communicates symbolically in a tertiary relation, where in the middle, between the sign and signified, the believers enter (or do not enter). Without their interpretation the process of communication from sign to signified is broken and no intellectual spark is transmitted. Religious electricity can only flow when the believer personally produces that interpretative connection. The spiritual fundamentalist therefore

\footnotetext{
${ }^{129}$ See Kwame Anthony Appiah, The Ethics of Identity (Princeton, NJ, 2005).

${ }^{130}$ See Hans Küng, Existiert Gott? Antwort auf die Gottesfrage der Neuzeit (München, 1978).

${ }^{131}$ See Heiner Bielefeldt, "Universalism Versus Relativism on the Necessity of Intercultural Dialogue on Human Rights" in Kai Hafez \& Mary Ann Kenny (eds.), The Islamic World and the West: An Introduction to Political Cultures and International Relations (2000).

${ }^{132}$ For more information about the following issue see Dierksmeier, Noumenon Religion.
} 
performatively contradicts himself when he precisely denies to others that which religiously electrifies him: the individual appropriation and interpretation of religious symbols. He can only account for the truth of his faith in a manner which he - if he wants to lead them into faith - must grant to others. The people which the religious fundamentalist wants to convert will only become relays of spirituality by way of their very own hermeneutic - or never reach authentic religiosity. The uniqueness of religious truth in the inner perspective and its plurality in the outer perspective are, correctly understood, one and the same. Consequently, with the demand for the toleration of adherents of other faiths, religious freedom is not curtailed but confirmed. ${ }^{133}$

Since secular fundamentalism misses the mark and spiritual fundamentalism contradicts itself, the metaphysical question concerning the identity of the global citizen whose freedom qualitative liberalism is committed to can be answered by no one other than the global citizen himself. And, of course, religious and spiritual voices will enter into this answer too. That is why we require a liberalism which is also spiritually literate. Instead of secularly determining once and for all what constitutes freedom under the aegis of qualitative freedom, discussion must be encouraged about what - here and now - we should safeguard as freedom. The best way for society to secure freedom of and from religion is by allowing and tolerating debates on spiritual questions, not by suppressing them. Let us trust in the power of procedural reason asserting itself precisely in such controversies to discover the best arguments!

The idea of qualitative freedom can integrate cultural specificity without a relativistic submission to local values. All normative claims fighting politically for their validation are always to be evaluated critically by a standard of legitimacy whose apex is the conceptual totality of all present and future persons. In terms of political implementation and realization, the path towards a cosmopolis of freedom runs through all those local and regional bilateral and multilateral institutions into which people and peoples gather together to protect their current interests. In terms of validity, however, the idea (preempted by Kant and, for the first time, systematically worked out by Krause) of a general federation of humanity is decisive. Endeavors that cannot be advocated in the name of humanity, will not find the support of qualitative freedom. Qualitative liberalism is thus especially amenable to post-national, supranational, and transnational as well as intergovernmental politics, since its idea of freedom, constraining itself with this very argument, consistently leads to the conception of universal human rights. ${ }^{134}$

\footnotetext{
${ }^{133}$ See Heiner Bielefeldt, "Misperceptions of Freedom of Religion or Belief," Human Rights Quarterly: A Comparative and International Journal of the Social Sciences, Philosophy, and Law 35:1 (2013).

${ }^{134}$ See Heiner Bielefeldt, Philosophie der Menschenrechte: Grundlagen eines weltweiten Freiheitsethos (Darmstadt, 1998); Heiner Bielefeldt, "Historical and Philosophical Foundations of Human Rights" in Catarina Krause \& Martin Scheinin (eds.), International Protection of Human Rights: A Textbook (Turku; Abo, 2009).
} 
Some hold, however, that without a firmly established global government, no globalization of the right to freedom is possible. ${ }^{135}$ Is that true? Do we need a global state, a global federal state, or at least a global federation of states, in order to assure freedom global respect? Is the imperative, continually repeated up until today by teachers of natural law, to leave the legally unregulated state of nature ("exeundum est e statu naturali") also true at the level of global law?

In my opinion there is an important difference between a hypothetical state of nature among individuals (before and apart from all societal organization) and an analogously conceived state of nature between states. ${ }^{136}$ Most global citizens are already legally integrated in (mostly national) communities so that - conceptually an immediate membership of all people in a state of global citizens is not required in order to satisfy the call for universal security through laws. ${ }^{137}$ This does not, however, vitiate the demand for the actual protection of human rights. Nevertheless, there exists the possibility that the real conditions in practice will one day sufficiently correspond with the ideal demands of theory. Then, however, the universal recognition of human rights must also be reliably enforceable, so that the affiliation of individuals to certain political communities leads to their systemic realization, and not (as in corrupt regimes) to their systematic suppression.

Nevertheless, as is well known, there are currently many places which normatively and/or actually do not meet this demand for a cosmopolitan protection of human rights. ${ }^{138}$ Where the present powers cannot secure a satisfactory protection of human rights (as in failing states) or do not want to (as in the IS terrorist state), the global community must come to the fore; especially in regard to violent conflicts. Religiously motivated civil wars and genocides are not something which one can put aside with reference to the national sovereignty of the respectively concerned territorial states.

Notwithstanding, it does not immediately follow that we must advocate a global government furnished with universal sanctioning powers. The historical genesis and the systematic validity of global acts of law are two different things. On the timeless level of philosophical validity, all global citizens are granted the unconditional protection of their human rights. Historically, however, we face the question about the respectively suitable conditions under which this demand could be most efficiently realized. A concretization and optimization of the existing institutions of global governance could, for example, at the moment present the most appropriate means for approximating towards this end. Perhaps the norm of universal human rights is presently better honored with certain networks and institutions, which in

\footnotetext{
${ }^{135}$ See James A. Yunker, Political Gloabalization: A New Vision of Federal World Government (Lanham, MD).

${ }^{136}$ See Martha Nussbaum, Frontiers of Justice, 237. See also: Pauline Kleingeld, Kant and Cosmopolitanism: The Philosophical Ideal of World Citizenship (Cambridge \& New York, 2011).

${ }^{137}$ See Shaw, Rawls, Kant's Doctrine of Right, and Global Distributive Justice.

${ }^{138}$ See James W. Nickel, "Is Today's International Human Rights System a Global Governance Regime?," The Journal of Ethics 6:4 (2002).
} 
their combination span the globe, than in prematurely grasping for supranational legal constructions that at the moment are not (yet) desired by the international community. Maybe humanity finds itself now already upon the path towards such a gradual expansion and differentiation of transnational norms and values when it comes to establishing and implementing sustainable social and environmental standards. The outcome of this process remains to be seen.

Many complain that hitherto the under-regulation of the global market enabled a race to the bottom: firms move to production locations where a lack of adequate legal guidelines leads to reduced costs for doing business with negative externalities; competitors feel forced to follow suit; economic sites consequently enter into a negative competition for the lowest ecological and legal standards in order to generate or maintain the flow of oversea investment-capital and thereby jobs and taxrevenues. ${ }^{139}$ Are we inevitably heading for a downward spiral, which, in the worst case scenario, only ends when all economic assets are privatized and the entire economic and social cost is socialized? Will the snowball of excessive profit-seeking grow into an unstoppable avalanche on the slope of an unbalanced global economic order? ${ }^{140}$ The empirical data does not entirely corroborate this prediction. ${ }^{141}$ The actual result of globalization for freedom and human rights turns out to be not quite so negative. ${ }^{142}$ We also see upward spirals. Benefitted by the technical facilitation of physical and informational commerce, a critical global public has emerged, the sheer existence of which has a normative effect. Pragmatic imperatives of business thus today often result in some firms, even in under-regulated societies, signing up to demanding transnational standards of corporate governance in order to, for instance, be attractive to global investors. ${ }^{143}$

Nevertheless, the regulation of the global public sphere can ultimately of course not only be entrusted to the discretion of economic organizations and nongovernmental institutions with insufficient democratic legitimation. ${ }^{144}$ Even the shrewdest incentive scheme cannot replace institutions of mandatory law. Not every conflict can be settled by mediation, not every tension can be bilaterally or multilaterally lifted, and not every outrage can be overcome by naming, blaming, and shaming.

\footnotetext{
${ }^{139}$ See Andrea Amaro \& William Miles, "Racing to the Bottom for FDI? Changing Role of Labor Costs and Infrastructure," The Journal of Developing Areas 40:1 (2006).

${ }^{140}$ See Andreas Georg Scherer \& Guido Palazzo, "Toward a Political Conception of Corporate Social Responsibility: Business and Society seen from a Habermasian Perspective," Academy of Management Review 32:4 (2007).

${ }^{141}$ See David M. Konisky, "Regulatory Competition and Environmental Enforcement: Is there a Race to the Bottom?," American Journal of Political Science 51:4 (2007).

${ }^{142}$ See Jagdish N. Bhagwati, In Defense of Globalization (New York, 2004).

${ }^{143}$ C. Lattemann, "On the Convergence of Corporate Governance Practices in Emerging Markts," International Journal of Emerging Markets 9:2 (2014).

${ }^{144}$ See Sangeeta Kamat, "The Privatization of Public Interest: Theorizing NGO Discourse in a Neoliberal Era," Review of International Political Economy 11:1 (2004).
} 
That has been unpleasantly confirmed by the global governance crises of recent years. While, that is, for some aims of humanity, the flexible approach of a creeping regulation through global governance proves to be perfectly appropriate, other aims are, in my opinion, better provided for through classical government institutions, which is why the speculation about an institutional optimization of humanity's global legal representation in no way appears idle. ${ }^{145}$

In every case, a global domestic policy practiced by everyone in the name of freedom has to press for inclusive participative procedures. If, for instance, the principle of "one man, one vote" holds true on the national level, why not - we need to ask from a liberal perspective - also apply it on a global level? ${ }^{146}$ Certainly, there are many pragmatic reservations (in rich countries), as to what might happen if one involved every global citizen equally (including those of poor countries) in the decision-making about questions of global governance. Yet, the ethical validity of these reservations seems questionable to me, ${ }^{147}$ especially so far as we postulate freedom - procedural and substantial - as a basic right of every single person as such. In short: "Everybody matters." ${ }^{148}$ I believe that the creditability of liberalism stands and falls with the resoluteness of liberals to strive for the globality of autonomy and, on the global level, to speak up for a "solidary liberalism."149

From a liberal and cosmopolitan perspective, therefore, we must strive for a global order which can cope with those ramifications of individual, corporative, and state action that affect the global sphere. ${ }^{150}$ For while problems arising within the state's territory (can) often become neutralized by national legislation (that is, via the so-called internalization of negative external effects) this is yet to be accomplished on the global level. Liberals should thus fight decidedly for a global economic law and for a global penal law with sufficient sanctioning powers, in addition to striving for an effective political representation of the world's entire population. The current global economic and legal order's legitimacy-deficit, the non-binding nature of its regulations, and its inability to sanction, clearly opposes the idea that all people should be able to autonomously determine the quality of their freedom.

Through whichever procedures and processes the global community seeks to make headway with these questions, the guiding perspective for selecting appropriate means to advance its ends can be outlined with clarity: Instead of a world of quantitatively boundless possibilities where only a few can attain everything, we

\footnotetext{
${ }^{145}$ On this, see the observations of the World Federalist Movement (http://www.wfmigp.org)

${ }^{146}$ See Parijs, Real Freedom For All, $228 \mathrm{f}$.

${ }^{147}$ Peter Singer, One World: The Ethics of Globalization (New Haven, CT, 2002).

148 "Everybody matters: that is our central idea. And it sharply limits the scope of our tolerance" (Appiah, Cosmopolitanism, 144).

${ }^{149}$ See Parijs, Real Freedom For All, 232.

${ }^{150}$ See Charles R. Beitz, "Cosmopolitanism and Global Justice," The Journal of Ethics 9:1/2 (2005).
} 
should strive for a world of qualitatively meaningful realities where significant chances are available to everyone. I believe the fascination for freedom will grip everyone, once we assert its indivisibility and assume the cosmopolitan responsibility this requires. The world was, is, and remains, the common property of all humanity - and it should be treated so as well: in the service of the promotion of the qualitative freedom of all.

Open Access This chapter is licensed under the terms of the Creative Commons Attribution 4.0 International License (http://creativecommons.org/licenses/by/4.0/), which permits use, sharing, adaptation, distribution and reproduction in any medium or format, as long as you give appropriate credit to the original author(s) and the source, provide a link to the Creative Commons licence and indicate if changes were made.

The images or other third party material in this chapter are included in the chapter's Creative Commons licence, unless indicated otherwise in a credit line to the material. If material is not included in the chapter's Creative Commons licence and your intended use is not permitted by statutory regulation or exceeds the permitted use, you will need to obtain permission directly from the copyright holder.

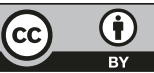




\section{Acknowledgments}

The most enjoyable moment in writing a book arrives when one pens the acknowledgments. It gives me great pleasure to extend my heartfelt thanks to so many friends and colleagues for all of their support.

Special mention must be made of my past and present co-workers at the Global Ethos Institute (Weltethos-Institut) at the University of Tübingen, who, for the sake of convenience, I hereby list alphabetically: Beata Beier, Christopher Gohl, Frieder Glauner, Florentine Hötzel, Christina Illek, Katharina Hoegl, Adrian von Jagow, Jonathan Keir, Joscha Krug, Manuel Mutter, Manuel Neumann, Esther Nezere, Hanna Schirovsky, Stephan Schlensog, Gustav Theile, Bernd Villhauer, Simon Walch, Michael Wihlenda; they have all supported me in the past months and years in the most manifold ways - from correcting typos and helping me with referencing software, through to providing philosophical criticism of the fundamentals. Bernd Villhauer's editorial and stylistic advice was especially significant. Despite the heavy-workload produced by the development of our academic institute since its establishment in 2012, thanks to this help I could now and then nonetheless concentrate upon my writing and in pushing this project forward. The same holds true for the English translation which could not have been accomplished without both their help and, most of all, the diligent and meticulous work by Dr. Richard Fincham from the American University in Cairo, who with great patience and attention to detail went over the entire text several times (for more on the process of translation see the "Note on Translation" preceding this volume).

I am especially delighted by the goodwill which Hans Küng showed my study from the outset. He strengthened my resolve to compose a theory of responsible freedom which would constitute the secular pillar of the Global Ethos Project (Projekt Weltethos) he established. Of equally significant personal and professional importance for me were my personal conversations with Amartya Sen in Boston. Furthermore, as a Fellow of the Global Justice Project, directed by Thomas Pogge in Yale, I was able to expose my theory to some very welcome "stress testing." Heartfelt thanks for all the extremely stimulating discussions there is thus extended to all participants, especially Daniel Putnam. 
As representatives of the many friends and colleagues of the Humanistic Management Network, whose suggestions are included in this work, I would like to especially thank Ernst von Kimakowitz and Michael Pirson, who for years always stood by my side with assistance and advice. May this book also promote our shared efforts for a more humane economy!

Friends and family have also inspired my work towards this project, for instance Sven Block, Stephan Breidenbach, Alexander Insam, Volker Rekittke and Elke Völmicke, as well as my parents, Rita and Josef Dierksmeier. A warm thank you to you all!

Thinking takes time and time requires money. I would therefore like to thank the Karl-Schlecht-Stiftung (KSG) for generously financially supporting the Global Ethos Institute, and especially Klaus Leisinger for his benevolent supervision of our project. I thank the Friedrich-Naumann-Stiftung für die Freiheit (FNF), especially Steffen Saebisch, for promoting this publication both financially and with publicity. I am also pleased that the persons responsible at the FNF have repeatedly given me the opportunity to test this book's argument in discussions - on their behalf I thank Jochen Merkle, who has often opened the forum of the Horber Akademie for me.

The present text harks back to my earlier work on the philosophy of freedom and again presents some material previously published in disparate articles in a revised form, in particular, material from the following studies: "Zur systematischen Liberalität in Kants Politik- und Staatsbegriff" in Henning Ottmann (ed.), Kants Lehre von Staat und Frieden (Baden Baden, 2009); "Freiheit und Globalisierung" in Philipp Rösler \& Christian Lindner (eds.), Freiheit: gefühlt - gedacht - gelebt: Liberale Beiträge zu einer Wertediskussion (Wiesbaden, 2009); "Freiheit in der Politischen Ökonomie von John Kenneth Galbraith," Zeitschrift für Politikwissenschaft / Journal of Political Science (2007); "Qualitative oder quantitative Freiheit?," Rechtsphilosophische Hefte 12 (2007); "Über die Wirtschaftstheorie in Fichtes Rechtslehre von 1812," Fichte-Studien 29 (2006); "John Rawls and the Rights of Future Generations" in Jörg Tremmel (ed.), Handbook of Intergenerational Justice (Cheltenham \& Northampton, 2006); "John Rawls und Kants langer Schatten," Zeitschrift für Politikwissenschaft / Journal of Political Science (2004); "Recht und Freiheit: Karl Christian Friedrich Krauses 'Grundlage des Naturrechts' im Kontext des Jenaer Idealismus,' International Yearbook of German Idealism/Internationales Jahrbuch für Deutschen Idealismus (2004); "Zur Theorie staalichen Handelns bei F. A. v. Hayek," Zeitschrift für Politikwissenschaft/Journal of Political Science (2003); "Die Wirtschaftsphilosophie des 'Krausismo,", Deutsche Zeitschrift für Philosophie (2003); "Über den gegenwärtigen Stand der Wirtschaftsphilosophie," Archiv für Rechts- und Sozialphilosophie (2003); Der absolute Grund des Rechts: Karl Christian Freidrich Krause in Auseinandersetzung mit Fichte und Schelling (Stuttgart-Bad Cannstatt, 2003). I thank all the friends and colleagues who assisted me with these previous studies.

This book wishes to contribute to the intellectual self-reflection of liberal groups. It owes much to intellectual challenges and suggestions from many friends and interlocutors who are intellectually as well as politically engaged in the cause of freedom, such as Marco Buschmann, Raban Daniel Fuhrmann, Torge Hamkens, 
Christoph Giesa, Stefan Kolev, Susanna Krüger, Christian Lindner, Michael Roick, and Michael Theurer. Many of them have had a strong impact upon my thinking, but none more so than Dr. Christopher Gohl. Both academically and politically he personifies the striving for "qualitative freedom" - as a procedural theorist and as a facilitator, as a thinker as well as an actor; he was in my mind's eye during the composition of many passages of this study, as a model of the procedural and dialogical dimension of qualitative freedom.

To conclude: Freedom is a fascinating idea whose realization constantly and permanently brings happiness. That freedom is not exhausted by the quantitative accumulation of options, but is rather primarily fulfilled by their quality, is something one can learn in various ways: through the strictly selective formal beauty of the arts, through moral self-commitments, or the intellectual striving for the truth, all of which renounce in unison the infinite multitude of abstract options for the sake of fewer yet more excellent possibilities. But I can personally imagine no better way of ever renewing this essential experience of qualitative freedom than in the commitment to the one person with whom I share my life, my wife Laura, to whom I dedicate this book. 


\section{Literature}

Abdel-Nour, Farid. 2000. Liberalism and Ethnocentrism. Journal of Political Philosophy 8 (2): 207-226.

Adams, John. 1984. Galbraith on Economic Development. Journal of Post Keynesian Economics 7 (1): 91-102.

Ahmed, A.K.N. 2004. Washington Consensus: How and Why It Failed the Poor. Dhaka: Shahitya Prakash.

Ahrens, Heinrich. 1850. Die organische Staatslehre auf philosophisch-anthropologischer Grundlage. Wien: Gerold.

1852. Die Rechtsphilosophie, oder, das Naturrecht; auf philosophisch-anthropologischer Grundlage. Wien: Gerold.

Alemparte, J.F. 1985. Aufnahme der deutschen Kultur in Spanien. Der Krausismo als Höhepunkt und sein Weiterwirken durch die Institución Libre de Enseñanza. In Karl Christian Friedrich Krause (1781-1832): Studien zu seiner Philosophie und zum Krausismo, Hg. Klaus-Michael Kodalle. Hamburg: Meiner.

Amadio, Carla. 1997. Ästhetik und Politik von der Grundlage der gesammten Wissenschaftslehre aus. Fichte-Studien 11: 99-112.

Amann, Wolfgang, Michael Pirson, Claus Dierksmeier, Ernst von Kimakowitz, and Heiko Spitzeck, Hg. 2011. Business Schools Under Fire: Humanistic Management Education as the Way Forward. Basingstoke: Palgrave Macmillan.

Amaro, Andrea, and William Miles. 2006. Racing to the Bottom for FDI? The Changing Role of Labor Costs and Infrastructure. The Journal of Developing Areas 40 (1): 1-13.

Anand, Paul, Graham Hunter, and Smith Ron. 2005. Capabilities and Well-Being: Evidence Based on the Sen-Nussbaum Approach to Welfare. Social Indicators Research 74 (1): 9-55.

Anders, Günther. 1956. Die Antiquiertheit des Menschen: Über die Seele im Zeitalter der zweiten industriellen Revolution. München: Beck.

Anderson, Mark W., Mario Teisl, and Caroline Noblet. 2012. Giving Voice to the Future in Sustainability: Retrospective Assessment to Learn Prospective Stakeholder Engagement. Ecological Economics 84: 1-6.

Andeweg, Rudy, and Galen Irwin. 2009. Governance and Politics of the Netherlands. London/ New York: Palgrave Macmillan (Originalausgabe: 2005).

Andreassen, Bård-Anders, and Stephen P. Marks, Hg. 2010. Development as a Human Right: Legal, Political, and Economic Dimensions. Antwerpen/Portland: Intersentia.

Appiah, Kwame Anthony. 2005. The Ethics of Identity. Princeton: Princeton University Press. 2007. Cosmopolitanism: Ethics in a World of Strangers. London: Penguin Group.

2009. Sen's Identities. In Arguments for a Better World: Essays in Honor of Amartya Sen, Bd. 1, Hg. Kaushik Basu and Ravi Kanbur. Oxford: Oxford University Press, . 
Arendt, Hannah, and Ronald Beiner. 1982. Lectures on Kant's Political Philosophy. Brighton: Harvester Press.

Argyris, Chris. 1984. Increasing Leadership Effectiveness. Malabar: R.E. Krieger (Originalausgabe: 1976).

Arlen, Jennifer, and Eric L. Talley. 2008. Experimental Law and Economics. Cheltenham/ Northampton: Edward Elgar.

Arneson, Richard. 2009. Meaningful Work and Market Socialism Revisited. Analyse und Kritik. Zeitschrift für Sozialwissenschaften 31 (1): 139.

Arnold, Dennis G., and Jared D. Harris, Hg. 2012. Kantian Business Ethics. Northampton: Edward Elgar .

Ayer, Alfred Jules. 1936. Language, Truth and Logic. London: Victor Gollancz Ltd.

Backhaus, Jürgen, and Reginald Hansen. 2000. Methodenstreit in der Nationalökonomie. Journal for General Philosophy of Science 31 (2): 307-336.

Baets, Walter, and Erna Baets-Oldenboom. 2009. Rethinking Growth: Social Intrapreneurship for Sustainable Performance. Basingstoke: Palgrave Macmillan.

Bailey, David, George Harte, and Roger Sugden. 2000. Corporate Disclosure and the Deregulation of International Investment. Accounting, Auditing and Accountability 13 (2): 197-218.

Baker, C. Richard. 2003. Investigating Enron as a Public Private Partnership. Accounting, Auditing and Accountability 16 (3): 446-466.

Balaban, Oded, and Anan Erev. 1995. The Bounds of Freedom: About the Eastern and Western Approaches to Freedom. New York: Peter Lang.

Baraúna, Guilherme, and Viktor Schurr. 1967. Die Kirche in der Welt von heute; Untersuchungen und Kommentare zur Pastoralkonstitution »Gaudium et spes« des 2. Vatikanischen Konzils. Salzburg: Müller.

Barraquero, Julián. 1878. Espíritu y práctica de la ley constitucional Argentina. Buenos Aires: Imprenta de la Tribuna.

Barry, Brian. 1973. The Liberal Theory of Justice: A Critical Examination of the Principal Doctrines in $>A$ Theory of Justice by John Rawls. Oxford: Clarendon Press. Press. - 1989. Theories of Justice: A Treatise on Social Justice. Berkeley: University of California

—. 1995. Justice as Impartiality. Oxford/New York: Harvester Wheatsheaf.

Bartuschat, Wolfgang. 1972. Zum systematischen Ort von Kants Kritik der Urteilskraft. Frankfurt a.M.: Klostermann.

. 1987. Apriorität und Empirie in Kants Rechtsphilosophie. Philosophische Rundschau 34 (1/2): 31-49.

Basoco, Juan Terradillos. 1996. El Institucionalismo y el nuevo enfoque de la Doctrina Penal. In La Institución Libre de Enseñanza: su influencia en la cultura española, Hg. Álvarez López. Cádiz; Universidad de Cádiz .

Baudrillard, Jean. 1970. La société de consommation: ses mythes, ses structures. Paris: Denoël.

Bauman, Zygmunt. 1988. Freedom. Milton Keynes: Open University Press.

Baumgarth, William P. 1978. Hayek and Political Order: The Rule of Law. Journal of Libertarian Studies 2: 11-28.

Bauschke, Martin. 2010. Die Goldene Regel: Staunen - Verstehen - Handeln. Berlin: EB-Verlag.

Bay, Christian. 1970. The Structure of Freedom. Stanford: Stanford University Press.

Beck, Lewis White. 1995. Kants »Kritik der praktischen Vernunft«. Ein Kommentar. München: Fink.

Beck, Ulrich, and Edgar Grande. 2004. Das kosmopolitische Europa: Gesellschaft und Politik in der zweiten Moderne. Frankfurt a.M.: Suhrkamp.

Becker, Gary S. 1976. The Economic Approach to Human Behavior. Chicago: University of Chicago Press.

- 1993. Human Capital: A Theoretical and Empirical Analysis, with Special Reference to Education. Chicago: University of Chicago Press (Originalausgabe: 1964).

. 1996. Accounting for Tastes. Cambridge, MA: Harvard University Press. 
2007. Economic Theory. New Brunswick: Aldine Transaction (Originalausgabe: 1971).

Becker, Gary S., and Richard A. Posner. 2009. Uncommon Sense: Economic Insights, from Marriage to Terrorism. Chicago/London: University of Chicago Press.

Beckert, Jens. 2002. Beyond the Market the Social Foundations of Economic Efficiency. Princeton: Princeton University Press.

Beiner, Ronald. 1992. What's the Matter with Liberalism? Berkeley/London: University of California Press.

Beitz, Charles R. 2000. Rawls's Law of People. Ethics 110 (4): 669.

- 2001. Human Rights as a Common Concern. American Political Science Review 95 (2): 269-282.

- 2005. Cosmopolitanism and Global Justice. The Journal of Ethics 9 (1/2): 11-27.

Benedict XVI. 2009. Charity in Truth- Caritas In Veritate: Encyclical Letter. San Francisco: Ignatius Press.

Benn, Stanley Isaac. 1988. A Theory of Freedom. Cambridge/New York: Cambridge University Press.

Benn, Stanley Isaac, and W.L. Weinstein. 1971. Being Free to Act, and Being a Free Man. Mind 80 (318): 194-211.

Bentham, Jeremy. 1970. Of Laws in General. In The Collected Works of Jeremy Bentham, ed. Herbert Lionel Adolphus Hart. London: University of London/Athlone Press (Originalausgabe 1782).

- 1830. The Rationale of Reward. London: R. Heward.

Bentham, Jeremy, and John Bowring. 1962. The Works of Jeremy Bentham. New York: Russell \& Russell.

Bentham, Jeremy, Étienne Dumont, Richard Hildreth. 1887. Theory of Legislation. London: Trübner (Originalausgabe: London 1864).

Berlin, Isaiah, Henry Hardy, and Ian Harris. 2002. Liberty: Incorporating Four Essays on Liberty. Oxford: Oxford University Press.

Bertram, Christopher, and Andrew Chitty, Hg. 1994. Has History Ended? Fukuyama, Marx, Modernity. Aldershot/Brookfield: Avebury.

Bhagwati, Jagdish N. 2004. Defense of Globalization. New York: Oxford University Press.

Bielefeldt, Heiner. 1998. Philosophie der Menschenrechte: Grundlagen eines weltweiten Freiheitsethos. Darmstadt: Wissenschaftliche Buchgesellschaft.

- 2000. Universalism Versus Relativism on the Necessity of Intercultural Dialogue on Human Rights. In The Islamic World and the West: An Introduction to Political Cultures and International Relations, Hg. Kai Hafez and Mary Ann Kenny. Leiden: Brill.

- 2003. Symbolic Representation in Kant's Practical Philosophy. Cambridge/New York: Cambridge University Press (Originalausgabe: 2001).

- 2009. Historical and Philosophical Foundations of Human Rights. In International Protection of Human Rights: A Textbook, Hg. Catarina Krause and Martin Scheinin. Turku: Åbo Akad. University.

- 2013. Misperceptions of Freedom of Religion or Belief. Human Rights Quarterly: A Comparative and International Journal of the Social Sciences, Philosophy, and Law 35 (1): 33-68.

Birch, Kean, and Vlad Mykhnenko. 2010. The Rise and Fall of Neoliberalism: The Collapse of an Economic Order? London/New York: Zed Books.

Blanchard, Olivier J., David Romer, Michael Spence, and Joseph E. Stiglitz. 2012. In the Wake of the Crisis: Leading Economists Reassess Economic Policy. Cambridge, MA: MIT Press.

Bloch, Ernst. 1991. Naturrecht und menschliche Würde. Frankfurt a.M.: Suhrkamp.

Bobzien, Susanne. 1988. Die Kategorien der Freiheit bei Kant. In Kant: Analysen, Probleme, Kritik, Hg. Hariolf Oberer and Gerhard Seel. Würzburg: Königshausen \& Neumann.

Bogues, Anthony. 2010. Empire of Liberty: Power, Desire, and Freedom. Hanover: Dartmouth College Press.

Bosanquet, Bernard. 1899. The Philosophical Theory of the State. London: Macmillan and co. 
Bostaph, Samuel. 1978. The Methodological Debate between Carl Menger and the German Historicists. Atlantic Economic Journal 6 (3): 3-16.

Bouillon, Hardy. 1991. Ordnung, Evolution und Erkenntnis: Hayeks Sozialphilosophie und ihre erkenntnistheoretische Grundlage. Tübingen: Mohr.

Boulding, Kenneth E. 1969. Economics as a Moral Science. The American Economic Review 59 (1): $1-12$.

1987. The Economics of Pride and Shame. Atlantic Economic Journal 15: 10-19.

Boym, Svetlana. 2010. Another Freedom: The Alternative History of an Idea. Chicago: University of Chicago Press.

Brachtendorf, Johannes. 1995. Fichtes Lehre vom Sein. Eine kritische Darstellung der Wissenschaftslehren von 1794, 1798/99 und 1812. Paderborn: Schöningh.

Bradley, Francis Herbert. 1927. Ethical Studies. Oxford: Clarendon Press (Originalausgabe: 1876).

Braun, Johann. 1991. Freiheit, Gleichheit, Eigentum: Grundfragen des Rechts im Lichte der Philosophie J. G. Fichtes. Tübingen: J.C.B. Mohr.

Bregenzer, Ignaz. 1894. Thier-Ethik Darstellung der sittlichen und rechtlichen Beziehungen zwischen Mensch und Thier. Bamberg: Buchner.

Briggs, Xavier. 2008. Democracy as Problem Solving: Civic Capacity in Communities Across the Globe. Cambridge, MA: MIT Press.

Brighouse, Harry, and Ingrid Robeyns. 2010. Measuring Justice: Primary Goods and Capabilities. Cambridge/New York: Cambridge University Press.

Brocker, Manfred. 1992. Arbeit und Eigentum: Der Paradigmenwechsel in der neuzeitlichen Eigentumstheorie. Darmstadt: Wiss. Buchges.

Bruni, Luigino. 2008. Reciprocity, Altruism and the Civil Society: In Praise of Heterogeneity. London/New York: Routledge.

Bubner, Rüdiger. 1986. Was heißt Synthesis? In Handlungstheorie und Transzendentalphilosophie, ed. Gerold Prauss. Frankfurt a.M.: Klostermann.

Buchanan, James. 1990. The Domain of Constitutional Economics. Constitutional Political Economy 1 (1): 1-18.

Buchanan, Allen Edward. 2000. Rawls's Law of Peoples: Rules for a Vanished Westphalian World. Ethics 110 (4): 697.

Buchheim, Thomas. 2006. Unser Verlangen nach Freiheit kein Traum, sondern Drama mit Zukunft. Hamburg: Meiner.

Burchell, Jon, and Joanne Cook. 2008. Stakeholder Dialogue and Organisational Learning: Changing Relationships between Companies and NGOs. Business Ethics: A European Review 17 (1): 35-46.

Burczak, Theodore A. 2002. The Contradictions between Hayek's Subjectivism and His Liberal Legal Theory. In FA Hayek as a Political Economist: Economic Analysis and Values, Bd. 45, Hg. Jack Birner, Pierre Garrouste, and Thierry Aimar. London: Routledge.

Burki, Shahid Javed, and Guillermo Perry. 1998. Beyond the Washington Consensus: Institutions Matter. Washington, DC: World Bank.

Burns, Timothy. 1994. After History? Francis Fukuyama and His Critics. Lanham: Rowman \& Littlefield.

Burtt, Edwin A. 1939. The English Philosophers: From Bacon to Mill. New York: Random House.

Bush, George W. 2001a. Our Mission, and Our Moment. Speeches since the Attacks of September 11. Washington, DC: White House.

Bush, Malcolm. 2001b. Amartya Sen, Development as Freedom. Social Service Review 75 (3): 514-517.

Bussmann, Hans. 1994. Eine systemanalytische Betrachtung des Schematismuskapitels in der Kritik der reinen Vernunft. Kant-Studien 85 (4): 394-418.

Button, Mark E. 2008. Contract, Culture and Citizenship: Transformative Liberalism from Hobbes to Rawls. Pennsylvania: University Park. 
Cadsby, Charles Bram, and Elizabeth Maynes. 1998. Choosing Between a Socially Efficient and Free-riding Equilibrium: Nurses Versus Economics and Business Students. Journal of Economic Behavior \& Organization 37 (2): 183-192.

Caney, Simon. 2002. Cosmopolitanism and the Law of Peoples. Journal of Political Philosophy 10 (1): 95-123.

Carmin, JoAnn, and Julian Agyeman. 2011. Environmental Inequalities Beyond Borders: Local Perspectives on Global Injustices. Cambridge, MA: MIT Press.

Carter, Ian. 1999. A measure of freedom. Oxford: University press.

Carter, John R., and Michael D. Irons. 1991. Are Economists Different, and If So, Why? The Journal of Economic Perspectives 5 (2): 171-177.

Carter, Ian, Matthew H. Kramer, and Hillel Steiner. 2007. Freedom: A Philosophical Anthology. Malden: Blackwell Publishing.

Casas, Bartolomé de las. 2003. An Account, Much Abbreviated, of the Destruction of the Indies, with Related Texts. Indianapolis: Hackett Publishing Company.

Cassirer, Ernst. 1916. Freiheit und Form. Studien zur deutschen Geistesgeschichte. Berlin: Cassirer. . 1953. The Philosophy of Symbolic Forms. New Haven: Yale University Press.

Cavallar, Georg F. 1999. F., Kant and the Theory and Practice of International Right. Cardiff: University of Wales Press.

Chan, Jennifer. 2007. Between Efficiency, Capability and Recognition: Competing Epistemes in Global Governance Reforms. Comparative Education 43 (3): 359-376.

Charvet, John. 1981. A Critique of Freedom and Equality. Cambridge/New York: Cambridge University Press.

Christman, John. 1991. Liberalism and Individual Positive Freedom. Ethics 101 (2): 343-359. - 2005. Saving Positive Freedom. Political Theory 33 (1): 79-88.

Christman, John Philip. 2009. The Politics of Persons: Individual Autonomy and Socio-historical Selves. Cambridge/New York: Cambridge University Press.

Clark, David A. 2005. Sen's Capability Approach and the Many Spaces of Human Well-Being. The Journal of Development Studies 41 (8): 1339-1368.

Cohen, Gerald Allan. 1995. Self-Ownership, Freedom, and Equality. Cambridge/Paris/New York: Cambridge University Press.

Colander, David, and Arjo Klamer. 1987. The Making of an Economist. The Journal of Economic Perspectives 1 (2): 95-111.

Comim, Flavio. 2008. Climate Injustice and Development: A Capability Perspective. Development 51 (3): 344-349.

Connolly, William E. 1993. The Terms of Political Discourse. Oxford: Blackwell.

— . 2007. Liberty as an $>$ Essentially Contested Concept $<$ In Freedom: A Philosophical Anthology, ed. Ian Carter and Matthew H. Kramer. Malden: Blackwell.

Cornia, Giovanni Andrea. 2004. Inequality, Growth and Poverty in an Era of Liberalization and Globalization. Oxford: Oxford University Press.

Cramer, Konrad. 2010. Um einen nationalsozialistischen Fichte von Innen bittend. August Faust über Fichte im Jahr 1938. In Wissen, Freiheit, Geschichte. Die Philosophie Fichtes im 19 und 20 Jahrhundert: Die Philosophie Fichtes im 19 und 20 Jahrhundert, Hg. Oliver-Pierre Rudolph and Jürgen Stolzenberg. Amsterdam: Rodopi.

Crisp, Roger. 1987. Persuasive Advertising, Autonomy, and the Creation of Desire. Journal of Business Ethics: 413-418.

Crocker, David A. 2008. Ethics of Global Development: Agency, Capability and Deliberative Democracy. Cambridge/New York: Cambridge University Press.

Crouch, Colin. 2011. The Strange Non-death of Neo-liberalism. Cambridge: Polity.

Cruz, Vera. 2000. Alonso de la, De dominio infidelium et iusto bello, I-II. Mexico: Universidad Nacional Autónoma de México.

Cudd, Ann E. 2005. Oppression by Choice. Journal of Social Philosophy 25: 20-49.

Cudd, Ann E., and Nancy Holmstrom. 2011. Capitalism, For and Against. Cambridge: Cambridge University Press. 
Cyclopaedia or: An Universal Dictionary of Arts, Sciences, and Literature. 1810. Philadelphia/ New York: Mesier.

Cyert, Richard Michael, and James G. March. 1992. A Behavioral Theory of the Firm. Cambridge, MA: Basil Blackwell.

D'Agostino, Fred. 1996. Free Public Reason: Making It Up as We Go. New York: Oxford University Press.

Dahrendorf, Ralf. 2008. The Modern Social Conflict: The Politics of Liberty. New Brunswick: Transaction.

Dasgupta, Partha. 1982. The Control of Resources. Oxford: Blackwell.

- 1986. Positive Freedom, Markets and the Welfare State. Oxford Review of Economic Policy 2: 25-36.

-1989. Power and control in the good polity. In The good polity: Normative analysis of the state, Hg. Alan P. Hamlin and Philip Pettit. Oxford.

Dauenhauer, Bernard P. 2002. Response to Rawls. In Ricoeur as Another: The Ethics of Subjectivity, Hg. Richard A. Cohen and James L. Marsh. New York: State University of New York Press.

De Long, James Bradford. 2000. The Triumph of Monetarism? The Journal of Economic Perspectives 14 (1): 83-94.

De Ruggiero, Guido. 1959. The History of European Liberalism. Boston: Beacon Press.

Dewey, John. 1929. Democracy and Education: An Introduction to the Philosophy of Education. New York: Macmillan Co.

. 2009. Democracy and Education: Freedom and Culture. Denver: Frederick Ellis (Originalausgabe: New York 1939).

Di Fabio, Udo. 2005. Die Kultur der Freiheit. München: Beck.

Díaz, Elias. 1999. Krausismo e Institución Libre de Enseñanza: Pensamiento social y politico. In Jornadas homenaje a Giner de los Ríos. Cádiz/Ronda: Universidad de Jaén.

Dierken, Jörg. 2005. Selbstbewusstsein individueller Freiheit: Religionstheoretische Erkundungen in protestantischer Perspektive. Tübingen: Mohr.

Dierksmeier, Claus. 1998. Das Noumenon Religion: Eine Untersuchung zur Stellung der Religion im System der praktischen Philosophie Kants. Berlin/New York: De Gruyter.

_. 1999a. Bundesrepublikanisches Staatskirchenrecht aus kantischer Perspektive. Rechtstheorie - Zeitschrift für Logik und Juristische Methodenlehre, Rechtsinformatik, Kommunikationsforschung, Normen- und Handlungstheorie, Soziologie und Philosophie des Rechts 30 (1): 110-112.

1999b. Kant - Forberg - Fichte. In Fichtes Entlassung - Der Jenaer Atheismusstreit vor 200 Jahren. Kritisches Jahrbuch der Philosophie, Hg. Klaus-Michael Kodalle. Würzburg: Königshausen und Neumann.

— 2000. Die Würde der Kunst - Überlegungen zu Schutzbereich und Schranken eines schrankenlosen Grundrechts. Juristenzeitung (JZ) 18 (55): 883-889.

- 2003a. Der absolute Grund des Rechts: Karl Christian Friedrich Krause in Auseinandersetzung mit Fichte und Schelling. Stuttgart-Bad Cannstatt: frommann-holzboog. - 2003b. Fichtes kritischer Schüler: Zur Fichtekritik K.C.F. Krauses (1781-1832). FichteStudien. Beiträge zur Geschichte und Systematik der Transzendentalphilosophie 21: 151-162. 2006. John Rawls on the Rights of Future Generations. In Handbook of Intergenerational Justice, 73-85, Hg. Jörg Tremel.

2007. Qualitative oder quantitative Freiheit? Rechtsphilosophische Hefte 12: 107-119.

2008. Harmonischer Liberalismus am Rio de la Plata. Liberal, Vierteljahreshefte für Politik und Kultur 50: 46-49.

- 2009. Zur systematischen Liberalität in Kants Politik- und Staatsbegriff. In Kants Lehre von Staat und Frieden, Hg. Henning Ottmann. Baden-Baden: Nomos-Verl.-Ges.

- 2010a. Krausism. In A Companion to Latin American Philosophy, Hg. Susana Nuccetelli, Ofelia Schutte, and Otávio Bueno. Hoboken: Wiley-Blackwell.

—. 2010b. Welche Freiheit? Liberal, Vierteljahreshefte für Politik und Kultur 4: 9-13. 
2011a. The freedom-responsibility nexus in management philosophy and business ethics. Journal of Business Ethics 101 (2): 263-283.

.2011b. Humanistic Ethics in the Age of Globality. London/New York: Palgrave Macmillan. . 2013. Kant on virtue. Journal of Business Ethics 113 (4): 597-609.

Dierksmeier, Claus, and Anthony Celano. 2012. Thomas Aquinas on Justice as a Global Virtue in Business. Business Ethics Quarterly 22 (2): 247-272.

Dierksmeier, Claus, and Michael Pirson. 2010. The Modern Corporation and the Idea of Freedom. Philosophy of Management 9 (3): 5-25.

Dietler, Wilhelm. 1787. Gerechtigkeit gegen Thiere. Mainz: Schiller.

Dimova-Cookson, Maria. 2003. A New Scheme of Positive and Negative Freedom: Reconstructing T. H. Green on Freedom. Political Theory 31 (4): 508-532.

Doering, Detmar. 2009. Traktat über Freiheit. München: Olzog.

Dudy, Peter. 2002. Menschenrechte zwischen Universalität und Partikularität: Eine interdisziplinäre Studie zur Idee der Weltinnenpolitik. Münster: Lit.

Dunn, Stephen. 2005. John Kenneth Galbraith and the Multinational Corporation (The New Industrial State). Challenge 48 (2): 90-112.

Dunn, Stephen P. 2010. The Economics of John Kenneth Galbraith: Introduction, Persuasion and Rehabilitation. New York: Cambridge University Press.

Düsing, Klaus. 1968. Die Teleologie in Kants Weltbegriff. Bonn: Bouvier.

Düsing, Edith. 1991. Das Problem der Individualität in Fichtes früher Ethik und Rechtslehre. Fichte-Studien 3: 29-50.

Dussel, Enrique D. 1985. Philosophy of Liberation. Maryknoll: Orbis Books.

Dworkin, Ronald. 1977. Taking Rights Seriously. London: Duckworth.

Dworkin, Gerald. 1988. The Theory and Practice of Autonomy. Cambridge/New York: Cambridge University Press.

Dworkin, Ronald. 2000. Sovereign Virtue: The Theory and Practice of Equality. Cambridge, MA/ London: Harvard University Press.

Eckel, Catherine, Martin Johnson, and Rick K. Wilson. 2002. Fairness and Rejection in the Ultimatum Bargaining Game. Political Analysis 10 (4): 376-393.

Ehrenberg, Alain. 2008. Das erschöpfte Selbst: Depression und Gesellschaft in der Gegenwart. Surkamp: Frankfurt a.M.

Eisler, Riane, and David Loye. 1983. The >Failure $<$ of Liberalism: A Reassessment of Ideology from a New Feminine-Masculine Perspective. Political Psychology 4 (2): 375-391.

Elegido, Juan. 2009. Business Education and Erosion of Character. African Journal of Business Ethics 4: 16-24.

Elkington, John, and Pamela Hartigan. 2008. The Power of Unreasonable People: How Social Entrepreneurs Create Markets that Change the World. Boston: Harvard Business School Press.

Ellacuría, Ignacio. 2013. Essays on History, Liberation, and Salvation. Maryknoll: Orbis Books.

Elster, Jon. 1979. Ulysses and the Sirens: Studies in Rationality and Irrationality. Cambridge/New York: Cambridge University Press.

Encyclopaedia Britannica, Or, A Dictionary of Arts, Sciences, and Miscellaneous Literature. 1810. Bd. 17. Edinburgh: A. Bell for A. Constable.

Erning, Bernhard. 1993. Hayeks Moralphilosophie: Freiheit und Gerechtigkeit in der Grossen Gesellschaft. Freiburg.

Esteban Mateo, León. 1985. El krausismo en España: Teoría y circunstancia (I). Historia de la Educación 4: 97-118.

— 1990. El Krausismo, la Institución Libre de Enseñanza y Valencia. Valencia: Universidad de Valencia.

Eucken, Walter. 1951. Unser Zeitalter der Misserfolge; fünf Vorträge zur Wirtschaftspolitik. Tübingen: Mohr.

—. 1952. Grundsätze der Wirtschaftspolitik. Bern: Francke. 
Eucken, Walter, Bernhard Külp, Viktor Vanberg, and Universität Freiburg i.Br. Institut für Allgemeine Wirtschaftsforschung, Hg. 2000. Freiheit und wettbewerbliche Ordnung: Gedenkband zur Erinnerung an Walter Eucken. Freiburg: Haufe.

Falkena, H.B. 1985. On Hayek's Philosophy of Limited Government and the Economic Order (Review Article). South African Journal of Economics 53 (4): 235-243.

Feder, Johann Georg Heinrich. 1972. Über die Rechte der Menschen in Ansehung der unvernünftigen Tiere. Neues hannovrisches Magazin 2: 945-960.

Fehr, Ernst, and Antonio Rangel. 2011. Neuroeconomic Foundations of Economic Choice Recent Advances. The Journal of Economic Perspectives 25 (4): 3-30.

Feinberg, Joel. 1992. Freedom and Fulfillment: Philosophical Essays. Princeton: Princeton University Press.

Fichte, Johann Gottlieb. 1964. In Gesamtausgabe der Bayerischen Akademie der Wissenschaften, ed. Reinhard Lauth and Hans Gliwitzky. Stuttgart-Bad Cannstatt: Fromman.

1982. Wissenschaftslehre nova methodo: Kollegnachschrift von K. Chr. Fr. Krause (179899), herausgegeben von: Erich Fuchs, Hamburg: Meiner.

Fine, Ben, Costas Lapavitsas, and Jonathan Pincus. 2001. Development Policy in the 21 st Century: Beyond the Post-Washington Consensus. London/New York: Routledge.

Fineman, Martha, and Terence Dougherty. 2005. Feminism Confronts Homo Economicus: Gender, Law and Society. Ithaca: Cornell University Press.

Fischer, Klaus H. 1990. Die Wissenschaft der Gesellschaft: Gesellschaftsanalyse und Geschichtsphilosophie des Lorenz von Stein unter besonderer Berücksichtigung seines gesellschaftswissenschaftlichen Entwurfs. Frankfurt a.M.: Haag und Herchen.

Fischer, David Hacket. 2004. Liberty and Freedom: A Visual History of America's Founding Ideas. Oxford: Oxford University Press.

Flach, Karl Hermann. 1971. Noch eine Chance für die Liberalen oder: Die Zukunft der Freiheit: Eine Streitschrift. Frankfurt a.M.: Fischer.

Flathman, Richard E. 1987. The Philosophy and Politics of Freedom. Chicago: University of Chicago Press.

Fleetwood, Steve. 1995. Hayek's Political Economy: The Socioeconomics of Order. London: Routledge.

Flikschuh, Katrin. 2007. Freedom: Contemporary Liberal Theory. Cambridge.

Flury, Andreas. 1999. Der moralische Status der Tiere: Henry Salt, Peter Singer und Tom Regan. Freiburg i.Br: Alber.

Foerster, Rolf Hellmut. 1967. Europa. Geschichte einer politischen Idee. München: Nymphenburger Verlagshandlung.

Føllesdal, Andreas, and Thomas Winfried Menko Pogge. 2005. Real World Justice: Grounds, Principles, Human Rights, and Social Institutions. Dordrecht: Springer.

Foner, Eric, Hg. 2011. Voices of Freedom: A Documentary History. New York: W.W. Norton \& Co (Originalausgabe: 2005).

Fonnesu, Luca. 1997. Die Aufhebung des Staates bei Fichte. Fichtes-Sudien 11: 85-98.

Fornari, Emanuela. 2007. Modernity Out of Joint: Global Democracy and Asian Values in Jürgen Habermas and Amartya K. Sen. Aurora: Davies Group.

Forster, Wolfgang. 2000. Karl Christian Friedrich Krauses frühe Rechtsphilosophie und ihr geistesgeschichtlicher Hintergrund. Ebelsbach: Aktiv Druck \& Verlag.

Fortlage, Carl. 1852. Genetische Geschichte der Philosophie seit Kant. Leipzig: Brockhaus.

Foucault, Michel. 1984. Von der Freundschaft als Lebensweise: Michel Foucault im Gespräch. Berlin: Merve Verlag.

France, Anatole. 1894. Le lys rouge. Paris: Calmann-Lévy.

Franceschet, Antonio. 2002. Kant and Liberal Internationalism: Sovereignty, Justice, and Global Reform. New York: Palgrave.

Frank, Robert H., Thomas Gilovich, and Dennis T. Regan. 1993. Does Studying Economics Inhibit Cooperation? The Journal of Economic Perspectives 7 (2): 159-171. 
Franke, Mark F.N. 2001. Global Limits: Immanuel Kant, International Relations, and Critique of World Politics. Albany: State University of New York Press.

Frankena, William K. 1939. The Naturalistic Fallacy. Mind 48 (192): 464-477.

Frankfurt, Harry. 1987. Equality as a Moral Ideal. Ethics 98 (1): 21-43.

Freeman, Samuel. 2001. Illiberal Libertarians: Why Libertarianism Is Not a Liberal View. Philosophy and Public Affairs 30 (2): 105-151.

Freeman, R. Edward. 2004. The Stakeholder Approach Revisited. Zeitschrift für Wirtschafts- und Unternehmensethik 5 (3): 228-241.

Freire, Paulo, and Antonio Faundez. 1989. Learning to Question: A Pedagogy of Liberation. Genf: WCC Publications.

Frey, Bruno S., and Stephan Meier. 2003. Are Political Economists Selfish and Indoctrinated? Evidence from a Natural Experiment. Economic Inquiry 41 (3): 448-462.

Freyer, Hans. 1920. Das Material der Pflichten. Eine Studie über Fichtes spätere Sittenlehre. KantStudien 25: 113-155.

- 1931. Revolution von rechts. Jena: Diederichs.

Fricker, Karl Viktor. 1872. Das Problem des Völkerrechts. Zeitschrift für die gesamte Staatswissenschaft 28: 91-144.

Friedman, Milton, Hg. 1953. Essays in Positive Economics. Chicago: University of Chicago Press. 1970. The Social Responsibility of Business Is to Increase Its Profits. New York Times Magazine, Heft 33, 13 September 1970.

Friedman, Milton, and Rose D. Friedman. 1990. Free to Choose: A Personal Statement. San Diego: Harcourts.

Fuhrmann, Raban D. 1999. Der Bürger der Bürgergesellschaft: »Bürgergutachten « aufgrund von fünf »Bürgergutachtenzellen «nach dem Verfahren »Planungszelle«. Berlin: Liberales Inst. der Friedrich-Naumann-Stiftung.

Fukuyama, Francis. 1992. The End of History and the Last Man. New York: Free Press.

Galbraith, John Kenneth. 1954. The Great Crash 1929. New York: Houghton Mifflin.

- 1958. The Affluent Society. New York: Houghton Mifflin.

- 1964. Economic Development. Cambridge: Harvard University Press.

Mifflin.

1971. A Contemporary Guide to Economics, Peace and Laughter. New York: Houghton 1973. Economics and the Public Purpose. New York: HarperCollins Distribution Services. 1975. Money, Whence it Came, Where it Went. New York: Houghton Mifflin.

. 1978. The Age of Uncertainty: Points of Departure. New York: Houghton Mifflin.

- 1979. Annals of an Abiding Liberal. New York: Houghton Mifflin.

-1983. A Life in our Times: Memoirs. New York: Balatine Books.

1985. The Anatomy of Power. New York: Houghton Mifflin.

1986a. A View from the Stands: Of People, Politics, Military Power, and the Arts.

New York: Mifflin.

- 1986b. The New Industrial State. New York: Houghton Mifflin (Originalausgabe: 1971).

1988. Capitalism, Communism, Coexistence: From the Bitter Past to a Better Prospect.

New York: Houghton Mifflin.

. 1993a. The Culture of Contentment. New York: Penguin Books.
.1993b. American Capitalism: The Concept of Countervailing Power. New York: Houghton

Mifflin (Originalausgabe 1952).

- 1996. The Good Society: The Humane Agenda. New York: Houghton Mifflin.

2004. The Economics of Innocent Fraud: Truth for our Time. New York: Houghton Mifflin.

Gallie, Walter Bryce. 1955. Essentially Contested Concepts. Proceedings of the Aristotelian

Society 56: 167-198.

Galston, William Arthur. 1995. Two Concepts of Liberalism. Ethics 105 (3): 516-534.

2002. Liberal Pluralism: The Implications of Value Pluralism for Political Theory and

Practice. Cambridge: Cambridge University Press. 
Gandal, Neil, Sonia Roccas, Lilach Sagiv, and Amy Wrzesniewski. 2005. Personal Value Priorities of Economists. Human Relations 58 (10): 1227-1252.

Garret, Don. 2004. Philosophy and History in the History of Modern Philosophy. In The Future for Philosophy, Hg. Brian Leiter. Oxford: Thomson/Social Science Press.

Garrett, Aaron, Richard Dean, Humphrey Primatt, John Oswald, and Thomas Young. 2000. Animal Rights and Souls in the Eighteenth Century. Bristol/Sterling: Thoemmes.

Garrido Domínguez, Francisco. 2001. Francisco Giner de los Ríos, creador de la Institución Libre de Enseñanza. Granada: Editorial Comares.

Gauthier, David P. 1986. Morals by Agreement. Oxford/New York: Oxford University Press.

Gefwert, Christoffer. 2000. Wittgenstein on Thought, Language, and Philosophy: From Theory to Therapy. Aldershot/Burlington: Ashgate.

Gehlen, Arnold. 1967. Anthropologische Forschung. Reinbek bei Hamburg: Rowohlt.

Geismann, Georg. 1991. Fichtes >Aufhebung< des Rechtsstaates. Fichte-Studien 3: 86-117.

Gerhardt, Volker, Hg. 1990. Der Begriff der Politik: Bedingungen und Gründe politischen Handelns. Stuttgart: Metzler.

—. 1995. Immanuel Kants Entwurf »Zum ewigen Frieden«: Eine Theorie der Politik. Darmstadt: Wissenschaftliche Buchgesellschaft.

2007. Partizipation: Das Prinzip der Politik. München: Beck.

Ghoshal, Sumantra. 2005. Bad Management Theories Are Destroying Good Management Practices. Academy of Management Learning \& Education 4: 75-91.

Giel, Klaus. 1985. Unvorgreifliche Gedanken über die Beziehung zwischen Krause und Fröbel. In Karl Christian Friedrich Krause (1781-1832): Studien zu seiner Philosophie und zum Krausismo, Hg. Klaus-Michael Kodalle and Evangelische Akademie Hofgeismar. Hamburg: F. Meiner Corp.

Gil-Cremades, Juan José. 1985. Die politische Dimension des Krausismo in Spanien. In Karl Christian Friedrich Krause (1781-1832): Studien zu seiner Philosophie und zum Krausismo, Hg. Klaus-Michael Kodalle. Hamburg: F. Meiner Corp.

Gill, Nick, and Matthew Gill. 2012. »The Limits to Libertarian Paternalism: Two New Critiques and Seven Best practice Imperatives. Environment and Planning C 30 (5): 924-940.

Gillroy, John Martin. 2009. Making Public Choices: Kant's Justice from Autonomy as an Alternative to Rawls' Justice as Fairness. Kant-Studien 91 (1): 44-72.

Giner de los Ríos, Francisco. 1899. La persona social: estudios y fragmentos. Madrid: Imprenta de Enrique Rojas.

Giovanola, Benedetta. 2009. Re-Thinking the Anthropological and Ethical Foundation of Economics and Business: Human Richness and Capabilities Enhancement. Journal of Business Ethics 88 (3): 431-444.

Girndt, Helmut. 1989. Über den Umgang mit der empfindungsfähigen Natur nach J. G. Fichte. In Transzendentalphilosophie als System: Die Auseinandersetzung zwischen 1794 und 1806, Hg. Alfred Mues. Hamburg.

Glauner, Friedrich. 1997. Sprache und Weltbezug Adorno. Heidegger, Wittgenstein. Freiburg: Alber.

Gohl, Christopher. 2008. Beyond Strategy: Prozedurale Politik. Zeitschrift für Politikberatung 1 (2): 191-212.

2011. Prozedurale Politik am Beispiel organisierter Dialoge: Wie politische Beteiligung professionell gestaltet werden kann - eine Grundlegung. Münster/Berlin: LIT.

Goldston, Eli, and Harold Demsetz. 1970. Discussion. The American Economic Review 60 (2): 479-484.

Graham, John R., Campbell R. Harvey, and Shiva Rajgopal. 2005. The Economic Implications of Corporate Financial Reporting. Journal of Accounting and Economics 40 (1-3): 3-73.

Gray, John. 1981. Hayek on Liberty, Rights, and Justice. (F.A. Hayek). Ethics 92: 73-84. . 1986. Hayek on Liberty. Oxford/New York: Blackwell.

1988. Mill's and Other Liberalisms. Critical Review 2 (2-3): 12-35.

1989. Liberalisms: Essays in Political Philosophy. London/New York: Routledge. 
2000. Two Faces of Liberalism. New York: New Press.

Grayson, David, et al. 2014. Social Intrapreneurism and All That Jazz. Sheffield: Greenleaf Publishing.

Green, Thomas Hill. 1883-1889. Works of Thomas Hill Green, herausgegeben von Richard Lewis Nettleship. New York: Longmans.

1941. Lectures on the Principles of Political Obligation. London: Longmans.

Gregor, Mary J. 1963. Laws of Freedom: A Study of Kant's Method of Applying The Categorical Imperative in The Metaphysik Der Sitten. Oxford/New York: Blackwell.

Griffin, James. 1994. The Distinction Between Criterion and Decision Procedure: A Reply to Madison Powers. Utilitas 6 (2): 177-182.

Gröschner, Rolf, Claus Dierksmeier, Michael Henkel, and Alexander Wiehart. 2000. Rechts- und Staatsphilosophie: Ein dogmenphilosophischer dialog. Berlin: Springer.

Groß, Stefan. 2011. Die Philosophie Karl Christian Friedrich Krauses im Kontext des deutschen Idealismus: Vom Bild des Absoluten; Krauses Lehre vom Göttlichen und Fichtes Wissenschaftslehre von 1804. Frankfurt: P.Lang.

Grundherr, Michael von. 2014. Kompetenz, Selbstwirksamkeitserwartung und die Rolle von Vorbildern in der Ordnungsethik. Zeitschrift für Wirtschafts- und Unernehmensethik 15 (3): 319-334.

Grusky, David B., S.M. Ravi Kanbur, and Amartya Sen. 2006. Poverty and inequality. Stanford: Stanford University Press.

Guala, Francesco. 2008. Paradigmatic Experiments: The Ultimatum Game from Testing to Measurement Device. Philosophy of Science 75 (5): 658-669.

Guillén, Malo, and José Luis. 2000. La Institución Libre de Enseñanza y la ciencia económica. Sistema Revista de Ciencias Sociales 157: 93-114.

- 2005. El krausismo económico español. Madrid: Real Academia de Ciencias Morales y Políticas.

Gülen, Fethullah. 2004. Toward a Global Civilization of Love \& Tolerance. New Jersey: Somerset.

Gurvitch, Georges. 1924. Fichtes System der konkreten Ethik. Tübingen: Mohr.

Gutierrez, Gustavo. 1973. A Theology of Liberation: History, Politics, and Salvation. Maryknoll: Orbis Books.

Guyer, Paul. 2000. Kant on Freedom, Law, and Happiness. Cambridge: Cambridge University Press.

Habermas, Jürgen. 1961. Über den Begriff der politischen Beteiligung. Neuwied am Rhein: Luchterhand.

- 1990. Strukturwandel der Öffentlichkeit: Untersuchungen zu einer Kategorie der bürgerlichen Gesellschaft. Frankfurt a.M.: Suhrkamp (Originalausgabe: 1962).

- 1995. Reconciliation Through the Public Use of Reason: Remarks on John Rawls's Political Liberalism. The Journal of Philosophy 92 (3): 109-123.

Habisch, André. 2011. Gesellschaftliches Unternehmertum - Blinder Fleck wirtschafts- und sozialwissenschaftlicher Gemeinwohltheorien. In Social Entrepreneurship - Social Business: Für die Gesellschaft unternehmen, Hg. Helga Hackenberg and Stefan Empter. Wiesbaden: VS Verlag für Sozialwissenschaften.

Hahn, Karl. 1969. Staat, Erziehung und Wissenschaft bei J.G. Fichte. München: Beck.

Hamlin, Alan P., and Philip Pettit. 1989. The Good Polity: Normative Analysis of the State. Oxford: Blackwell Pub.

Hamm-Brücher, Hildegard. 2011. Und dennoch...: Nachdenken über Zeitgeschichte, Erinnern für die Zukunft. München: Siedler.

Hamm-Brücher, Hildegard, and Norbert Schreiber. 2009. Demokratie, das sind wir alle. München: Siedler.

Hamowy, Ronald. 1982. The Hayekian Model of Government in an Open Society. Journal of Libertarian Economics 6: 137-144.

Harada, Tetsushi. 1989. Politische Ökonomie des Idealismus und der Romantik: Korporatismus von Fichte, Müller und Hegel. Berlin: Duncker u. Humblot. 
Hart, Herbert Lionel Adolphus. 1963. Law, Liberty, and Morality. Stanford: University Press.

Hasselmann, Christel. 2005. Hans Küngs Projekt Weltethos interkulturell gelesen. Nordhausen: Bautz.

Hayek, Friedrich August von. 1972. The Constitution of Liberty. Chicago: Cornell University Press (Originalausgabe: 1960).

1979. Law, Legislation and Liberty: A New Statement of the Liberal Principles of Justice and Political Economy, Bd. 2, London 1976, Bd. 3. London: Routledge.

Heal, Geoffrey M. 2008. When Principles Pay: Corporate Social Responsibility and the Bottom Line. New York: Columbia Business School.

Hedrick, Todd. 2010. Rawls and Habermas: Reason, Pluralism, and the Claims of Political Philosophy. Stanford: Stanford University Press.

Hegel, Georg Wilhelm Friedrich. 1969. Hegels Werke in 20 Bänden, herausgegben von: Eva Moldenhauer und Karl Markus Michel. Frankfurt a.M.: Suhrkamp.

Heinrich, Dieter, Immanuel Kant, Friedrich von Gentz, and August Wilhelm Rehberg, Hg. 1967. Über Theorie und Praxis. Frankfurt a.M.: Suhrkamp.

Heller, Eberhard. 1974. Die Theorie der Interpersonalität im Spätwerk J. G. Fichtes: Dargest. in den »Thatsachen des Bewusstseyns « von 1810/11, München.

Helm, Dieter, Hg. 1989. The Economic Borders of the State. Oxford: Clarendon Press.

Hennecke, Hans Jörg, and Friedrich August von Hayek. 2000. Die Tradition der Freiheit. Düsseldorf: Verlag Wirtschaft und Finanzen.

Hennessy, C.A.M., and Paul Avrich. 1962. Collection (Library of Congress), The Federal Republic in Spain: Pi y Margall and the Federal Republican Movement, 1868-74. Oxford: Greenwood Press.

Henrich, Dieter. 1991. Konstellationen: Probleme und Debatten am Ursprung der idealistischen Philosophie (1789-1795). Stuttgart: Klett Cotta.

Herzog, Lisa Maria. 2014. Freiheit gehört nicht nur den Reichen: Plädoyer für einen zeitgemäßen. München: Liberalismus.

Hetzel, Hermann. 1889. Die Humanisierung des Krieges in ihrer culturgeschichtlichen Entwicklung. Frankfurt an der Oder.

Hicks, Douglas A. 2002. Gender, Discrimination, and Capability: Insights from Amartya Sen. The Journal of Religious Ethics 30 (1): 137-154.

Hill, Lisa Cohen Elliot D. 1999. Homo Economicus, Different Voices, and the Liberal Psyche. International Journal of Applied Philosophy 13 (1): 21-46.

Hinz, Manfred O. 1981. Fichtes »System der Freiheit«: Analyse eines widersprüchlichen Begriffs. Stuttgart: Klett-Cotta.

Hirschmann, Nancy J. 2003. The Subject of Liberty: Toward a Feminist Theory of Freedom. Princeton: Princeton University Press.

Hobbes, Thomas. 1996. Leviathan, Menston (Originalausgabe: 1651).

Hobhouse, Leonard. 1911. Trelawny, Liberalism. New York: Williams \& Norgate.

Hobson, John. 1909. The Crisis of Liberalism: New Issues of Democracy. London: King.

Hodgkinson, Virginia, and Michael W. Foley, Hg. 2009. The Civil Society Reader. Libanon: Tufts (Originalausgabe: 2003).

Höffe, Otfried. 1983. Immanuel Kant. übersetzt von: Marshall Farrier. München: Beck.

1988. Naturrecht ohne naturalistischen Fehlschluss. In Den Staat braucht selbst ein Volk von Teufeln: Philosophische Versuche zur Rechts- und Staatsethik, Hg. Otfried Höffe. Stuttgart: Reclam.

— 1994. Öffentliche oder politische Vernunft? Zu Rawls II. In Zeitschrift für Philosophische Forschung, 259-269.

- 1998. Den Staat braucht selbst ein Volk von Teufeln: Philosophische Versuche zur Rechtsund Staatsethik. Stuttgart: Reclam (Originalausgabe: 1988).

Hohlfeld, Paul. 1874. Über Krause und Fröbel, Die Neue Zeit 3, 7.

Homann, Karl Blome-Drees Franz. 1992. Wirtschafts- und Unternehmensethik. Göttingen: Vandenhoeck \& Ruprecht. 
Honneth, Axel. 2004. Organized Self-Realization. European Journal of Social Theory 7 (4): 463-478.

- 2011. Das Recht der Freiheit - Grundriß einer demokratischen Sittlichkeit. Frankfurt a.M.: Suhrkamp-Verlag.

Hornbostel, Stefan. 2014. Schisma oder Diversifikation. Das Verhältnis von Natur-, Sozial- und Geisteswissenschaften. In Geistes- und Sozialwissenschaften an der Universität von morgen, Hg. Mechthild Dreyer, Uwe Schmidt, and Klaus Dicke. Wiesbaden: Springer.

Hospers, John, and Paul Avrich. 1971. Collection (Library of Congress), Libertarianism: A Political Philosophy for Tomorrow. Los Angeles: Nash.

Howaldt, Jürgen, and Michael Schwarz. 2010. Soziale Innovation « im Fokus: Skizze eines gesellschaftstheoretisch inspirierten Forschungskonzepts. Bielefeld: Transcript.

Hoy, Calvin M. 1984. A Philosophy of Individual Freedom: The Political Thought of F.A. Hayek. Westport: Greenwood.

Hudson, Hud. 1991. Wille, Willkür, and the Imputability of Immoral Actions. Kant-Studien: Philosophische Zeitschrift der Kant-Gesellschaft 82: 179-196.

Hühn, Matthias P., and Claus Dierksmeier. 2014. Will the Real A. Smith Please Stand Up! Journal of Business Ethics:1-14.

Hulten, Michel van, ed. 2009. Transparency International. Leiden: Elsevier.

Humboldt, Wilhelm. 1967. Ideen zu einem Versuch, die Grenzen der Wirksamheit des Staats zu bestimmen. Stuttgart: Reclam.

Hume, David. 1801. Philosophical Essays Concerning Human Understanding (1751) Pre-Imprint Collection. London: Library of Congress.

- 1953. Theory of Knowledge. Containing the Enquiry Concerning Human Understanding. Austin: University of Texas Press.

Huntington, Samuel P.. 1996. The Clash of Civilizations and the Remaking of World Order. New York.

Ingram, David. 2003. Between Political Liberalism and Postnational Cosmopolitanism: Toward an Alternative Theory of Human Rights. Political Theory 31 (3): 359-391.

Ivaldo, Marco. 1999. Die systematische Position der Ethik nach der Wissenschaftslehre nova methodo und der Sittenlehre 1798. Fichte-Studien 16: 237-254.

James, David. 2011. Fichte's Social and Political Philosophy: Property and Virtue. Cambridge/ New York: Cambridge University Press.

Janke, Wolfgang. 1991. Anerkennung. Fichtes Grundlegungen des Rechtsgrundes. Kant-Studien 82 (1): 197-218.

Jansen, Christian. 2011. The formation of German Nationalism, 1740-1850. In: The Oxford Handbook of Modern German History, 234.

Jasper, Scott, ed. 2010. Securing Freedom in the Global Commons. Stanford: Stanford Security Studies.

Jáuregui, Carlos A., and Mabel Moraña. 2007. Colonialidad y crítica en América Latina: Bases para un debate. Puebla: Universidad de las Américas Puebla.

Jensen, Michael C., and William H. Meckling. 1976. Theory of the Firm: Managerial Behavior, Agency Costs and Ownership Structure. Journal of Financial Economics 3 (4): 305-360.

Jevons, William Stanley. 1871. The Theory of Political Economy. London: Macmillan.

1874. The Principles of Science: A Treatise on Logic and Scientific Method. London: Macmillan.

Jolls, Christine, Cass R. Sunstein, and Richard Thaler. 1998. A Behavioral Approach to Law and Economics. Stanford Law Review 50 (5): 1471-1550.

Kabat-Zinn, Jon, and Richard Davidson. 2012. The Mind's Own Physician: A Scientific Dialogue with the Dalai Lama on the Healing Power of Meditation. Oakland: New Harbinger Publications.

Kahlo, Michael, Ernst Amadeus Wolff, and Rainer Zaczyk. 1992. Fichtes Lehre vom Rechtsverhältnis: Die Deduktion der [Paragraphen] 1-4 der Grundlage des Naturrechts und ihre Stellung in der Rechtsphilosophie. Frankfurt a.M.: V. Klostermann. 
Kamat, Sangeeta. 2004. The Privatization of Public Interest: Theorizing NGO Discourse in a Neoliberal Era. Review of International Political Economy 11 (1): 155-176.

Kant, Immanuel. 1900. Gesammelte Schriften, Bd. 1-22, herausgegeben von der Preussischen Akademie der Wissenschaften, Bd. 23 Deutsche Akademie der Wissenschaften zu Berlin, ab Bd. 24 Akademie der Wissenschaften zu Göttingen, Berlin (et seqq.).

Karier, Thomas. 1993. The Heresies of John Kenneth Galbraith. Challenge 36 (4): 23-28.

Kater, Thomas, and Recht Politik. 1999. Geschichte: Zur Einheit der politischen Philosophie Immanuel Kants. Würzburg: Königshausen \& Neumann co.

Kaulbach, Friedrich. 1978a. Das Prinzip Handlung in der Philosophie Kants. Berlin: De Gruyter.

- 1978b. Das transzendental-juridische Grundverhältnis im Vernunftbegriff Kants und der

Bezug zwischen Recht und Gesellschaft. In Recht und Gesellschaft - Festschrift für Helmut Schelsky zum 65 Geburtstag, Hg. Friedrich Kaulbach and W. Krawietz. Berlin: Duncker und Humblot.

Kautz, Julius, Hg. 1858. Theorie und Geschichte der Nationalökonomik. Wien: Gerold.

Kautz, Steven J. 1995. Liberalism and Community. Ithaca: Cornell University Press.

Kavka, Gregory S. 1995. Why Even Morally Perfect People Would Need Government. Social Philosophy and Policy 12 (1): 1-18.

Keck, Werner. 1998. Zwischen evolutionärer und gesellschaftsvertraglicher Fundierung des Staates: Eine vergleichende Analyse der Staatsauffassungen von Rawls, Buchanan, Hayek und Nozick. Berlin: P+H Wiss. Verl.

Kelly, Terrence. 2001. Sociological not Political: Rawls and the Reconstructive Social Sciences. Philosophy of the Social Sciences 31 (1): 3-19.

Kersting, Wolfgang. 1993. Wohlgeordnete Freiheit: Immanuel Kants Rechts- und Staatsphilosophie. Frankfurt a.M.: Suhrkamp (Originalausgabe: 1984).

. 2004. Kant über Recht. Paderborn: Mentis.

. 2009. Verteidigung des Liberalismus. Hamburg: Murmann.

Keynes, John Maynard. 1931. Essays in Persuasion. London: MacMillan.

Khader, Serene J. 2011. Adaptive Preferences and Women's Empowerment. Oxford: Oxford University Press.

Kienzler, Wolfgang. 1997. Wittgensteins Wende zu seiner Spätphilosophie 1930 - 1932 eine historische und systematische Darstellung. Frankfurt a.M.: Suhrkamp.

Kilan, Banu. 2009. J. Rawls's Idea of an >Overlapping Consensus< and the Complexity of $>$ Comprehensive Doctrines $<$. Ethical Perspectives 16 (1): 21-60.

Killingback, Timothy, and Etienne Studer. 2001. Spatial Ultimatum Games, Collaborations and the Evolution of Fairness. Proceedings of the Biological Sciences 268 (1478): 1797-1801.

Kirchgässner, Gebhard. 2008. Homo Oeconomicus: The Economic Model of Individual Behavior and Its Applications in Economics and Other Social Sciences. New York: Springer.

Kitagawa, Joseph Mitsuo. 1990. Spiritual Liberation and Human Freedom in Contemporary Asia. New York: P.Lang.

Kläver, Michael. 2000. Die Verfassung des Marktes: Friedrich August von Hayeks Lehre von Staat und Markt im Spiegel grundgesetzlicher Staats- und Verfassungsrechtslehre. Stuttgart: Lucius und Lucius.

Kleingeld, Pauline. 2011. Kant and Cosmopolitanism: The Philosophical Ideal of World Citizenship. Cambridge/New York: Cambridge University Press.

Knippenberg, Joseph. 1993. The Politics of Kant's Philosophy. In Kant \& Political Philosophy The Contemporary Legacy, Hg. Ronald Beiner. New Haven: Yale University Press.

Kodalle, Klaus-Michael. 1997. Der Stellenwert der Historiographie im Kontext des Fichteschen Geschichtsdenkens. Fichte-Studien 11: 259-285.

. 2006. Annäherungen an eine Theorie des Verzeihens. Mainz: Steiner.

Kodalle, Klaus-Michael, and Evangelische Akademie Hofgeismar, Hg. 1985. Karl Christian Friedrich Krause (1781-1832): Studien zu seiner Philosophie und zum Krausismo. Hamburg: F. Meiner, cop. 
Kodalle, Klaus-Michael, and Martin Ohst, eds. 1999. Fichtes Entlassung: Der Atheismusstreit vor 200 Jahren. Würzburg: Königshausen \& Neumann.

Kohlberg, Lawrence. 1987. Child Psychology and Childhood Education: A Cognitivedevelopmental View. New York: Longman.

Köhler, Michael. 1992. Zur Begründung des Rechtszwangs im Anschluss an Kant und Fichte. In Fichtes Lehre vom Rechtsverhältnis: Die Deduktion der [Paragraphen] 1-4 der Grundlage des Naturrechts und ihre Stellung in der Rechtsphilosophie, Hg. Michael Kahlo, Ernst A. Wolff, and Rainer Zaczyk. Frankfurt a.M.: V. Klostermann.

1993. Iustitia distributiva. Zum Begriff und zu den Formen der Gerechtigkeit. Archiv für Rechts- und Sozialphilosophie (ARSP) 79: 457-482.

Konisky, David M. 2007. Regulatory Competition and Environmental Enforcement: Is There a Race to the Bottom? American Journal of Political Science 51 (4): 853-872.

Koslowski, Stefan. 1989. Die Geburt des Sozialstaats aus dem Geist des deutschen Idealismus: Person und Gemeinschaft bei Lorenz von Stein. Weinheim: VCH.

Koslowski, Peter. 1997. Methodology of the Social Sciences, Ethics, and Economics in the Newer Historical School: From Max Weber and Rickert to Sombart and Rothacker. Berlin/New York: Springer.

Köveker, Dietmar. 1996. Grenzverhältnisse: Kant und das »Regulative Prinzip« in Wissenschaft und Philosophie. Berlin: Duncker \& Humblot.

Kramer, Matthew H. 2003. The Quality of Freedom. Oxford/New York: Oxford University Press.

Krasnoff, Larry. 1999. How Kantian Is Constructivism? Kant-Studien 90 (4): 385-409.

Krause, Karl Christian Friedrich. 1803. Grundlage des Naturrechts, oder philosophischer Grundriss des Ideales des Rechts. Erste Abtheilung, Jena.

—. 1804. Anleitung zur Naturphilosophie. I. Deduction der Natur, II. Anleitung zur Construction der Natur, Jena; Leipzig.

- 1828a. Vorlesungen über Grundwahrheiten der Wissenschaft, zugleich in ihrer Beziehung zu dem Leben. Nebst einer kurzen Darstellung und Würdigung der bisherigen Systeme der Philosophie, vornehmlich der neuesten von Kant, Fichte, Schelling und Hegel, und der Lehre Jacobi's. Für Gebildete aus allen Ständen, Göttingen.

- 1828b. Abriss des Systemes der Philosophie des Rechtes oder des Naturrechts, Göttingen. - 1851. Das Urbild der Menschheit, Göttingen: Dieterich, (Originalausgabe 1811).

. 1874. Das System der Rechtsphilosophie - Vorlesungen für Gebildete aus allen Ständen, herausgegeben von: K.A.D. Röder. Leipzig: Schulze.

- 1888. System der Sittenlehre. I. Versuch einer wissenschaftlichen Begründung der Sittenlehre; II. Abhandlungen und Einzelgedanken zur Sittenlehre, herausgegeben von: P. Hohlfeld and A. Wünsche. Weimar: Schulze.

- 1889. Zur Geschichte der neueren philosophischen Systeme, herausgegeben von: P. Hohlfeld and A. Wünsche. Weimar: Schulze.

- 1890a. Das Eigenthümliche der Wesenslehre nebst Nachrichten zur Geschichte der Aufnahme derselben, vornehmlich von Seiten deutscher Philosophen, herausgegeben von: P. Hohlfeld and A. Wünsche. Weimar: Schulze.

. 1890b. Grundlage des Naturrechts oder philosophischer Grundriss des Ideales des Rechts. Zweite Abtheilung, herausgegeben von Georg Mollat, Bd. I, Bd. II, Weimar.

1892. Vorlesungen über Naturrecht oder Philosophie des Rechts und des Staates, herausgegeben von: R. Mucke. Leipzig: Schulze.

- 1893a. Der Erdrechtsbund an sich selbst und in seinem Verhältnisse zum Ganzen und zu allen Einzeltheilen des Menschheitlebens, aus dem Nachlass herausgegeben von: Georg Mollat, Weimar.

—. 1893b. Erklärende Bemerkungen und Erläuterungen [Kommentar] zu J.G. Fichtes Grundlage des Naturrechts, aus dem Nachlass. herausgegeben von: Georg Mollat. Leipzig: Schulze.

—. 1904. Lebenlehre oder Philosophie der Geschichte zur Begründung der Lebenkunstwissenschaft. Leipzig: Dietrich. 
1920. Entwurf eines europäischen Staatenbundes als Basis des allgemeinen Friedens und als rechtliches Mittel gegen jeden Angriff wider die innere und äußere Freiheit Europas, herausgegeben von: H. Reichel. Leipzig: Meiner. (Originalausgabe 1814)

_ 1981. Vorlesungen zum System der Philosophie, (Teil I/II), herausgegeben von Siegfried Plegerl, Breitenfurt: Dieterich (Originalausgabe: Göttingen 1828).

Krieken, Albert Th. 1873. Ueber die sogenannte organische Staatstheorie: Ein Beitrag zur Geschichte des Staatsbegriffs. Leipzig: Duncker u. Humbolt.

Kristjánsson, Kristján. 1996. Social Freedom: The Responsibility View. Cambridge/New York: Cambridge University Press.

Kroner, Richard. 1924. Von Kant bis Hegel, Tübingen Bd. 1: 1921; Bd. 2.

Kuhn, Thomas S. 1962. The Structure of Scientific Revolutions. Chicago: University of Chicago Press.

Küng, Hans. 1978. Existiert Gott? Antwort auf die Gottesfrage der Neuzeit. München: Piper. 1990. Projekt Weltethos. München: Piper.

1995. Weltpolitik und Weltethos. Evangelische Akademie Bad Boll: Aktuelle Gespräche, 43, 4: 30-35.

- 1998. Nachhaltige Entwicklung und Weltethos. In Denkanstöße '99 Ein Lesebuch aus Philosophie, Natur- und Humanwissenschaften, Hg. Heidi Bohnet-von der Thüsen. München: Piper.

- 2002a. Menschen-Rechte und Menschen-Verantwortlichkeiten. In Dokumentation zum Weltethos, ed. Hans Küng. Piper: München.

- 2002b. Tracing the Way: Spiritual Dimensions of the World Religions. übersetzt von: John Bowden. London: Continuum.

—. 2002c. Zur Problematik von Weltpolitik, Weltstaat und Weltethos. In Weltrepublik Globalisierung und Demokratie, Hg. Stefan Gosepath and J.C. Merle. München: Beck.

- 2005. Welt - Sport - Ethos. Weltethos. In Deutscher Evangelischer Kirchentag, Hg. Eckhard Nagel. Hannover: Gütersloher Verl.-Haus. 1994).

2007b. Der Islam: Wesen und Geschichte. München/Zürich: Piper.

2010a. Anständig wirtschaften. Warum Ökonomie Moral braucht. Piper: München.

2010b. Weltethos und globale Führungsverantwortung. In Führung. Macht. Sinn: Ethos und Ethik für Entscheider in Wirtschaft, Gesellschaft und Kirche, Hg. Uto Meier and Bernhard Still. Regensburg: Pustet.

—. 2013. Weltmusik - Weltreligionen - Weltethos. Interkulturelle Kommunikation durch Musik. In Kommunikation ist möglich Theologische, ökumenische und interreligiöse Lernprozesse, Festschrift für Bernd Jochen Hilberath, Hg. Christine Büchner, Christine Jung, Bernhard Nitsche, and Lucia Scherzberg. Ostfildern: Grünewald.

- 2014. We Need Bridge-Builders - No Survival for the World Without a Global Ethic. In East-West Divan In Memory of Werner Mark Linz. London: Ginko.

Küng, Hans, and Das Judentum. 1991. Die religiöse Situation der Zeit. München: Piper.

Küng, Hans, and Karl-Josef Kuschel. 1998. Wissenschaft und Weltethos. München: Piper.

Küng, Hans, Klaus M. Leisinger, and Josef Wieland. 2010. Manifest Globales Wirtschaftsethos: Konsequenzen und Herausforderungen für die Weltwirtschaft $($ Deutsch/Englisch $)=$ Manifesto Global Economic Ethic: Consequences and Challenges for Global Businesses (German/ English). München: Piper.

Küng, Hans, Günther Gebhardt, and Stephan Schlensog. 2012. Handbuch Weltethos: Eine Vision und ihre Umsetzung. München: Piper.

Kunze, Ludwig. 1911. Die pädagogischen Gedanken Karl Christian Friedrich Krauses in ihrem Zusammenhang mit seiner Philosophie dargestellt, Langensalza.

Kuper, Andrew. 2000. Rawlsian Global Justice: Beyond The Law of Peoples to a Cosmopolitan Law of Persons. Political Theory 28 (5): 640-674. 
Kuschel, Karl-Josef. 1999. Jesus im Spiegel der Weltliteratur. Eine Jahrhundertbilanz in Texten und Einführungen. Patmos: Düsseldorf.

.2011. Im Ringen um den wahren Ring: Lessings »Nathan der Weise«-eine Herausforderung der Religionen. Ostfildern: Patmos.

Kymlicka. 1989. Will, Liberalism, Community and Culture. Oxford: Clarendon.

Lafont, Cristina. 2003. Procedural Justice? Implications of the Rawls-Habermas Debate for Discourse Ethics. Philosophy \& Social Criticism 29 (2): 163-181.

Lakoff, George. 2006. Whose Freedom? The Battle over America's Most Important Idea. New York: Picador.

Lama, Dalai. 2011. Beyond Religion: Ethics for a Whole World. Boston: De Gruyter.

Landau, Peter. 1985. Karl Christian Friedrich Krauses Rechtsphilosophie. In Karl Christian Friedrich Krause (1781-1832) - Studien zu seiner Philosophie und zum Krausismo, Hg. Klaus-Michael Kodalle. Hamburg: Meiner.

— 1986. Gesellschaftliches Recht und das Prinzip freier Körperschaftsbildung in der Rechtsphilosophie von Heinrich Ahrens. In Recht, Gericht, Genossenschaft und Policey Studien zu Grundbegriffen der germanistischen Rechtshistorie, Hg. Gerhard Dilcher and Bernhardt Distelkamp. Berlin: Schmidt.

Langer, Claudia. 1986. Reform nach Prinzipien: Untersuchungen zur politischen Theorie Immanuel Kants. Stuttgart: Klett-Cotta.

Laperche, Blandine, James K. Galbraith, and Dimitri Uzunidis, Hg. 2006. Innovation, Evolution and Economic Change: New Ideas in the Tradition of Galbraith. Cheltenham/Northampton: Elgar.

Larmore, Charles E. 1996. The Morals of Modernity. Cambridge, UK/New York: Cambridge University Press.

Laski, Harold. 1962. The Rise of European Liberalism. London: Unwin Books.

Lattemann, C. 2014. On the Convergence of Corporate Governance Practices in Emerging Markets. International Journal of Emerging Markets 9 (2): 316-332.

Lecea, Teresa Rodriguez des. 1985. Der spanische Krausismo als praktische Philosophie. In Karl Christian Friedrich Krause (1781-1832) Studien zu seiner Philosophie und zum Krausismo, Hg. Klaus-Michael Kodalle. Hamburg.

Lehmann, Karl. 2003. Frei vor Gott: Glauben in öffentlicher Verantwortung. Freiburg i.Br.: Herder.

Leibenstein, Harvey. 1987. Inside the Firm: The Inefficiencies of Hierarchy. Cambridge, MA: Harvard University Press.

Leisinger, Klaus M. 2007. Capitalism with a human face. Journal of Corporate Citizenship 28: $113-132$.

Leisinger, Klaus M., Aron Cramer, Faris Natour. 2010. »Making Sense of the United Nations Global Compact Human Rights Principles. In in: (Hg.)The United Nations Global Compact: Achievements, Trends and Challenges, Hg. Andreas Rasche and Georg Kell. Cambridge: Cambridge University Press.

Leiter, Brian, ed. 2004. The Future for Philosophy. Oxford: Oxford University Press.

Leo XIII. 1941. Human Liberty, Encyclical Letter. New York: The Paulist Press.

Leonard, Mark. 2005. Why Europe Will Run the 21 st Century. London/New York: Fourth Estate.

Leoni, Bruno. 1961. Freedom and the Law. Princeton: Van Nostrand.

Levine, Robert. 1997. A Geography of Time - On Tempo, Culture And The Pace of Life: The Temporal Misadventures of a Social Psychologist, or: How Every Culture Keeps Time Just a Little Bit Differently? New York: Basic Books.

Li, Shaomin, Mark Fetscherin, Illan Alon, Christoph Lattemann, and Kuang Yeh. 2010. Corporate Social Responsibility in Emerging Markets. Management International Review 50 (5): 635-654.

Lincoln, Abraham. 1953. The Collected Works of Abraham Lincoln, herausgegeben von: Roy Prentice Basler und der Abraham Lincoln Association. New Jersey: New Brunswick.

Lippke, Richard L. 1989. Advertising and the Social Conditions of Autonomy. Business \& Professional Ethics Journal 8 (4): 35-58. 
Locke, John. 1960. Two Treatises of Government. herausgegeben von: Peter Laslett. Cambridge, UK: Dent (Originalausgabe: 1689).

López-Domínguez, Virginia. 1999. Die Idee des Leibes im Jenaer System. Fichte-Studien 16: 273-293.

López-Morillas, Juan. 1980. El krausismo español: perfil de una aventura intelectual. Madrid: Fondo de Cultura Económica (Originalausgabe: 1958).

Lorimer, James, Hg. 1872. The Institutes of Law: A Treatise of the Principles of Jurisprudence, as Determined by Nature. Edinburgh: T. \& T. Clark.

Louden, Robert B. 1986. Kant's Virtue Ethics. Philosophy 61 (238): 473-489.

Lowry, S. Todd. 1987. The Archaeology of Economic Ideas: The Classical Greek Tradition. Durham: Duke University Press.

Lyons, David. 1982. Utility and Rights. In Ethics, Economics, and the Law, ed. J. Roland Pennock and John W. Chapman. New York: New York University Press.

MacCallum, Gerald C., Jr. 1967. Negative and Positive Freedom. The Philosophical Review 76 (3): 312-334.

MacCauley, Clay. 1917a. Krause's League for Human Right and Thereby World Peace. Tokyo: Nabu Press.

. 1917b. Krause's Proposition for a European League of States. The Advocate of Peace (1894-1920) 79(11): 337-339.

. 1919. Krause's 1818 League of Peace. The Advocate of Peace (1894-1920) 81(2): 43-44. 1925. Karl Christian Friedrich Krause: Heroic Pioneer for Thought and Life. Berkely: Gazette Press.

Macedo, Stephen. 1995. Liberal Civic Education and Religious Fundamentalism: The Case of God v. John Rawls? Ethics 105 (3): 468-496.

2000. Diversity and Distrust. Cambridge, MA: Harvard University Press.

MacGilvray, Eric. 2011. The Invention of Market Freedom. New York: Cambridge University Press.

Macpherson, Crawford Brough. 1973. Democratic Theory: Essays in Retrieval. Oxford: Clarendon Press.

Majumdar, Tapas. 1998. Amartya Sen in Search of Impure Welfare Economics: Finding New Space. Economic and Political Weekly 33 (45): 2860-2862.

Mankiw, N. Gregory, and Romer David, Hg. 1991. New Keynesian Economics, Cambridge, MA: MIT Press.

Manzeschke, Arne, Veronika Drews-Galle, and Marburger Arbeitskreis. 2010. Theologische Wirtschafts- und Technikethik, Sei ökonomisch! Prägende Menschenbilder zwischen Modellbildung und Wirkmächtigkeit. Berlin: Lit.

Marcuse, Herbert. 1941. Reason and Revolution: Hegel and the Rise of Social Theory. London/ New York: Oxford University Press.

— 1967. Der eindimensionale Mensch: Studien zur Ideologie der fortgeschrittenen Industriegesellschaft. übersetzt von: Alfred Schmidt. Neuwied: Luchterhand.

Marglin, Stephen A. 1999. John Kenneth Galbraith and the Myths of Economics. In Between Friends: Perspectives on John Kenneth Galbraith, Hg. Helen Sasson, Derek Curtis Bok, and Andrea D. Williams. Boston: Houghton Mifflin.

Marris, Robin Lapthorn. 1964. The Economic Theory of »Managerial « Capitalism. London: MacMillan.

Marwell, Gerald, and Ruth E. Ames. 1981. Economists free ride, does anyone else? Experiments on the provision of public goods, IV. Journal of Public Economics 15 (3): 295-310.

Marx, Karl, and Friedrich Engels. 1988. Werke, [1839 bis 1844]. Berlin: Dietz.

Mattson, Kevin. 2004. When America Was Great: The Fighting Faith of Postwar Liberalism. New York: Routledge.

Mavrotas, George, and F. Anthony. 2007. Shorrocks und World Institute for Development Economics Research, Advancing Development: Core Themes in Global Economics. Houndmills/New York: Palgrave Macmillan. 
McCabe, Donald L., Kenneth D. Butterfield, and Linda Klebe Treviño. 2006. Academic Dishonesty in Graduate Business Programs: Prevalence, Causes, and Proposed Action. Academy of Management Learning \& Education 5 (3): 294-305.

McCloskey, Deirdre N. 1994. Knowledge and Persuasion in Economics. Cambridge/New York: Cambridge University Press.

McFadden, Daniel. 2006. Free Markets and Fettered Consumers. The American Economic Review 96 (1): 3-29.

Megone, Christopher. 1987. One Concept of Liberty. Political Studies 35 (4): 611-622.

Melé, Domènec. 2009. Editorial Introduction: Towards a More Humanistic Management. Journal of Business Ethics 88 (3): 413-416.

Melé, Domènec, and Claus Dierksmeier, Hg. 2012. Human Development in Business: Values and Humanistic Management in the Encyclical Caritas in Veritate. New York: Palgrave Macmillan.

Menendez Ureña, Enrique. 1990. Algunas consequencias del panenteismo krausista: Ecología y mujer. El Basilisco: Revista de Filosofia, Ciencias Humanas, Teoria de la Ciencia y de la Cultura, Segunda Epoca 4 (3/4): 51-58.

Menger, Carl. 1883. Untersuchungen über die Methode der Sozialwissenschaften, und der politischen Ökonomie insbesondere. Leipzig: Verlag von Duncker \& Humblot.

Menninger, Karl. 1969. Number Words and Number Symbols. A Cultural History of Numbers. Cambridge, MA: M.I.T. Press.

Mill, John Stuart. 1859. Dissertations and Discussions; Political, Philosophical and Historical. London: John W. Parker and Son.

-1864. Utilitarianism. London: Longman.

Mill, James. 1939. Government. In The English Philosophers: From Bacon to Mill, ed. Edwin A. Burtt. New York: Random House.

Mill, John Stuart. 1991. On Liberty and Other Essays, herausgegben von: John Gray. Oxford/New York: Oxford Paperbacks.

Miller, David. 1983. Constraints on Freedom. Ethics 94 (1): 66-86.

- 1985. Reply to Oppenheim. Ethics 95 (2): 310-314.

Mills, Claudia. 1998. Choice and Circumstance. Ethics 109 (1): 154-165.

Mintzberg, Henry. 2004. Managers Not MBAs: A Hard Look at the Soft Practice of Managing and Management Development. San Francisco: Berrett-Koehler.

Mintzberg, Henry, Robert Simons, and Kunal Basu. 2002. Beyond Selfishness. MIT Sloan Management Review 44 (1): 67-74.

Mirowski, Philip, and Esther-Mirjam Sent, Hg. 2002. Science Bought and Sold: Essays in the Economics of Science. Chicago: University of Chicago Press.

Mirra, Carl. 2005. Enduring Freedom or Enduring War? Prospects and Costs of the New American 21st Century. Washington, DC: Maisonneuve Press.

Mishan, E.J. 1972. The Futility of Pareto-Efficient Distributions. The American Economic Review 62 (5): 971-976.

Mishra, Pankaj. 2012. From the Ruins of Empire: The Revolt Against the West and the Remaking of Asia. London: Penguin.

Mohl, Robert. 1960. Die Geschichte und Literatur der Staatswissenschaften in Monographien dargestellt - 3 Bände. Graz: Akademische Druck- u. Verlagsanstalt (Originalausgaben: Erlangen 1855-1858).

Mollat, Georg B. 1891. Lesebuch zur Geschichte der deutschen Staatswissenschaft von Kant bis Bluntschli. Osterwieck: Zickfeldt.

Monreal, Susana. 1993. Krausismo en el Uruguay: Algunos fundamentos del Estado tutor. Montevideo: Universidad Católica del Uruguay Dámaso A. Larrañaga.

Moore, George Edward Wisser Burkhard. 2005. Principia Ethica. New York: Barnes \& Noble Books (Originalausgabe: 1903).

Moorthy, K. Sridhar. 1985. Using Game Theory to Model Competition. Journal of Marketing Research 22 (3): 262-282. 
Moosmayer, Dirk C. 2013. Die Intention betriebswirtschaftlicher Hochschullehrer zur Beeinflussung von Werten: Konzeptionelle Entwicklung und globale empirische Überprüfung. Frankfurt a.M.: PL Academic Research.

Moraña, Mabel, Enrique D. Dussel, and Carlos A. Jáuregui, Hg. 2008. Coloniality at Large: Latin America and the Postcolonial Debate. Durham: Duke University Press.

Morris, Brian. 1993. Bakunin: The Philosophy of Freedom. Montréal/New York: Black Rose Books.

Müller, Kirstin-Maike. 1999. Konzepte einer Weltinnenpolitik. Hamburg: IFFS.

Murray, R. Malcolm, Jan Narveson, Hg. 2007. Liberty, Games and Contracts: Jan Narveson and the Defence of Libertarianism. Aldershot/Burlington: Ashgate Publication.

Mutsaku Kamilamba, Kande. 2003. Desarrollo y liberación: Utopías posibles para Africa y América Latina. México City: Instituto Teconógico y de Estudios Superiores de Monterrey.

Nagel, Thomas. 1975. Review: Libertarianism Without Foundations. The Yale Law Journal 85 (1): 136-149.

- 1986. The View from Nowhere. New York: Oxford University cop.

- 2003. Rawls and Liberalism. In The Cambridge Companion to Rawls, Hg. Samuel Freeman. Cambrigde: Cambridge University Press.

Narveson, Jan. 1988. The Libertarian Idea. Philadelphia: Temple University Press.

Nathan, Ganesh. 2014. Social Freedom in a Multicultural State. New York: Palgrave Macmillan.

Naumann, Friedrich. 1911. Gegenwart und Zukunft des Liberalismus: Rede. München: Buchh. Nationalverein.

Neal, Patrick. 1994. Does He Mean What He Says? (Mis)Understanding Rawls's Practical Turn. (John Rawls). Polity 27 (1): 77-111.

Nelson, Eric. 2005. Liberty: One Concept Too Many? Political Theory 33 (1): 58-78.

Neurath, Otto, and Rainer Hegselmann. 1979. Wissenschaftliche Weltauffassung, Sozialismus und Logischer Empirismus. Suhrkamp: Frankfurt a.M.

Nevile, Ann. 2007. Amartya K. Sen and social exclusion. Development in Practice 17 (2): 249-255.

Nickel, James W. 2002. Is Today's International Human Rights System a Global Governance Regime? The Journal of Ethics 6 (4): 353-371.

Niehans, Jürg. 1990. A History of Economic Theory: Classic Contributions, 1720-1980. Baltimore/ London: John Hopkins University Press.

Norman, W.J. 1991. Taking >Free Action< Too Seriously. Ethics 101 (3): 505-520.

Novak, Michael. 1997. Economics as Humanism. First Things: A Monthly Journal of Religion and Public Life 76: 18-19.

Nozick, Robert. 1975. Anarchy, State, and Utopia. Oxford: Moderne Verl.-Ges (Originalausgabe: 1974).

Núñez Encabo, Mannuel. 1976. Manuel Sales y Ferré: Los orígenes de la sociología en España. Madrid: Edicusa.

Nussbaum, Martha Craven. 1988. Nature, Function, and Capability: Aristotle on Political Distribution. Oxford Studies in Ancient Philosophy: 145-184.

- 1992. Human Functioning and Social Justice in Defense of Aristotelian Essentialism. Political Theory 20 (2): 202-246.

- 2006. Frontiers of Justice: Disability, Nationality, Species Membership. Cambridge, MA: Belknap Press.

- 2010. Not for Profit: Why Democracy Needs the Humanities. Princeton: Princeton University Press.

- 2011. Creating Capabilities: The Human Development Approach. Cambridge, MA: Belknap Press of Harvard University Press.

O'Neill, Onora. 1979. The Most Extensive Liberty. Proceedings of the Aristotelian Society: 45-59. 1989. Constructions of Reason: Explorations of Kant's Practical Philosophy. Cambridge/ New York: University Press.

- 1992. Autonomy, Coherence, and Independence. In Liberalism, Citizenship, and Autonomy, Hg. David Milligan and William Watts Miller. Aldershot/Brookfield: Avenbury. 
2002. Justice, Gender, and International Boundaries. In Global Justice and Transnational Politics Essays on the Moral and Political Challenges of Globalization, Hg. Pablo De Greiff and Ciaran Cronin Cambridge, MA: MIT Press, .

Oberer, Hariolf Seel Gerhard. 1988. Kant: Analysen, Probleme, Kritik, Würzburg.

Okin, Susan Moller, and Jane J. Mansbridge. 1994. Feminism. Aldershot/Brookfield: Elgar.

Olsaretti, Serena. 2004. Liberty, Desert and the Market: A Philosophical Study. Cambridge: Cambridge University Press.

Oppenheim, Felix. 1981. Political Concepts: A Reconstruction. Chicago: University Press. 1985. Constraints on Freedom< as a Descriptive Concept. Ethics 95 (2): 305-309.

Orden Jiménez, Rafael V. 1998. El Sistema de la Filosofía de Krause: Génesis y desarrollo del Panenteísmo. Madrid: Universidad Pontificia de Comillas.

Ortega y Gasset, José, and Helene Weyl. 1946. Concord and Liberty. New York: Norton.

Owen, J. Judd. 2001. Religion and the Demise of Liberal Rationalism: The Foundational Crisis of the Separation of Church and State. Chicago: The University of Chicago Press.

Packard, Vance. 2007. The Hidden Persuaders. Brooklyn: Ig. Publ.

Pakpahan, Agus. 2007. Freedom for Farmers, Freedom for All. Bogor: Ideals.

Parfit, Derek. 2009. All That Matters. Oxford: Bd. I \& II.

Parijs, Philippe. 1995. Real Freedom for All: What (If Anything) Can Justify Capitalism? Oxford: Clarendon.

Parker, Richard. 2005. John Kenneth Galbraith: His Life, His Politics, His Economics. New York: Farrar, Straus and Giroux.

Pawlowski, Hans-Martin, Stefan Smid, and Rainer Specht. 1989. Die Praktische Philosophie Schellings und die gegenwärtige Rechtsphilosophie. Stuttgart-Bad Cannstatt: Fromman.

Pecorino, Paul, and Mark Boening. 2010. Fairness in an Embedded Ultimatum Game. Journal of Law and Economics 53 (2): 263-287.

Peterman, James F. 1992. Philosophy as Therapy: An Interpretation and Defense of Wittgenstein's Later Philosophical Project. Albany: State University of New York Press.

Petersen, Anders. 2011. Authentic Self-realization and Depression. International Sociology 26 (1): $5-24$.

Pettit, Philip. 1997. Republicanism: A Theory of Freedom and Government. Oxford/New York: Clarendon Press.

- 2001. A Theory of Freedom: From the Psychology to the Politics of Agency. Oxford/New York: Polity.

Philippovich, Eugen von. 1910. Die Entwicklung der wirtschaftspolitischen Ideen im 19. Jahrhundert. Sechs Vorträge. Tübingen: Mohr.

Pieper, Josef. 1966. Verteidigungsrede für die Philosophie. München: Kösel-Verlag.

Pieper, Annemarie. 1996. Kant und die Methode der Analogie. In Kant in der Diskussion der Moderne, Hg. Gerhardt Schönrich and Yasushi Kato. Frankfurt a.M.: Suhrkamp.

Piernas y Hurtado, José Manuel. 1891. Tratado de hacienda pública y examen de la española. Madrid: Tip. de M. Ginés Hernández.

Pinckaers, Servais. 1995. The Sources of Christian Ethics. Washington, DC: Catholic University of America Press.

Plamenatz, John Petrov. 1958. English Utilitarians. Oxford: Blackwell.

Plessner, Helmuth. 1965. Die Stufen des Organischen und der Mensch; Einleitung in die philosophische Anthropologie. Berlin: De Gruyter.

- 1983. Conditio humana. Surkamp: Frankfurt a.M.

Pogge, Thomas. 1998. Is Kant's Rechtslehre Comprehensive? The Southern Journal of Philosophy 36: 161-187.

2002. World Poverty and Human Rights: Cosmopolitan Responsibilities and Reforms. Cambridge, MA: Oxford Polity Press.

- ed. 2007. Freedom From Poverty as a Human Right: Who Owes What to the Very Poor? New York/Oxford/Paris: Oxford Univeristy. 
Prauss, Gerold. 1986. Handlungstheorie und Transzendentalphilosophie. Frankfurt a.M.: Klostermann.

Pressman, Steven, and Gale Summerfield. 2009, The Economic Contributions of Amartya Sen. In Leading Contemporary Economists: Economics at the Cutting Edge, Hg. Steven Pressman. London: Routledge.

Primatt, Humphry. 1776. A Dissertation on the Duty of Mercy and Sin of Cruelty to Brute Animals. London: T.Cadell.

Princen, Sebastiaan. 2004. Trading up in the Transatlantic Relationship. Journal of Public Policy 24 (1): 127-144.

Proudhon. 1842. Traité du domaine de propriété, ou de la distinction des biens; considérés principalement par rapport au domaine privé. Paris: Cans et compagnie.

Putnam, Hilary. 2002. The Collapse of the Fact/Value Dichotomy and Other Essays. Cambridge, MA: Harvard University Press.

. 2003. For Ethics and Economics without the Dichotomies. Review of Political Economy 15 (3): 395-412.

- 2004. Ethics Without Ontology. Cambridge, MA: Harvard University Press.

Pykett, Jessica, Rhys Jones, Mark Whitehead, Margo Huxley, Kendra Strauss, Nick Gill, Kate McGeevor, Lee Thompson, and Janet Newman. 2011. Interventions in the Political Geography of >Libertarian Paternalism<. Political Geography 30 (6): 301-310.

Qizilbash, Mozaffar. 2011. Sugden's Critique of Sen's Capability Approach and the Dangers of Libertarian Paternalism. International Review of Economics 58 (1): 21-42.

Querol Fernández, Francisco. 2000. La filosofía del derecho de K. Ch. F. Krause: con un apéndice sobre su proyecto europeísta. Madrid: University Pontificia Comillas.

Quine, Willard van Orman. 1951. Main Trends in Recent Philosophy: Two Dogmas of Empiricism. The Philosophical Review 60 (1): 20-43.

Quine, Willard. 1987. Quiddities: An Intermittently Philosophical Dictionary. Cambridge, MA: Harvard University Press.

Rabe, Christine Susanne. 2006. Gleichwertigkeit von Mann und Frau: Die Krause-Schule und die bürgerliche Frauenbewegung im 19. Jahrhundert. Köln: Böhlau.

Rahner, Karl. 1970. Freiheit und Manipulationen in Gesellschaft und Kirche. München: Kösel.

Rana, Aziz. 2010. The two Faces of American Freedom. Cambridge: Harvard University Press.

Rasche, Andreas, and Georg Kell, Hg. 2010. The United Nations Global Compact: Achievements, Trends and Challenges. Cambridge/New York: Cambridge University Press.

Rawls, John. 1996. Political Liberalism. New York: Columbia University Press (Originalausgabe: 1993).

— 1999. A Theory of Justice. Cambridge, MA: Belkinap Press of Harvard University Press (Originalausgabe: 1971).

- 2001. Justice as fairness: A restatement, herausgegeben von: Erin Kelly. Cambridge, MA: Harvard University Press.

- 2002. The Law of Peoples: With »The Idea of Public Reason Revisited «. Cambridge, MA: Harvard University Press (Originalausgabe: 1999).

Rawls, John, and Barbara Herman. 2000. Lectures on the History of Moral Philosophy. Cambridge, MA: Harvard University Press.

Raz, Joseph. 1986. The Morality of Freedom. Oxford: Clarendon. Press.

Rebellato, José Luis. 1995. La encrucijada de la ética: Neoliberalismo, conflicto norte-sur, liberación. Montevideo: Ed. Nordan-Comunidad.

Rebonato, Riccardo. 2012. Taking Liberties: A Critical Examination of Libertarian Paternalism. London/New York: Palgrave Macmillan.

Regan, Tom. 1989. Animal Rights and Human Obligations. Englewood Cliffs: Prentice Hall.

Reichenbach, Hans, and Maria Reichenbach. 1951. Der Aufstieg der wissenschaftlichen Philosophie. Berlin: F.A. Herbig. 
Reidy, David A. 2004. Rawls on International Justice: A Defense. Political Theory 32 (3): 291-319.

Reiff, Mark R. 2013. Exploitation and Economic Justice in the Liberal Capitalist State. Oxford: University Press.

Reinalter, Helmut. 2006. Projekt Weltethos: Herausforderungen und Chancen für eine neue Weltpolitik und Weltordnung. Innsbruck: Studien Verlag.

Rescher, Nicholas. 1987. Ethical Idealism: An Inquiry into the Nature and Function of Ideals. Berkeley: University of California Press.

Reynolds, Jack, James Chase, Ed Mares, and James Williams, Hg. 2010. Postanalytic and Metacontinental: Crossing Philosophical Divides. London: Continuum.

Ricardo, David. 1821. On the Principles of Political Economy and Taxation. London: John Murray (Originalausgabe: 1817).

Ricardo, David, Miscellaneous Pamphlet Collection (Library of Congress) und Commercial Pamphlet Collection (Library of Congress), 1921, An Essay on the Influence of a Low Price of Corn on the Profits of Stock: Shewing the Inexpediency of Restrictions on Importation: With Remarks on Mr. Malthus' Two Last Publications: »An Inquiry into the Nature and Progress of Rent « and »The Grounds of an Opinion on the Policy of Restricting the Importation of Foreign Coin«, London (Originalausgabe: 1815).

Richardson, Henry S., and Paul Weithman, Hg. 1999a. Development and Main Outlines in Rawls's Theory of Justice. New York: Garland Publications.

—, Hg. 1999b. The Two Principles and Their Justifications. New York: Routledge.

Richter, Melvin. 1964. The Politics of Conscience; T. H. Green and His Age. Cambridge: Weidenfeld \& Nicolson.

Rickert, Heinrich. 1923. Die philosophischen Grundlagen von Fichtes Sozialismus. Logos Internationale Zeitschrift der Philosophie der Kultur 9: 149-180.

Riedel, Manfred. 1977. Fichtes zweideutige Umkehr der naturrechtlichen Begriffsbildung. Zeitschrift für Philosophische Forschung 31 (1): 5-18.

Rifkin, Jeremy. 2004. The European Dream. How Europe's Vision of the Future is Quietly Eclipsing the American Dream. New York: Penguin.

Riley, Patrick. 1992. Kant's Two Conceptions of the Will in Their Political Context. In Essays on Kant's Political Philosophy, Hg. Howard Lloyd Williams. Chicago: University of Chicago.

Ripstein, Arthur. 2009. Force and Freedom: Kant's Legal and Political Philosophy. Cambridge, MA/London: Harvard University Press.

Robbins, Lionel. 1932. An Essay on the Nature and Significance of Economic Science. London/ New York: MacMillan.

- 1961. Hayek on Liberty. Economica 28 (109): 66-81.

Roberts, J. Timmons, and Bradley C. Parks. 2007. A Climate of Injustice: Global Inequality, North-South Politics, and Climate Policy. Cambridge, MA: MIT Press.

Rohs, Peter. 2007. Johann Gottlieb Fichte. München: Beck.

Römpp, Georg. 1999. Ethik des Selbstbewusstseins: Der Andere in der idealistischen Grundlegung der Philosophie: Kant, Fichte, Schelling, Hegel. Berlin: Duncker \& Humblot.

Roos, Nikolas H.M. 1994. Hayek's Kantian Heritage and Natural Law. In Hayek, Co-ordination and Evolution: His Legacy in Philosophy, Politics, Economics and the History of Ideas, Hg. Jack Birner and Rudy van Zijp. London: Routledge.

Rorty, Richard. 1989. Contingency, Irony, and Solidarity. New York: Cambridge University Press.

Rosales, Jacinto. 1999. Die Begrenzung. Vom Anstoß zur Aufforderung. Fichte-Studien 16: 167-190.

Rösler, Philipp, and Christian Lindner, Hg. 2009. Freiheit: gefühlt - gedacht - gelebt. Liberale Beiträge zu einer Wertediskussion. Wiesbaden: VS, Verl. für Sozialwiss.

Rössler, Beate. 2003. Kongenial und aufmerksam. Rezension zu John Rawls: Geschichte der Moralphilosophie. Deutsche Zeitschrift für Philosophie 51 (2): 325-329.

Rothbard, Murray Newton. 1973. For a New Liberty. New York: MacMillan.

- 1977. Government and the Economy. Kansas City: Sheed Andrews and Michel. 1982. The Ethics of Liberty. Atlantic Highlands: Humanities Press. 
Rothlin, Stephan. 1992. Gerechtigkeit in Freiheit: Darstellung und kritische Würdigung des Begriffs der Gerechtigkeit im Denken von Friedrich August von Hayek. Frankfurt a.M.: Lang.

Rowland, Barbara M. 1987. Ordered Liberty and the Constitutional Framework: The Political Thought of Friedrich A Hayek. Westport: Greenwood Press.

Rubinstein, Ariel. 2006. A Sceptic's Comment on the Study of Economics. The Economic Journal 116 (510): 1-9.

Ruger, Jennifer Prah. 2010. Health and Social Justice. Oxford/New York: Oxford University Press. Ryan, Alan. 1987. The Philosophy of John Stuart Mill. Houndmills: MacMillan.

Sahlins, Marshall David. 1972. Stone Age Economics. New York: Aldine de Gruyter.

Salt, Henry Stephens. 1980. Animals' Rights. Considered in Relation to Social Progress. Clarks Summit: Society for Animal Rights (Originalausgabe: 1892).

Samuels, Warren J. 1984. Galbraith on Economics as a System of Professional Belief. Journal of Post Keynesian Economics 7 (1): 61-76.

Samuelson, Paul A. 1938. A Note on the Pure Theory of Consumer's Behaviour. Economica 5 (17): 61-71.

Sandel, Michael J. 1994. Review on John Rawls: Political Liberalism. Harvard Law Review 107 (7): 1765-1794.

Sanz del Río, Julián. 1882. El derecho y el Estado según Krause. Boletín de la Institutción Libre de Enseñanza, 6.

Sassenbach, Ulrich. 1992. Der Begriff des Politischen bei Immanuel Kant. Würzburg: Königshausen und Neumann.

Sasson, Helen, Derek Curtis Bok, and Andrea D. Williams, Hg. 1999. Between Friends: Perspectives on John Kenneth Galbraith. Boston: Houghton Mifflin.

Satz, Debra, and Rob Reich, Hg. 2009. Toward a Humanist Justice: The Political Philosophy of Susan Moller Okin. Oxford/New York: Oxford University Press.

Say, Jean-Baptiste. 1803. Traité d'économie politique, ou simple exposition de la manière dont se forment, se distribuent, et se composent les richesses. Paris.

Scanlon, Thomas. 1998. What We Owe to Each Other. Cambridge, MA: Belknap Press of Harvard University Press.

Schelling, Thomas C. 1984. Choice and Consequence. Cambridge, MA: Harvard University Press.

Scherer, Andreas Georg, and Guido Palazzo. 2007. Toward a Political Conception of Corporate Social Responsibility: Business and Society Seen from a Habermasian Perspective. Academy of Management Review 32 (4): 1096-1120.

Schiller, Friedrich. 2004. Briefe über die ästhetische Erziehung des Menschengeschlechts. In Werke, München.

Schindler, David Christopher. 2012. The Perfection of Freedom: Schiller, Schelling and Hegel between the Ancients and the Moderns. Eugene: Cascade Books.

Schlensog, Stephan, and Hans Küng. 2006. Der Hinduismus: Glaube, Geschichte, Ethos. München: Piper.

Schlensog, Stephan, and Walter Lange, Hg. 2008. Weltethos in der Schule: Unterrichtsmaterialien der Stiftung Weltethos. Tübingen: Stiftung Weltethos.

Schlick, Moritz. 1918. Allgemeine Erkenntnislehre. Berlin: Springer.

Schmitz, Heinz-Gerd. 1990. Moral oder Klugheit? Überlegungen zur Gestalt der Autonomie des Politischen im Denken Kants. Kant-Studien 81 (1): 413-422.

Schneider, Alfred Theodor. 1907. Karl Christian Friedrich Krause als Geschichtsphilosoph. Leipzig: Bär \& Hermann.

Scholz, Johannes-Michael. 1982a. Krausistische Staatskritik in der spanischen $>$ Restauración. In Aspekte europäischer Rechtsgeschichte: Festgabe für Helmut Coing zum 70 Geburtstag, Hg. Christoph Bergfeld. Frankfurt a.M.: Vittorio Klostermann.

—. 1982b. La función sociopolítica del krausismo. In Reinvindicación de Krause, Hg. Friedrich Ebert Fundación. Madrid: Fundación Friedrich Ebert.

$117-163$. 
Schönecker, Dieter. 2013. Das gefühlte Faktum der Vernunft. Skizze einer Interpretation und Verteidigung. Deutsche Zeitschrift für Philosophie 1: 91-107.

Schönherr-Mann, Hans-Martin. 2010. Globale Normen und individuelles Handeln: Die Idee des Weltethos aus emanzipatorischer Perspektive. Würzburg: Königshausen \& Neumann.

Schönherr-Mann, Hans-Martin, and Hans Küng. 2008. Miteinander leben lernen: Die Philosophie und der Kampf der Kulturen. München/Zürich: Piper.

Schönrich, Gerhard. 1986. Die Kategorien der Freiheit als handlungstheoretische Elementarbegriffe. In Handlungstheorie und Transzendentalphilosophie, Hg. Gerold Prauss. Frankfurt a.M.: Klostermann.

Schönrich, Gerhard, and Yasushi Kato, Hg. 1996. Kant in der Diskussion der Moderne. Frankfurt a.M.: Suhrkamp.

Schrader, Wolfgang H. 1972. Empirisches und absolutes Ich. Zur Geschichte des Begriffs Leben in der Philosophie J.G. Fichtes. Stuttgart-Bad Cannstatt: Frommann-Holzboog.

1997. Konstruktion versus Unmittelbarkeit. Zum Verhältnis von Philosophie und Leben bei J.G. Fichte. Fichte-Studien 11: 367-377.

Schulte, Günter. 1979. Vernunft und Natur - Transzendentalphilosophie als Symptom. In Erneuerung der Transzendentalphilosophie im Anschluß an Kant und Fichte: Festschrift für Reinhard Lauth zum 60 Geburtstag, Hg. Klaus Hammacher, and Albert Mues. Stuttgart-Bad Cannstatt: Frommann-Holzboog.

Sen, Amartya. 1992. Inequality Reexamined. New York/Cambridge, MA: Russell Sage Foundation. . 1993. Capability and Well-Being. In The Quality of Life, Hg. Martha Nussbaum, and Amartya Sen. Oxford: Clarendon Press.

-1999a. Development as Freedom. New York: Knopf.

1999b. Galbraith and the Art of Description. In Between Friends: Perspectives on John Kenneth Galbraith, Hg. Helen Sasson, Derek Curtis Bok, and Andrea D. Williams. Boston: Houghton Mifflin.

- 2002. Rationality and Freedom. Cambridge, MA/London: Belknap Press of Harvard University Press.

- 2007. Identity and Violence: The Illusion of Destiny. New York/London: Penguin Books.

- 2009. The Idea of Justice. Cambridge, MA: Belknap Press of Harvard University Press.

Sensen, Oliver. 2011. Kant on Human Dignity. Berlin/New York: De Gruyter.

Serra, Narcís, and Joseph E. Stiglitz, Hg. 2008. The Washington Consensus Reconsidered: Towards a New Global Governance. Oxford/New York: Oxford University Press.

Shackle, George Lennox Sharman. 1972. Epistemics and Economics: A Critique of Economic Doctrines. Cambridge: Cambridge University Press.

Shaw, Brian J. 2005. Rawls, Kant's Doctrine of Right, and Global Distributive Justice. The Journal of Politics 67 (1): 220-249.

Shklar, Judith N., and Bernard Yack, Hg. 1996. Liberalism Without Illusions: Essays on Liberal Theory and the Political Vision of Judith N. Shklar. Chicago: University of Chicago Press.

Sidgwick, Henry. 1981. The Methods of Ethics. Indianapolis: Hackett Publications.

Siep, Ludwig. 1992. Praktische Philosophie im Deutschen Idealismus. Frankfurt a.M.: Suhrkamp. Silber, John R. 1965. Der Schematismus der praktischen Vernunft. Kant-Studien 56 (3-4): 253-273.

Simhony, Avital. 1993a. Beyond Negative and Positive Freedom: T. H. Green's View of Freedom. Political Theory 21 (1): 28-54.

- 1993b. On Forcing Individuals to be Free: T.H. Green's Liberal Theory of Positive Freedom. Political Studies 39 (1): 303-320.

Simhony, Avital, and D. Weinstein. 2001. The New Liberalism: Reconciling Liberty and Community. Cambridge: Cambridge University Press.

Simon, Herbert A. 1979. Models of Thought. New Haven: Yale University Press.

Singer, Peter. 2002. One World: The Ethics of Globalization. New Haven: Yale University Press.

Skinner, Quentin. 1998. Liberty Before Liberalism. Cambridge/New York: Cambridge University Press. 
Smith, Lauritz. 1790. Über die Natur und Bestimmung der Tiere wie auch von den Pflichten der Menschen gegen die Tiere. Kopenhagen: Proft.

Snow, Charles Percy. 1959. The Two Cultures. London.

Solow, Robert M. 1997. How Did Economics Get That Way and What Way Did It Get? Daedalus 126 (1): $39-58$.

Sombart, Werner. 1929. Die drei Nationalökonomien: Geschichte und System der Lehre von der Wirtschaft. München: Duncker und Humblot.

Soto, Domingo, and Venancio Diego Carro. 1967. De Iustitia et Iure. (De la justicia y del derecho). Madrid: Instituto de estudios políticos.

Sperling, John G., and Suzanne W. Helburn. 2004. The Great Divide: Retro vs. Metro America. Sausalito: PoliPoint Press.

Spitzeck, Heiko, Michael Pirson, and Claus Dierksmeier. 2011. Banking with Integrity: The Winners of the Financial Crisis? New York: Palgrave Macmillan.

Stadler, Christian Maria. 1996. J.G. Fichtes Grundlegung des ethnischen Idealismus, oder, Transzendentale Deduktion zwischen Wissen und Wollen. Cuxhaven: Junghaus.

- 2000. Freiheit in Gemeinschaft: Zum transzendentalphilosophischen Rechtsbegriff Johann Gottlieb Fichtes. Cuxhaven: Junghaus.

Steele, G.R. 1993. The Economics of Friedrich Hayek. New York: MacMillan.

Steiner, Hillel. 1994. An Essay on Rights. Cambridge, MA/Oxford: Blackwell.

Steltemeier, Rolf. 2015. Liberalismus. Ideengeschichtliches Erbe und politische Realität einer Denkrichtung. Baden-Baden: Nomos.

Stephen, M. Gardiner. 2004. Ethics and Global Climate Change. Ethics 114 (3): 555-600.

Stigler, George J., and Gary S. Becker. 1977. De Gustibus non est et disputandum. American Economic Review 67 (2): 76-90.

Stiglitz, Joseph E. 2006. Making Globalization Work. New York: Siedler.

Stilz, Anna. 2009. Liberal Loyalty: Freedom, Obligation, and the State. Princeton: Princeton University Press.

Stoetzer, Carlos Otto. 1985. Raíces intelectuales de la Constitución argentina de 1853. Jahrbuch für Geschichte Lateinamerikas = Anuario de Historia de América Latina (JbLA) 22: 295-339. 1998. Karl Christian Friedrich Krause and His Influence in the Hispanic World. Köln: Böhlau.

Streeten, Paul. 2004. Amartya Sen. Rationality and Freedom. Economic Development and Cultural Change 52 (4): 889-891.

Summers, Lawrence H., Nils Gottfries, and Birgit Grodal. 1991. The Scientific Illusion in Empirical Macroeconomics Comments Source. The Scandinavian Journal of Economics 93 (2): 129-148.

Swanton, Christine. 1992. Freedom: A Coherence Theory. Indianapolis: Hackett.

Takada, Makoto. 2010. Zum intersubjektiven Verständnis des Ich in der Wissenschaftslehre nova methodo. Fichte-Studien 35: 345-356.

Tan, Kok-Chor. 2001. The Law of Peoples: With >The Idea of Public Reason Revisited ( Review). Canadian Journal of Philosophy 31 (1): 113-120.

Taylor, Charles. 1985. What's Wrong with Negative Liberty? Philosophical Papers, Bd. 2, Hg. Charles Taylor. Cambrigde.

Taylor, Robert H. 2002. The Idea of Freedom in Asia and Africa. Stanford.

Taylor, Robert S. 2011. Reconstructing Rawls: The Kantian Foundations of Justice as Fairness. State College: Pennsylvania State University/Pennsylvania State University Press.

Ten, Chin Liew, Hg. 2008. Mill's On Liberty: A Critical Guide. Cambridge/New York: Cambridge University Press.

Thaler, Richard H. 1991. Quasi Rational Economics. New York: Russell Sage Foundation.

Thaler, Richard H., and Cass R. Sunstein. 2003. Libertarian Paternalism. The American Economic Review 93 (2): 175-179. 
Thierry, Aimar. 2002. 13 Coordination, Survival and Normativity: A Hayekian Perspective Revisited. In FA Hayek as a Political Economist: Economic Analysis and Values, Bd. 45, Hg. Jack Birner, Pierre Garrouste, and Aimar Thierry. London: Routledge.

Thrasher, John. 2014. John Tomasi: Free Market Fairness. Public Choice 159 (1-2): 309-311.

Tietjen, Hartmut. 1980. Fichte und Husserl: Letztbegründung, Subjektivität u. praktische Vernunft im transzendentalen Idealismus. Frankfurt a.M: Klostermann.

Tinder, Glenn E. 2007. Liberty: Rethinking an Imperiled Ideal. Grand Rapids: Eerdmans.

Tönnies, Ferdinand. 1912. Gemeinschaft und Gesellschaft Grundbegriffe der reinen Soziologie. Berlin: K. Curtius.

Tremmel, Jörg. 2009. Welche Prinzipien der Generationengerechtigkeit würden Vertreter aller Generationen unter dem Rawls'schen Schleier der Unwissenheit festlegen?. Zeitschrift für politische Phliosophie, 201-234.

Trend, John Brande. 1934. The origins of modern Spain. Cambridge/New York: Cambridge University Press (Originalausgabe: 1921).

Turner, Adair. 2012. Economics after the Crisis: Objectives and Means. Cambridge, MA: MIT Press.

Ubel, Peter A. 2009. Free Market Madness: Why Human Nature is at Odds with Economics- and Why It Matters. Boston: Harvard Business Press.

Ulrich, Peter, Dorothea Bauer, and Michael S. Assländer. 2006. John Stuart Mill: Der vergessene politische Ökonom und Philosoph. Bern: Haupt.

Unruh, Peter. 1993. Die Herrschaft der Vernunft: Zur Staatsphilosophie Immanuel Kants. BadenBaden: Nomos Verl.-Ges-.

Ureña, Enrique. 1991. K.C.F. Krause: Philosoph, Freimaurer, Weltbürger: Eine Biographie. Stuttgart-Bad Cannstatt: Fromman-Holzboog.

Ureña, Enrique M. 2001. Philosophie und gesellschaftliche Praxis: Wirkungen der Philosophie K.C.F. Krauses in Deutschland, 1833-1881. Stuttgart-Bad Cannstatt: Fromman-Holzboog.

Useem, Michael. 1996. Investor Capitalism: How Money Managers are Changing the Face of Corporate America. New York: Basic Books.

Vaihinger, Hans, Max Scheler, Bruno Bauch, Max Frischeisen-Köhler, Arthur Liebert, and Paul Menzer. 1942. Kant-Studien. Berlin/New York.

Valentin, Veit. 1920. Geschichte des Völkerbundgedankens in Deutschland ein geistesgeschichtlicher Versuch. Berlin: Engelmann.

Vanberg, Viktor. 1988. `Ordnungstheorie< as Constitutional Economics: The German Conception of a >Social Market Economy<. In ORDO: Jahrbuch für die Ordnung von Wirtschaft und Gesellschaft, Hg. Walter Eucken, Bd. 39.

Vanberg, Viktor, and James M. Buchanan. 1981. Liberaler Evolutionismus oder vertragstheoretischer Konstitutionalismus? Zum Problem institutioneller Reformen bei F.A. von Hayek und J.M. Buchanan. Tübingen: Mohr.

Venn, Ronald, and Nicola Berg. 2013. Building Competitive Advantage through Social Intrapreneurship. South Asian Journal of Global Business Research 2 (1): 104-127.

Verene, Donald Phillip. 2011. The Origins of the Philosophy of Symbolic Forms: Kant, Hegel, and Cassirer. Evanston: Northwestern University Press.

Verweyen, Hansjürgen. 1975. Recht und Sittlichkeit in J.G. Fichtes Gesellschaftslehre. Freiburg: Alber.

Vester, Wolfgang. 1935. Sozialphilosophie und Sozialpolitik der deutschen Rechtsphilosophie des XIX. Jahrhunderts: (Krause, Ahrens, Röder). Cottbus: Grosse.

Viner, Jacob. 1961. Review: Hayek on Freedom and Coercion. Southern Economic Journal 27 (3): 230-236.

Vinten, Gerald. 2002. The Corporate Governance Lessons of Enron. Corporate Governance: The International Journal of Business in Society 2 (4): 4-9.

Vitoria, Francisco, Luciano Pereña, and C. Baciero. 1989. Relectio De indis. Carta Magna de los Indios: 450 aniversario, 1539-1989. Madrid: Consejo Superior de Investigaciones Cientificas. 
Vollrath, Ernst. 1987. Grundlegung einer philosophischen Theorie des Politischen. Würzburg: Königshausen + Neumann.

von Kimakowitz, Ernst, Michael Pirson, Heiko Spitzeck, Claus Dierksmeier, and Wolfgang Amann. Hg. 2010. Humanistic Management in Practice. New York: Palgrave Macmillan.

von Mises, Ludwig. 1980. Nationalökonomie: Theorie des Handelns und Wirtschaftens. München:

Philosophia Verl. (unveränderter Nachdruck der Originalausgabe, Genf 1940).

von Schmoller, Gustav. 1904. Über einige Grundfragen der Sozialpolitik und der Volkswirtschaftslehre. Leipzig: Duncker \& Humblot.

Waldron, Jeremy. 1993. Liberal Rights: Collected Papers, 1981-1991. Cambridge/New York: Cambridge University Press.

Waligorski, Conrad. 1990. The Political Theory of Conservative Economists. Lawrence: University Press of Kansas.

Wallner, Nico. 1926. Fichte als politischer Denker: Werden und Wesen seiner Gedanken über den Staat. Halle: M. Niemeyer.

Walsh, Vivian. 1996. Rationality, Allocation, and Reproduction. Oxford/New York: Oxford University Press.

2007. Amartya Sen on Rationality and Freedom. Science and Society 71 (1): 59-83.
2009. Fact/Value Dichotomy. In Handbook of Economics and Ethics, Hg. Jan Peil and Irene van Staveren Cheltenham/Northampton: Edward Elgar.

Walzer, Michael. 2007. Thinking Politically: Essays in Political Theory. New Haven: Yale University Press.

Webley, Simon More Elise. 2003. Does Business Ethics Pay? Ethics and Financial Performance. London: Institute of business ethics.

Wegner, Gerhard. 1991. Wohlfahrtsaspekte evolutorischen Marktgeschehens: Neoklassisches Fortschrittsverständnis und Innovationspolitik aus ordnungstheoretischer Sicht. Tübingen: Mohr.

Weinstein, D. 1998. Equal Freedom and Utility: Herbert Spencer's Liberal Utilitarianism. Cambridge: Cambridge University Press.

Weiske, Julius, and Franz Bopp. 1839. Rechtslexikon für Juristen aller teutschen Staaten enthaltend die gesammte Rechtswissenschaft, Leipzig.

Wertheimer, Alan. 1975. Social Theory and the Assessment of Social Freedom. Polity 7 (3): 334-360.

Wilhelm, Morris M. 1972. The Political Thought of Friedrich A. Hayek. POST Political Studies 20 (2): 169-184.

Willaschek, Marcus. 2002. Which Imperatives for Right? On the Non-Prescriptive Character of Juridicial Laws in Kant's Metaphysics of Morals. In Kant's Metaphysics of Morals: Interpretative Essays, Hg. Mark Timmons. Oxford: Oxford University Press.

- 2009. Right and Coercion: Can Kant's Conception of Right Be Derived from His Moral Theory? International Journal of Philosophical Studies 17 (1): 49-70.

Williams, Bernard Arthur Owen. 1985. Ethics and the Limits of Philosophy. Cambridge, MA: Harvard University Press.

Williams, Howard Lloyd, Hg. 1992. Essays on Kant's Political Philosophy. Chicago: University of Chicago Press.

2011. On Rawls, Development and Global Justice: The Freedom of Peoples. Houndmills/ New York: Palgrave Macmillan.

Williams, Rowan, and Larry Elliott. 2010. Crisis and Recovery: Ethics, Economics, and Justice. New York: Palgrave Macmillan.

Williamson, Oliver E. 1970. Corporate Control and Business Behavior: An Inquiry into the Effects of Organization Form on Enterprise Behavior. Englewood Cliffs: Prentice Hall.

Willms, Bernard. 1967. Zur Dialektik der Planung: Fichte als Theoretiker einer geplanten Gesellschaft. In Säkularisation und Utopie, Hg. Ernst Wolfgang Böckenförde. Stuttgart: Kohlhammer. 
Wilshire, Bruce W. 2002. Fashionable Nihilism: A Critique of Analytic Philosophy. Albany: State University of New York Press.

Wittgenstein, Ludwig. 1953. Philosophical Investigations. Oxford: Blackwell.

Wittgenstein, Ludwig, and Bertrand Russell. 1922. Tractatus logico-philosophicus. London: Kegan Paul.

Wolff, Jonathan, and Avner De-Shalit. 2007. Disadvantage. Oxford/New York: Oxford University Press.

Wollgast, Siegfried. 1985. Karl Christian Friedrich Krause (1781-1832) - Bemerkungen zu seinem Menschheitbund und Friedensplan. In Philosophie und Frieden - Beiträge zum Friedensgedanken in der deutschen Klassik, Hg. Erhard Lange. Weimar: Böhlau.

Wood, Adrian. 1975. A Theory of Profits. Cambridge: Cambridge University Press.

Young, Robert. 1986. Personal Autonomy: Beyond Negative and Positive Liberty. London/New York: St. Martin's Press.

Yunker, James A. 2007. Political Globalization: A New Vision of Federal World Government. Lanham: University Press of America.

Zaczyk, Rainer. 1981. Das Strafrecht in der Rechtslehre J. G. Fichtes. Berlin: Duncker Humblot.

Zak, Paul J. 2004. Neuroeconomics. Philosophical Transactions: Biological Sciences 359 (1451): $1737-1748$.

Zeitler, Christoph. 1995. Spontane Ordnung, Freiheit und Recht: Zur politischen Philosophie von Friedrich August von Hayek. Frankfurt a.M.: Lang.

Zintl, Reinhard. 1983. Individualistische Theorien und die Ordnung der Gesellschaft: Untersuchungen zur Politischen Theorie von James M. Buchanan und Friedrich A.v. Hayek. Berlin: Duncker \& Humblot.

Zöller, Günter, Hg. 2011. Der Staat als Mittel zum Zweck: Fichte über Freiheit, Recht und Gesetz. Baden-Baden: Nomo. 